Copyright: The author, Heather De-Quincey, 2020.

\title{
The development of a surrogate soil to assist the revegetation and stabilisation of metal-mine tailings
}

\author{
Heather De-Quincey
}

Submitted to Swansea University in fulfilment of the requirements for the degree of Doctor of Philosophy.

Swansea University

2020 


\begin{abstract}
Abandoned mines are considered among the most severe of environmental issues, and are a significant danger to environmental, animal, and human health (Mehta et al., 2020). To date, $\sim 600,000$ abandoned mines exist, the costly reclamation of which often falls to publicly funded bodies (Archer \& Caldwell, 2004; Mayes et al., 2009). Traditional reclamation methods are financially unattainable at $\sim £ 50$ million per large mine (McKenna, 2002), and an alternative, lower-cost method is required (Garcia, 2008).

One contemporary reclamation method found to be effective is that of capping mine waste with a soil cover (O'Kane \& Ayres, 2012). In this research, an adhesive surrogate soil capping layer for the hydraulic application to steep-sided metal-mine tailings was developed at the cost of $\sim £ 6 . \mathrm{m}^{-2}$ (at the time of writing).

The surrogate soil was refined throughout a series of trials. A rainfall trial was conducted to develop an adhesive and erosion resistant soil material. A germination trial $(\mathrm{N}=500)$ determined the soil materials which best assisted rapid plant establishment. The successful results of these laboratory-based trials guided a nine-month field trial on an abandoned $\mathrm{Pb}$ mine, Nantymwyn (UK) $(\mathrm{N}=154)$.

The field trial concluded that the surrogate soils effectively resisted erosion and supported the early (seven month) growth of metal-tolerant grass species. The grasses contained $\mathrm{Pb}, \mathrm{Zn}, \mathrm{Cd}$ and $\mathrm{Cu}$ concentrations at $<1 \%$ of the phytotoxic threshold. However, seasonal climatic events and a negative water balance ultimately led to complete grass mortality after nine months. Tailings bank destabilisation also influenced grass survival. The research revealed that the soil's available water supply was of greater impact to plant survival than metal toxicity. The results indicated that should the soils water-holding capacity be improved, the application of a carefully designed surrogate soil has the potential to support vegetative cover on steep, bare metal-mine tailings.
\end{abstract}




\section{Declaration}

This work has not previously been accepted in substance for any degree and is not being concurrently submitted in candidature for any degree.

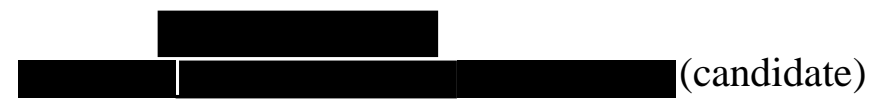

Date: $05-10-20$

\section{Statement 1}

This thesis is the result of my own investigations, except where otherwise stated.

Where correction services have been used, the extent and nature of the correction is clearly marked in a footnote(s).

Other sources are acknowledged by footnotes giving explicit references. A bibliography is appended.

Signed

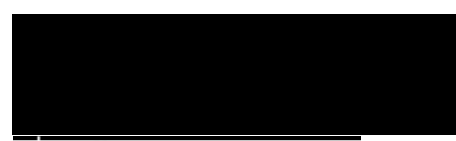
(candidate)

Date: $05-10-20$

\section{Statement 2}

I hereby give consent for my thesis, if accepted, to be available for photocopying and for inter-library loan, and for the title and summary to be made available to outside

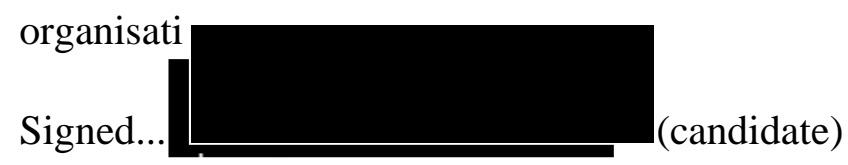

Date: $05-10-20$ 


\section{Contents}

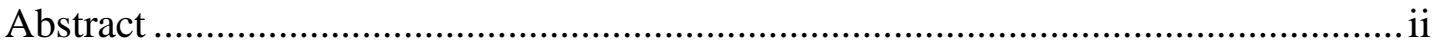

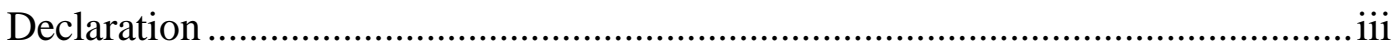

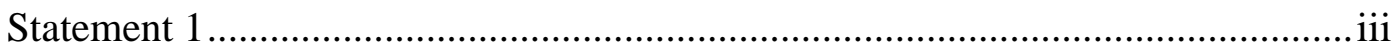

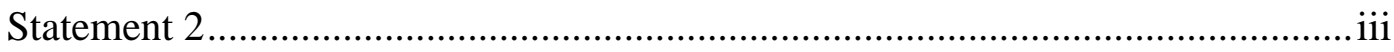

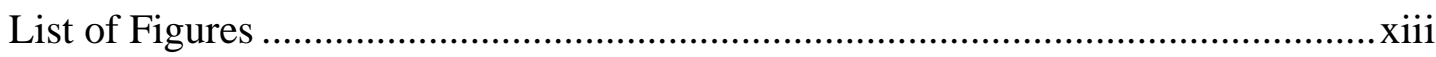

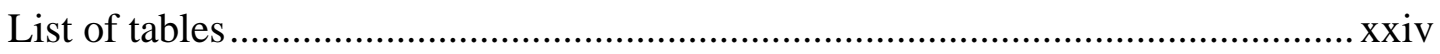

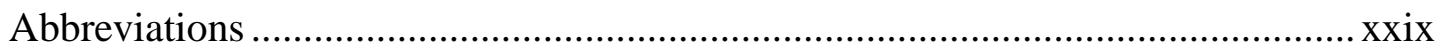

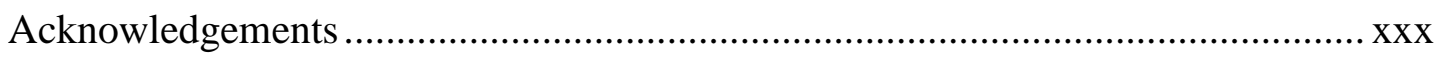

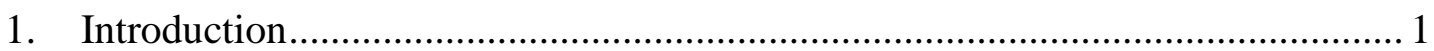

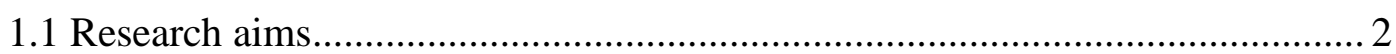

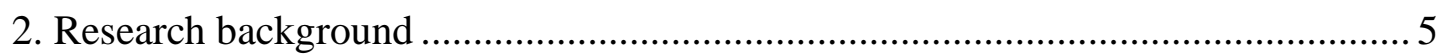

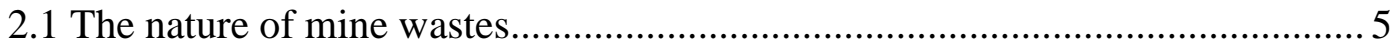

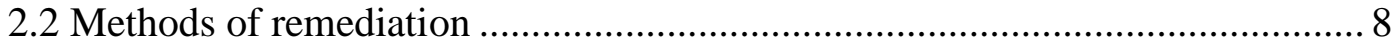

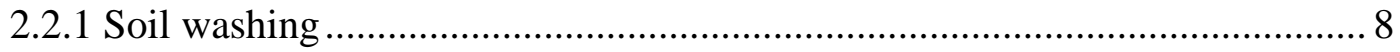

2.2.2 Stabilisation/Solidification treatment techniques..................................... 9

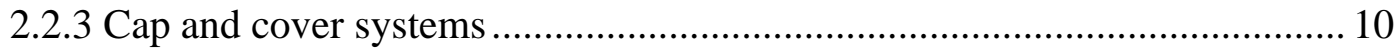

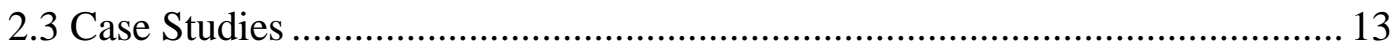

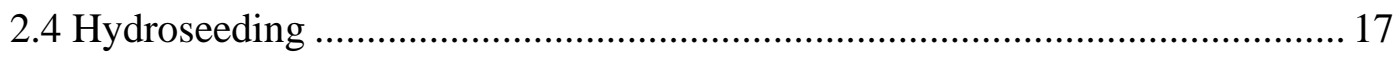

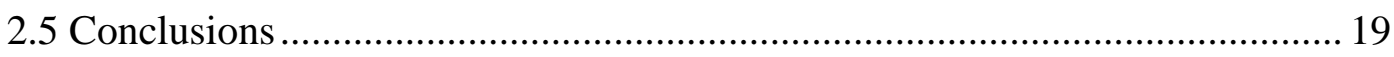

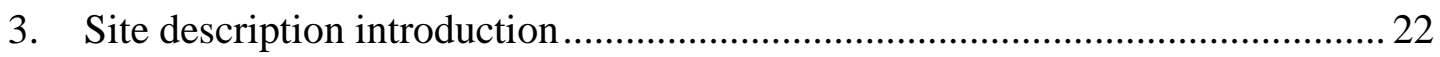

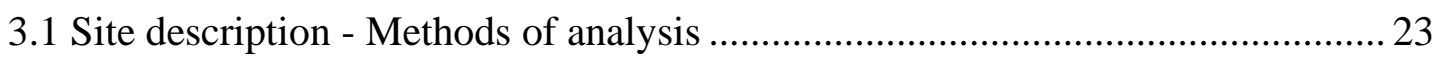

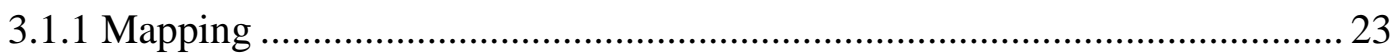

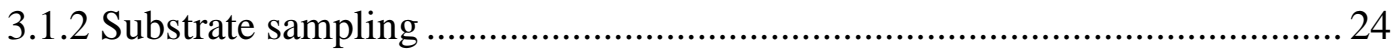

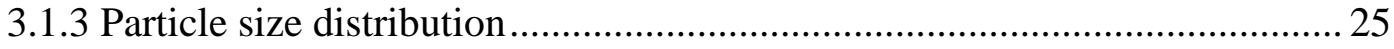

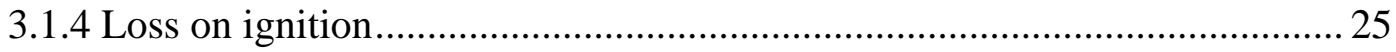

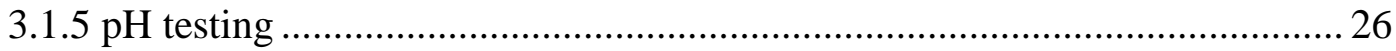




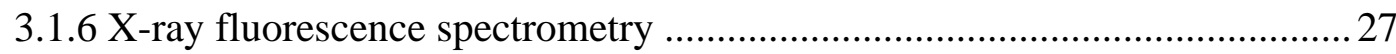

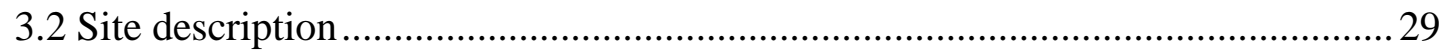

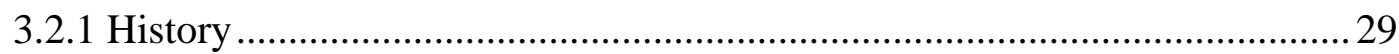

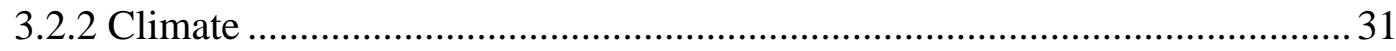

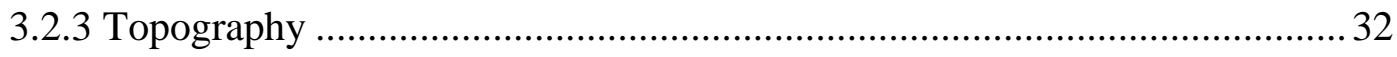

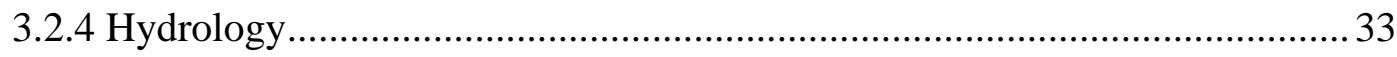

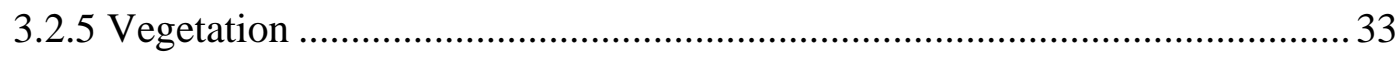

3.2.6 Substrate sampling of the Deep Boat Level .............................................. 35

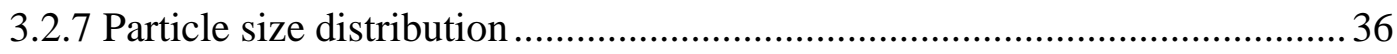

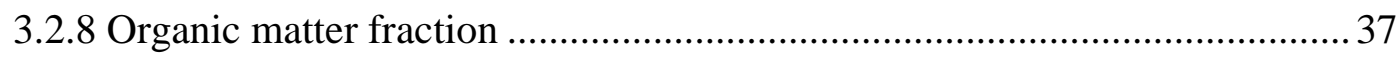

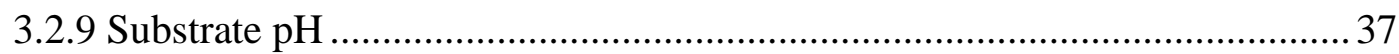

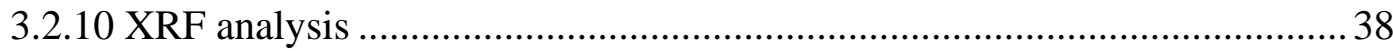

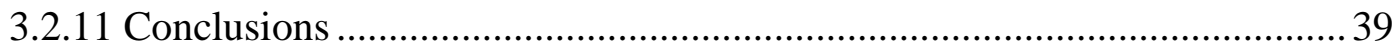

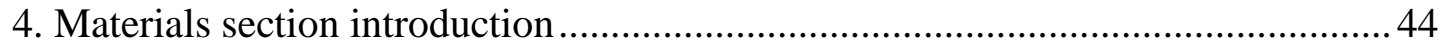

4.1 Materials - Methods of material characterisation............................................... 47

4.1.1 Mass spectrometry for carbon:nitrogen............................................... 47

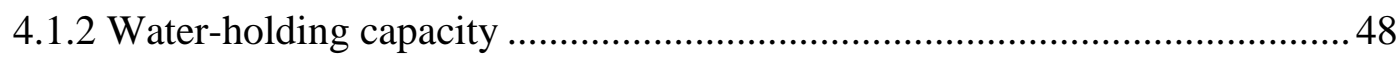

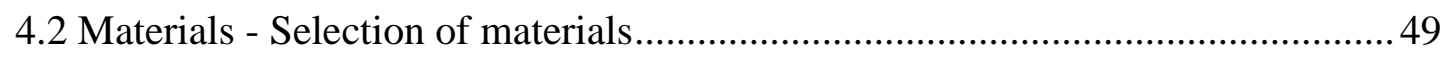

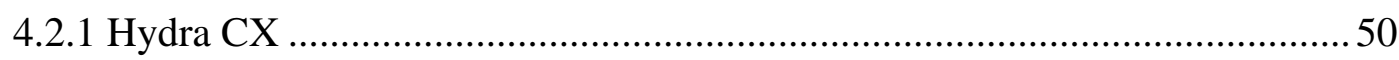

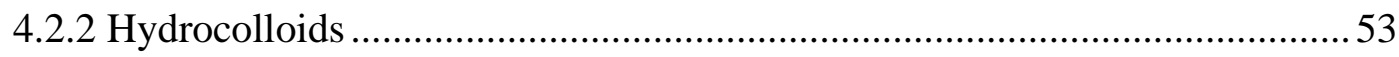

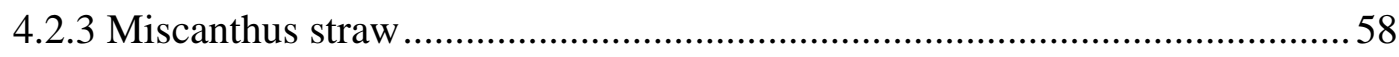

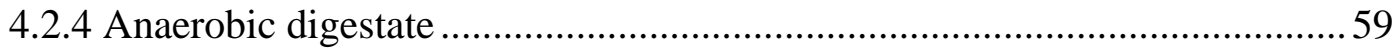

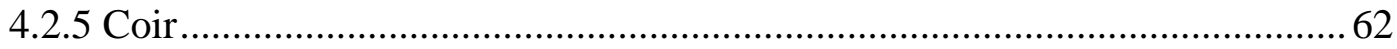

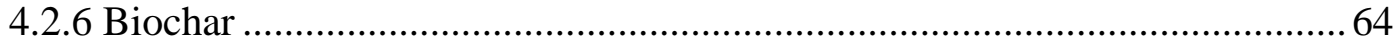

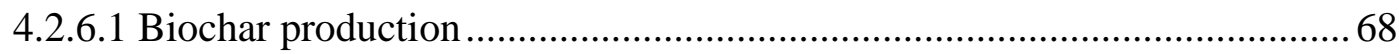

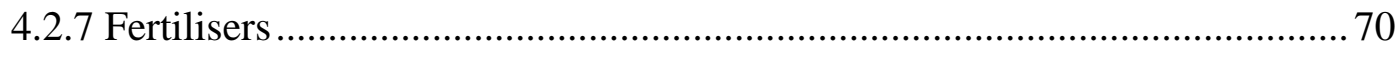

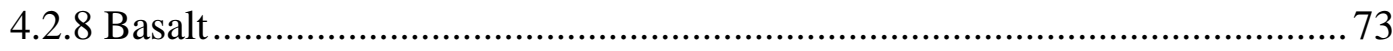


4.3 Selecting vegetation .74

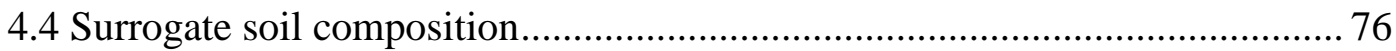

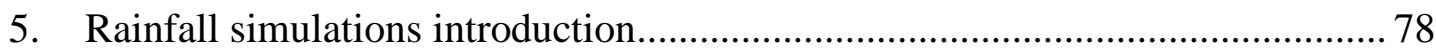

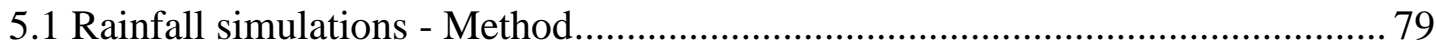

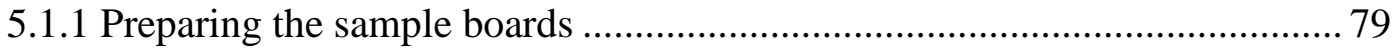

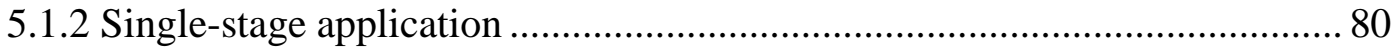

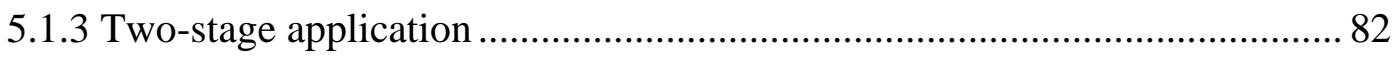

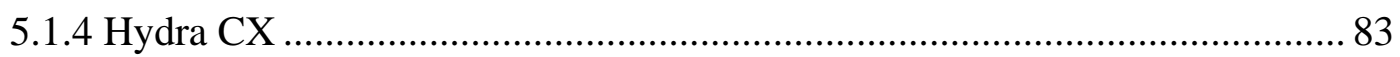

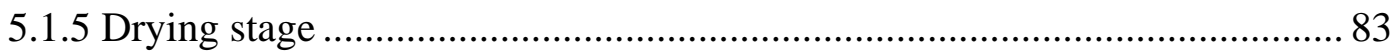

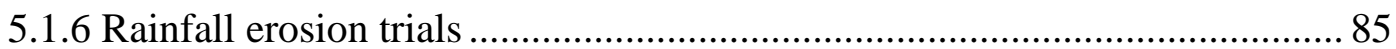

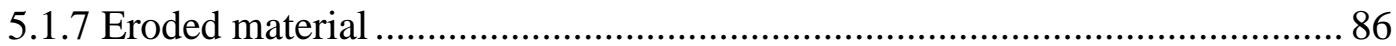

5.1.8 Run-off: Munsell colours and suspended organic matter ........................... 86

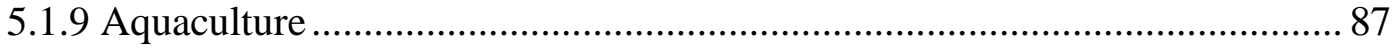

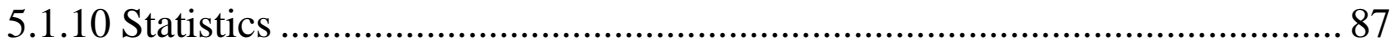

5.2 Rainfall simulations - Results and discussion.................................................. 89

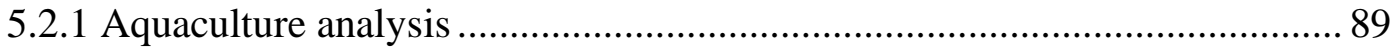

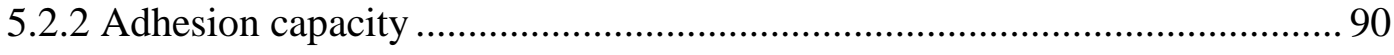

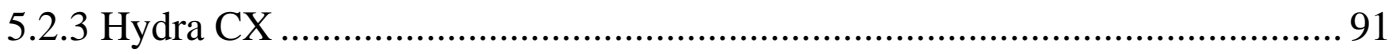

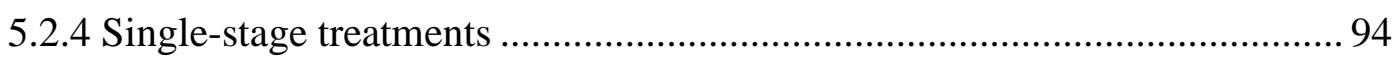

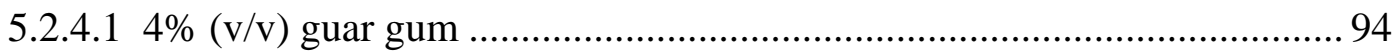

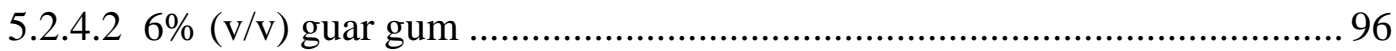

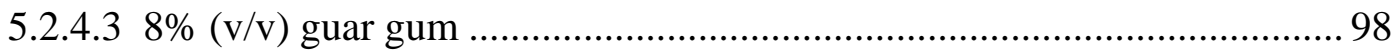

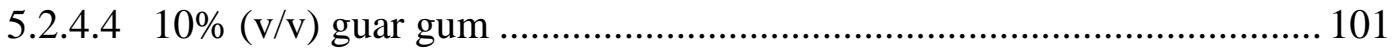

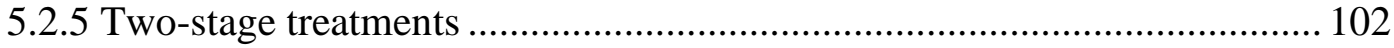

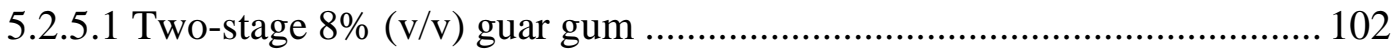

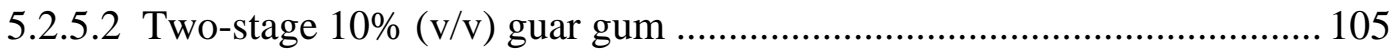

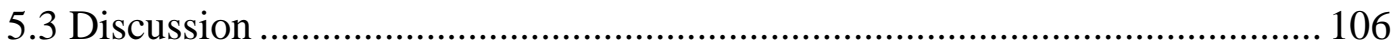




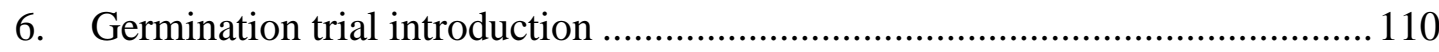

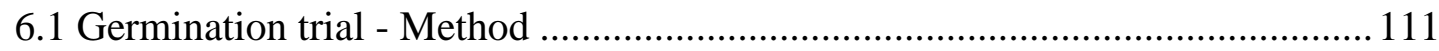

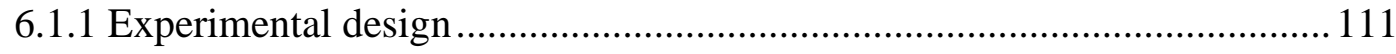

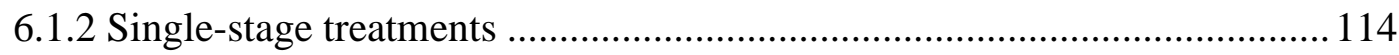

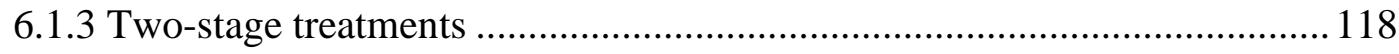

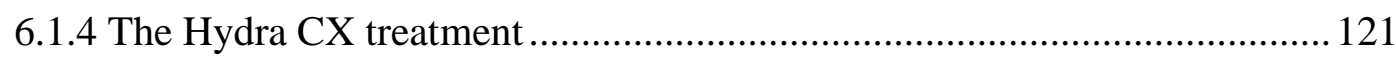

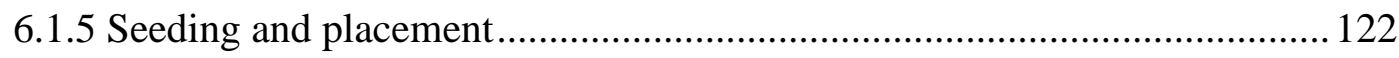

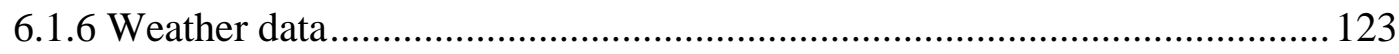

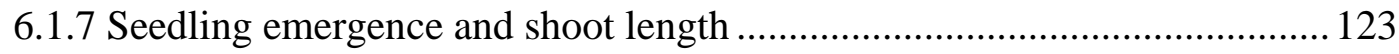

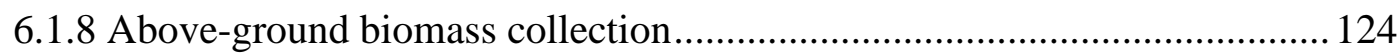

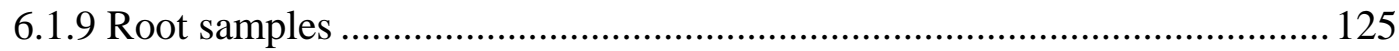

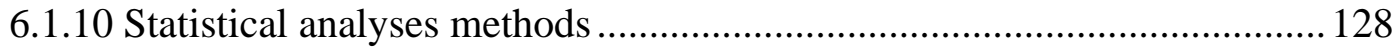

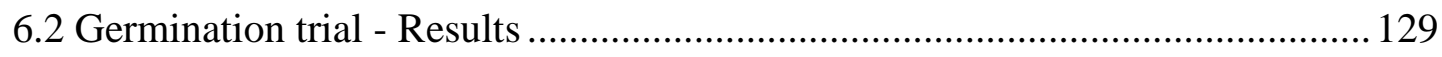

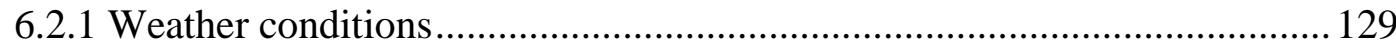

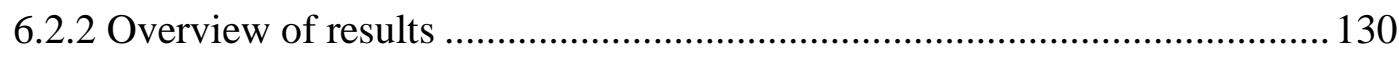

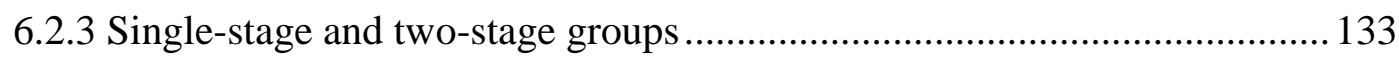

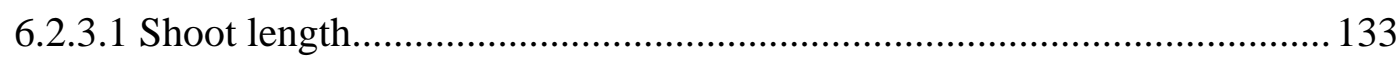

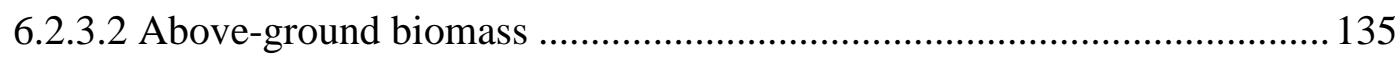

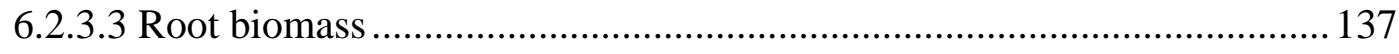

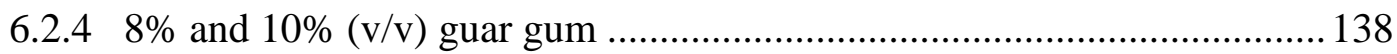

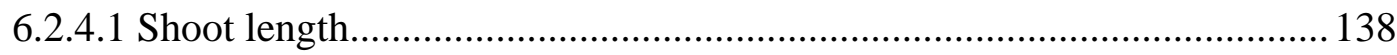

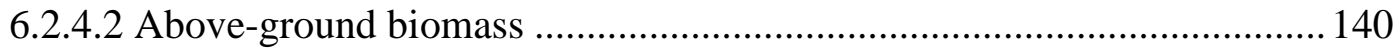

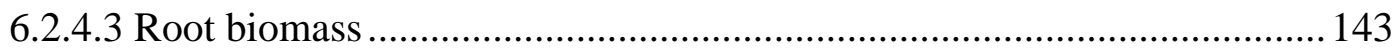

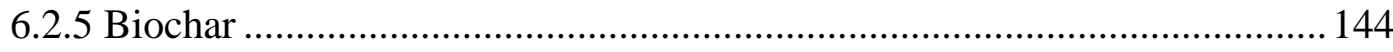

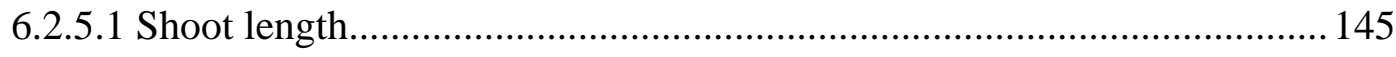


6.2.5.2 Above-ground biomass 146

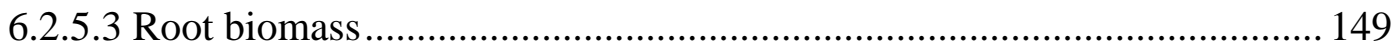

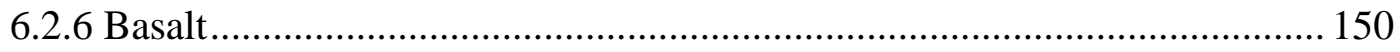

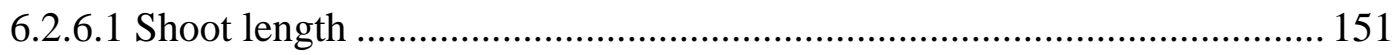

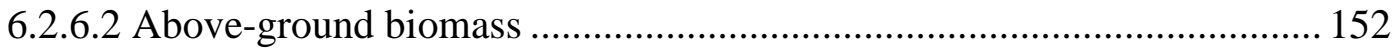

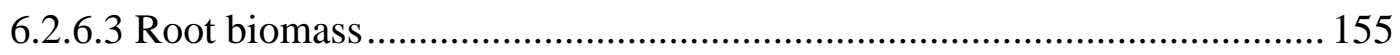

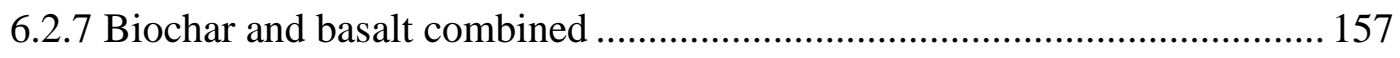

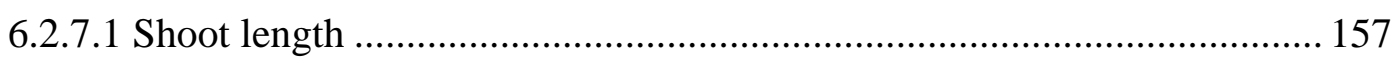

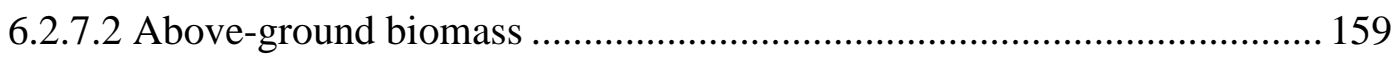

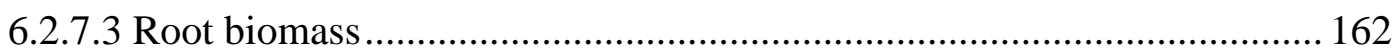

6.2.8 Summary of the germination trial results .............................................. 163

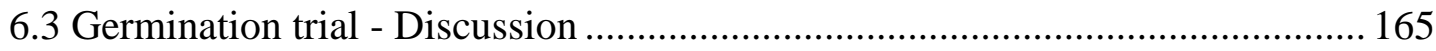

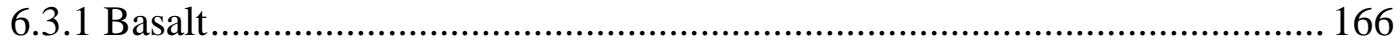

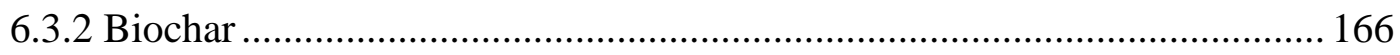

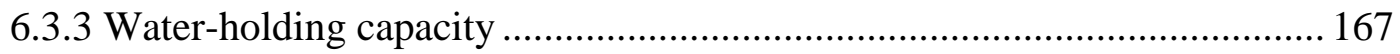

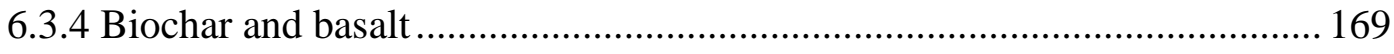

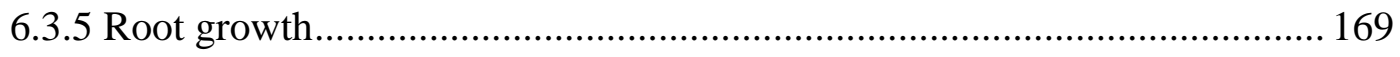

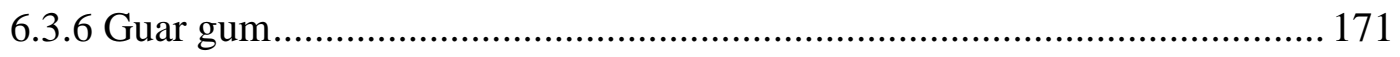

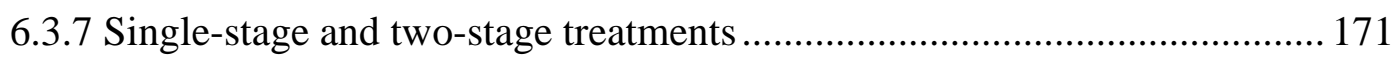

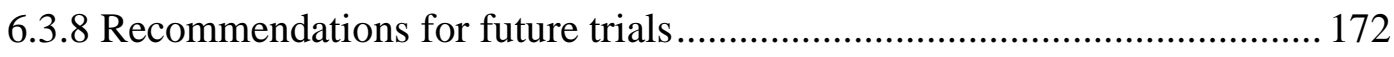

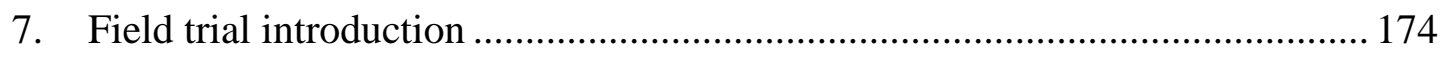

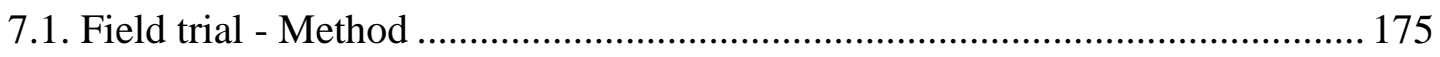

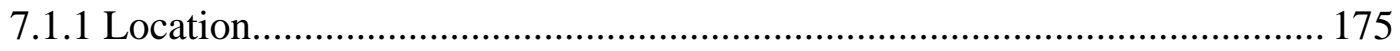

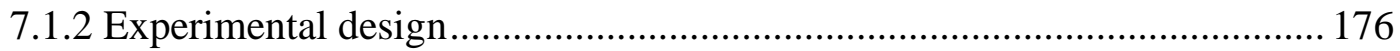

7.1.3 Preparing the surrogate soil materials .................................................. 179

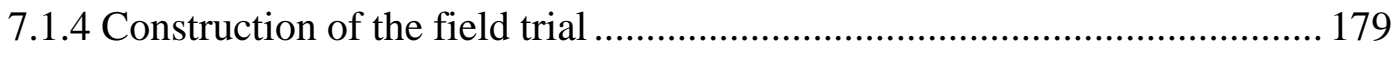

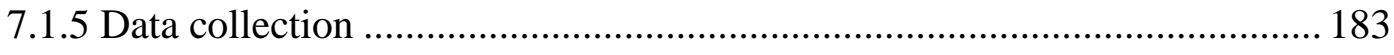




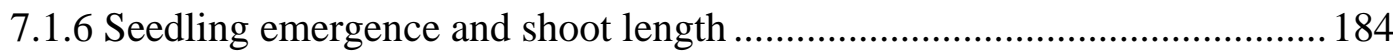

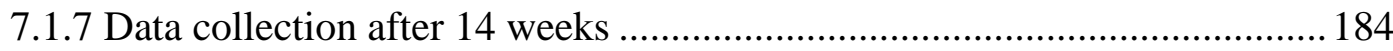

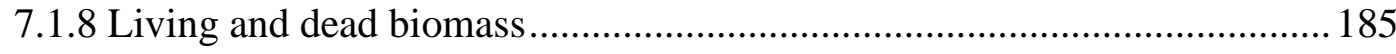

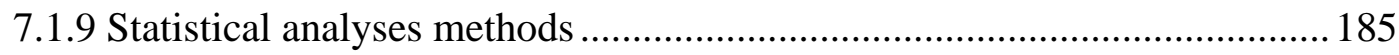

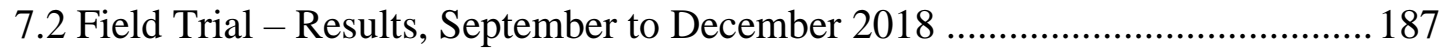

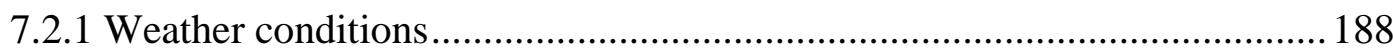

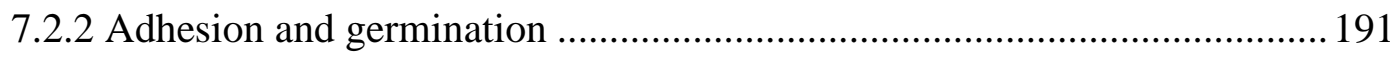

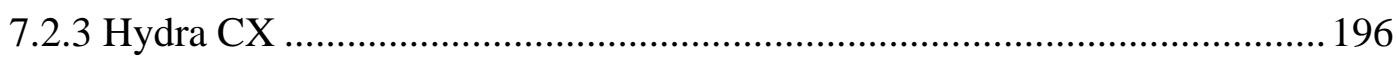

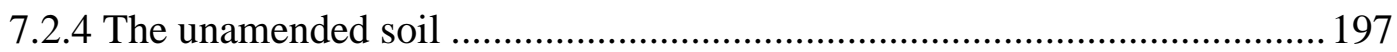

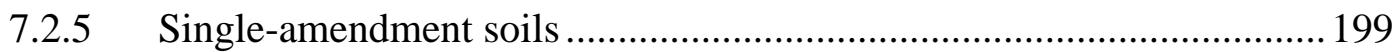

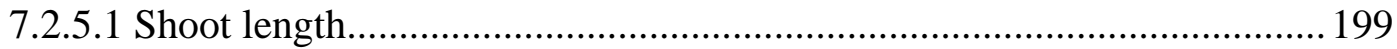

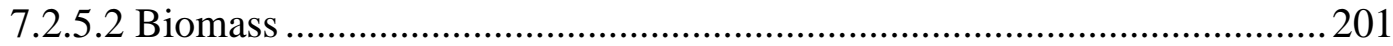

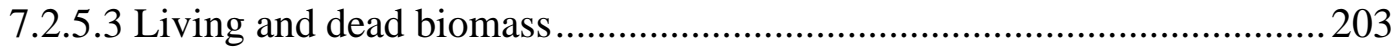

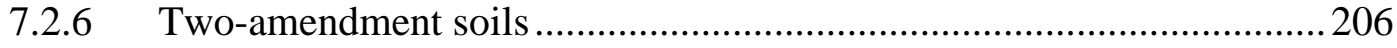

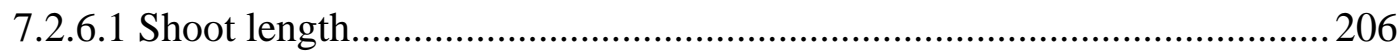

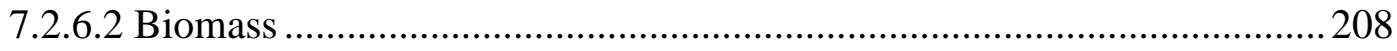

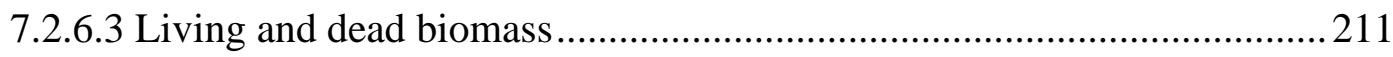

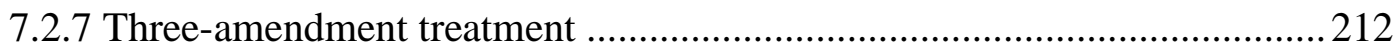

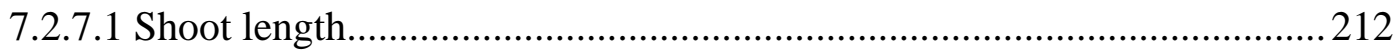

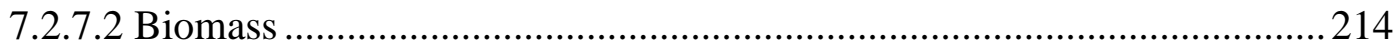

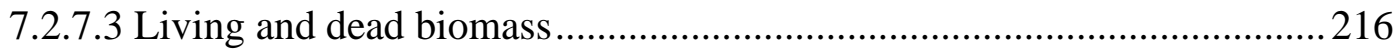

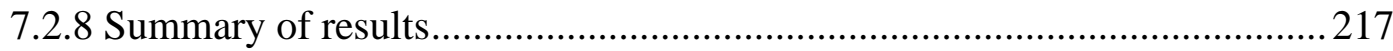

7.3 Field trial - Discussion, September to December 2018 _...............................221

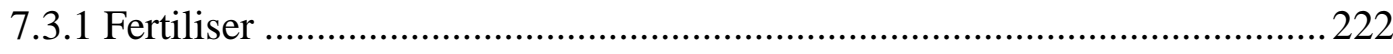

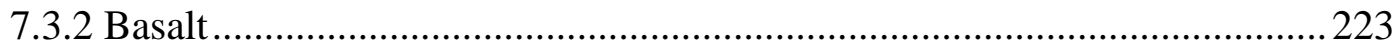




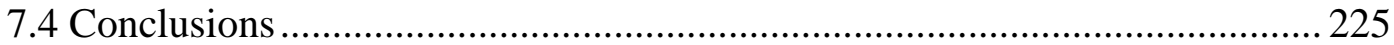

8. Field trial introduction, January to June 2019 ............................................. 228

8.1 Field trial - Methods of data collection, January to June 2019 ....................... 229

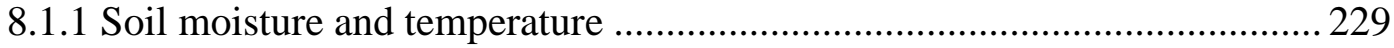

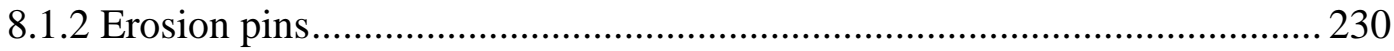

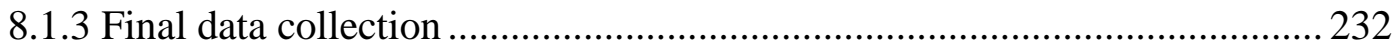

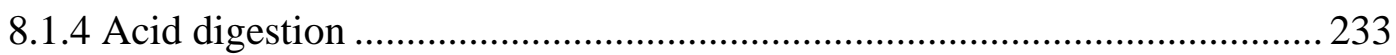

8.1.5 Microwave plasma atomic emission spectroscopy …............................... 234

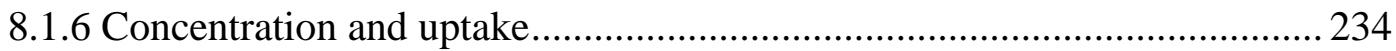

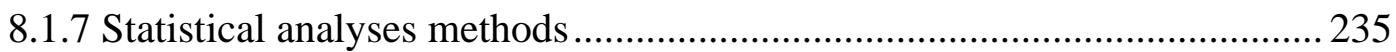

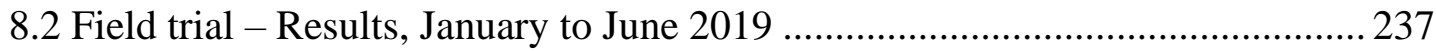

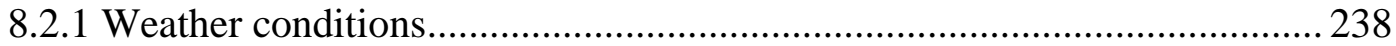

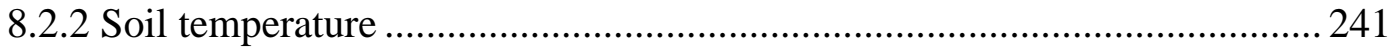

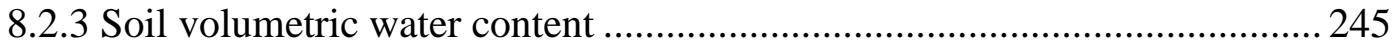

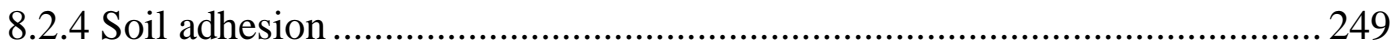

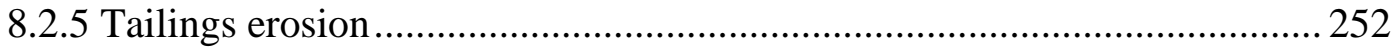

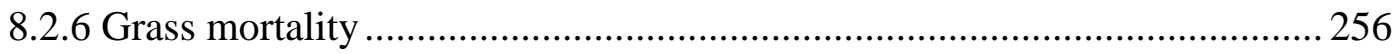

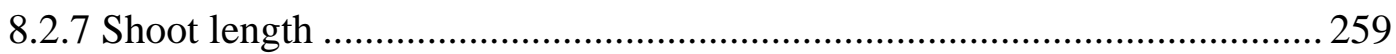

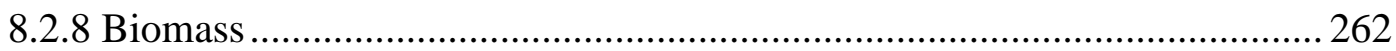

8.2.9 Metal concentration and uptake in biomass ............................................ 263

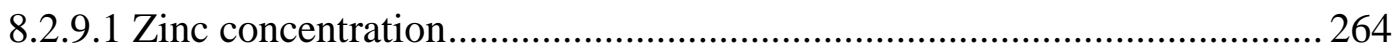

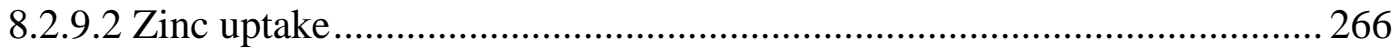

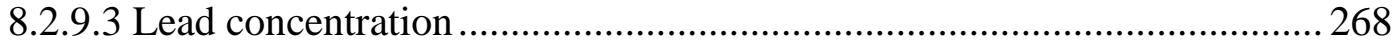

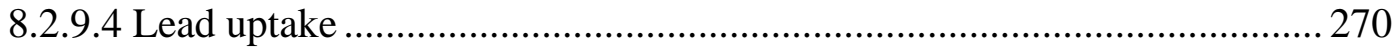

8.2.9.5 Copper and cadmium concentration................................................. 271

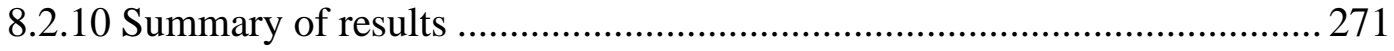


8.3 Field trial - Discussion, January to June 2019 ............................................2275

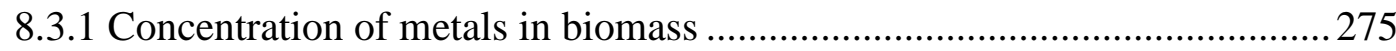

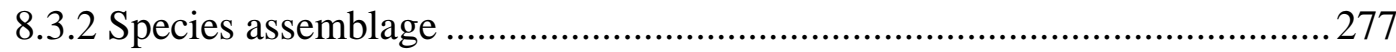

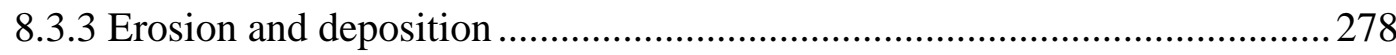

8.3.4 Soil volumetric water content and temperature......................................2. 279

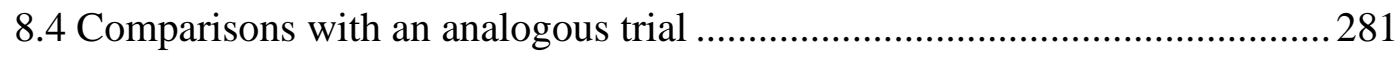

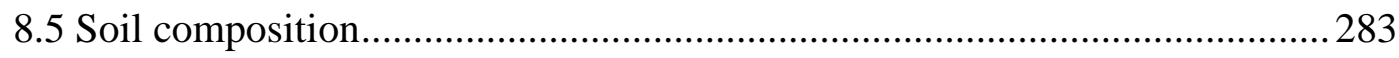

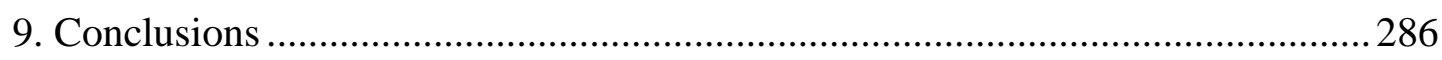

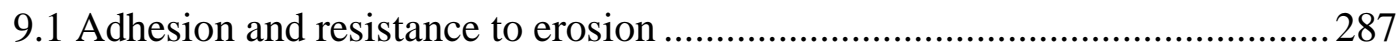

9.2 Recalcitrance of the surrogate soil materials.............................................228

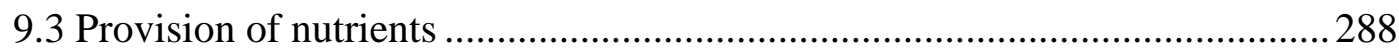

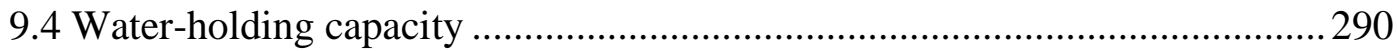

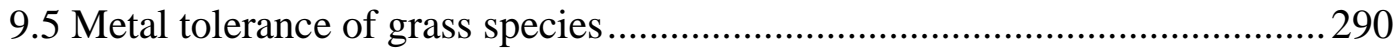

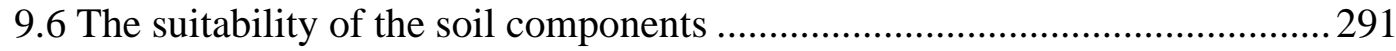

9.7 Conclusions and suggestions for future research .....................................292

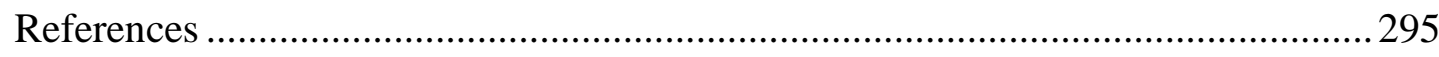

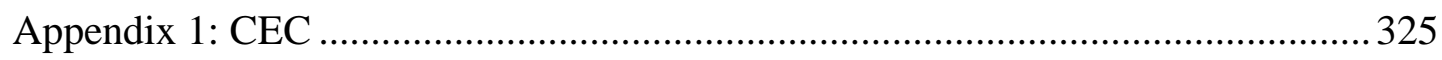

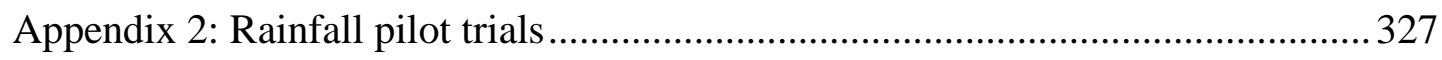

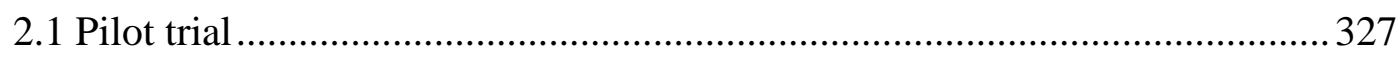

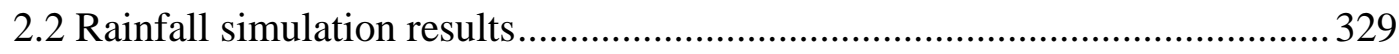

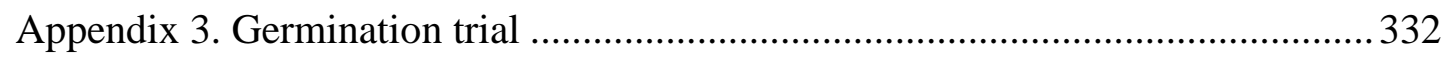

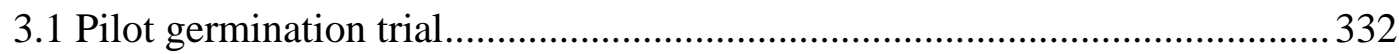

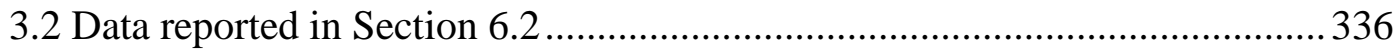

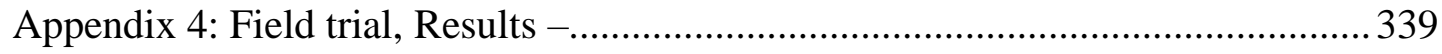

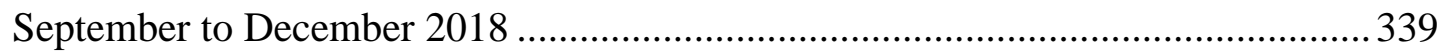

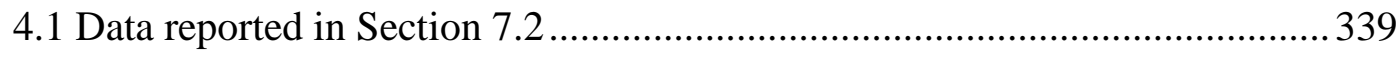

Appendix 5: Field trial - Results, January to June 2019....................................... 343 
5.1 Temperature data.

5.2 Erosion and deposition

5.3 Progress of surrogate soils pots throughout the field trial (biochar) 348

5.4 Progress of surrogate soils pots throughout the field trial (basalt) 350

5.5 Progress of surrogate soils pots throughout the field trial (fertiliser) 352

5.6 Data for Section 8.2.7 (shoot length) and 8.3 (above-ground biomass) ........ 354

5.7 Data for Section 8.2.9 (metal concentration in biomass) 355

5.8 Data for Section 8.2.9 (metal uptake in biomass) 357

5.9 Cadmium concentrations in biomass 361

5.10 Copper concentrations in biomass 362

5.11 Photos of the Nantymwyn field trial, February 2020 363 Appendix 6. Frongoch 365 


\section{List of Figures}

Figure 2.1: The bare tailings of the Nantymwyn $\mathrm{Pb}$ mine, Wales................... 7

Figure 2.2: A soil washing facility .......................................... 9

Figure 2.3: The integration of lime and cement into gold mine tailings at the McLaren Gold Mine site, Montana................................................. 10

Figure 2.4: A geotextile liner being applied to the re-profiled tailings at Frongoch $\mathrm{Pb} / \mathrm{Zn}$ mine, Wales...................................................... 12

Figure 2.5: Frongoch $\mathrm{Pb} / \mathrm{Zn}$ mine before (top, 2010) and after (bottom, 2016) a deep cap and cover system was applied...........................................14

Figure 2.6: The graded tailings at Touro Copper Mine.............................15

Figure 2.7: Three years growth of Agrostis capillaris after the integration of compost into the tailings at Touro Copper Mine............................................16

Figure 2.8: Grass roots growing in $\mathrm{Pb} / \mathrm{Zn}$ tailings capped with 3 " of compost with $5 \%$

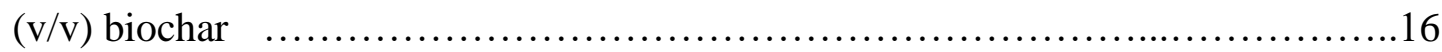

Figure 2.9: Grass growth at the end of a three month pot trial......................17

Figure 2.10: Hydroseeding a $45^{\circ}$ railway embankment slope........................ 18

Figure 2.11: Hope Silver Mine before (July 2010) and after (August 2011) hydroseeding silver mine tailings with a biochar compost.........................19

Figure 3.1: An aerial map of the Nantymwyn field site ............................23

Figure 3.2: An aerial map of the Nantymwyn field site with sample locations.........24

Figure 3.3A) Nantymwyn Lead Mine (red), located in Wales, UK. B) The Upper Boat Level and Deep Boat Level of Nantymwyn (2018)...........................29

Figure 3.4: The tailings at the Deep Boat Level, Nantymwyn, circa 1970, before a quantity of the tailings were removed for the construction of the Llyn Brianne Dam..30

Figure 3.5: The Deep Boat Level of Nantymwyn Lead Mine, outlined in red, in Rhandirmwyn........................................................... 31

Figure 3.6: A 3D map of the Nantymwyn field site, 2018..........................30

Figure 3.7: An ephemeral water body at Nantymwyn, April 2018..................33

Figure 3.8: The bare tailings (interior) at Nantymwyn (2018).....................35

Figure 3.9: Betula pendina growing around the perimeter of the Nantymwyn

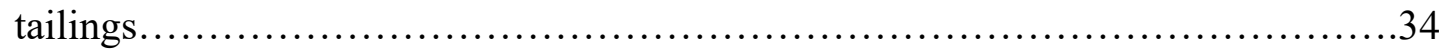


Figure 3.10: Anthoxanthum odoratum growing on the tailings at Nantymwyn.

Figure 3.11: A patch of Silen vulgaris growing on the Nantymwyn mine tailings....35

Figure 3.12: The interior mine substrate at Nantymwyn, with 10 pence for scale....36

Figure 3.13: The perimeter mine substrate at Nantymwyn.......................38

Figure 3.14: The field site at Nantymwyn, 2018 ............................40

Figure 3.15: The area selected for the field trial, Nantymwyn, 2018 .............41

Figure 4.1: Hydra CX applied to a $45^{\circ}$ slope..................................46

Figure 4.2: The dry Hydra CX material...................................48

Figure 4.3: Powdered guar gum. Five pence for scale..........................52

Figure 4.4: Chopped miscanthus straw. Five pence for scale.....................59

Figure 4.5: The anaerobic digestion process................................60

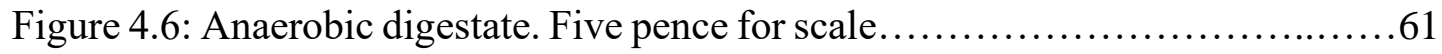

Figure 4.7: Shredded coir. Five pence for scale..............................63

Figure 4.8: Schematic diagram of The Pyrocal BigChar-1000...................69

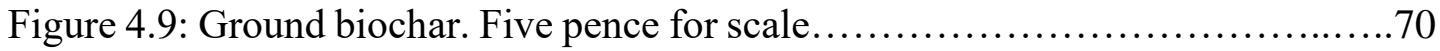

Figure 4.10: Granular fertiliser. Five pence for scale......................... 72

Figure 4.11: Ground basalt. Five pence for scale...............................74

Figure 5.1: A wooden board with the surrogate soil applied, in the rainfall simulator......................................................... 79

Figure 5.2: The eroded material from a rainfall simulation, and the material which was

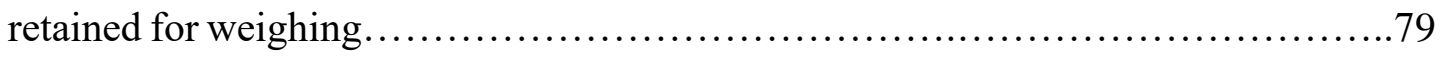

Figure 5.3: A surrogate soil sample being homogenised by a hand blender............81

Figure 5.4: Sample boards drying at $20^{\circ}$, drying in the greenhouse.................84

Figure 5.5: The wire mesh suspended below the droplet box, and below that, the $\mathrm{V}$-shaped collection tray....

Figure 5.6: $\mathrm{TON}, \mathrm{NH}_{4}{ }^{+}$and $\mathrm{PO}_{4}{ }^{3-}$ concentration $\left(\mu \mathrm{mol} . \mathrm{L}^{-1}\right)$ in leachate from each treatment, with the sample standard deviation.

Figure 5.7: Median weight $\left(\mathrm{g} \cdot \mathrm{m}^{-2}\right)$ of eroded surrogate soil material following a one-hour rainfall simulation.

Figure 5.8: The three replicates of the Hydra CX soil treatment, following three days drying period after application. 
Figure 5.9: The three replicates of the Hydra CX soil plots following one hour of

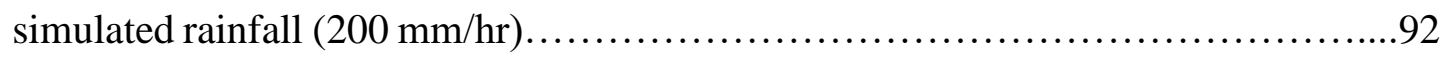

Figure 5.10: Run-off samples taken during the Hydra CX rainsplash trial.............92

Figure 5.11: Three replicates of the $4 \%$ guar gum treatment, following three days drying period after application.............................................. 94

Figure 5.12: The three replicates of the $4 \%$ guar treatment following one hour of

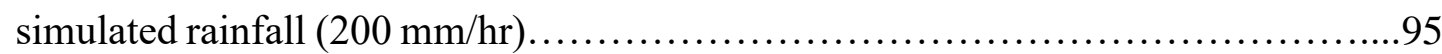

Figure 5.13: Run-off samples collected from the 4\% guar treatment................95

Figure 5.14: Three replicates of the $6 \%$ guar gum treatment, following three days drying period after application..............................................96

Figure 5.15: The three replicates of the $6 \%$ guar treatment following one hour of

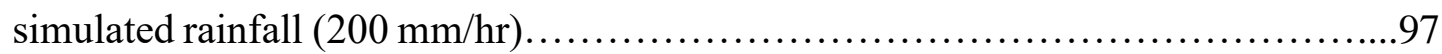

Figure 5.16: Run-off samples collected from the $6 \%$ guar treatment................98

Figure 5.17: Three replicates of the $8 \%$ guar gum treatment following three days drying period........................................................... 98

Figure 5.18: The three replicates of the $8 \%$ guar treatment after one hour simulated

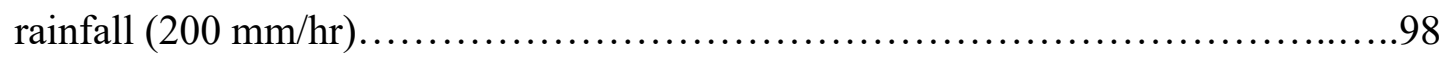

Figure 5.19: The wet material which became unstuck from the bulk material in the rainfall simulations .......................................................... 100

Figure 5.20: Run-off samples collected from the 8\% guar treatment...............100

Figure 5.21: Three replicates of the $10 \%$ guar gum treatment following a three day drying period................................................................ 101

Figure 5.22: The three replicates of the $10 \%$ guar treatment following one hour

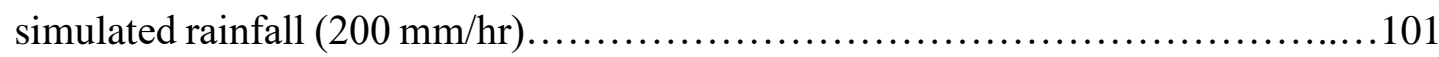

Figure 5.23: Run-off samples collected from the 10\% guar treatment...............102

Figure 5.24: Three replicates of the two-stage $8 \%$ guar gum treatment following three days drying period........................................................ 103

Figure 5.25: The three replicates of the two-stage $8 \%$ guar treatment following one

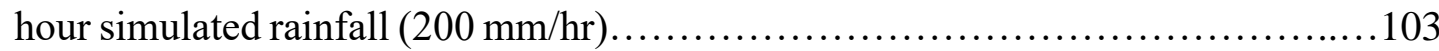

Figure 5.26: Run-off samples collected from the two-stage 8\% guar treatment......104

Figure 5.27: The three replicates of the two-stage 10\% guar treatment, following three hours drying period... 105

Figure 5.28: The three replicates of the two-stage 10\% guar treatment after one hour simulated rainfall $(200 \mathrm{~mm} / \mathrm{hr})$. 105 
Figure 5.29: Run-off samples collected from the two-stage 10\% guar treatment....106

Figure 6.1: A pot from the germination trial................................. 112

Figure 6.2: The placement of the pots and potholders for the germination trial......112

Figure 6.3: The labelled and numbered 25 replicates of a single-stage treatment at the start of the germination trial (July 2018)..................................... 117

Figure 6.4: 0.6 g of Agrostis capillaris and 0.6 g of Agrostis stolonifera seeds......122

Figure 6.5: A block of 40 pots constructed for the germination trial (July 2018) in randomised locations .................................................... 123

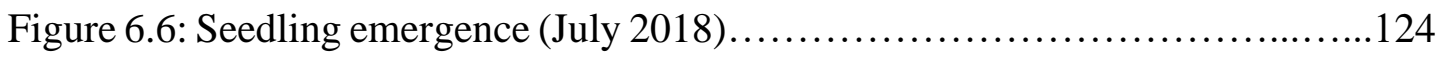

Figure 6.7: A microscope image of the roots of one replicate from the germination trial, tightly interwoven with the growing medium....

Figure 6.8: A microscope image of the roots of one replicate from the germination trial, tightly interwoven with the growing medium. 126

Figure 6.9: The dry roots of one replicate in the germination trial, photographed before the roots were separated from the growing medium.

Figure 6.10: The roots of one replicate from the germination trial, soaking in water to soften the growing medium.

Figure 6.11: The roots of one replicate, placed on a lightbox in order to separate the roots from the growing medium. .128

Figure 6.12: Rainfall $(\mathrm{mm})$, maximum and minimum air temperatures $\left({ }^{\circ} \mathrm{C}\right)$ throughout the duration of the germination trial, July to August 2018 . 130

Figure 6.13: The mean final shoot length for all treatments $(\mathrm{mm})$ at the end of the sixweek germination trial (August 2018). 131

Figure 6.14: The mean above-ground biomass $\left(\mathrm{g} \cdot \mathrm{m}^{-2}\right)$ at the end of the six-week germination trial (August 2018).

Figure 6.15: The mean root biomass $\left(\mathrm{g} \cdot \mathrm{m}^{-2}\right)$ at the end of the six-week germination trial (August 2018)

Figure 6.16: Mean tallest shoot length $(\mathrm{mm})$ in the single-stage, two-stage, and Hydra CX surrogate soil treatments throughout the germination trial (August 2018)........133

Figure 6.17: The mean final tallest shoot length $(\mathrm{mm})$ in each treatment group, at the end of the six-week germination trial (August 2018).............................134

Figure 6.18: Mean above-ground biomass produced by the treatment groups at the end of the six-week germination trial (August 2018). 135 
Figure 6.19: The mean root biomass $\left({\left.\mathrm{g} . \mathrm{m}^{-2}\right)}^{2}\right.$ produced by each treatment group, singlestage, two-stage, and Hydra CX, at the end of the six-week germination trial.

Figure 6.20: Mean tallest shoot length for the treatment groups, 8\% guar $(n=200)$, $10 \%$ guar $(n=200)$ and Hydra CX $(n=25)$ throughout the six-week germination trial.

Figure 6.21: The mean final tallest shoot $(\mathrm{mm})$ produced by the treatment groups, $8 \%$ guar $(n=200), 10 \%$ guar $(n=200)$ and Hydra CX $(n=25)$ at the end of the six-week trial.

Figure 6.22: The mean above-ground biomass produced in the treatment groups, $8 \%$ guar $(n=200), 10 \%$ guar $(n=200)$ and Hydra CX $(n=25)$ at the end of the six-week germination trial (August 2018)............................................. 140

Figure 6.23: Two-stage, $8 \%$ guar gum, with biochar and basalt, at week six..........141

Figure 6.24: Two-stage, 10\% guar gum, with biochar and basalt, at week six........142

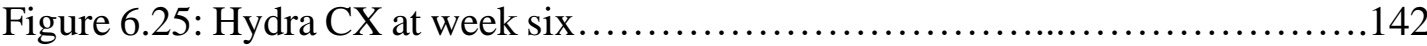

Figure 6.26: The mean root biomass $\left(\mathrm{g} . \mathrm{m}^{-2}\right)$ produced by each treatment group, the $8 \%$ guar $(n=64)$, the $10 \%$ guar $(n=64)$ and Hydra CX $(n=8)$ at the end of the six-week germination trial.

Figure 6.27: The mean final tallest shoot length $(\mathrm{mm})$ in the treatment groups

Figure 6.28: The mean above-ground biomass $\left(\mathrm{g} \cdot \mathrm{m}^{-2}\right)$ produced by the treatment group ................................................................ 146

Figure 6.29: Grass growth in the Hydra CX soil at the end of the six-week germination trial (August 2018).

Figure 6.30: Grass growth in an unamended, two-stage, 10\% guar treatment at the end of the six-week germination trial (August 2018). 148

Figure 6.31: Grass growth in a biochar, two-stage, 10\% guar treatment at the end of the six-week germination trial (August 2018) .................................148

Figure 6.32: The mean root biomass $\left(\mathrm{g} . \mathrm{m}^{-2}\right)$ produced by each treatment group......149

Figure 6.33: The mean tallest shoot $(\mathrm{mm})$ produced by the treatment groups..........151

Figure 6.34: Mean above-ground biomass produced in the treatment groups ........152

Figure 6.35: Grass growth in an unamended, two-stage, $10 \%$ guar treatment at the end of the six-week germination trial (August 2018).................................154

Figure 6.36: Grass growth in a basalt, two-stage, $10 \%$ guar treatment at the end of the six-week germination trial (August 2018) ................................... 154

Figure 6.37: Grass growth in the Hydra CX soil at the end of the six-week germination trial (August 2018). 155 
Figure 6.38: The mean root biomass $\left(\mathrm{g} . \mathrm{m}^{-2}\right)$ produced by each treatment group......155

Figure 6.39: The mean tallest shoot length $(\mathrm{mm})$ in the treatment groups

Figure 6.40: Mean above-ground biomass $\left(\mathrm{g}^{\mathrm{m}} \mathrm{m}^{-2}\right)$ produced by each treatment group.

Figure 6.41: The grass produced by the soils which contained basalt, at the end of the six-week germination trial (August 2018). 151

Figure 6.42: The grass produced by the soils which contained biochar and basalt, at the end of the six-week germination trial (August 2018). 161

Figure 6.43: Mean root biomass $\left(\mathrm{g} \cdot \mathrm{m}^{-2}\right)$ produced by each treatment group 162

Figure 7.1: The field site. The red line indicates the placement of the fencing.....173

Figure 7.2: Wooden boards were used to create consistent plot sizes 176

Figure 7.3: A) The sample bags containing the dry materials required for the base layer and top layer, and B) two bags per plot, the base layer and top layer.... 179

Figure 7.4: The seeded base layer of one plot. 180

Figure 7.5: The seeded top layer, applied on top of the base layer.... 181

Figure 7.6: One seeded Hydra CX plot 182

Figure 7.7: One seeded tailings plot. 183

Figure 7.8: The 14 replicates of the $30 \mathrm{~cm}^{2}$ unseeded tailings plots of the field trial (Nantymwyn, December 2018)

Figure 7.9: The $30 \mathrm{~cm}^{2}$ plots of the seeded tailings treatment at week 14 (Nantymwyn, December 2018). 188

Figure 7.10: Precipitation (mm) at Rhandirmwyn from September to December 2018

Figure 7.11: Daytime (red) and evening (blue) temperatures $\left({ }^{\circ} \mathrm{C}\right)$ from September to December 2018, as recorded by an in-situ data logger at Nantymwyn.

Figure 7.12: Soil-moisture deficit at Nantymwyn, September 2018 to December 2018

Figure 7.13: One plot from each $30 \mathrm{~cm}^{2}$ seeded treatments, one week after application at Nantymwyn

Figures 7.14a and b: Nantymwyn, week 2 (September 2018) of the field trial 193

Figures 7.15a and b: Nantymwyn, week 8 (November 2018) of the field trial 193

Figures 7.16a and b: Nantymwyn, week 13 (December 2018) of the field trial. 193 
Figure 7.17: The mean tallest shoot length $(\mathrm{mm})$ for each of the nine surrogate soil treatments applied during the field trial at Nantymwyn.

Figure 7.18a and b: $30 \mathrm{~cm}^{2}$ grass plots at the field trial, Nantymwyn. The grass was

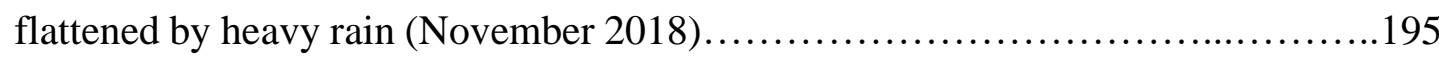

Figure 7.19: $30 \mathrm{~cm}^{2}$ Hydra CX plots at the field trial, Nantymwyn...................196

Figure 7.20: $30 \mathrm{~cm}^{2}$ Hydra CX plots at the field trial, Nantymwyn..................196

Figure 7.21: The $30 \mathrm{~cm}^{2}$ plots of the unamended treatment of the field trial, Nantymwyn.

Figure 7.22: Biomass yield (g. $\left.\mathrm{m}^{-2}\right)$ for the Hydra CX and the unamended treatment plots at the time of sampling the Nantymwyn field trial, December $2018(\mathrm{n}=7) \ldots \ldots 198$

Figure 7.23: The median proportions of dead and living grass in the Hydra CX and the unamended treatments plots after 14 weeks of the Nantymwyn field trial $(n=7) \ldots . .199$

Figure 7.24: The mean final tallest shoot $(\mathrm{mm})$ of the grass produced by the Hydra CX, the unamended treatment, and the single-amendment treatments after 14 weeks of the field trial at Nantymwyn..................................................201

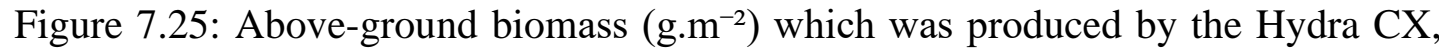
the unamended treatment, and the single-amendment treatments trialled at the Nantymwyn field trial, September to December 2018

Figure 7.26: The median proportions of dead and living grass in the Hydra CX, the unamended treatment and the single-amendment treatment plots after 14 weeks of the Nantymwyn field trial $(n=7)$. .203

Figure 7.27: The $30 \mathrm{~cm}^{2}$ plots of the biochar treatment at the Nantymwyn field trial, week 14 (December 2018). ... .203

Figure 7.28: The $30 \mathrm{~cm}^{2}$ plots of the basalt treatment at the Nantymwyn field trial, week 14 (December 2018). .205

Figure 7.29: The $30 \mathrm{~cm}^{2}$ plots of the fertiliser treatment at the Nantymwyn field trial, week 14 (December 2018). .205

Figure 7.30: The mean final tallest shoot $(\mathrm{mm})$ of the grass produced by the Hydra CX, the unamended treatment, the single-amendment, and two-amendment treatments in the Nantymwyn field trial after 14 weeks. .206

Figure 7.31: Above-ground biomass $\left(\mathrm{g} . \mathrm{m}^{-2}\right)$ which was produced by the Hydra CX, the unamended treatment, and the single-amendment and two-amendment treatments trialled at the Nantymwyn field trial, September to December 2018 .208

Figure 7.32: The 14 replicates of the $30 \mathrm{~cm}^{2}$ plots of the basalt:fertiliser treatment at the Nantymwyn field trial. 210 
Figure 7.33: The 14 replicates of the $30 \mathrm{~cm}^{2}$ plots of the biochar:basalt treatment at the Nantymwyn field trial.

Figure 7.34: The 14 replicates of the $30 \mathrm{~cm}^{2}$ plots of the biochar:fertiliser treatment at the Nantymwyn field trial.

Figure 7.35: The median proportions of dead and living grass in the Hydra CX, the unamended treatment, the single-amendment and two-amendment treatment plots after 14 weeks of the Nantymwyn field trial $(n=7)$

Figure 7.36: The final mean tallest shoot length $(\mathrm{mm})$ of the grass produced by each of the treatments in the Nantymwyn field trial

Figure 7.37: Above-ground biomass $\left(\mathrm{g} . \mathrm{m}^{-2}\right)$ which was produced by the treatments at the Nantymwyn field trial, September to December 2018.

Figure 7.38: The 14 replicates of the biochar:basalt:fertiliser treatment at the Nantymwyn field trial (December 2018) ...................................216

Figure 7.39: The median proportions of dead and living grass in treatment plots after 14 weeks of the Nantymwyn field trial $(n=7)$ 216

Figure 8.1: A) A soil plot prepared for the insertion of the sensor prongs, and B) the cables leading to a waterproof housing box which contained the data logger. 230

Figure 8.2: Erosion pin placement, indicated by yellow circles. The red line marks the fence. Nantymwyn, January 2019.

Figure 8.3: Erosion pin number 4, which measured deposition 232

Figure 8.4: The seven replicates of the $30 \mathrm{~cm}^{2}$ seeded mine tailings plots at the Nantymwyn field trial, June 2019. 237

Figure 8.5: Heavy snow in early January 2019, at the Nantymwyn field site........238

Figure 8.6: Precipitation (mm) at Rhandirmwyn from December to June 2019. 238

Figure 8.7: Day-time (red) and night-time (blue) air temperatures $\left({ }^{\circ} \mathrm{C}\right)$ from December 2018 to June 2019, as recorded hourly by an in-situ i-Button data logger at Nantymwyn....

Figure 8.8: A) A soil plot prepared for the insertion of the sensor prongs, and B) the cables leading to a waterproof housing box which contained the data logger. 241

Figure 8.9: Erosion pin placement, indicated by yellow circles. The red line marks the fence. Nantymwyn, January 2019.

Figure 8.10: Erosion pin number 4, which measured deposition.

Figure 8.11: The mean volumetric water content of the biochar soils (red, $n=4)$ and the without biochar soils (blue, $n=4$ ), at Nantymwyn, February to June 2019. 247 
Figure 8.12: Several of the $30 \mathrm{~cm}^{2}$ surrogate soil plots with a small amount of eroded material (straw) surrounding the area (March 2019).............................250

Figure 8.13: One $30 \mathrm{~cm}^{2}$ plot (biochar:basalt) throughout the 40 weeks of the

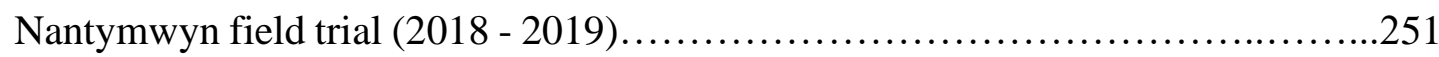

Figure 8.14: A map, produced in Cloud Compare, of the erosion pin placement (yellow circles) and the Nantymwyn field trial, 2019................................252

Figures 8.15a and b: Debris build-up at the bottom of the west-facing tailings slope at

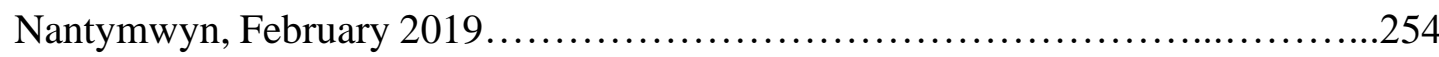

Figures 8.16a and b: Debris build-up at the bottom of the west-facing tailings slope at Nantymwyn, March 201926..............................................255

Figures 8.17a - d: One $30 \mathrm{~cm}^{2}$ plot, documented at: (a) week 22, (b) week 23, (c) week

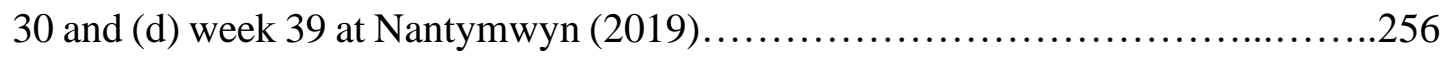

Figures 8.18a - d: One $30 \mathrm{~cm}^{2}$ plot documented at: (a) week 22, (b) week 23, (c) week

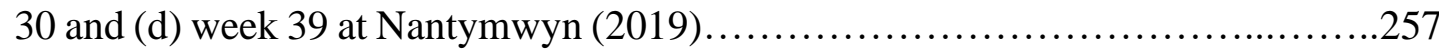

Figures 8.19a - d: One $30 \mathrm{~cm}^{2}$ plot, documented at: (a) week 28, (b) week 31, (c) week

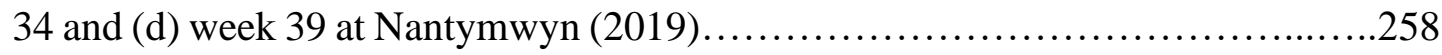

Figure 8.20: The median tallest shoot length $(\mathrm{mm})$ for each of the nine treatments from January to June 2019, at Nantymwyn. $\mathrm{N}=63$ .259

Figure 8.21: Several $30 \mathrm{~cm}^{2}$ surrogate soil plots at Nantymwyn with rain-flattened grass. March 2019. .261

Figure 8.22: The above-ground biomass yield $\left(\mathrm{g} . \mathrm{m}^{-2}\right)$ produced each treatment at Nantymwyn by week 40 (June 2019). .262

Figure 8.23: The median $\mathrm{Zn}$ concentration recorded in biomass produced by each treatment $(n=5)$, in the Nantymwyn field trial by the end of week $40 \ldots \ldots \ldots \ldots \ldots . .264$

Figure 8.24: The median $\mathrm{Zn}$ uptake $\left(\mathrm{mg} . \mathrm{m}^{-2}\right)$ recorded in biomass produced by each treatment $(n=5)$ in the Nantymwyn field trial by the end of week 40 (June 2019)...266

Figure 8.25: The median $\mathrm{Pb}$ concentration recorded in biomass for each treatment (n $=5$ ), in the Nantymwyn field trial by the end of week 40 (June 2019).... .268

Figure 8.26: The median $\mathrm{Pb}$ uptake $\left(\mathrm{mg} . \mathrm{m}^{-2}\right)$ recorded in biomass for each treatment $(n=5)$, at the Nantymwyn field trial by the end of week 40 (June 2019) ............270

Figure A1: $1 \%(\mathrm{v} / \mathrm{v})$ guar gum in $1000 \mathrm{ml}$ of soil material on a wooden board at $20^{\circ}$. .341

Figure A2: Translational slumping of the surrogate soil material (with $4 \%$ guar gum) on a wooden board at $20^{\circ}$.... 
Figures A3 and A4: Slumping of a surrogate soil (1000 ml) with $8 \%(\mathrm{v} / \mathrm{v})$ guar gum, on a wooden board at $20^{\circ}$

Figure A5: Maximum (red) and minimum (blue) daily temperatures throughout the four-week pilot trial (June to July 2018) ...................................... 348

Figure A6: One soil treatment after three weeks of the pilot germination trial 348

Figure A7: The surrogate soil pots of the germination trial, four weeks after application (July 2018). .349

Figure A8: One biochar surrogate soil plot that was situated on the north facing bank at Nantymwyn, throughout the 40 weeks of the field trial. . .

Figure A9: One basalt surrogate soil plot that was situated on the west facing bank at Nantymwyn, throughout the 40 weeks of the field trial .364

Figure A10: One fertiliser surrogate soil plot that was situated on the west facing bank at Nantymwyn, throughout the 40 weeks of the field trial. 366

Figure A11: The concentration of cadmium in the biomass produced in the Nantymwyn field trial, $2018-2019$ 375

Figure A12: The concentration of copper in the biomass produced in the Nantymwyn field trial, $2018-2019$ 376

Figures A13 A and B: Surrogate soils plots at the Nantymwyn field trial, February 2020 .

Figure A14 A and B: Grass regrowing in the surrogate soil plots at the Nantymwyn field trial, February 2020. 378

Figure A15: The location of Frongoch lead/zinc mine (in red), situated $14 \mathrm{Km}$ southeast of Aberystwyth (Wales, UK).

Figure A16: An aerial view of Frongoch lead/zinc mine (Wales).

Figure A17: Frongoch lead/zinc mine tailings, before surrogate soil was applied....380

Figure A18: Frongoch lead/zinc mine tailings, three weeks after hydroseeding with biochar (5\% v/v), straw, digestate, basalt, fertiliser, and 10\% (v/v) guar gum. 74\% ground cover was recorded (October 2018) 380

Figure A19: Frongoch lead/zinc mine tailings, seven months after hydroseeding with biochar (5\% v/v), straw, digestate, basalt, fertiliser, and 10\% (v/v) guar gum. 24\% ground cover was recorded (April 2019).

Figure A20: Frongoch lead/zinc mine tailings, 13 months after hydroseeding with biochar (5\% v/v), straw, digestate, basalt, fertiliser, and 10\% (v/v) guar gum. 36\% ground cover was recorded (October 2019). 
Figure A21: Precipitation $(\mathrm{mm})$ recorded at Trawscoed weather monitoring station,

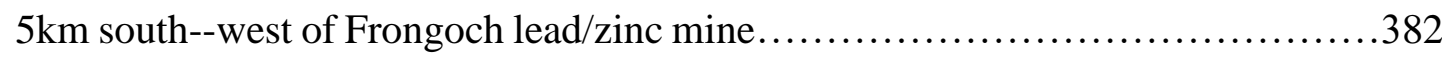

Figure A22: Precipitation (mm) at Rhandirmwyn from January to June 2019........382 


\section{List of tables}

Table 3.1: The particle size distribution of the interior $(\mathrm{n}=16)$ and perimeter $(\mathrm{n}=9)$ Nantymwyn tailings samples..................................................37

Table 3.2: The concentration $\left(\mathrm{mg} \cdot \mathrm{kg}^{-1}\right)$ of potentially toxic elements within the interior and perimeter Nantymwyn tailings samples, soil samples from a nearby pasture $(\mathrm{n}=$ and normal background concentrations of metals in UK soils (NBC).............38

Table 4.1: Hydra CX specifications as per the material safety data sheet.............52

Table 4.2: The material specifications of guar gum ...........................57

Table 4.3: The material specifications of miscanthus straw.......................59

Table 4.4: The material specifications of the anaerobic digestate..................61

Table 4.5: The material specifications of the coir..............................63

Table 4.6: The material specifications of the biochar...........................69

Table 4.7: The material specifications of the fertiliser..........................72

Table 4.8: The material specifications of the basalt...........................73

Table 5.1: Rainfall trial design - Single-stage application.......................80

Table 5.2: Rainfall trial design - Two-stage application, with 8 or $10 \%$ guar gum....82

Table 5.3: The median concentration of $\mathrm{TON}, \mathrm{NH}^{+}{ }_{4}$, and $\mathrm{PO}_{4}{ }^{3-}\left(\mu \mathrm{mol} . \mathrm{L}^{-1}\right)$ in leachate collected from the surrogate soil treatments during the rainfall simulation............90

Table 5.4: The median weight $\left(\mathrm{g} \cdot \mathrm{m}^{-2}\right)$ of eroded material, for each surrogate soil treatment, during the rainfall simulation

Table 6.1: The water-holding capacity (WHC) and $\mathrm{pH}$ of the single-stage soil treatments used in the germination trial..................................... 114

Table 6.2: The components of the soil treatments in the single-stage group..........115

Table 6.3 The water-holding capacity and $\mathrm{pH}$ of the two-stage soil treatments used in the germination trial.................................................... 118

Table 6.4: The components of the two-stage soil treatments (per pot) constructed for the germination trial................................................ 120

Table 6.5: The Hydra CX treatments constructed for the germination trial...........121

Table 6.6: The mean tallest shoot length $(\mathrm{mm})$ for each group....................133

Table 6.7: The mean weight of the dried above-ground biomass $\left(\mathrm{g} . \mathrm{m}^{-2}\right)$, for each group. 135 
Table 6.8: The mean root biomass $\left(\mathrm{g} \cdot \mathrm{m}^{-2}\right)$ for each group.

Table 6.9: The mean tallest shoot length $(\mathrm{mm})$ in each of the three treatment groups, $8 \%$ guar, $10 \%$ guar, and Hydra CX, at the end of the six-week germination trial......139

Table 6.10: Mean weight (g. $\left.\mathrm{m}^{-2}\right)$ of dried above-ground biomass that was produced by each treatment group, $8 \%$ guar, $10 \%$ guar, and Hydra CX, at the end of the six-week germination trial.

Table 6.11: The mean root biomass that was produced in each of the three treatment groups, the $8 \%$ guar group, the $10 \%$ guar group, and Hydra CX at the end of the sixweek germination trial

Table 6.12: The mean final tallest shoot length $(\mathrm{mm})$ in each of the three treatment groups, Hydra CX, the unamended treatments, and those that contained biochar, at the end of the six-week germination trial

Table 6.13: The mean weight of dried above-ground biomass $\left(\mathrm{g} \cdot \mathrm{m}^{-2}\right)$ for each of the treatment groups, Hydra CX, the unamended treatments, and those that contained biochar, and Hydra CX, at the end of the six-week germination trial 146

Table 6.14: The mean weight of root biomass $\left(\mathrm{g} \cdot \mathrm{m}^{-2}\right)$ for each of the treatment groups, the Hydra CX, the unamended treatments, those that contained biochar, at the end of the six-week germination trial

Table 6.15: The mean final shoot length $(\mathrm{mm})$ for the treatment groups, the Hydra CX, the unamended treatments, those that contained biochar, and those than contained basalt, at the end of the six-week germination trial.

Table 6.16: The mean weight of dried above-ground biomass $\left(\mathrm{g} \cdot \mathrm{m}^{-2}\right)$ for each of the treatment groups, the Hydra CX, the unamended treatments, those that contained biochar, and those than contained basalt, at the end of the six-week germination trial.

Table 6.17: The mean weight of root biomass $\left(\mathrm{g} \cdot \mathrm{m}^{-2}\right)$ for each of the treatment groups, the Hydra CX, the unamended treatments, those that contained biochar, and those that contained basalt, at the end of the six-week germination trial. .156

Table 6.18: The mean final shoot length $(\mathrm{mm})$ for the treatment groups, for each of the treatment groups, the Hydra CX, the unamended treatments, those that contained biochar, those that contained basalt, and those that contained both biochar and basalt, at the end of the six-week germination trial .158

Table 6.19: Mean weight of dried above-ground biomass $\left(\mathrm{g} \cdot \mathrm{m}^{-2}\right)$ for each of the treatment groups, the Hydra CX, the unamended treatments, those that contained biochar, those that contained basalt, and those that contained both biochar and basalt, at the end of the six-week germination trial

Table 6.20: The mean weight of root biomass $\left(\mathrm{g} \cdot \mathrm{m}^{-2}\right)$ for each of the treatment groups, Hydra CX (one treatment of 8 replicates), unamended (four treatments of 8 replicates), 
basalt (four treatments of 8 replicates) biochar (four treatments of 8 replicates) and biochar:basalt (four treatments of 8 replicates) ............................... 162

Table 7.1: The experimental design of the 11 surrogate soil treatments which were applied to the bare Nantymwyn tailings.................................... 178

Table 7.2: The mean tallest shoot length $(\mathrm{mm})$ of the grass in each of the three singleamendment treatments and the Hydra CX plots at the Nantymwyn field trial....

Table 7.3: The median weight $\left(\mathrm{g} \cdot \mathrm{m}^{-2}\right)$ of dried above-ground biomass that was produced by the Hydra CX, the unamended treatment, and the single-amendment treatments of the Nantymwyn field trial after 14 weeks.

Table 7.4: Median weight $\left(\mathrm{g} \cdot \mathrm{m}^{-2}\right)$ of living and dead biomass in each singleamendment treatment of the Nantymwyn field trial............................203

Table 7.5: The mean tallest shoot length of the grass in each of the single-amendment, two-amendment, and the Hydra CX plots at the Nantymwyn field trial.

Table 7.6: The median weight $\left(\mathrm{g} \cdot \mathrm{m}^{-2}\right)$ of dried above-ground biomass that was produced by the Hydra CX, the unamended treatment, the single-amendment and twoamendment treatments of the Nantymwyn field trial after 14 weeks.

Table 7.7: Median weight $\left(\mathrm{g} \cdot \mathrm{m}^{-2}\right)$ of living and dead biomass in each singleamendment and two-amendment treatment of the Nantymwyn field trial

Table 7.8: The mean tallest shoot length $(\mathrm{mm})$ of the grass in each of the treatment plots at the Nantymwyn field trial. The data was collected after 14 weeks, in December 2018 .

Table 7.9: The median weight $\left(\mathrm{g} . \mathrm{m}^{-2}\right)$ of dried above-ground biomass that was produced by the treatments after 14 weeks of the Nantymwyn field trial.

Table 7.10: Median weight $\left(\mathrm{g} \cdot \mathrm{m}^{-2}\right)$ of living and dead biomass in each treatment of the Nantymwyn field trial.

Table 8.1: The Agilent 4200 MP-AES detection limits for heavy metals

Table 8.2: The monthly mean temperatures $\left({ }^{\circ} \mathrm{C}\right)$ of the one bare tailings plot and the monthly mean of the nine surrogate soils plots at the Nantymwyn field trial .234

Table 8.3: The mean monthly temperatures $\left({ }^{\circ} \mathrm{C}\right)$ of the four surrogate soil plots that contained biochar and the mean temperature of the four surrogate soils plots that did not contain biochar at the Nantymwyn field trial, 2019.

Table 8.4: The monthly mean volumetric water content (\%) of the bare tailings plot (and the nine surrogate soils plots at Nantymwyn, 2019.

Table 8.5: The monthly mean volumetric water content (\%) of the four surrogate soil plots that contained biochar and the mean of the four surrogate soils plots that did not contain biochar.... .248 
Table 8.6: The mean tallest shoot length $(\mathrm{mm})$ in each of the treatment groups,

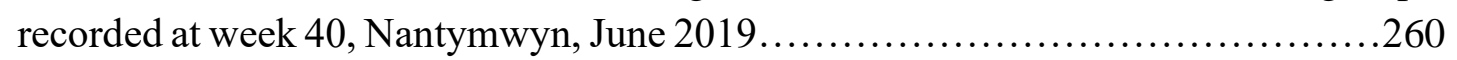

Table 8.7: The median weight $\left(\mathrm{g} . \mathrm{m}^{-2}\right)$ of dried above-ground biomass that was produced by each surrogate soil treatment at Nantymwyn by June 2019 . . .

Table 8.8: Median $\mathrm{Zn}$ concentration $\left(\mathrm{mg} \cdot \mathrm{kg}^{-1}\right)$ in the dried above-ground biomass that was produced by each surrogate soil treatment at Nantymwyn, and from the local pasture. .265

Table 8.9: Median zinc uptake $\left(\mathrm{mg} \cdot \mathrm{m}^{-2}\right)$ in the dried above-ground biomass that was produced by each surrogate soil treatment at Nantymwyn, and from the local pasture.

Table 8.10: Median lead concentration $\left(\mathrm{mg} \cdot \mathrm{kg}^{-1}\right)$ in the dried above-ground biomass that was produced by each treatment at the Nantymwyn field trial by week 40 ......269

Table 8.11: Median $\mathrm{Pb}$ uptake (mg. $\left.\mathrm{m}^{-2}\right)$ in the dried above-ground biomass that was produced by each treatment in the Nantymwyn field trial by week 40 .

Table A1: Data reported in Section 2.1: Aquaculture - The total organic nitrogen $(\mathrm{TON})$, ammonium $\left(\mathrm{NH}_{4}\right)$, and phosphate (PO4) ( $\mu$ mol.L) in the leachate samples taken from the rainsplash trials

Table A2: Data reported in Section 2.2. The total eroded material $\left(\mathrm{g} \cdot \mathrm{m}^{-2}\right)$ from each surrogate soil in the rainsplash trials

.344

Table A3: The components of the single-stage surrogate soil treatments (per pot) of the pilot germination trial. .346

Table A4: The components of the two-stage surrogate soil treatments (per pot) of the pilot germination trial

Table A5: Data reported in Figure 6.13: The mean shoot length (mm) for the grass grown in each surrogate soil treatment in the germination trial (August 2019)........350

Table A6: Data reported in Figure 6.14. The mean above-ground biomass $\left(\mathrm{g} . \mathrm{m}^{-2}\right)$ for the grass grown in each surrogate soil treatment in the germination trial.............351

Table A7: Data reported in Figure 6.15. The mean root biomass $\left(\mathrm{g} \cdot \mathrm{m}^{-2}\right)$ for the grass grown in each surrogate soil treatment in the germination trial....................352

Table A8: Data reported in Figure 7.11: The minimum and maximum daily temperatures $\left({ }^{\circ} \mathrm{C}\right)$ throughout the Nantymwyn field trial, weeks $1-17 \ldots \ldots \ldots \ldots \ldots . \ldots 353$

Table A9: Data reported in Section 7.2. The weekly mean shoot length $(\mathrm{mm})$ of each of the surrogate soil treatments at Nantymwyn, from week 2 to $143 \ldots \ldots \ldots \ldots \ldots . \ldots 356$

Table A10: Data reported in Section 7.2. The quantity of biomass (g) produced by each replicate in each surrogate soil treatment at the end of week $14 \ldots \ldots \ldots \ldots \ldots \ldots \ldots . \ldots . \ldots 356$ 
Table A11: Data reported in Section 8.2.1. Air temperature $\left({ }^{\circ} \mathrm{C}\right)$ at the Nantymwyn field trial, from weeks 18 to 40, January to June 2019.

Table A12: Data reported in Section 8.3.3. Erosion rates recorded by the erosion pins, at the Nantymwyn field trial, weeks 19 to 40 (January to June 2019). SD refers to the sample standard deviation .361

Table A13: The median shoot length $(\mathrm{mm})$ of the grass in the surrogate soil plots throughout the Nantymwyn field trial, January to June 2019. 368

Table A14: The above-ground biomass (g) recorded per plot in the surrogate soil plots at the Nantymwyn field trial, June 2019. 368

Table A15: Zinc $(\mathrm{Zn})$, cadmium $(\mathrm{Cd})$, copper $(\mathrm{Cu})$, and lead $(\mathrm{Pb})$ concentrations in biomass for each treatment in the Nantymwyn field trial, June 2019

Table A16: The uptake of zinc in biomass for each treatment in the Nantymwyn field trial, June 2019 371

Table A17: The uptake of zinc in biomass for each treatment in the Nantymwyn field trial, June 2019.

373 


\section{Abbreviations}

$\mathrm{AD}$

$\mathrm{Bt}$

CEC

DEFRA

DON

ISO

LTA

M

$\mathrm{Mt}$

MPAES Microwave plasma atomic emission spectroscopy

NBC Normal background concentrations

OM Organic matter

PTE Potentially toxic elements

PWP

USDA United States Department of Agriculture

USEPA United States Environmental Protection Agency

WHC Water-holding capacity

VWC Volumetric water content

XRF

X-ray fluorescence 


\section{Acknowledgements}

The following $\sim 400$ pages are a reflection of the huge amount of support I've had over the past several years. In particular, my wonderful network of friends and office mates, who have made the day to day office life enjoyable, and who I have learnt more from than I ever expected. I would also like to thank my livein carer (and partner), Dennis, for weathering 2020 with me, and for the endless supply of coffee and patience.

I am indebted to KESS II for being the primary funders of this research. I would also like to thank Jane and Mick Crane, who provided access to Nantymwyn, and who supplied me with many cups of tea on cold winter mornings. My thanks also go to Natural Resources Wales, in particular Paul Edwards, Tom Williams and Peter Stanley, for assisting with any query I put to them.

I am incredibly grateful to Sion Brackenbury of TerrAffix, and David Holland of Salix RW, not only for funding this research, but for the many hours of advice, support, and inspiration along the way, and without whom this would not have been possible.

I owe an incredible amount to my second supervisor, Professor Alayne StreetPerrott, who's endless patience and extraordinary knowledge has been inspiring, to say the least. I cannot imagine being at the end of this journey without having met Alayne at the start.

Finally, I cannot express enough gratitude to my primary supervisor, Dr. Iain Robertson, whose balance of humour, encouragement, and advice has provided sanity on more than one occasion. I am deeply indebted to him for his consistent support and guidance 


\section{Introduction}

A mine generates a substantial quantity of polluting waste materials during its lifetime (Falagán et al., 2017). Over the past 20 years the methods of mining have changed, and the economics of moving vast amounts of earth have improved and lower-grade ores that were once uneconomical are now obtainable. At active mines, typically $1-5 \%$ of the excavated material is usable ore, and the rest is waste. Globally, this equates to the production of $\sim 350 \mathrm{Bt}$ of mine waste annually (Lemière et al., 2015). To date, in Europe alone it is estimated that between 2.5 and 4.5 million contaminated sites exist (Bardos et al., 2018), with 6300 Mt of mine waste stored at abandoned mines sites (Letcher \& Vallero, 2011). Metal mines wastes are highly recalcitrant and can persist for centuries (Kuppusamy et al., 2016).

As mines are often located in remote areas, these operations can disturb or destroy unique habitats which host a diverse assemblage of plant and animal communities (McKenna, 2002). Two-thirds of active mines and exploration areas surveyed in 2004 overlapped with global areas of conservation value and watershed stress (Hollingsworth et al., 2007).

A mine's closure phase is costly and slow, even when well planned (Garcia, 2008; Block, 2020). As a result, until the late 1980s it was common for mines to continue to operate with annual losses and often force themselves to bankruptcy to evade the expensive closure phase, which led to a high occurrence of abandoned, unremediated mines (Carter, 2000). To date, globally, only 9\% of inactive mines are registered as closed (Churr, 2020).

When closure was instantaneous, the immediate loss of jobs resulted in lost site knowledge. In small towns the wealthiest of its population migrated, and if the town escaped economic collapse it was usually a result of substantial government assistance (Mchaina, 2000). Mines that were abandoned without closure began to negatively influence the reputation of extraction firms and impact their ability to obtain operating licenses (International Council of Mines and Metals [ICMM], 2019). For these reasons, from 2006 many governments set out legislative requirements for mine operators to produce closure plans and financial assurance against unexpected and 
instantaneous closure, sometimes with up to $90 \%$ of the expected reclamation funds requested before operations began (ICMM, 2019).

The legislative framework for enforced reclamation is of great value for the communities nearby active mines. However, as legislation was late-coming, currently more than 600,000 abandoned mines with no clear attribution of responsibility remain (Archer \& Caldwell, 2004; Mayes et al., 2009). The environmental and financial liability has often fallen to publicly-funded government bodies who require inexpensive methods of reclamation to address the numerous unremediated abandoned sites which continue to pollute the surrounding area long after closure (Beaulieu, 2001; Garcia, 2008; ICMM, 2019).

In this context, 'reclamation' refers to heavily contaminated or geologically unstable land that is transformed into a space suitable for construction or recreational use (ICMM, 2019). In the UK, until the late 1990s, statutory policy for reclamation work was limited to ensuring the geotechnical and chemical stability of a site. However, there is an increasing interest in nature-based, low-intervention reclamation processes (Parry \& Chiverrell, 2019). Contemporary reclamation policies have now expanded to combine technical activities (engineering and construction), biological activities (soils and vegetation) and biodiversity and conservation goals (Coppin, 2013; World Wildlife Fund, 2015).

\subsection{Research aims}

The primary objective of this thesis is to provide a method of metal-mine reclamation which is applicable to abandoned sites and is financially attainable for publicly funded or government bodies.

Mine wastes have a poor physical structure, a lack of organic matter and nutrients, poor water relations, extremes of $\mathrm{pH}$, and high concentrations of toxic elements. The waste is subject to accelerated erosion, due to typically being stored in steep-sided dry stacked heaps, which are devoid of vegetation. Natural pedogenic processes take decades or longer, and create only sparse revegetation (Cross et al., 2017). This research aims to develop and test a constructed soil-like cover for the hydraulic 
application to steep-sided waste heaps to assist the revegetation of bare metal-mine waste.

As the constructed surrogate soil is required to be practically applied to the mine waste, there are certain restrictions to its design which would exist in a purely theoretical study. Of primary concern, the soil-like material must be applied with a hydroseeder, as this is the only equipment suitable for applying materials to steep slopes at a distance. If the soil material cannot be applied with a hydroseeder the solution is not a practical one. Consequently, the materials used to construct the growing medium in this study may not be those which are most desirable growing medium. A balance was to be found between developing a material which can be applied in the field, from an industrial perspective, and a soil which can produce the grass growth sufficient to control erosion. The objective of this study is to begin the development process, and to start examining which materials will meet that balance in a cost-effective manner.

These objectives will be met by:

i) Investigating suitable surrogate soil materials and soil binding agents.

ii) Establishing the surrogate soil materials and binding agents most resistant to rainfall erosion using rainfall simulations.

iii) Assessing the adhesive soil's ability to support grass seed germination.

iv) Conducting an outdoor field trial on a mine to assess the surrogate soils suitability for supporting long-term plant establishment in a field environment.

The thesis is divided into nine chapters. Following the Introduction, Chapter 2 reviews contemporary nature-based reclamation methods and case studies. Chapter 3 provides the field site description, and the chemical and physical site-specific challenges to be overcome. Chapter 4 examines the surrogate soil materials used in this research. Chapter 5 describes the rainfall simulations, and in Chapter 6, the most adhesive soils are tested in a germination trial. Chapter 7 presents the results of the initial three months of the field trial, and Chapter 8 details the final months of the trial. Finally, conclusions from this study are given in Chapter 9. 


\section{Research background}

\subsection{The nature of mine wastes}

The properties of mine wastes are determined by the material mined, the extraction process, and the physical state of the remaining materials (dry stacked or sludge) (Edraki et al., 2014). Mine wastes contain hazardous substances such as heavy metals and organic contaminants, which are unevenly dispersed among the waste due to the nature of processing and storage. This results in wastes which are physically and chemically heterogeneous (Fashola et al., 2016).

Each mine poses unique challenges, and to manage mine waste effectively it is essential that the physical and chemical properties are understood.

Three major types of mine wastes are produced during the mining process: overburden, spoil, and tailings.

Overburden is the initial material removed to gain access to the ore deposits below. Overburden is stockpiled near the mine in a waste dump and can be used as a capping material in reclamation strategies, although it is often of coarse texture, low nutrient value, low organic matter (OM) content (Rai et al., 2011) and mostly composed of unweathered rocks (Yong et al., 2018).

Metal-mine spoil can be a mixture of soil, rock, and an unrecoverable quantity of the mined material (Sheoran \& Poonia, 2010). Spoil is often stored in large dumps of highly-permeable, unconsolidated and gravelly textured material (2-4 $\mathrm{mm}$ ) (Tordoff et al., 2000; Martín-Moreno et al., 2018). The nutrient content is typically very low, much lower than that of the overburden, with an OM content of $<3 \%$ and an elevated heavy metal content (Martin \& Wolfgang, 2002; Lamb et al., 2018).

Tailings constitute the bulk of mine waste, often accounting for more than $90 \%$ of the material mined (Munksguard \& Lottermoser, 2010; Kaniki \& Tumba, 2019). The term 'tailings' is a generic one used to describe the by-product of several extractive industries and therefore the specific nature of tailings varies, however, the term usually describes a mixture of crushed rock and processing fluids from the extraction and separation process (Martín-Crespo et al., 2018). 
Tailings management has been often quoted as the most pressing issue facing the mining industry (Priscu, 2017; Kaniki \& Tumba, 2019; Zinck, 2019). As the best quality deposits have been steadily depleted, the remaining ore quality has been in decline (Bowker \& Chambers, 2015). Greater quantities of ore are therefore required to yield the same volume of minerals, which creates more tailings per tonne of ore mined (Hutchison \& Ellison, 1992; Edraki et al., 2014). Approximately 7 Bt of tailings are generated each year (Mudd \& Borger, 2013).

Tailings typically contain high levels of sulphidic minerals which become reactive and unstable when exposed to oxygen and water ( $\mathrm{Li}$ et al., 2016). The oxidation of sulphidic minerals such as pyrite $\left(\mathrm{FeS}_{2}\right)$, chalcopyrite $\left(\mathrm{CuFeS}_{2}\right)$, and sphalerite ([Zn, $\mathrm{Fe}] \mathrm{S}$ ) leads to acidification and the dissolution of metals into water and creates extremes of $\mathrm{pH}$. Although oxidation can be a rapid process, in tailings, this reaction can potentially continue for centuries due to the large volumes of material and the limited diffusion of oxygen (Li et al., 2016; Falagán et al., 2017).

The mobility of metals and plant nutrients are influenced by $\mathrm{pH}$. At a lower $\mathrm{pH}$, most metals (such as lead $[\mathrm{Pb}]$ and zinc $[\mathrm{Zn}]$ ) are in their most soluble form (lead ion $\left[\mathrm{Pb} 2^{+}\right]$ and zinc ion $\left.\left[\mathrm{Zn}^{2+}\right]\right)$. At $\sim \mathrm{pH} 6.5-7$, metals precipitate out of solution into their solid phase (lead and zinc sulphide) as they react with hydroxide and become less bioavailable.

Metals are more mobile in acidic soils, whereas essential plant nutrients such as N, P,

$\mathrm{K}, \mathrm{Ca}$ and $\mathrm{Mg}$ are less mobile and therefore less bioavailable (Gutierrez et al., 2016; Touceda-González et al., 2017). Generally, plant nutrients are most bioavailable at $\sim$ pH $6.5-8$ (Xiang et al., 2009), although the relationship between $\mathrm{N}$ uptake and $\mathrm{pH}$ is very plant specific and highly dependent on the plants metabolism (Fageria \& Zimmermann, 1998). However, in most plants, as the soil $\mathrm{pH}$ increases to $>\mathrm{pH} 8, \mathrm{~N}$ becomes less available for plant uptake as an increasing fraction of soil $\mathrm{N}$ is converted from stable $\mathrm{NH}_{4}^{+}$to $\mathrm{NH}_{3}$, which can be lost to the atmosphere (Xiang et al., 2009).

A low soil $\mathrm{pH}$ simultaneously reduces nutrient mobility and increases metal mobility, which poses considerable challenges for plant establishment. Mine wastes are also very low in OM, which leads to poor germination and vegetation establishment, as well as a diminished microbial life. As no plant senescence occurs, nor does OM 
addition through plant litter, the mine waste remains bare (Figure 2.1) (Asensio et al. 2014).

As tailings support very little vegetation (Figure 2.1), the bare slopes are subject to accelerated erosion and instability (Igwe \& Chukwu, 2018). If the mine was abandoned before the tailings were placed in permanent storage, tailings are usually stored in dry stacked heaps, known as tailings dumps, which often remain at the angle of repose $\left(\sim 18^{\circ}\right)$ (Leavitt et al., 2000; McKenna, 2002). The highly permeable tailings receive almost all precipitation as deep percolation and are susceptible to slip failures. For this reason, slope instability and erosion is considered to be the greatest challenge regarding mine tailings management (Poulsen et al., 2014).

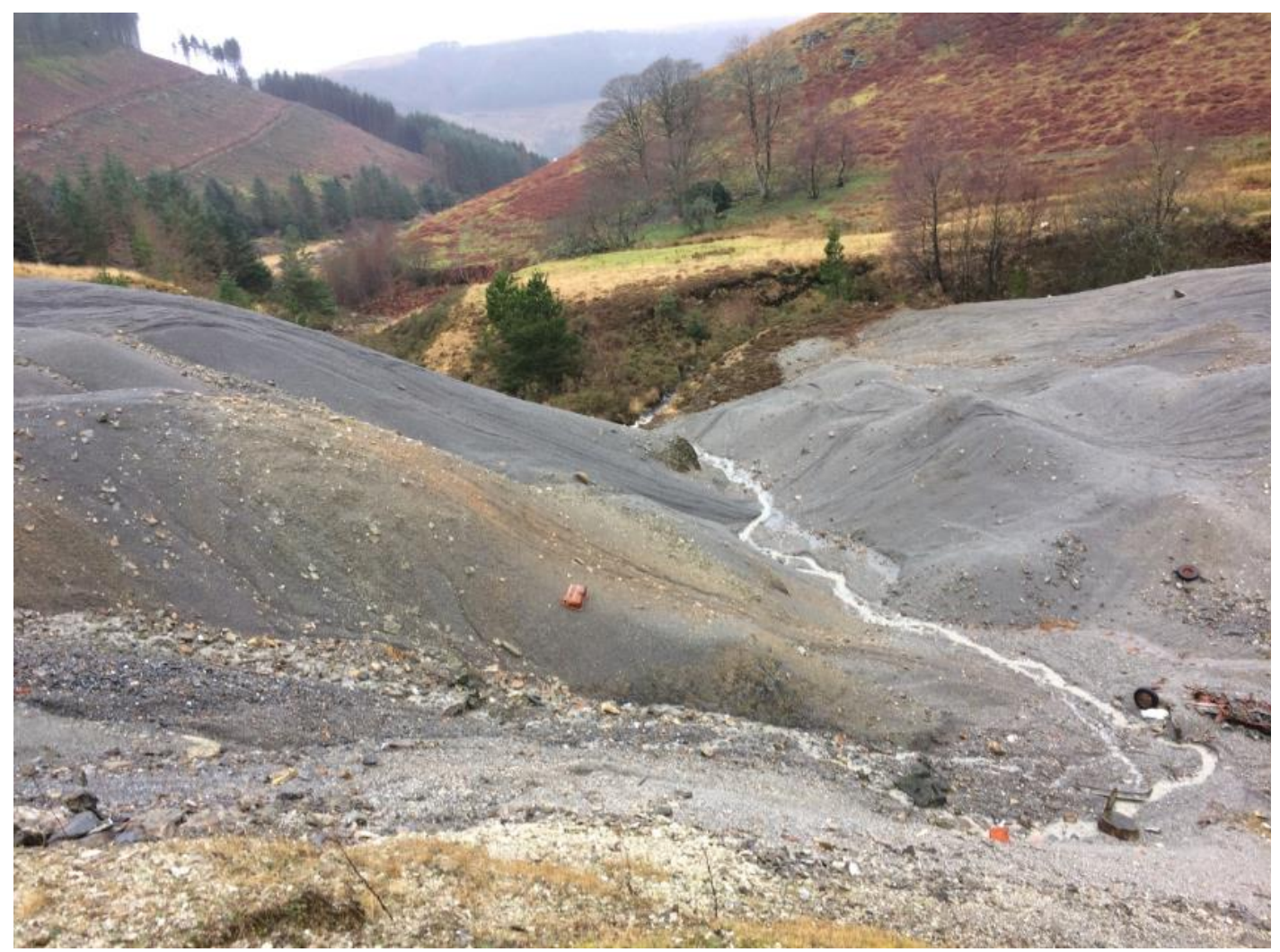

Figure 2.1: The bare tailings of the Nantymwyn Pb mine, Wales 


\subsection{Methods of remediation}

Traditional reclamation approaches rely on geochemical intervention to reduce the metal content or the mobility of the metals within the substrate (Hollingsworth et al., 2007). Many active and passive treatments strategies are available. The most widely used methods are briefly outlined in the following sections.

\subsubsection{Soil washing}

Soil washing (Figure 2.2) is the term generally applied to ex-situ techniques where the contaminated soils are excavated and washed in an extraction fluid such as triethylamine or propane. The contaminated fines and washwater then require treatment or disposal. The process has the potential to substantially reduce the volume of contaminated soil, and is often used as a pre-treatment step for other remediation techniques (Fox, 1996; Sharma \& Pathak, 2014).

Soil washing is considered an effective technique for the removal of both organic and inorganic contaminants, with a removal efficiency of $>60 \%$. However, the technology is only applicable to soils of low to moderate contamination (Kim et al., 2012). The repeated flushing cycles, the cost of transporting the tailings or the movement of the instrument to the site, as well as the costs of disposing of the contaminated fines and washwater make soil washing an expensive process. Discounting the transport of the instrument or tailings, treatment costs are typically $£ 200-250$ per ton (Surriya, 2015). 


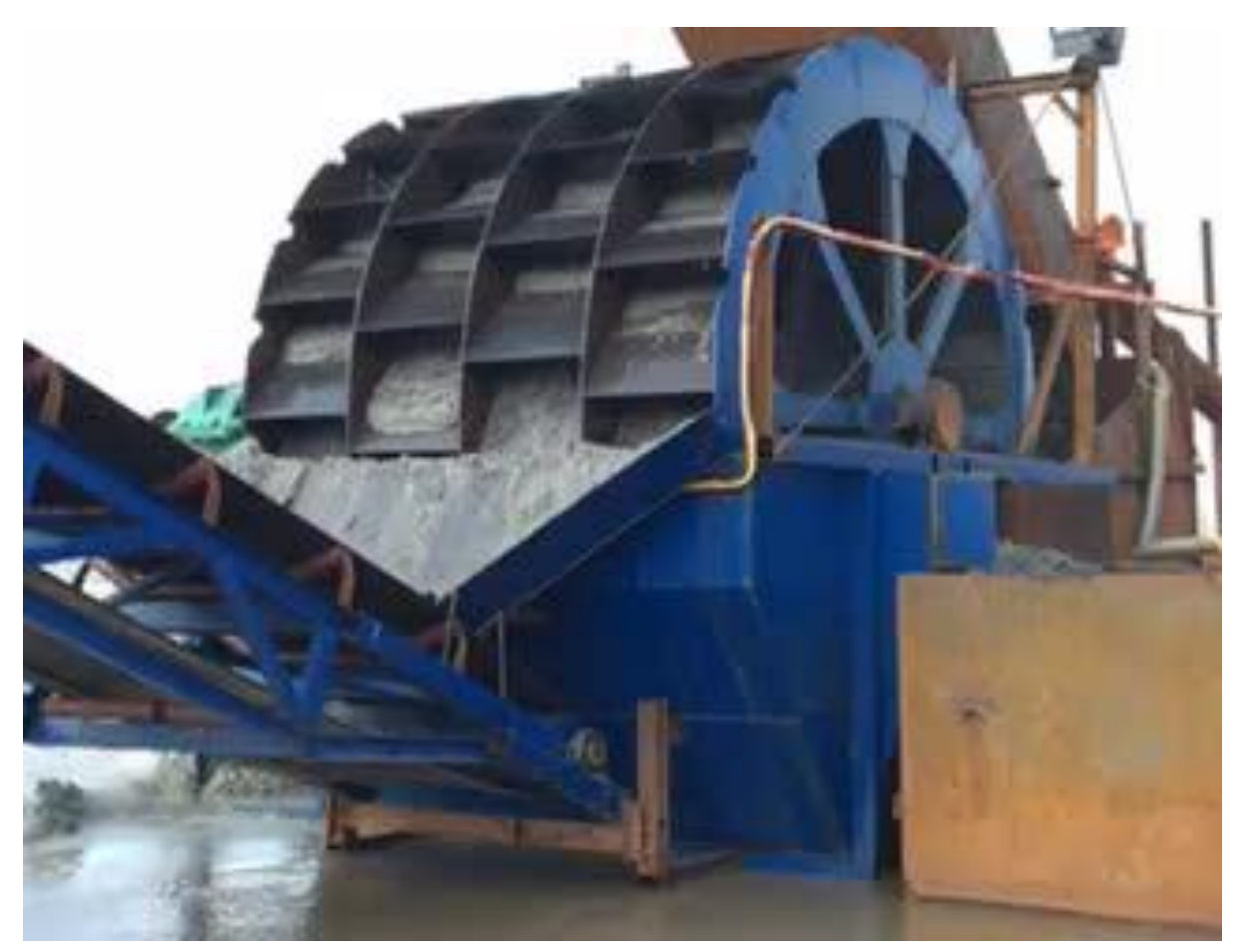

Figure 2.2: A soil washing facility (www.accumenwaste.co.uk)

\subsubsection{Stabilisation/Solidification treatment techniques}

Stabilisation/solidification ( $\mathrm{S} / \mathrm{S})$ is a widely-used remediation technique by which additives are integrated into the contaminated medium to chemically and physically stabilise the material. S/S processes improve the physical handling of the waste and reduces the surface area and solubility of the waste (United States Environmental Protection Agency [USEPA], 2012). This process may be performed either ex-situ by excavation, or in-situ by the injection of stabilising compounds such as cement, pozzolans, lime, fly ash or asphalt into the soil (Figure 2.3). Approximately $25 \%$ of the United States sites of most concern, known as Superfund sites, have undergone S/S processes (USEPA, 2012). 
As a range of additives are available, $\mathrm{S} / \mathrm{S}$ processes are considered to be one of the cheaper methods of active treatment; typically $£ 700-900$ per ton (Federal Remediation Technologies Roundtable [FRTR], 2018). However, while the process itself may be inexpensive, the addition of stabilising compounds substantially increases the mass of the waste. The waste is also required to be stored in a sealed repository which adds considerable costs to the project.

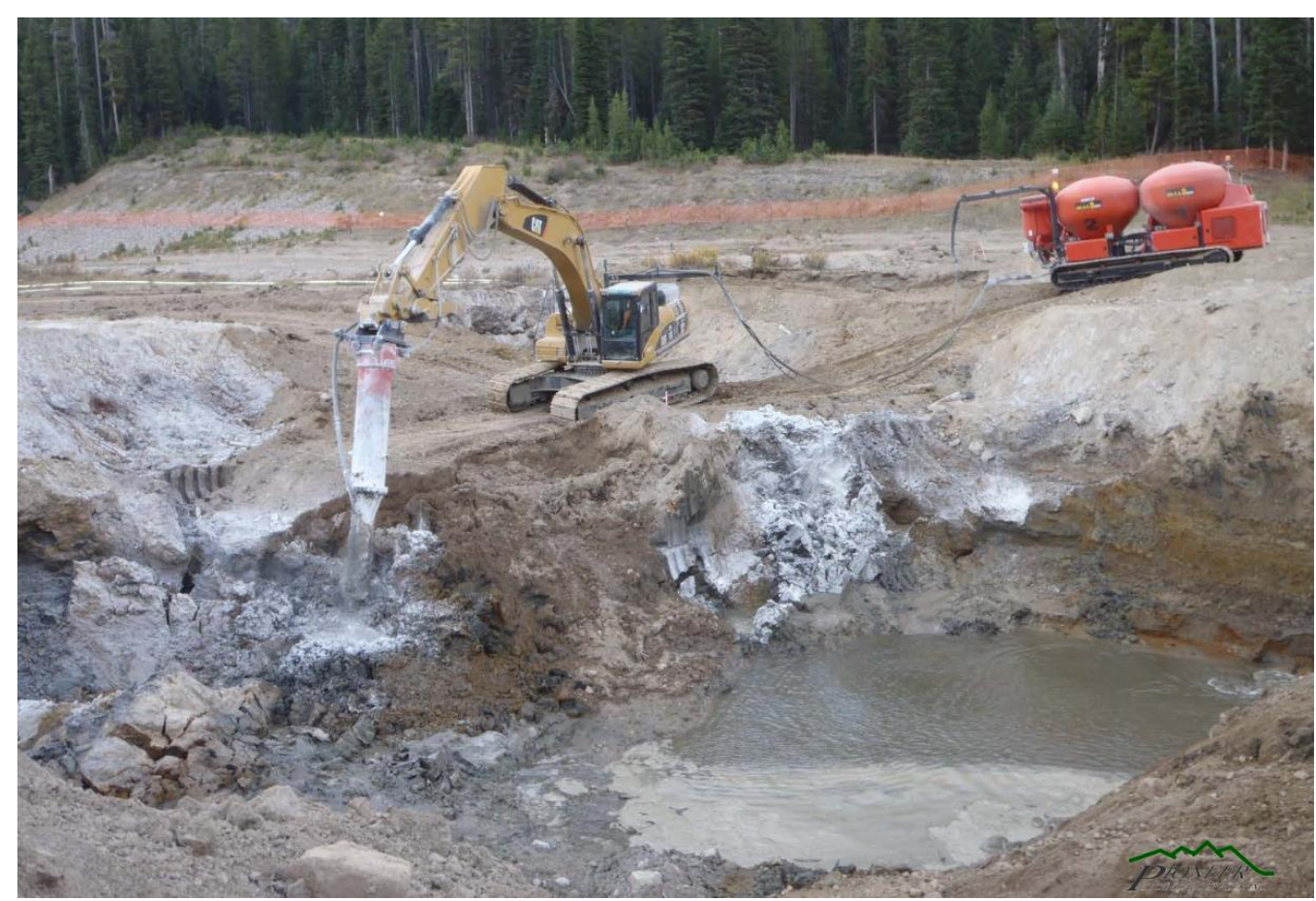

Figure 2.3: The integration of lime and cement into gold mine tailings at the McLaren Gold Mine site, Montana (M. Davin, The McLaren Tailings Reclamation Project 2019, pers. comm.)

\subsubsection{Cap and cover systems}

While many contemporary closure plans still include the previously discussed methods, reclamation practices are transitioning away from hard-engineering solutions and towards passive treatment systems. International closure regulations now recognise the impact of climate change on mine-related infrastructure, and modern closure plans require the design of systems that can be responsive to a changing climate (O’Kane \& Ayres, 2012). 
To ensure the future protection of people and the environment, regulations now require a post-closure plan of 1000 years (Mcleary, 2009; Slingerland \& Beier, 2018). It is widely agreed that hard-engineering solutions for tailings management are not adaptable to climate projections 1000 years from now (O'Kane \& Ayres, 2012). As a result, the preference for active treatments have been surpassed by passive, naturebased solutions (Pauleit et al., 2017). The most desirable method for the surface stabilisation of mine wastes is broadly accepted to be by vegetation (Tordoff et al., 2000).

Vegetation as a soil reinforcement is a well-understood method of slope stabilisation. Most soils have a very low tensile strength which can be improved greatly by the roots of vegetation, an increase of $\sim 400 \%$ compared to that of unrooted soils (Burylo et al., 2011; Wieder \& Shoop, 2017). The provision of biomass also reduces soil erosion by intercepting and dispersing raindrops, which slows the velocity and improves transpiration rates (Operstein \& Frydman, 2000). The ultimate aim of a cap and cover system is, therefore, to provide an environment which will assist the establishment of a vegetative cover and restore the mine surface to a stable, natural condition and limit erosion (O'Kane \& Ayres, 2012).

Tailings are often graded before a cap and cover system is applied. Re-grading involves the use of bulldozers to shape the overburden into a landform with slopes and drainage patterns that create geotechnical stability and blend in with the natural topography (Simcock \& Ross, 2018). Once bulk-reshaping is complete, the tailings are capped with a geotextile liner to reduce water infiltration and create a barrier between the tailings and the soil cover layer (Figure 2.4).

A capping layer of soil is applied to the surface of the geotextile liner. The thickness of a cap is usually defined by the regulatory authorities but is also dependent on the mine waste and the local availability of adequate capping material (Davies et al., 2016). 


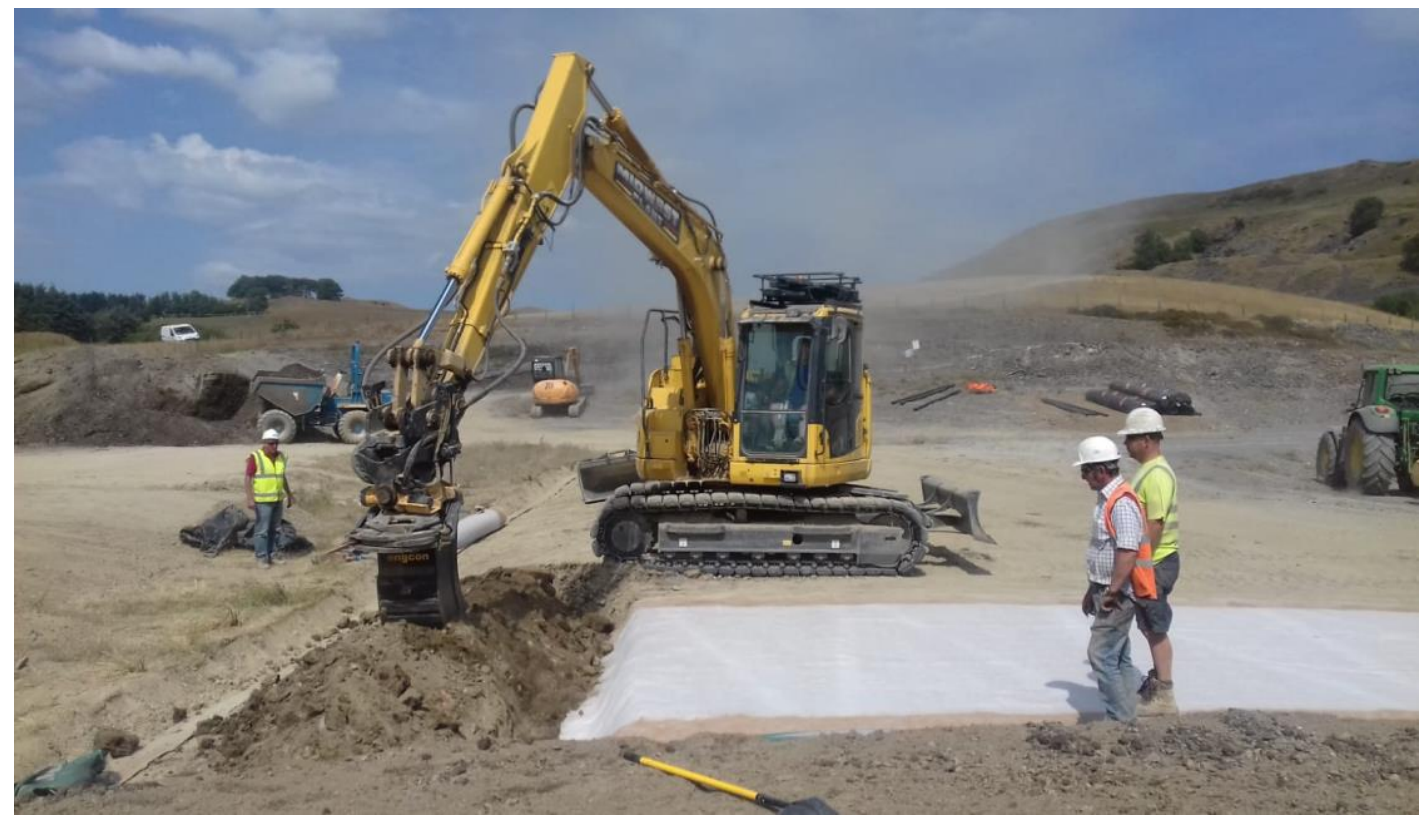

Figure 2.4: A geotextile liner being applied to the re-profiled tailings at Frongoch Pb/Zn mine, Wales (A. Brown, 2018, pers. comm)

Deep caps $(0.5-1 \mathrm{~m})$ are mostly composed of a thick layer of rocky material from a donor site, or overburden where available, and capped with a shallow layer of topsoil (CIRIA, 2017). The thick barrier layer between the tailings and the plant roots enable deep caps to support a diverse community of vegetation and trees with less risk of vertical transmission of contaminants (Tsegaye et al., 2007). Despite being limited to application on flat ground and shallow slopes, and the greater material requirements, deep caps are by far the most common form of cap and cover systems (United States Department for Agriculture [USDA], 2019).

Shallow caps $(<0.5 \mathrm{~m})$ can be applied to steeper terrain and are lower cost (Arnold $e t$ al., 2015; USDA, 2019). Shallow caps have a more complex composition and are predominantly composed of a combination of organic materials with a binding agent. The lower self-mass of the thin soil layer does not require the re-profiling of the landscape. However, the vegetation that can be supported is limited to shallow-rooting plants that will not pierce the liner below (Kingsbury, 2008; Lamb et al., 2014). 


\subsection{Case Studies}

Cap and cover systems are common for coal mine reclamation (Angel et al., 2008; Willscher et al., 2010; Bolan et al., 2014), however, to date, examples of successful metal-mine reclamation projects using this method are limited. Nonetheless, those reclamation projects which have been successful have taken a similar approach. Careful characterisation of the tailings was conducted, and the main limitations to plant growth were identified before appropriate remedial treatment was formulated. Many studies were preceded by small-scale pot trials followed by field trials (Tordoff et al., 2000; Gil-Loaiza et al., 2016).

Revegetation relies on the provision of a suitable soil environment. Studies which have self-evaluated as either unsuccessful or a partial success have often discussed an inadequate soil medium lacking in OM (Leavitt et al., 2000; Tordoff et al., 2000). One such study (Courtney, 2018) was conducted at Tara Gold Mine, Ireland, where $100 \mathrm{~kg} \cdot \mathrm{ha}^{-1}$ NPK fertiliser was applied to the bare tailings and seeded with metaltolerant grass cultivars (Festuca rubra, Agrostis stolonifera, and Agrostis capillaris). A complete loss of seedlings occurred within 12 months. A similar study by Leavitt et al. (2000) applied fertiliser to overburden and also reported large seedling losses $(\sim 60 \%)$. In both cases, the authors comment that the seedlings failed due to drought and nutrient deficiency rather than toxicity, which an OM layer would have mitigated. The same result has been reported in other cases where tailings were seeded and fertilised but no OM was applied (Hester \& Harrison, 1997; Yao et al., 2012; Davies et al., 2016).

The most effective cap and cover systems have been those which included a high OM capping material. Reclamation work conducted at Frongoch $\mathrm{Pb} / \mathrm{Zn}$ mine (Wales) is an example of a simple but effective approach (Figure 2.5). The tailings were re-profiled and a clay liner was applied. The liner was capped with $300-450 \mathrm{~mm}$ clay and finished with $100 \mathrm{~mm}$ of soil (Atkins, 2015). Agrostis capillaris (common bent) was seeded at 0.3 g.m $\mathrm{m}^{-2}$. One year later ground cover was assessed as $~ 55 \%$ (R. LawCooper, 2019, pers. comm). The cost of the liner and cover material was $\sim £ 12 . \mathrm{m}^{-2}$, with additional costs associated with the re-shaping of the tailings (P. Edwards, 2019, pers. comm.). 

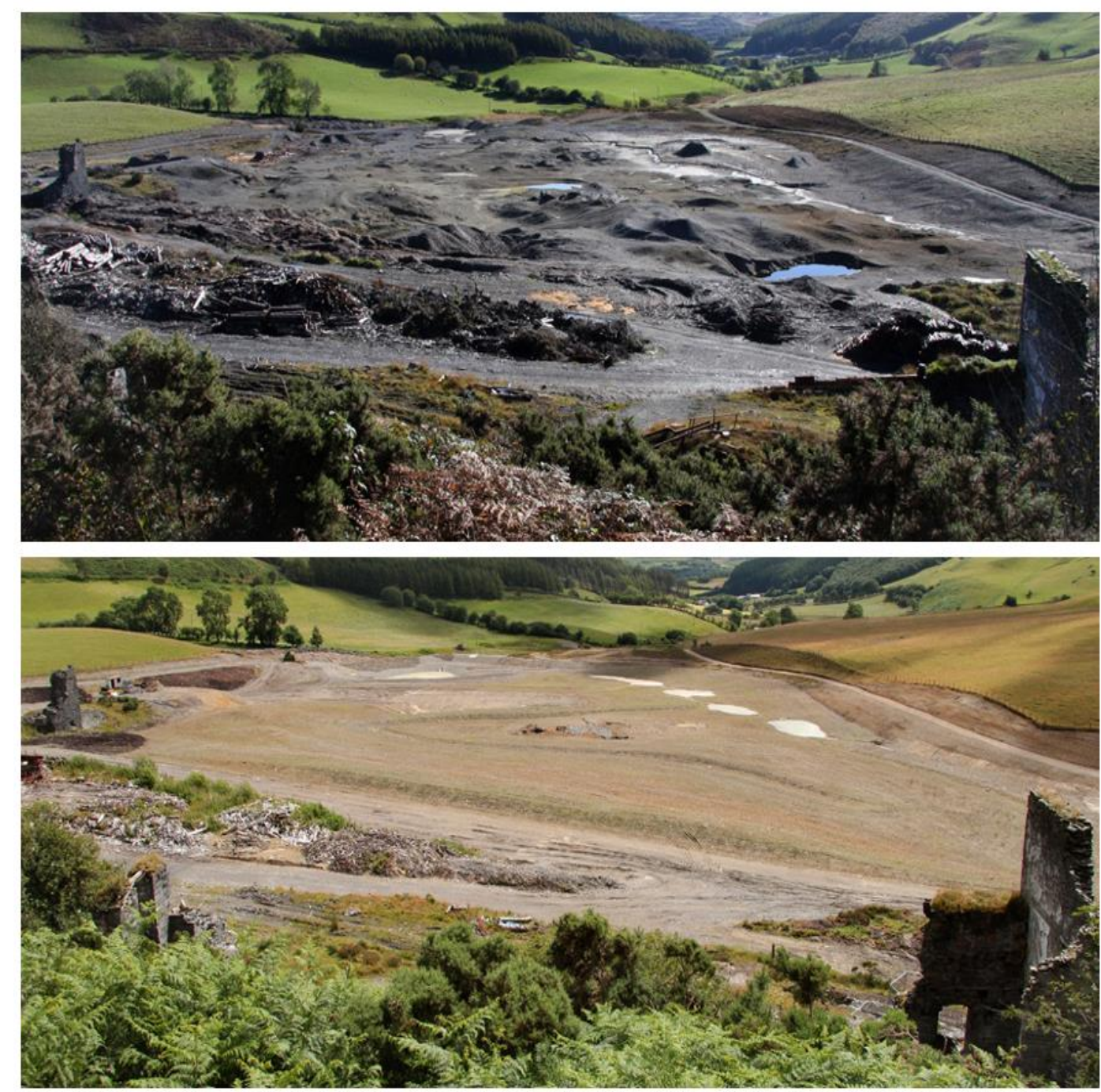

Figure 2.5: Frongoch Pb/Zn mine before (top, 2010) and after (bottom, 2016) a deep cap and cover system was applied (Edwards et al., 2016)

Currently, the most successful example of the revegetation of metal-mine tailings was a two-year field trial by Touceda-González et al. (2017) in Spain. The tailings were graded but not capped with a liner (Figure 2.6). Instead, compost was integrated into the top $50 \mathrm{~cm}$ of the surface (1:3 compost: tailings).

Initially, during a period of high temperatures and low precipitation $>65 \%$ seedling mortality occurred (Touceda-González et al., 2017). The grasses used, Agrostis capillaris, are cool-season grasses which suffer with direct and intense sunlight (Lyons et al., 2007). However, at the end of the two-year study the grass had recovered and had produced $>300$ g.m $\mathrm{m}^{-2}$ of biomass (Figure 2.7). 


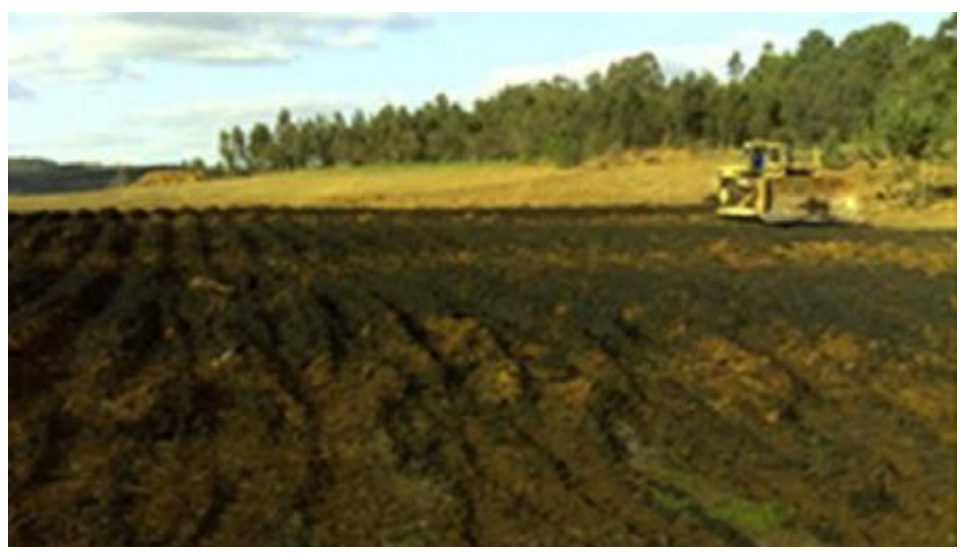

Figure 2.6: The graded tailings at Touro Copper Mine (Touceda-González et al., 2017)

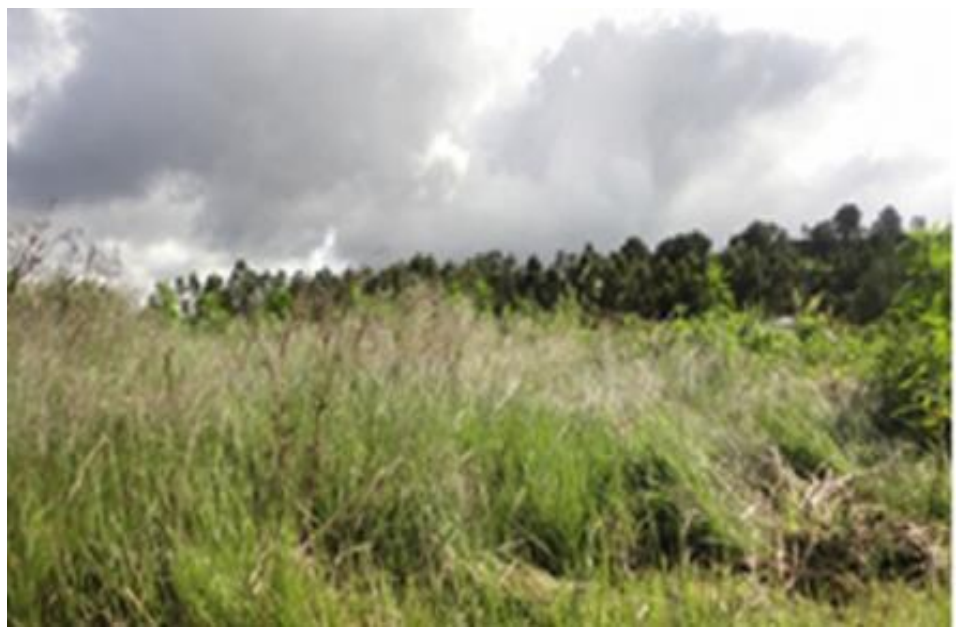

Figure 2.7: Three years growth of Agrostis capillaris after the integration of compost into the tailings at Touro Copper Mine (ToucedaGonzález et al., 2017)

Many factors contributed to the success of the study conducted by Touceda-González et al. (2017). The re-profiling of the tailings reduced soil erosion and eliminated the downslope movement of water, nutrients, and seeds. A substantial quantity of compost was integrated into the tailings, which provided the structure, water-holding capacity (WHC) and nutrients necessary for seedling establishment. The integration of compost into the tailings aided substantial plant growth, despite the direct contact between the Agrostis grass and the tailings. This demonstrated the metal tolerance of the species used, the impact of OM on plant production, and the ability of $\mathrm{OM}$ to dilute the metals.

While the costs of this method were not discussed, it can be assumed that the machinery intensive operation was costly over large areas. The usual method of reclamation, capping with overburden and seeding, is not nearly as involved as the method undertaken by Touceda-González et al. (2017), and a similar degree of soil movement can cost $£ 25-45 . \mathrm{m}^{-2}$ (Kingsbury, 2008). 
One study (De-Quincey, 2017) explored a lower-intervention method, and demonstrated that compost is not required to be integrated into the tailings, nor is a geotextile barrier required, and metal-tolerant grasses can survive in tailings simply capped with compost. In a three-month outdoor pot trial, $\mathrm{Pb} / \mathrm{Zn}$ mine tailings were capped with $5 \mathrm{~cm}$ of municipal compost amended with basalt $(0.5 \% \mathrm{v} / \mathrm{v})$, cockleshell $(0.5 \% \mathrm{v} / \mathrm{v})$ and biochar $(5 \% \mathrm{v} / \mathrm{v})$. Biochar is discussed further in Chapter 4.2. In three months, the soil cap produced $\sim 25$ g.m ${ }^{-2}$ of biomass and the grass roots had grown through the soil cap and into the tailings (Figures 2.8 and 2.9). As the majority of the reclamation costs are associated with the re-shaping of the tailings (Kingsbury, 2008; Arnold et al., 2015), if it were possible to apply a shallow cap to mine tailings without the need for grading the tailings and integrating the materials into the surface, the costs can be substantially reduced.

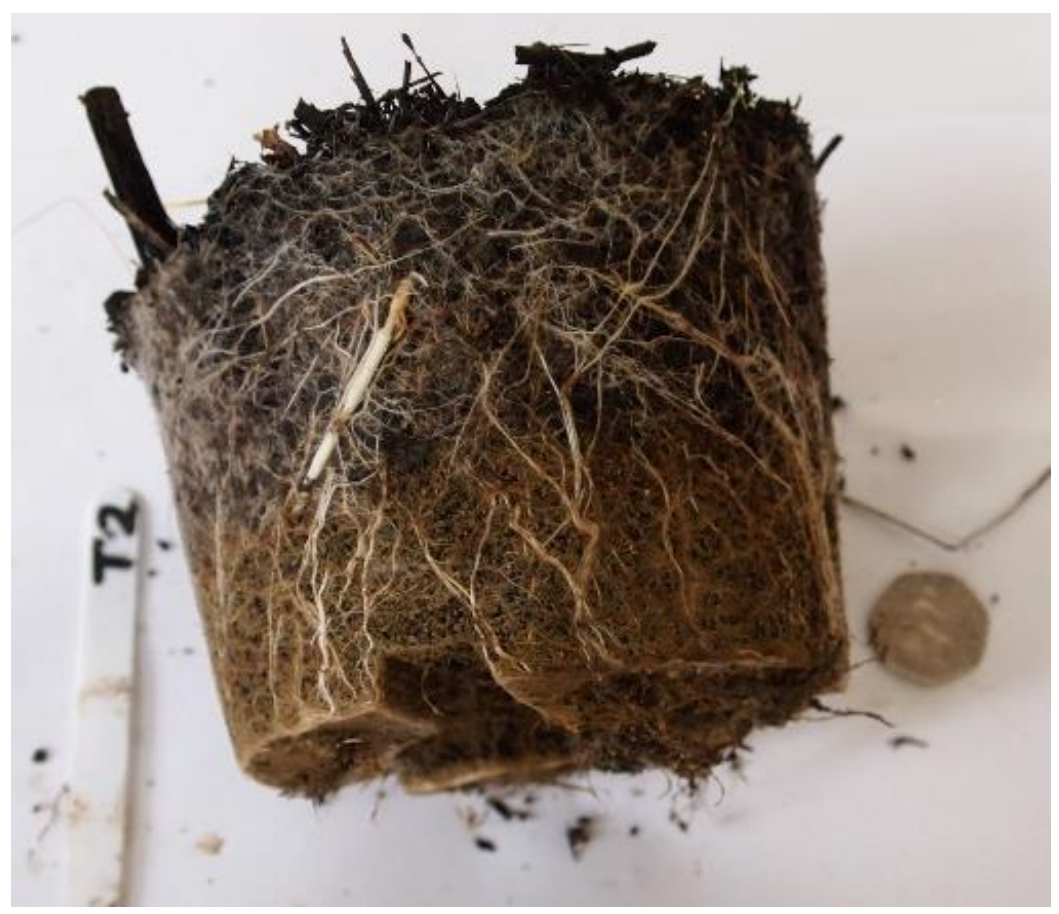

Figure 2.8: Grass roots growing in Pb/Zn tailings capped with 3" of compost with 5\% (v/v) biochar (De-Quincey, 2017) 


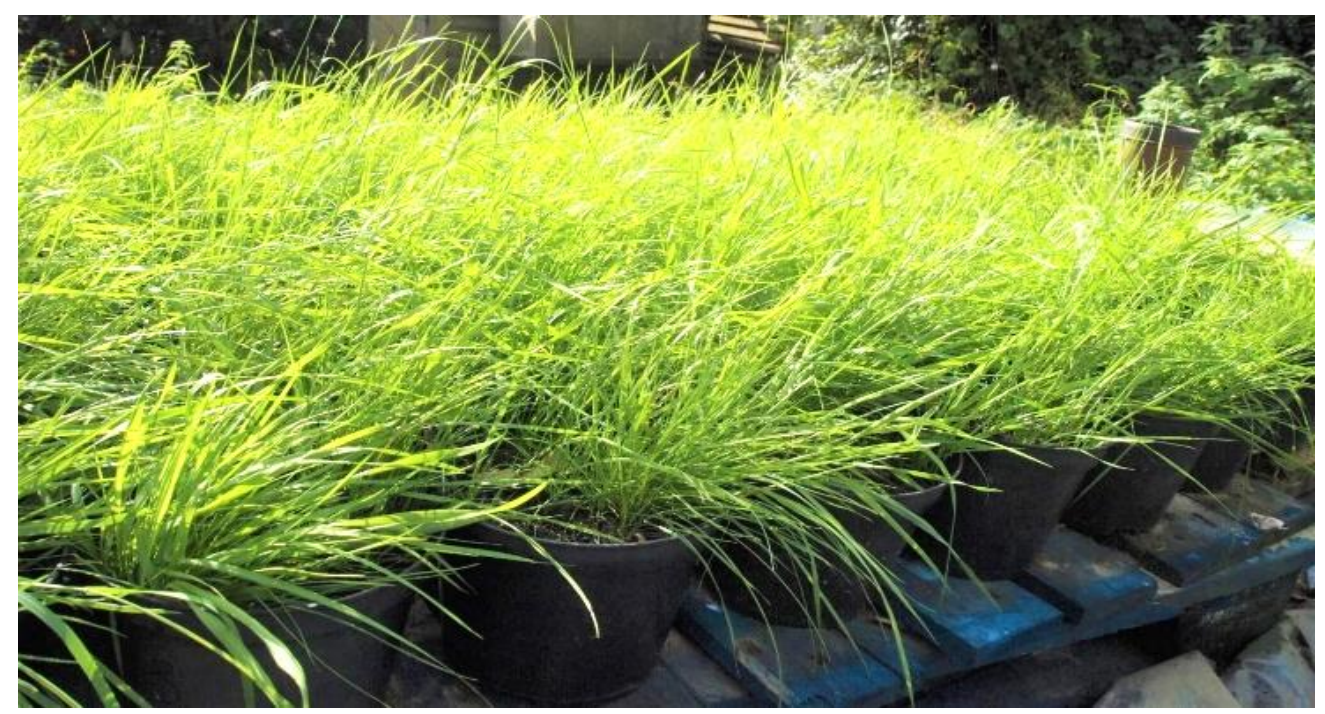

Figure 2.9: Grass growth at the end of a three-month pot trial. Metal-mine tailings, capped with $5 \mathrm{~cm}$ of compost and $5 \%(\mathrm{v} / \mathrm{v})$ biochar, and seeded with metal-tolerant species (De-Quincey, 2017)

\subsection{Hydroseeding}

Where it is not possible or cost-effective to reduce slopes with heavy machinery, soils have been applied to steep slopes by hydroseeding (Martínez-Ruiz et al., 2007; Kingsbury, 2008). Hydroseeding is the hydraulic application of a homogeneous slurry of seed, fertiliser, binding agent and mulch from either the top or bottom of the slope (Fields-Johnson et al., 2009) (Figure 2.10).

Hydroseeding is a technique regularly used to revegetate construction sites (Soupir et al., 2004), golf courses (Donze \& Lanze, 2015), road embankments (Dunifon et al., 2011) and riverbanks (Panagopoulos, 2014). Numerous studies report the successful use of hydroseeding for coal spoil reclamation in alpine environments (Simcock \& Ross, 2018), on coarse, nutrient-poor overburden (Willscher et al., 2010) and on steep, exposed slopes (Ross et al., 2003).

Despite multiple reports of the application of hydroseeded soils to coal mine spoil, examples of hydroseeding metal-mines are so sparsely documented that the details are difficult to ascertain. Tynach $\mathrm{Pb} / \mathrm{Zn} / \mathrm{Cu}$ Mine in Ireland is one such case. It is briefly referenced by Courtney (2018) however, no technical documents exist. Another such case is that of the Jelšava Mg Mine, Slovakia (Fazekaš et al., 2018), but again, no technical details are provided. 


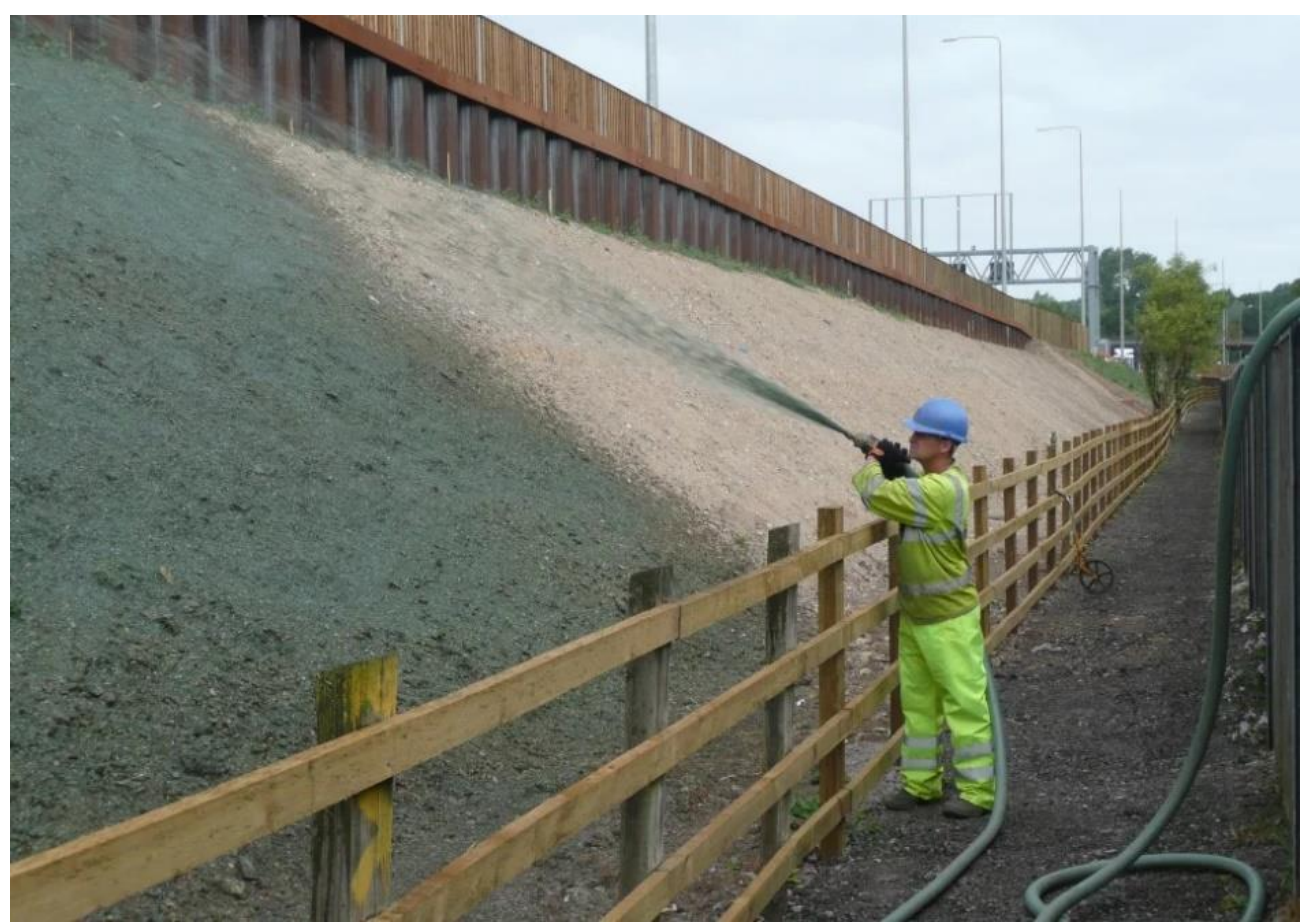

Figure 2.10: Hydroseeding a $45^{\circ}$ railway embankment slope (www.Salixrw.com)

The lack of trials at metal mines is possibly a result of the numerous challenges of hydroseeding such a hostile environment. Hydroseeding machinery requires the soil to be in the form of a slurry. A wet soil material has a greater self-mass than a dry one, therefore only a shallow cap can be applied to slopes. A strong adhesive binding agent is necessary to adhere the soil to the slopes, and it is essential for the binding agent to resist rainfall erosion until the vegetation has anchored the soil. The soil is also required to provide all the necessary properties to aid rapid germination in only a thin cover. An inadequate soil cover can delay germination, and erosion can ultimately lead to the failure of the entire soil cap (Tordoff et al., 2000).

Despite the numerous challenges of hydroseeding steep metal-mine tailings, one study to date has reported the successful revegetation of bare slopes at Hope Silver Mine, Colorado (Anawar et al., 2015; Aspen Center for Environmental Studies [ACES], 2017) (Figure 2.11).

At Hope Mine, the slopes were covered with a coir mesh netting and hydroseeded with a $5 \mathrm{~cm}$ deep layer of compost, biochar $(5 \% \mathrm{v} / \mathrm{v})$ and seeds. The compost layer was capped with an erosion protection layer which contained a hydrocolloidal binding agent (M. Williams, 2017, pers. comm.). 


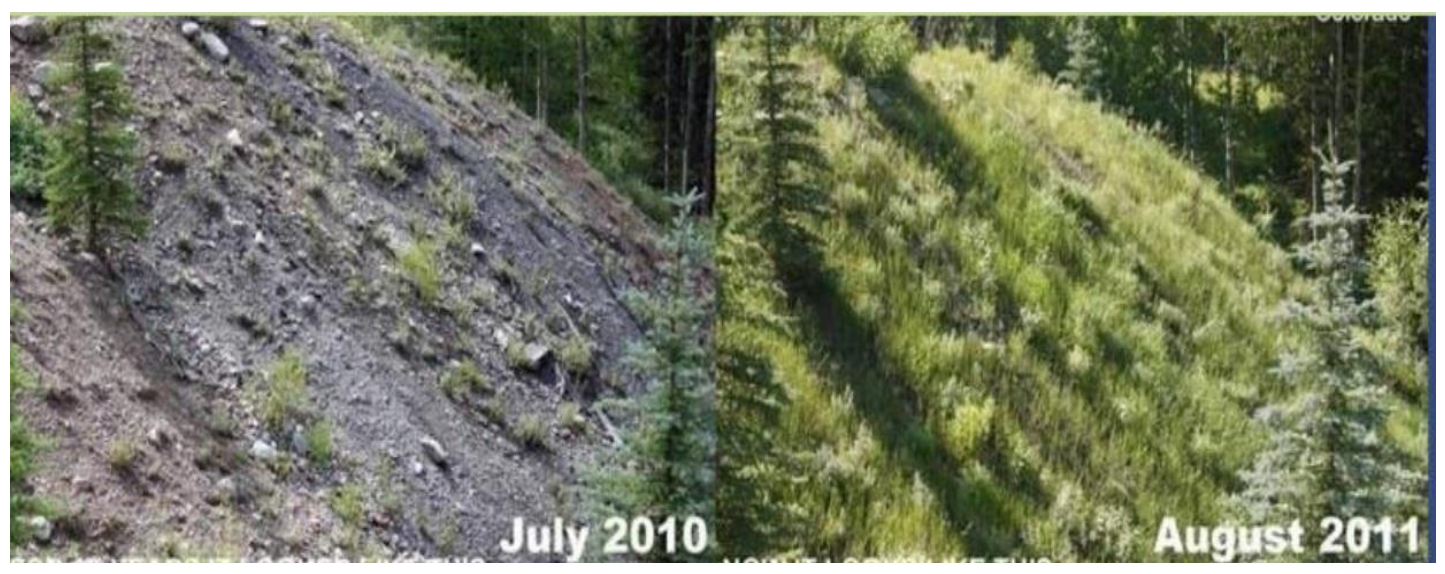

Figure 2.11: Hope Silver Mine before (July 2010) and after (August 2011) hydroseeding silver mine tailings with a biochar compost (M. Williams, pers. comm., 2017).

The compost and biochar blend was reported to increase plant growth by $313 \%$ in one year. However, the river downhill undercut the bank and the re-contouring of the slope became crucial for safety. The re-contouring damaged the site and monitoring was ceased (M. Williams, 2017, pers. comm.). Due to the abandonment of the experiment the details regarding this trial are not well reported, and the long-term results are not known.

\subsection{Conclusions}

Metal-mine tailings are among the most ecologically hostile environments for vegetation (Tordoff et al., 2000). A poor physical structure, a lack of organic matter and nutrients, poor water relations, an extreme of $\mathrm{pH}$, and high metal concentrations are some of the issues which must be fully resolved for revegetation to be successful (Mendez et al., 2007; Gutierrez et al., 2016; Venkateswarlu et al., 2016). Natural soil forming processes take decades or longer, and on mine sites create only a sparse vegetative cover (Cross et al., 2017). Thus, the most effective, economical, and timely method of establishing a soil is to introduce one.

Decades of field-based research has affirmed the efficacy of cap and cover systems for metal-mine reclamation (Harley, 1976; Bradshaw, 1997; O’Kane \& Ayres, 2012). However, the traditional cap and cover systems can be prohibitively expensive in the case of abandoned mines where publicly funded bodies bear the costs (USDA, 2019). Contemporary research has shown that low-intervention methods which involve the 
application of hydroseeded shallow caps can yield promising results (ACES, 2017). This method has led to the successful and long-term revegetation of coal mines (Kingsbury, 2007; Willscher et al., 2010; Simcock \& Ross, 2018). The trial at Hope Mine (ACES, 2017) indicated that a hydroseeded shallow cap can also be applied to metal-mine tailings with encouraging preliminary results.

The outcomes of previous trials have indicated that for a surrogate soil to produce successful grass growth several challenges must be overcome. The soil is required to:

i) Adhere to both coarse and fine-grained surfaces, due to the heterogenous nature of mine tailings. Once the soil has adhered, it must be resistant to prolonged rainfall.

ii) Contain recalcitrant materials to ensure a sustained cover of the tailings and provide a lasting growth medium for the grasses.

iii) Provide the available nutrients necessary for rapid and sustained plant growth.

iv) Have an appropriate water-holding capacity, which can retain an available water and soluble nutrient supply for plant hydration, yet was free-draining as not to cause soil deformation through an increased self-mass, and;

v) The resulting soil was required to be highly viscous, with materials of $<2 \mathrm{~mm}$ in size to enable application with the hydroseeder.

The plant species used are required to be metal-tolerant and fast-growing, to produce a rapid ground cover and root structure in order to control erosion. 


\section{Site description introduction}

An abandoned mine was chosen for the field trial location, the details of which are presented in Section 3 of this thesis.

The following Site Description is divided into two parts. The first part (Section 3.1) details the methods used for the analysis of the mine tailings taken from the field trial location. The subsequent section (Section 3.2) describes the location of the mine, the historic weather records, the vegetation on site and the results of the analyses. Section 3.2 concludes with a discussion of the results. These analyses allowed a suitable surrogate soil type material to be designed to overcome the limitations to plant growth at the mine. 


\subsection{Site description - Methods of analysis}

This section describes the methods used to obtain the field data in Chapter 3.2.

\subsubsection{Mapping}

A drone fitted with aerial LiDAR surveying equipment was flown over the Nantymwyn field site by Jakob Iglehaut. The surveying equipment captured 300,000,000 individual images, which were photogrammetrically processed to create a $2 \mathrm{D}$ and $3 \mathrm{D}$ geospatial data map in the mesh processing software Cloud Compare (Figure 3.1). All maps included in this work were produced by the author.

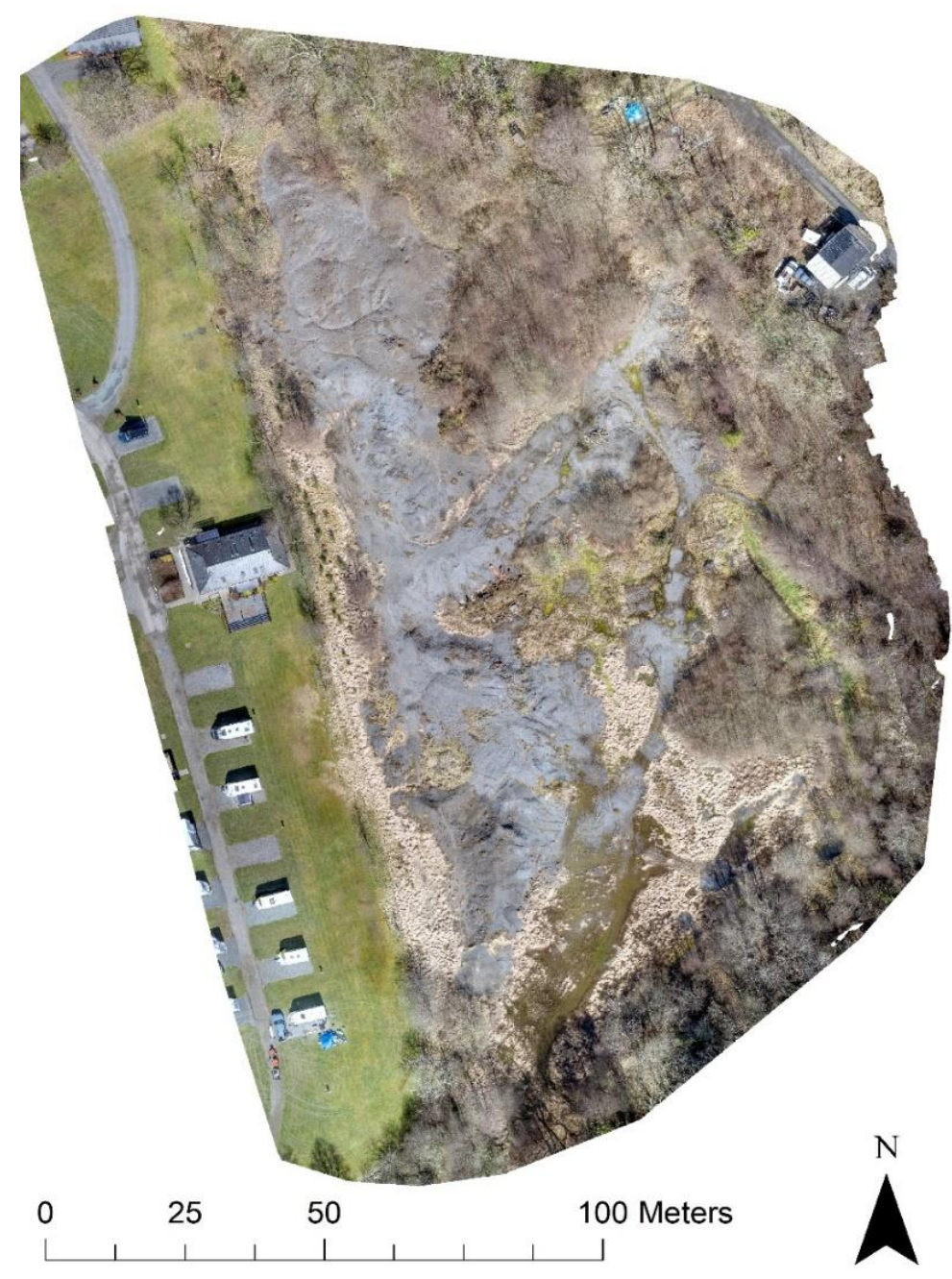

Figure 3.1: An aerial map of the Nantymwyn field site (2018), created using Cloud Compare 


\subsubsection{Substrate sampling}

Surface tailings samples $(100-150 \mathrm{~g})$ were collected from 25 randomly chosen areas of the field trial site. The samples were taken using a handheld UMS soil corer (55 mm diameter, $80.16 \mathrm{~cm}^{3}$ volume) from the top $35 \mathrm{~mm}$ of tailings and were transferred to individually labelled $350 \mathrm{ml}$ plastic containers. A Garmin EPX 10 GPS unit was used to record the origin of the samples, and the coordinates used to plot the locations on a map (Figure 3.2).

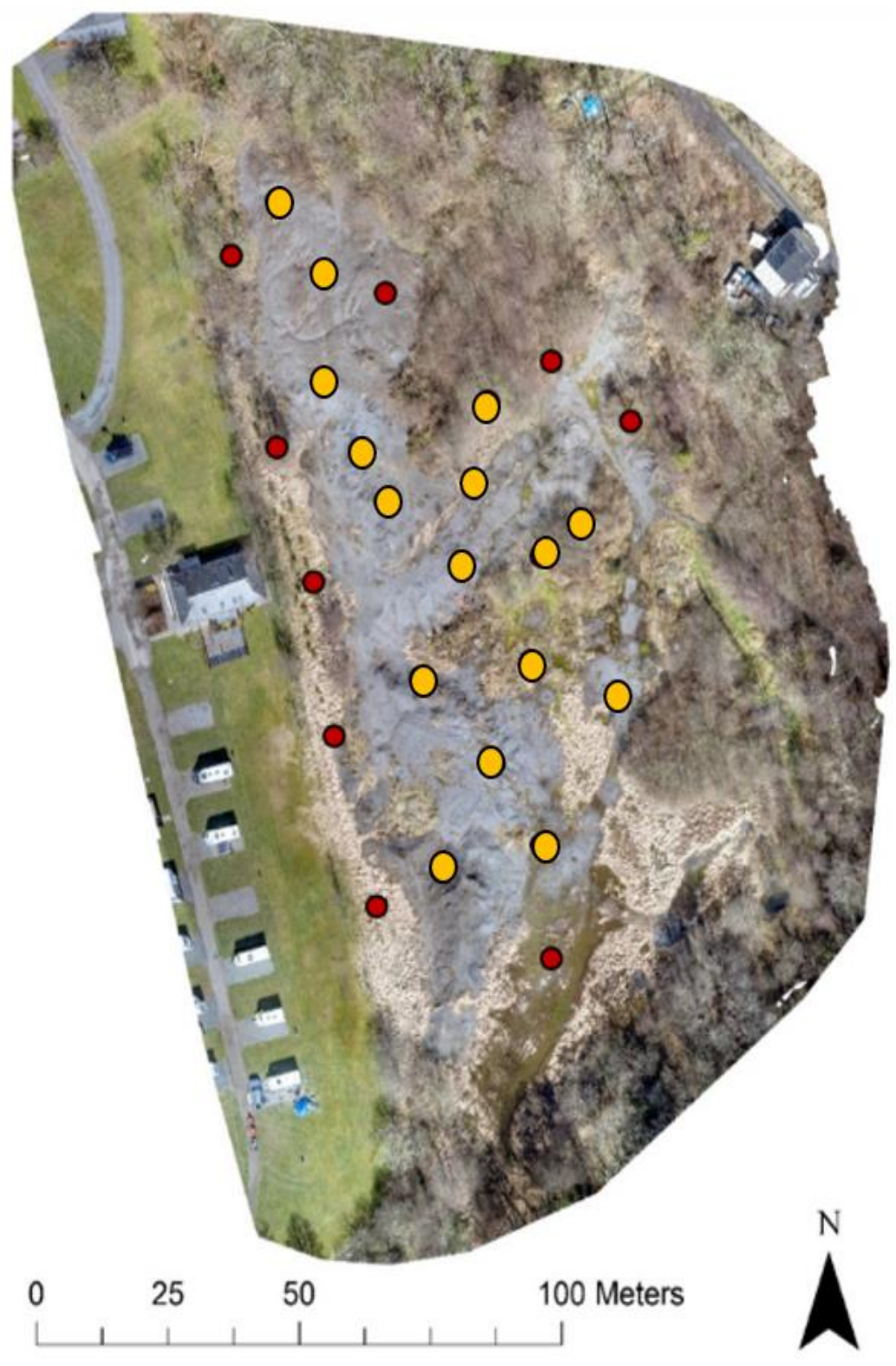

Figure 3.2: An aerial map of the Nantymwyn field site (2018) with the locations from which the substrate samples were taken. Interior samples were taken from the locations marked with yellow dots, and perimeter sample locations are marked with red dots. 
The samples were dried in individual aluminium containers in a Swallow OP Series large capacity drying oven for 48 hours at $105^{\circ} \mathrm{C}$, as per the International Organization of Standardization (ISO) recommendation (ISO, 11272:2017).

The samples were retained in the plastic containers at room temperature until analysis, which occurred within seven days. Wherever possible, after non-destructive analysis (such as particle size distribution) the sub-sampled tailings were returned to the original bulk sample. After destructive analysis (such as loss on ignition) sub-samples were not returned to the bulk sample and instead were returned to the mine.

\subsubsection{Particle size distribution}

The particle size distribution analysis was undertaken in the manner prescribed by ISO standards (ISO, 11796:1989). Each sample was analysed individually. The sample was weighed and placed inside the uppermost in a series of 10 stacked circular sieves (2 mm, $1.4 \mathrm{~mm}, 1 \mathrm{~mm}, 850 \mu \mathrm{m}, 710 \mu \mathrm{m}, 600 \mu \mathrm{m}, 500 \mu \mathrm{m}, 250 \mu \mathrm{m}, 180 \mu \mathrm{m}, 106 \mu \mathrm{m})$. The sieves were stacked on an Endecotts M100 sieve shaker and shaken for 15 minutes each. The weight of the material retained in each sieve was recorded.

\subsubsection{Loss on ignition}

Loss on ignition (LOI) is a technique widely used to determine the OM content in soils. Ignition loss is the sum of the mass loss of volatile compounds such as $\mathrm{H}_{2} \mathrm{O}, \mathrm{CO}_{2}$, and sulphides. The non-combustible materials remain after the LOI testing, which allows for the calculation of the OM content in the samples (ISO, 18230:2015).

The 25 samples of tailings taken from the locations marked in Figure 3.2 were analysed for OM content. A Carbolite Gero CWFB-1100 muffle furnace was used to perform a loss on ignition test in accordance with ISO 18230:2015 with the minor amendments detailed as follows.

Porcelain crucibles and lids were labelled and weighed to the nearest $0.0001 \mathrm{~g}$ using a Mettler Toledo AB204-S analytical balance scale. Individual porcelain crucibles were filled with the tailings samples and covered with a lid. The individual filled crucibles 
were re-weighed using the same scales. All 25 samples were placed inside the muffle furnace to undergo heating simultaneously.

The ISO standard (ISO, 18230:2015) recommends the heating process take place for $60 \pm 10$ minutes at $1000{ }^{\circ} \mathrm{C}$. However, due to the high $\mathrm{Pb}$ content in the tailings, the tailings were heated to $550{ }^{\circ} \mathrm{C}$ for 24 hours \pm 30 minutes to avoid lead oxide $(\mathrm{PbO})$ formation, which occurs $\sim 880^{\circ} \mathrm{C}$ (Blair, 1998). Performing an LOI test on samples using a lesser heat for a longer time is a common practice in samples which contain $\mathrm{Pb}$ (Concas et al., 2011; Lopareva-Pohu et al., 2011).

After 24 hours, the crucibles were removed from the furnace and placed in a desiccator to cool for 30 minutes. The samples were re-weighed, and the mass loss was determined using the following formula, as stated in ISO 11536:2015:

$$
\operatorname{LOI} \%(\mathrm{~m} / \mathrm{m})=\frac{m_{2}-m_{3}}{m_{2}-m_{1}} \times 100
$$

In the above formula $\mathrm{m}_{1}$ is the mass of the crucible and lid $(\mathrm{g}) ; \mathrm{m}_{2}$ is the mass of the crucible, lid and untreated sub-sample of mine tailings $(\mathrm{g}) ; \mathrm{m}_{3}$ is the mass of the crucible, lid and sub-sample of mine tailings after ignition (g).

\subsection{5 pH testing}

The $\mathrm{pH}$ of the materials were tested in accordance with ISO 10390:1994. A Voltcraft pH-100 meter was calibrated using an acid (potassium hydrogen phthalate, $\mathrm{pH} 4$ ) and a neutral potassium phthalate buffer $(\mathrm{pH} 7)$.

For each material, a $5 \mathrm{ml}$ sample was ground to $<2 \mathrm{~mm}$ and weighed. The sample was added to $25 \mathrm{ml}$ of deionised water and shaken using a mechanical shaker for $60 \pm 10$ minutes.

Immediately after the sample had been shaken, the $\mathrm{pH}$ meter was placed inside. A reading to two decimal places was taken after the $\mathrm{pH}$ value had stabilised. 


\subsubsection{X-ray fluorescence spectrometry}

$\mathrm{X}$-ray fluorescent spectrometry (XRF) is a widely used technique for the analysis of major ( $\mathrm{Si}, \mathrm{Al}, \mathrm{Fe}, \mathrm{Mg}, \mathrm{Ca}, \mathrm{Na}, \mathrm{K})$ and trace elements ( $\mathrm{Co}, \mathrm{Cu}, \mathrm{Zn})$ in soils and rock. $\mathrm{XRF}$ is considered to be a reliable technique, particularly for $\mathrm{Pb}, \mathrm{Zn}, \mathrm{Ni}$ and $\mathrm{Cu}(\mathrm{Wu}$ et al., 2012).

During analysis the elements present as X-ray peaks, the height of which corresponds to the concentration of the element. XRF provides quantitation analysis for elements $>1 \mathrm{mg} \cdot \mathrm{kg}^{-1}$.

Prior to sample analyses, two mineral standards (Guano Valley and Green River Shale) provided by the United States Geological Survey (USGS) were analysed to assure the accuracy of the XRF instrument.

XRF analysis was completed using a Rigaku Nex-CG instrument. The instrument required that samples be prepared in $32 \mathrm{~mm}$ plastic pots which are constructed from a smaller inner and larger outer plastic ring. The seal between the two holds a prolene film in place over the bottom of the circular pot.

The empty sample pots were weighed, and the weight recorded. Individual sample pots were filled with dried, ground sample (one pot per replicate) and pressed with a steel hand press to compact the sample. Additional sample material was filled and pressed until reaching a satisfactory depth. Pots were re-weighed to determine the sample weight. The height (mm) of the sample inside the pot was also recorded. A plastic lid firmly sealed the pot. Two standards per run were used for calibration. 


\subsection{Site description}

\subsubsection{History}

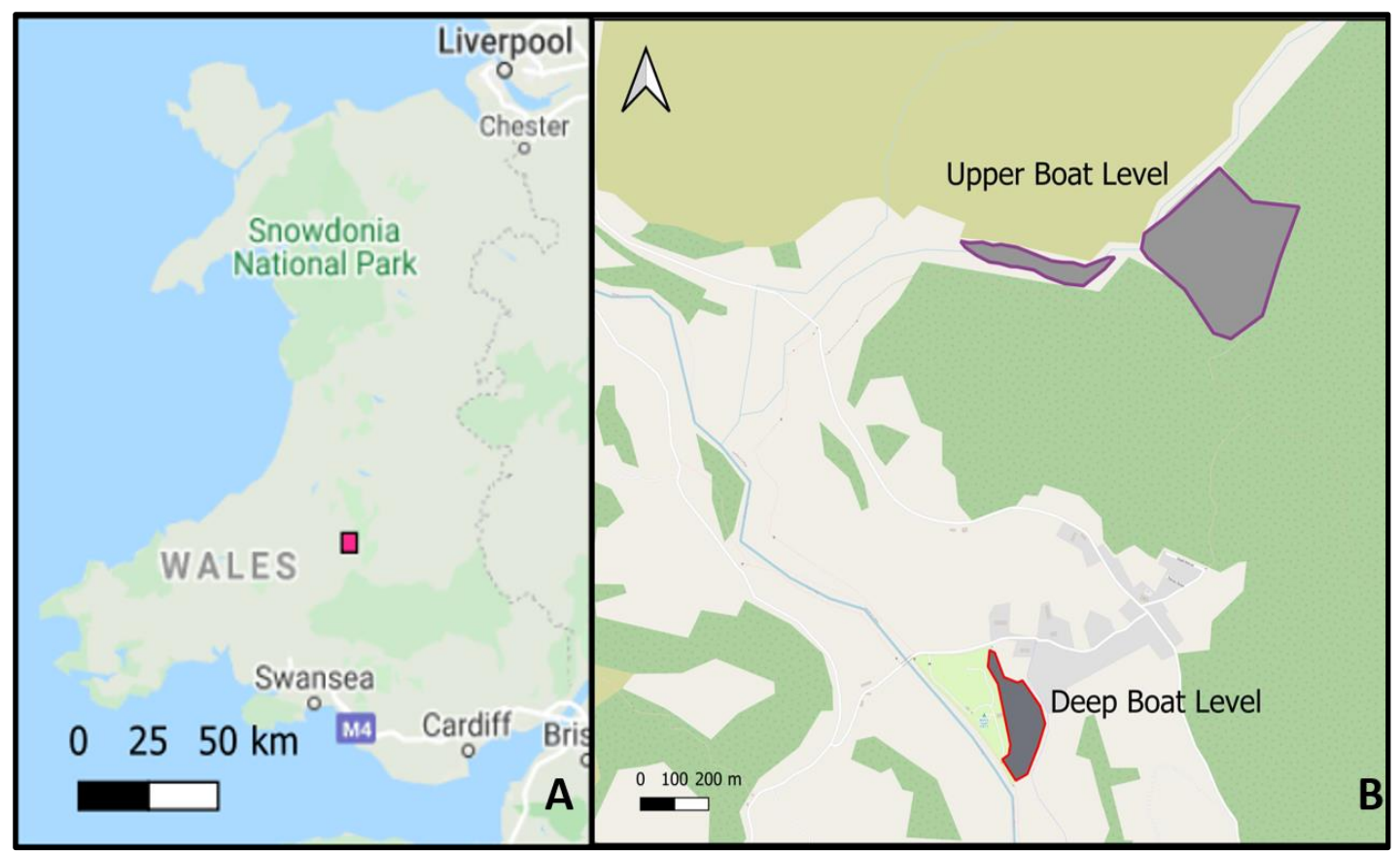

Figure 3.3: A) Nantymwyn Lead Mine (red), located in Wales, UK. B) The Upper Boat Level and Deep Boat Level of Nantymwyn (2018)

The abandoned Nantymwyn $\mathrm{Pb}$ mine (Figure 3.3A) is geographically divided into two levels, the Upper Boat Level (52 $05^{\prime} 15.94$ N, $\left.3^{\circ} 46^{\prime} 13.25 \mathrm{~W}\right)$ and the Deep Boat Level $\left(52^{\circ} 04^{\prime} 31.74 \mathrm{~N}, 3^{\circ} 46^{\prime} 48.28 \mathrm{~W}\right)$ (Figure 3.3B). The Upper Boat Level was opened in 1775 and is situated on Pen Cerrig Mwyn Mountain at an altitude of 246 m (Hall, 1993).

The Deep Boat Level was constructed in 1785, $146 \mathrm{~m}$ below the Upper Boat Level on the banks of the River Towe. The Deep Boat Level was constructed to explore a lode and to drain the vast amounts of water which overwhelmed the Upper Level (Northern Mine Research Society [NMRS], 1992).

The wet climate and constant flow of water on the steep, mountainous terrain compromised the already steep tailings dumps, and in 1920 an outburst and slope failure caused numerous fatalities and injuries (NMRS, 1992). Following the outburst, work ceased on the Upper Boat Level and focussed on mining the Deep Level. A new 
flotation method introduced in 1927 briefly invigorated dwindling production (NMRS, 1992). The flotation process involved grinding the coarse ores and adding a chemical flotation reagent to alter particle hydrophobicity to separate the concentrate. The new process increased extraction productivity from $\sim 60 \%$ to $\sim 80 \%$ (NMRS, 1992). However, the flotation method produced a residue of very mobile, fine-grained metals and chemicals rather than the larger particles produced by the original crushing methods (Owen, 1999; Bulatovic, 2007).

The increased productivity allowed work to continue on the Deep Boat Level until 1932 when a drop in the price of $\mathrm{Pb}$ caused the mine to become economically unviable. Later that year The Nantymwyn Ltd. was liquidated, and the mine abandoned (NMRS, 1992).

In 1969, 250,000 tonnes of tailings were removed from the Deep Boat Level for the construction of the Llyn Brianne dam (Owen, 1999) (Figure 3.4). The site has remained undisturbed since. Due to its isolation, the Deep Boat Level was chosen for the field trial (Figure 3.5). The description in this chapter relate only to analyses conducted at this location.

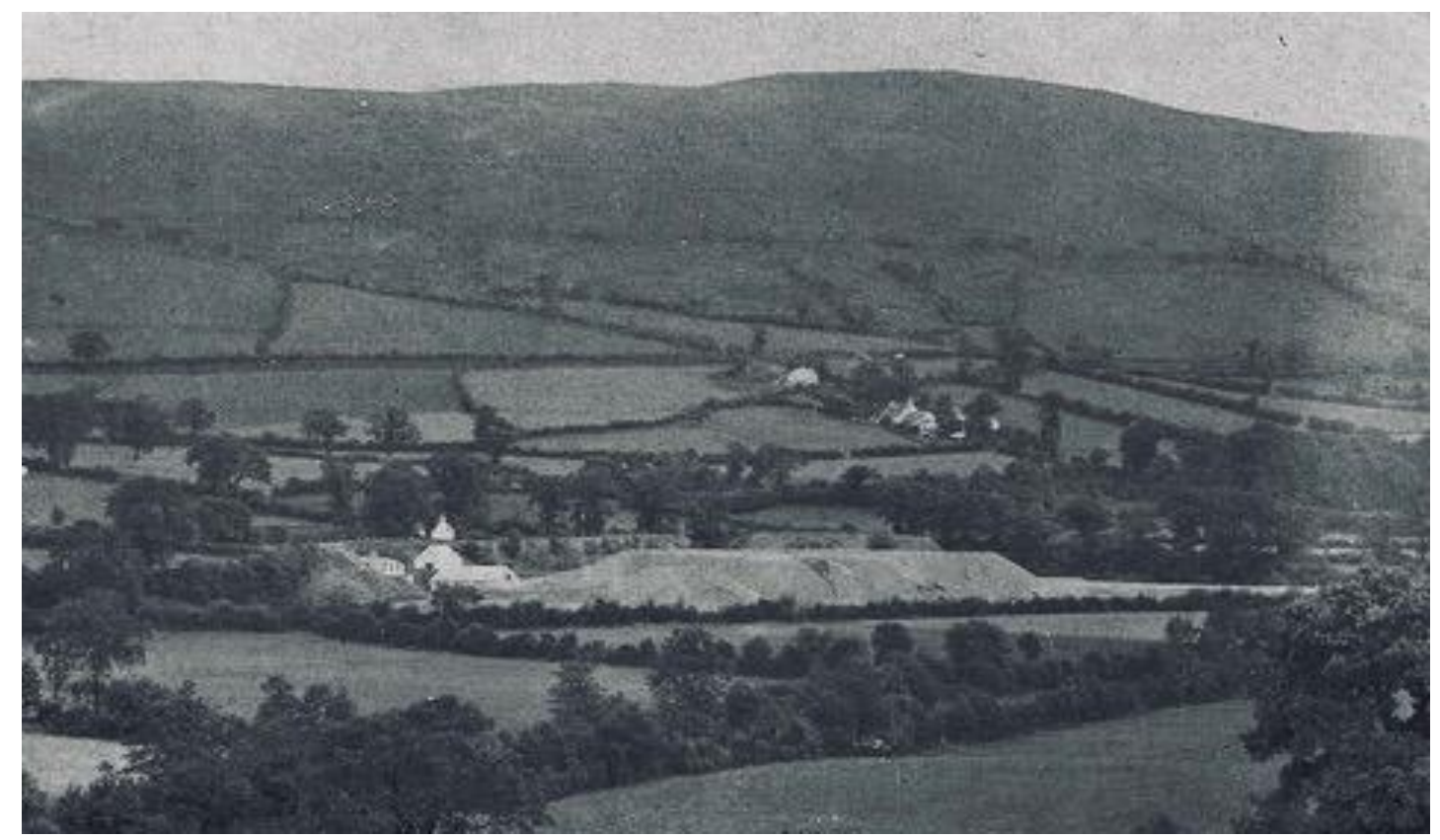

Figure 3.4: The tailings at the Deep Boat Level, Nantymwyn, circa 1970, before a quantity of the tailings were removed for the construction of the Llyn Brianne Dam (A. Jones, 2018, pers. comm.) 


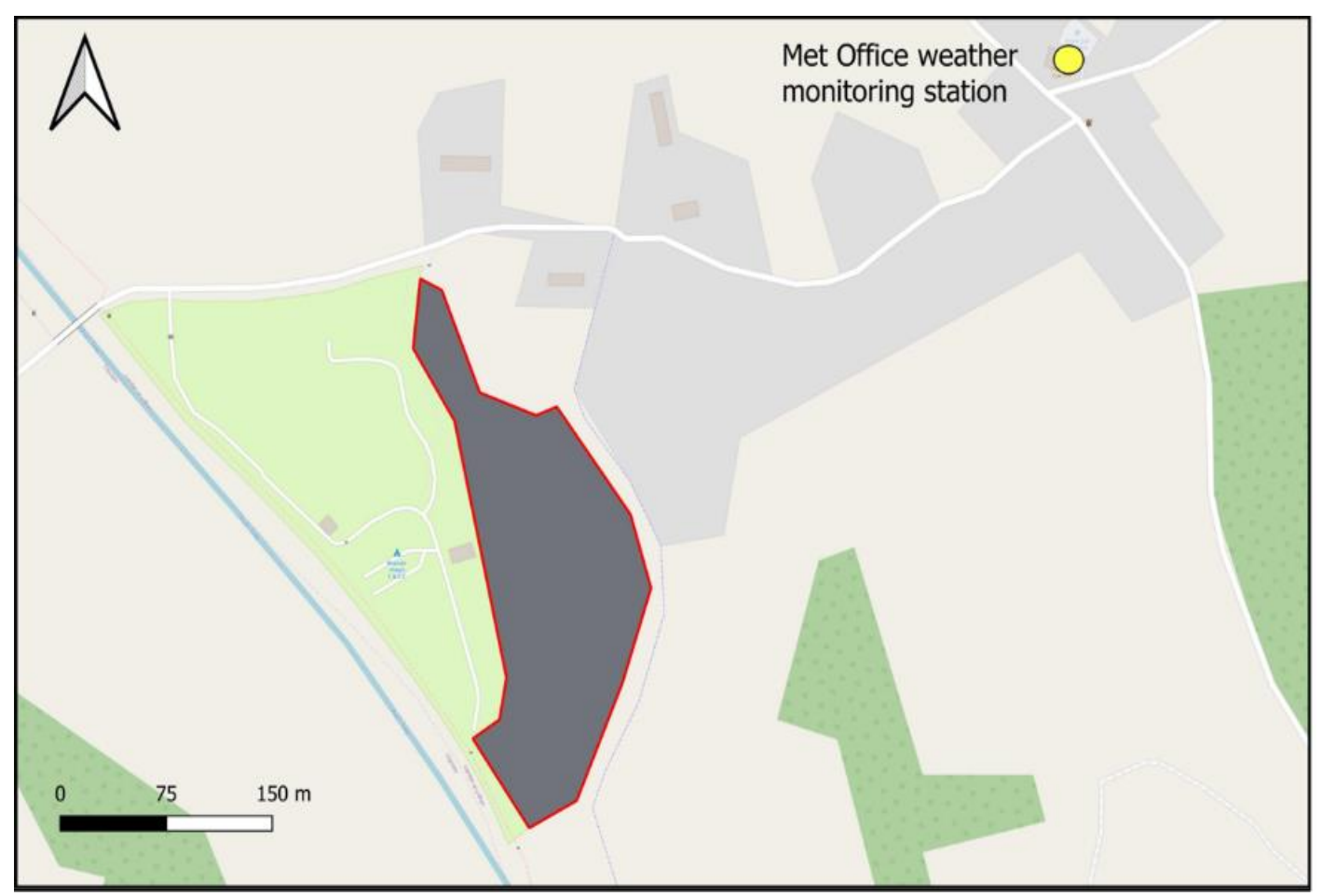

Figure 3.5: The Deep Boat Level of Nantymwyn Lead Mine, outlined in red, in Rhandirmwyn (Wales, UK, 2018)

\subsubsection{Climate}

The Deep Boat Level lies at a valley bottom and is shaded from the rising sun by Pen Cerrig Mwyn Mountain and from the setting sun by Cwm y Rhaedr. Based on nine years of weather data (2007 - 2016), the Deep Boat Level received, on a July day, only seven hours of direct daylight (www.WorldWeatherOnline.com, 2017). The daytime mean temperature was $19^{\circ} \mathrm{C}$, and night-time mean was $10^{\circ} \mathrm{C}$. By September, the hours of daylight received per day fell to five, with mean day and night temperatures of 14 ${ }^{\circ} \mathrm{C}$ and $9{ }^{\circ} \mathrm{C}$, respectively. On a day on which it rained, rainfall increased from $6.1 \mathrm{~mm}$ a day in July to $8 \mathrm{~mm}$ by September (www.WorldWeatherOnline.com, 2017).

Between 2007 and 2016, frost typically began in October, with frequent snowfall from November through to April. During these months, three to four hours of direct sunlight per day were recorded. February was consistently the coldest month with mean daytime and night-time temperatures of $4{ }^{\circ} \mathrm{C}$ and $0{ }^{\circ} \mathrm{C}$, respectively (www.WorldWeatherOnline.com, 2017). 


\subsubsection{Topography}

The field site slopes towards the south west. Slightly downhill of the Deep Boat Level is a campsite and beyond that the River Towe.

The site features many small inhomogeneous tailings dumps (Figure 3.6). After the partial removal of the tailings for the dam construction, the reduced slopes of the remaining waste were $<4 \mathrm{~m}$ in height. Most of the slopes remain at or near the angle of repose $\left(\sim 19^{\circ}\right)$.

The highest point of the field site is $119 \mathrm{~m}$ elevation and the lowest $113 \mathrm{~m}$.

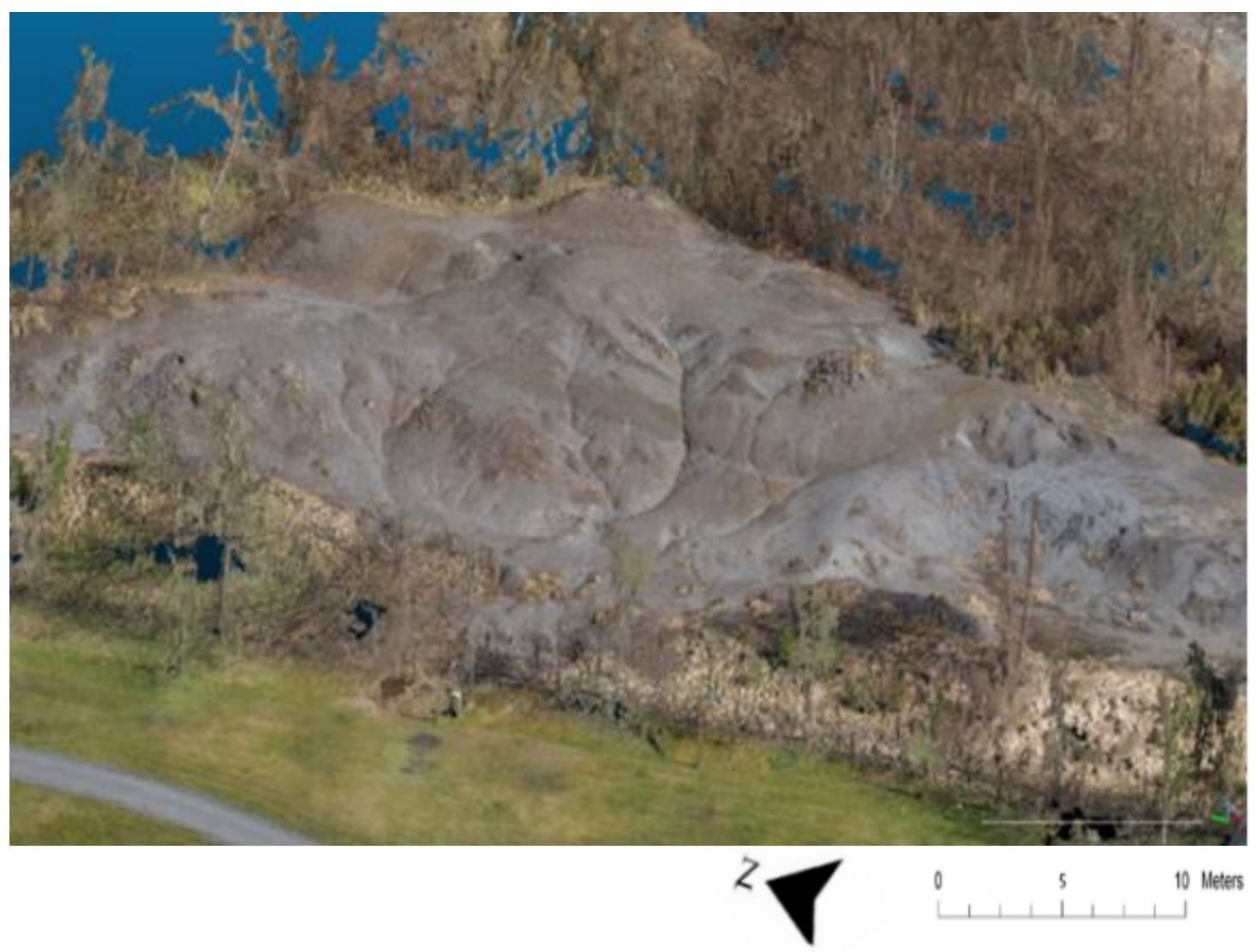

Figure 3.6: A 3D map of the Nantymwyn field site, 2018, produced in Cloud Compare 


\subsubsection{Hydrology}

Despite the volumes of water the Deep Boat Level once received it has since become a relatively dry landscape as a result of a re-directed stream (Atkins, 2011). A small ephemeral water body which linked the old waterwheel housing and the River Towe was present during the wetter months (Figure 3.7).

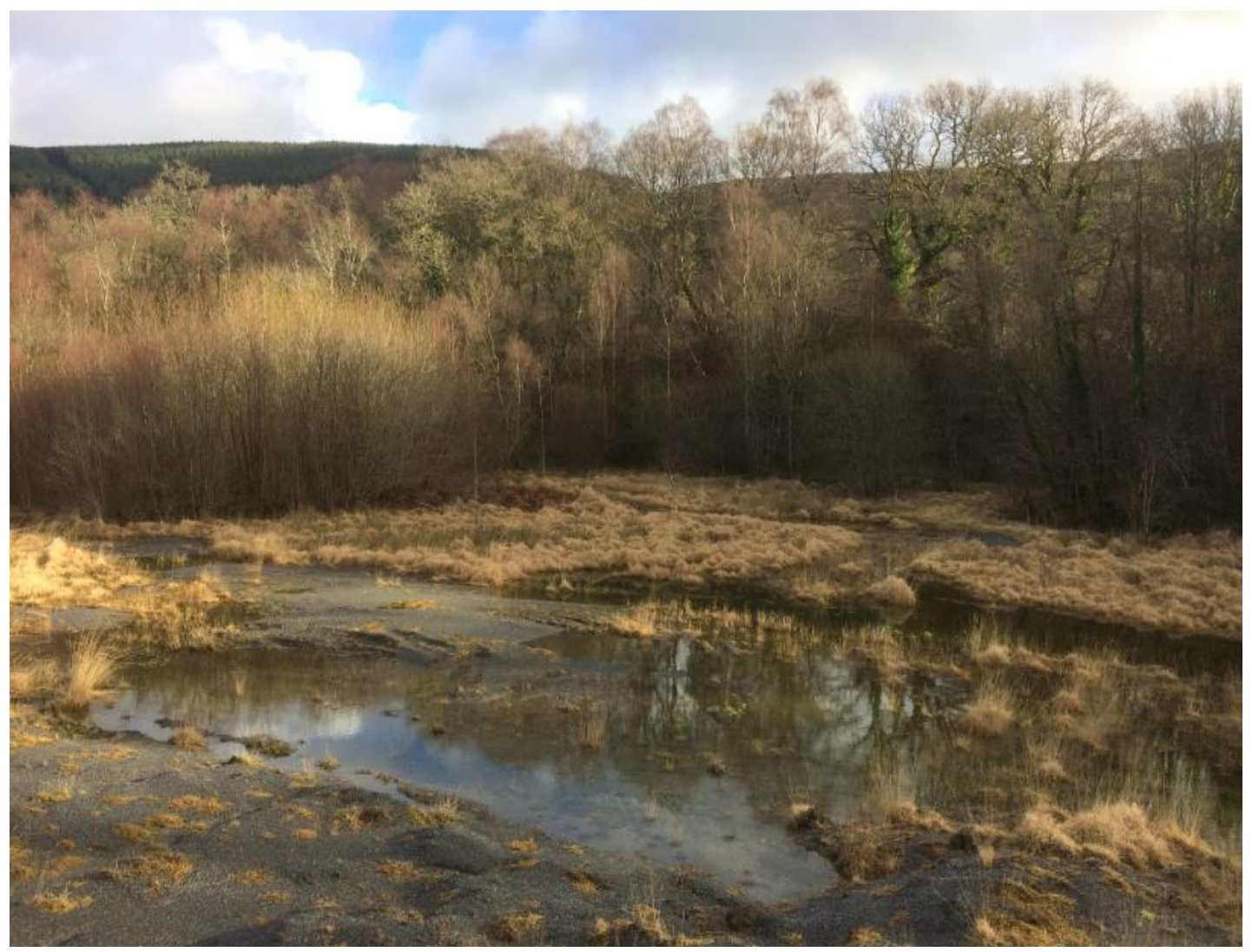

Figure 3.7: An ephemeral water body at the southernmost perimeter of the field site at Nantymwyn, which linked the water wheel to the River Towe. April 2018

\subsubsection{Vegetation}

Much of the site was unvegetated bare ground (Figure 3.8) with small patches of metallophyte lichen. The perimeter supported several tree species, predominantly Alnus, Fraxinus, and Betula pendina (alder, ash and birch) (Figure 3.9) as well as several metal-tolerance species of grass, Silen vulgaris (Figure 3.10), Festuca, Agrostis and Anthoxanthum odoratum (bladder campion, fescue, bentgrass and sweet vernal grass) (Figure 3.11). 
The ephemeral water body supported vegetation during the spring and autumn (Figure 3.7). A small patch of Rubus fruticosus (blackberry) had established at the bottom of the entry track where pig manure and garden waste had been deposited.

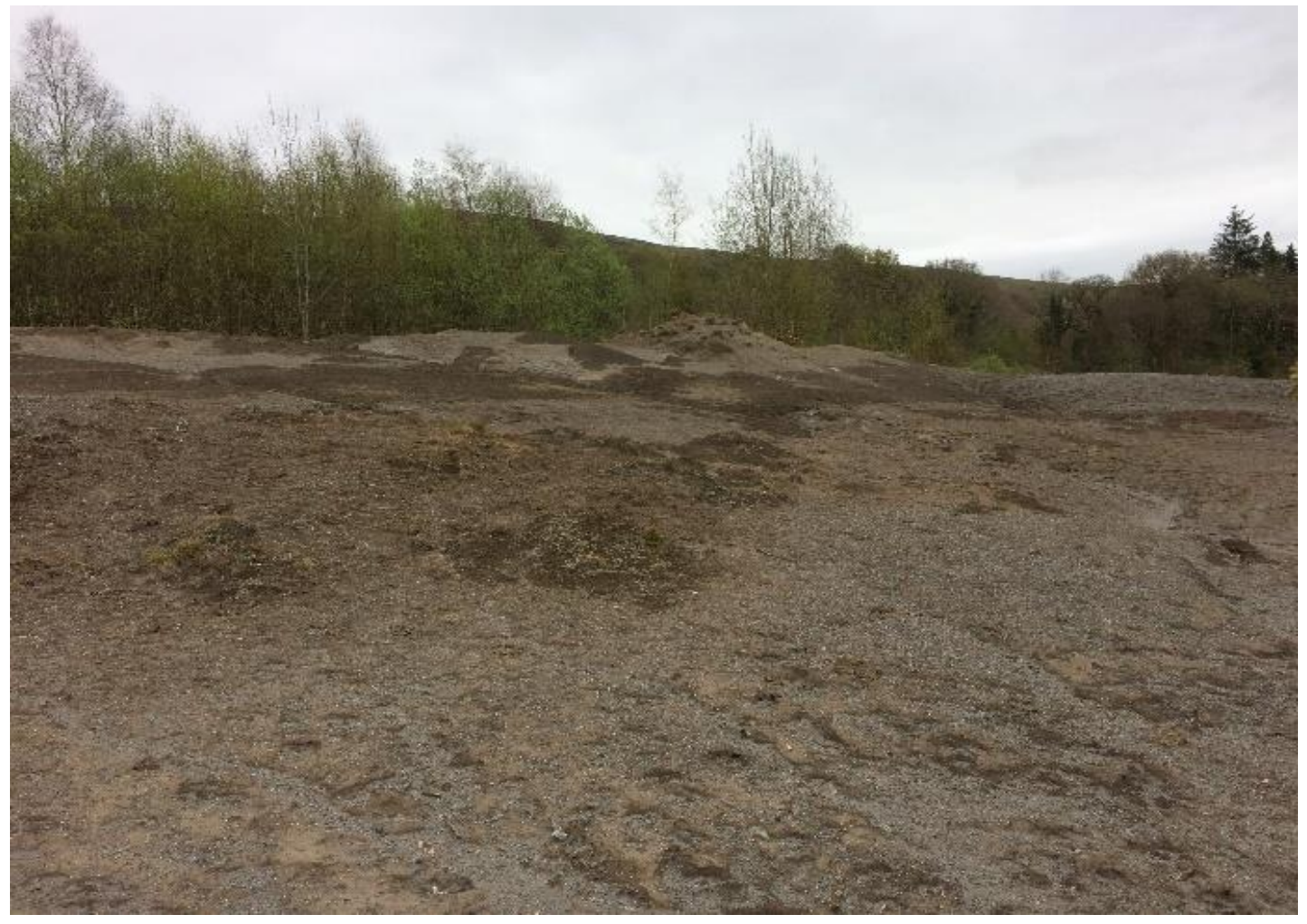

Figure 3.8: The bare tailings (interior) at Nantymwyn (2018)

Figure 3.9: Betula pendina growing around the perimeter of the Nantymwyn tailings (2018)

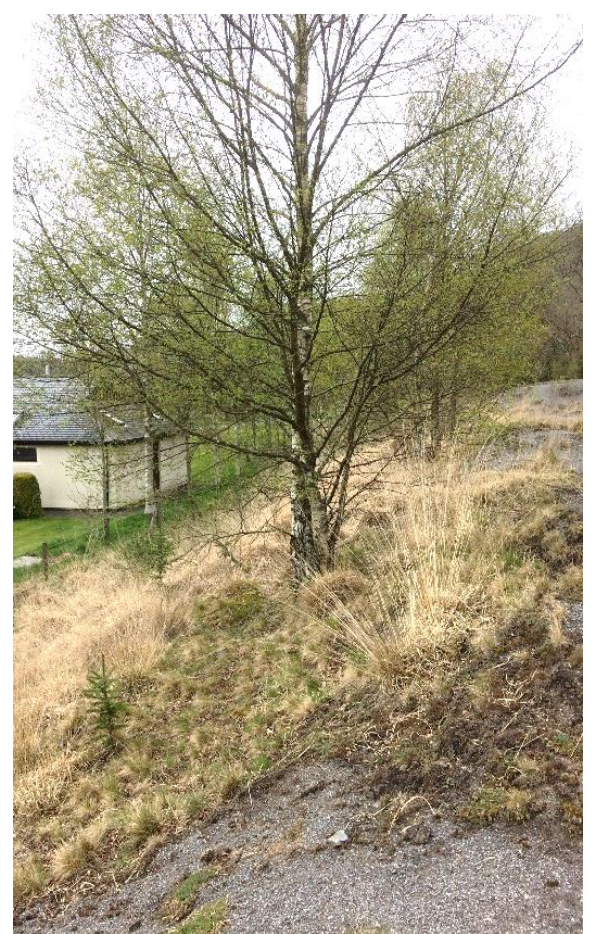




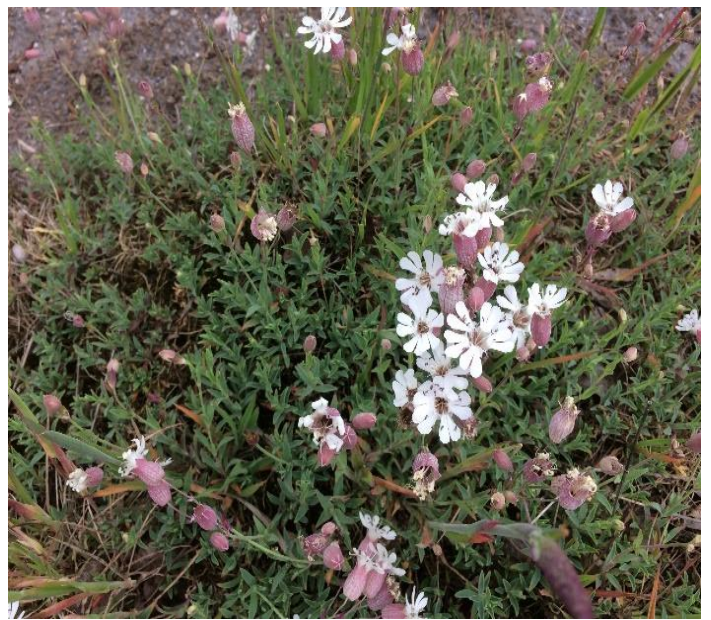

Figure 3.10: A patch of Silen vulgaris growing on the Nantymwyn mine tailings (2018)

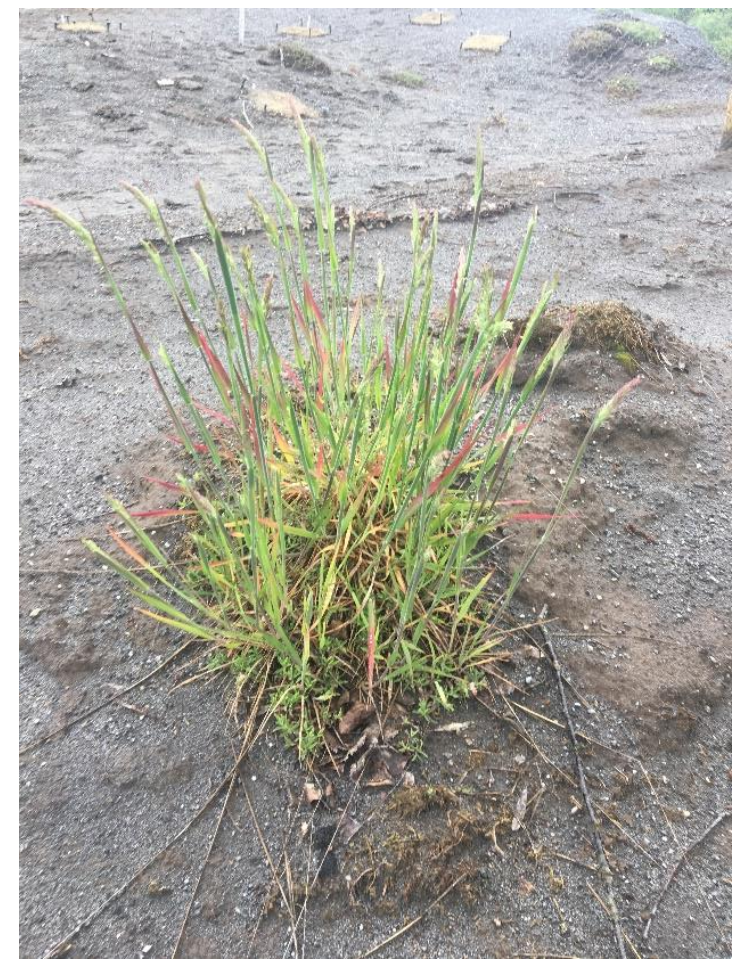

Figure 3.11: Anthoxanthum odoratum growing on the tailings at Nantymwyn (2018)

\subsubsection{Substrate sampling of the Deep Boat Level}

The substrate was sampled using the method outlined in Section 3.1.2, from the locations in Figure 3.2.

As clear differences were observed in the physical characteristics of the tailings samples, the 25 samples were divided into two groups, interior (Figure 3.12, n = 16) and perimeter (Figure 3.13, $\mathrm{n}=9$ ), and were analysed as two separate groups. 


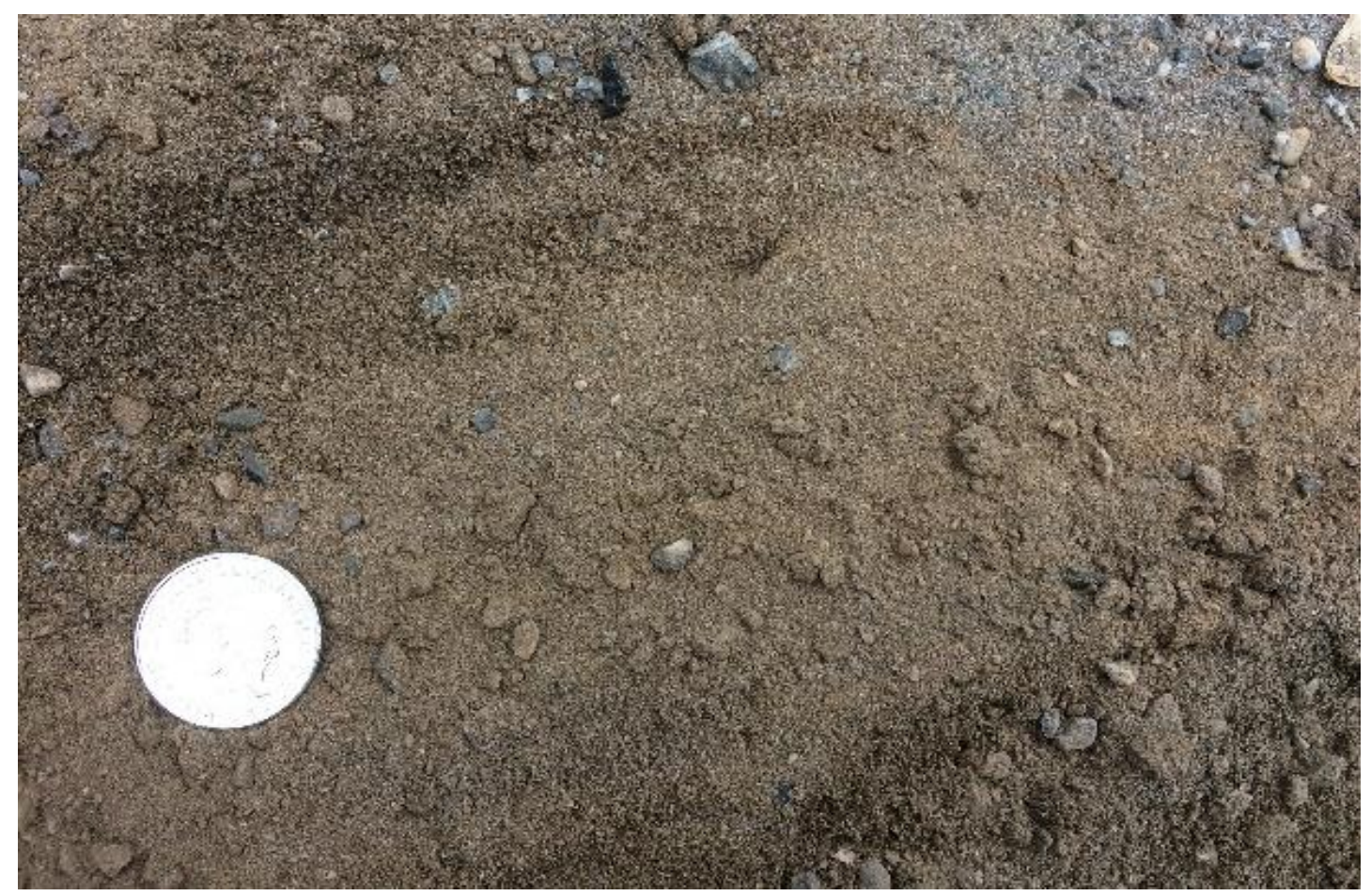

Figure 3.12: The interior mine substrate at Nantymwyn, with 10 pence for scale (2018)

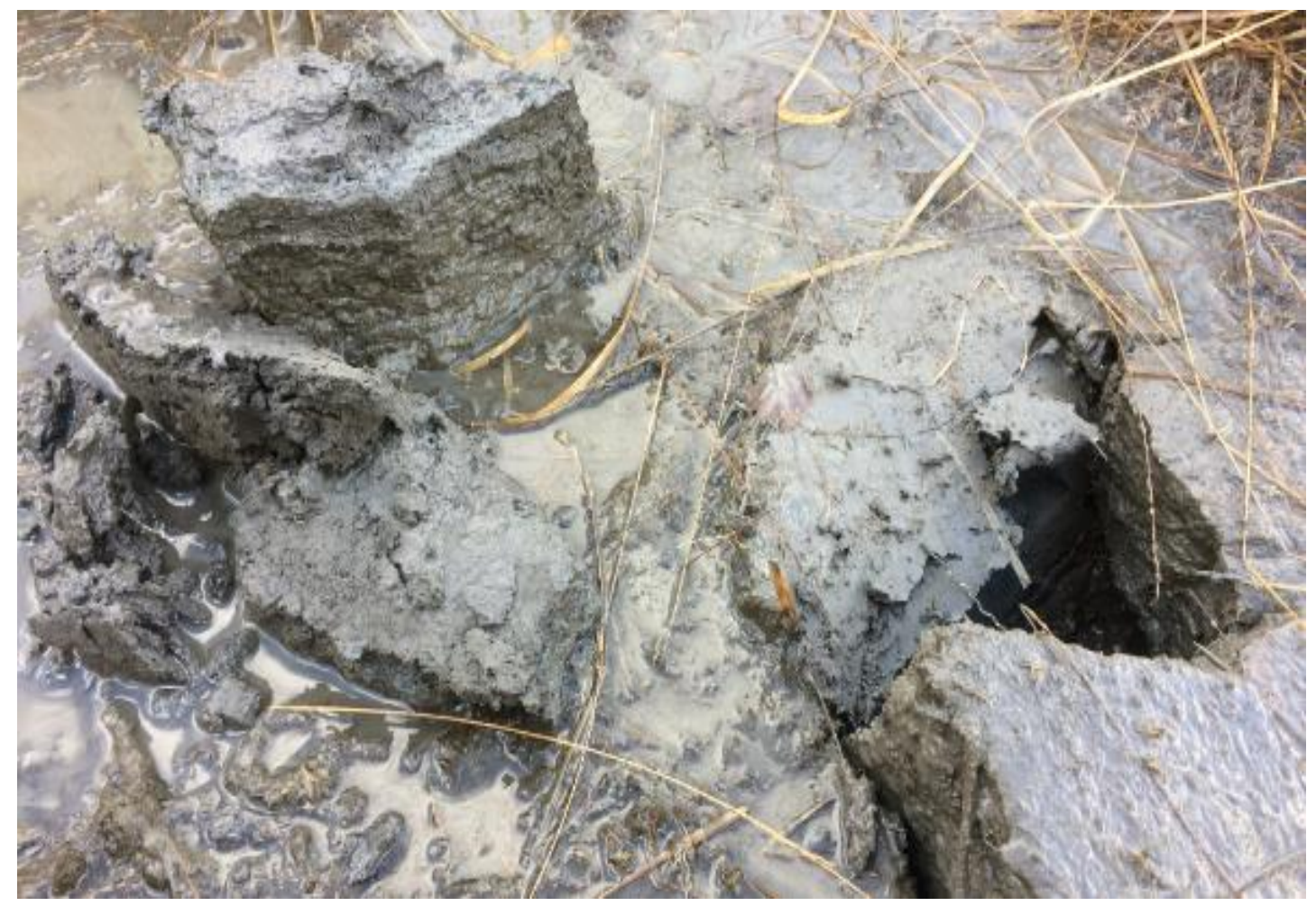

Figure 3.13: The perimeter mine substrate at Nantymwyn (2018) 


\subsubsection{Particle size distribution}

Particle size distribution was determined using the method described in Section 3.1.3.

The samples were classified using the soil classification criterion outlined in ISO 14688-1:2002 (Table 3.1).

Table 3.1: The particle size distribution of the interior $(n=16)$ and perimeter $(n=9)$ Nantymwyn tailings samples (mean \% by weight).

\begin{tabular}{cccccc}
\hline \hline Particle & $6.3-2$ & $2-0.63$ & $0.63-0.2$ & $0.063-0.2$ & $\leq 0.002$ \\
size $(\mathrm{mm})$ & Fine & $\begin{array}{c}\text { Coarse } \\
\text { gravel }\end{array}$ & $\begin{array}{c}\text { Medium } \\
\text { sand }\end{array}$ & $\begin{array}{c}\text { Fine } \\
\text { sand }\end{array}$ & $\begin{array}{c}\text { Silt and } \\
\text { sand }\end{array}$ \\
\hline Interior & 7 & 9 & 32 & 43 & 9 \\
Perimeter & 2 & 6 & 32 & 41 & 19 \\
\hline
\end{tabular}

The interior tailings samples were of a sandy texture; however, the perimeter samples had a clayey-sand composition.

\subsubsection{Organic matter fraction}

The fraction of $\mathrm{OM}$ was determined by a loss on ignition process as described in Section 3.1.4.

The interior $\mathrm{OM}$ fraction of the samples was a mean of $2.1 \% \pm 1.3(\mathrm{n}=16)$. The perimeter samples were higher in OM, a mean of $3.4 \% \pm 1.7(n=9)$.

\subsubsection{Substrate $\mathbf{p H}$}

The $\mathrm{pH}$ of the interior and perimeter samples were determined by the method outlined in Section 3.1.5.

The interior substrate samples were $\mathrm{pH} 3.5 \pm 1.5(\mathrm{n}=16)$. The perimeter substrates samples had a $\mathrm{pH}$ of $6.1 \pm 1.6(\mathrm{n}=9)$. 


\subsubsection{XRF analysis}

The metal concentration of the samples were determined by the method outlined in Section 3.1.6.

Potentially toxic elements (PTE's) are often discussed in comparison with normal background concentrations (NBC's). However, as the area has been mined since the late first century (NMRS, 1992) NBC's for even 'uncontaminated' local areas are higher than normal (Table 3.2). It was more pragmatic to compare the tailings with local soils than with national averages, as the soil has likely to never have been, or will be, an average soil.

Soil was sampled from pasture adjacent to the mine $(\mathrm{n}=25)$ for XRF analysis, which was conducted using the method described in Section 3.1.5. The 25 tailings samples were also analysed for PTE concentration (Table 3.2).

Table 3.2: The concentration $\left(m g . \mathrm{kg}^{-1}\right)$ of potentially toxic elements within the interior $(n=16)$ and perimeter $(n=9)$ Nantymwyn tailings samples, soil samples from a nearby pasture $(n=25)$, and normal background concentrations of metals in UK soils (NBC). The tailings samples and pasture soils were sampled in April 2018. ND indicates that the element was not detected in the sample. \pm indicates the sample standard deviation.

\begin{tabular}{cccccc}
\hline $\begin{array}{c}\text { Potentially toxic } \\
\text { element }\end{array}$ & $\mathrm{Cu}$ & $\mathrm{Zn}$ & $\mathrm{Cd}$ & $\mathrm{Pb}$ & $\mathrm{As}$ \\
\hline Interior & 177 & 11666 & 31 & 8980 & $\mathrm{ND}$ \\
& $( \pm 15)$ & $( \pm 106)$ & $( \pm 4)$ & $( \pm 94)$ & \\
Perimeter & 126 & 31446 & 11 & 7770 & $\mathrm{ND}$ \\
& $( \pm 21)$ & $( \pm 311)$ & $( \pm 2)$ & $( \pm 162)$ & \\
Pasture & 100 & 471 & 0.97 & 6300 & $\mathrm{ND}$ \\
& $( \pm 3)$ & $( \pm 6)$ & $( \pm 0.1)$ & $( \pm 108)$ & \\
NBC & $18.8^{1}$ & $125^{2}$ & $1.8^{1}$ & $125^{1}$ & $10^{3}$ \\
\hline (Environment Agency, 2019) & & & &
\end{tabular}


The mean concentration of $\mathrm{Cu}, \mathrm{Zn}$ and $\mathrm{Pb}\left(\mathrm{mg}^{\mathrm{kg}} \mathrm{kg}^{-1}\right)$ found in the pasture soils were considerably higher than normal background levels for the UK. Notably, $\mathrm{Pb}$ was $50 \mathrm{x}$ greater in the pasture samples than the NBC. However, the concentration of all metals were lower in the pasture than in the tailings.

\subsubsection{Conclusions}

The perimeter tailings samples contained an $\mathrm{OM}$ content $(3.4 \%)$ and silt and clay fraction (19\%) similar to that found in some grassland soils. In the soils of the Texas savanna, silt and clay fractions of $19 \%$ were found, with an OM content of 3.1\% (Liao et al., 2006). In Colorado, Aridic Paleustoll soils populated with $\mathrm{C}_{4}$ grasses contained a clay and silt fraction of $23 \%$, with an OM content of $4.7 \%$ (Plante et al., 2011). The $\mathrm{pH}$ of the field trial perimeter soils ( $\mathrm{pH}$ 6.1) was also similar to that of two pastureland Welsh Podzols (brown earth), one at Trawsgoed ( $\mathrm{pH}$ 5.9), and one at Pwllperian ( $\mathrm{pH}$ 6.0) (Walker et al, 2004).

The $\mathrm{OM}$ content, silt and clay fraction, and $\mathrm{pH}$ of the field trial perimeter soils were more favourable to plant growth than that of the interior, as evidenced by the abundance of vegetation surrounding the site (Section 3.2.5). However, the concentration of PTE's in the perimeter soils were similar to the interior, yet the interior samples were devoid of vegetation (Figure 3.8) whereas the perimeter was not (Figure 3.9).

The perimeter of the site was populated with acid tolerant plants such as Agrostis (which is tolerant of $\mathrm{pH} 4.0-6.5$, Wilson \& Rapson, 1995) and Anthoxanthum odoratum (tolerant of $\mathrm{pH} 5.5$ - 7.0, Wagner et al., 1999). The higher $\mathrm{pH}$ of the perimeter substrate $(\mathrm{pH} 6.1 \pm 1.6)$ compared to the interior substrate $(\mathrm{pH} 3.5 \pm 1.5)$ made the perimeter a more suitable environment for the plants which had established there.

The higher OM and silt and clay content in the perimeter soils provided the plants with a number of benefits. OM content directly influences yield (Machmuller et al., 2015; Oldfield et al., 2018). The optimum amount of OM in a soil is between 4 and $8 \%$, $<3.4 \%$ is considered to be low, and $<2 \%$ requires intervention (Fullen, 1998; Loveland \& Webb, 2003; Oldfield et al., 2018). The interior samples contained a mean 
OM content of $2.1 \% \pm 1.3(\mathrm{n}=16)$, whereas the perimeter contained $3.4 \% \pm 1.7(\mathrm{n}=$ 9). The difference in the substrates OM content is one factor which had a clear effect on plant production.

Whilst $\mathrm{OM}$ is widely considered to be essential for plant production, in naturally formed soils, clay is responsible for many of the properties that makes soil an ideal medium for plant growth. In a reclamation setting, the addition of clay to sandytextured colliery spoil has been found to provide a more favourable WHC, texture, bulk density, structure and porosity (Mukhopadhyay et al., 2019). WHC is a crucial limiting factor in the reclamation of mine soils (Novak et al., 2016), and the accumulation of clay around the perimeter and the increased water retention had impacted plant establishment and produced a soil which is sufficient for grass growth.

Clay is also responsible for soil aggregation, and soils without clay have a low cohesion and are more susceptible to erosion (Liao et al., 2006; de Blasio, 2011). A high clay content (and consequently a high WHC) can, however, increase the selfmass of a soil and lead to land slips and slides (Igwe \& Chidinma, 2019). Although the clay and silt content was low, the highest clay and OM fractions were found at the bottom of the slope which was an indicator of sediment mobilty, and illustrated the high erodability of the tailings (Kamala et al., 2014). As the silt/clay content in the tailings was low (9\%), it was deduced that the lack of clay had reduced aggregation and accelerated erosion.

The site was chemically, physically, and topographically heterogeneous, with many different microtopographies. The periphery of the site was very different to the interior section, and to ensure that the existing vegetation did not interfere with the field trial a site within the interior of the tailings dump was selected (Figure 3.14). The overall slope angle of the chosen area was $\sim 15^{\circ}$ ( 1 in 3.85 or a $26 \%$ gradient) with a westfacing aspect (Figures 3.14 and 3.15). 


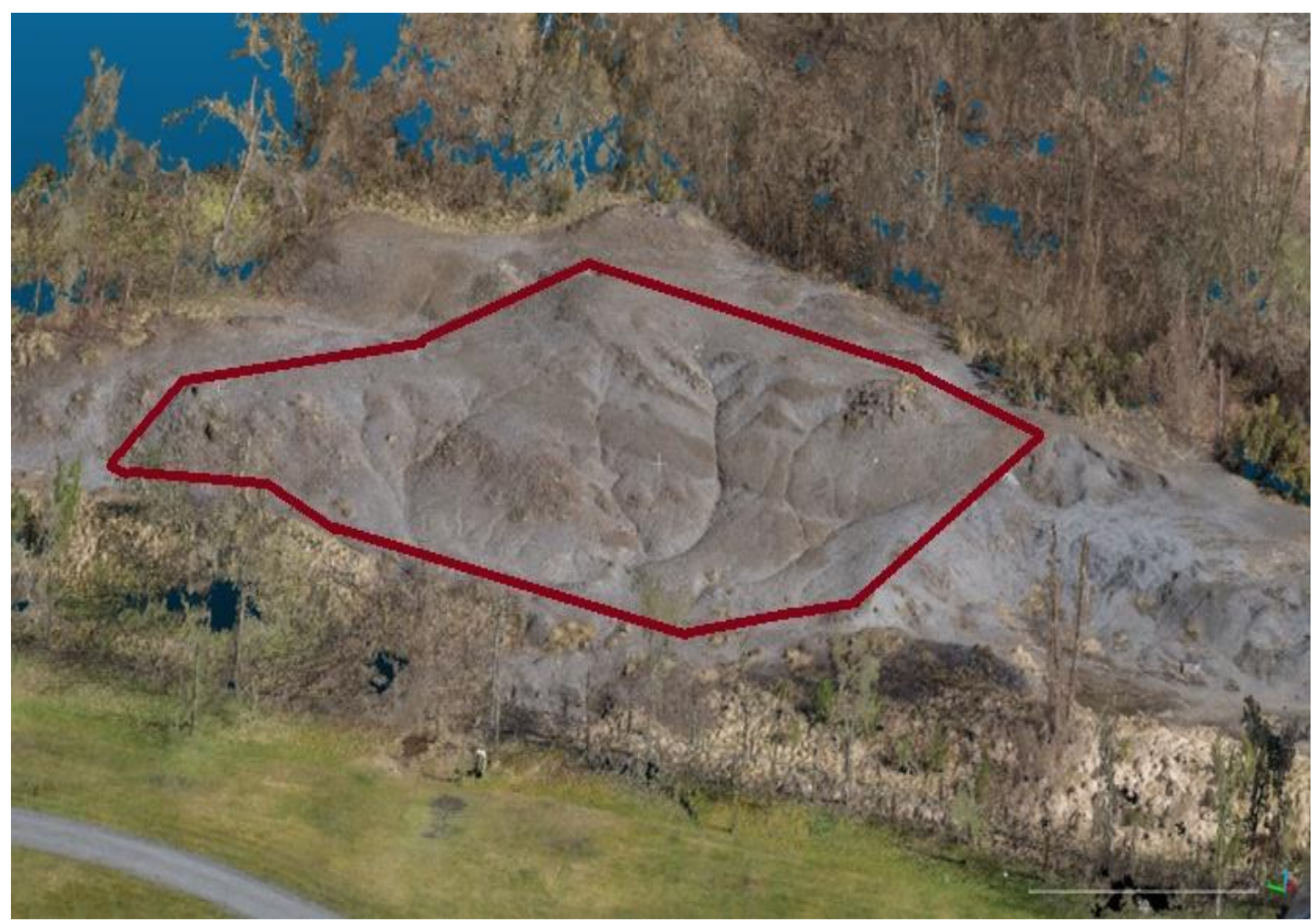

Figure 3.14: The field site at Nantymwyn, 2018. The red line indicates the location of the fence.

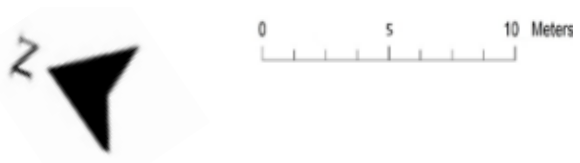



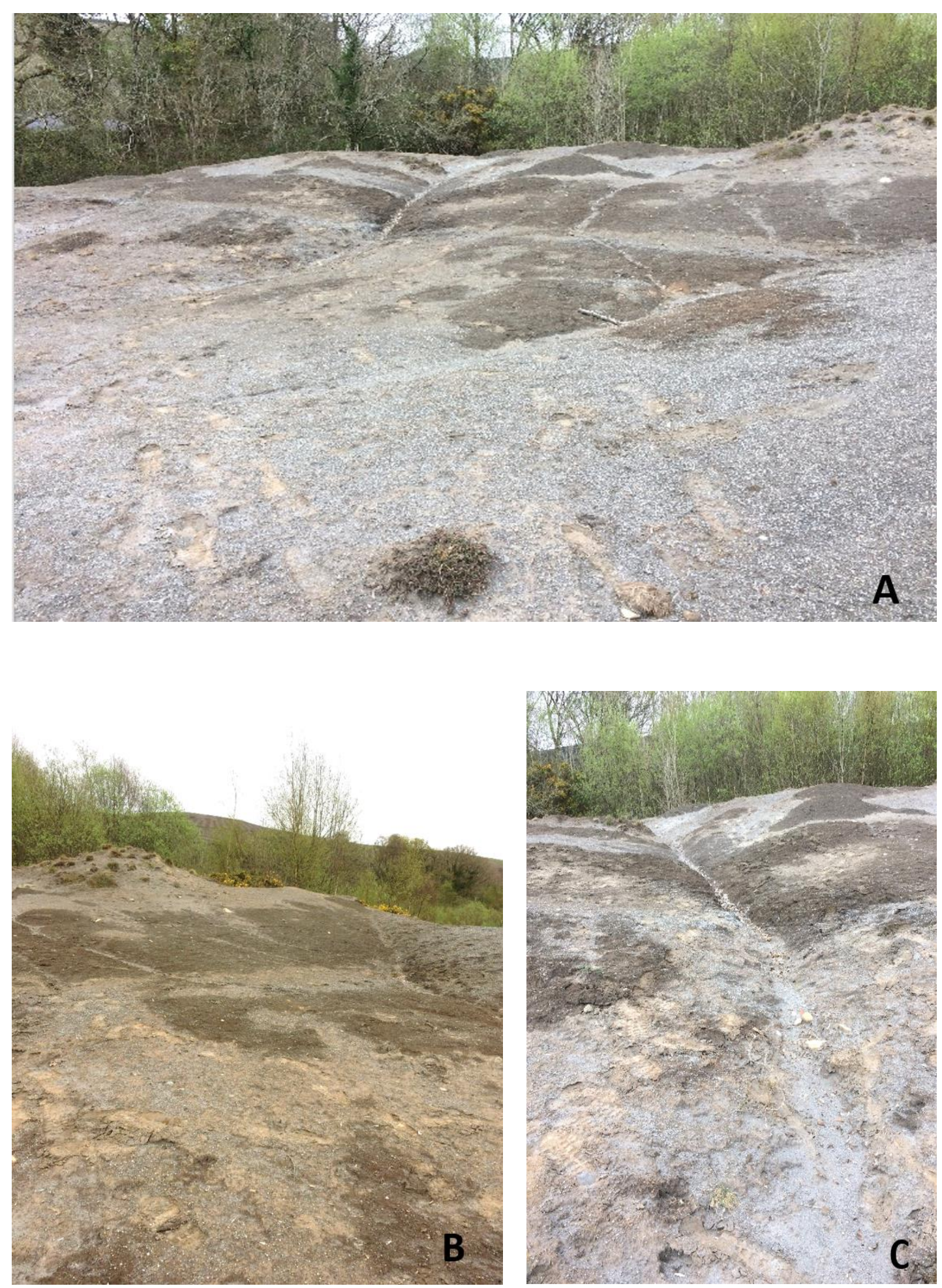

Figure 3.15: A, B, C: The area selected for the field trial, Nantymwyn, 2018. 


\section{Materials section introduction}

Throughout the text, the constructed soil-like media to be applied to the mine tailings is referred to as a surrogate soil. It is acknowledged that the surrogate soil is not a genuine soil, and will not contain the structure, the particle and pore size, or many of the soil bacteria that make up a natural soil. Nor will the surrogate soil experience important soil formation processes such as bioturbation and other soil fauna processes. However, a soil (artificially constructed or not) was deemed the most appropriate term for the growing medium, and was the most pragmatic and understandable within the land reclamation industry. Other choices included 'artificial soil'; however, the International Organization for Standardization defines an artificial soil as 70\% quartz sand, 20\% kaolinite clay, and 10\% sphagnum peat (ISO, 11267:1999). A 'constructed soil' had connotations of a construction material. 'Surrogate soil' was chosen due to the pragmatism of the term, literally meaning 'substitute', and for the connotations of the surrogate soil as a replacement for original soil lost to dispersal.

Various materials were considered for the development of the surrogate soil. As mentioned in the Research Aims, this thesis was intended to have a practical outcome, and be applicable from an industry perspective. Because of this, certain limitations existed. The greatest limitation was that of the method of deployment. Hydroseeding requires the maximum length of the soil materials to be $<2 \mathrm{~mm}$ due to the size of the spray nozzle. The materials had to be pliable enough to not block the pump, and the hydrocolloid required to bind the materials together should remain viscous and not form balls, which could also block the pump. The material has to spray evenly, but once on the ground, had to maintain a porous structure rather than forming a dense mat.

The most desirable material for a surrogate soil would be a soil-like material, such as compost. However, as compost cannot be deployed with a hydroseeder due to its tendency to clog the pump and disperse unevenly, compost was excluded from the list of potential materials.

Other limitations included the supply of the materials. Some materials which were preferable, such as clay, were excluded due a lack of a reliable supply chain. Small volumes could often be purchased, however, the volumes required for genuine 
reclamation efforts could not be sought. As the intention was to produce a solution which could be used outside of this study, materials which were unfeasible for a realworld solution were excluded.

As is often the case in a commercial setting, the cost of the final product was paramount. A key aim of the study was to develop a solution which was financially attainable. A comparative reclamation practice at Frongoch mine, where a geotextile liner was capped with clay and soil, cost $\sim £ 12 . \mathrm{m}^{-2}$ with additional costs associated with the re-shaping of the tailings (P. Edwards, 2019, pers. comm.). As Frongoch has $110,000 \mathrm{~m}^{-2}$ of exposed tailings, this equates to a cost in excess of $£ 1.3 \mathrm{M}$. In Wales alone, > 1300 abandoned metal-mines remain unremediated. To be a feasible solution, the cost of these endeavours must be reduced to $<£ 12 . \mathrm{m}^{-2}$, and preferably $<£ 6 . \mathrm{m}^{-2}$. Other materials were excluded throughout the process due to unexpected issues, such as dormant seeds germinating within the materials (as was found with flax straw). Sphagnum peat was rejected due to the environmental concerns about peat harvesting. Polyacrylamide was rejected by Natural Resources Wales. Some preferred combinations and proportions of materials and were tested with the hydroseeder and caused blockages or settled in the tank rather than remaining in suspension. The final materials chosen were not a result of a constructing an ideal soil which fulfilled all needs (nutrients, structure, density), but rather a process of balancing the needs of the whole project, such as cost, successful deployment, a reliable supply, industry acceptability, and a soil which produced a vegetative ground cover.

The 'Selection of materials' chapter was written with these limitations in mind and was predominantly focussed on the materials which met the practical requirements of the hydroseeder, fitted the budget, and could be reliably sourced. The materials which were rejected were mostly omitted for brevity.

The composition of the materials was first tested with the hydroseeder to ensure the material suited the application method. Subsequently, the materials were trialled in a rainfall erosion trial (Section 5), a pot trial (Section 6), and a field trial (Sections 7 and 8). In some cases, new materials are added or omitted throughout the trials. These are discussed in the relevant sections.

The following Materials chapter is divided into two parts. The first part details the methods used for the analyses of the materials in surrogate soil (Section 4.1). The 
subsequent section (Section 4.2) describes the physical and chemical characteristics of the materials and concludes with a discussion of the results. 


\subsection{Materials - Methods of material characterisation}

This section details the methods used to obtain the data reported in the Selection of Materials section (Section 4.2).

\subsubsection{Mass spectrometry for carbon:nitrogen}

A Sercon GSL elemental analyser interfaced with PDZ-Europa 20-20 isotope-ratio mass spectrometer was used to determine the total organic carbon and total nitrogen (TOC:TN) of the organic materials.

For each sample, the $\mathrm{C}$ content was approximated based on the characterisation of similar materials. The mass of each sample was adjusted to supply $100-150 \mu \mathrm{g}$ of C per sample to match the $\mathrm{C}$ content within the acetanilide standard used. Samples were weighed using a five-digit balance (Mettler Toledo AB204-5).

The appropriate mass of the material was placed inside tin capsules. Using tweezers, the capsules were folded into spheres and placed into a loading tray with the exact weights recorded. The acetanilide standards were measured prior to sample preparation to avoid contamination.

The process of approximating the $\mathrm{N}$ content of each material was conducted in the same manner. Each sample was weighed to provide approximately $200-300 \mu \mathrm{g}$ of $\mathrm{N}$ per sample to match the $\mathrm{N}$ in an atropine standard. For both $\mathrm{C}$ and $\mathrm{N}$ analytical runs, one standard was analysed for every test sample to verify the accuracy of the instrument. Five separate analytical runs were conducted to determine for TOC, and five more for TN. The elemental analyser was operated by Professor Neil Loader at Swansea University. 


\subsubsection{Water-holding capacity}

The water-holding capacity of the materials were determined by the method prescribed in ISO 11267:1999.

A square of a fine nylon mesh gauze (Normesh, 950 microns) was used to seal the base of a cylindrical metal soil sample holder, (height $5 \mathrm{~cm}$, diameter $8 \mathrm{~cm}$, volume $\left.94.99 \mathrm{~cm}^{3}\right)$. The gauze and empty sample holder were weighed, along with a plastic lid, to the nearest $0.0001 \mathrm{~g}$ using a Mettler Toledo AB204-S analytical balance scale. The sample holder was filled with the material to be tested and capped with a lid to eliminate evaporation.

Using a plastic spatula, the sample holder was transferred to a water bath. The water bath was slowly filled with room temperature municipal water until the sample holder was submerged.

After three hours a plastic spatula was used to remove the sample holder from the water bath. The sample was left to drain on a tray of very wet finely-ground quartz sand for a further two hours. The sample was re-weighed to provide the $S$ value in the equation below. The sample was dried in a Swallow large capacity drying oven for 12 hours at $105{ }^{\circ} \mathrm{C}$. The dried weight of the material provided the $\mathrm{D}$ value in the following equation, as stated in ISO 11267:1999:

$$
\mathrm{WHC}=\underline{\mathrm{S}-\mathrm{T}-\mathrm{D}} \times 100
$$

$\mathrm{D}$

In the above formula, the WHC is the water-holding capacity of the material expressed as a percent of the dry mass; $\mathrm{S}$ is the mass of the water-saturated material, the mass of the sample holder, the gauze and lid together; $\mathrm{T}$ is the mass of the sample holder with gauze and lid, and D is the dry mass of substrate. 


\subsection{Materials - Selection of materials}

The preferable material for a soil cap is topsoil which has been carefully stockpiled during a mines operational phase (Nsiah \& Schaaf, 2019). However, from the early 1980s, the frustration and cost of managing invasive species that flourished in the disturbed soils led to an approach of burying the topsoil (Simcock \& Ross, 2018). For many abandoned mines, topsoil is simply not present, potentially having been eroded, contaminated, buried, dispersed or dumped during the mines operational phase (Sheoran \& Poonia, 2010). When topsoil is not present, it is necessary to create an entirely new surrogate soil (Lopareva-Pohu et al., 2011).

A surrogate soil for the capping of metal-mine tailings is required to fulfil many functions. It should provide the physical structure and nutrients necessary for plant growth and should also adhere to both coarse and fine-grained surfaces. The resulting material is then required to be suitable for application with hydroseeding equipment. For the soil materials to be sprayed ay high pressure with the hydroseeder, the materials must be in the form of a slurry, with at least a 2:1 water:soil ratio (North American Green, 2008). The nozzle of the hydroseeding pump is $2 \mathrm{~mm}$ in diameter, and only materials smaller than this are able to pass through the nozzle.

Owing to the substantial challenges of constructing this complex medium, the fabrication of a surrogate soil is usually based on site-specific pot trials (Gil-Loaiza et al., 2016; Novak et al., 2018). Subsequent field trials then advise on the physical limitations of the landscape, such as compaction, drainage, erosion and crusting (Gil-Loaiza et al., 2016).

Shallow surrogate soil caps for hydroseeding can be composed of a variety of materials. The bulk constituent is often a cellulose fibre, which can be synthetic (such as polyester or shredded cellulose plastics) or organic (such as straw or paper mulch) (Martínez-Ruiz et al., 2007; Donze \& Lanze, 2015). Other materials commonly used are cow manure (González-Alday et al., 2009), fertiliser (Oliveira et al., 2013; Donze \& Lanze, 2015), lime (Clemente et al., 2016) seaweed (Oliveira et al., 2013), bentonite clay (Toé Casagrande, 2006; Donze \& Laze, 2015), and a hydrocolloid to increase viscosity and improve adhesion (Merlin et al., 1999; Martínez-Ruiz et al., 2007; Oliveira et al., 2013). Ideally, tailor-made soils are constructed from carefully selected 
materials; however, practically, the most commonly used materials are those which are local, readily available, and often regarded as waste material (Vanchipura \& Jiji, 2018).

The materials trialled in this research are detailed in the following sections.

\subsubsection{Hydra CX}

Several erosion-control hydroseeding mediums are commercially available. One often-used hydroseeding material is Hydra CX ${ }^{\mathrm{TM}}$ (by North American Green, 2008) which was developed in collaboration with the United States Department for Agriculture (USDA) (Tensar, 2012). Hydra CX $\mathrm{XX}^{\mathrm{TM}}$ is referred to as Hydra CX throughout the remaining text.

Hydra CX has been designed for application on slopes of up to 4:1 ( $18^{\circ}$, Figure 4.1) (North American Green, 2018) and is a popular erosion control matrix in many of North American states (Wisconsin Department of Transport [DoT], 2014; Georgia DoT, 2016; Minnesota DoT, 2019; Middleton \& King, 2019). The product has also

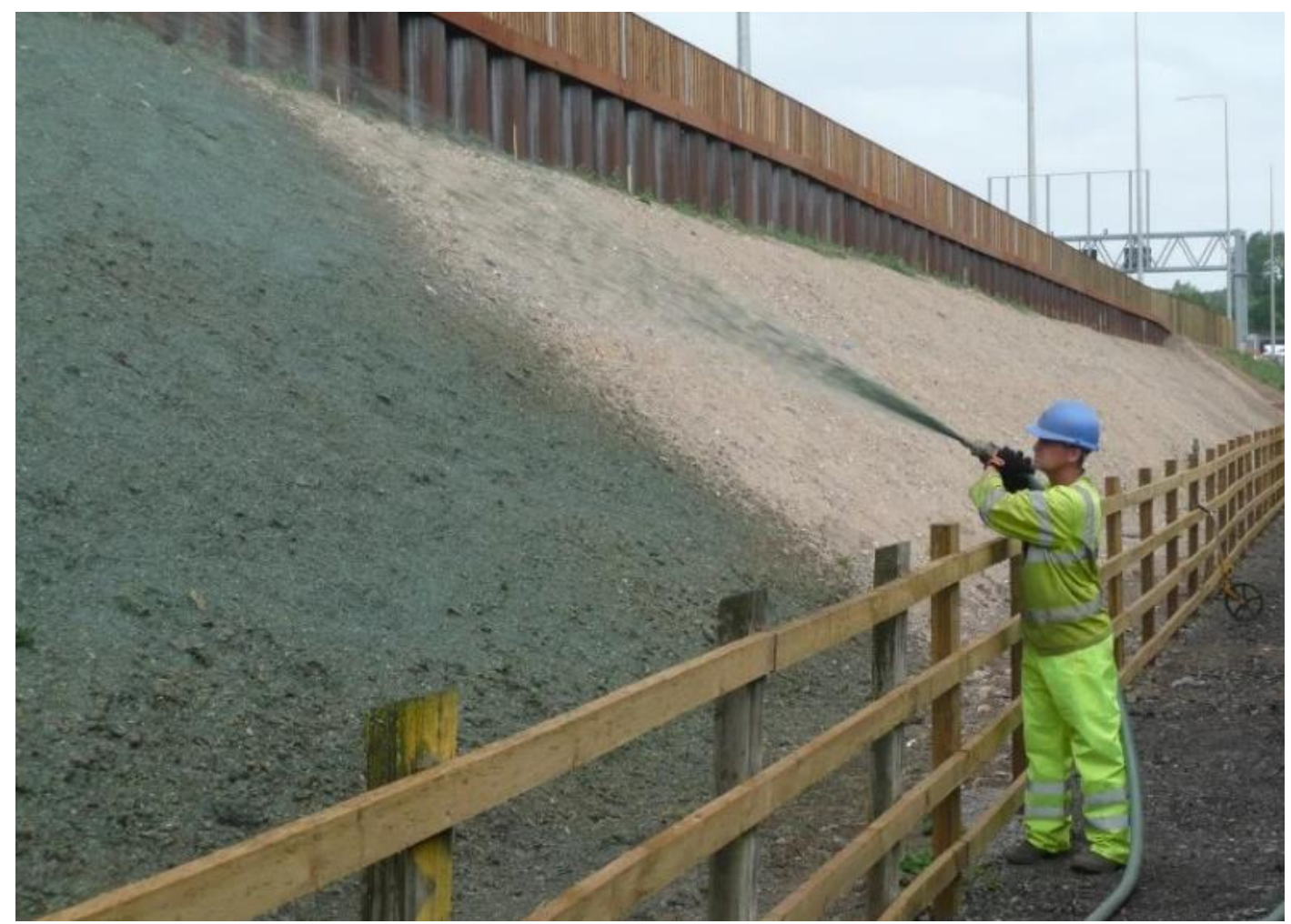

Figure 4.1: Hydra CX being hydroseeded (SalixRW) 
been approved for use by the Chartered Institute of Water and Environmental Management (CIWEM) in the UK (Noble, 2012).

Hydra CX has been applied to areas of low to moderate metal contamination, such as motorway embankments (North American Green, 2008), however, the technical documents relating to the product do not list soils of high contamination as within its recommended usage (North Amercian Green, 2018; Middleton \& King, 2019). Hydra $\mathrm{CX}$ was therefore unlikely to be intended for direct use on metal-mine tailings.

The product has been proven to adhere to and revegetate steep slopes (North American Green, 2008; Colonial, 2018; Salix, 2019). Consequently, the material has overcome the challenge of balancing the competing factors of cost, water-holding capacity, nutrient content, drainage, supply of component materials, and suitable adhesion and erosion control for plant establishment within a shallow soil cap. While it may not prove to be suitable for the revegetation of metal-mine tailings, Hydra CX is a valuable material to examine to understand the requirements of an adhesive surrogate soil.

The specifications of the material are detailed in Table 4.1. 
Table 4.1: Hydra CX specifications as per the material safety data sheet (Tensar, 2012).

Material content

\begin{tabular}{l|l}
\hline Mechanically processed straw (\%) & $65 \pm 3$ \\
Mechanically processed reclaimed cotton plant material (\%) & $25 \pm 3$ \\
Proprietary hydrocolloidal tackifiers and activators (\%) & $10 \pm 1$ \\
\hline
\end{tabular}

Specifications

\begin{tabular}{l|c}
\hline Total organic matter $(\%)$ & $90.0 \pm 4$ \\
$\mathrm{C} / \mathrm{N}$ & $<38: 1$ \\
Thickness $(\mathrm{mm})$ & 4.6 \\
Water holding capacity $(\%) * 1$ & $75 \pm 0.4$ \\
$\mathrm{pH} * 2$ & $7.3 \pm 0.02$ \\
\hline
\end{tabular}

Nutrient content

\begin{tabular}{l|c}
\hline Total N (mg. $\left.\mathrm{kg}^{-1}\right)$ & 8700 \\
$\mathrm{P}\left(\mathrm{mg} \cdot \mathrm{kg}^{-1}\right)$ & 2000 \\
$\mathrm{~K}\left(\mathrm{mg} \cdot \mathrm{kg}^{-1}\right)$ & 24900 \\
\hline
\end{tabular}

*1 Determined by the method in Section 4.1.2 *2 Determined by the method in Section 3.1.5 


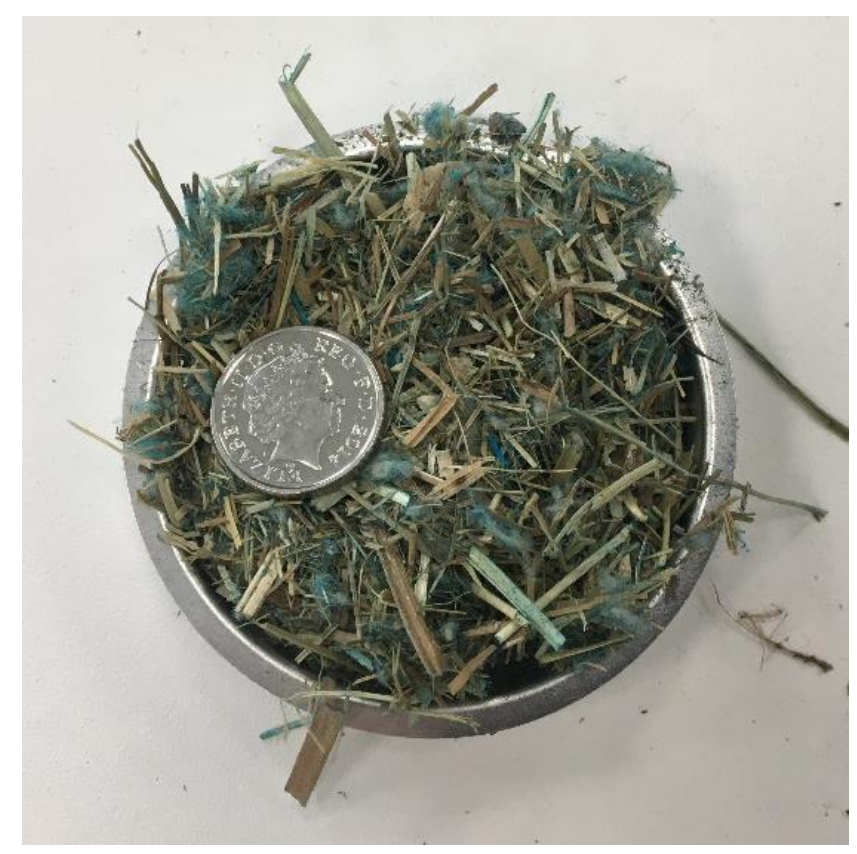

Figure 4.2: The dry Hydra CX material

The characteristics of the surrogate soil Hydra CX are vastly different to that of natural topsoils (Martín-Moreno et al., 2016; Alaniz, 2019). Hydra CX is produced from short fibres (straw) and long fibres (cotton) (Figure 4.2) and compared to topsoil, Hydra CX is C-rich (Moukoumi et al., 2006), has a considerably higher OM content (Moukoum et al., 2006; Alaniz, 2019), a greater WHC (Nave et al., 2009), and a higher N, P, and K content (Alaniz, 2019). Hydra CX resembles compost rather than topsoil, and while compost is often used as the bulk constituent of surrogate soils in cap and cover systems, it does not hydroseed well and is an unsuitable material for this purpose (S. Brackenbury, 2018, pers. comm.).

Hydra CX has a well-established reputation for stimulating rapid revegetation (North American Green, 2008; Colonial, 2018; Salix, 2019). For this reason, Hydra CX will be tested as a benchmark of success for the new surrogate soil and as a demonstration of what can already be achieved by an existing product not designed for metal-mine reclamation.

\subsubsection{Hydrocolloids}

Hydrocolloids are moisture-retentive, long-chain polymers which form viscous solutions when dispersed in water (Saha \& Bhattacharya, 2010). Hydrocolloids are 
used for a range of applications, including suspension and flocculation, and are added to materials to improve adhesion and viscosity, such as within the food industry (Saha \& Bhattacharya, 2010).

In a hydroseeding slurry, the colloid acts to reduce erosion, windborne dust, and losses of seed and fertiliser that delay vegetation establishment (Merlin et al., 1999). The retention of seeds and nutrients within the soil decreases the need for multiple applications which reduces the cost of materials.

A successful colloid must be fluid when dissolved in water and be permeable enough when dry to enable root penetration. The two most common forms of colloids used in hydroseeding are polyacrylamides and guar gums (Merlin et al., 1999; Watson et al., 2016).

Polyacrylamides exist in many forms, but those used for erosion control are anionic polymer-based materials. Polyacrylamide is widely considered as an effective soil binding agent for hydroseeding and water quality improvement (Soupir et al., 2004). In highly erodible silty soil, low application rates of polyacrylamide $\left(\sim 2\right.$ g.m $\left.{ }^{-2}\right)$ can reduce run-off and improve water quality by stabilising the soil structure, flocculating suspended sediments, improving infiltration and reducing overland flow (California Stormwater Handbook [CSH], 2003; Cahn, 2018). As polyacrylamide is $\sim 20 \% \mathrm{~N}$ and has a WHC of $>1000 \%$, it is often used to improve agricultural soils and increase germination rates (Frantz et al., 1993).

In dry polyacrylamide, degradation begins relatively rapidly ( 2 months) (CSH, 2003). The degradation rate in soil and water is between 10 and $25 \%$ per year (Watson et al., 2016; Chalker-Scott, 2019). As polyacrylamide deteriorates the potential for the release of carcinogenic acrylamide monomers increases. Acrylamide is highly soluble in water, and conflicting opinions exist regarding the safety of polyacrylamides in the environment (Wen et al., 2010; Watson et al., 2016; Cahn, 2018), which has led the USEPA to restrict its application (King \& Noss, 1989). Numerous studies report that the mobility of polyacrylamide in the environment is limited due to its high molecular weight, adhesion to surfaces, retention in porous media, and because molecules are too large for dermal absorption (Stahl et al., 2000; Xiong et al., 2018). However, due to the carcinogenic effects at low doses $\left(0.06 \mathrm{mg} . \mathrm{L}^{-1}\right.$, Xiong et al., 2018), controversy 
remains regarding its usage, and it is rare for research not to mention its potential toxicity.

While polyacrylamide has strong adhesive qualities, its application is limited and is considered ineffective on sandy or loamy soils and gravel (CSH, 2003). Although polyacrylamide is water-soluble it tends to adhere to itself rather than dissolving into water and can be a challenging material to handle and apply (Cahn, 2018). At concentrations of $>10 \mathrm{mg} . \mathrm{L}^{-1}$ the injection pumps in hydroseeding equipment can become blocked (Cahn, 2018). When applied to soil, concentrations $>2$ g.m ${ }^{-2}$ can increase overland flow, decrease water infiltration, decrease soil saturation and reduce germination rates (Kay-Shoemake et al., 1998; Akhter et al., 2001; Dou et al., 2012). Erodible surfaces which are not successfully stabilised by $<2 \mathrm{~g} \cdot \mathrm{m}^{-2}$ require the use of an alternative or a combination of colloids.

The Hydra CX technical specification sheet (Tensar, 2012) is vague regarding the choice of hydrocolloids, and instead reports "proprietary hydrocolloid tackifiers". The product sheets for similar North American Green products are more detailed and report a combination of $90 \%$ polyacrylamide and $10 \%$ guar gum. While Hydra CX appears on the US DoT (Department of Transport) Qualified Products List in most North American states, it is absent from the lists specific to Washington, Alaska, Idaho and Oregon, all states that have banned the use of polyacrylamide (Georgia DoT, 2016; Alaska DoT, 2018; Idaho DoT, 2019; Minnesota DoT, 2019; New York State DoT, 2019; Oregn DoT, 2019; Washington State DoT, 2019). Although not explicit, the omission of Hydra CX from these states indicates that Hydra CX contains polyacrylamide.

Guar gums are another commonly used hydrocolloid (Nur et al., 2013; Thombare et al., 2016), and are polymers of galactose and mannose (galactomannan) which are extracted from the seeds of the leguminous plant Cyamopsis tetragonoloba.

Galactomannans dissolve and hydrate readily in water and form highly viscous solutions. Even at low concentrations (1\%), lab trials have demonstrated the effective dust control, moisture retention, and improvements to the tensile and shear strength of metal-mine tailings (Thombare et al., 2016). These characteristics increase with corresponding increases in guar gum application (Mudgil et al., 2014; Kaith et al., 2015; Ding et al., 2016). 
Guar gums are ubiquitous within the food and pharmaceutical industry. An abundance of research exists on its properties and behaviour, and guar is considered safe for a wide variety of applications (Mudgil et al., 2014). Guar degrades into lower molecular weight fragments which can be fully and harmlessly digested by animals (Nur et al., 2013; Mudgil et al., 2014). The degradation of guar is strongly correlated to temperature, at $25{ }^{\circ} \mathrm{C}$ decay has been reported to begin as rapidly as within 14 days, which can decrease the guars efficacy during hot weather (Kaith et al., 2015). Substantial thermal degradation occurs at temperatures of $\sim 50{ }^{\circ} \mathrm{C}$ which results in an increased and irreversible solidity (Wang et al., 2000; Nur et al., 2013).

To date, studies regarding the use of guar in temperate soils are limited. In tropical climates, however, guar has been integrated into sandy soils to improve water retention (Kaith et al., 2015; Thombare et al., 2016), accelerate root development, and improve nutrient absorption in water-deficient soils (Wang \& Wang, 2009).

Owing to its ease of application, low cost and biodegradability, guar gum remains the most popular choice for flocculation, soil stabilisation and dust control (Wang \& Wang, 2009; Nur et al., 2013; Thombare et al., 2016). For this reason, powdered guar gum was selected as the colloidal component of the surrogate soil.

Powdered guar gum (Figure 4.3) was supplied by Rantec Corporation®. The guar gum was the costliest component of the surrogate soil, and at the time of purchase cost $£ 2$ .kg. Due to the high cost of the guar gum, this component was to be added to the surrogate soil in the least proportion possible to have the desired effect on erosion. The specifications for the material are detailed in Table 4.2. 
Table 4.2: The material specifications of guar gum. Mean, $n=5 . \pm$ refers to the sample standard deviation.

\begin{tabular}{l|c}
\hline \multicolumn{1}{c|}{ Guar gum } & Mean \\
\hline Total organic matter (\%) & $96 \pm 0.9$ \\
$\mathrm{C} / \mathrm{N}$ & $83 \pm 5.5$ \\
$\mathrm{~N}\left(\mathrm{mg} \cdot \mathrm{kg}^{-1}\right)$ & $3963 \pm 20$ \\
$\mathrm{P}\left(\mathrm{mg} \cdot \mathrm{kg}^{-1}\right) * 1$ & $483 \pm 30$ \\
Water holding capacity (\%) & $280 \pm 1.6$ \\
$\mathrm{pH}$ & $6.03 \pm 0.1$ \\
\hline
\end{tabular}

*1 $\overline{\text { Reported in the product Technical Specification Sheet (Rantec Corportation }}{ }^{\circledR}$, 2009)

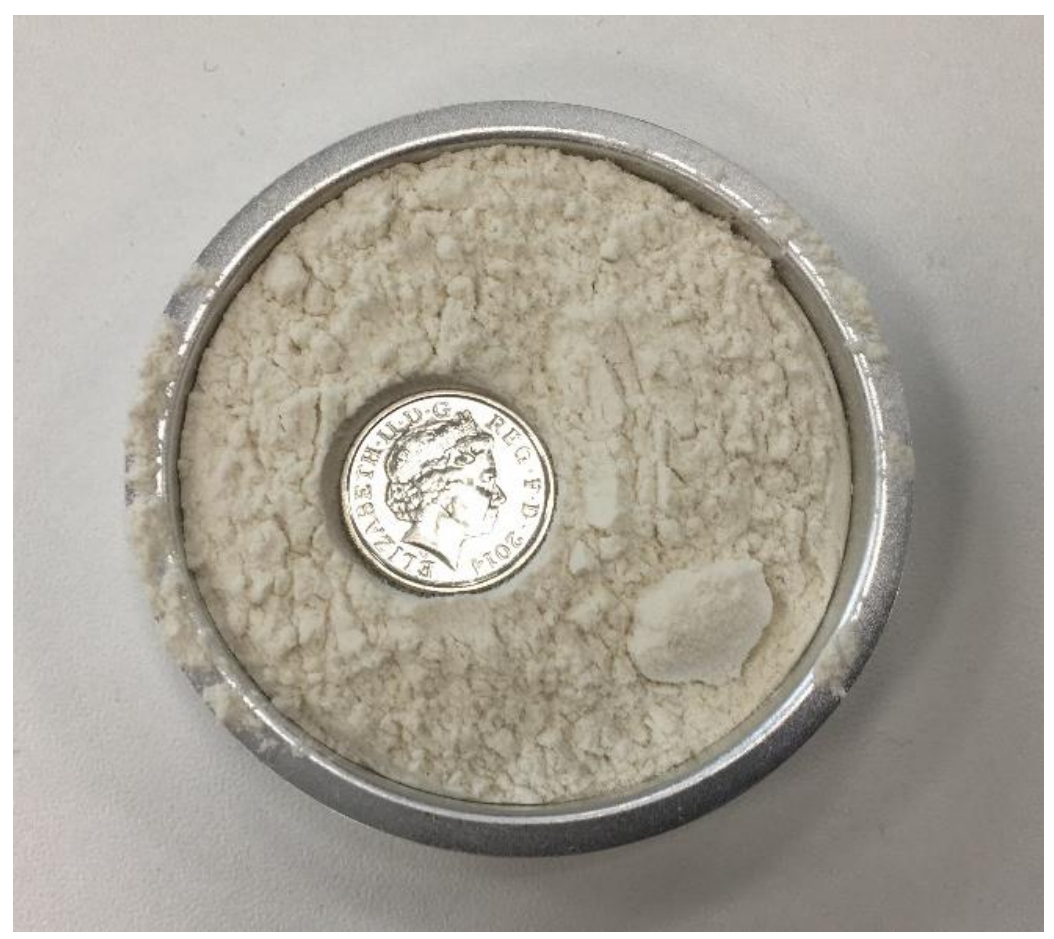

Figure 4.3: Powdered guar gum. Five pence for scale 


\subsubsection{Miscanthus straw}

Straw is a standard bulk component of hydroseeding mediums and is used to provide structure to the soil. It is abundant, inexpensive and lightweight (Babcock \& McLaughlin, 2013).

Miscanthus $x$ giganteu (giant miscanthus) is an exceptionally productive perennial $\mathrm{C}_{4}$ grass (Samson, 2018; Pidlisnyuk et al., 2019). As a mulch material, miscanthus is recalcitrant in soils and decomposes at a rate of $\sim 35 \%$ per year (Eiland et al., 2001). The slow decomposition rate has been attributed to its high lignin content and high C:N (> 60:1), both important variables in mass loss (Amougou et al., 2012; Eiland et al., 2001).

The layering of miscanthus straw on soil provides a long-term ground cover, reduces erosion, improves water retention, and decreases sediment and nutrient losses (Mostaghimi et al., 1994). A miscanthus straw ground cover has led to higher germination rates and greater biomass production compared to treatments without straw (Brofas et al., 2007).

In this study, dried miscanthus straw (Figure 4.4) was provided by Aberystwyth University (Wales) at no cost due to being a waste product. The miscanthus straw was chopped to $<2 \mathrm{~cm}$, as was required by the hydroseeding equipment. The specifications for the material are detailed in Table 4.3. 
Table 4.3: The material specifications of miscanthus straw. Mean, $n=5$. \pm refers to the sample standard deviation.

\begin{tabular}{l|c}
\hline \multicolumn{1}{c|}{ Miscanthus straw } & Mean \\
\hline Total organic matter (\%) & $98 \pm 0.3$ \\
$\mathrm{C} / \mathrm{N}$ & $54 \pm 2.3$ \\
$\mathrm{~N}\left(\mathrm{mg} \cdot \mathrm{kg}^{-1}\right)$ & $7340 \pm 325$ \\
Water holding capacity (\%) & $307 \pm 6$ \\
$\mathrm{pH}$ & $6.1 \pm 0.1$ \\
\hline
\end{tabular}

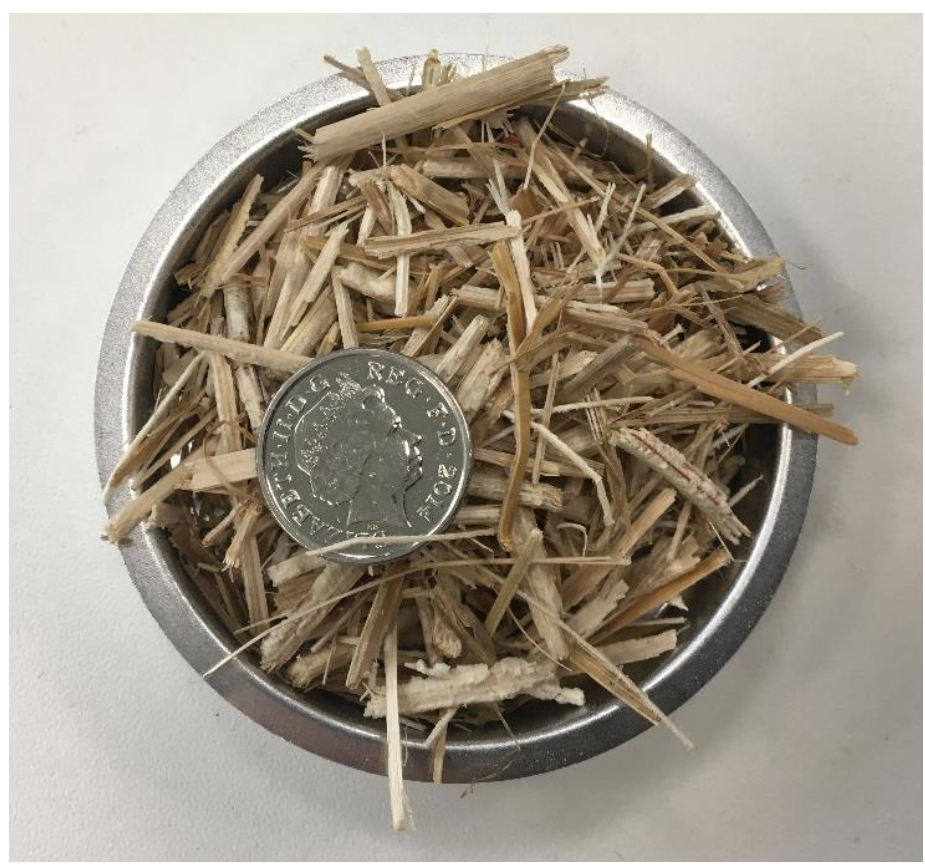

Figure 4.4: Chopped miscanthus straw. Five pence for scale

\subsubsection{Anaerobic digestate}

Anaerobic digestate $(\mathrm{AD})$ is the treated organic solids derived from animal manure or sewage sludge (Wijesekara et al., 2016). In the AD process (Figure 4.5), OM is loaded into a closed water-filled vessel to initiate microbial decomposition. This stage of the process lasts $\sim 18-30$ days (Zhang et al., 2018). The process begins at a temperature of $30-40{ }^{\circ} \mathrm{C}$ and slowly rises to $50-70{ }^{\circ} \mathrm{C}$. During the final stage, the liquid is drained from the fibres for use as a high nutrient liquid fertiliser, and the fibres are air-dried 
(The Waste and Resources Action Programme [WRAP], 2012). The resulting fibre is often used as a soil amendment as it is high in essential nutrients, $1-5 \% \mathrm{~N}$ (Smith et al., 2007; Alburquerque et al., 2012) and $1-4 \% \mathrm{~K}$, with an OM content of $40-70 \%$ (WRAP, 2012).

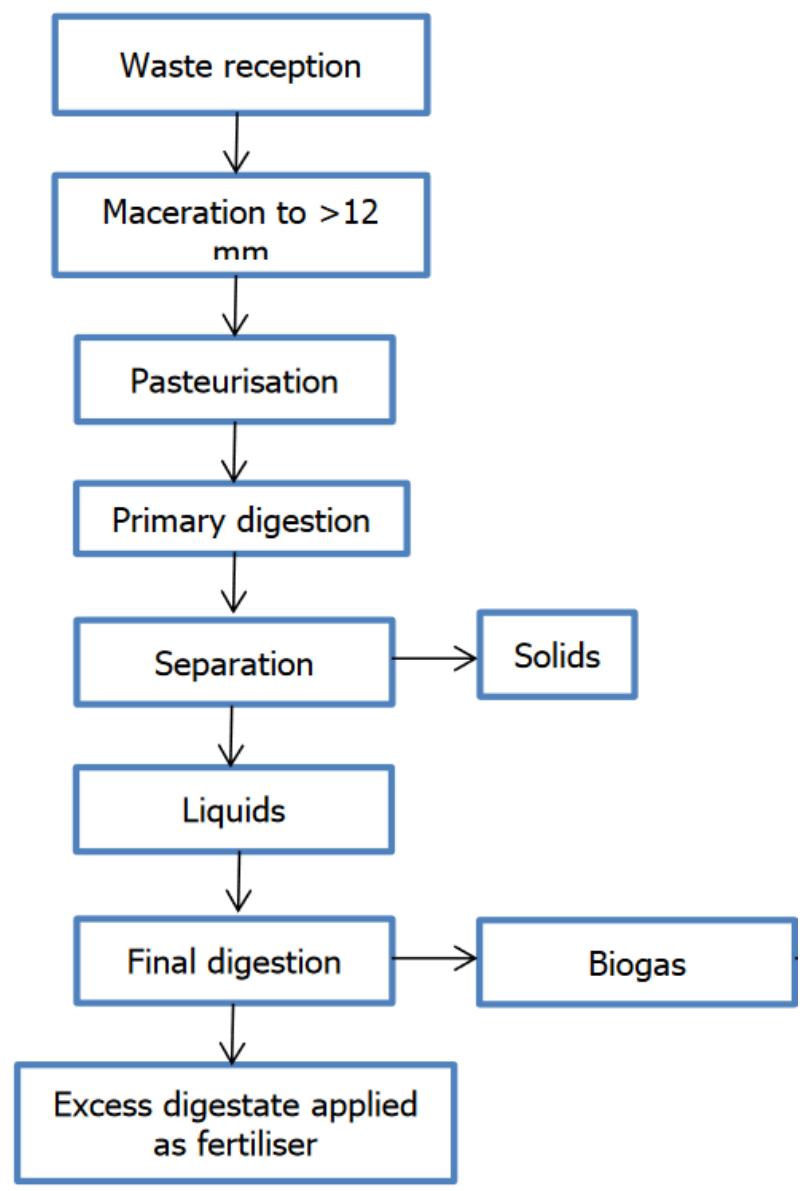

Figure 4.5: The anaerobic digestion process. Contains data from The Waste and Resources Action Programme (2012)

The use of digestate for mine reclamation has long been promoted by the USEPA (USEPA, 1983; Bolan et al., 2014). Extensive research has demonstrated that the inclusion of digestate to mine waste decreases the bulk density, porosity and aggregation of mine spoils (Wijesekara et al., 2016) and increases the hydraulic conductivity, infiltration, WHC (Farrell \& Jones, 2009) and nutrient content (Brofas et al., 2000; Smith et al., 2007; Jeżowski et al., 2017), and reduces erodibility (Zanuzzi et al., 2009). However, due to the rapid decomposition of digestates, studies $>1$ year have reported that repeat applications are necessary to maintain these benefits (Bendfeldt et al., 2001; Alghamdi et al., 2018). 
Dried digestate fibre which was produced from dairy cow manure (Figure 4.6) was provided by AWS Burdens Environmental (AWSBE) in Llanadog, Wales at a cost of $\sim 15$ pence. $\mathrm{kg}^{-1}$. The specifications for the material are detailed in Table 4.4.

Table 4.4. The material specifications of the anaerobic digestate. Mean, $n=5 . \pm$ refers to the sample standard deviation.

\begin{tabular}{l|c}
\hline \multicolumn{1}{c|}{ Digestate } & Mean \\
\hline Total organic matter (\%) & $82 \pm 3.1$ \\
$\mathrm{C} / \mathrm{N}$ & $24 \pm 0.2$ \\
$\mathrm{~N}\left(\mathrm{mg} \cdot \mathrm{kg}^{-1}\right)$ & $18600 \pm 155$ \\
Water holding capacity (\%) & $914 \pm 1.0$ \\
$\mathrm{pH}$ & $7.4 \pm 0.1$ \\
\hline
\end{tabular}

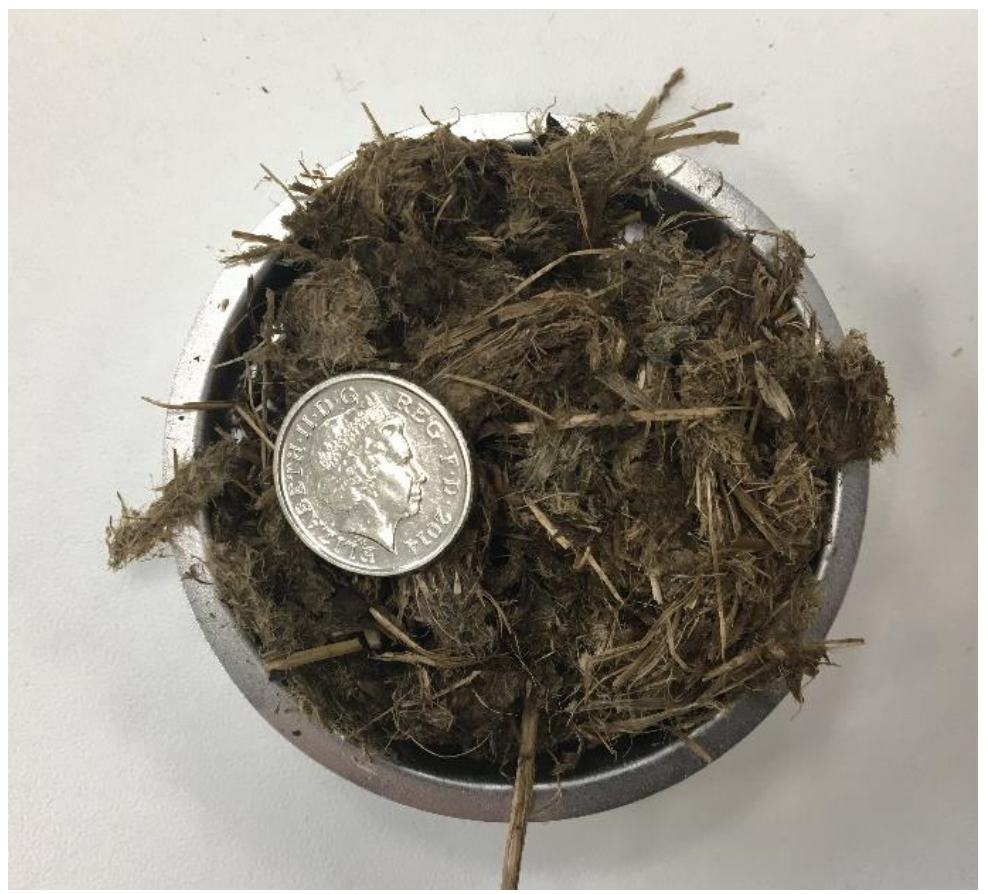

Figure 4.6: Anaerobic digestate. Five pence for scale 


\subsubsection{Coir}

Coir (shredded coconut husks) is a strong, durable and inexpensive material, and is the main component of many biodegradable geotextiles (Vanchipura \& Jiji, 2018; Nsiah \& Schaaf, 2019).

Numerous reclamation and revegetation projects have used coir matting to protect highly erodible slopes (Rao \& Dutta, 2005; Anawar et al., 2015). Coir mats are often used as a base layer cap which is covered with OM (ACES, 2017), but coir can also be applied on top of seeded soil to protect against seed losses (Maiti \& Maiti, 2015; ECB Verdyol, 2019), reduce evapotranspiration (Nsiah \& Schaaf, 2019), and regulate soil temperature (Maiti \& Maiti, 2015).

Coir is a fibrous material, and integrating coir into soil has been shown to improve the bulk density, pore space, infiltration rate, and drainage and aeration in the root zone (Nsiah \& Schaaf, 2019). The interlocking fibres have also been reported to increase the pliability and shear strength of the soil (Rao \& Dutta, 2005; Toé Casagrande et al., 2006). Coir has a high WHC, usually $400-500 \%$, which improves the water retention of coir amended soil in drought-prone areas and increases the survival of seedlings (Shanmugasundaram et al., 2014; Maiti \& Maiti, 2015).

As well as the favourable WHC of coir, of relevance to this study is coir's high cationexchange capacity (CEC) (> 140 cmol. $\mathrm{kg}^{-1}$, Jeyaseeli \& Raj, 2010), which is the measure of how many exchangeable cations can be retained on the material's surface. The CEC of a material forms through the aging and degradation of the material, the adsorption of dissolved OM (Sanchez-Monedero et al., 2018), and the creation of oxygenated functional groups (such as aryl C-H [carbon - hydrogen] and aryl C-O [carbon - oxygen] on the materials surface (Ahmed et al., 2016), which provides the surface with a slight negative charge (Cheng et al., 2008). A soils CEC is an important property, as many plant nutrients are cations (ammonium $\mathrm{NH}_{4}^{+}$, calcium $\mathrm{Ca}^{2+}$, magnesium $\mathrm{Mg}^{2+}$, and potassium $\mathrm{K}^{+}$) and the CEC influences the materials ability to retain nutrients, which in turn determines the soils response to fertilisers (Borchard et al., 2012). The high CEC of coir, the large surface area and high carrying capacity for elements on the surface aids nutrient retention in soils where leaching can occur (Jeyaseeli \& Raj, 2010). 
Coir fibre (Figure 4.7) was supplied by Botanicoir Lanka at a cost of $\sim £ 1 . \mathrm{kg}^{-1}$. The specifications for the coir are detailed in Table 4.5.

Table 4.5. The material specifications of the coir. Mean, $n=5 . \pm$ refers to the sample standard deviation.

\begin{tabular}{l|c}
\hline \multicolumn{1}{c|}{ Coir } & Mean \\
\hline Total organic matter (\%) & $89 \pm 0.4$ \\
$\mathrm{C} / \mathrm{N}$ & $136 \pm 7.4$ \\
$\mathrm{~N}\left(\mathrm{mg} \cdot \mathrm{kg}^{-1}\right)$ & $30,000 \pm 2620$ \\
Water holding capacity (\%) & $440 \pm 1.8$ \\
$\mathrm{pH}$ & $5.7 \pm 0.4$ \\
\hline
\end{tabular}

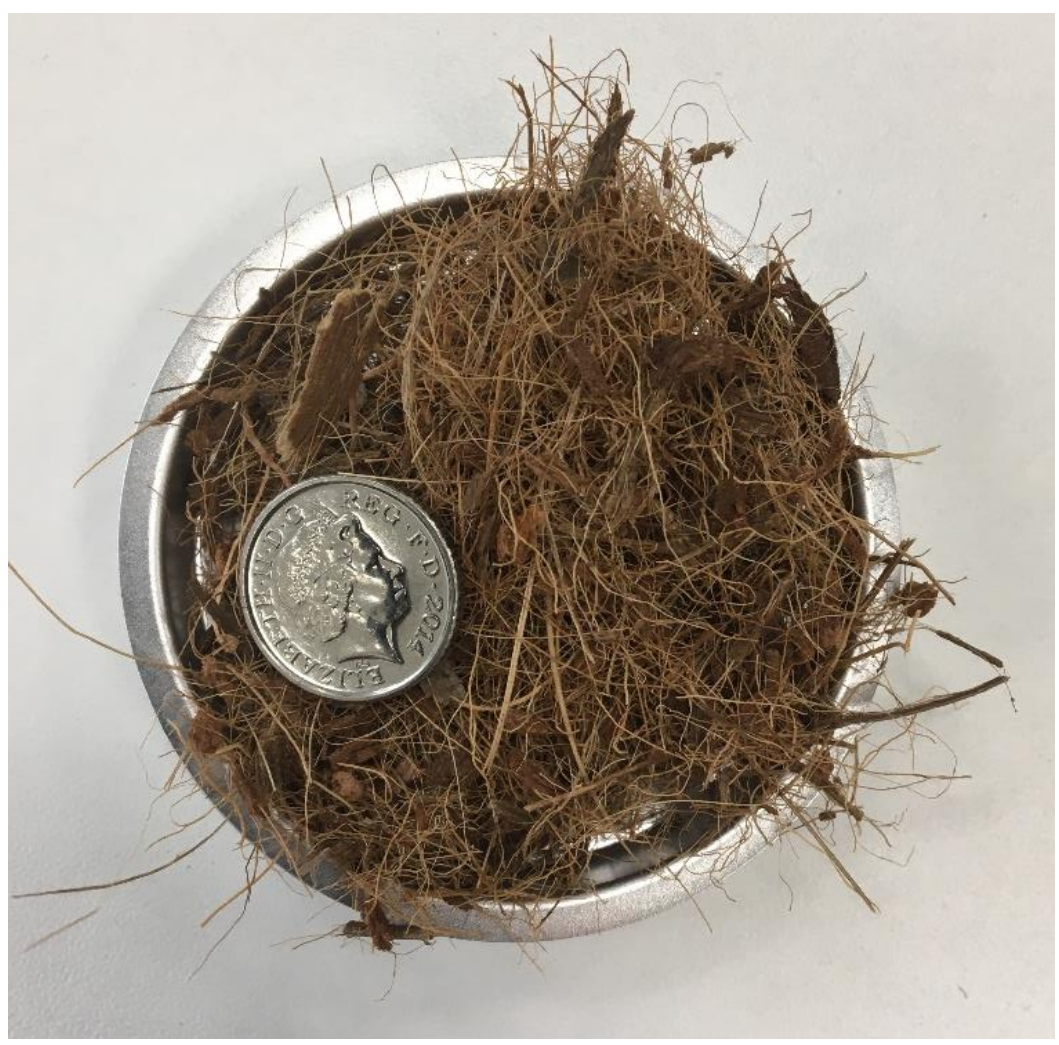

Figure 4.7: Shredded coir. Five pence for scale 


\subsubsection{Biochar}

Biochar is a carbonaceous material produced by the thermal decomposition of biomass during pyrolysis (Lehmann \& Joseph, 2015). Biochar is differentiated from charcoal by biochar's inability to burn readily, and its use as a soil amendment for agronomy (Crombie et al., 2013) and for the remediation of soil and water (Zhang et al., 2013; Jayawardhana et al., 2016; Cairns et al., 2020). Biochar exhibits two key properties important for remediation; its structure and CEC (Sun et al., 2014).

Biochar maintains a structural imprint of the feedstocks original physical characteristics (Downie et al., 2009). Biochar can be produced from a variety of feedstocks, however, wood feedstocks are commonly agreed upon as containing the porous structure and large surface area most suitable for the retention of heavy metals on the biochar's surface (Kloss et al., 2012; Rajkovich et al., 2012; Lahori et al., 2017). The pore structure of biochar resembles the cellular structure of the wood, and the majority of the surface area consists of coarse macropores (>10 $\mu \mathrm{g}$ ) which are interconnected with micropores of $<0.2 \mu \mathrm{g}$ (Brown et al., 2006). The surface area and the total pore volume of the biochar are fundamentally correlated, as highly porous structures have a high surface area. This provides a greater number of potential adsorption sites (Chen et al., 2011).

The CEC of the biochar is also of influence to the adsorption of heavy metal cations (Zhao et al., 2017). As with coir, the CEC develops as the biochar ages and oxygenated functional groups form. For example, the CEC of a fresh biochar was reported to increase from $26.6 \mathrm{cmol} \mathrm{kg}^{-1}$ at the time of production to $>173 \mathrm{cmol} \mathrm{kg}^{-1}$ within 15 months (El-Naggar et al., 2019). The reported CEC of different biochars vary considerably, from $0.17 \mathrm{cmolkg}^{-1}$ to $211 \mathrm{cmol} \mathrm{kg}^{-1}$ (or greater in aged chars, ElNaggar et al., 2019), which is largely a result of the feedstock and the temperature at which the biochar was produced (Purakayastha et al., 2015).

The pyrolysis temperature and the biochar's CEC are also related (Zhao et al., 2017). As the pyrolysis temperature increases, the biochar's $\mathrm{C}$ structure can become crystallised, the porous structure is destroyed, and the CEC is reduced (Gai et al., 2014; Banik et al., 2018). For this reason, many biochars are produced at temperatures $<600{ }^{\circ} \mathrm{C}$ (Setton et al., 2002; Chai et al., 2012), and $300-500{ }^{\circ} \mathrm{C}$ has been deemed 
optimal for both CEC and structure retention (Claoston \& Samsuri, 2014; Banik et al., 2018).

The high CEC of biochar has important implications for biochar-plant interactions. Overwhelmingly, it has been reported that the addition of biochar to contaminated soils can reduce heavy metal concentrations in plant tissue (Puga et al., 2015; Novak et al., 2018; He et al., 2019). A meta-study (Tang et al., 2013) concluded that mean concentrations of $\mathrm{Cd}, \mathrm{Pb}, \mathrm{Cu}$ and $\mathrm{Zn}$ in plant tissues decreased by 38, 39, 25, and 17\%, respectively, when plants were grown in biochar-amended soils compared to unamended soils. Root to shoot translocation of heavy metals were also reduced (Zhang et al., 2013, Chen et al., 2018).

In the majority of studies, the primary mechanism determined responsible for the decreased metal concentration in plant matter is the biochar-induced increase in soil CEC, which immobilised metal cations within the soil $\left(\mathrm{Pb}^{2+}, \mathrm{Cu}^{2+}, \mathrm{Zn}^{2+}, \mathrm{Cd}^{2+}\right)$ and subsequently reduced plant uptake (Inyang et al., 2012; Rizwan et al., 2016). As biochars are typically slightly alkaline, the immobilisation of metals is also enhanced by the increased soil $\mathrm{pH}$ which enables greater precipitation from the soluble to solid phase (Chen et al., 2018).

The CEC required to produce a significant effect on metal uptake in plants grown in contaminated soil is not a well examined field. This is as many studies examine the physical properties of biochar, including pore structure, surface area, CEC, and ash content (Mukherjee et al., 2011; Purakayastha et al., 2016; Suliman et al., 2016), but do not use the biochar in a soil remediation trial. Those that do, tend to examine the metals-biochar interactions and not metals-biochar-plant interactions (Fellet et al., 2011; Kim et al., 2014; Lucchini et al., 2014). Of those studies which examine metalsbiochar-plant interactions, it is common to refer to biochars presumed high CEC, but without testing for it (Bian et al., 2014; Liu et al., 2017; Novak et al., 2018). The lack of studies which examine the CEC of the biochar used, the interaction between the biochar and the metals, and metal uptake in plants, is a considerable gap in the academic literature to date.

Biochar has also been reported to provide benefits to plants grown in uncontaminated soils. Biochar has the potential to enhance long-term soil fertility (Lehmann et al., 2011; Lefebvre et al., 2019), reduce nutrient leaching (Kammann et al., 2015), and 
increase soil biota density and diversity (Lehmann et al., 2011) which positively impacts plant growth. The reported effects of biochar on plant productivity are, however, heterogeneous and highly dependent on plant and soil type (Novak et al., 2018) and the length of the study (Jones et al., 2012). Biochar has a greater effect on crop yield when integrated into leachable, acidic or nutrient deficient soils due to the increased soil water and nutrient retention (Jeffery et al., 2017; Verheijen et al., 2009; Liu et al., 2013). However, in soils of adequate nutrient and water content, biochar has been found to delay germination and decrease overall crop yield (Jeffrey et al., 2017).

The initial decrease in yield has been attributed to biochar's CEC and negative surface charge which retains nutrient cations on the biochar's surface. The high CEC and associated immobilisation of nutrients has been reported to create a short-term ( $<1$ year) decrease in crop yield when compared to unamended soils (Jay et al., 2015). However, studies of $>3$ years report that as the nutrients are slowly leached from the biochar, the nutrients are released to the plants which leads to a more enduring and resilient plant growth. For this reason, biochar amended soils are often reported to produce more consistent growth long-term (Jeffrey et al., 2011; Biederman \& Harpool, 2013; Crane-Droesch, 2013).

Several biochar-related effects other than CEC have been found to be influential in supporting plant growth. The WHC of biochar amended soils have been extensively investigated (Glaser et al., 2002; Anawar et al., 2015; Yargicoglu et al., 2015; Lahori et al., 2017). For example, it has been demonstrated that the WHC of Regosols can be increased $>45 \%$ with the addition of $5 \%$ biochar (Gavili et al., 2019). In sandy soil, moisture retention increased by $18 \%$ upon the addition of $45 \%(\mathrm{v} / \mathrm{v})$ biochar (Glaser et al., 2002). The increase in WHC has largely been attributed to the porous nature of biochar which improves water retention (Major et al., 2010; Hardie et al., 2014).

The changes to a soil's WHC following biochar addition does not appear to be uniform across all soil types, however. In loamy and clay soils, biochar appears to have little effect on WHC (Glaser et al., 2002; Hardie et al., 2014), which was attributed to the already high WHC of clay soil. In some studies it has been found that integrating biochar into a clayey soil reduced the soil's wettability and increased overland flow (Kinney et al., 2012; Smetanová et al., 2013). Therefore, improvements to a soil's 
water retention by biochar addition may be most greatly observed in sandy textured soils.

The biochar-related effects on soil (higher WHC, greater long-term nutrient retention and improved soil aeration) creates more favourable plant conditions, which indirectly effect metal uptake in plants grown in contaminated mediums. The improved soil conditions assists plant growth and have frequently been reported to increase plant biomass (Chan et al., 2007; Shaaban et al., 2018). When metal uptake occurred, the greater quantity of biomass (compared to that grown without biochar) was shown to dilute the metals among the increased biomass, which in turn reduced the metal concentration within the plant (Lahori et al., 2017), i.e., although uptake may be the same in two plants, if one plant is small and one large, the larger one will contain a lower concentration of metals. The positive impacts of biochar on plant production are more pronounced in field trials than in pot trials (Jones et al., 2012) and presents more clearly in long-term studies (Jeffrey et al., 2011).

As biochar is effective at limiting the mobility of toxic elements as well as improving soil conditions and plant growth, there is a clear benefit to incorporating biochar into a soil cover for mine reclamation, although the influence of biochar on plant production may not be seen immediately. Many successful greenhouse trials have occurred (Karami et al., 2011; Rodríguez-Vila et al., 2014; Moreno-Barriga et al., 2017). While not specifically mine tailings, numerous field trials have also examined the phytoremediation of metal contaminated land using a biochar compost (Bopp et al., 2016; Yang et al., 2016; Shen et al., 2017; O’Connor et al., 2018). The most pertinent example is that of the previously discussed Hope Mine reclamation project (Section 2.4) where metal-mine waste was hydroseeded using a biochar compost and reported a 313\% increase in biomass in one year (ACES, 2017). In this research, surrogate soils both with and without biochar were trialled to examine the effects of biochar application for mine reclamation.

The biochar used in this research was produced from waste Larix kaempferi (larch) wood, as using Phytophthora affected wood was an effective method of using one type of waste to treat another. The CEC of the biochar was not examined due to time and cost constraints. However, larch biochar produced by the same pyrolysis unit was measured as a median $(\mathrm{n}=6)$ of $48.5 \pm 33.8 \mathrm{cmol} . \mathrm{kg}^{-1}$ by Harries (2017) using a 
method outlined in Hendershot et al., (2006). The full method is detailed in Appendix 1.

The CECs reported for woody biochars range from $10.8 \mathrm{cmol} . \mathrm{kg}^{-1}$ for Leucaena leucocephala (white lead tree) (Jien \& Wang, 2013), $14.4 \mathrm{cmol} \cdot \mathrm{kg}^{-1}$ for Populus tremula (poplar) (Kloss et al., 2012), $55.5 \mathrm{cmol}^{\mathrm{kg}} \mathrm{kg}^{-1}$ for Pseudotsuga menziesii (douglas fir) (Suliman et al., 2016), and $70.2 \mathrm{cmol.kg}^{-}$for Malus domestica (apple tree) (Zhao et al., 2017). The CEC of the larch was determined as within the range typical of woody biochars.

\subsubsection{Biochar production}

The design of the pyrolysis unit is subject to intellectual property restrictions; therefore, certain details cannot be discussed in this document. Briefly, however, the pyrolysis unit features two principal components (Figure 4.8). The first is a kiln unit with incorporated feedstock intake, which delivers the feedstock to the rotary hearth via an elevator. The rotary hearth maintains a temperature of $400-500{ }^{\circ} \mathrm{C}$ to preserve the structure of the feedstock and retain a high CEC (Banik et al., 2018). The feedstock progresses downwards through the hearth, which is fed oxygen through primary air controls. The off-gasses reach temperatures of $400-900{ }^{\circ} \mathrm{C}$ and rise towards the thermal oxidiser at the top of the kiln. The counter-flow of the gases restricts air from entering the chamber. The high temperatures and limited oxygen results in the pyrolysis of the feedstock. Once the feedstock has progressed through the hearth, the finished biochar is discharged into a receiver container (Harries, 2017). The second component is a thermal oxidiser which ensures full oxidation of the organic compounds. Off-gases are ducted from the kiln past air controls to the thermal oxidiser chamber (Harries, 2017). The conversion process takes $\sim 90$ seconds to complete.

Biochar was provided by TerrAffix Soil Solutions (Swansea, Wales) at a cost of $£ 5 . \mathrm{kg}^{-1}$. The biochar was ground to $<5 \mathrm{~mm}$ for inclusion in the surrogate soil (Figure 4.9). The specifications for the material are detailed in Table 4.6. 


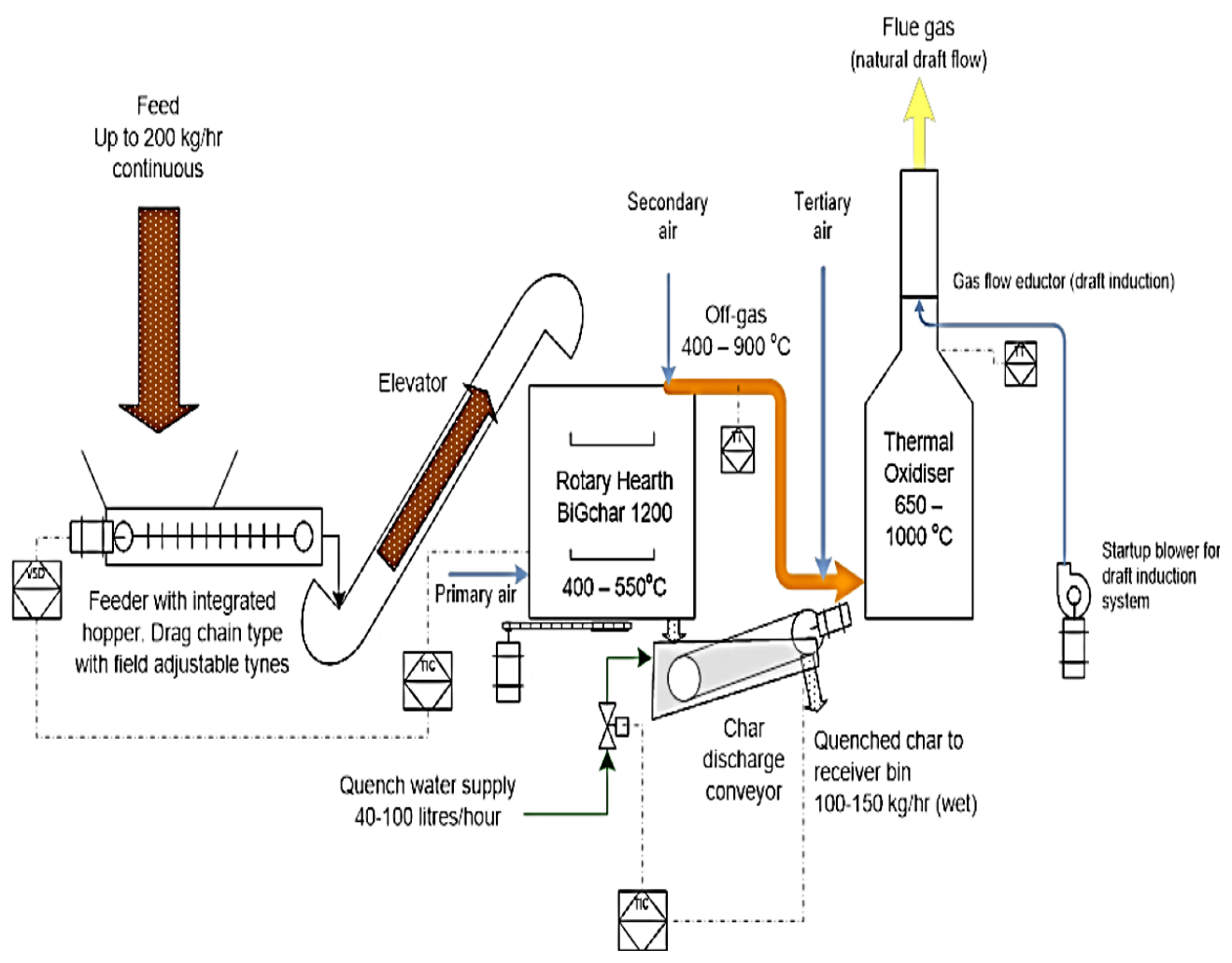

Figure 4.8: Schematic diagram of the Pyrocal BigChar 1000, which produced the biochar used in the rainsplash, germination and field trials (Harries, 2017)

Table 4.6. The material specifications of the biochar. Mean, $n=5$. \pm refers to the sample standard deviation.

\begin{tabular}{l|c}
\hline \multicolumn{1}{c|}{ Biochar } & Mean \\
\hline Total organic matter (\%) & $22 \pm 0.4$ \\
$\mathrm{C} / \mathrm{N}$ & $289 \pm 58$ \\
$\mathrm{~N}\left(\mathrm{mg} \cdot \mathrm{kg}^{-1}\right)$ & $1700 \pm 1$ \\
$\mathrm{P}\left(\mathrm{mg} \cdot \mathrm{kg}^{-1}\right)$ & $12 \pm 7.8$ \\
Water holding capacity (\%) & $274 \pm 34$ \\
$\mathrm{pH}$ & $7.5 \pm 0.3$ \\
\hline
\end{tabular}




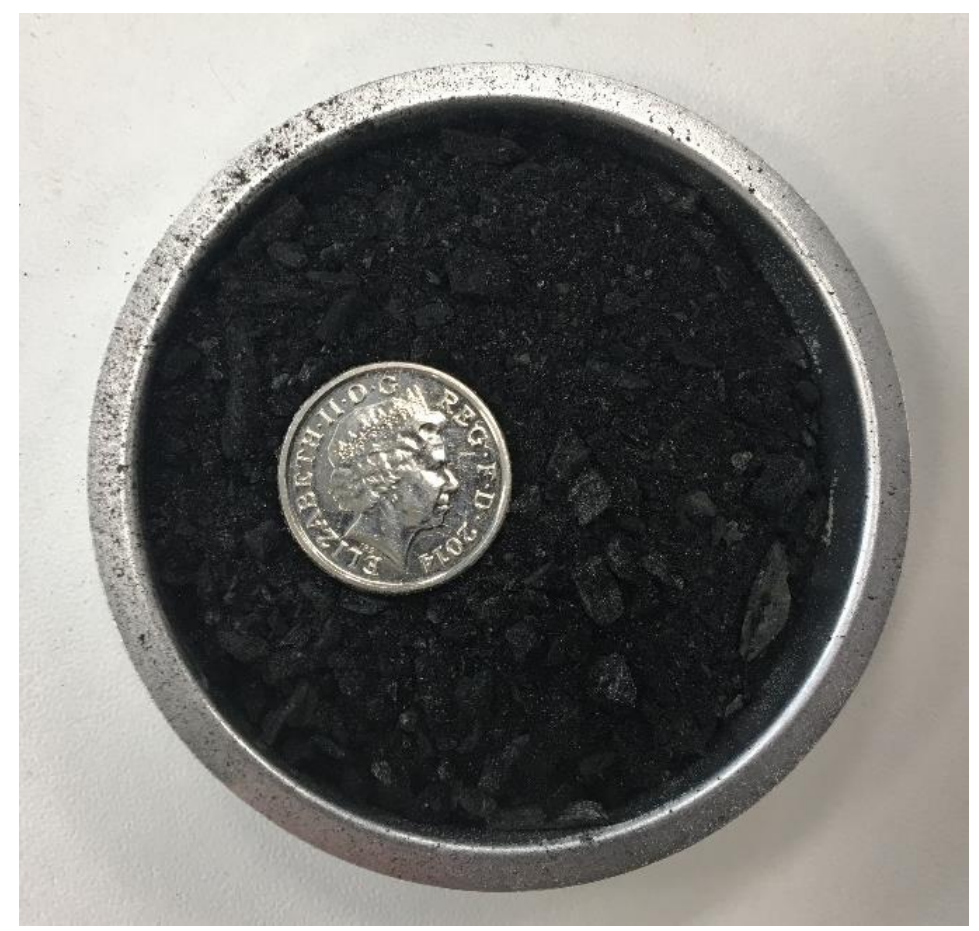

Figure 4.9: Ground biochar. Five pence for scale

\subsubsection{Fertilisers}

The restoration of a plant community and the promotion of $\mathrm{N}$ cycling processes is a crucial objective of land reclamation practices (Malloch et al., 2015; Peltz \& Harley, 2016; Simcock \& Ross, 2018). In a fully-functioning vegetated temperate soil, $100 \mathrm{~g} \cdot \mathrm{m}^{-1} \mathrm{~N}$ is required (Bradshaw, 1997). A quantity of $\mathrm{N}$ is provided by precipitation $\left(10-30 \mathrm{~kg} \cdot \mathrm{ha}^{-1}\right.$ per year), but the main source is via biological fixation by $\mathrm{N}$-fixing microorganisms (Machmuller et al., 2015). The fixed $\mathrm{N}$ accumulates in the plant biomass and is transported to the soil surface through plant uptake and decomposition. As the plant decomposes, the $\mathrm{N}$ accumulates on the surface in an organic form. The rate of release through decomposition is $\sim 100 \mathrm{~kg} \cdot \mathrm{ha}^{-1}$ per year in temperate soils, approximately $10 \%$ of the required amount (Bradshaw, 1997).

Economically, the $\mathrm{N}$ requirements of a surrogate soil cannot be provided by fertilisers alone. However, until the organic $\mathrm{N}$ pool and $\mathrm{N}$ cycling processes are fully established, the requirements are usually met by field fertilisation, most often through fertiliser produced by ammonium nitrate, either in crystal or soluble form (Schoenholtz et al., 1992; Agegnehu \& Amede, 2017). 
Fertilisers have been incorporated into surrogate soils at a range of application rates, from 11 g.m ${ }^{-2}\left(\mathrm{NH}_{4} \mathrm{NO}_{3}\right.$ crystals, Malloch et al., 2015) to $30 \mathrm{~g} \cdot \mathrm{m}^{-2}$ (a soluble chemical fertiliser, Martínez-Ruiz et al., 2007). The low application rate is as the intention is often not to create a perfect soil, but to create one which is economical, practical, and with materials which are readily available. The purpose of a surrogate soil for mine reclamation of often not to produce the density of grass typical of a pasture, but instead the intention is to produce enough grass growth to control erosion (Martínez-Ruiz et al., 2007).

As mentioned in Section 4, in a commercial setting the cost of application is paramount. The required application rate of fertiliser can be reduced through the simultaneous use of biochar. The interactions between biochar and $\mathrm{N}$ have been concisely summarised in an extensive meta-analysis of 1080 experiments conducted by Nguyen et al. (2017). The authors concluded that when biochar is initially applied to a soil, a reduction in available $\mathrm{N}$ (in the form of $\mathrm{NH}_{4}{ }^{+}$) occurs due to the adsorption of $\mathrm{N}$ onto the biochar. Consequently, plant growth is negatively affected in the shortterm ( $<1$ month). However, in biochar amended soils $\mathrm{N}$ releases at a slower but more regulated rate than in soils without biochar. In studies of $>1$ month, losses from leaching were reduced which resulted in a higher $\mathrm{N}$ plant uptake and greater plant growth (Hamer et al., 2004; Nguyen et al., 2017). Improvements in plant production were seen in both pot trials (Chan et al., 2007; van Zwieten et al., 2010) and field trials (Steiner et al., 2008; Major et al., 2010). It was thus concluded that fertiliser-enriched biochar could be used as a slow-release source of $\mathrm{N}$ to support long-term plant growth (Clough et al., 2013; Nguyen et al., 2017).

Granular fertiliser (3 - $5 \mathrm{~mm}$, Figure 4.10), manufactured from the mycelium of soil fungus, was provided by Internationale Geotextil GmbG. After application and rehydration, the granulated substance serves as a slow-release source of $\mathrm{NH}_{4}{ }^{+}$. The $\mathrm{NH}_{4}{ }^{+}$fertiliser is a waste product of the mushroom cultivation process, and so is abundant and inexpensive

The $\mathrm{NH}_{4}+$ fertiliser was intended for one-time application (Internationale Geotextil $\mathrm{GmbH}, 2019)$. The specifications for the material are detailed in Table 4.7. 
Table 4.7. The material specifications of the fertiliser. Mean, $n=5$. \pm refers to the sample standard deviation.

\begin{tabular}{l|c}
\hline \multicolumn{1}{c|}{ Fertiliser } & \\
\hline Total organic matter (\%) & $85 \pm 0.6$ \\
$\mathrm{C} / \mathrm{N}$ & $6 \pm 1.2$ \\
$\mathrm{~N}\left(\mathrm{mg} \cdot \mathrm{kg}^{-1}\right)$ & $74000 \pm 1$ \\
$\mathrm{P}\left(\mathrm{mg} \cdot \mathrm{kg}^{-1}\right)^{*}$ & $1004 \pm 7$ \\
$\mathrm{pH}$ & $7.2 \pm 0.3$ \\
\hline
\end{tabular}

$\overline{* \text { Reported in the product specification sheet (Internationale Geotextil GmbH, 2019) }}$

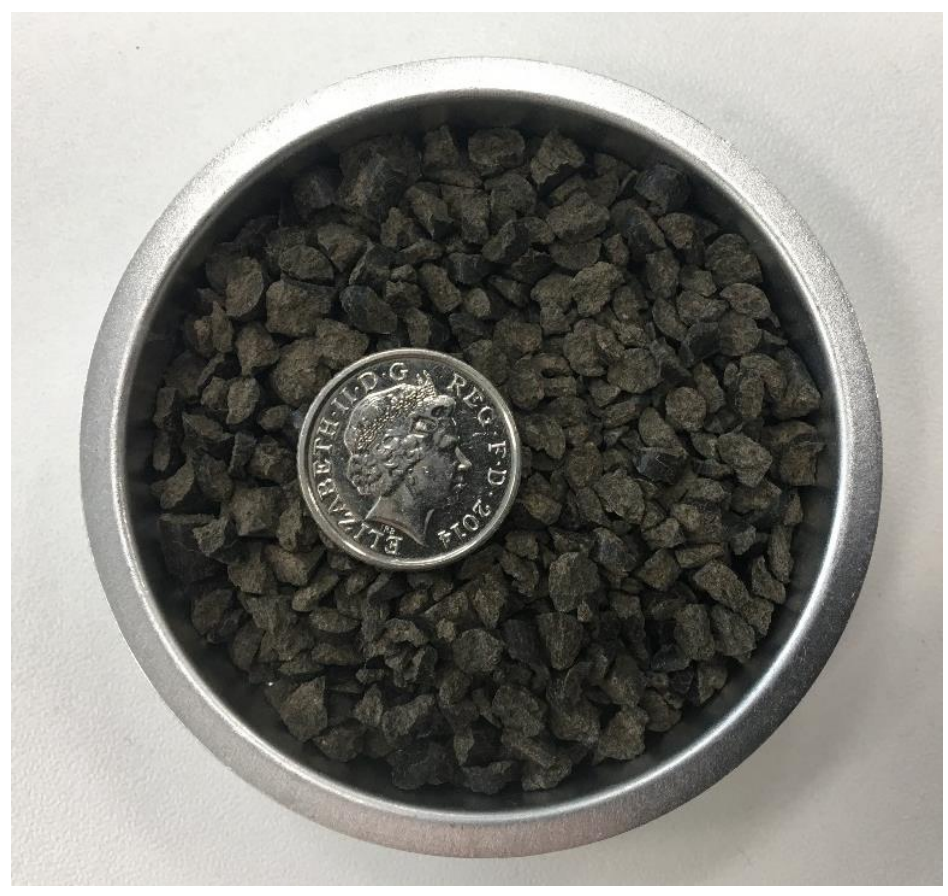

Figure 4.10: Granular fertiliser. Five pence for scale 


\subsubsection{Basalt}

Due to the heterogeneous nature of the surrogate soil materials, the potential existed for a highly variable mineral composition (Wijesekara et al., 2016). Amendments should, therefore, be included as a means of ensuring the mineral content of the surrogate soil. Ground basalt is a commonly used soil additive to increase soil $\mathrm{pH}$ and improve the mineral content of soils, particularly P and Si (Porder \& Ramachandran, 2012; Anda et al., 2013).

Phosphorus is central to soil processes that regulate nutrient cycling, $\mathrm{C}$ storage and OM content and quality (Porder \& Ramachandran, 2012; Abreuq et al., 2015; Macdonald et al., 2016). Although not well-investigated, Si is also crucial to plant production, and increases the uptake of $\mathrm{K}, \mathrm{Ca}$ and $\mathrm{Mg}$, particularly in stressed plants (Akter \& Akagi, 2010; Greger et al., 2018). Si is a key component of cell walls and is responsible for the production of strong shoots. Si also regulates leaf transpiration rates, and a basalt amendment has been shown to aid resistance to drought (Gillman et al., 2002; Hartmann et al., 2013). These effects instigate increases in plant height, root biomass and yield (de Villiers, 1961; Akter \& Akagi, 2010) in both pot (Gillman et al., 2002) and field trials (Anda et al., 2009; ten Berge et al., 2012; Anda et al., 2013).

The $\mathrm{P}$ requirements of the selected grasses are $\sim 0.04$ g.m ${ }^{-2}$ (Syers et al., 2008).

Ground basalt (Figure 4.11) was provided by Remin Scotland Ltd (www.ReminScotland.com) at a cost of $\sim £ 4 . \mathrm{kg}^{-1}$. Basalt fines were sieved to $2 \mathrm{~mm}$ before inclusion in the surrogate soil. The specifications for the material are detailed in Table 4.8 .

Table 4.8. The material specifications of the basalt, as determined by XRF analysis. Mean, $n=5 . \pm$ refers to the sample standard deviation

\begin{tabular}{|c|c|}
\hline Basalt (mg.kg $\left.{ }^{-1}\right)$ & \\
\hline $\mathrm{P}$ & $2094 \pm 953$ \\
\hline $\mathrm{Si}$ & $16136 \pm 1216$ \\
\hline $\mathrm{pH}$ & $9.6 \pm 0.2$ \\
\hline
\end{tabular}




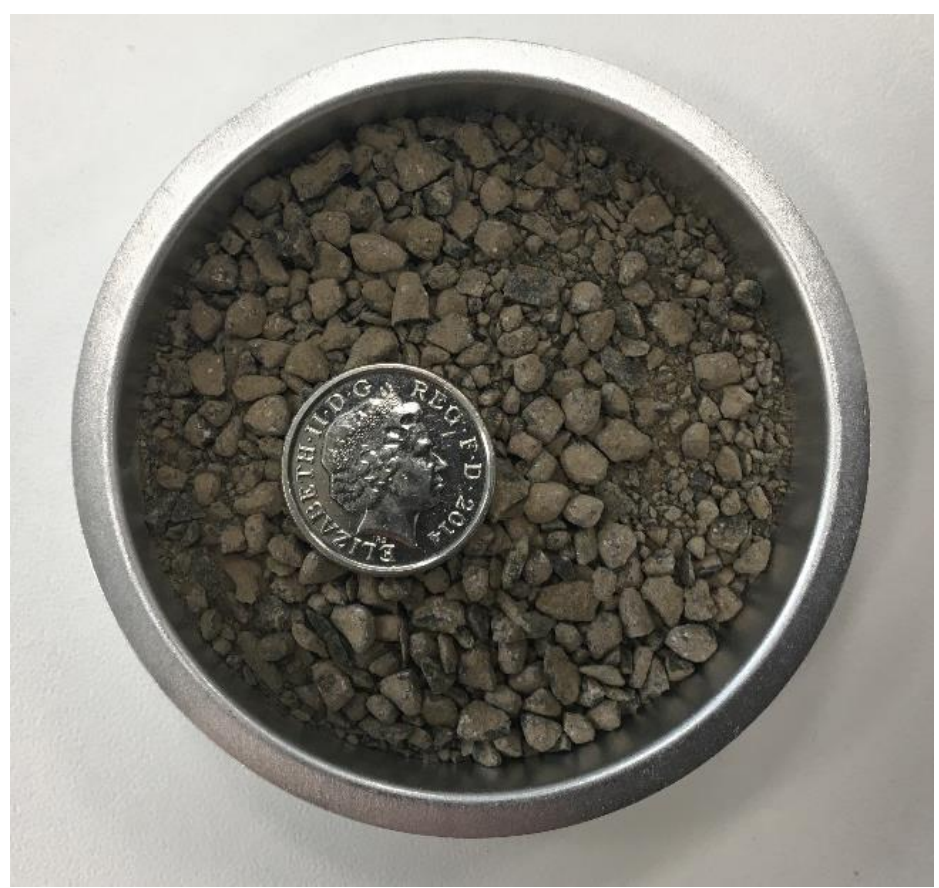

Figure 4.11: Ground basalt. Five pence for scale.

\subsection{Selecting vegetation}

Successful cap-and-cover systems are underpinned by the management of the colonisation and succession of species (Hollingsworth et al., 2007). Vegetation selection is based on successful analogous studies, with a preference for a diverse metal-tolerant community that mimics the existing native assemblage. Ideally, these plants should be able to facilitate nutrient cycling and soil formation, both essential processes which initiate ecosystem complexity (O'Kane \& Ayres, 2012; Burges et al., 2016).

While land reclamation aims to enable the natural succession of species long-term, in many cases the initial introduction of non-native species is necessary to achieve the minimum ground cover required by law (Holl, 2002). To achieve these legal requirements, revegetation focusses on establishing rapid-growing species that control erosion. However, monitoring > 35 years has suggested that these species may impede long-term ecosystem recovery by out-competing native ones (Bradshaw, 1997; Holl, 2002; Martins Azevedo et al., 2005). 
Fortunately, there are many well-researched metal-tolerant grasses which are native to the UK. Many abandoned $\mathrm{Pb} / \mathrm{Zn}$ mines, if undisturbed, exhibit a sparse colonisation of a limited assemblage of these plants. Agrostis capillaris, Agrostis stolonifera, Festuca ovina, Festuca rubra and Anthoxanthum odoratum predominate (Antonovics, 2006; Smith \& Bradshaw, 2006; Alvarenga et al., 2014). These species are termed 'pseudo-metallophytes' (Burges et al., 2016).

To date, little contemporary research exists regarding the mechanisms of metaltolerance in these species. However, the theory has been proposed that in these species the genes for metal-tolerance are highly heritable, and when coupled with the high selection pressures of contaminated sites the result has been a rapid evolution of heavy metal tolerance (Humphries \& Nicholls, 1984; Patra et al., 2004; Smith \& Bradshaw, 2006).

A. capillaris was first investigated for the revegetation of a metal-contaminated site in Swansea, South Wales (UK) (Gadgil, 1969). A $2.5 \mathrm{~cm}$ deep surrogate soil of sewage sludge and NPK fertiliser was applied to smelter waste and planted with seedlings relocated from metal mines throughout the UK. When supplied annually with fertiliser, growth within the first two years was reported as positive. However, when fertiliser was no longer applied annually plant growth declined to an unrecoverable state (Goodman \& Gemmell, 1978). Later trials at the same location confirmed that A. capillaris successfully colonised metalliferous waste when sufficient fertiliser was applied (Antovics et al., 1971; Thompson \& Proctor, 1983).

A. capillaris is one of the most common species selected to revegetate metalcontaminated land, internationally as well as within the UK. The most notable study was conducted in Spain and produced 300 g.m $\mathrm{m}^{-2}$ of biomass (Touceda-González et al., 2017). Agrostis stolonifera is often included alongside A. capillaris due to a tolerance for salinity as well as metals (Courtney, 2018) and its mat-forming dense root system (Wu \& Antonovics, 1975). Agrostis grasses root well in tailings and are considered to be somewhat drought-resistant, which is crucial as it has been speculated that the low WHC of mine tailings affects many plants much sooner than the toxicity (Smith \& Bradshaw, 2006).

Varieties of Festuca rubra and Festuca ovina have been developed specifically for the direct seeding of metalliferous wastes, but each exhibit different characteristics. $F$. 
rubra was developed for acid soils and F. ovina for calcareous soils (Tordoff et al., 2000). Festuca rubra and F. ovina are used for erosion control as they quickly establish on bare ground and are competitive colonisers (Leuchtmann \& Schardl, 2010). Festuca rubra and ovina are tolerant of a wide range of pollutants, particularly $\mathrm{Pb}$ and Zn (Brown \& Brinkmann, 1992; Tordoff et al., 2000), but also As, Hg (Patra et al., 2004) and $\mathrm{Cu}$ (Smith \& Bradshaw, 2006).

Anthoxanthum odoratum differs from the other grass species discussed as although tolerant of $\mathrm{Pb}$ and $\mathrm{Zn}$, it is not tolerant of $\mathrm{Cu}$ (Qureshu et al., 1985). It is, however, highly tolerant of drought as well as acidic, poor, and nutrient-deficient soils. This has been suggested to be due to the plants thin, numerous and extensive rhizomes which can explore further within the soil (Quereshi et al., 1985).

Several of the grasses are metal-tolerant by means of avoidance (Agrostis and A. Odoratum), and others through isolation of the accumulated metals in the cell walls (Festuca). Still, even the avoidant species can accumulate $>5000 \mathrm{mg} \cdot \mathrm{kg}^{-1} \mathrm{~Pb}$ and $1000 \mathrm{mg} \cdot \mathrm{kg}^{-1} \mathrm{Zn}$ in highly contaminated substrates (Tordoff et al., 2000). Concentrations such as these and a low resistance to trampling preclude the area from livestock grazing. Revegetated areas should be well fenced to discourage this, but as herbivory cannot be completely avoided grasses which are metal-tolerant though exclusion were preferable for this purpose.

\subsection{Surrogate soil composition}

In temperate grasslands, the $\mathrm{N}$ requirement necessary for sustained plant growth is $\sim 100$ g.m ${ }^{-2}$ (Bradshaw, 1997). The selected grass species have comparatively very low $\mathrm{N}$ requirements, $3-7 \mathrm{~g} . \mathrm{m}^{-2}$ is sufficient (Bradshaw et al., 2009), which is less than that annually supplied by precipitation $\left(10-30\right.$ g.m $\mathrm{m}^{-2} \mathrm{~N}$, Machmuller et al., 2015). Agrostis and Festuca have been found to colonise substrates with almost no available N (Tallec et al., 2008).

Historic weather data for the Nantymwyn area showed that heavy rainfall was to be expected during the winter months (www.WorldWeatherOnline.com, 2017). Consequently, nutrient leaching was anticipated (Djodjic et al., 2004). Previous research has shown that $\mathrm{N}$ is integral to the success of reclamation projects (Bradshaw, 
1997; Martínez-Ruiz et al., 2007; Malloch et al., 2015). As a result, $\mathrm{N}$ and $\mathrm{P}$ in excess of the plant requirements were provided to the soil.

In the surrogate soil, $140 \mathrm{ml} . \mathrm{m}^{-2}$ of $\mathrm{NH}_{4}+$ fertiliser supplied $10.5 \mathrm{~g} . \mathrm{m}^{-2} \mathrm{~N}$. The anaerobic digestate provided another $10.2 \mathrm{~g} \cdot \mathrm{m}^{-2} \mathrm{~N}$ (in $640 \mathrm{~g} \cdot \mathrm{m}^{-2}$ of material) which was more than adequate for the grasses.

The selected grasses require a low but constant supply of $\mathrm{P}\left(\sim 0.04\right.$ g.m $\mathrm{m}^{-2}$, Syers et al., 2008). As basalt has a high $\mathrm{pH}$ (9.6, Table 4.8), and the grasses favour acidic soils, only a small amount of basalt was included $\left(7 \mathrm{ml} . \mathrm{m}^{-2}\right)$, which provided the soil with 0.03 g.m $\mathrm{m}^{-2} \mathrm{P}$. The remainder was supplied by the $\mathrm{NH}_{4}+$ fertiliser, 1.1 g.m $\mathrm{m}^{-2} \mathrm{P}$ in 35 ml. $\mathrm{m}^{-2}$.

Biochar has been reported to exert a multitude of effects on soil, both positive and negative. While, overall, biochar can increase crop yields long-term through improvements to the soil properties (Crane-Droesch, 2013), including through nutrient retention (Kammann et al., 2015), the reverse has also been reported (Jeffrey et al., 2017). The CEC of biochar can be both a help and hindrance. On one hand, biochar has been reported to increase the moisture retention of sandy soils (Glaser et al., 2009) but to decrease moisture retention and water infiltration in clay soils (Kinney et al., 2012; Smetanová et al., 2013). The mine tailings are of a sandy texture (Table 3.1), however the surrogate soil was not to be sandy textured. Hence, biochar addition had the potential to reduce water infiltration and increase overland flow in the surrogate soil.

It is clear that the addition of biochar to the soil can lead to both beneficial and unintended detrimental outcomes, and biochar should be incorporated into the soil with some consideration. It was proposed biochar should be incorporated into the surrogate soil at the lowest rate necessary to be effective. Two previous trials have shaped the design of this research, that of ACES (2017) and De-Quincey (2017). Both trials incorporated biochar into the soil at $5 \%(\mathrm{v} / \mathrm{v})$. Many other studies which have examined the use of biochar to assist revegetation, either through soil improvement or for the alleviation of contaminants, have also determined $5 \%(\mathrm{v} / \mathrm{v})$ to be the optimal proportion (Elad et al., 2010; Houben \& Sonnet, 2015; Shen et al., 2016; Gavili et al., 2019). Thus, the rate of $5 \%(\mathrm{v} / \mathrm{v})$ biochar was chosen. 


\section{Rainfall simulations introduction}

The materials selected to create a surrogate soil cover on the mine tailings were underwent a series of trials. As stated in the Research Aims, it was first necessary to establish the surrogate soil materials and binding agents most resistant to rainfall erosion. In later trials, the ability of the surrogate soil to enable grass seed germination would be examined. However, in field conditions, if the soil were unable to adhere to the steep slopes of the tailings, grass germination would be severely impeded. Foremost, it was crucial that the surrogate soil adhere to the slopes without deformation or substantial erosion.

At Nantymwyn, the mean July rainfall (on a day on which it rained) from 2015 - 2017 was $6.1 \mathrm{~mm}$ (www.WorldWeatherOnline.com, $2018^{1}$ ). The highest rainfall rate on record in the UK was $92 \mathrm{~mm}$ over one hour, and $238 \mathrm{~mm} 24$ hours (July 1901, Met Office, 2010). While this is an extreme weather event in the UK, this would not be uncommon in tropical (Rahardjo et al., 2012) or Mediterranean climates (Kelsch et al., 200). Mining often occurs in areas with more extreme weather than the UK, such as the Ekati Mine in the Arctic Circle, or the Grasberg Mine in Indonesia. Due to climate change, extreme weather events are predicted to become more frequent in the future (Met Office, 2010). A suitable rainfall intensity to trial the effectiveness of the guar gum is not one of a typical hourly average, as this does not reflect the extreme weather that occurs with increasing frequency, or determine the strength of the surrogate soil over successive days of rainfall. Therefore, a rate of $200 \mathrm{~mm} / \mathrm{h}$ was used.

A soil which could be applied in one layer would be the most economical option, as this would require the use of the hydroseeder (and staff) only once. However, several studies have employed a method of applying the soil cap in two layers, either as a coir base layer capped with soil (ACES, 2017), or a clay cap with topsoil (Atkins, 2015). Therefore, a single and two-stage approach will be trialled, where soil is applied either in one layer, or as a base and top layer. 


\subsection{Rainfall simulations - Method}

Trials were conducted to assess the materials adhesion on a steep $\left(20^{\circ}\right)$ slope under intense rainfall $(200 \mathrm{~mm} / \mathrm{hr})$ using a rainfall simulator, described in Section 5.1.6.

\subsubsection{Preparing the sample boards}

Wooden slope plots (as recommended by Merlin et al., 1999) were constructed using $12 \mathrm{~mm}$ thick plywood (Figure 5.1). On each sample board a $30 \times 30 \mathrm{~cm}^{2}$ square was delineated to correspond with the rainfall area. A scalpel was used to scarify a cross hatch pattern of $2 \mathrm{~cm}^{2}$ squares onto the boards. During the rainfall simulation, wooden guttering directed the water and any eroded material downslope to a circular sieve with a $1.4 \mathrm{~mm}$ mesh bottom. Any eroded soil material was retained in the sieve, whilst the water continued towards the drain. The material was retained for weighing (Figure $5.2)$.

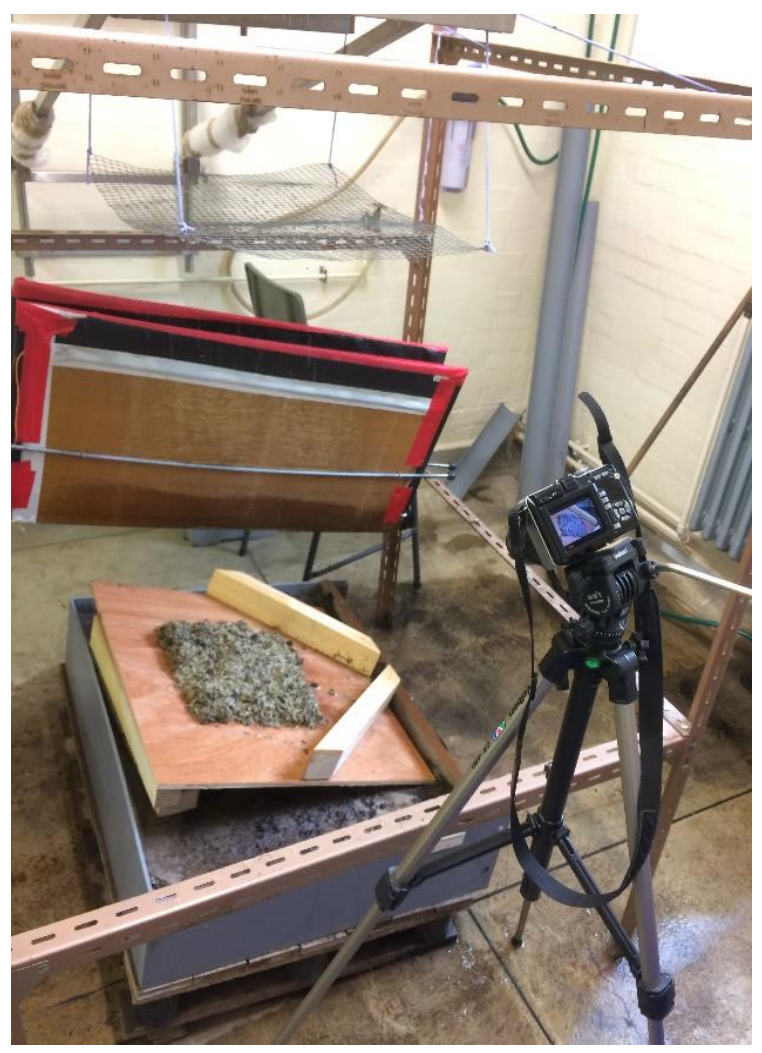

Figure 5.1: A wooden board with the surrogate soil applied, in the rainfall simulator

Figure 5.2: The eroded material from a rainfall simulation, which was retained in a sieve for weighing

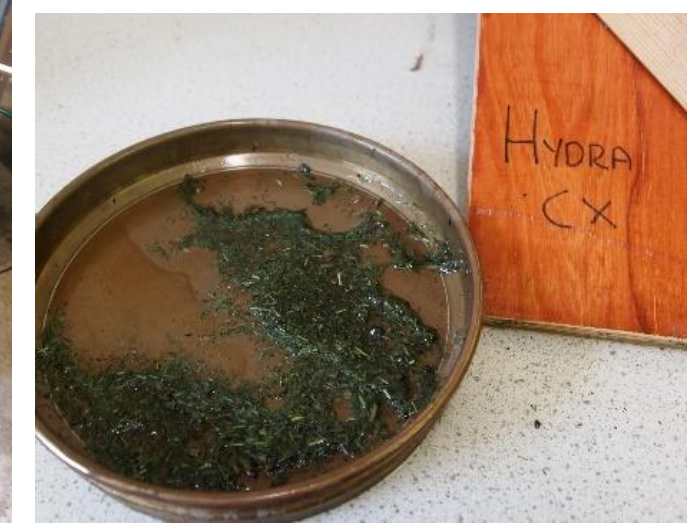


As informed by the pilot study (Appendix 2.1) the surrogate soil was applied to a depth of $2 \mathrm{~cm}, \sim 700 \mathrm{ml}$ material per plot. The materials were measured volumetrically to ensure the same quantity of materials were applied to each board. As the proportion of guar gum incrementally increased the proportion of straw and digestate was reduced to maintain an equal $700 \mathrm{ml}$ material for all plots.

Two different application approaches were trialled: single-stage and two-stage. The treatments in these categories are referred to as being in either the 'single-stage group' or 'two-stage group'. These two groups are further subdivided by the percentage of guar gum in the treatment $(2,4,6,8$ or $10 \%)$. Hydra CX was trialled as an example of an erosion control product of acceptable standards, and was applied in accordance with the product technical sheet (Tensar, 2012).

\subsubsection{Single-stage application}

In the single-stage group, the materials were combined to produce a single medium for the intention of hydroseeding in one application. The proportions of materials were as described in Table 5.1.

Table 5.1: Rainfall trial design - Single-stage application

\begin{tabular}{cc|cccc|cc|cc}
\hline \hline \multicolumn{2}{c|}{ Guar gum } & \multicolumn{2}{c|}{ Digestate } & \multicolumn{2}{c|}{ Straw } & \multicolumn{2}{c|}{ Biochar } & \multicolumn{2}{c}{ Total } \\
$(\%)$ & $(\mathrm{ml})$ & $(\%)$ & $(\mathrm{ml})$ & $(\%)$ & $(\mathrm{ml})$ & $(\%)$ & $(\mathrm{ml})$ & $(\%)$ & $(\mathrm{ml})$ \\
\hline 4 & 28 & 63 & 441 & 28 & 196 & 5 & 35 & 100 & 700 \\
6 & 42 & 62 & 434 & 27 & 189 & 5 & 35 & 100 & 700 \\
8 & 56 & 61 & 427 & 26 & 182 & 5 & 35 & 100 & 700 \\
10 & 70 & 60 & 420 & 25 & 175 & 5 & 35 & 100 & 700 \\
\hline
\end{tabular}


The dry materials and water for each plot were measured volumetrically using glass measuring beakers. The dry materials (straw, anaerobic digestate, biochar, guar gum) were combined in a large plastic measuring jug and homogenised using a metal trowel to thoroughly disperse the guar gum. An electric hand blender, supported by a retort stand, was used to produce consistent mixing conditions for the samples (Figure 5.3). The steel beaters of the electric hand blender were placed inside the container of dry materials. Municipal water was then slowly poured from a measuring cylinder whilst the hand blender operated at a low speed ( 60 revolutions per minute). Water was added to the samples at a ratio of 1:2 dry materials:water. All samples were homogenised thoroughly for 15 minutes, which is the recommended mixing time for Hydra CX. Each treatment was produced separately and sequentially, and the equipment was cleaned between treatments.

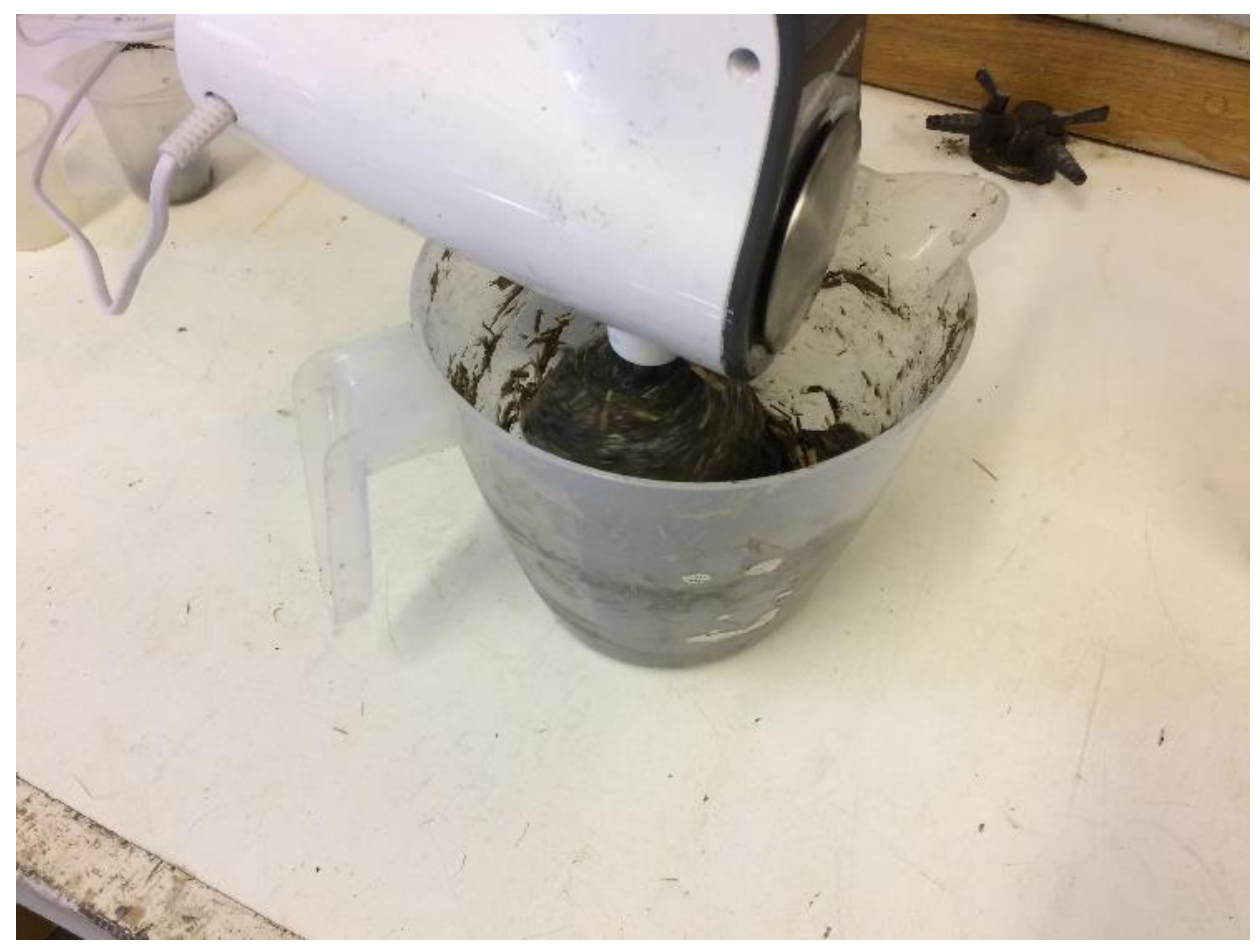

Figure 5.3: A surrogate soil sample being homogenised by a hand blender 
After 15 minutes the metal beaters were removed from the sample. Any material which had adhered to the beaters was removed and returned to the bulk sample. Whilst the boards were flat, using a metal trowel, the sample was spread onto plywood within the $30 \times 30 \mathrm{~cm}^{2}$ square plot, leaving a small gap to allow for the spread and settling of materials. The boards were then immediately moved to a drying location and placed at a $20^{\circ}$ slope, which was slightly steeper than angle of the tailings dumps at Nantymwyn (15 ${ }^{\circ}$, Section 3.2.3).

\subsubsection{Two-stage application}

The two-stage treatment group involved the application of a base layer of growing medium (350 ml, $1 \mathrm{~cm}$ depth) which was capped with an equal volume of an erosion protection layer.

The base layer was composed of coir fibres $(95 \% \mathrm{v} / \mathrm{v})$ and biochar $(5 \% \mathrm{v} / \mathrm{v})$, the volume of which totalled $350 \mathrm{ml}$ with a $1 \mathrm{~cm}$ depth. The base layer contained no guar gum.

Guar gum was added to the top layer at 8 and $10 \%(\mathrm{v} / \mathrm{v})$ of the total material volume of this layer. The top layer was composed of straw (63 or 64\%), digestate (27 or $28 \%$ ) and guar ( 8 or $10 \%)$. The volume of materials in the top layer totalled $350 \mathrm{ml}(700 \mathrm{ml}$ per plot, Table 5.2).

Table 5.2: Rainfall trial design - Two-stage application, with 8 or $10 \%$ guar gum.

\begin{tabular}{cc|cc|c|cc|cc|cc|c}
\hline \hline \multicolumn{4}{c|}{ Base layer } & \multicolumn{7}{c|}{ Top layer } \\
\hline \hline \multicolumn{2}{c|}{ Coir } & \multicolumn{2}{|c|}{ Biochar } & Total & \multicolumn{2}{c|}{ Straw } & \multicolumn{2}{c|}{ Digestate } & Guar gum & Total \\
$(\%)$ & $(\mathrm{ml})$ & $(\%)$ & $(\mathrm{ml})$ & $(\mathrm{ml})$ & $(\%)$ & $(\mathrm{ml})$ & $(\%)$ & $(\mathrm{ml})$ & $(\%)$ & $(\mathrm{ml})$ & $(\mathrm{ml})$ \\
\hline 95 & 332.5 & 5 & 17.5 & 350 & 64 & 224 & 28 & 98 & 8 & 28 & 350 \\
95 & 332.5 & 5 & 17.5 & 350 & 63 & 220.5 & 27 & 94.5 & 10 & 35 & 350 \\
\hline
\end{tabular}


The production of the two-stage treatments began with the application of the base layer. The coir and biochar were measured using a glass measuring beaker and combined in a plastic container. Water was added slowly whilst the material was homogenised using a hand blender (1:2 dry materials:water) for 15 minutes. A metal trowel was used to spread the base layer over to $30 \mathrm{x} 30 \mathrm{~cm}^{2}$ plot.

To produce the top layer, the straw, digestate and guar gum were measured volumetrically using glass measuring beakers and were combined in a container. Water (1:2 dry materials:water) was slowly poured from a measuring cylinder whilst the hand blender operated at a low speed. All samples were homogenised thoroughly for 15 minutes, after which the sample was spread onto the plot. The boards were then immediately moved to a drying location and placed at a $20^{\circ}$ slope.

\subsubsection{Hydra CX}

Hydra CX was trialled as an example of a successful adhesive surrogate soil, and was applied in accordance with the accompanying product technical sheet. Each replicate was created individually and sequentially. $700 \mathrm{ml}$ of dry Hydra CX was measured into a plastic jug. Municipal water (1:2 Hydra CX:water) was added slowly whilst the material was homogenised using the hand blender for 15 minutes. After 15 minutes the material was applied to the plot using a metal trowel and, once completed, immediately transferred to a drying location and placed at a $20^{\circ}$ angle.

\subsubsection{Drying stage}

A three-day drying period following hydroseeding is preferential (Tensar, 2012). Adequate material adhesion throughout the three-day drying period was required for the sample to be considered for the rainfall erosion trials. The samples were inspected visually and assessed for their adhesive performance. If it were estimated that $\geq 20 \%$ of the material had failed, the sample would not undergo the rainfall erosion testing. The rainfall simulation occurred on the fourth day following the drying period and inspection. 
To establish what nutrients are lost during rainfall, overland flow was retained and analysed for total organic nitrogen, ammonium, and phosphate (TON, $\mathrm{NH}_{4}{ }^{+}$and $\mathrm{PO}_{4}{ }^{3}$ ) concentrations.

Initially a greenhouse was used to house the sample boards (Figure 5.4). However, due to a rodent problem and some sample destruction the sample boards were moved inside the rainfall simulator room to dry. The treatment with $4 \%$ guar gum was located within the greenhouse, whereas those that contained 6, 8 and 10\% (v/v) guar gum, were dried inside.

A Fisher Refrigerator/Freezer thermometer was used to measure the temperature in both drying locations throughout the drying periods. Temperatures inside the greenhouse ranged between 16 and $50{ }^{\circ} \mathrm{C}$, with a mean of $32{ }^{\circ} \mathrm{C}$. Temperatures inside the rainfall simulator room ranged between 17 and $24{ }^{\circ} \mathrm{C}$ with a mean of $21^{\circ} \mathrm{C}$.

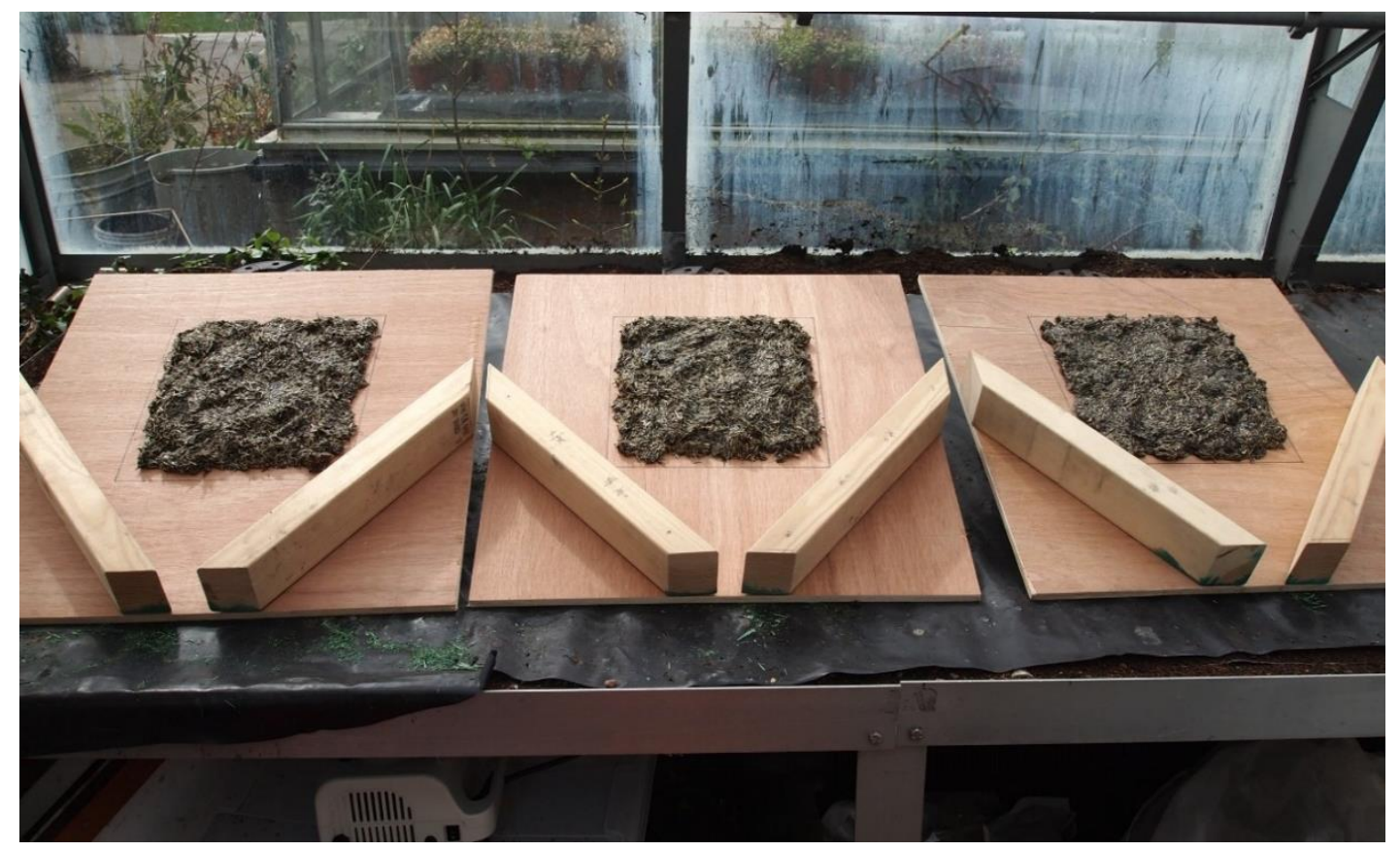

Figure 5.4: Sample boards drying at $20^{\circ}$, drying in the greenhouse 


\subsubsection{Rainfall erosion trials}

The rainfall simulation trials were conducted following the protocol described by Kibet et al. (2014), with minor adjustments for the rainfall simulator used.

Rainfall simulations were conducted using a laboratory rainfall simulator constructed by Clarke \& Walsh (2007) (Figure 5.5). Municipal water was supplied from a 25 L settling tank into $400 \times 400 \mathrm{~mm}$ raindrop box with 190 Teflon tube drop-formers of $0.5 \mathrm{~mm}$ diameter. The water flow from the droplet box to the droplet formers was regulated by a switch, which was activated when the water in the droplet box reached the required level. An adjustable sensor in the droplet box was used to select the head required to produce the chosen rainfall intensity.

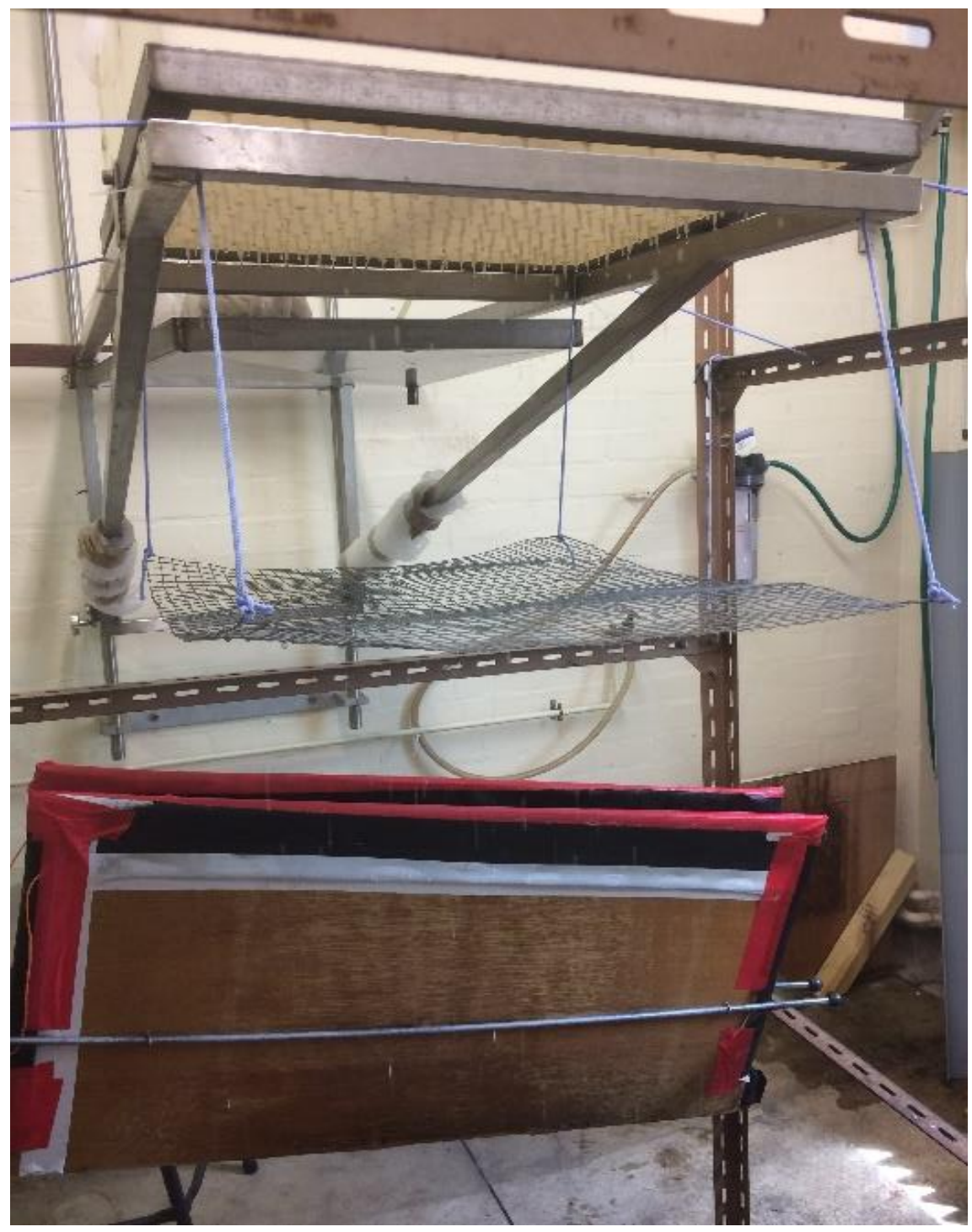

Figure 5.5: The wire mesh suspended below the droplet box, and below that, the V-shaped collection tray 
The uniform water pressure ensured minimum variation in the rainfall intensity. A small plastic priming board was used to agitate the droplet formers at regular intervals throughout the trials to ensure that air bubbles did not block the droplet formers. A wire mesh suspended $500 \mathrm{~mm}$ below the droplet box dispersed the droplets, which randomised the droplet landing positions on soil plot below.

The sample boards were placed $1.5 \mathrm{~m}$ below the droplet box on an angle of $20^{\circ}$ and subjected to 60 minutes of simulated rainfall. Rainfall rates were measured using a $\mathrm{V}$-shaped collection tray suspended below the droplet box, which funnelled water into a measuring cylinder. For each simulation, rainfall was measured for one minute immediately prior to and immediately following the simulation. The total rainfall for the 60-minute simulation was estimated from the mean of these two measurements. The mean rainfall rate across all simulations was $200.49 \pm 1.06 \mathrm{~mm} / \mathrm{hr}$.

\subsubsection{Eroded material}

The sample boards were removed after 60 minutes of simulated rainfall. A plastic spatula was used to remove the eroded material that was mobilised to outside of the delineated square. This material, along with that which was in the sieve, was consolidated in a foil container. The eroded material from each sample remained in a separate container.

The eroded material was dried for 12 hours at $105{ }^{\circ} \mathrm{C}$ in a Swallow Drying Oven and then weighed. During the rainfall trials, samples were considered to be unsuccessful when $>5 \%$ of the bulk material were eroded.

\subsubsection{Run-off: Munsell colours and suspended organic matter}

For each simulation, 30 minutes into the trial, plastic guttering was used to funnel the run-off into individual clear $100 \mathrm{ml}$ Sterilin plastic containers. These containers were photographed against a white background and visually assessed for their hue, value, and chroma, as well as their suspended OM content. 
The individual run-off samples were filtered using single-use $45 \mu \mathrm{m}$ filters and a syringe. The syringe was flushed with deionised water between samples. $100 \mathrm{ml}$ of run-off per sample was collected and transferred into Sterilin plastic containers and stored in a laboratory freezer $\left(-18{ }^{\circ} \mathrm{C}\right)$, where they remained until analysis 14 days later.

\subsubsection{Aquaculture}

The samples were analysed by Dr Bettina Walker of Swansea University. A Seal Analytical Continuous Flow system (AA3) was used to determine the concentration of TON $\left(\mathrm{NO}_{3-}{ }^{-}+\mathrm{NO}_{2-}\right), \mathrm{NH}_{4}^{+}$and $\mathrm{PO}_{4}{ }^{3-}$ within the sample. During continuous flow analysis (CFA), each sample was injected into a flowing carrier solution. The sample was mixed with a reagent which, when mixed with the sample, produced a colour characteristic of a specific concentration. CFA is widely considered to be reliable and precise, and the use of carefully controlled flow conditions ensure that the colour development reaction is reproducible (Jones, 1999; Dafner, 2015; Van Staden, 2015).

The Hydra CX material contained a green dye. As the CFA process relies on the sample colour to determine the nutrient concentrations the Hydra CX treatment was not analysed.

\subsubsection{Statistics}

A Shapiro-Wilk test for normality determined that the TON ( $\mathrm{p} \leq 0.045), \mathrm{NH}_{4}{ }^{+}$ $(\mathrm{p} \leq 0.001)$ and $\mathrm{PO}_{4}{ }^{3-}$ concentration data $(\mathrm{p} \leq 0.001)$ were not normally distributed. The median concentration of each element $\left(\mu \mathrm{mol} . \mathrm{L}^{-1}\right)$ within the run-off samples (3 replicates, $\mathrm{N}=21$ ) were compared using a Kruskal-Wallis $\mathrm{H}$ test and a Dunn's posthoc test. An alpha level of 0.05 was used.

Erosion was estimated by the mean quantity of soil recovered in the collection gutter and sieve at the end of the experiment $(n=3)$. The data was not normally distributed (Shapiro-Wilk: $\mathrm{p} \leq 0.001)$. The medians of the failed material $\left(\mathrm{g} . \mathrm{m}^{-2}\right)$ for each treatment were statistically compared using a Kruskal-Wallis H test and a Dunn's posthoc test $(\mathrm{p} \leq 0.05)$. 
The statistical software R (version 5.3.2, R Core Team, 2018) was used for all analyses. 


\subsection{Rainfall simulations - Results and discussion}

\subsubsection{Aquaculture analysis}

Run-off from each rainfall simulation was analysed for TON $\left(\mathrm{NO}_{3-}+\mathrm{NO}_{2-}\right), \mathrm{NH}_{4}{ }^{+}$and $\mathrm{PO}_{4}{ }^{3-}\left(\mu \mathrm{mol} . \mathrm{L}^{-1}\right)$ to determine the relationship between increasing proportions of guar gum and nutrient retention (Figure 5.6, Table 5.3).

The continuous flow system (CFA) quantified the nutrient concentration within the sample. A colour response indicated a specific concentration, and as Hydra CX contained a green dye it was not possible to analyse the run-off in this way. Consequently, Hydra CX was excluded from the aquaculture analysis.

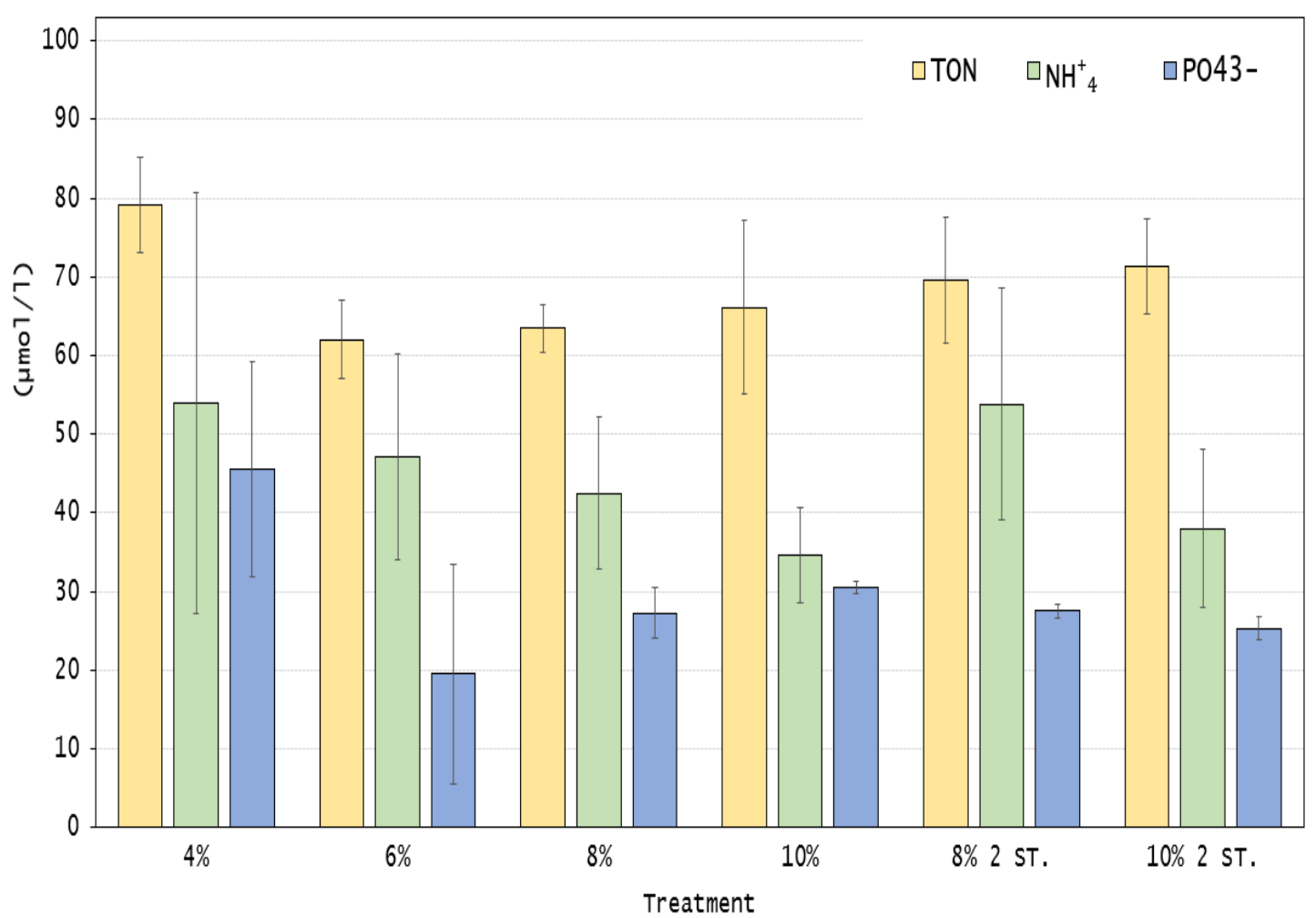

Figure 5.6: TON, $\mathrm{NH}_{4}^{+}$and $\mathrm{PO}_{4}^{3-}$ concentration $\left(\mu \mathrm{mol} . \mathrm{L}^{-1}\right)$ in leachate from each surrogate soil treatment, with the sample standard deviation. The percentage refers to the proportion $(v / v)$ of guar gum in the soil. The 4, 6, 8 and $10 \%$ treatments were single-stage treatments. The ' 2 ST' indicates a two-stage treatment, with the indicated guar gum content. 
Table 5.3: The median concentration of TON, $\mathrm{NH}_{4}^{+}$, and $\mathrm{PO}_{4}{ }^{3-}\left(\mu \mathrm{mol} . \mathrm{L}^{-1}\right)$ in leachate collected from the surrogate soil treatments during the rainfall simulation. For all treatments, $n=3$.

\begin{tabular}{cccc}
\hline \hline Treatment & $\begin{array}{c}\text { TON } \\
\left(\mu \mathrm{mol} . \mathrm{L}^{-1}\right)\end{array}$ & $\begin{array}{c}\mathrm{NH}_{4}^{+} \\
\left(\mu \mathrm{mol} . \mathrm{L}^{-1}\right)\end{array}$ & $\begin{array}{c}\mathrm{PO}_{4}^{3-} \\
\left(\mu \mathrm{mol} . \mathrm{L}^{-1}\right)\end{array}$ \\
\hline Single-stage 4\% & $79.1 \pm 6.0$ & $53.9 \pm 26.8$ & $45.5 \pm 13.6$ \\
Single-stage 6\% & $62.1 \pm 5.0$ & $47.1 \pm 13.0$ & $19.5 \pm 13.9$ \\
Single-stage 8\% & $63.5 \pm 3.0$ & $42.5 \pm 9.6$ & $27.3 \pm 3.3$ \\
Single-stage 10\% & $66.1 \pm 11.0$ & $34.6 \pm 6.0$ & $30.5 \pm 0.8$ \\
& & & $27.6 \pm 0.9$ \\
Two-stage 8\% & $69.6 \pm 8.0$ & $53.8 \pm 14.8$ & $25.3 \pm 1.5$ \\
Two-stage 10\% & $71.3 \pm 6.0$ & $38.0 \pm 10.0$ & \\
\hline
\end{tabular}

\subsubsection{Adhesion capacity}

Erosion was estimated by the median quantity of soil recovered in the sieve at the end of the experiment (Figure 5.7, Table 5.3.). For all treatments, $\mathrm{n}=3$.

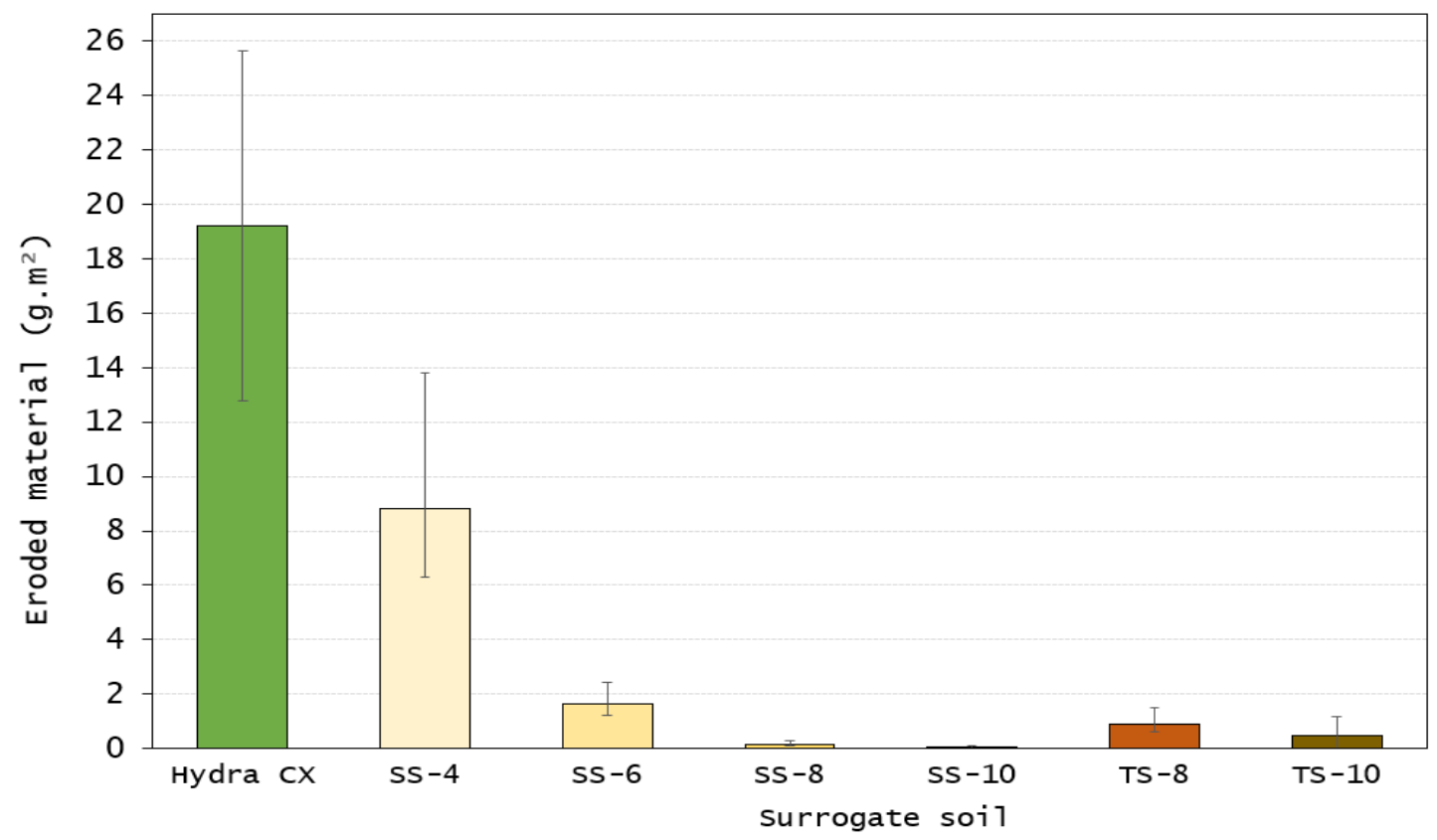

Figure 5.7: Median weight ( $\left.\mathrm{g} . \mathrm{m}^{-2}\right)$ of eroded surrogate soil material following a one-hour rainfall simulation. SS refers to the single-stage surrogate soils, and TS to the two-stage soils. The number which follows refers to the percentage of guar gum incorporated into the soil. For example, SS-4 is a single-stage treatment, with $4 \%(v / v)$ guar gum 
Table 5.4: The median weight $\left(\right.$ g. $\left.\mathrm{m}^{-2}\right)$ of eroded material, for each surrogate soil treatment, during the rainfall simulation. For all treatments, $n=3$.

\begin{tabular}{cccc}
\hline \hline Treatment & $\begin{array}{c}\text { Median } \\
\left(\mathrm{g} . \mathrm{m}^{-2}\right)\end{array}$ & $\begin{array}{c}\text { Min } \\
\left(\mathrm{g} . \mathrm{m}^{-2}\right)\end{array}$ & $\begin{array}{c}\text { Max } \\
\left(\mathrm{g} . \mathrm{m}^{-2}\right)\end{array}$ \\
\hline Hydra CX & 9.61 & 6.78 & 21.63 \\
Single-stage 4\% & 4.40 & 1.20 & 7.30 \\
Single-stage 6\% & 0.81 & 0.03 & 0.92 \\
Single-stage 8\% & 0.08 & 0.02 & 0.17 \\
Single-stage 10\% & 0.02 & 0.00 & 0.05 \\
& & & 0.84 \\
Two-stage 8\% & 0.45 & 0.13 & 0.23 \\
Two-stage 10\% & 0.23 & 0.12 & \\
\hline
\end{tabular}

\subsubsection{Hydra CX}

Throughout the three-day drying period, the Hydra CX showed successful adhesion to the wooden plots, with no visible failure in the material (Figure 5.8). In the rainfall simulator, erosion began between 15 and 17 minutes for all replicates.
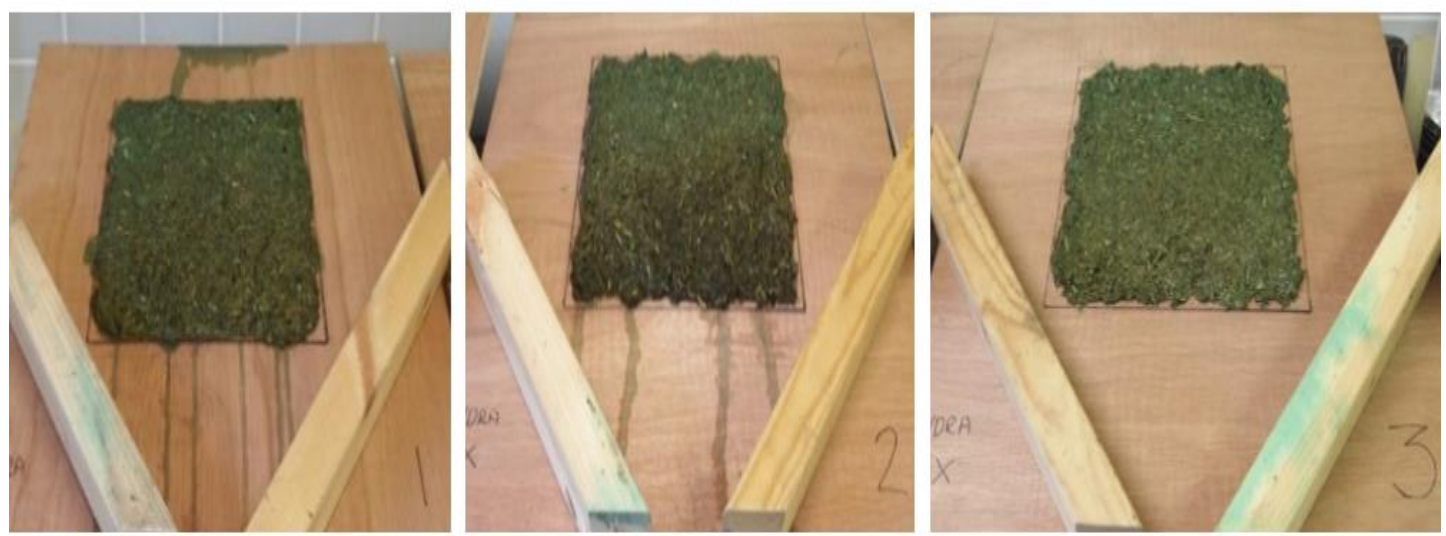

Figure 5.8: The three replicates of the Hydra CX soil treatment, following three days drying period after application 
A considerable quantity of material failed during the one-hour trial $\left(19.2 \pm 6.4\right.$ g.m ${ }^{-2}$, 74\% material adhesion, Figure 5.9). A Kruskal-Wallis with Dunn's post-hoc test determined this to be significantly greater volume of eroded materials than in five of the six subsequent soil treatments $(\mathrm{H}[6]=14.43, \mathrm{p} \leq 0.001, \mathrm{~N}=21)$, the details of which are discussed in the following sections.
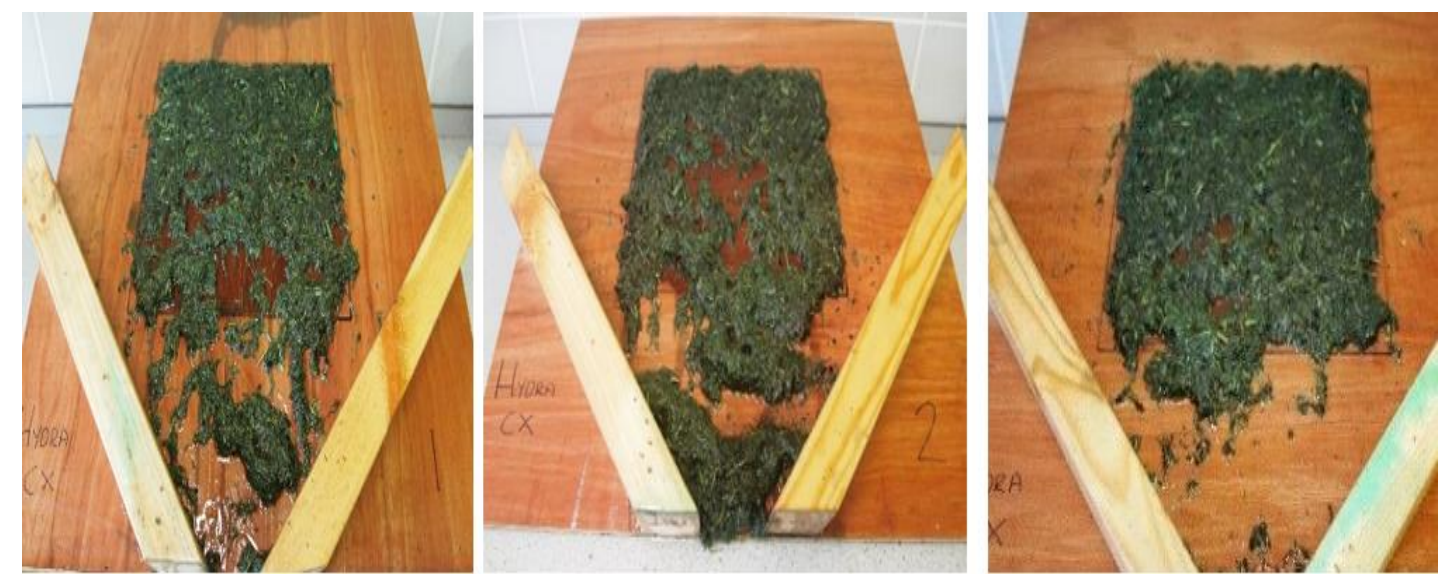

Figure 5.9: The three replicates of the Hydra CX soil plots following one hour of simulated rainfall $(200 \mathrm{~mm} / \mathrm{hr})$

Due to the green dye in the Hydra CX, the run-off samples could not be analysed using the Munsell colour chart. Despite the colouring, large amounts of suspended materials could be seen within the samples (Figure 5.10).
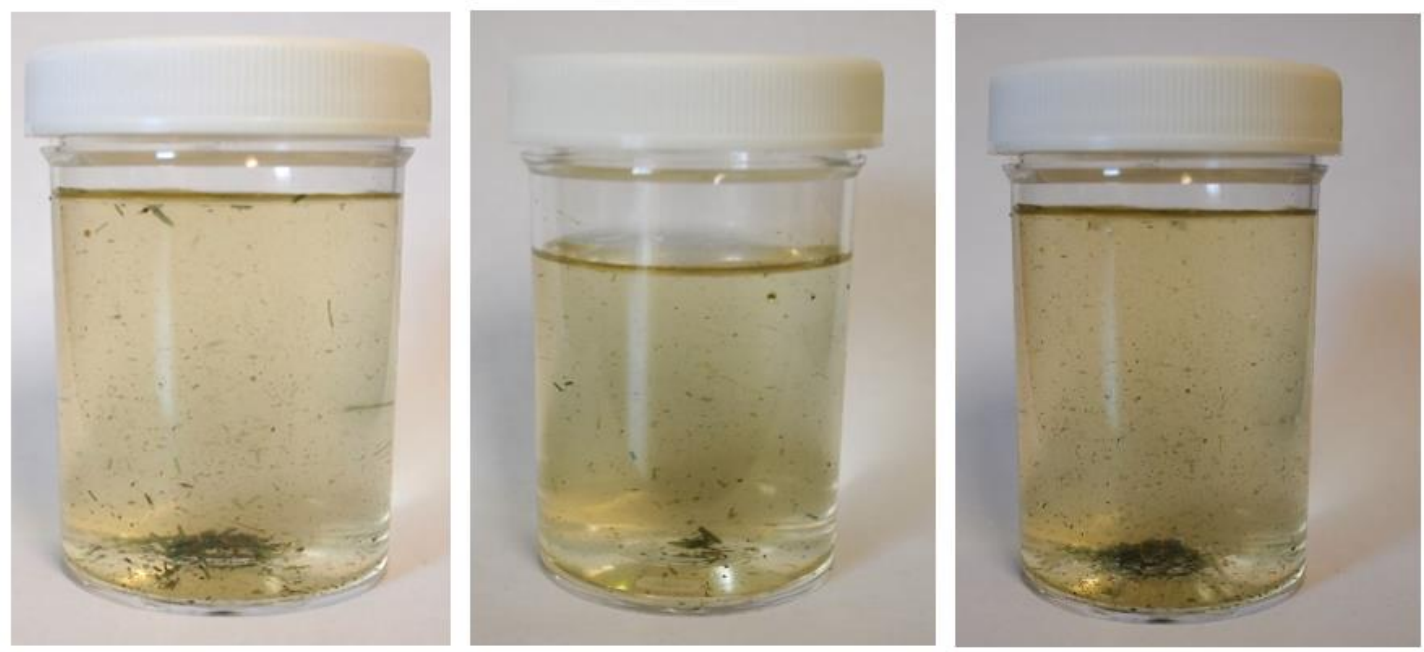

Figure 5.10: Run-off samples taken during the Hydra CX rainsplash trial 
It was speculated that Hydra CX contains polyacrylamide due to the materials behaviour when wet and the frequent use of polyacrylamide in other North American Green Products (North American Green, 2008; North American Green, 2018). In the run-off samples, the OM took > 20 minutes to settle, which also indicates the presence of polyacrylamide, which is a flocculent.

The poor adhesion of the Hydra CX may have been a result of the unsuitability of the wooden boards due to the potential inclusion of polyacrylamide in the material. The experimental surrogate soil media contained guar rather than polyacrylamide, and all experimental treatments displayed better resistance to erosion. However, Merlin et al. (1999) examined the efficacy of both guar gum and polyacrylamide (individually) and determined wood to be the most effective surface for both materials to adhere to for rainfall testing. Thus, the wooden boards were unlikely to be the sole cause of the materials erosion. 


\subsubsection{Single-stage treatments}

\subsubsection{4\% (v/v) guar gum}

The surrogate soil material in the $4 \%$ guar gum treatment demonstrated only moderate adhesion throughout the drying period, and a substantial amount of material had loosened. However, some of the material that had failed appeared to re-fix to the board outside of the delineated plot, which indicated that the materials were pliable when wet and became adhesive upon drying (Figure 5.11).
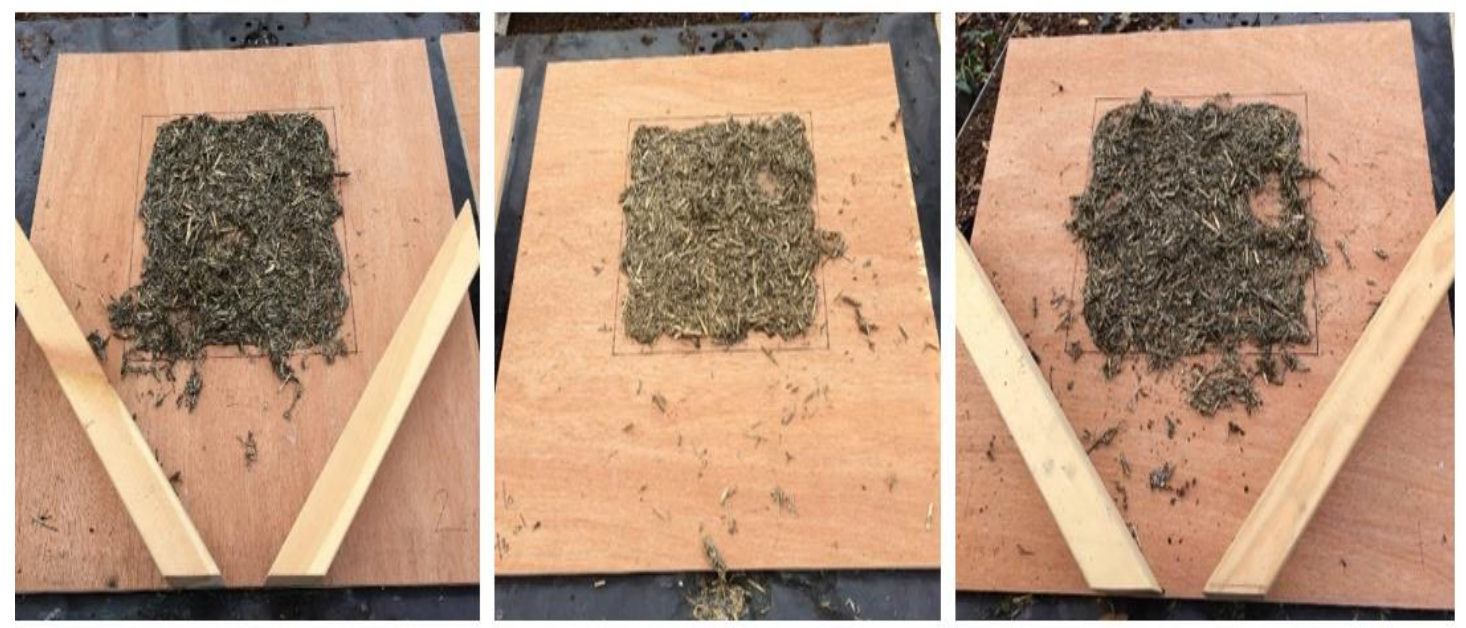

Figure 5.11: Three replicates of the 4\% guar gum treatment, following three days drying period after application

In the rainfall simulator, rainfall penetration was high, and erosion began immediately (Figure 5.12). Although the total particle displacement was relatively large, very little material failed during the rainfall simulation that had not already failed during the drying stage. Overall adhesion was reasonable $(\sim 85 \%)$. 

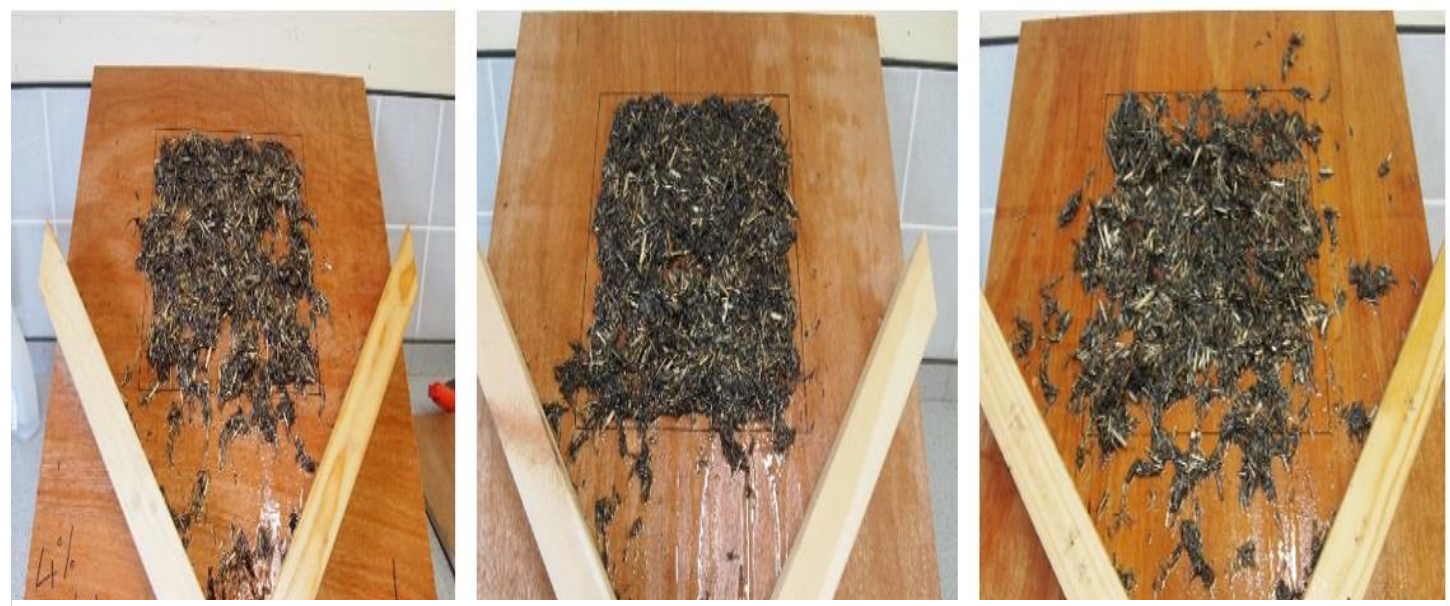

Figure 5.12: The three replicates of the 4\% guar treatment following one hour of simulated rainfall $(200 \mathrm{~mm} / \mathrm{hr})$

A Kruskal-Wallis test determined that there was no significant difference in the failed material between the $4 \%$ guar gum treatment and the Hydra CX (medians of $8.8 \pm$ 4.9 g. $\mathrm{m}^{-2}$ and $19.2 \pm 6.4$ g. $\mathrm{m}^{-2}$, respectively). The large variation between three plots of each treatment suggested that neither treatment would produce reliable results under intense and prolonged rainfall in field situations on a slope of $20^{\circ}$.

The surface run-off was a slightly darker hue and value than that of other treatments (2.5Y 7/1 and 7.5Y 8/2 on the Munsel Colour Chart) with a large amount of suspended OM (Figure 5.13). A Kruskal-Wallis with Dunn's post-hoc test revealed significantly higher TON $(\mathrm{H}[6]=12.46, \mathrm{p} \leq 0.029)$ and $\mathrm{PO}_{4}{ }^{3-}$ concentrations $(\mathrm{H}[6]=15.85$, $\mathrm{p} \leq 0.007)$ in run-off than almost all other treatments, the details of which are discussed in the following sections.
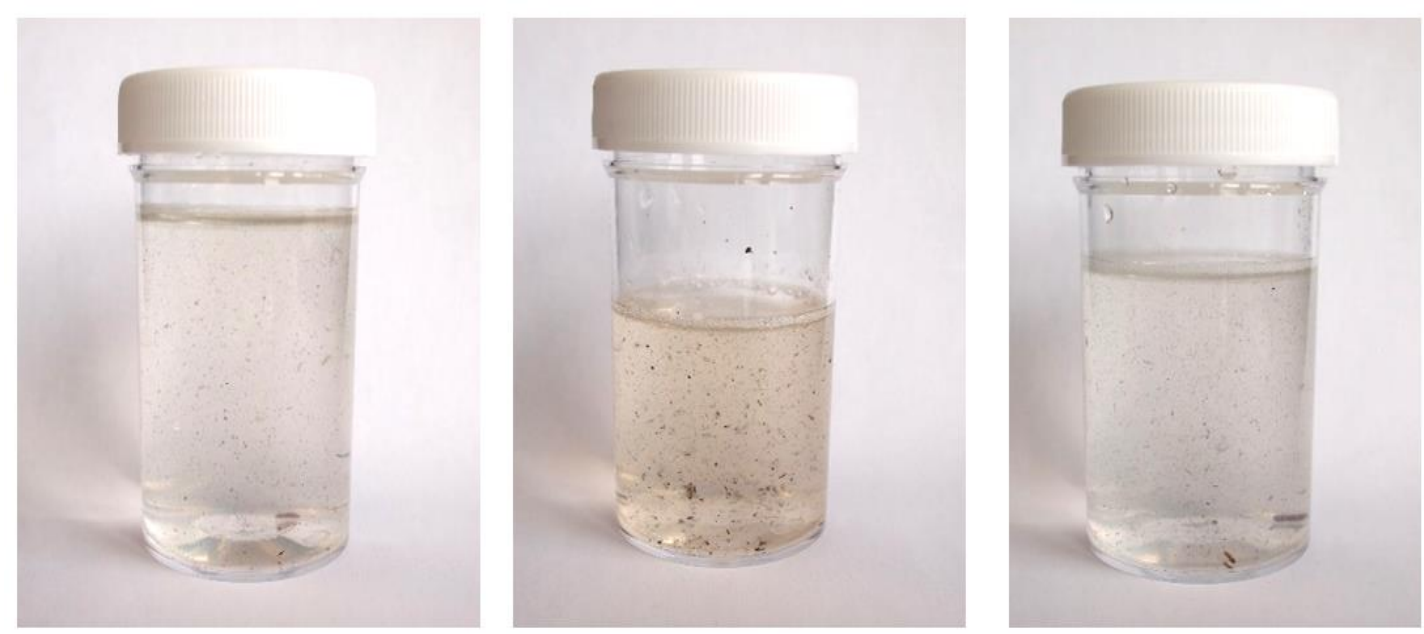

Figure 5.13: Run-off samples collected from the 4\% guar treatment 


\subsubsection{6\% (v/v) guar gum}

The adhesion of the $6 \%$ guar gum treatment was visually and quantitatively more successful throughout the drying period than the previous treatments, with no visible material failure (Figure 5.14).
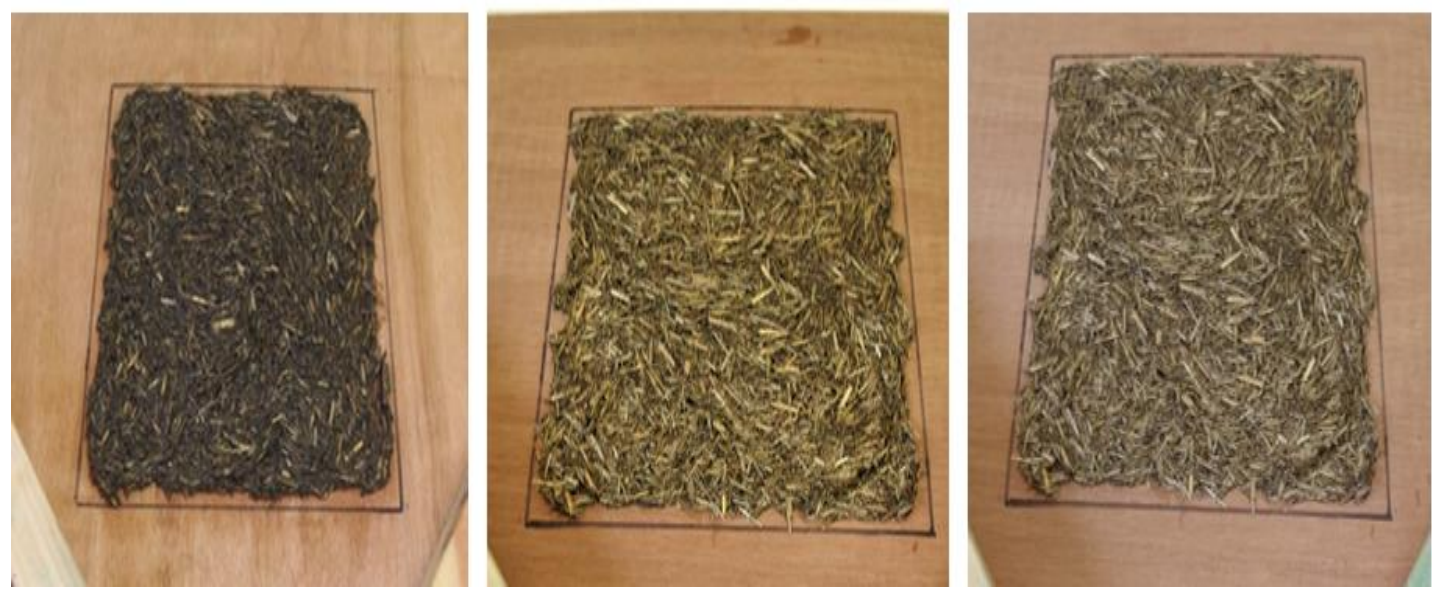

Figure 5.14: Three replicates of the 6\% guar gum treatment, following three days drying period after application

Due to difficulties with rodents in the greenhouse (Section 5.1) the 6\% guar soil was the first treatment to be dried inside the rainfall simulator room. Throughout the trial, the inside drying location was cooler than the greenhouse $\left(21 \pm 3{ }^{\circ} \mathrm{C}\right)$ and the drying period had the potential to be slower and less effective than in the warmer greenhouse location $\left(29 \pm 13{ }^{\circ} \mathrm{C}\right)$. This was especially relevant as the $4 \%$ guar soil was less adhesive when wet.

In the rainfall simulator, the $6 \%$ guar soil showed a more effective adhesion capacity (98\%) than the $4 \%$ soil (85\%), with significantly less failed material (Kruskal-Wallis, $\mathrm{p} \leq$ 0.001) (Figure 5.15). Substantial erosion still occurred but at a much slower rate, and material displacement outside of the delineated plots commenced in the $23^{\text {rd }}-31^{\text {st }}$ minute rather than immediately. 

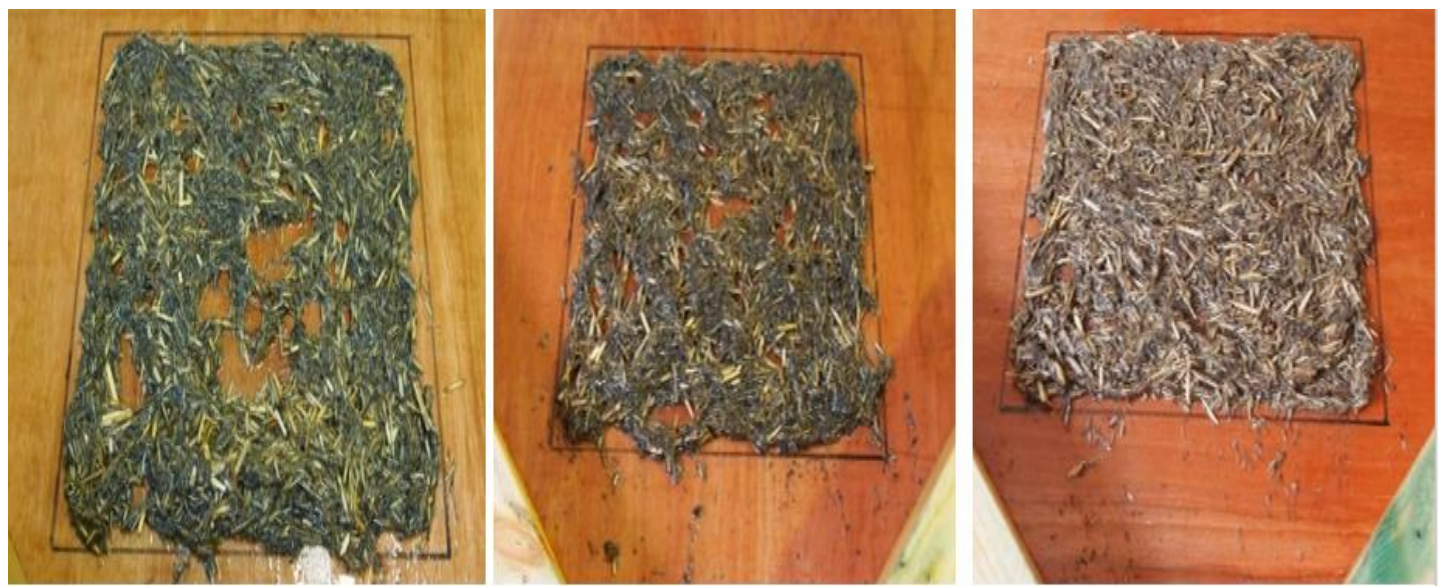

Figure 5.15: The three replicates of the 6\% guar treatment following one hour of simulated rainfall $(200 \mathrm{~mm} / \mathrm{hr})$

In the $6 \%$ guar soil, raindrop penetration and aggregate break-up was high which produced large, localised areas of failure. Numerically, this produced less failed material overall (a median of $1.62 \pm 0.8$ g.m $\mathrm{m}^{-2}$, only $2 \%$ of the total material), as little of the material was displaced outside of the delineated plot. However, it can be extrapolated from the rate of material failure that should the experiment have continued for longer a complete failure would have occurred.

The run-off from the $6 \%$ guar soil contained a significantly lower median TON concentration (Kruskal-Wallis, $\mathrm{p} \leq 0.025$ ) than the $4 \%$ guar. No pairwise differences between $6 \%$ guar and the subsequent treatments existed, therefore the increase in guar gum did not correspond to an increase in retained nutrients. If the addition of guar gum was solely for nutrient retention, $6 \%$ guar gum would be adequate.

The run-off samples from the $6 \%$ treatment contained less OM than that of the $4 \%$ treatment, which was reflected in the colour chart observations $(7.5 \mathrm{Y} 8 / 1$ and $7 / 2$, and 2.5Y 7/1) (Figure 5.16). 

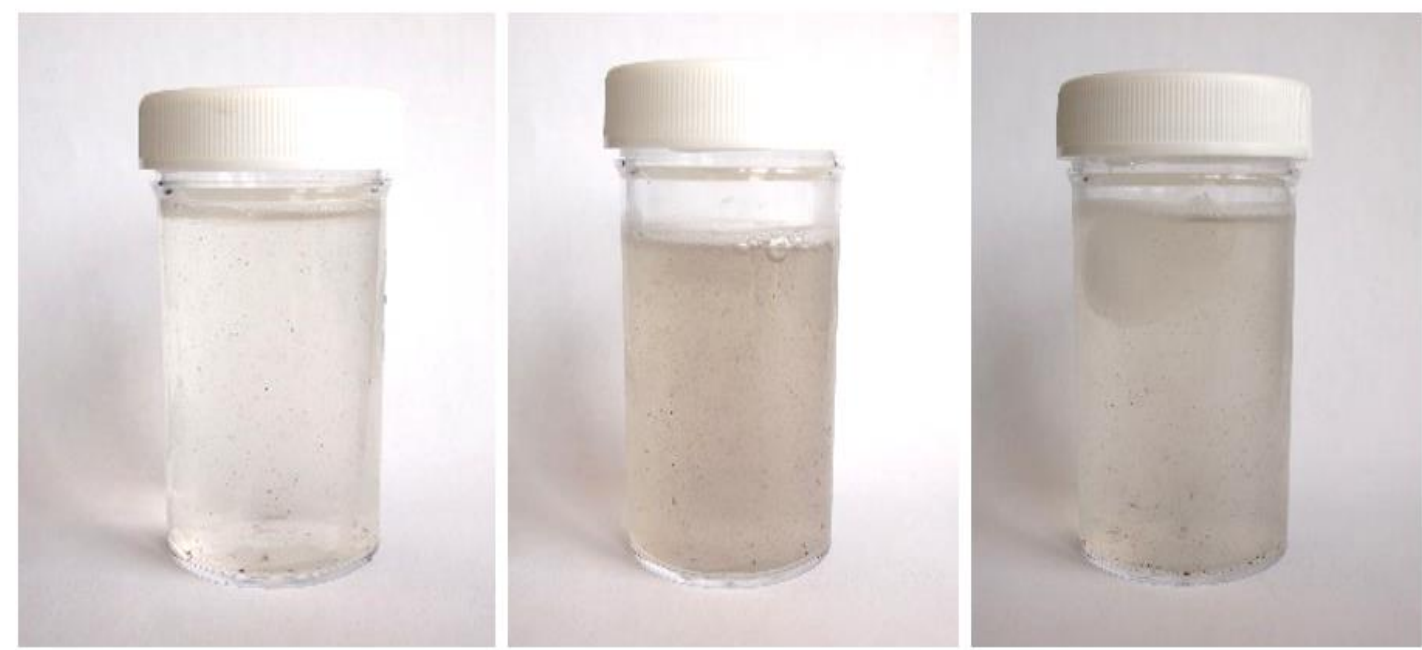

Figure 5.16: Run-off samples collected from the 6\% guar treatment

\subsubsection{8\% (v/v) guar gum}

The material in the $8 \%$ guar soil displayed complete adhesion in all replicates throughout the drying stage with no visible failure (Figure 5.17).

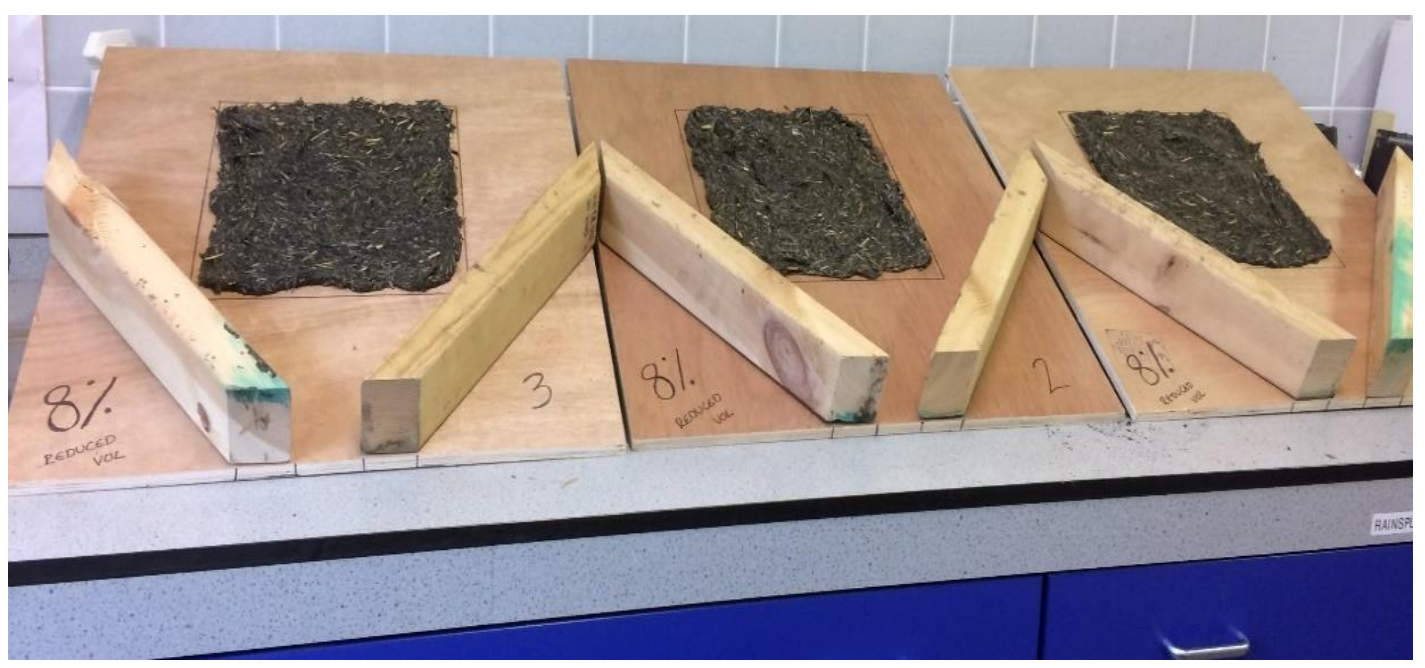

Figure 5.17: Three replicates of the $8 \%$ guar gum treatment following three days drying period 
In the rainfall simulator, the $8 \%$ treatment demonstrated an effective resistance to erosion with minimal particle displacement ( 99\% adhesion). However, in a manner similar to that seen in the $6 \%$ treatment, substantial raindrop penetration created discrete areas of failure $\geq 3 \mathrm{~cm}$ wide (Figure 5.18). Quantitatively, only a small amount of material was displaced outside of the plot (a median of $0.16 \pm 0.1 \mathrm{~g} \cdot \mathrm{m}^{-2}$ ), which was a significant improvement compared to the use of 6\% guar gum (Kruskal-Wallis: $\mathrm{p} \leq 0.047)$ and the Hydra CX $(\mathrm{p} \leq 0.001)$. Figure 5.19 shows the wet failed material from treatment $6 \%$ (left) and $8 \%$ (right).
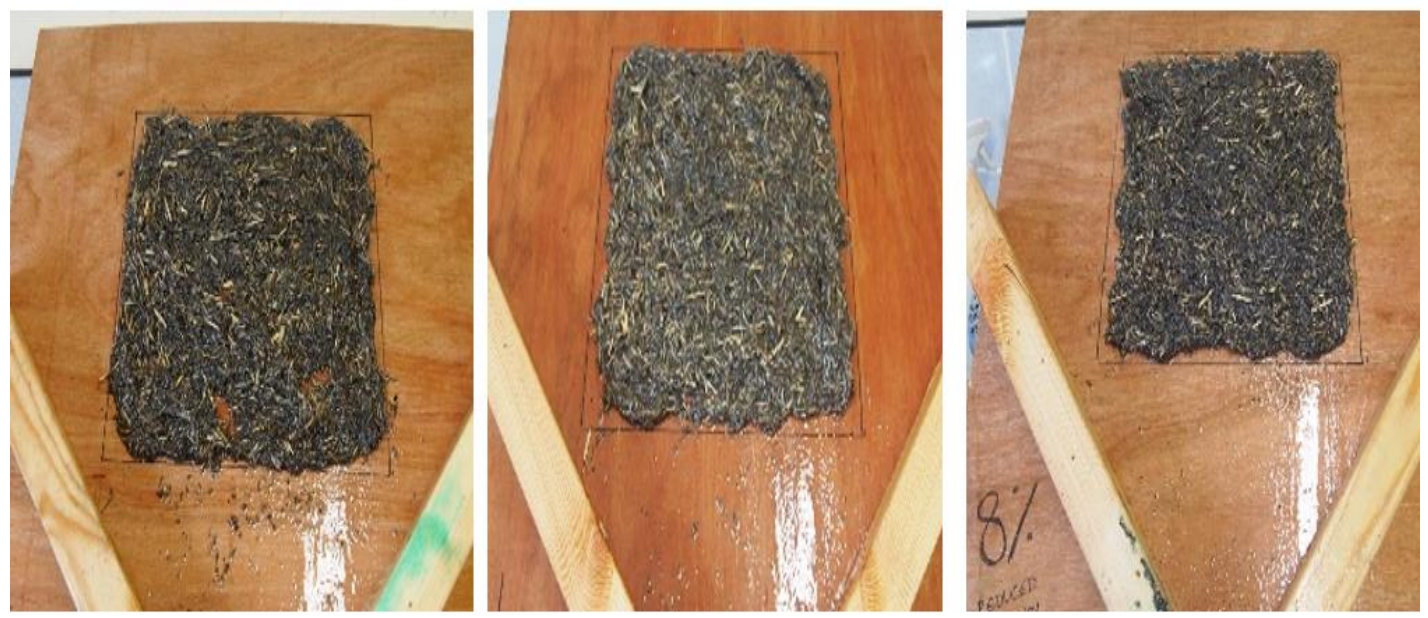

Figure 5.18: The three replicates of the $8 \%$ guar treatment after one hour simulated rainfall (200 $\mathrm{mm} / \mathrm{hr}$ ) 


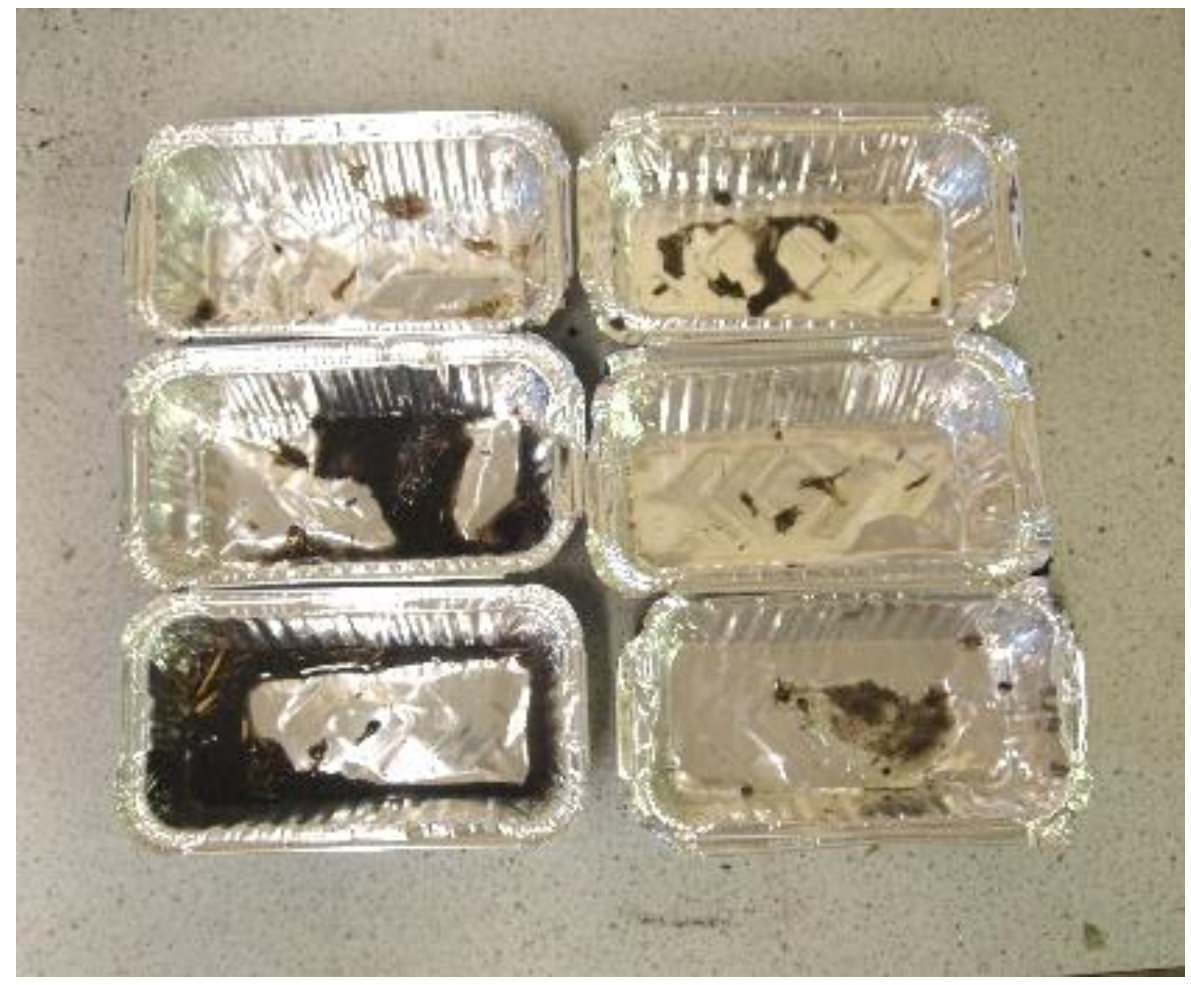

Figure 5.19: The wet material which became unstuck from the bulk material in the rainfall simulations. On the left are the three replicates of the 6\% guar gum soil, and on the right are the three replicates of the 8\% guar gum soil

Compared to the previous treatments, run-off was a lighter hue and chroma (10Yr/8/1) with less suspended OM (Figure 5.20). Despite the erosion within the plot, little OM was lost from the plot itself.
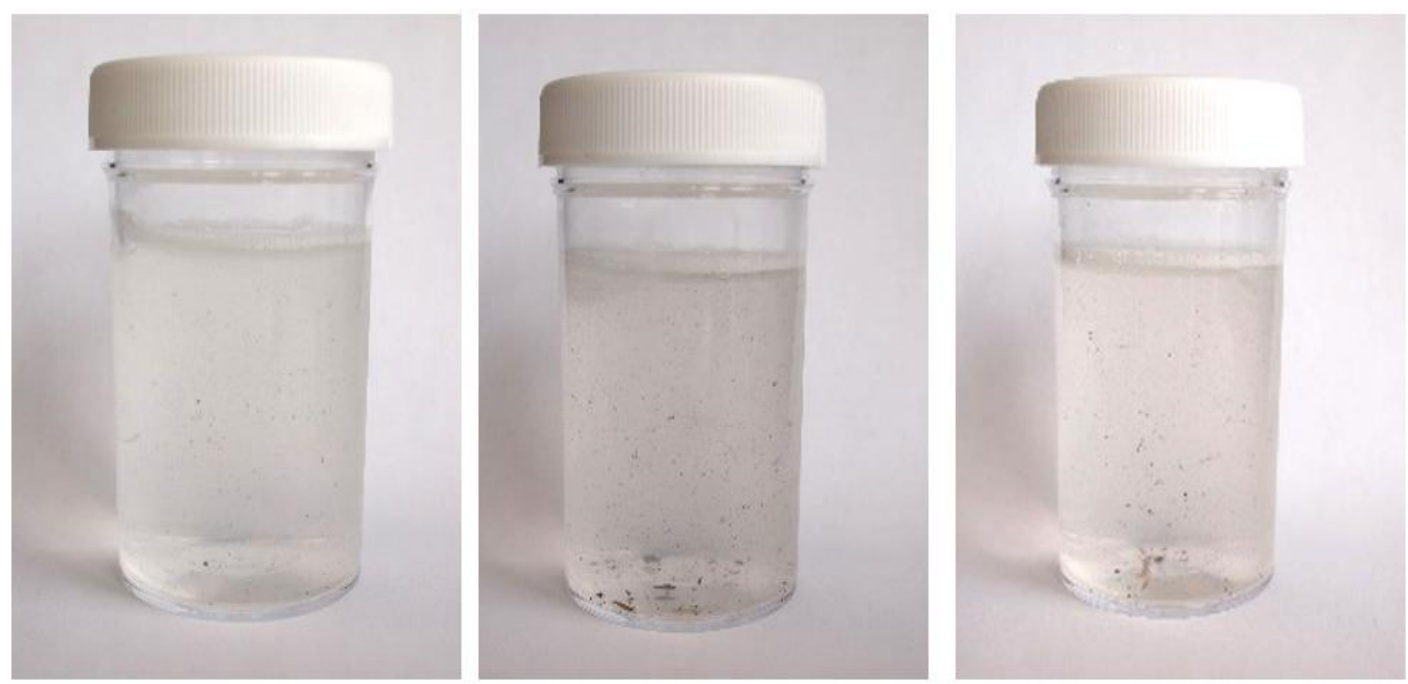

Figure 5.20: Run-off samples collected from the $8 \%$ guar treatment 


\subsubsection{4 $10 \%(v / v)$ guar gum}

Satisfactory adhesion was observed in the $10 \%$ treatment throughout the drying period (Figure 5.21). In the rainfall simulator, minimal rainfall penetration occurred yet, crucially, the material was fully wetted. Soil breakup and particle displacement were the lowest of all treatments with negligible material failure (a median of $0.04 \pm 0.0$ g. $\mathrm{m}^{-2}$ ), significantly less than all other soils $(\mathrm{p} \leq 0.001)$, including the $8 \%$ guar soil ( $\mathrm{p}$ $\leq 0.001$ ). Adhesion capacity was $99 \%$ (Figure 5.22).
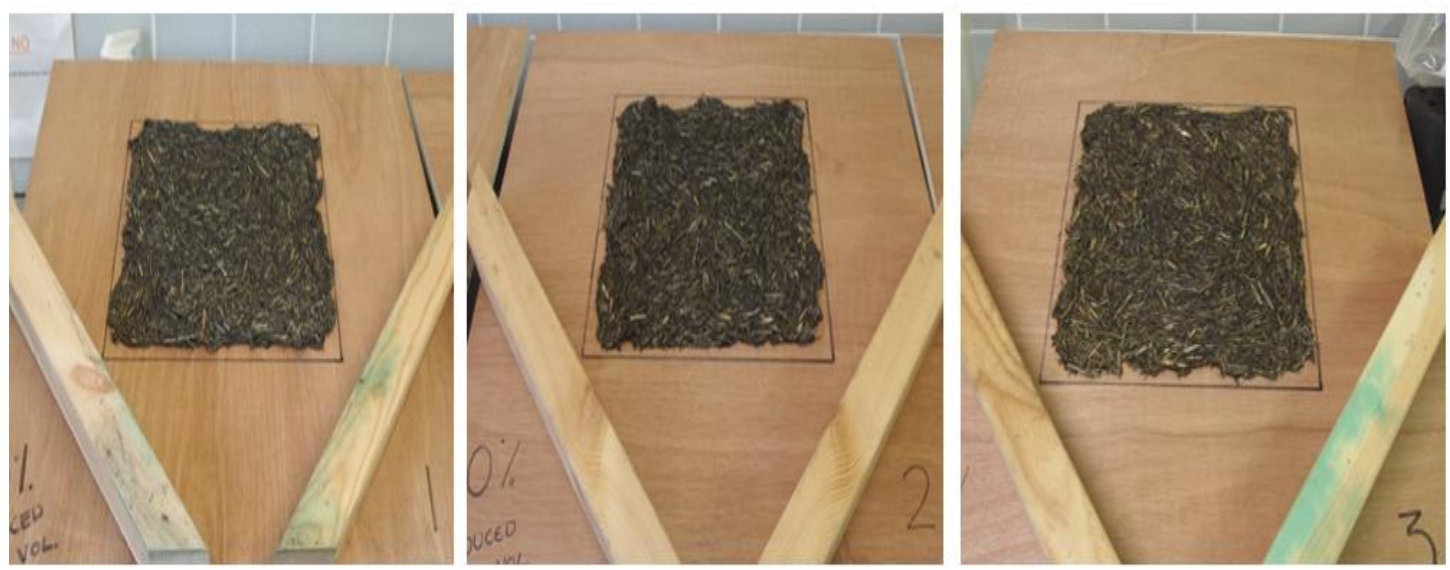

Figure 5.21: Three replicates of the 10\% guar gum treatment following a three days drying period
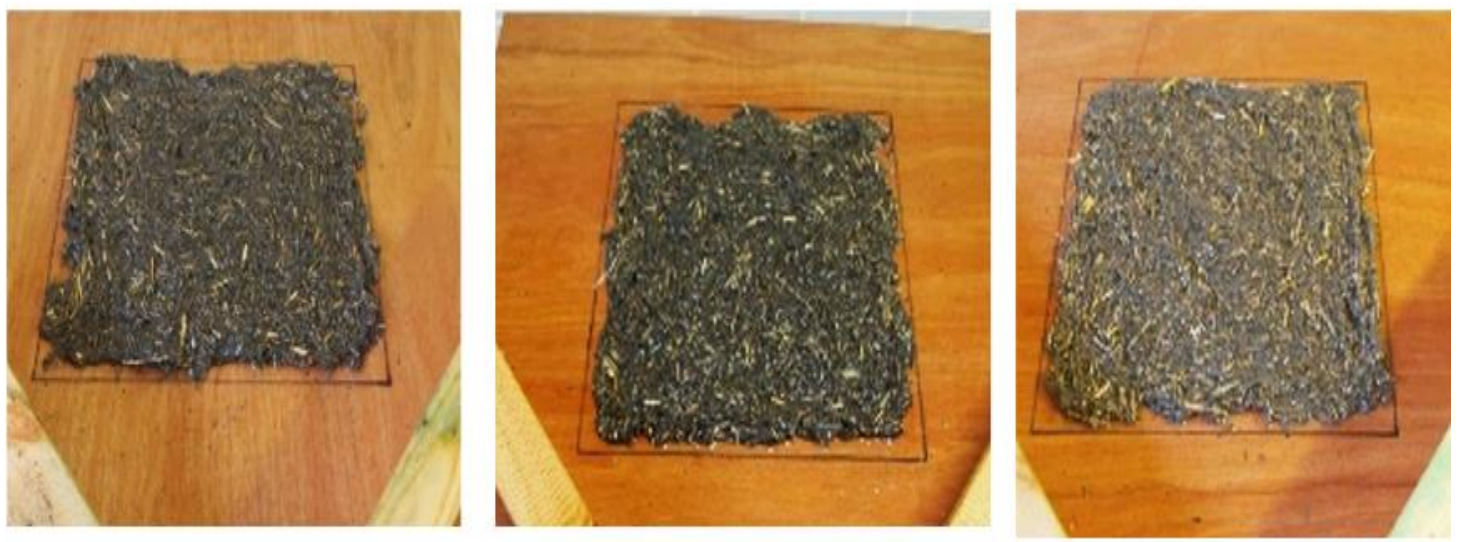

Figure 5.22: The three replicates of the 10\% guar treatment following one hour simulated rainfall $(200 \mathrm{~mm} / \mathrm{hr})$ 
The low erosivity was reflected in the light hue and chroma of the run-off (10 Yr/8/1) which contained very little organic matter (Figure 5.23).
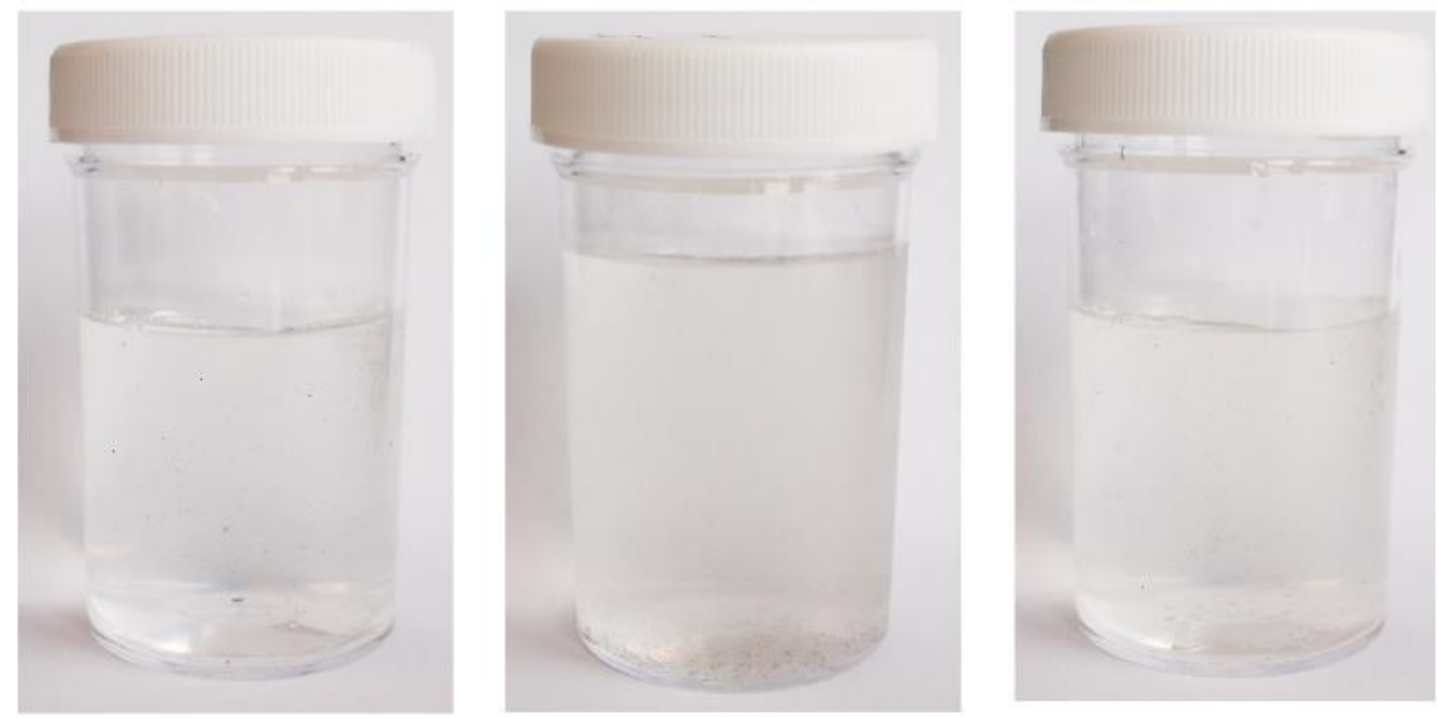

Figure 5.23: Run-off samples collected from the 10\% guar treatment

\subsubsection{Two-stage treatments}

\subsubsection{Two-stage $8 \%(v / v)$ guar gum}

The two-stage treatments were constructed as two separate layers. The first layer, a combination of coir and biochar, did not contain guar gum and served as an OM layer. The guar gum was incorporated into the top erosion protection layer, which was composed of straw and digestate.

The material showed sufficient adhesion throughout the drying stage for inclusion in the rainsplash trials. A small amount of material was displaced when the plots were first tilted to $20^{\circ}$, however, as with other plots, the displaced material dried firmly to the boards after this initial displacement. The initial failed material was included in the overall volume of failed material (Figure 5.24). 

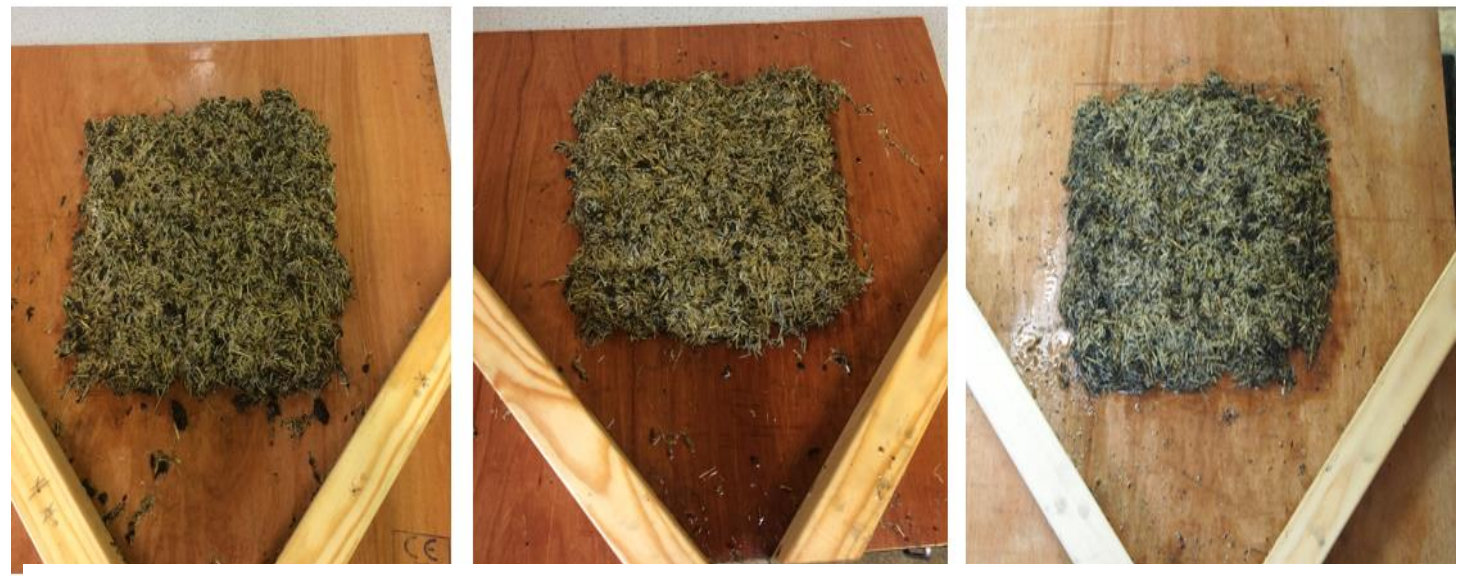

Figure 5.24: Three replicates of the two-stage 8\% guar gum treatment following three days drying period

In the rainfall simulations, aggregate break-up and erosivity was low and resulted in a high $(\sim 95 \%)$ adhesion capacity. Erosion began 45 - 50 minutes into the simulation (Figure 5.25).
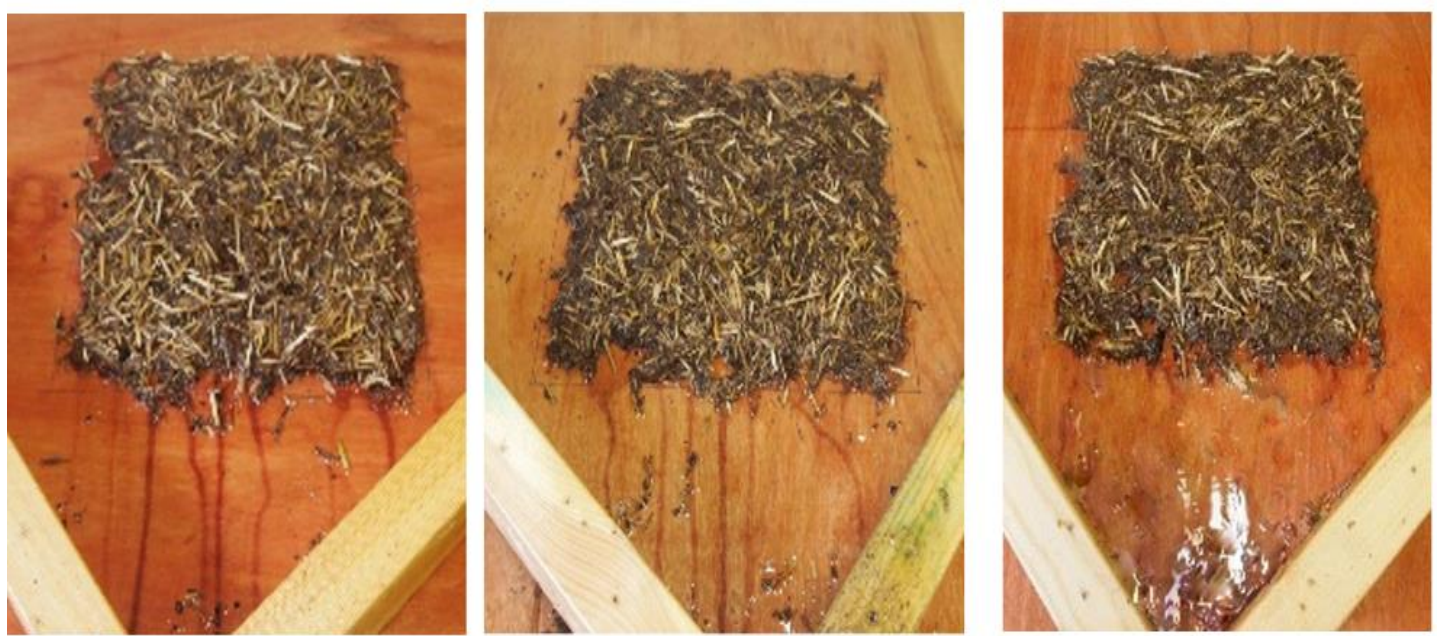

Figure 5.25: The three replicates of the two-stage 8\% guar treatment following one hour of simulated rainfall $(200 \mathrm{~mm} / \mathrm{hr})$ 
The hue and chroma of the run-off were the same as that of the single-stage $8 \%$ treatment (10Yr/8/1) and contained very little OM (Figure 5.26). A Kruskal-Wallis test determined that no significant difference existed in the quantity of eroded material in the two-stage $8 \%$ treatment compared to the single-stage $8 \%$ treatment $(0.16 \pm 0.1$ and $0.9 \pm 0.6$ g.m $\mathrm{m}^{-2}$, respectively).
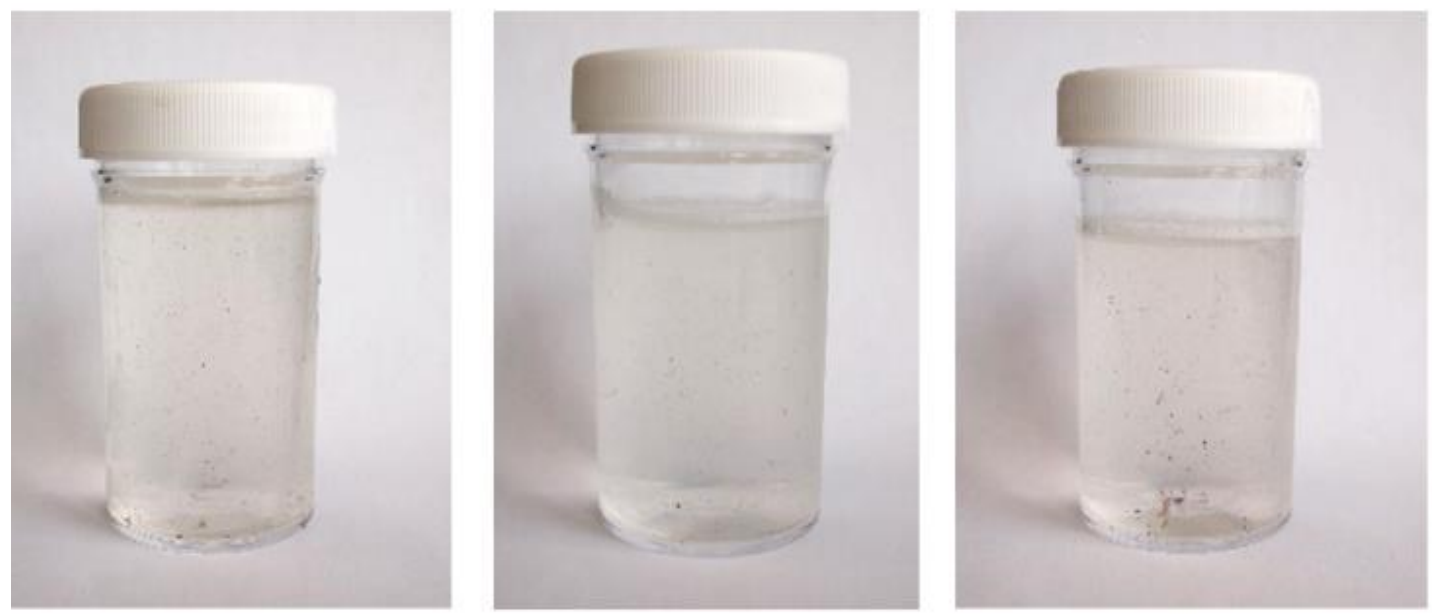

Figure 5.26: Run-off samples collected from the two-stage 8\% guar treatment 


\subsubsection{Two-stage 10\% (v/v) guar gum}

Adhesion throughout the drying stage was satisfactory with no visible failure of materials (Figure 5.27). In the rainfall simulation, negligible erosion occurred in the two-stage $10 \%$ treatment (median, $0.46 \pm 0.7$ g.m $\mathrm{m}^{-2}$ ) (Figure 5.28).
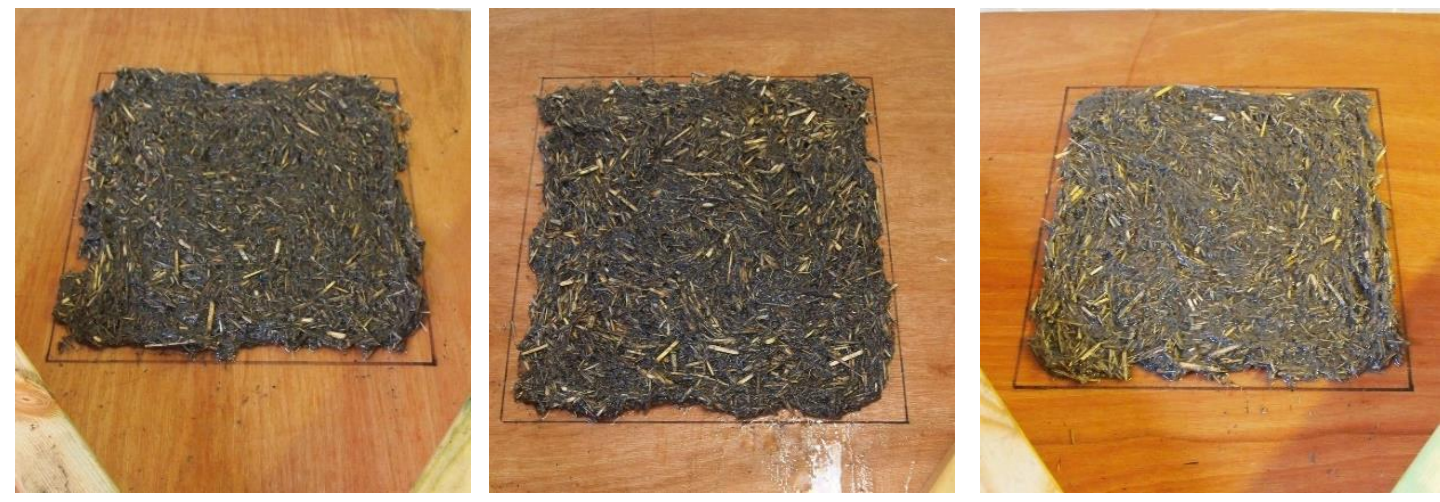

Figure 5.27: The three replicates of the two-stage 10\% guar treatment, following a three-day drying period
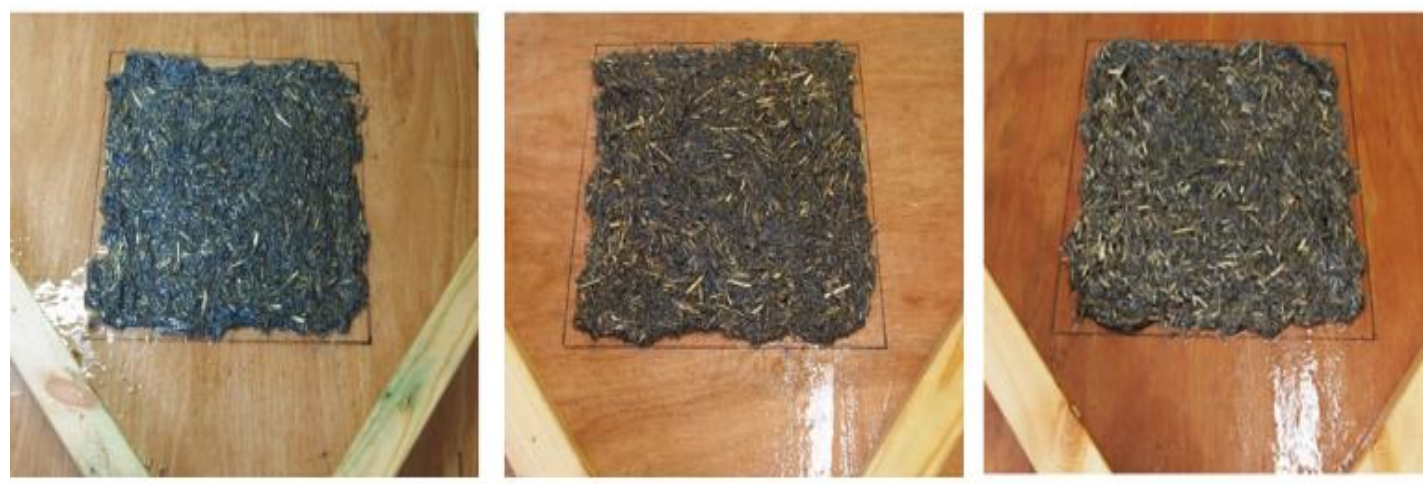

Figure 5.28: The three replicates of the two-stage $10 \%$ guar treatment after one hour simulated rainfall $(200 \mathrm{~mm} / \mathrm{hr})$

A significantly greater quantity of the surrogate soil failed in the two-stage $10 \%$ compared to the single-stage $10 \%$ soil (Kruskal-Wallis: $p \leq 0.025$ ), however, this can be attributed to the high performance of the single-stage treatment (99\% adhesion) rather than the failure of the two-stage treatment (97\% adhesion). 
No significant differences were found between the two-stage 8 and 10\% treatments with regards to the nutrient content in run-off or the volume of the eroded materials. The hue, chroma and suspended particles in the run-off were also, visually, the same $(10 \mathrm{Yr} / 8 / 1)$ (Figure 5.29).
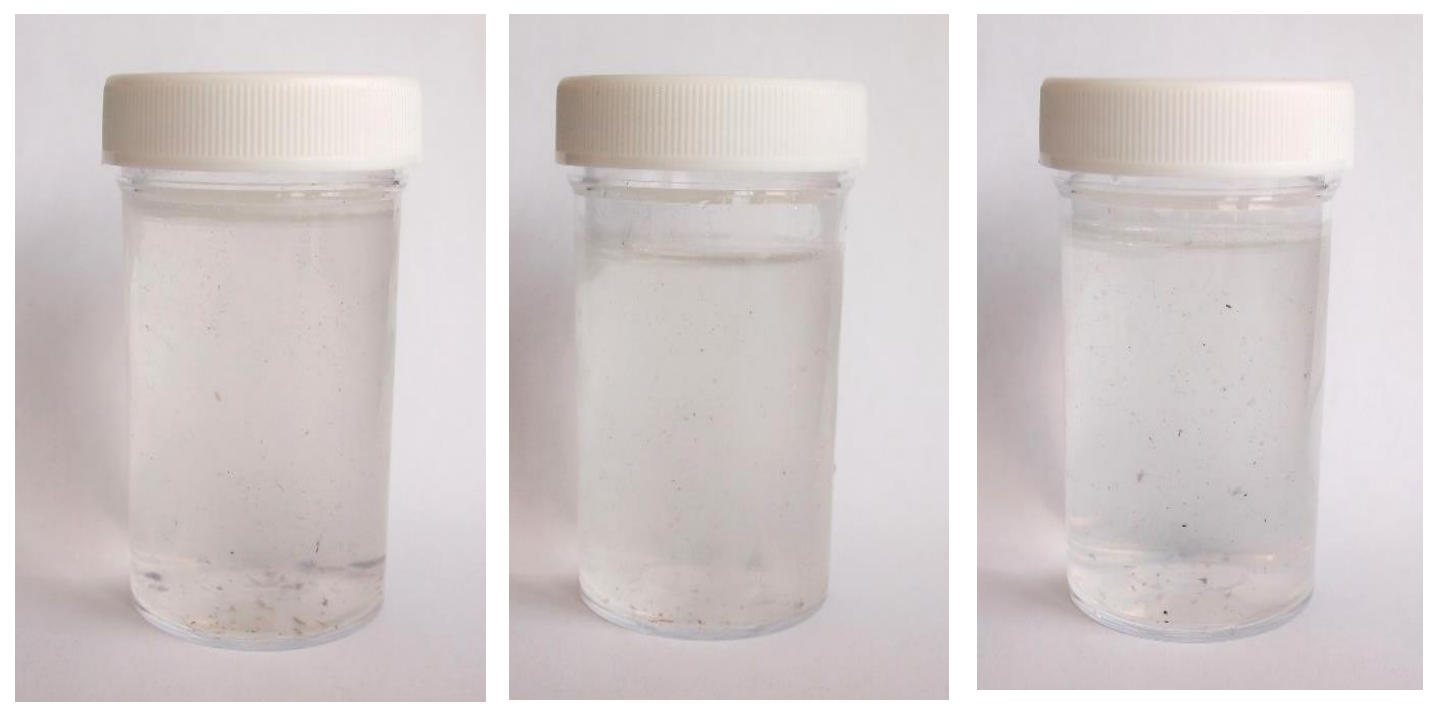

Figure 5.29: Run-off samples collected from the two-stage 10\% guar treatment

\subsection{Discussion}

Several adhesive soils were exposed to one hour of heavy simulated rainfall (200 $\mathrm{mm} / \mathrm{hr}$ ) to assess each materials erosivity and loss of essential plant nutrients under intense rainfall. Hydra CX, a commercially available erosion control media, was trialled as an example of commercially acceptable standards and what could be achieved by an already existing product.

All of the test surrogate soils successfully resisted erosion, more so than the Hydra CX product. The combination of hydrocolloids in the Hydra CX may not have been appropriate for this particular test, yet this is unlikely to be the sole cause. The product specification sheet, and various users of the product (Noble, 2012; Tensar, 2012; Middleton \& King, 2019) describe Hydra CX as suitable for application on $18^{\circ}$ slopes. The wooden plots, set at $20^{\circ}$, may have been too steep for the material to withstand intense rainfall. The countries which approve the use of Hydra CX for slope revegetation have temperate climates (North American Green, 2018; Middleton \& King, 2019, UK; Noble, 2012). Rainfall events of $200 \mathrm{~mm} / \mathrm{hr}$ are more characteristic 
of tropical climates (Nsiah \& Schaaf, 2019), and it is doubtful that the Hydra CX was intended to withstand the high rainfall intensity.

Although the guar gum application rate recommended by the product specification sheet was between $0.67 \%$ and $2.47 \%$ (v/v) per plot (Rantec Corporation, 2009), a pilot study revealed that adhesion was not sufficient until a rate of $4 \%(\mathrm{v} / \mathrm{v})$ was applied (Appendix 2.1). The choice of surrogate soil materials used in this rainfall trial may have impacted this. Products such as paper pulp, manure, bentonite clay and polypropylene fibres are more frequently used (Codd \& Head, 2010; Donze \& Lanze, 2015), and the recommended application rate may have been more suited to these materials. However, as Hydra CX contained 10\% (v/v) hydrocolloids (Tensar, 2012), it does not appear anomalous that $1-2 \%$ guar gum was insufficient.

At the inclusion of $6 \%(\mathrm{v} / \mathrm{v})$ guar gum, a noticeable improvement in the adhesive quality of the material was observed. This was evident in the reduced volume of eroded material, but also in the nutrient content, colour and visible OM in the run-off. Beyond the inclusion of $6 \%$ guar, an increase in guar gum did not correspond to an increase in retained nutrients, and the TON, $\mathrm{NH}_{4}{ }^{+}$and $\mathrm{PO}_{4}{ }^{3-}$ concentrations were similar for all subsequent treatments. Particle displacement within the 8 and $10 \%$ soils was neglible, and it is congruent that nutrient loss should be similarly low.

Whilst the $6 \%$ soil produced adequate adhesion short-term, localised areas of failure occurred which, longer-term, would compromise the stability of the material. Satisfactory stabilisation was only observed with the addition of $\geq 8 \%$ guar gum.

The single-stage and two-stage 8 and $10 \%$ guar gum treatments performed similarly, and adhesion was $95-99 \%$. The mass of the eroded material ranged from 0.04 to 0.90 g.m $\mathrm{m}^{-2}$ (median) material per plot, which is not a substantial loss under intense rainfall. Merlin et al., (1999) conducted rainsplash experiments using compost treated with guar gum and polyacrylamide $(1-10 \% \mathrm{v} / \mathrm{v})$. The soils were applied to wooden boards on a $47^{\circ}$ angle, and experienced $52 \mathrm{~mm} / \mathrm{hr}$ of simulated rainfall for 20 minutes. The adhesion capacity of the guar gum soils was $85-90 \%$, and for polyacrylamide was $65-70 \%$ for guar gum. By this standard, the materials used in this trial suitably resisted erosion and are considered a success.

For the application of soils to slopes of $>20^{\circ}$, surrogate soils with either 8 or $10 \%$ $(\mathrm{v} / \mathrm{v})$ guar gum can successfully withstand intense rainfall without experiencing 
excessive erosion or loss of soil nutrients. Similar results can be obtained regardless of whether a single-stage or two-stage approach is applied. 


\section{Germination trial introduction}

In the following chapter, the adhesive soils which were most resistant to rainfall erosion were used in a six-week germination trial. As both the single and two-stage treatments with 8 and $10 \%$ guar gum proved to be resistant to erosion, these materials formed the basis for the further development of the soils.

The provision of biomass has multiple aims. The tensile strength of soils can be improved greatly by the roots of vegetation (Burylo et al., 2011; Wieder \& Shoop, 2017). The provision of biomass also reduces soil erosion by intercepting and dispersing raindrops, which slows the velocity and improves transpiration rates (Operstein \& Frydman, 2000). The ultimate aim of the surrogate soil is, therefore, to provide an environment which will assist the establishment of a vegetative cover and which will limit erosion. Thus, the parameters which will be measured are those which determine the success of the soil at assisting grass growth. These are the quantity of biomass produced, the amount of ground cover produced, and the root growth.

In the germination trial, the surrogate soil and grasses were not applied to mine tailings. The soil and grasses would be trialled at a later point on the mine. If the soils were applied to the tailings in the germination trial, and the grasses died, it would be difficult to ascertain whether this was due to toxicity or other causes (MP-AES analysis was unavailable at this time). To ensure that the grasses success or failure was a result of the soil, and no other factor, the tailings were omitted from this stage of the trial. 


\subsection{Germination trial - Method}

The outdoor germination trial was conducted in accordance with ISO 17126:2005, with minor amendments regarding the watering schedule.

The trial was conducted on private land in Swansea, South Wales (UK), coordinates $51^{\circ} 57^{\prime} 74.98 \mathrm{~N}, 4^{\circ} 03^{\prime} 42.50 \mathrm{~W}$.

A four-week pilot trial was conducted from the $1^{\text {st }}-29^{\text {th }}$ June 2018 . Unusually hot and dry weather (only four days of rain in the 42 days of the trial, and a mean high temperature of $28{ }^{\circ} \mathrm{C}$, a mean low of $23^{\circ} \mathrm{C}$ ) led to the premature closure of the trial, and adjustments were made to the soil composition and watering schedule. These adjustments are detailed in the following sections. Full details of the pilot trial are in Appendix 3.

\subsubsection{Experimental design}

The six-week germination trial was conducted from the $10^{\text {th }}$ July $-29^{\text {th }}$ August 2018. A randomised block experimental design was adopted with 20 treatments and 25 repetitions $(\mathrm{N}=500)$.

The germination trial consisted of 17 variations of the test surrogate soils. Three unseeded surrogate soils were used to determine the existence of dormant seeds within the materials.

The pots used were conical black plastic, $5.5 \mathrm{~cm}$ top diameter, $4 \mathrm{~cm}$ bottom diameter, $4.5 \mathrm{~cm}$ height, with an exposed surface area of $23.8 \mathrm{~cm}^{2}$ (Figure 6.1). Holes at the bottom of the pot provided adequate drainage. 


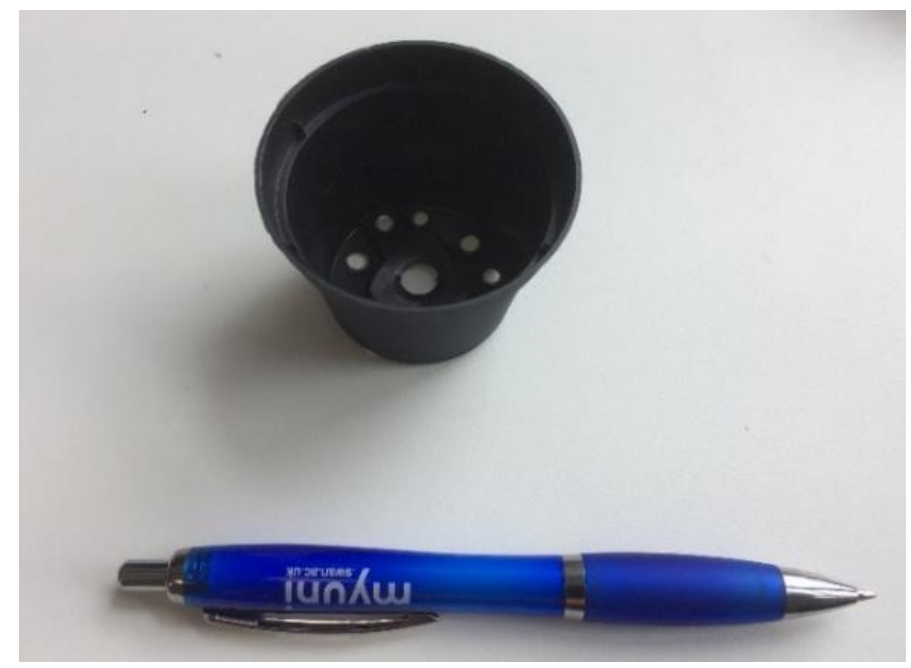

Figure 6.1: A pot from the germination trial

At the trial location, vegetation was cleared from flat ground and plastic laid down to restrict regrowth. The surrounding vegetation was reduced throughout the trial.

The individual pots were placed in trays of 40 pot holders. The plastic trays were placed on upturned containers with perforated bottoms to allow for free drainage. The containers stood on a flat platform of approximately $5.5 \mathrm{~m}$ x $1.2 \mathrm{~m}$ (Figure 6.2).

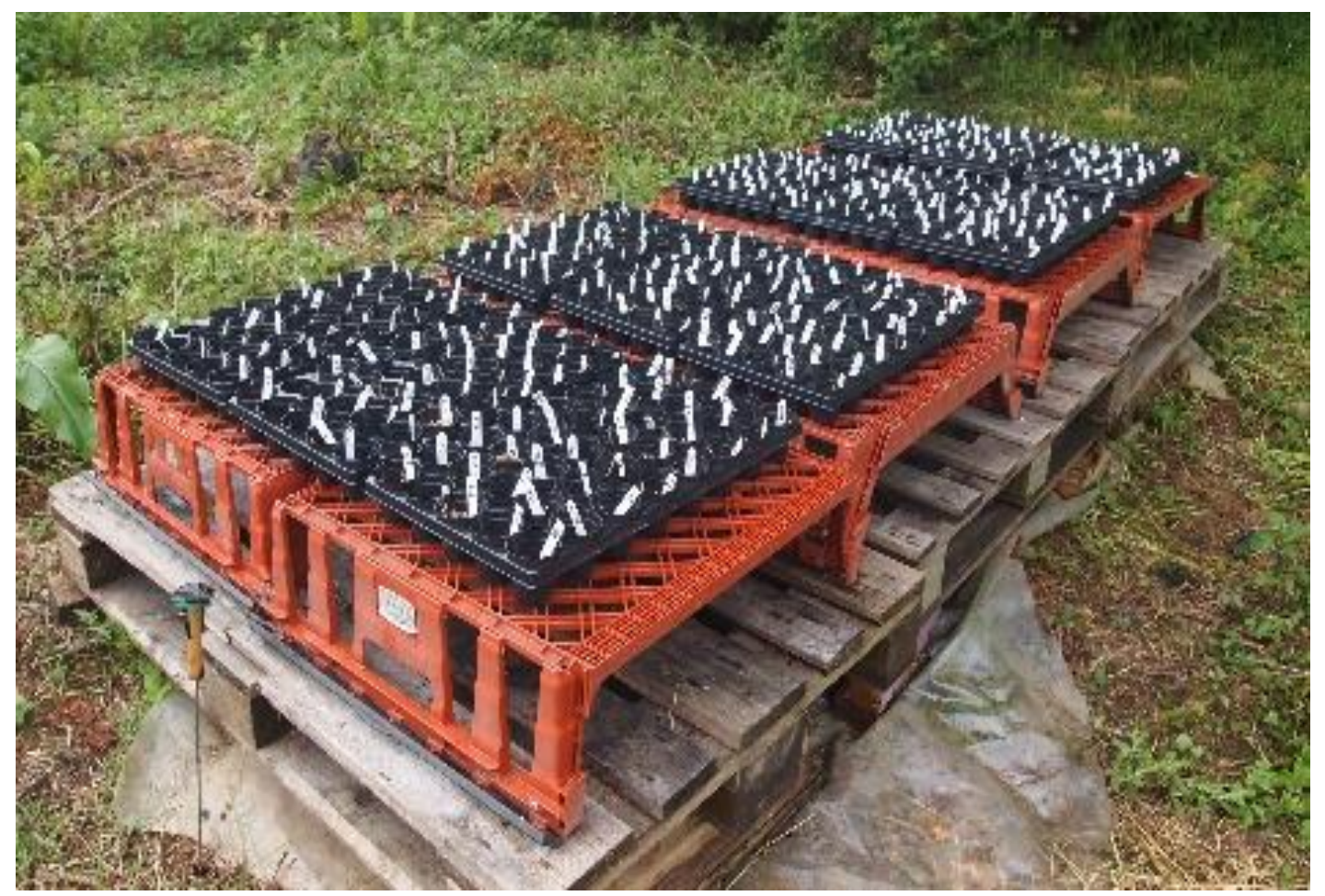

Figure 6.2: The placement of the pots and pot holders for the germination trial, July 2018. The Maxim i-Button temperature logger can be seen in the foreground 
All materials were measured volumetrically to ensure that each pot contained the same amount of material and a depth of $2 \mathrm{~cm}$.

Two separate application approaches were tested; a single-stage and two-stage, as per the rainfall erosion tests (Section 5.2). The two groups were further subdivided by the soil's guar gum content, either $8 \%$ or $10 \%(\mathrm{v} / \mathrm{v})$, which created the following five treatment groups:

- Single-stage, $8 \%$ guar

- $\quad$ Single-stage, $10 \%$ guar

- Two-stage, $8 \%$ guar

- Two-stage, $10 \%$ guar

- Hydra CX 


\subsubsection{Single-stage treatments}

The treatments in the single-stage group contained a homogenous mixture of the materials. This produced a material that would be applied in a single layer of surrogate soil.

In the single-stage group, for both 8 and $10 \%$ guar gum, the unamended soil treatments contained neither biochar nor basalt fines (Table 6.2).

The experimental soils contained straw $(57-60 \%)$, digestate $(28-32 \%)$, guar gum (8 or $10 \%)$, biochar $(5 \%)$ and/or basalt fines $(0.5 \%)$.

An unseeded soil treatment (U, Table 6.1) determined the possibility of dormant seeds in the materials.

Each pot contained $25 \mathrm{ml}$ of material. When increasing proportions of guar gum, biochar and basalt were added, the relative proportions of straw and digestate were reduced to maintain the same $25 \mathrm{ml}$ total for all treatments (Table 6.2).

Table 6.1: The components of the soil treatments in the single-stage group (per pot). $U$ represents and unseeded soil treatment, whereas $S$ indicates a seeded soil.

\begin{tabular}{l|cc|cccc|cc|cc|cc}
\hline \hline & \multicolumn{2}{c|}{ Straw } & \multicolumn{2}{c|}{ Digestate } & \multicolumn{2}{c|}{ Biochar } & \multicolumn{2}{c|}{ Basalt } & \multicolumn{2}{c}{ Guar gum } & \multicolumn{2}{c}{ Total } \\
\multicolumn{2}{c}{$(\%)$} & $(\mathrm{ml})$ & $(\%)$ & $(\mathrm{ml})$ & $(\%)$ & $(\mathrm{ml})$ & $(\%)$ & $(\mathrm{ml})$ & $(\%)$ & $(\mathrm{ml})$ & $(\%)$ & $(\mathrm{ml})$ \\
\hline $\mathrm{U}$ & 60 & 15 & 32 & 8 & 0 & 0 & 0 & 0 & 8 & 2 & 100 & 25 \\
$\mathrm{~S}$ & 60 & 15 & 32 & 8 & 0 & 0 & 0 & 0 & 8 & 2 & 100 & 25 \\
$\mathrm{~S}$ & 60 & 15 & 32 & 8 & 0 & 0 & 0.5 & 0.13 & 8 & 2 & 100 & 25 \\
$\mathrm{~S}$ & 57 & 14.25 & 30 & 7.5 & 5 & 1.25 & 0 & 0 & 8 & 2 & 100 & 25 \\
$\mathrm{~S}$ & 57 & 14.25 & 29.5 & 7.36 & 5 & 1.25 & 0.5 & 0.13 & 8 & 2 & 100 & 25 \\
\hline & & & & & & & & & & & & \\
$\mathrm{S}$ & 59 & 14.8 & 31 & 7.8 & 0 & 0 & 0 & 0 & 10 & 2.5 & 100 & 25 \\
$\mathrm{~S}$ & 59 & 14.8 & 31 & 7.8 & 0 & 0 & 0.5 & 0.13 & 10 & 2.5 & 100 & 25 \\
$\mathrm{~S}$ & 58 & 14.5 & 27 & 6.75 & 5 & 1.25 & 0 & 0 & 10 & 2.5 & 100 & 25 \\
$\mathrm{~S}$ & 58 & 14.5 & 27 & 6.75 & 5 & 1.25 & 0.5 & 0.13 & 10 & 2.5 & 100 & 25 \\
\hline
\end{tabular}


The WHC of the single-stage soils are detailed in Table 6.2. The water-holding capacity and $\mathrm{pH}$ were determined using the methods in Section 4.1.2 and 3.1.5.

Table 6.2 The mean water-holding capacity (WHC) and $p H$ of the single-stage soil treatments used in the germination trial, as per Table 6.1. For each surrogate soil, $n$ $=5$.

\begin{tabular}{|c|c|c|}
\hline \multicolumn{3}{|l|}{ Materials } \\
\hline $8 \%$ guar gum and: & Mean & \pm \\
\hline \multirow[t]{2}{*}{ Straw, digestate } & WHC (\%) & $66 \pm 0.7$ \\
\hline & $\mathrm{pH}$ & $7.25 \pm 0.06$ \\
\hline \multirow[t]{2}{*}{ Straw, digestate, biochar } & WHC $(\%)$ & $70 \pm 1.0$ \\
\hline & $\mathrm{pH}$ & $7.13 \pm 0.04$ \\
\hline \multirow[t]{2}{*}{ Straw, digestate, basalt } & $\mathrm{WHC}(\%)$ & $66 \pm 0.6$ \\
\hline & $\mathrm{pH}$ & $6.93 \pm 0.02$ \\
\hline \multirow[t]{2}{*}{ Straw, digestate, biochar, basalt } & $\mathrm{WHC}(\%)$ & $69 \pm 1.1$ \\
\hline & $\mathrm{pH}$ & $7.02 \pm 0.1$ \\
\hline \multicolumn{3}{|l|}{$10 \%$ guar gum and: } \\
\hline \multirow[t]{2}{*}{ Straw, digestate } & WHC (\%) & $69 \pm 0.03$ \\
\hline & $\mathrm{pH}$ & $7.18 \pm 0.08$ \\
\hline \multirow[t]{2}{*}{ Straw, digestate, biochar } & WHC $(\%)$ & $82 \pm 0.4$ \\
\hline & $\mathrm{pH}$ & $7.03 \pm 0.02$ \\
\hline \multirow[t]{2}{*}{ Straw, digestate, basalt } & WHC $(\%)$ & $80 \pm 0.05$ \\
\hline & $\mathrm{pH}$ & $6.91 \pm 0.4$ \\
\hline \multirow[t]{2}{*}{ Straw, digestate, biochar, basalt } & $\mathrm{WHC}(\%)$ & $75 \pm 0.4$ \\
\hline & $\mathrm{pH}$ & $7.01 \pm 0.01$ \\
\hline
\end{tabular}


Before the surrogate soils were prepared, a circle of fine nylon mesh gauze (Normesh, 950 microns) was placed at the bottom of each black plastic pot to limit the soil material loss in run-off.

In each treatment, material enough for five replicates was bulked and homogenised before the soil was divided among as many pots.

The unamended soils were constructed prior to the amended ones. The straw and digestate were measured volumetrically using glass measuring beakers and were combined in a large plastic container.

The steel beaters of an electric hand blender, held by a retort stand, were placed inside the container of dry materials. Municipal water (1:2 dry materials:water) was slowly poured from a measuring cylinder whilst the hand blender operated at a low speed $(\sim 60$ revolutions per minute). All samples were homogenised thoroughly for 15 minutes.

A small metal spoon was used to divide the material between five pots, which were labelled with the treatment letter and replicate number (Figure 6.3). Each treatment was produced separately and sequentially, and equipment was cleaned between treatments to avoid contamination.

The treatments which included the addition of biochar and/or basalt fines were constructed in the manner previously described, but with the additional materials added to the container with the straw and digestate. The same process was used to construct the replicates in the 8 and $10 \%$ treatments. 


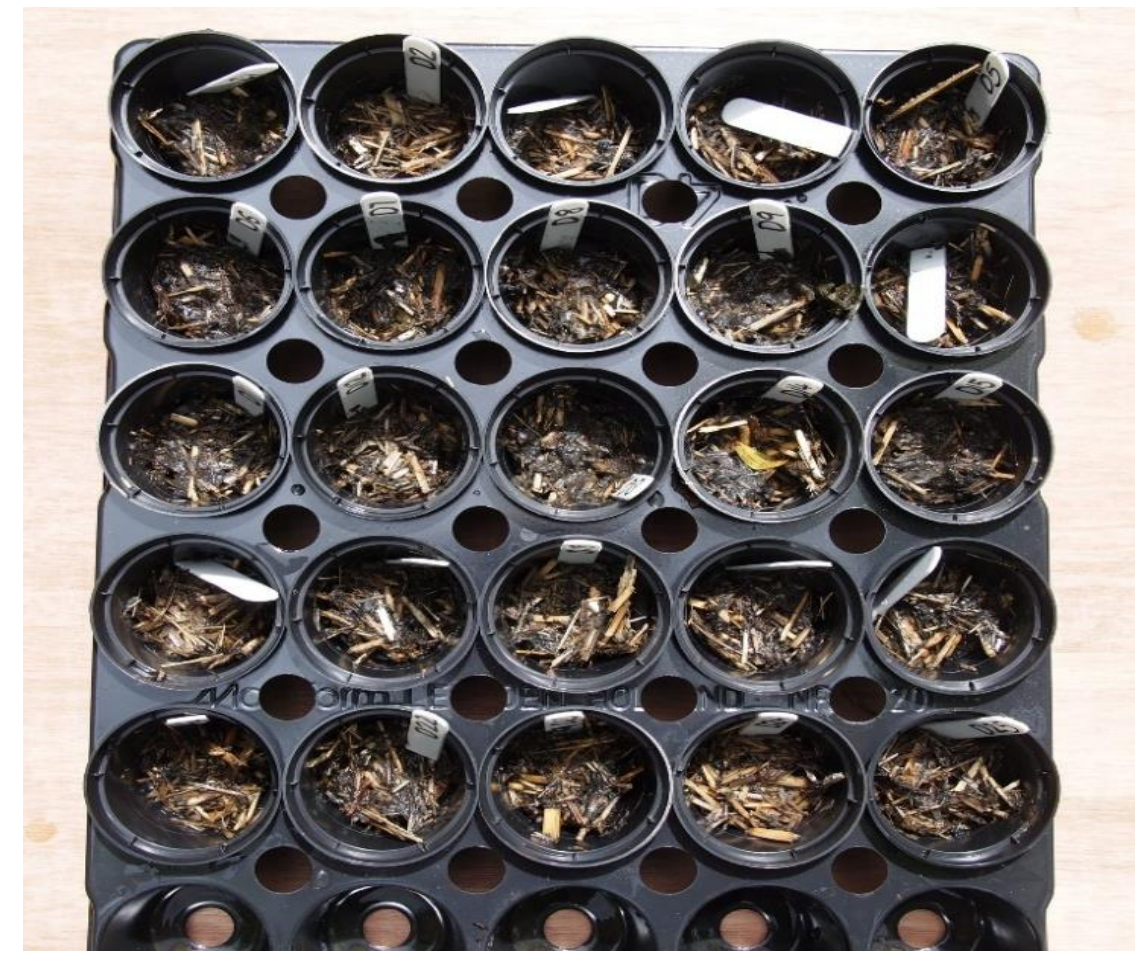

Figure 6.3: The labelled and numbered 25 replicates of a single-stage treatment at the start of the germination trial (July 2018) 


\subsubsection{Two-stage treatments}

The characteristics of the single-stage surrogate soils used in the germination trial are specified in Table 6.3.

Table 6.3 The water-holding capacity and pH of the two-stage soil treatments used in the germination trial

\begin{tabular}{|c|c|c|c|}
\hline \multicolumn{3}{|c|}{ Two-stage surrogate soil treatment } & Mean \\
\hline $8 \%$ guar gum & Unamended & $\begin{array}{l}\text { WHC (\%) } \\
\mathrm{pH}\end{array}$ & $\begin{array}{c}69 \pm 0.05 \\
7.33 \pm 0.02\end{array}$ \\
\hline & Biochar & $\begin{array}{l}\mathrm{WHC}(\%) \\
\mathrm{pH}\end{array}$ & $\begin{array}{c}72 \pm 0.3 \\
7.01 \pm 0.01\end{array}$ \\
\hline & Basalt & $\begin{array}{l}\mathrm{WHC}(\%) \\
\mathrm{pH}\end{array}$ & $\begin{array}{c}69 \pm 0.4 \\
6.82 \pm 0.1\end{array}$ \\
\hline & Biochar:basalt & $\begin{array}{l}\mathrm{WHC}(\%) \\
\mathrm{pH}\end{array}$ & $\begin{array}{c}72 \pm 0.6 \\
6.99 \pm 0.1\end{array}$ \\
\hline $10 \%$ guar gum & Unamended & $\begin{array}{l}\text { WHC }(\%) \\
\mathrm{pH}\end{array}$ & $\begin{array}{c}71 \pm 0.4 \\
7.27 \pm 0.05\end{array}$ \\
\hline & Biochar & $\begin{array}{l}\mathrm{WHC}(\%) \\
\mathrm{pH}\end{array}$ & $\begin{array}{c}85 \pm 0.5 \\
6.99 \pm 0.02\end{array}$ \\
\hline & Basalt & $\begin{array}{l}\text { WHC }(\%) \\
\mathrm{pH}\end{array}$ & $\begin{array}{l}71 \pm 0.02 \\
6.51 \pm 0.3\end{array}$ \\
\hline & Biochar:basalt & $\begin{array}{l}\mathrm{WHC}(\%) \\
\mathrm{pH}\end{array}$ & $\begin{array}{c}85 \pm 0.7 \\
7.03 \pm 0.01\end{array}$ \\
\hline
\end{tabular}


The two-stage treatment group involved the application of a base layer of seeded growing medium $(12.5 \mathrm{ml}, 1 \mathrm{~cm}$ depth), which was capped with an equal volume of erosion protection material (Table 6.4).

In the unamended soil, the base layer was composed of coir fibres $(48-50 \% \mathrm{v} / \mathrm{v})$ and digestate $(47-50 \% \mathrm{v} / \mathrm{v})$. In the test treatments, biochar $(5 \% \mathrm{v} / \mathrm{v})$ and/or basalt fines $(0.5 \% \mathrm{v} / \mathrm{v})$ were added. The base layer totalled $12.5 \mathrm{ml}$ and was applied to a $1 \mathrm{~cm}$ depth. Where biochar and basalt were added, the proportions of coir and digestate were reduced to maintain an equal $25 \mathrm{ml}$ for all pots.

The base layer was homogenised using water (1:2 dry materials:water) and an electric hand blender, in the same manner as that of the single-stage treatments.

The top layer was composed of straw $(62-64 \%)$, digestate $(28 \%)$ and guar gum (8 or $10 \%)$. The top layer was also prepared and homogenised using a hand blender and water, in the same manner as the base layer. As with the base layer, the top layer totalled $12.5 \mathrm{ml}$ and was applied to a depth of $1 \mathrm{~cm}$. As the proportion of guar gum increased the proportion of straw and digestate was reduced to maintain the same volume and depth for all pots.

One unseeded and unamended two-stage treatment determined the possibility of dormant seeds in the coir (U, Table 6.4). 
Table 6.4: The components of the two-stage soil treatments (per pot) constructed for the germination trial (July 2018). U represents and unseeded soil treatment, whereas $S$ indicates a seeded soil

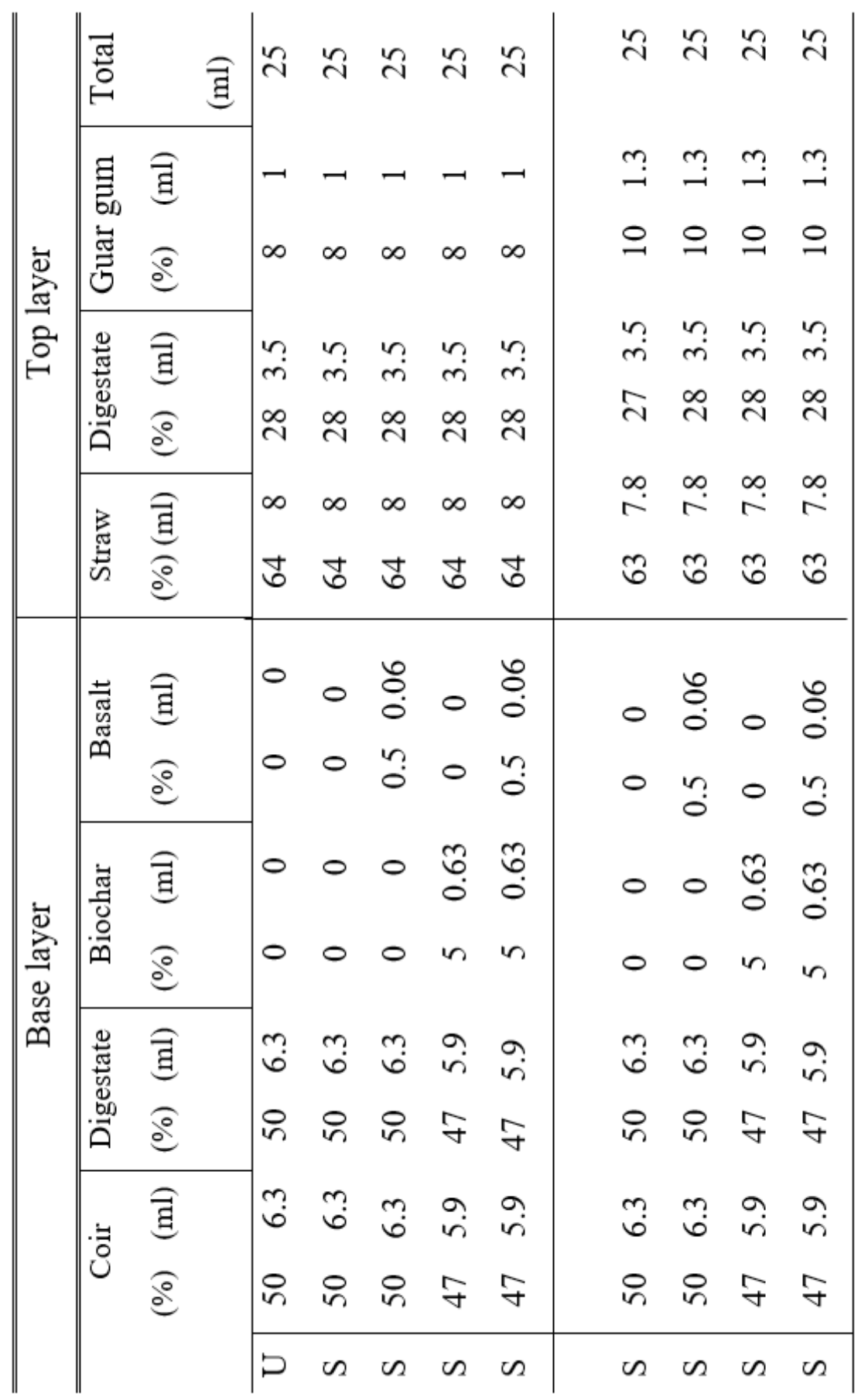




\subsubsection{The Hydra CX treatment}

Hydra CX was applied in accordance with the accompanying product technical sheet (Tensar, 2012). Material enough for five replicates was bulked, and water (1:2 dry materials:water) was added slowly whilst the material was homogenised using the hand blender for 15 minutes. After 15 minutes the material was divided between five pots.

Two Hydra CX soil treatments were prepared, one seeded $(n=25)$ and one unseeded $(\mathrm{n}=25)$ (Table 6.5). The WHC of the Hydra CX was $75 \pm 0.4 \%$. The $\mathrm{pH}$ was $7.3 \pm$ 0.02 .

Table 6.5: The Hydra CX treatments constructed for the germination trial (July 2018).

$U$ represents and unseeded soil treatment, whereas $S$ indicates a seeded soil.

\begin{tabular}{c|cc}
\hline \hline & \multicolumn{2}{c}{ Hydra CX } \\
\multicolumn{1}{c}{$(\%)$} & $(\mathrm{ml})$ \\
\hline $\mathrm{U}$ & 100 & 25 \\
$\mathrm{~S}$ & 100 & 25
\end{tabular}




\subsubsection{Seeding and placement}

All pots were seeded on the same day with 50\% Agrostis capillaris $(0.6 \mathrm{~g})$ and $50 \%$ Agrostis stolonifera seeds (0.6 g), equivalent to $250 \mathrm{~kg} \cdot \mathrm{ha}^{-1}$ (Figure 6.4). Seeds enough for 10 pots were weighed using an Ohaus Valor 3000 compact scale and were distributed by hand onto the soils surface.

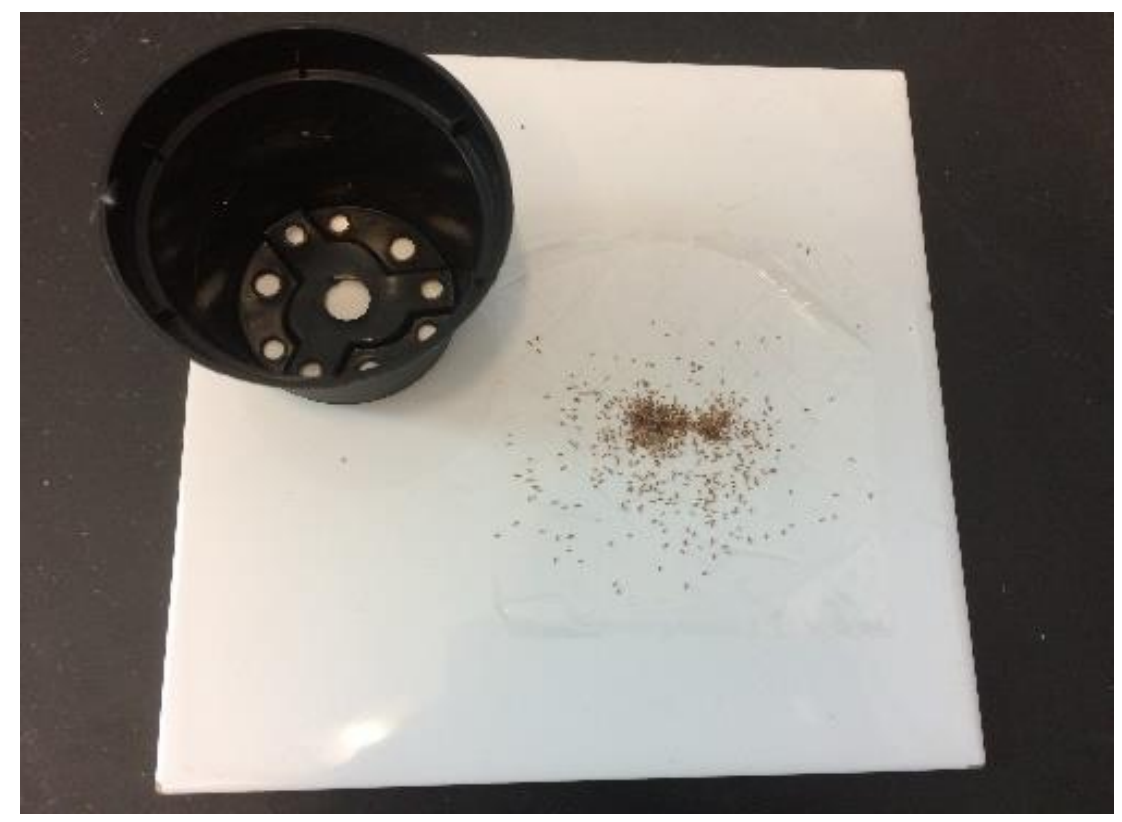

Figure 6.4: $0.6 \mathrm{~g}$ of Agrostis capillaris and $0.6 \mathrm{~g}$ of Agrostis stolonifera seeds

Each pot was hand-watered with $8 \mathrm{~mm}$ of municipal water, which was the mean daily rainfall on a day on which it rained at Nantymwyn in September (2007 - 2016, www.WorldWeatherOnline.com, 20181 ), as November was the proposed start date of the field trial. A random number generator in R (version 3.4.3, R Core Team, 2017) was used to randomise the locations of the pots (Figure 6.5). 


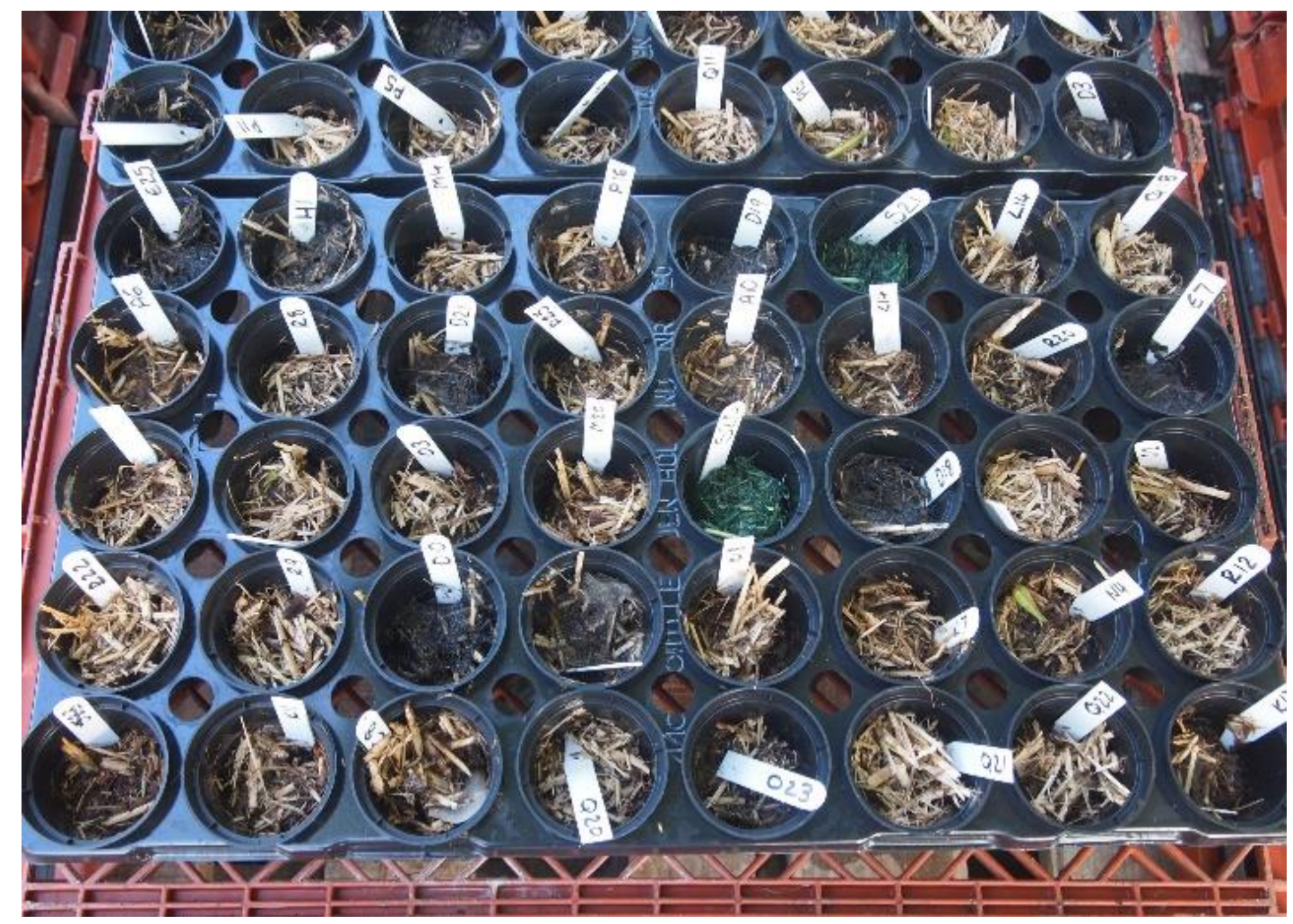

Figure 6.5: A block of 40 pots constructed for the germination trial (July 2018) in randomised locations

\subsubsection{Weather data}

Hourly temperature readings were provided by a Maxim ${ }^{\mathrm{TM}}$ iButton $^{\circledR}$ (DS1920) temperature logger. The daytime and night-time mean temperatures were calculated as a mean of 12 daytime ( 7 am to $7 \mathrm{pm}$ ) and 12 night-time readings ( $7 \mathrm{pm}$ to $7 \mathrm{am}$ ).

A rain gauge adjacent to the platform provided daily rainfall readings in $\mathrm{mm}$. This was recorded at $10 \mathrm{pm}$ every evening. Unless it rained, every pot was hand-watered every third day with $8 \mathrm{~mm}$ of municipal water.

\subsubsection{Seedling emergence and shoot length}

For all treatments, the day on which seedling emergence began was noted (Figure 6.6). At the end of each week the pots were grouped by their treatment and photographed.

Weekly measurements of the greatest shoot length in each pot were taken $(n=25)$. Using a metal ruler, shoot length was measured from the base to the tip of the stem, as 
suggested in ISO 18763:2016. Any volunteer species were noted as well as any visual changes to the sample. After the measurements were taken the pots were returned to their randomly assigned placement.

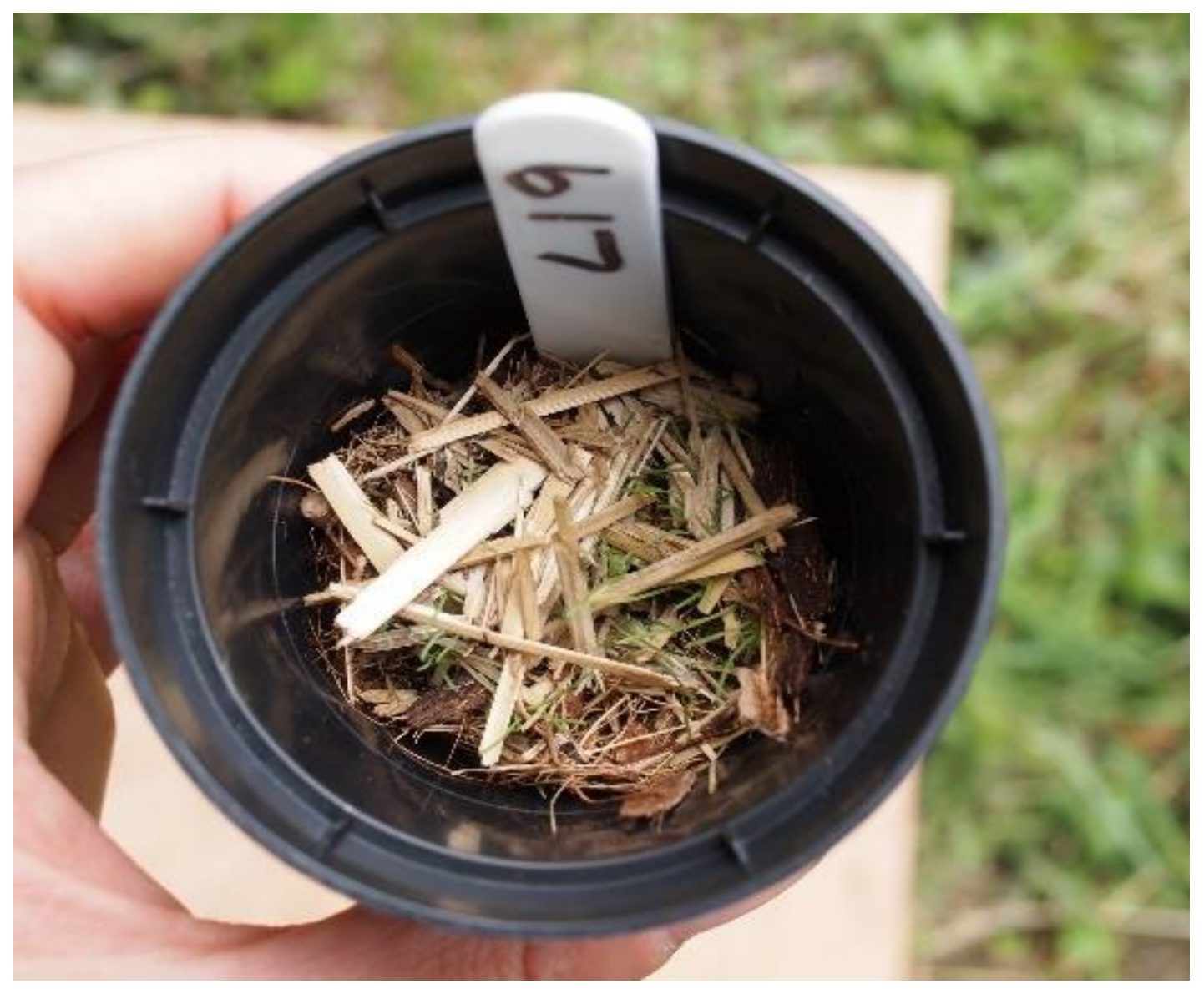

Figure 6.6: Seedling emergence (July 2018)

\subsubsection{Above-ground biomass collection}

At the end of the trial, the shoots in each pot were cut at the base and collected in individual plastic sample bags. The samples were immediately frozen in a home freezer $\left(-18^{\circ} \mathrm{C}\right)$ for $<24$ hours before being transferred to a laboratory freezer $\left(-18^{\circ} \mathrm{C}\right)$. Samples were in transit for $\sim 25$ minutes. 


\subsubsection{Root samples}

After the grass shoots were collected the soil and root samples were photographed. Several root samples were photographed under a Celestron Microcapture Pro microscope (200 x magnification) before separation from the growing medium (Figures 6.7 and 6.8).

Each sample was bagged individually and immediately placed inside a home refrigerator at $4{ }^{\circ} \mathrm{C}$ for $<24$ hours before being transferred to the university cold storage $\left(4{ }^{\circ} \mathrm{C}\right)$. Samples were in transit for $\sim 25$ minutes.

The random number generator in $\mathrm{R}$ ( $\mathrm{R}$ Core Team, 2017) was used to select eight of the 25 root samples from each treatment in order to quantify the mean root biomass $\left(\mathrm{g} \cdot \mathrm{m}^{-2}\right)$ produced by each soil treatment (200 samples in total). The soil and root samples remained in the university cold storage until analysis. Due to the timeconsuming nature of soil washing, some samples were in storage for several days, others for > six weeks.

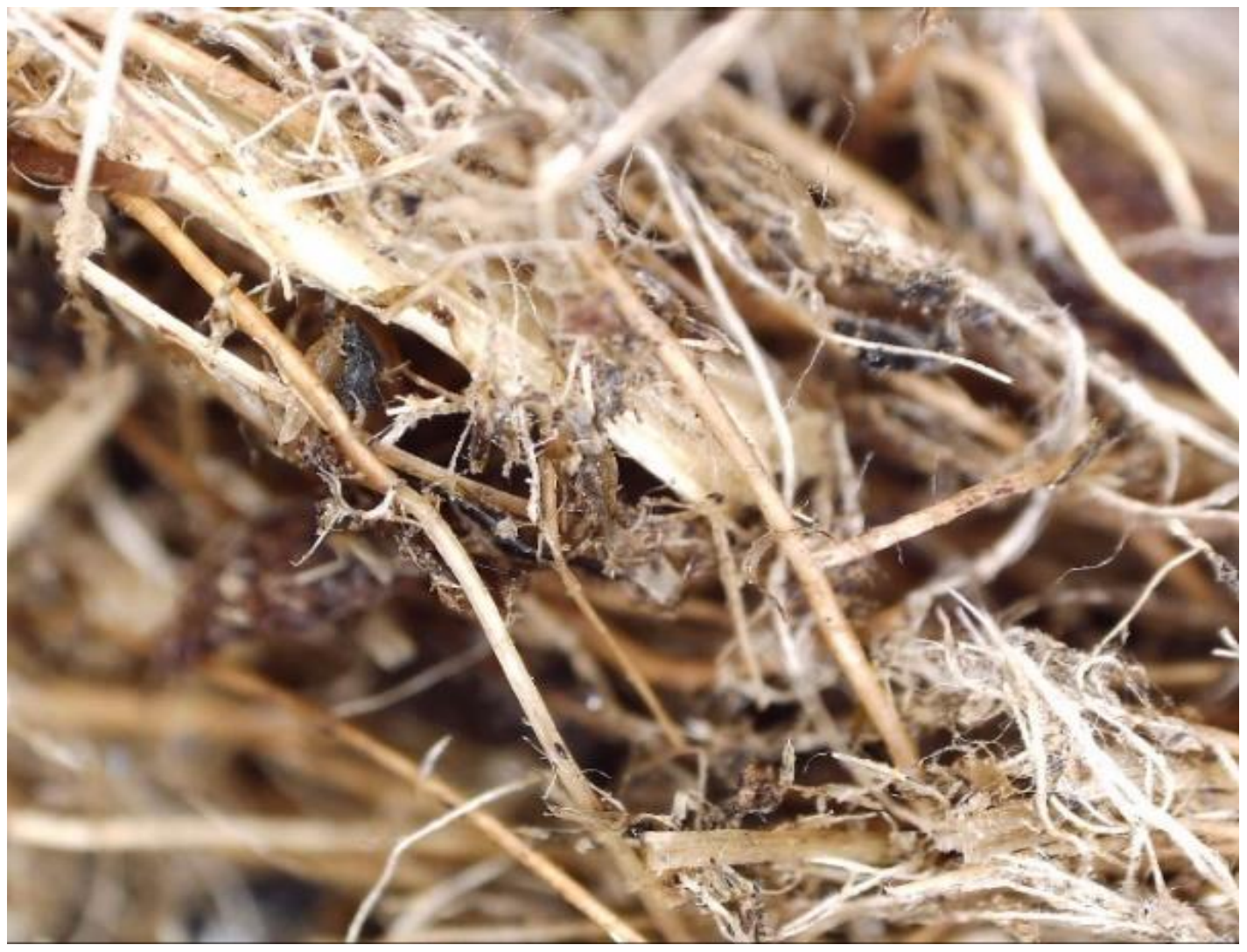

Figure 6.7: A microscope image of the roots of one replicate from the germination trial, tightly interwoven with the growing medium 


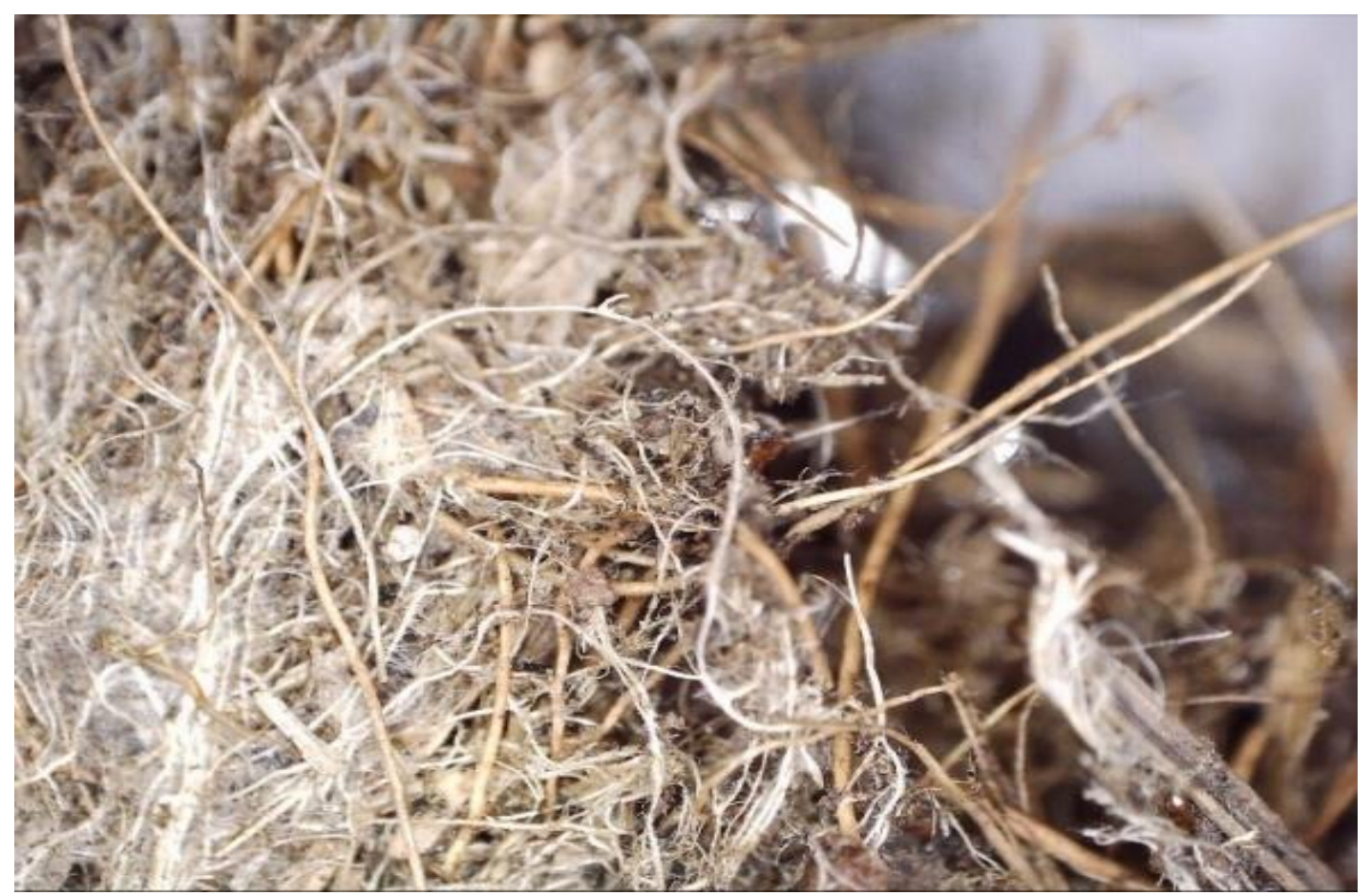

Figure 6.8: A microscope image of the roots of one replicate from the germination trial, tightly interwoven with the growing medium

A method described by Sierra et al. (2003) was used to separate the soil carefully from the roots. The samples were removed from the pots (Figure 6.9) and placed in a shallow bath of water for 30 minutes to fully saturate and soften the soil (Figure 6.10). Large fragments of straw were removed from the soil with tweezers. Each sample was then processed by washing and sieving the content sequentially through $4,2,1.40$ and $0.85 \mathrm{~mm}$ sieves.

As the coir fibre could not be washed from the sample, the coir and roots were dried using a paper towel and flattened onto the screen of a light box (Figure 6.11). Using tweezers, the strands of coir were separated from the roots. On the light box, the fine root network was flattened again to reduce overlap and were photographed.

Each root sample was oven dried in a Swallow oven for 24 hours at $80{ }^{\circ} \mathrm{C}$, as proposed by Sierra et al. (2003) before the sample was weighed using a 5-digit balance (Mettler Toledo AB204-5).

The root biomass was calculated as the mean root tissue $(\mathrm{mg}) /$ soil volume $\left(\mathrm{cm}^{3}\right)$, as per the method described by Olmo \& Villar (2018). 


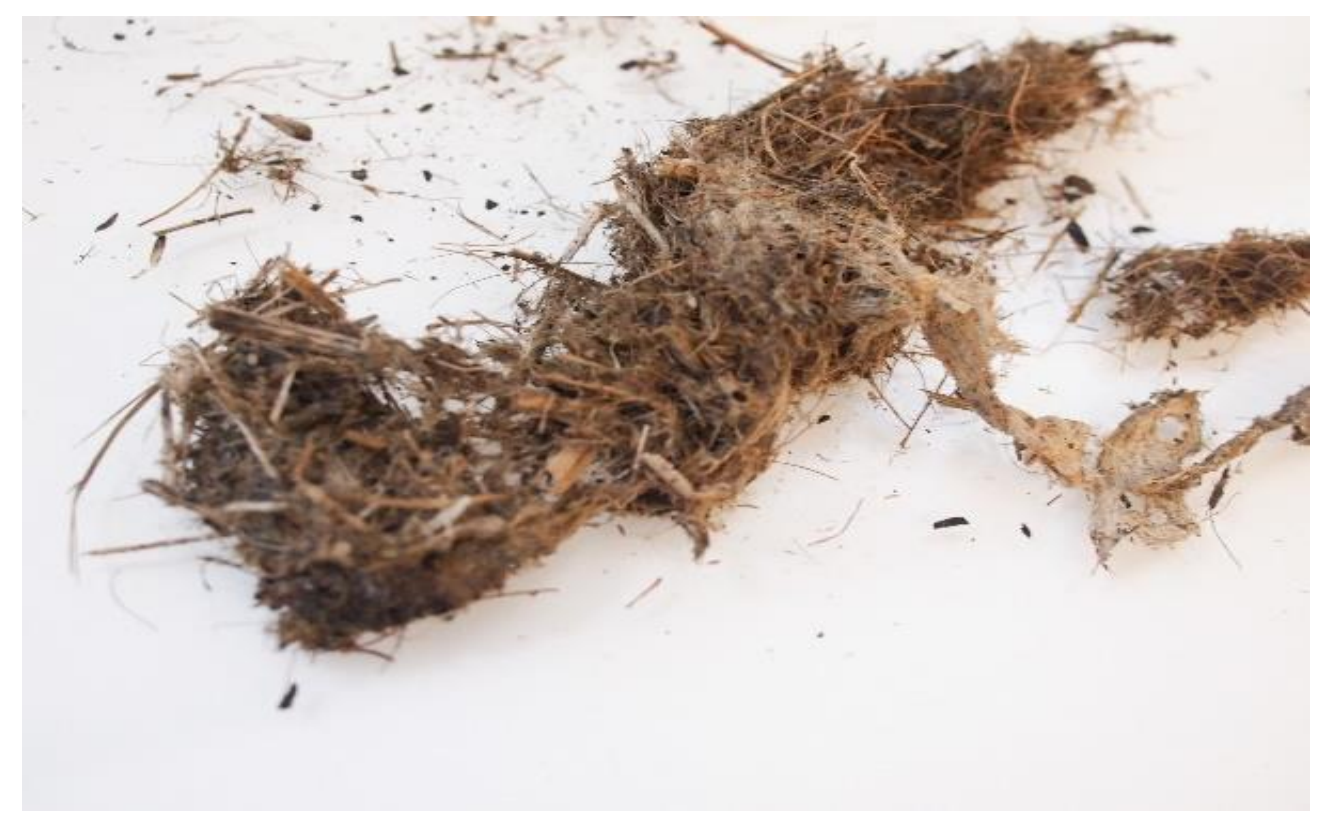

Figure 6.9: The dry roots of one replicate in the germination trial, photographed before the roots were separated from the growing medium

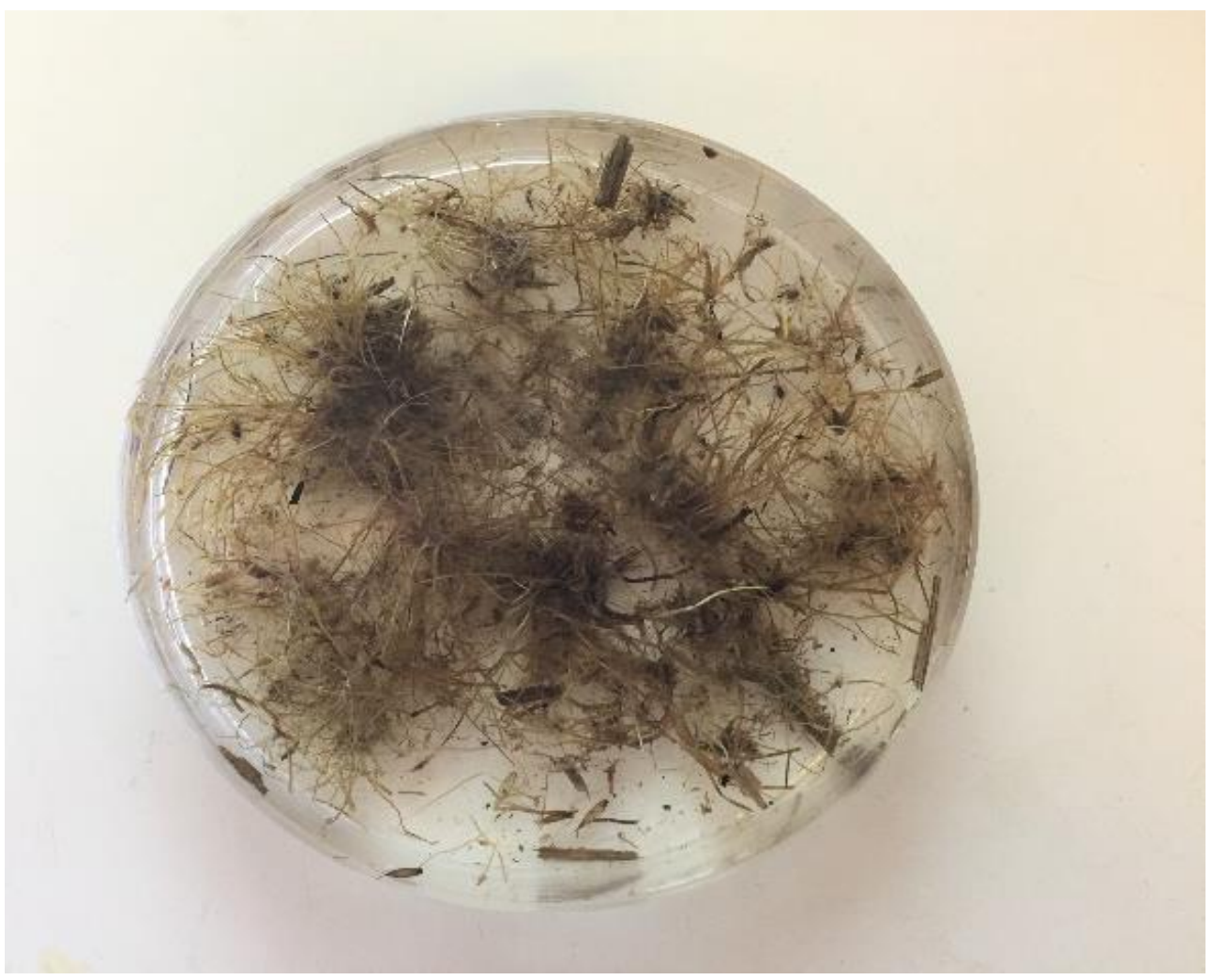

Figure 6.10: The roots of one replicate from the germination trial, soaking in water to soften the growing medium 


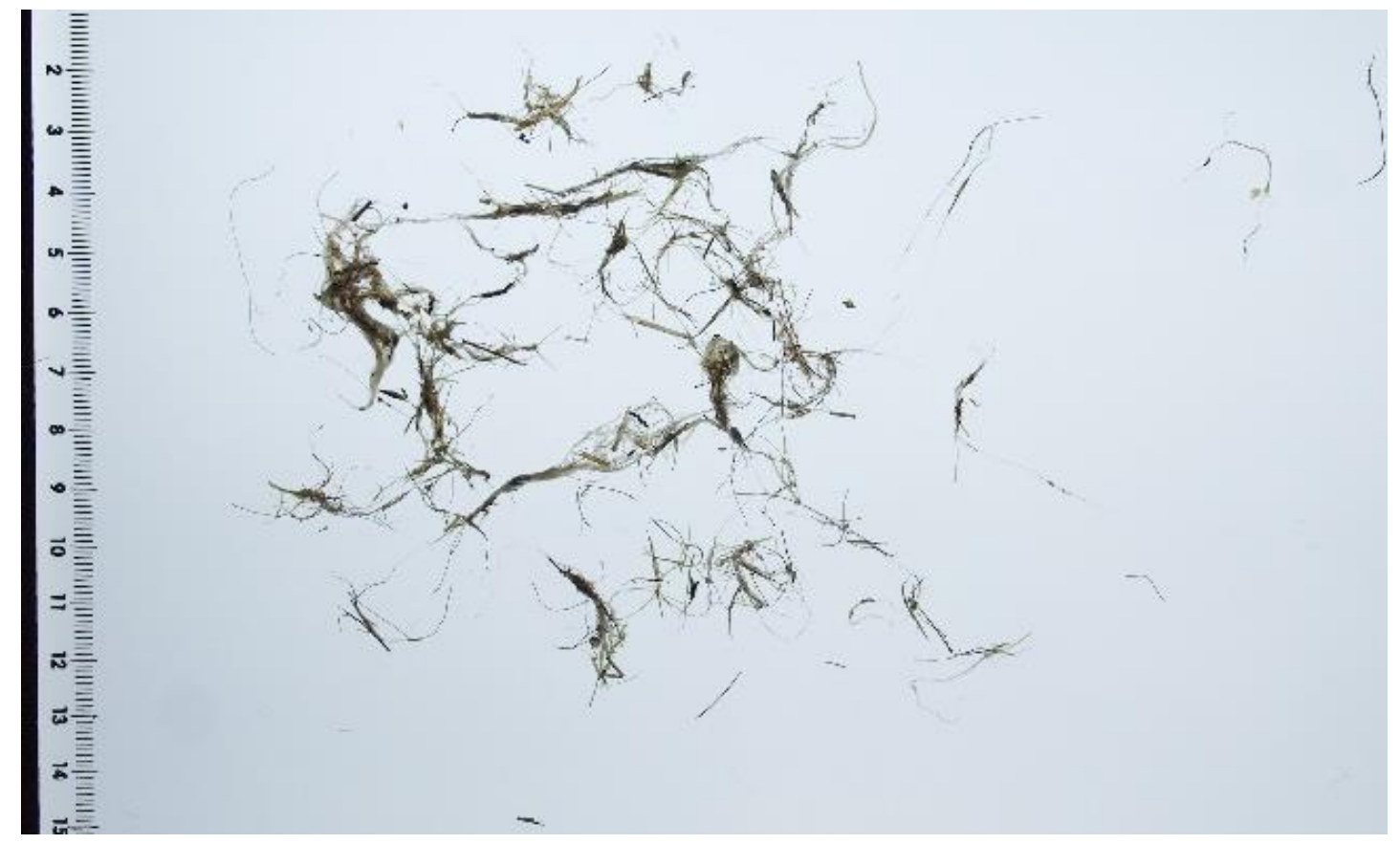

Figure 6.11: The roots of one replicate, placed on a lightbox in order to separate the roots from the growing medium

\subsubsection{Statistical analyses methods}

The germination trial consisted of 20 treatments of 25 replicates each $(\mathrm{N}=500)$. Three treatments remained unseeded to determine the existence of dormant seeds within the materials. As these soils remained bare throughout the six-week trial it was established that no dormant seeds were present, and these treatments $(n=75)$ were omitted from analysis.

A Shapiro-Wilks test confirmed that the shoot length $(\mathrm{p} \leq 2.22, \mathrm{~N}=425)$, aboveground biomass yield $(\mathrm{p} \leq 2.21, \mathrm{~N}=425)$ and root biomass data $(\mathrm{p} \leq 1.75, \mathrm{~N}=425)$ were normally distributed. Therefore, a one-way ANOVA was used to compare the means of three or more groups $(\mathrm{p} \leq 0.05)$. A Tukey's post-hoc test informed of any pairwise differences indicated by the ANOVA. All analyses were completed using the statistical software R, version 5.3.2 (R Core Team, 2017).

For comparisons of two groups or treatments, a T-test was used $(\mathrm{p} \leq 0.05)$.

Throughout the text, the sample standard deviation is presented as \pm . 


\subsection{Germination trial - Results}

The results presented in this section describe the soils ability to assist grass seed germination. The rate of shoot growth, the mean final shoot length, and the quantities of above-ground and root biomass that were produced by the 16 variations of surrogate soil are presented. As some pots contained tall grass of a thin ground cover, and other swards were short and dense, the ground cover was qualitatively assessed using photographs combined with the shoot length and above-ground biomass data.

To compare one soil treatment type with another, the individual soil treatments were grouped into the single-stage and two-stage groups (Section 6.2.3), those with 8 or $10 \%$ guar gum (v/v) (Section 6.2.4), and those with additional biochar and/or basalt fines (Sections 6.2.5 - 6.2.7). The single-stage treatments are indicated by the prefix SS and the two-stage with the prefix TS. The 8 and $10 \%$ guar gum treatments are indicated by 8 and 10 . For example, the single-stage treatments with $8 \%$ guar gum are referred to in this chapter as SS-8. Occasionally, the guar gum treatments are referred to simply as the ' $8 \%$ treatments' or ' $10 \%$ treatments' for brevity.

\subsubsection{Weather conditions}

Throughout the six-week trial $\left(10^{\text {th }}\right.$ July $-29^{\text {th }}$ August 2018), hourly temperature monitoring provided 12 daytime temperatures and 12 night-time temperatures. The mean daytime temperature throughout the germination trial was $23.1^{\circ} \mathrm{C}$, which was $2.2{ }^{\circ} \mathrm{C}$ above the 1981-2010 long-term average (Met Office, 2018 ${ }^{1,3}$ ). July 2018 was the second warmest July since 1910. The mean night-time temperature was $16.9{ }^{\circ} \mathrm{C}$ (Figure 6.12). Sunshine was $138 \%$ of the long-term average (1981-2010, Met Office, $\left.2018^{1,3}\right)$.

A rain gauge recorded $123 \mathrm{~mm}$ of rainfall throughout the 42 days of the germination trial, which was $84 \%$ of the long-term average (1961 - 1990) in July and 100\% of the long-term average (1961 - 1990) in August (NRW, 2018 ${ }^{1,4}$ ). The soil moisture deficit for the Swansea area was $77-100 \mathrm{~mm}$ in July and $41-70 \mathrm{~mm}$ in August (NRW, $2018^{1,4}$ ), as averaged across the MORECS (Meteorological Office Rainfall and Evaporation Calculation System) square number 155. 


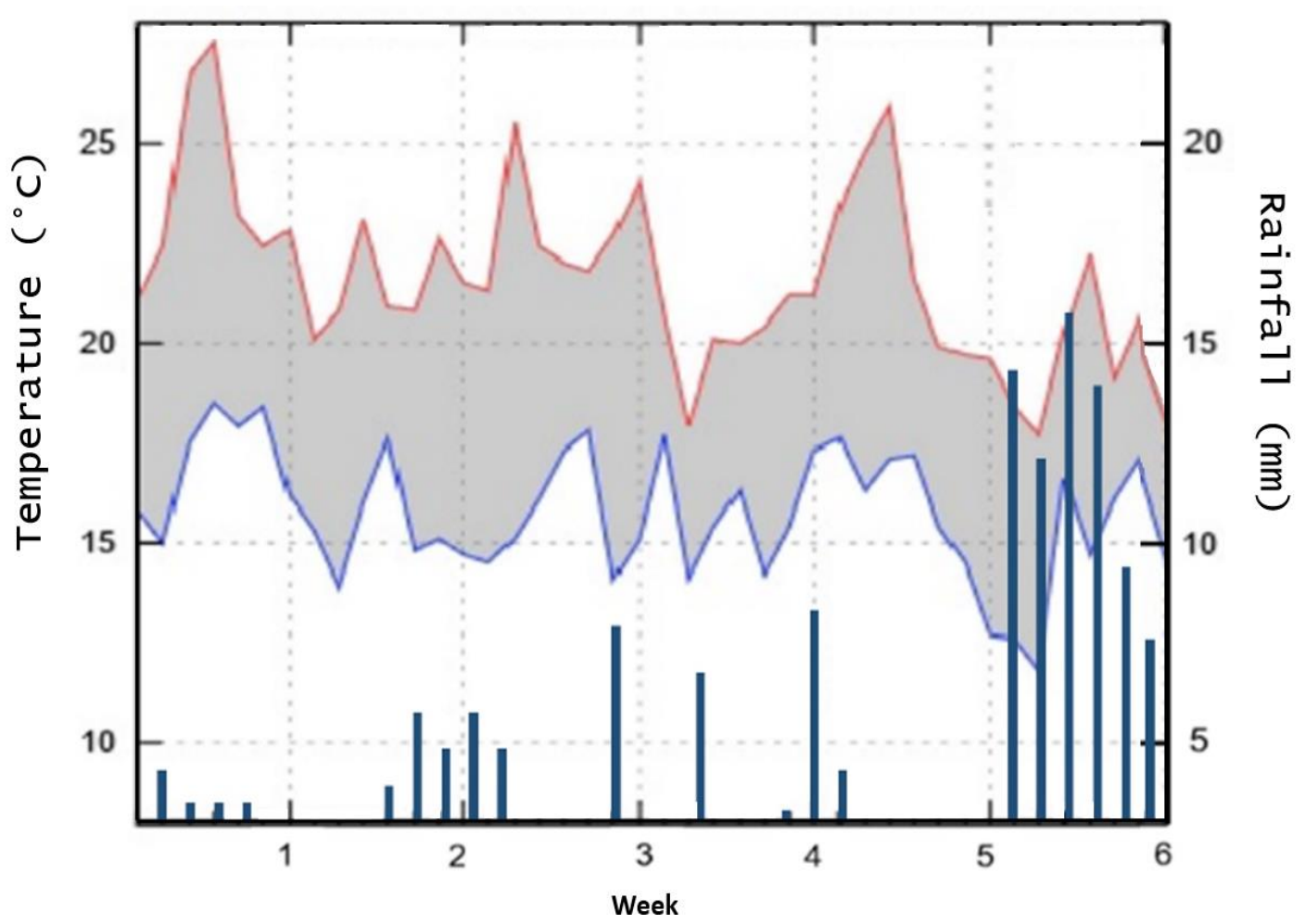

Figure 6.12: Rainfall (mm), maximum and minimum air temperatures $\left({ }^{\circ} \mathrm{C}\right)$ throughout the duration of the germination trial, July to August 2018.

\subsubsection{Overview of results}

A graphical summary of the data from each treatment are presented in Figures 6.13 6.15. The chapter commences with the comparison of the two-stage treatments $(n=200)$ and their single-stage counterparts $(n=200)$.

The soil treatments are also divided into $8 \%(\mathrm{n}=200)$ and $10 \%(\mathrm{n}=200)(\mathrm{v} / \mathrm{v})$ guar gum to evaluate the effects of differing proportions of guar gum on plant growth.

Finally, plant responses to the inclusion of biochar and/or basalt fines were investigated by comparison (ANOVA, $\mathrm{p} \leq 0.05$ ) with an unamended group that contained neither biochar nor basalt. All eight test soils were statistically compared throughout with a commercially available erosion control medium, Hydra CX (North American Green, 2018) which provided a benchmark of acceptable growth produced by the test surrogate soils. 


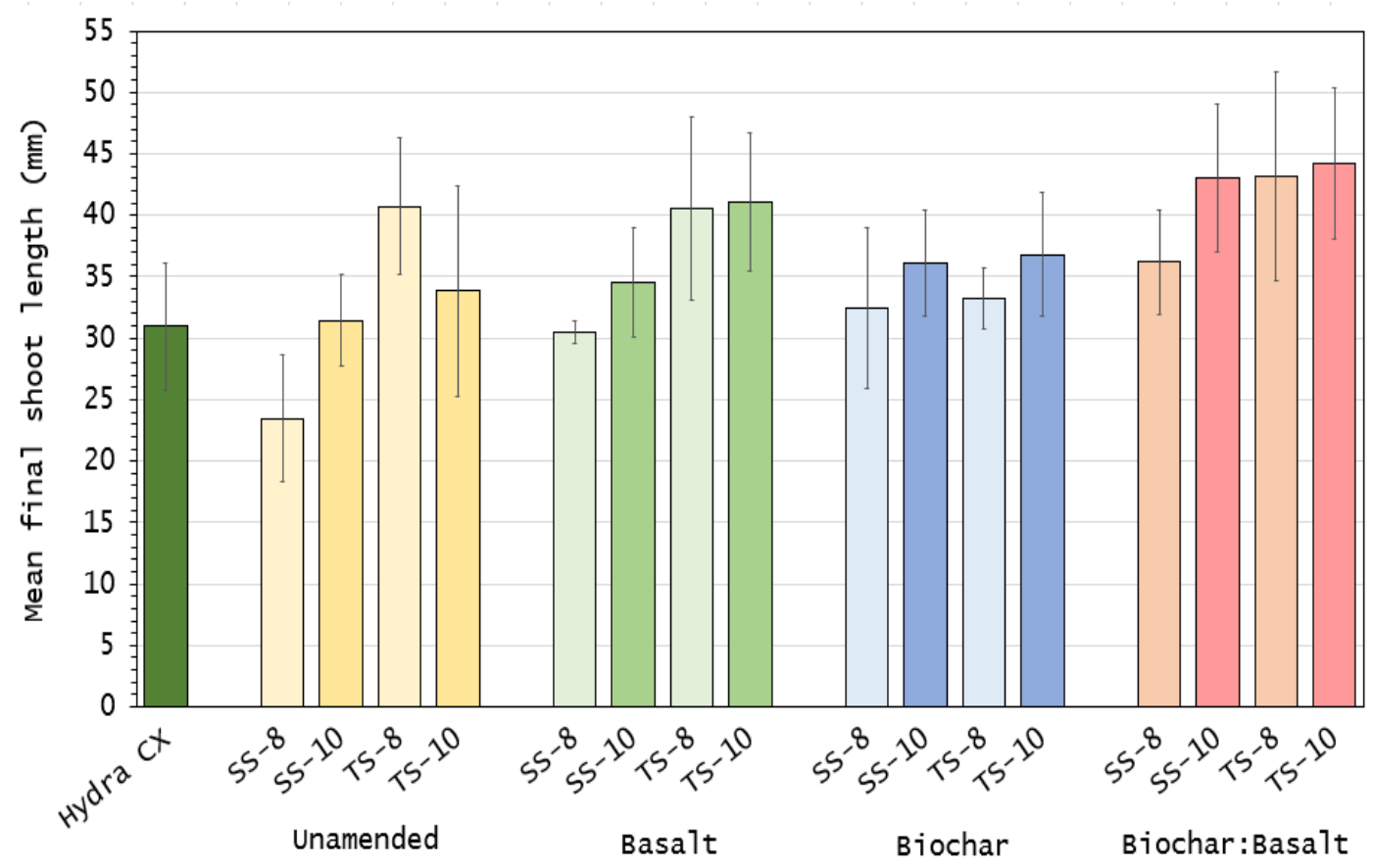

Figure 6.13: The mean final shoot length for all treatments $(\mathrm{mm})$ at the end of the six-week germination trial (August 2018). SS indicates a single-stage treatment. TS indicates a twostage treatment. 8 and 10 indicate the proportion of guar gum $(v / v)$ incorporated into the soil. The error bars represent the sample standard deviation.

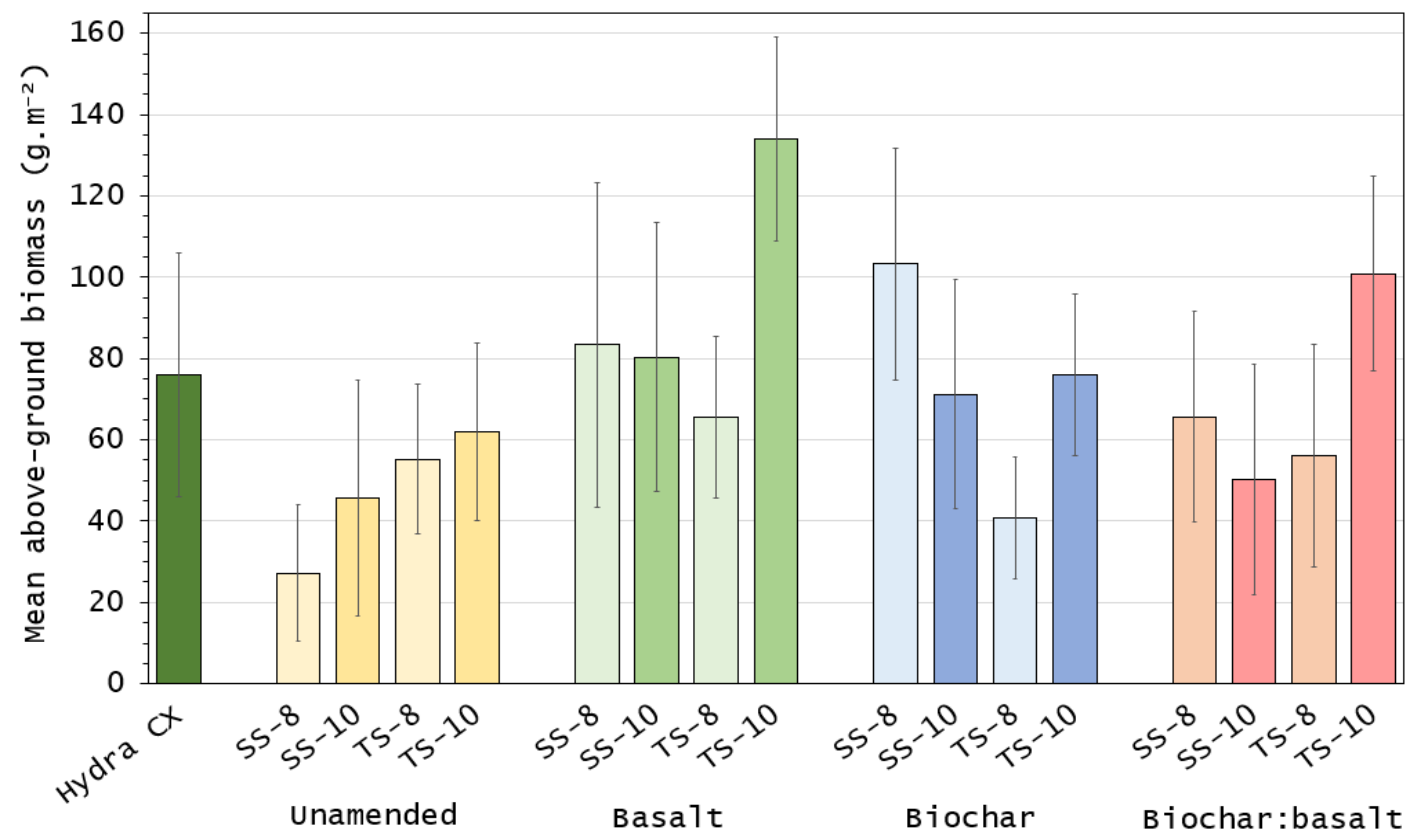

Figure 6.14: The mean above-ground biomass $\left(g . m^{-2}\right)$ at the end of the six-week germination trial (August 2018). SS indicates a single-stage treatment. TS indicates a two-stage treatment. 8 and 10 indicate the proportion of guar gum $(v / v)$ incorporated into the soil. The error bars represent the sample standard deviation. 


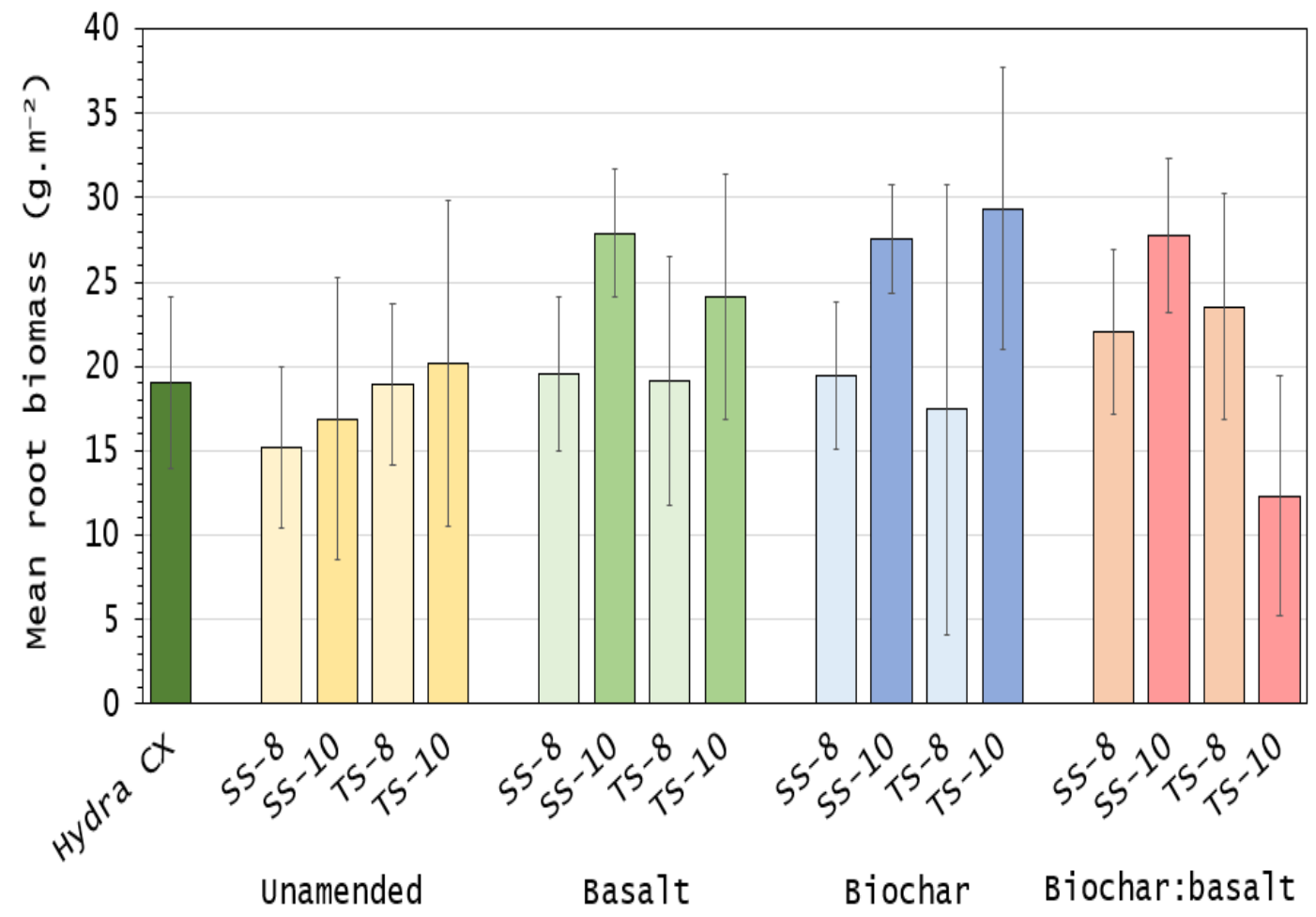

Figure 6.15: The mean root biomass $\left(\mathrm{g} . \mathrm{m}^{-2}\right)$ at the end of the six-week germination trial (August 2018). SS indicates a single-stage treatment. TS indicates a two-stage treatment. 8 and 10 indicate the proportion of guar gum $(v / v)$ incorporated into the soil. The error bars represent the sample standard deviation. 


\subsubsection{Single-stage and two-stage groups}

\subsubsection{Shoot length}

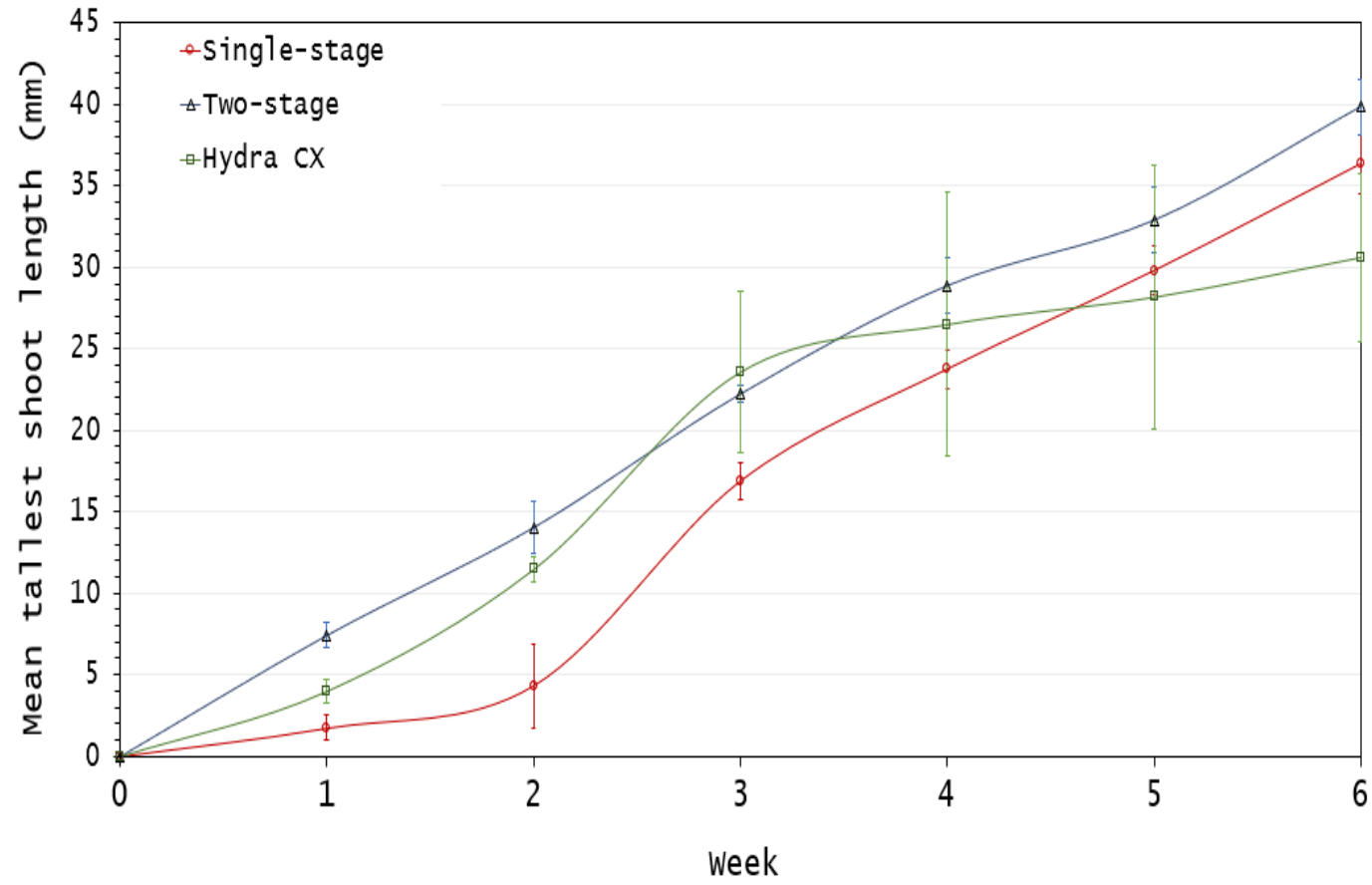

Figure 6.16: Mean tallest shoot length $(\mathrm{mm})$ in the single-stage, two-stage, and Hydra CX surrogate soil treatments throughout the germination trial (August 2018). The error bars represent the sample standard deviation. Single-stage (eight treatments, 25 replicates in each, $n=200$ ), Two-stage (eight treatments, 25 replicates in each, $n=200$ ) and Hydra $C X(n=25)$.

Table 6.6: The mean tallest shoot length $(\mathrm{mm})$ for each group, Single-stage (eight treatments of 25 replicates, $n=200$ ), Two-stage (eight treatments of 25 replicates, $n$ $=200$ ) and Hydra CX (one treatment, $n=25$ ), at the end of the six-week germination trial (August 2018). \pm indicates the sample standard deviation.

\begin{tabular}{cccccc}
\hline Group & $\mathrm{n}$ & $\begin{array}{c}\text { Mean } \\
(\mathrm{mm})\end{array}$ & $\begin{array}{c} \pm \\
(\mathrm{mm})\end{array}$ & $\begin{array}{c}\text { Min } \\
(\mathrm{mm})\end{array}$ & $\begin{array}{c}\text { Max } \\
(\mathrm{mm})\end{array}$ \\
\hline Single-stage & 200 & 36 & 8 & 24 & 46 \\
Two-stage & 200 & 39 & 6 & 19 & 65 \\
Hydra CX & 25 & 30 & 5 & 20 & 46 \\
\hline
\end{tabular}


Germination commenced uniformly across all 16 treatments, on either day four or five. When grouped, the grass produced by the TS treatments had a steadier growth trajectory than that of the SS and Hydra CX treatments. The grass in the Hydra CX treatment slowed in growth after week three and, compared to that of the test surrogate soils, the height began to plateau thereafter (Figure 16.6).

The mean shoot length in the TS treatments was significantly taller $(+11 \%, \mathrm{p} \leq 0.02)$ than that produced by the SS treatments and the Hydra CX $(+25 \%, \mathrm{p} \leq 0.01)$ (ANOVA: $\mathrm{F}[2,432]=14.46)($ Table 6.6 and Figure 6.17).

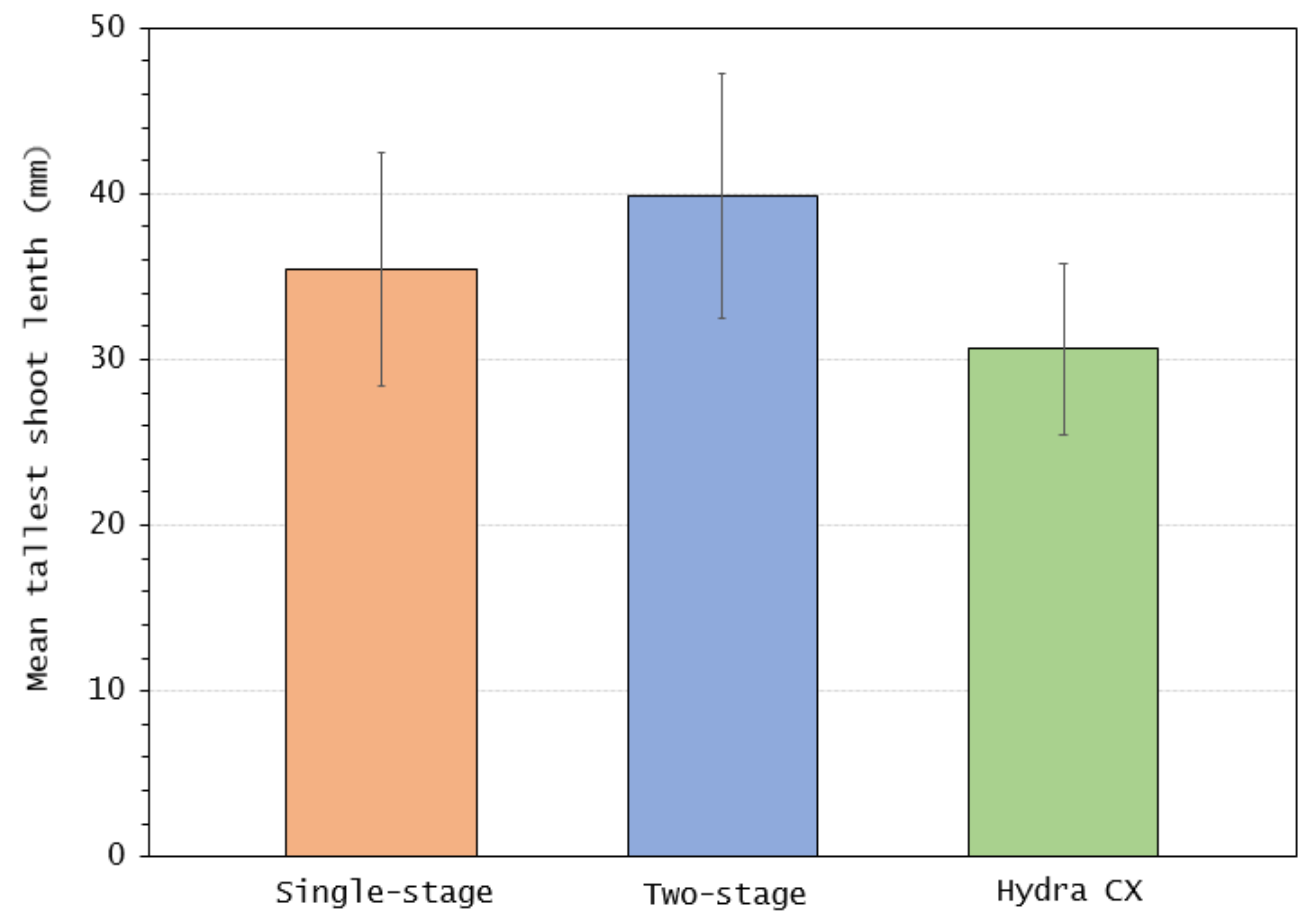

Figure 6.17: The mean final tallest shoot length $(\mathrm{mm})$ in each treatment group, at the end of the six-week germination trial (August 2018). Single-stage, $n=200$ (eight treatments, 25 replicates in each). Two-stage, $n=200$ (eight treatments, 25 replicates in each). Hydra $C X, n=25$ (one group). Error bars represent the sample standard deviation. 


\subsubsection{Above-ground biomass}

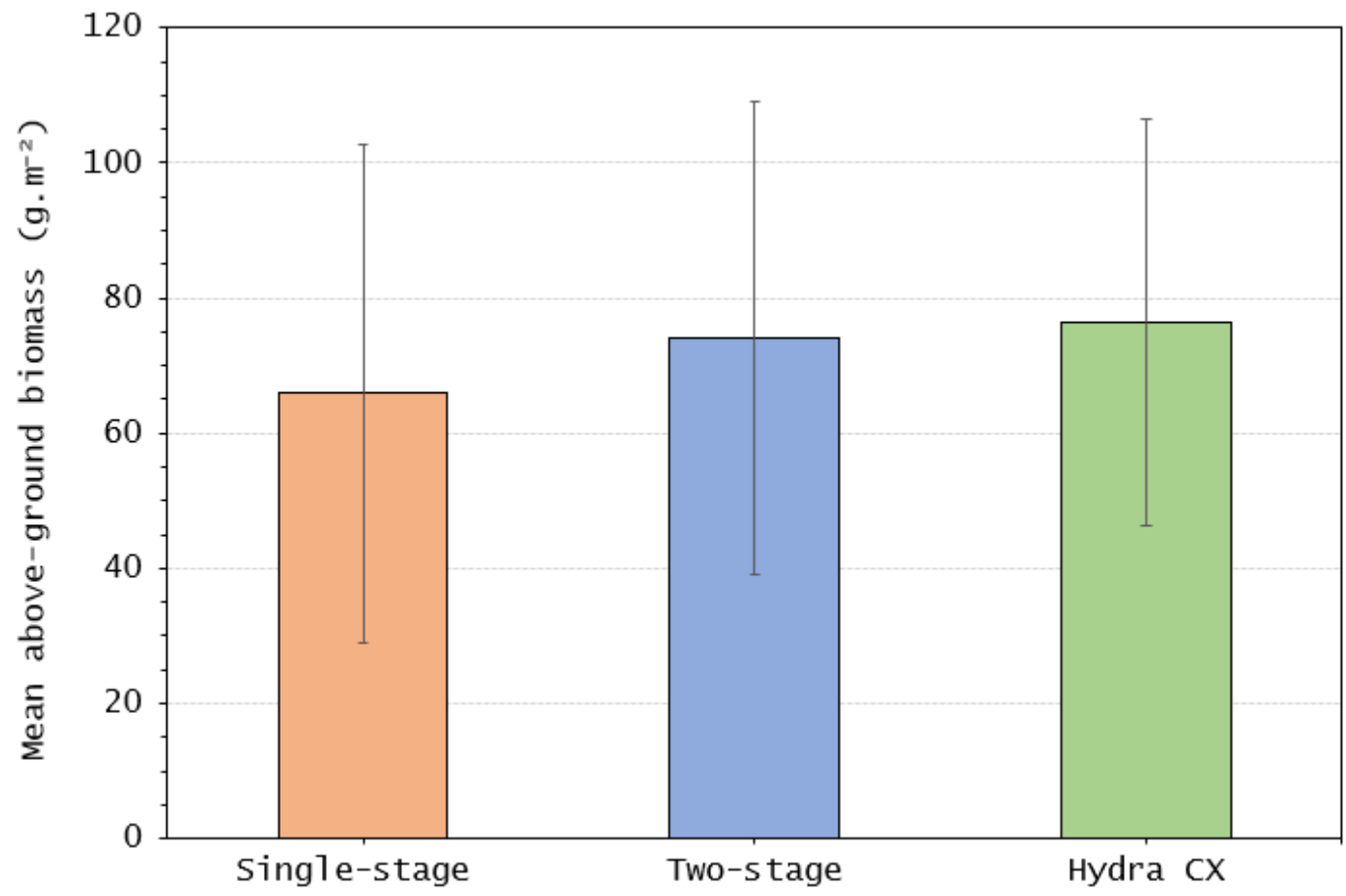

Figure 6.18: Mean above-ground biomass $\left(\mathrm{g} . \mathrm{m}^{-2}\right)$ produced by the treatment groups at the end of the six-week germination trial (August 2018). Single-stage, $n=200$. Twostage, $n=200$. Hydra CX, $n=25$. Error bars represent the sample standard deviation.

Table 6.7: The mean weight of the dried above-ground biomass $\left(\right.$ g. $\left.\mathrm{m}^{-2}\right)$, for each group, single-stage, two-stage, and Hydra CX, at the end of the six-week germination trial (August 2018). \pm refers to the sample standard deviation.

\begin{tabular}{cccccc}
\hline \hline Group & $\mathrm{n}$ & $\begin{array}{c}\text { Mean } \\
\left(\mathrm{g} . \mathrm{m}^{-2}\right)\end{array}$ & $\begin{array}{c} \pm \\
\left(\mathrm{g} . \mathrm{m}^{-2}\right)\end{array}$ & $\begin{array}{c}\text { Min } \\
\left(\mathrm{g} . \mathrm{m}^{-2}\right)\end{array}$ & $\begin{array}{c}\text { Max } \\
\left(\mathrm{g} . \mathrm{m}^{-2}\right)\end{array}$ \\
\hline Single-stage & 200 & 65.8 & 36.8 & 20.7 & 71.2 \\
Two-stage & 200 & 74.0 & 34.9 & 50.0 & 130.0 \\
Hydra CX & 25 & 76.4 & 29.5 & 12.5 & 100.0 \\
\hline
\end{tabular}


The grass was significantly taller in the TS group than the SS and Hydra CX groups, yet no pairwise differences $(\mathrm{p} \leq 0.05)$ existed in the mean volume of above-ground biomass produced by each group (ANOVA: F $[2,14]=0.196$ ) (Table 6.7 and Figure $6.18)$.

When the treatments were grouped in SS or TS categories, several differences between the individual treatments were hidden. While there were no differences in the mean of the pooled groups (eight groups in TS and eight in SS), significant differences were found between the means of individual groups. A T-test revealed the between treatment differences in biomass production, which were visually apparent in Figure 6.18.

The T-test determined that three of the eight TS treatments produced significantly more biomass than the equivalent SS treatment (Figure 6.14). These were the TS-8 unamended $(+68 \%, \mathrm{p} \leq 0.001, \mathrm{t}=5.42)$, TS-10 basalt $(+49 \%, \mathrm{p} \leq 0.001, \mathrm{t}=6.09)$ and the TS-10 biochar:basalt $(+67 \%, \mathrm{p} \leq 0.001), \mathrm{t}=6.45$.

One SS treatment produced significantly more biomass than its TS counterpart, the SS-8 biochar $(+67 \%, \mathrm{p} \leq 0.026, \mathrm{t}=2.29)$.

No significant differences existed in the other five treatment pairs. 


\subsubsection{Root biomass}

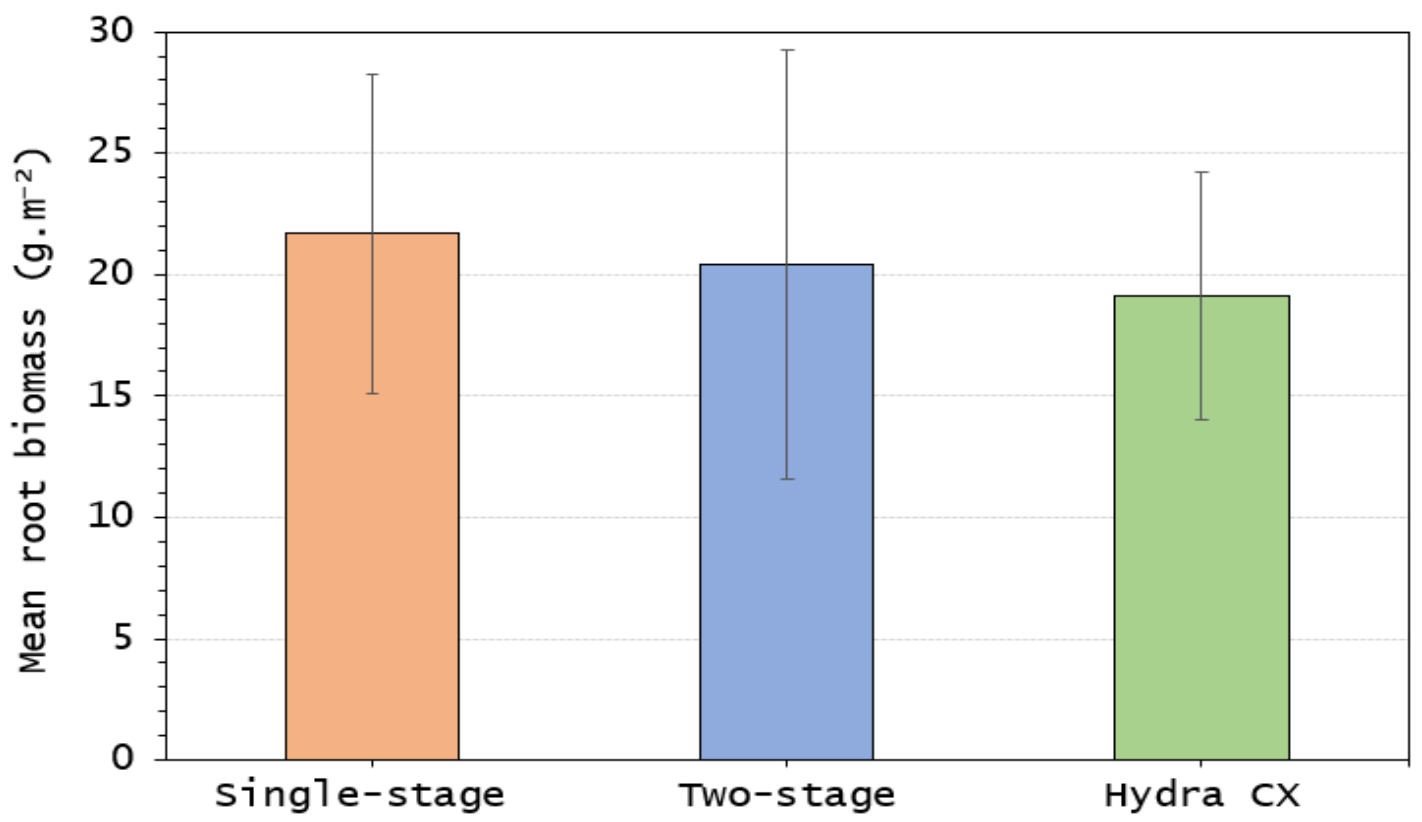

Figure 6.19: The mean root biomass $\left(\mathrm{g} . \mathrm{m}^{-2}\right)$ produced by each treatment group, single-stage, two-stage, and Hydra CX, at the end of the six-week germination trial (August 2018). Singlestage, $n=64$. Two-stage, $n=64$. Hydra $C X, n=8$. Error bars represent the sample standard deviation.

Table 6.8: The mean root biomass $\left(g^{.} \mathrm{m}^{-2}\right)$ for each group, single-stage, two-stage, and Hydra CX, at the end of the six-week germination trial (August 2018). \pm refers to the sample standard deviation.

\begin{tabular}{cccccc}
\hline \hline Group & $\mathrm{n}$ & $\begin{array}{c}\text { Mean } \\
\left(\mathrm{g} . \mathrm{m}^{-2}\right)\end{array}$ & $\begin{array}{c} \pm \\
\left(\mathrm{g} . \mathrm{m}^{-2}\right)\end{array}$ & $\begin{array}{c}\text { Min } \\
\left(\mathrm{g} . \mathrm{m}^{-2}\right)\end{array}$ & $\begin{array}{c}\text { Max } \\
\left(\mathrm{g} \cdot \mathrm{m}^{-2}\right)\end{array}$ \\
\hline Single-stage & 64 & 22.1 & 6.6 & 8.7 & 36.4 \\
Two-stage & 64 & 20.6 & 9.2 & 12.2 & 46.9 \\
Hydra CX & 8 & 19.0 & 4.6 & 12.5 & 26.3 \\
\hline
\end{tabular}

The SS group was composed of eight individual treatments $(n=64)$ as was the TS group $(n=64)($ Table 6.8).

When the treatments were grouped into SS and TS treatments, a one-way ANOVA indicated that no significant pairwise differences $(\mathrm{p} \leq 0.05)$ existed in the production of root biomass (Figure 6.19 and Table 6.8). 


\subsection{4 $8 \%$ and $10 \%(v / v)$ guar gum}

The results presented in this section detail the effects of differing proportions of guar gum on seedling emergence.

In this trial, half of the treatments contained $8 \%(\mathrm{v} / \mathrm{v})$ guar gum, and half contained $10 \%(\mathrm{v} / \mathrm{v})$. For each $8 \%$ treatment, a $10 \%$ counterpart treatment existed also, the only variable being the proportion of guar gum.

A one-way ANOVA with Tukeys post-hoc test was used to compare the means of the three groups, $8 \%$ guar (eight treatments of 25 replicates, $n=200$ ), 10\% guar (eight treatments of 25 replicates, $n=200$ ) and Hydra CX (one treatment of 25 replicates). The results of the shoot length, above-ground biomass and root biomass are presented.

\subsubsection{Shoot length}

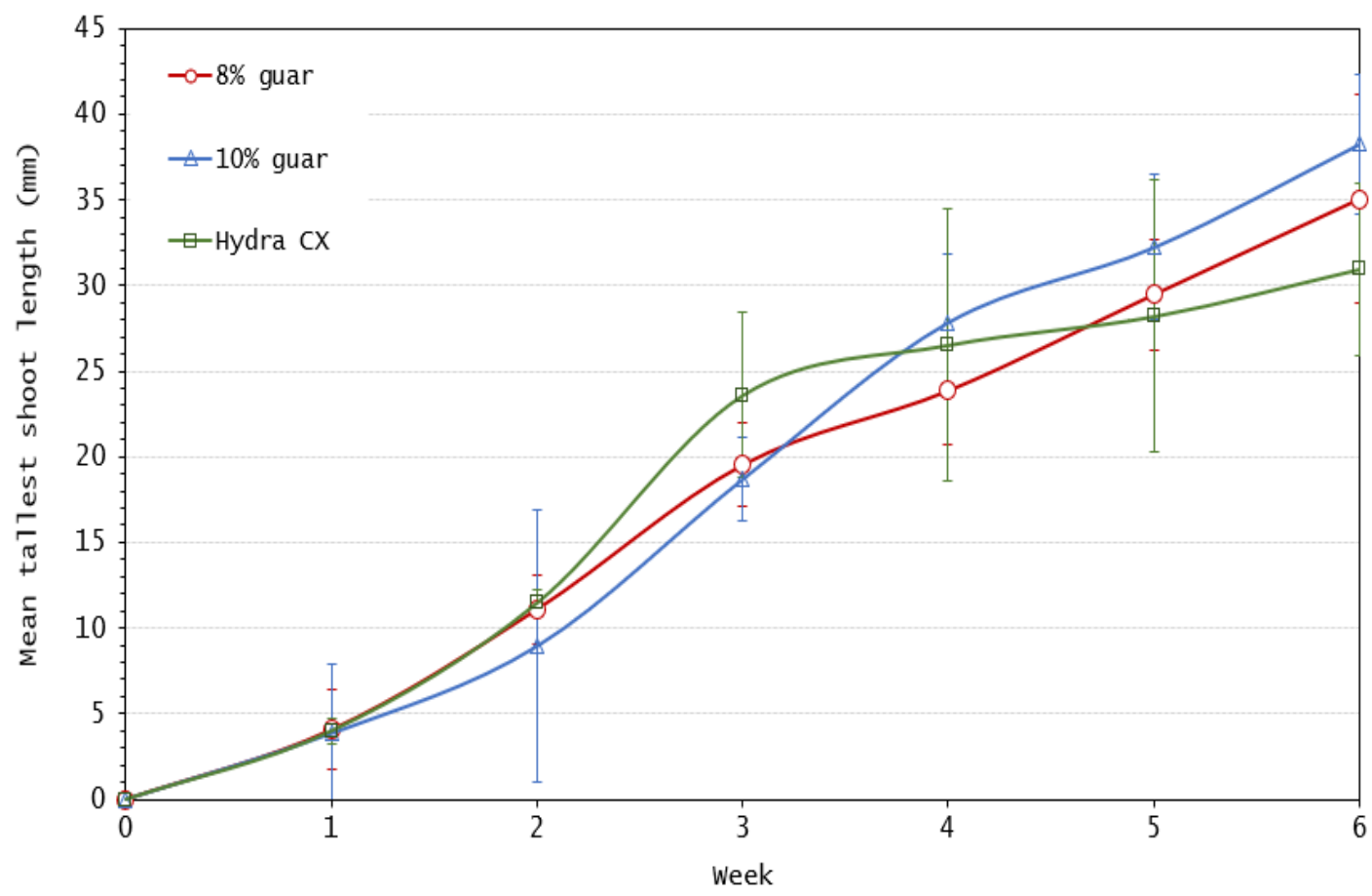

Figure 6.20: Mean tallest shoot length for the treatment groups, 8\% guar $(n=200), 10 \%$ guar $(n=200)$ and Hydra CX $(n=25)$ throughout the six-week germination trial (August 2018). The error bars represent the sample standard deviation. 


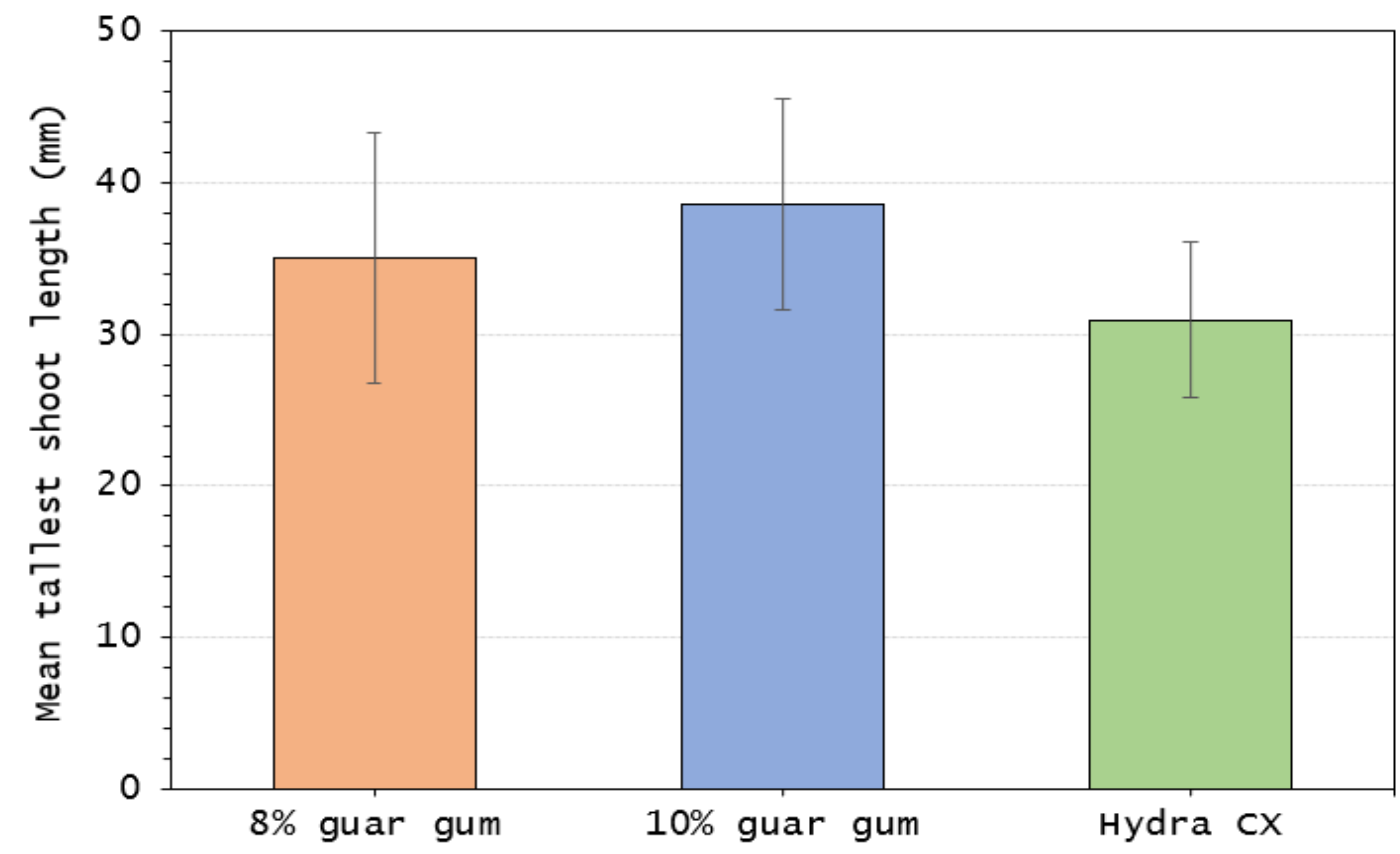

Figure 6.21: The mean final tallest shoot $(\mathrm{mm})$ produced by the treatment groups, $8 \%$ guar $(n=200), 10 \%$ guar $(n=200)$ and Hydra CX $(n=25)$ at the end of the six-week trial (August 2018). Error bars represent the sample standard deviation.

Table 6.9: The mean tallest shoot length $(\mathrm{mm})$ in each of the three treatment groups, $8 \%$ guar, $10 \%$ guar, and Hydra CX, at the end of the six-week germination trial (August 2018). \pm indicates the sample standard deviation.

\begin{tabular}{cccccc}
\hline \hline Group & $\mathrm{n}$ & $\begin{array}{c}\text { Mean } \\
(\mathrm{mm})\end{array}$ & $\begin{array}{c} \pm \\
(\mathrm{mm})\end{array}$ & $\begin{array}{c}\text { Min } \\
(\mathrm{mm})\end{array}$ & $\begin{array}{c}\text { Max } \\
(\mathrm{mm})\end{array}$ \\
\hline $8 \%$ guar & 200 & 35 & 8 & 15 & 66 \\
$10 \%$ guar & 200 & 38 & 7 & 19 & 60 \\
Hydra CX & 25 & 30 & 5 & 20 & 46 \\
\hline
\end{tabular}

When the treatments were grouped, the mean tallest shoot length of the grass in the $10 \%$ treatments was significantly higher $(+22 \%, \mathrm{p} \leq 0.001)$ at the end of the trial than that of the Hydra CX (ANOVA: F [2,432] = 14.46) (Table 6.9 and Figures 6.20 and $6.21)$. 


\subsubsection{Above-ground biomass}

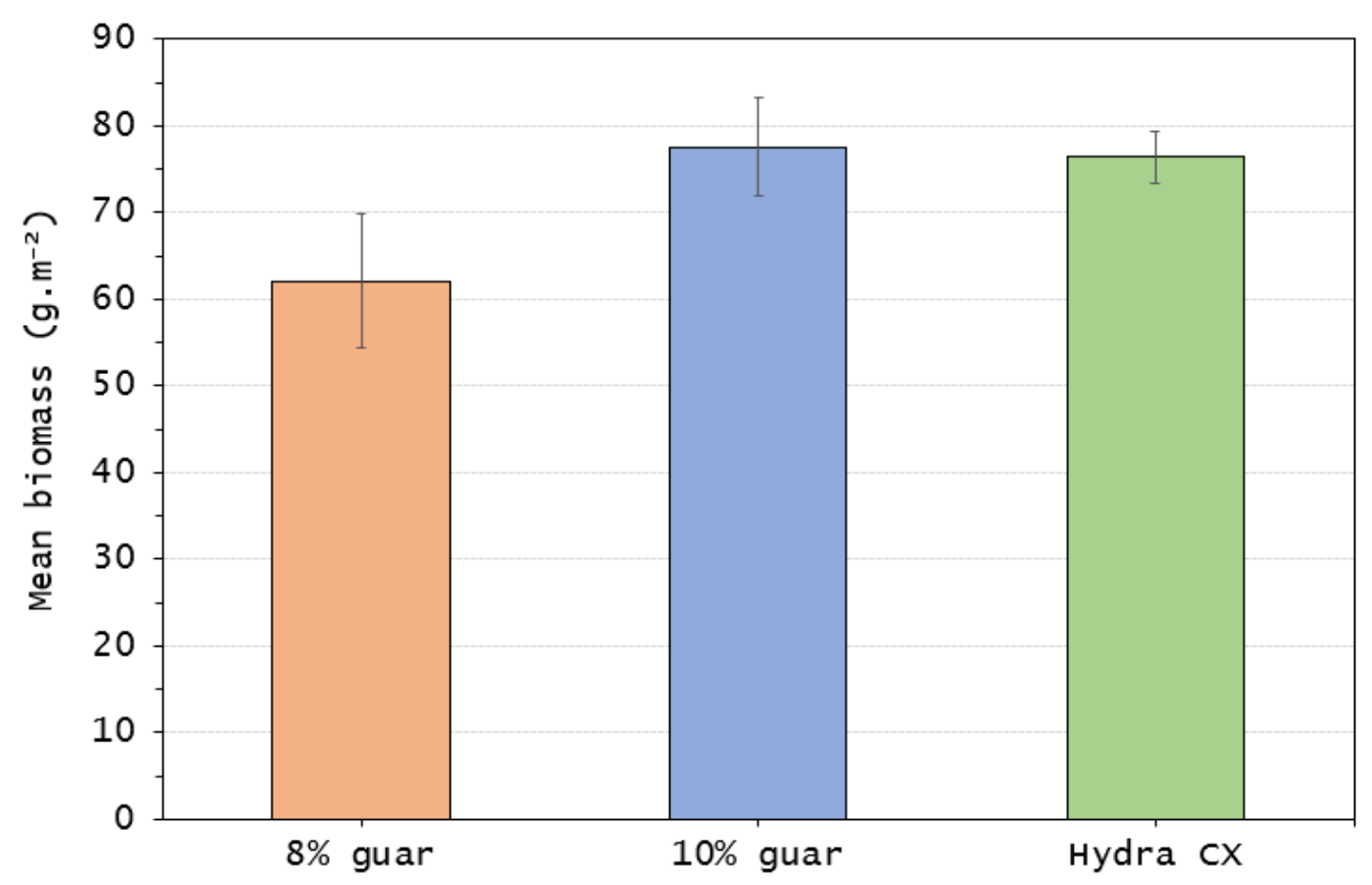

Figure 6.22: The mean above-ground biomass produced in the treatment groups, $8 \%$ guar $(n=200), 10 \%$ guar $(n=200)$ and Hydra CX $(n=25)$ at the end of the six-week germination trial (August 2018) Error bars represent the sample standard deviation.

Table 6.10: Mean weight $\left(g . \mathrm{m}^{-2}\right)$ of dried above-ground biomass that was produced by each treatment group, 8\% guar, 10\% guar, and Hydra CX, at the end of the six-week germination trial (August 2018). \pm indicates the sample standard deviation.

\begin{tabular}{cccccc}
\hline \hline Group & $\mathrm{n}$ & $\begin{array}{c}\text { Mean } \\
\left(\mathrm{g} . \mathrm{m}^{-2}\right)\end{array}$ & $\begin{array}{c} \pm \\
\left(\mathrm{g} \cdot \mathrm{m}^{-2}\right)\end{array}$ & $\begin{array}{c}\text { Min } \\
\left(\mathrm{g} \cdot \mathrm{m}^{-2}\right)\end{array}$ & $\begin{array}{c}\text { Max } \\
\left(\mathrm{g} . \mathrm{m}^{-2}\right)\end{array}$ \\
\hline $8 \%$ guar & 200 & 62.1 & 7.6 & 10 & 159 \\
$10 \%$ guar & 200 & 77.5 & 5.7 & 10 & 171 \\
Hydra CX & 25 & 76.4 & 3.0 & 21 & 130 \\
\hline
\end{tabular}


The Hydra CX soil produced 76.4 g.m $\mathrm{m}^{-2}$ of above-ground biomass (Table 6.10), significantly more than that of the $8 \%$ group $(\mathrm{p} \leq 0.029)$ (ANOVA: $\mathrm{F}[2,422]=3.23$ ) and comparable to that of the $10 \%$ group $\left(77.5 \mathrm{~g} \cdot \mathrm{m}^{-2}\right.$, Table 6.10$)$.

The addition of $10 \%$ guar gum had an overall positive effect on above-ground biomass yield (Figure 6.22). In five of the eight treatments, above-ground biomass was greater in the $10 \%$ treatment than in the $8 \%$ (Figures 6.23 and 6.24). As a group, this equated to a mean $22 \%$ increase $(\mathrm{p} \leq 0.028)$ compared produced by the $8 \%$ group.

Although the $10 \%$ guar treatments yielded taller shoots than that of the Hydra CX, the increased height did not translate to a greater quantity of above-ground biomass (Figures 6.21 and 6.22). Therefore, the $10 \%$ treatments produced taller stems but less ground cover than the Hydra CX. Visually, patchy growth can be seen in many of the $10 \%$ treatments when compared to Hydra CX, with some bare pots (Figures 6.24 and $6.25)$.

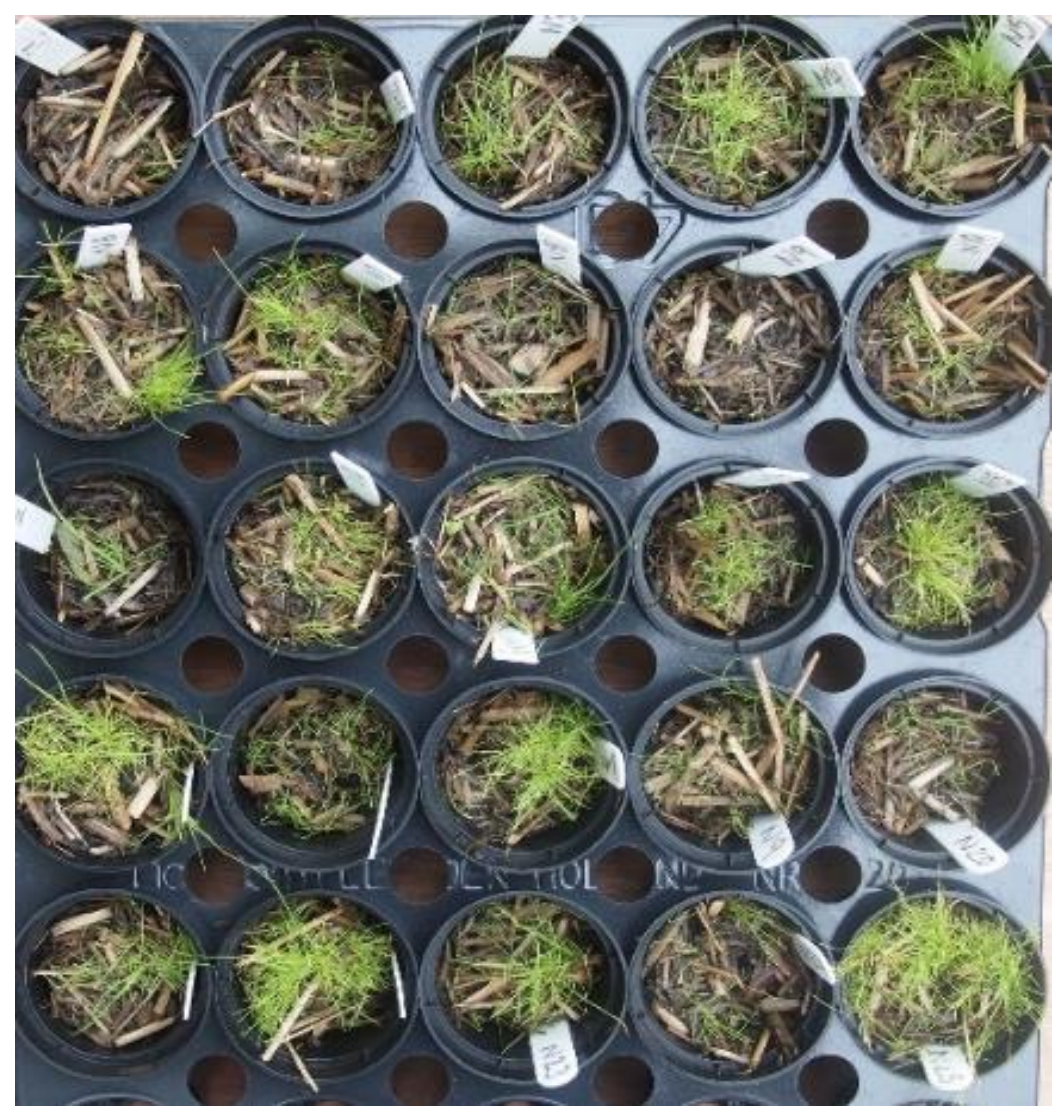

Figure 6.23: Two-stage, 8\% guar gum, with biochar and basalt, at week six 


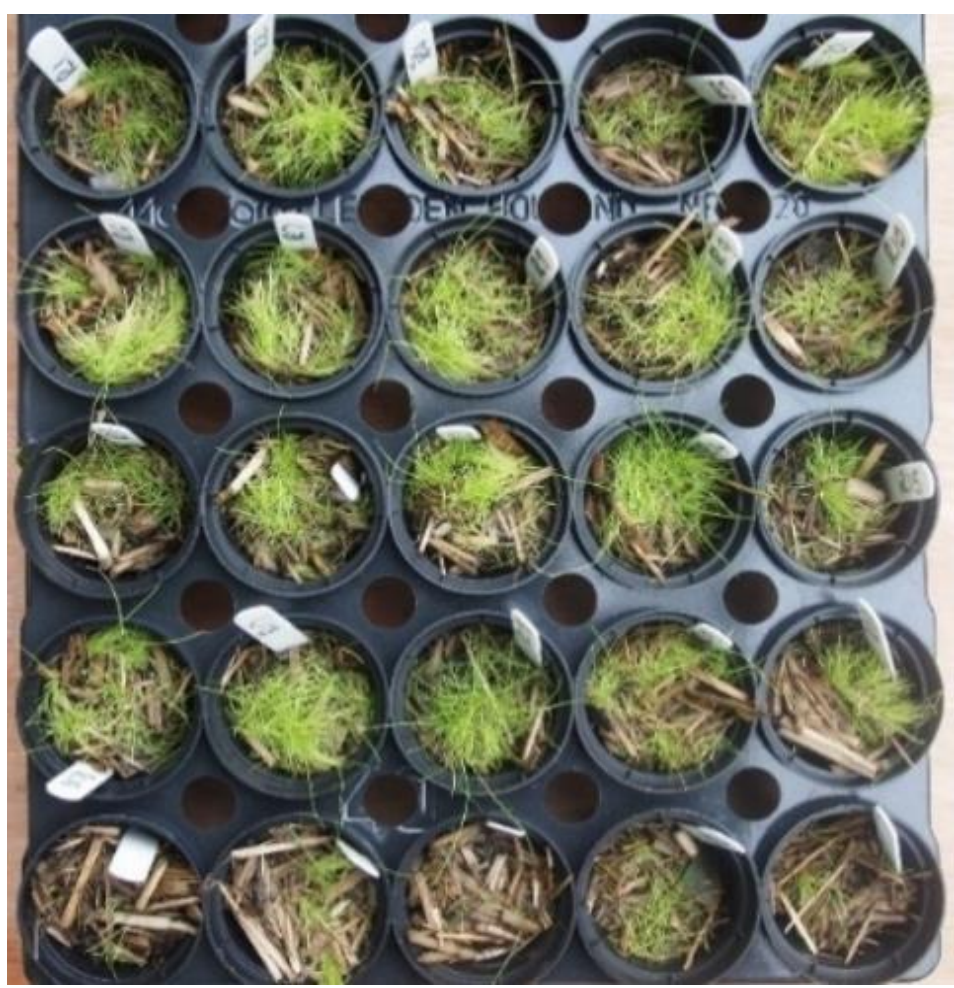

Figure 6.24: Two-stage, 10\% guar gum, with biochar and basalt, at week six

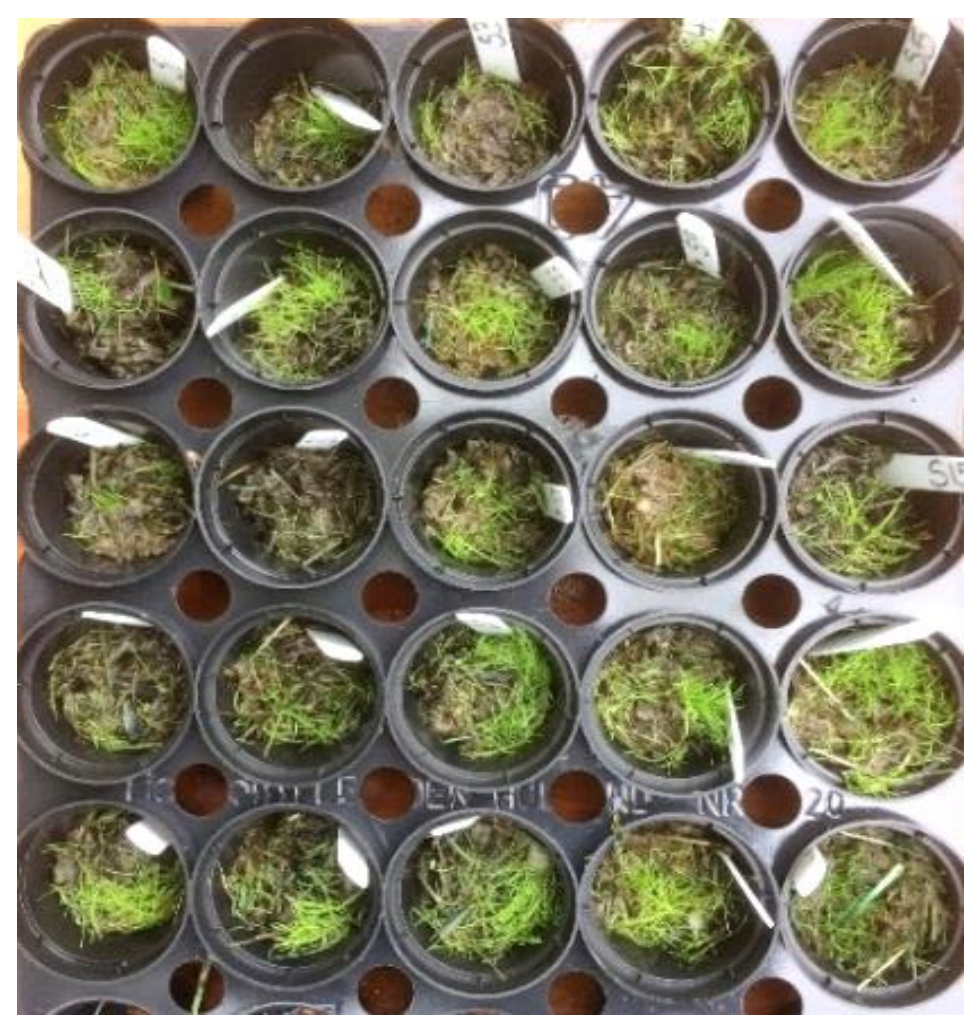

Figure 6.25: Hydra CX at week six 


\subsubsection{Root biomass}

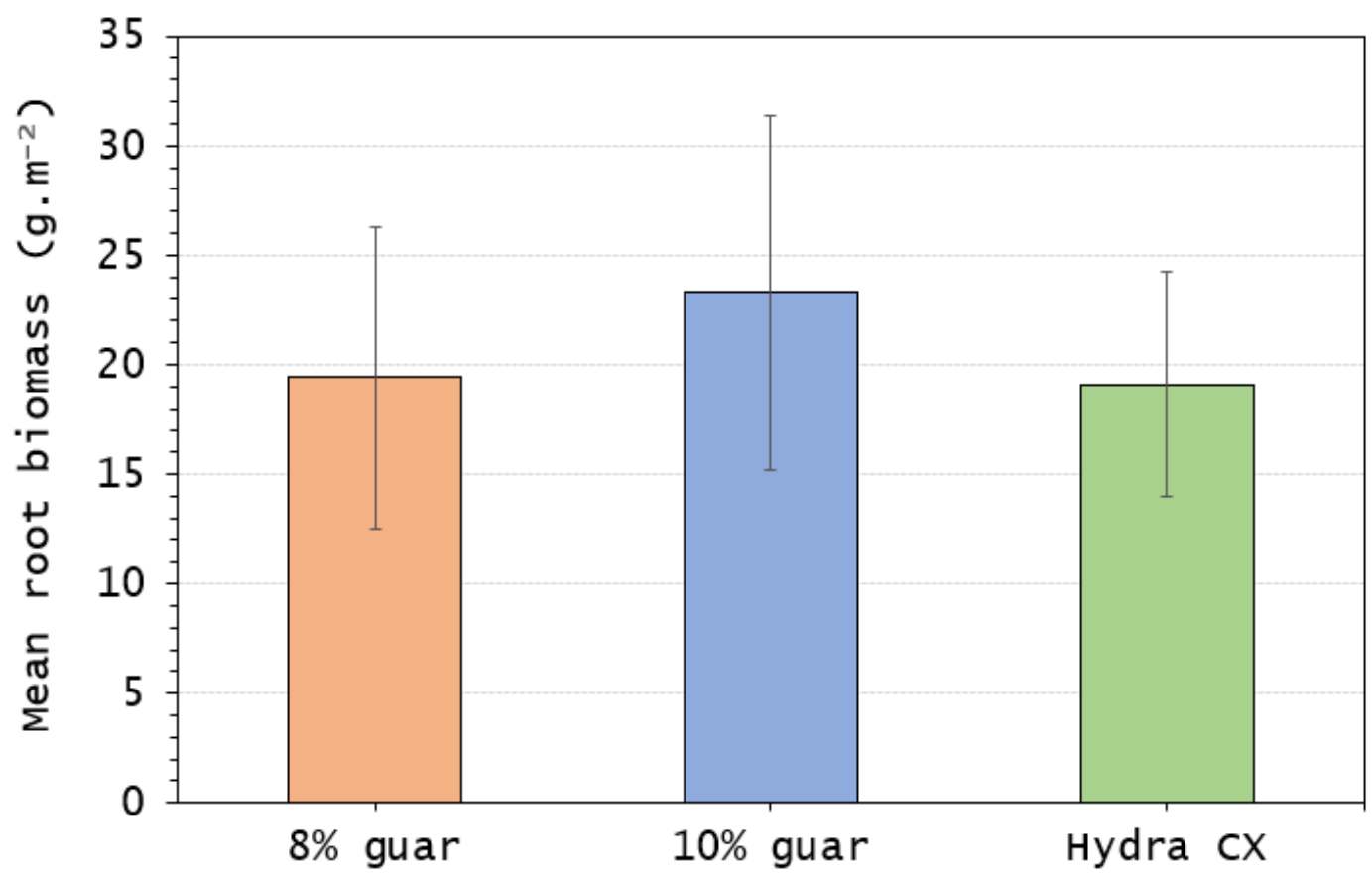

Figure 6.26: The mean root biomass $\left(\mathrm{g} \cdot \mathrm{m}^{-2}\right)$ produced by each treatment group, the $8 \%$ guar $(n=64)$, the 10\% guar $(n=64)$ and Hydra CX $(n=8)$ at the end of the six-week germination trial. Error bars represent the sample standard deviation.

Table 6.11: The mean root biomass that was produced in each of the three treatment groups, the 8\% guar group, the 10\% guar group, and Hydra CX at the end of the sixweek germination trial (August 2018). \pm indicates the sample standard deviation.

\begin{tabular}{cccccc}
\hline \hline Group & $\mathrm{n}$ & $\begin{array}{c}\text { Mean } \\
\left(\mathrm{g} . \mathrm{m}^{-2}\right)\end{array}$ & $\begin{array}{c} \pm \\
\left(\mathrm{g} \cdot \mathrm{m}^{-2}\right)\end{array}$ & $\begin{array}{c}\text { Min } \\
\left(\mathrm{g} \cdot \mathrm{m}^{-2}\right)\end{array}$ & $\begin{array}{c}\text { Max } \\
\left(\mathrm{g} \cdot \mathrm{m}^{-2}\right)\end{array}$ \\
\hline $8 \%$ & 64 & 19.4 & 6.9 & 1.2 & 46.9 \\
$10 \%$ & 64 & 23.3 & 8.1 & 18.2 & 44.4 \\
Hydra CX & 8 & 19.0 & 4.1 & 12.5 & 26.3 \\
\hline
\end{tabular}

In seven of the eight treatment pairs, the $10 \%$ guar gum treatments produced a greater quantity of root biomass than the 8\% (Table 6.11 and Figure 6.26). However, as a group, these differences were too small to be significant, and a one-way ANOVA reported no pairwise differences $(\mathrm{p} \leq 0.05)$ between groups in root biomass yield $(\mathrm{F}[2,333]=0.017)$. 


\subsubsection{Biochar}

In the following section, the 'biochar group' is composed of the four treatments which contained biochar but no other amendments (four treatments of 25 replicates, $n=100$ ).
i) Single-stage $8 \%$ with biochar
ii) Single-stage $10 \%$ with biochar
iii) Two-stage $8 \%$ with biochar
iv) Two-stage $10 \%$ with biochar

The 'unamended' group consists of the four unamended treatments with neither biochar nor basalt (four treatments of 25 replicates, $n=100$ ).

i) Single-stage $8 \%$ with no soil amendments

ii) Single-stage $10 \%$ with no soil amendments

iii) Two-stage $8 \%$ with no soil amendments

iv) Two-stage $10 \%$ with no soil amendments

The treatments which contained both biochar and basalt are discussed separately in section 6.2.7.

A one-way ANOVA with Tukey's post-hoc test $(\mathrm{p} \leq 0.05)$ was used to compare the means of the measured parameters of the three groups: the biochar group, the unamended group, and the Hydra CX $(\mathrm{n}=25)$. 


\subsubsection{Shoot length}

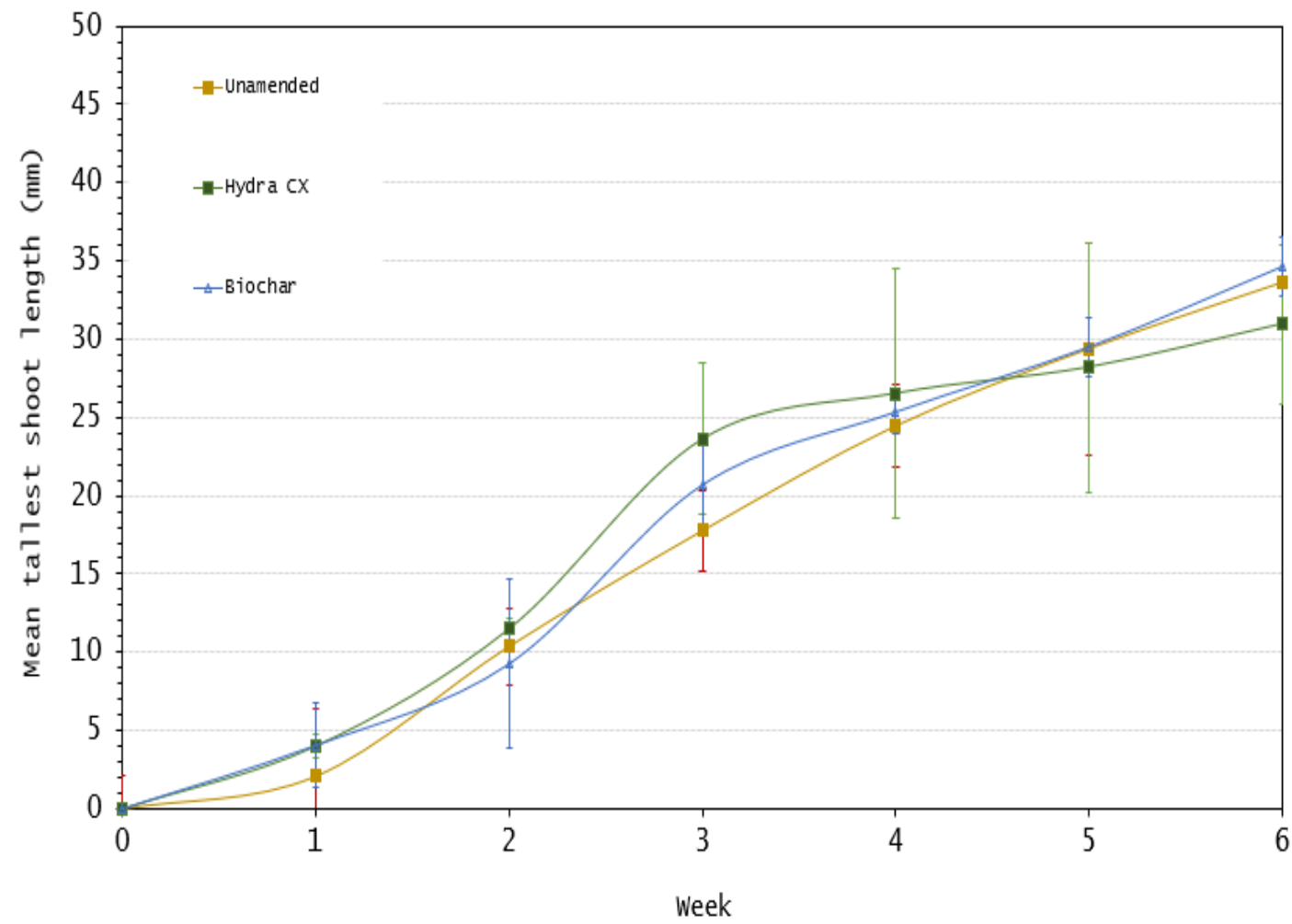

Figure 6.27: The mean final tallest shoot length $(\mathrm{mm})$ in the treatment groups, unamended $(n=100)$, biochar $(n=100)$ and Hydra $C X(n=25)$ throughout the six-week germination trial (August 2018). Error bars represent the sample standard deviation.

Table 6.12: The mean final tallest shoot length $(\mathrm{mm})$ in each of the three treatment groups, Hydra CX, the unamended treatments, and those that contained biochar, at the end of the six-week germination trial (August 2018). \pm refers to the sample standard deviation.

\begin{tabular}{cccccc}
\hline Group & $\mathrm{n}$ & $\begin{array}{c}\text { Mean } \\
(\mathrm{mm})\end{array}$ & $\begin{array}{c} \pm \\
(\mathrm{mm})\end{array}$ & $\begin{array}{c}\text { Min } \\
(\mathrm{mm})\end{array}$ & $\begin{array}{c}\text { Max } \\
(\mathrm{mm})\end{array}$ \\
\hline Hydra CX & 25 & 30 & 5 & 20 & 46 \\
Unamended & 100 & 34 & 8 & 15 & 50 \\
Biochar & 100 & 35 & 5 & 20 & 50 \\
\hline
\end{tabular}


Throughout the trial, rate of grass growth in the unamended treatments was similar to that of the biochar treatments (Figure 6.27). At the end of six weeks, both groups had produced grass of a similar mean tallest shoot length (Table 6.12).

Overall, the Hydra CX treatment produced slightly shorter grass than the test soils (30 mm, Table 6.12), however, a one-way ANOVA determined no significant pairwise differences $(\mathrm{p} \leq 0.05)$ in the final shoot lengths.

\subsubsection{Above-ground biomass}

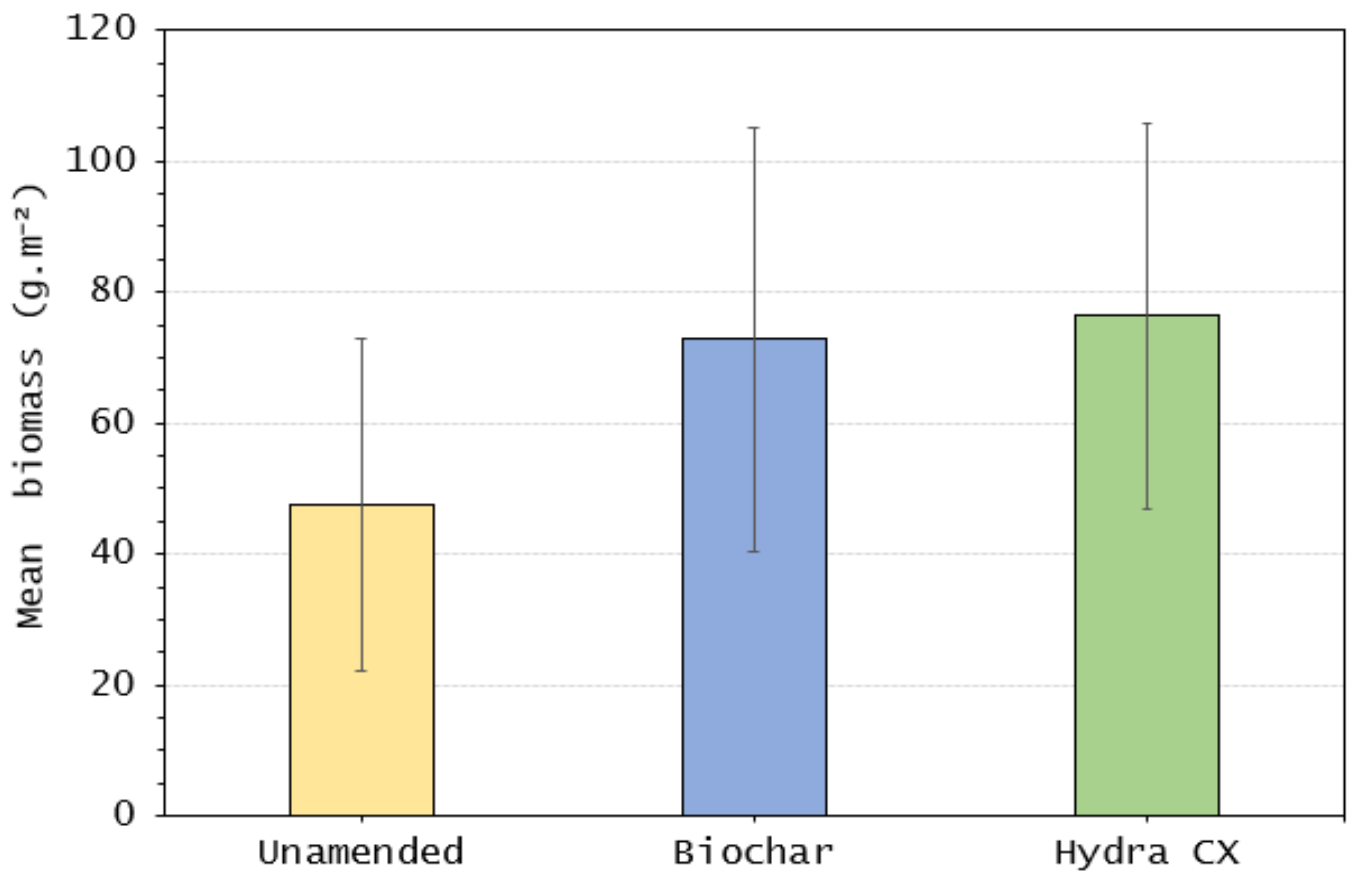

Figure 6.28: The mean above-ground biomass $\left(g . \mathrm{m}^{-2}\right)$ produced by the treatment groups, unamended $(n=100)$, biochar $(n=200)$ and Hydra $C X(n=25)$ groups in the six-week germination trial (August 2018). Error bars represent the sample standard deviation. 
Table 6.13: The mean weight of dried above-ground biomass $\left(g . \mathrm{m}^{-2}\right)$ for each of the treatment groups, Hydra CX, the unamended treatments, and those that contained biochar, and Hydra CX, at the end of the six-week germination trial (August 2018). \pm indicates the sample standard deviation.

\begin{tabular}{cccccc}
\hline \hline Group & $\mathrm{n}$ & Mean $\left(\mathrm{g} \cdot \mathrm{m}^{-2}\right)$ & \pm & Min & Max \\
\hline Hydra CX & 25 & 76.4 & 30.1 & 21 & 130 \\
Unamended & 100 & 47.5 & 25.6 & 10 & 131 \\
Biochar & 100 & 72.8 & 32.5 & 10 & 160 \\
\hline
\end{tabular}

The unamended surrogate soil treatment group produced significantly less biomass than both the biochar treatment group (a 42\% difference, $\mathrm{p} \leq 0.001$ ) and the Hydra CX (a 47\% difference, $\mathrm{p} \leq 0.001$ ) (ANOVA: F[2, 222] = 22.02) (Table 6.13 and Figure 6.28). The results confirm what can be seen visually, that the unamended treatments, overall, produced a far sparser coverage than those that contained biochar, and the Hydra CX soil (Figures 6.29-6.31).

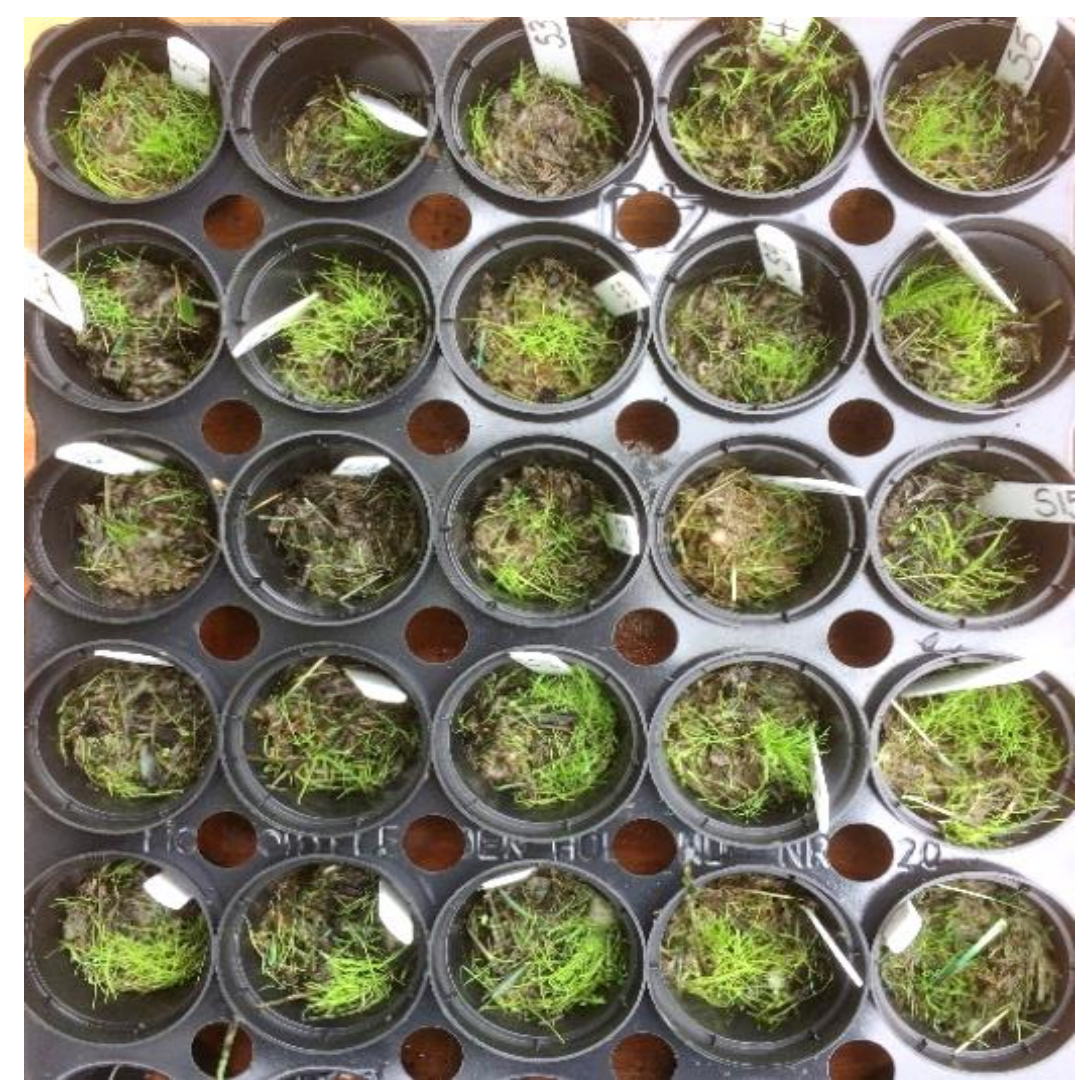

Figure 6.29: Grass growth in the Hydra CX soil at the end of the sixweek germination trial (August 2018) 


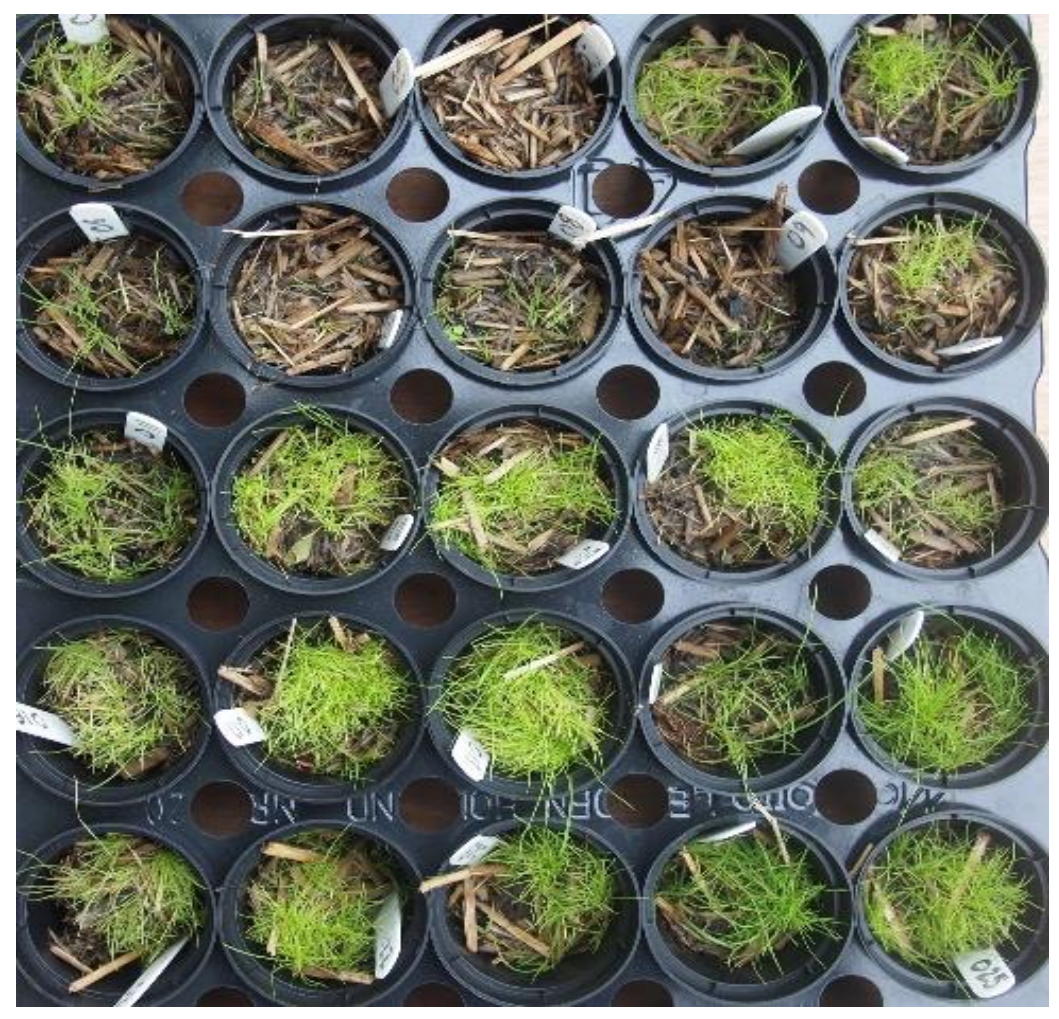

Figure 6.30: Grass growth in an unamended, two-stage, $10 \%$ guar treatment at the end of the six-week germination trial (August 2018)

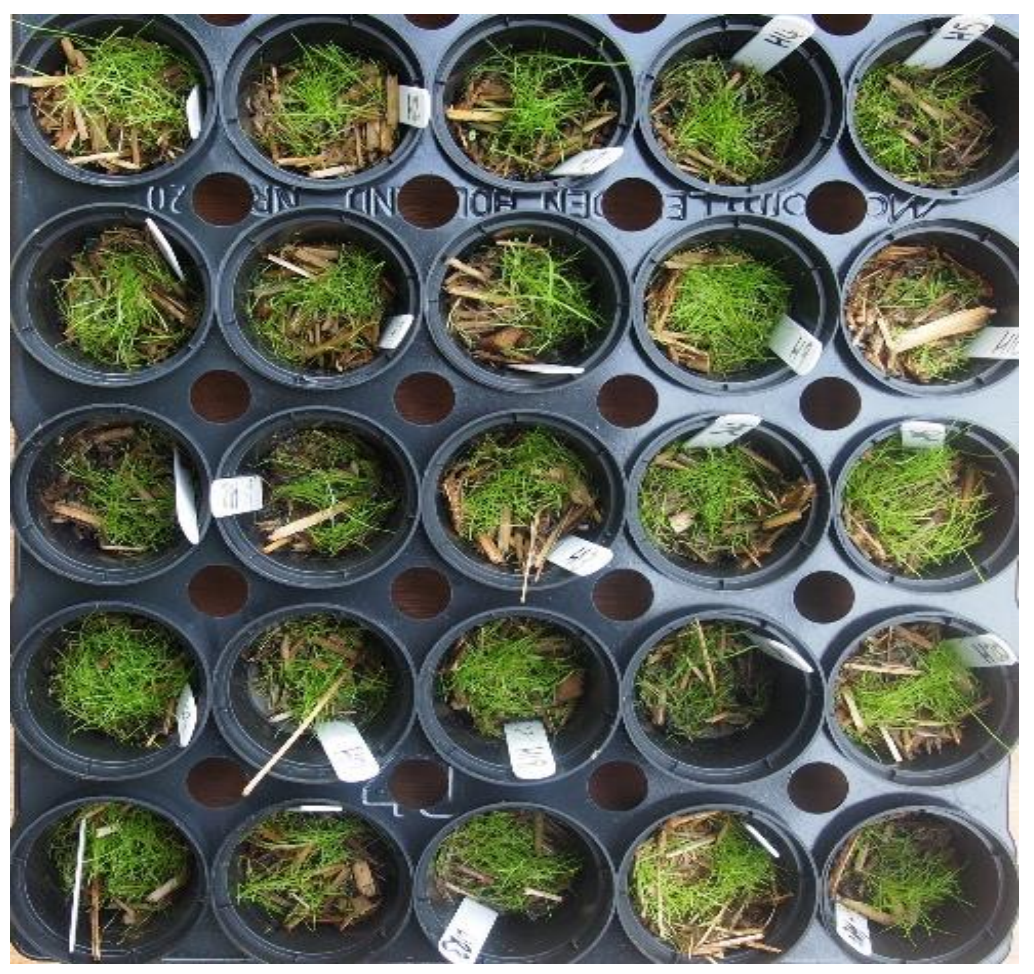

Figure 6.31: Grass growth in a biochar, two-stage, 10\% guar treatment at the end of the six-week germination trial (August 2018) 


\subsubsection{Root biomass}

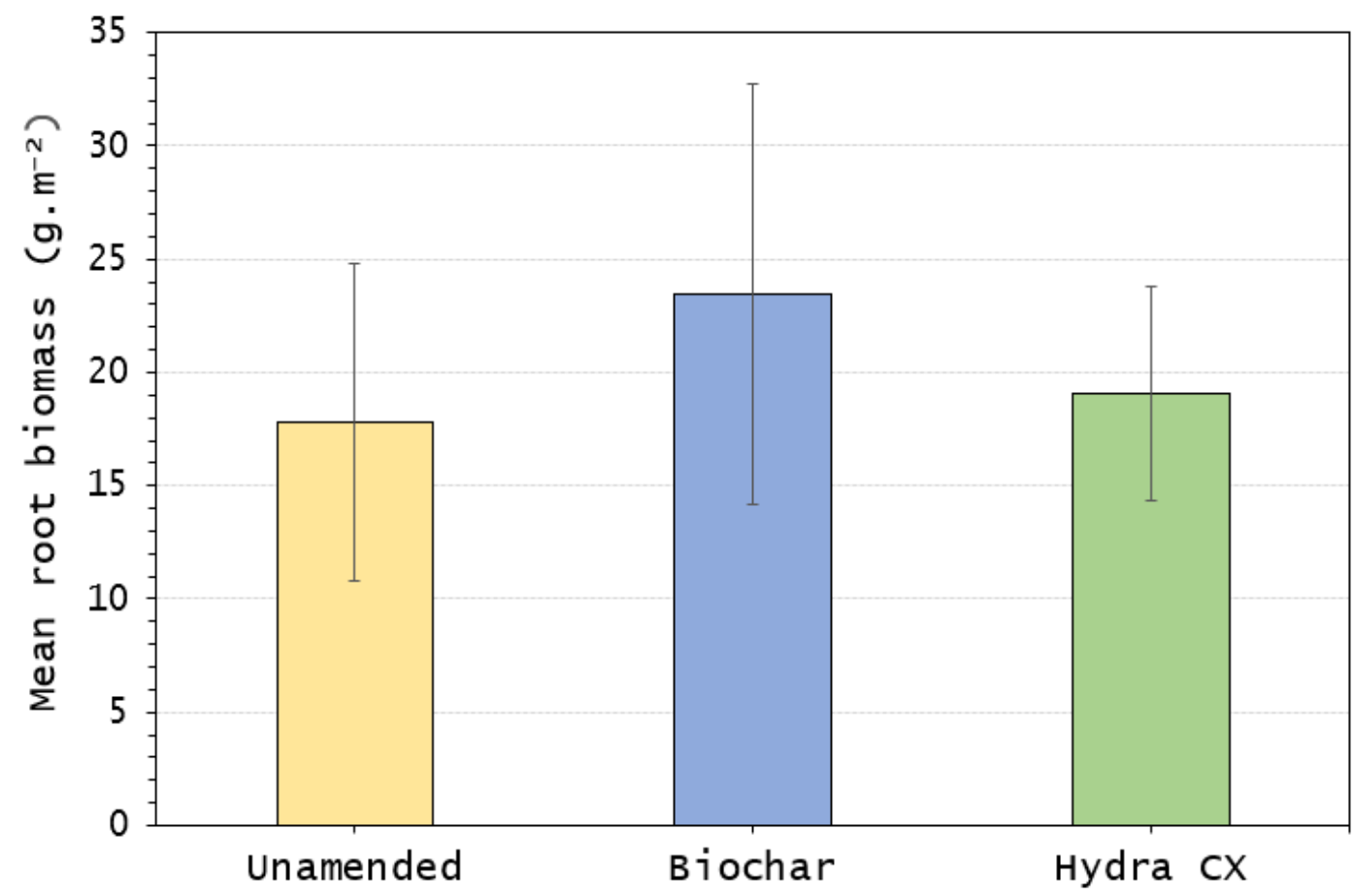

Figure 6.32: The mean root biomass $\left(g . m^{-2}\right)$ produced by each treatment group, unamended $(n=32)$, biochar $(n=32)$ and Hydra $C X(n=8)$ at the end of the six-week germination trial (August 2018). Error bars represent the sample standard deviation

Table 6.14: The mean weight of root biomass $\left(g . \mathrm{m}^{-2}\right)$ for each of the treatment groups, the Hydra CX, the unamended treatments, those that contained biochar, at the end of the six-week germination trial (August 2018). \pm indicates the sample standard deviation.

\begin{tabular}{cccccc}
\hline Group & $\mathrm{n}$ & $\begin{array}{c}\text { Mean } \\
\left(\mathrm{g} \cdot \mathrm{m}^{-2}\right)\end{array}$ & $\begin{array}{c} \pm \\
\left(\mathrm{g} \cdot \mathrm{m}^{-2}\right)\end{array}$ & $\begin{array}{c}\text { Min } \\
\left(\mathrm{g} \cdot \mathrm{m}^{-2}\right)\end{array}$ & $\begin{array}{c}\text { Max } \\
\left(\mathrm{g} \cdot \mathrm{m}^{-2}\right)\end{array}$ \\
\hline Hydra CX & 8 & 19.0 & 4.1 & 12.5 & 26.3 \\
Unamended & 32 & 17.8 & 7.1 & 8.7 & 39.9 \\
Biochar & 32 & 23.4 & 9.4 & 1.2 & 46.9 \\
\hline
\end{tabular}


The unamended soil treatments produced not only less above-ground biomass than the biochar amended soils and the Hydra CX, but also less below-ground biomass (Table 6.14 and Figure 6.32).

Overall, the biochar treatments yielded a significantly greater quantity of root biomass than those without ( $\mathrm{p} \leq 0.018$, ANOVA: $\mathrm{F}[2,69]=4.04)$. However, in the biochar soils, a large variance in root biomass was seen $\left(1.2 \mathrm{~g} \cdot \mathrm{m}^{-2}-46.9 \mathrm{~g} \cdot \mathrm{m}^{-2}\right.$, Table 6.14$)$.

No pairwise differences were found between the biochar treatments and the Hydra CX.

\subsubsection{Basalt}

In the following section, the basalt group was composed of the four treatments which contained basalt as the only amendment (four treatments of 25 replicates, $n=100$ ).

i) Single-stage $8 \%$ with basalt

ii) Single-stage $10 \%$ with basalt

iii) Two-stage $8 \%$ with basalt

iv) Two-stage $10 \%$ with basalt

The treatments with both basalt and biochar are discussed in Section 6.2.7.

A one-way ANOVA was used to determine the effects of the inclusion of basalt, as compared with the unamended group, the biochar group, and the Hydra CX. 


\subsubsection{Shoot length}

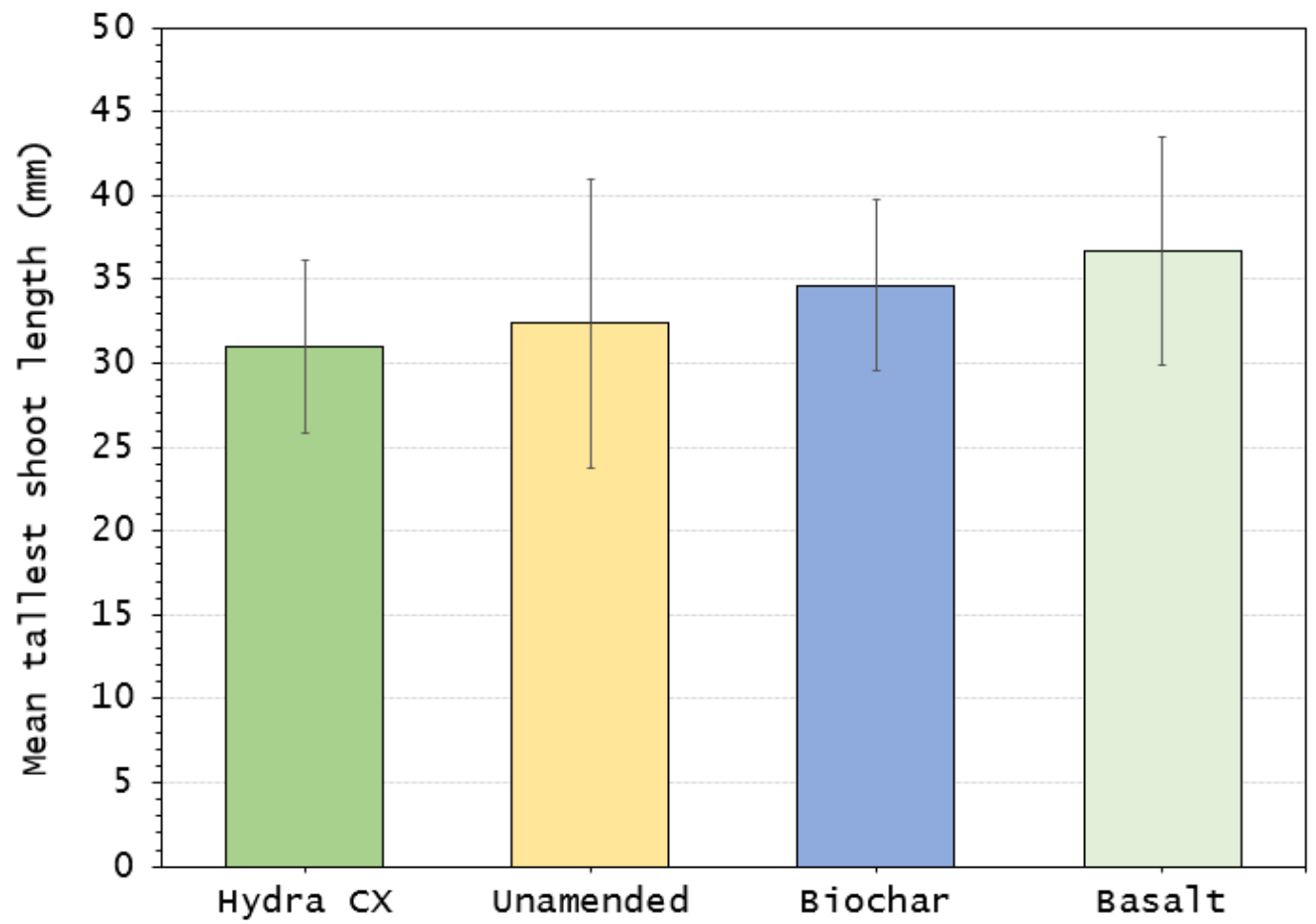

Figure 6.33: The mean tallest shoot $(\mathrm{mm})$ produced by the treatment groups, unamended $(n=100)$, biochar $(n=100)$, basalt $(n=100)$ and Hydra CX $(n=25)$, throughout the six-week germination trial (August 2018). Error bars represent the sample standard deviation.

Table 6.15: The mean final shoot length ( $\mathrm{mm}$ ) for the treatment groups, the Hydra CX, the unamended treatments, those that contained biochar, and those than contained basalt, at the end of the six-week germination trial (August 2018). \pm indicates the sample standard deviation.

\begin{tabular}{cccccc}
\hline \hline Group & $\mathrm{n}$ & $\begin{array}{c}\text { Mean } \\
(\mathrm{mm})\end{array}$ & $\begin{array}{c} \pm \\
(\mathrm{mm})\end{array}$ & $\begin{array}{c}\text { Min } \\
(\mathrm{mm})\end{array}$ & $\begin{array}{c}\text { Max } \\
(\mathrm{mm})\end{array}$ \\
\hline Hydra CX & 25 & 30 & 5 & 20 & 46 \\
Unamended & 100 & 32 & 8 & 15 & 50 \\
Biochar & 100 & 35 & 8 & 20 & 50 \\
Basalt & 100 & 37 & 6 & 29 & 60 \\
\hline
\end{tabular}


The final mean shoot length of the grass produced by the basalt treatments was, when grouped, significantly larger than that of the unamended group $(\mathrm{p} \leq 0.002)$ and the Hydra CX treatment $(\mathrm{p} \leq 0.002)$ (ANOVA: F $[2,222]=10.8)$. The addition of basalt produced a comparable mean shoot length to that of the biochar group, with no significant pairwise differences (Figure 6.33).

\subsubsection{Above-ground biomass}

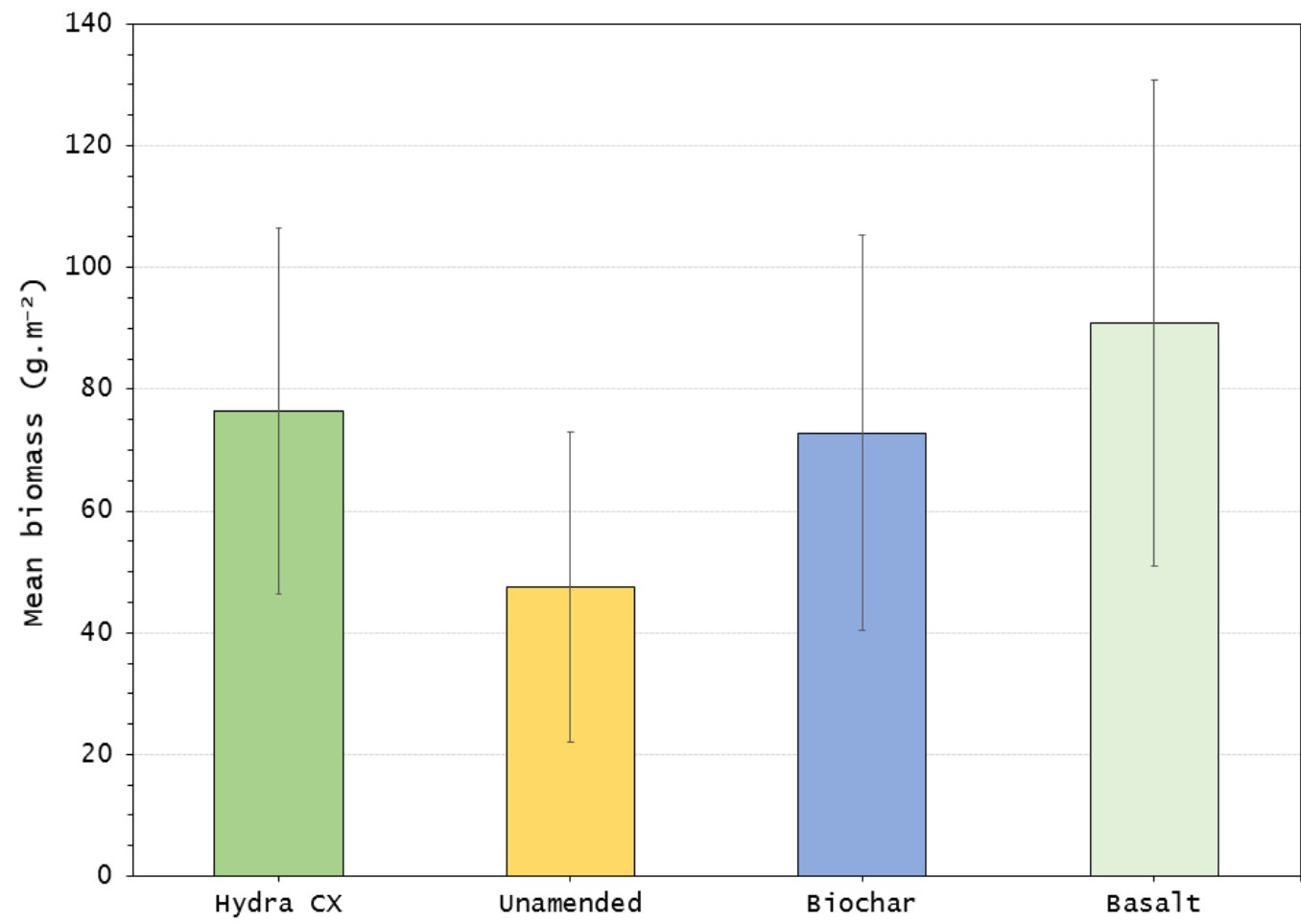

Figure 6.34: Mean above-ground biomass produced in the treatment groups, Hydra $C X(n=25)$, unamended $(n=100)$, biochar $(m=100)$, and basalt $(n=100)$ at the end of the six-week germination trial. Error bars represent the sample standard deviation. 
Table 6.16: The mean weight of dried above-ground biomass $\left(g . m^{-2}\right)$ for each of the treatment groups, the Hydra CX, the unamended treatments, those that contained biochar, and those than contained basalt, at the end of the six-week germination trial (August 2018). \pm indicates the sample standard deviation.

\begin{tabular}{cccccc}
\hline \hline Group & $\mathrm{n}$ & $\begin{array}{c}\text { Mean } \\
\left(\mathrm{g} . \mathrm{m}^{-2}\right)\end{array}$ & $\begin{array}{c} \pm \\
\left(\mathrm{g} \cdot \mathrm{m}^{-2}\right)\end{array}$ & $\begin{array}{c}\text { Min } \\
\left(\mathrm{g} \cdot \mathrm{m}^{-2}\right)\end{array}$ & $\begin{array}{c}\text { Max } \\
\left(\mathrm{g} . \mathrm{m}^{-2}\right)\end{array}$ \\
\hline Hydra CX & 25 & 76.4 & 30.1 & 21 & 130 \\
Unamended & 100 & 47.5 & 25.6 & 10 & 131 \\
Biochar & 100 & 72.8 & 32.5 & 10 & 160 \\
Basalt & 100 & 90.7 & 39.9 & 10 & 170 \\
\hline
\end{tabular}

A one-way ANOVA with a Tukey's post-hoc test confirmed that the basalt treatment group outperformed the unamended treatments by a large margin (a mean 62\% difference, $\mathrm{p} \leq 0.002$ ) (Table 6.16 and Figure 6.34). The soils which contained basalt also produced, on average, significantly more biomass than the Hydra CX treatments $(17 \%, \mathrm{p} \leq 0.008)$ and the biochar treatment group $(23 \%, \mathrm{p} \leq 0.008)(\mathrm{F}[3,420]=$ 18.38).

Overall, the basalt groups produced a greater quantity of grass which was also taller than the other treatment groups, thereby creating more ground cover. This can also be confirmed visually (Figures $6.35-6.37$ ). 


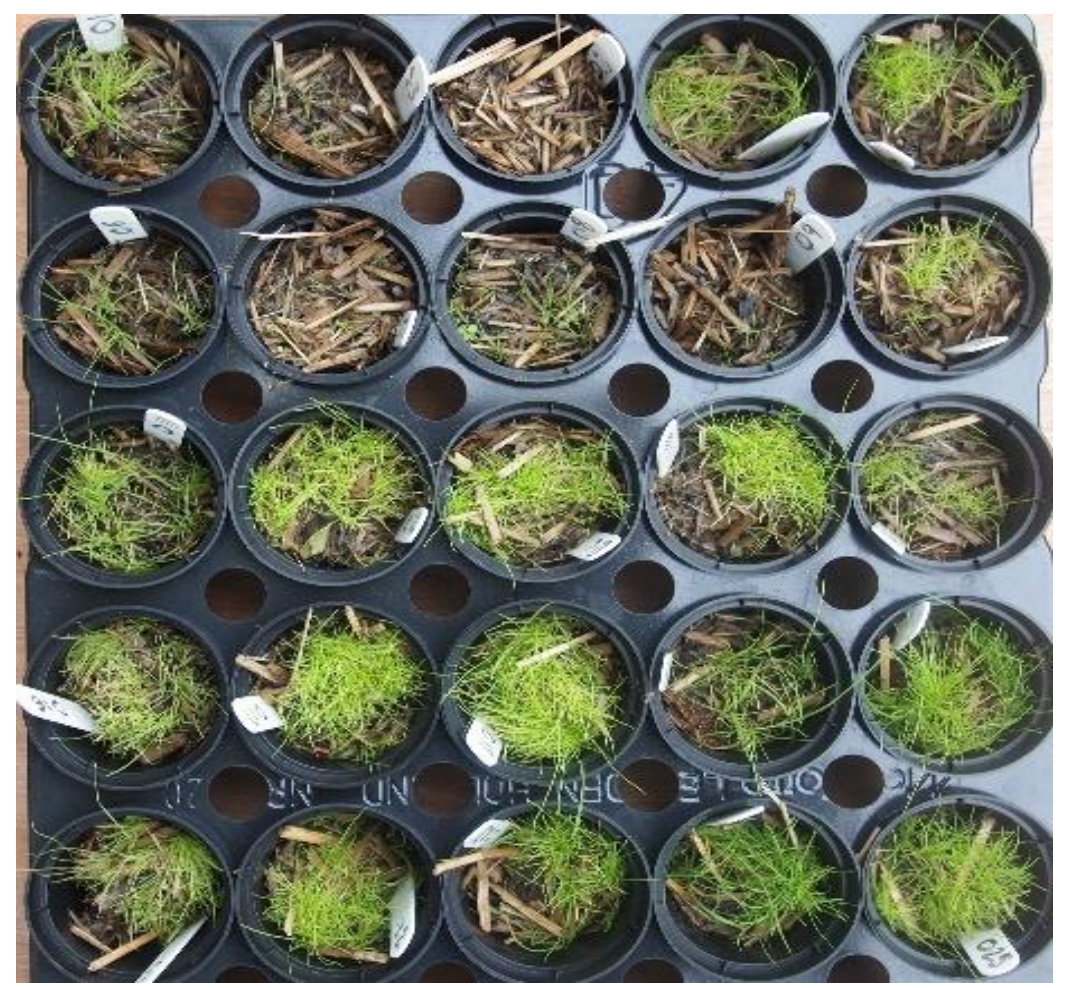

Figure 6.35: Grass growth in an unamended, two-stage, $10 \%$ guar treatment at the end of the six-week germination trial (August 2018)

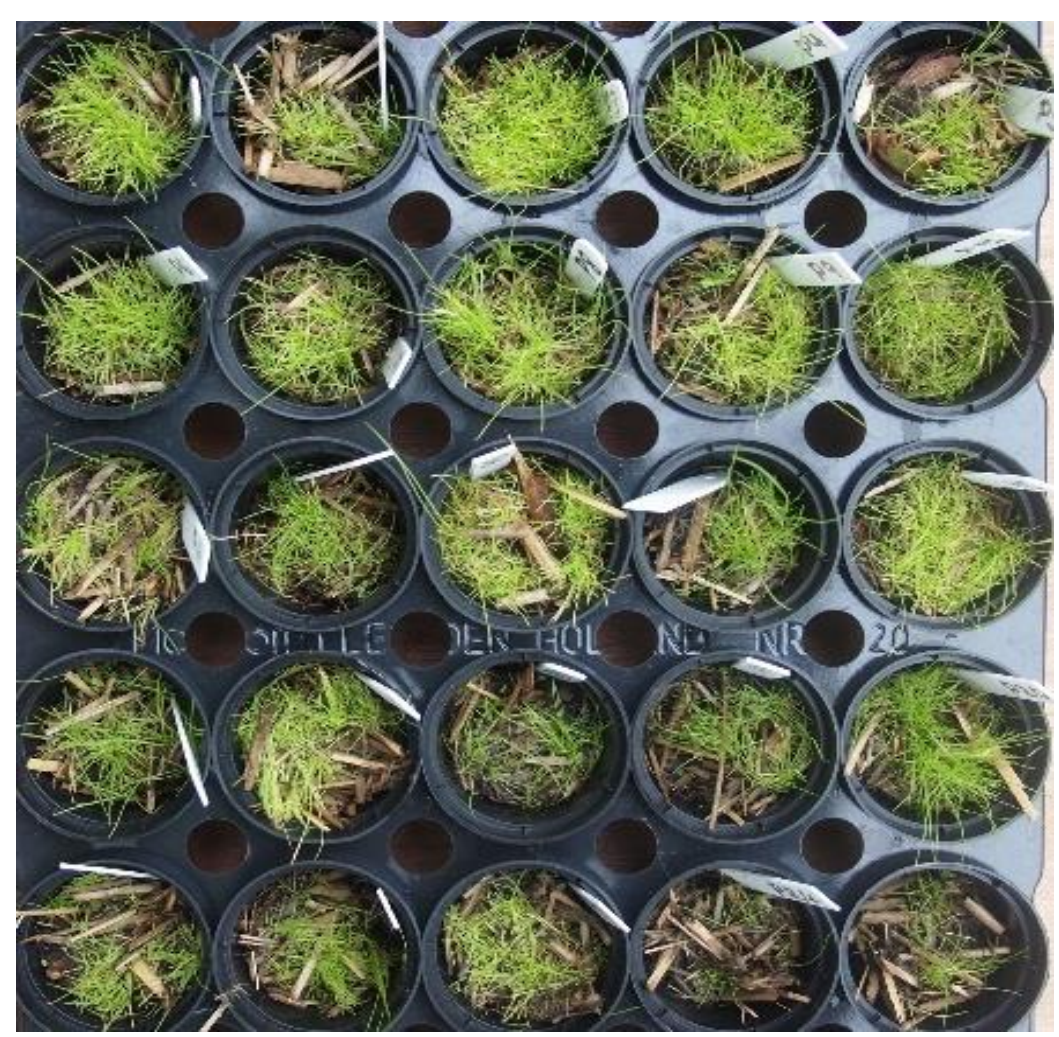

Figure 6.36: Grass growth in a basalt, two-stage, $10 \%$ guar treatment at the end of the six-week germination trial (August 2018) 


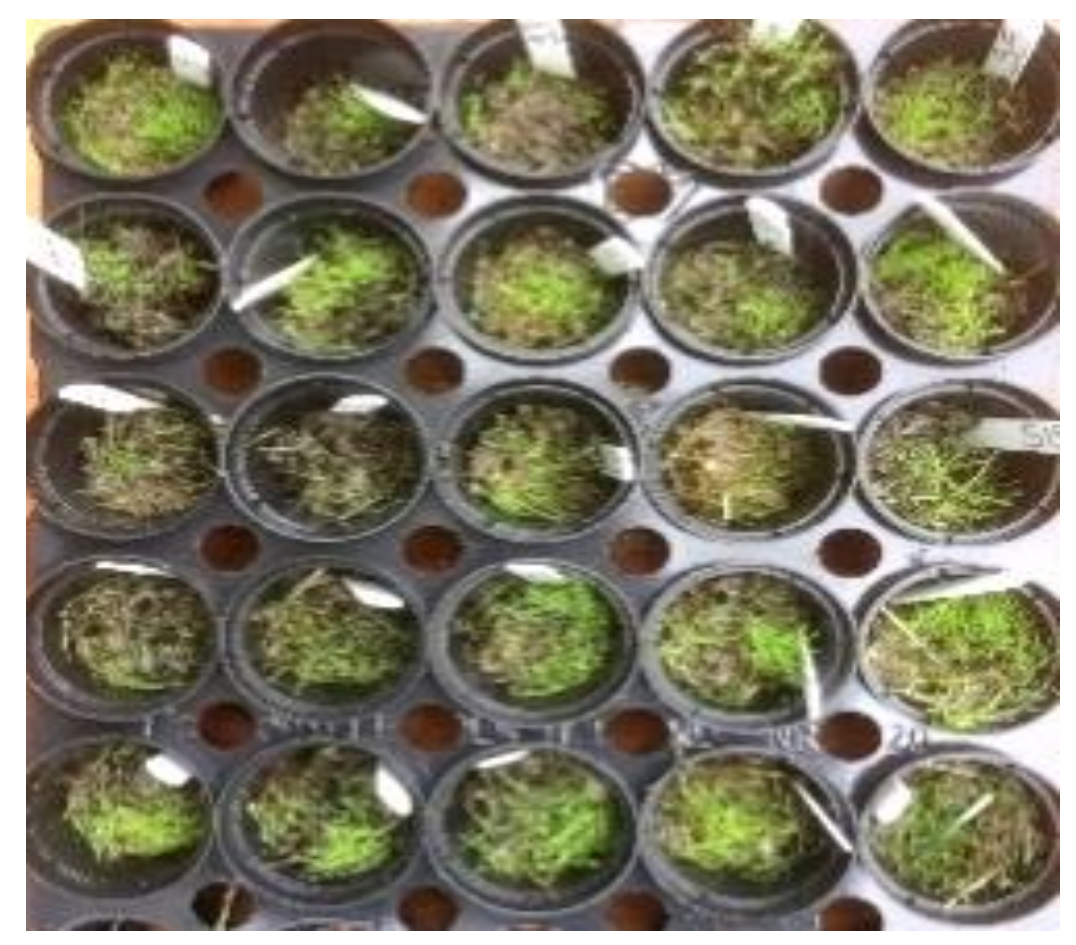

Figure 6.37: Grass growth in the Hydra CX soil at the end of the six-week germination trial (August 2018)

\subsubsection{Root biomass}

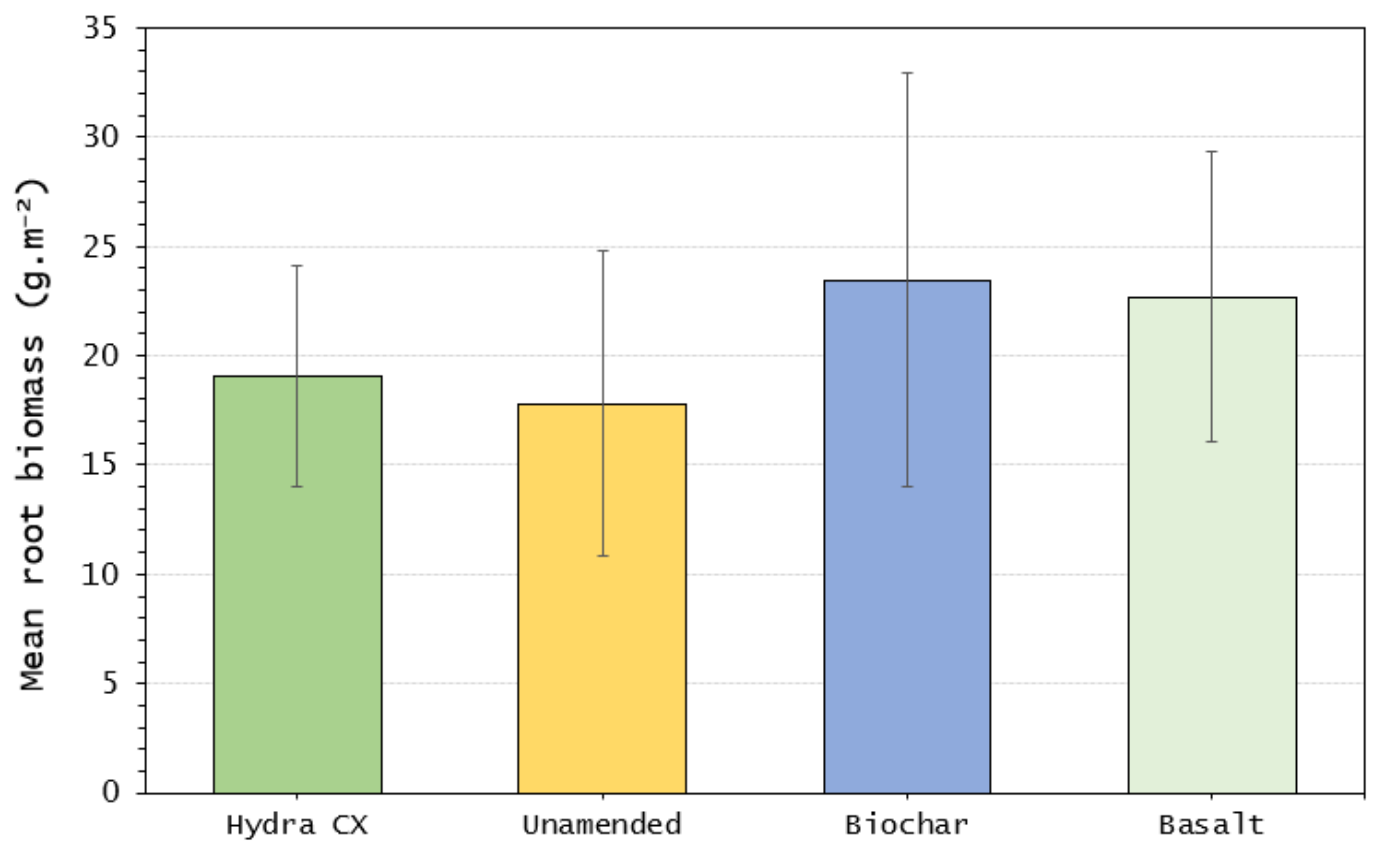

Figure 6.38: The mean root biomass $\left(\mathrm{g} \cdot \mathrm{m}^{-2}\right)$ produced by each treatment group, unamended $(n=32)$, biochar $(n=32)$, basalt $(n=32)$ and Hydra $C X \quad(n=8)$ at the end of the six-week germination trial. Error bars represent the sample standard deviation 
Table 6.17: The mean weight of root biomass $\left(g \cdot \mathrm{m}^{-2}\right)$ for each of the treatment groups, the Hydra CX, the unamended treatments, those that contained biochar, and those that contained basalt, at the end of the six-week germination trial (August 2018). \pm indicates the sample standard deviation.

\begin{tabular}{cccccc}
\hline \hline Group & $\mathrm{n}$ & $\begin{array}{c}\text { Mean } \\
\left(\mathrm{g} . \mathrm{m}^{-2}\right)\end{array}$ & $\begin{array}{c} \pm \\
\left(\mathrm{g} . \mathrm{m}^{-2}\right)\end{array}$ & $\begin{array}{c}\text { Min } \\
\left(\mathrm{g} . \mathrm{m}^{-2}\right)\end{array}$ & $\begin{array}{c}\text { Max } \\
\left(\mathrm{g} \cdot \mathrm{m}^{-2}\right)\end{array}$ \\
\hline Hydra CX & 8 & 19.0 & 4.6 & 12.5 & 26.3 \\
Unamended & 32 & 17.8 & 7.1 & 8.7 & 39.9 \\
Biochar & 32 & 23.4 & 904 & 1.2 & 46.9 \\
Basalt & 32 & 22.6 & 6.8 & 8.6 & 35.4 \\
\hline
\end{tabular}

As well as creating a denser grass sward, basalt also had a positive impact on root growth (Table 6.17 and Figure 6.39).

The addition of basalt corresponded to a $24 \%$ mean increase in root biomass $(\mathrm{p} \leq 0.014)$. (ANOVA: F[3, 99] = 3.69) when compared to the unamended soils.

Although the basalt group produced a greater quantity of above-ground biomass than the biochar and the Hydra CX treatments (Table 6.15), no pairwise differences in root biomass were found. 


\subsubsection{Biochar and basalt combined}

The treatments which contained biochar $(5 \% \mathrm{v} / \mathrm{v})$ and basalt $(0.5 \% \mathrm{v} / \mathrm{v})$ are referred to as the 'biochar:basalt' group throughout this section. This group was composed of all four surrogate soil treatments which contained both amendments, regardless of the proportion of guar gum or single or two-stage application.

i) Single-stage $8 \%$ with biochar and basalt

ii) Single-stage $10 \%$ with biochar and basalt

iii) Two-stage $8 \%$ with biochar and basalt

iv) Two-stage $10 \%$ with biochar and basalt

\subsubsection{Shoot length}

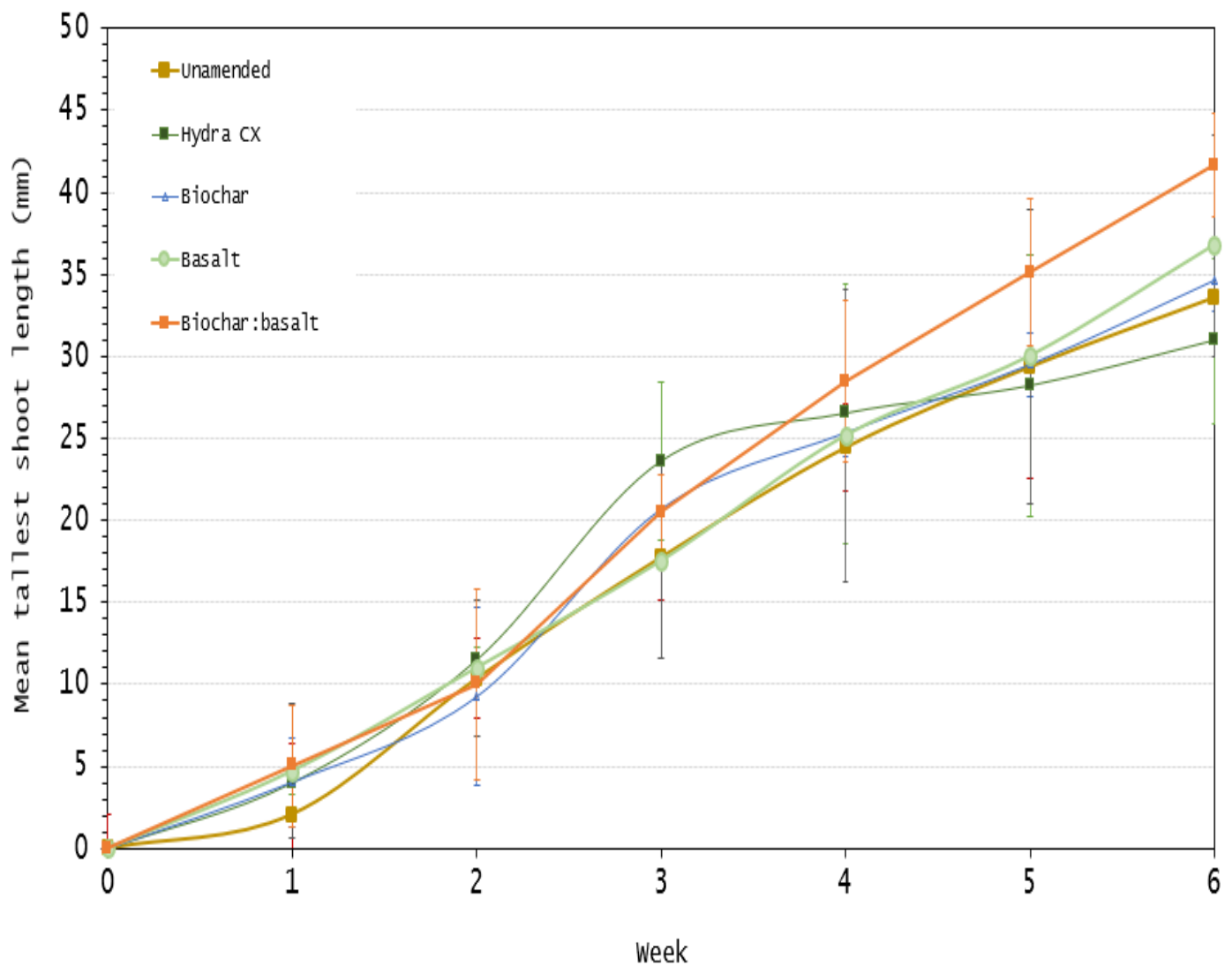

Figure 6.39: The mean tallest shoot length $(\mathrm{mm})$ in the treatment groups, the Hydra CX, the unamended $(n=100)$, biochar $(n=100)$, basalt $(n=100)$, biochar:basalt $(n=100)$ throughout the six-week germination trial. Error bars represent the sample standard deviation 
Table 6.18: The mean final shoot length ( $\mathrm{mm}$ ) for the treatment groups, for each of the treatment groups, the Hydra CX, the unamended treatments, those that contained biochar, those that contained basalt, and those that contained both biochar and basalt, at the end of the six-week germination trial (August 2018). \pm indicates the sample standard deviation.

\begin{tabular}{cccccc}
\hline \hline Group & $\mathrm{n}$ & $\begin{array}{c}\text { Mean } \\
(\mathrm{mm})\end{array}$ & $\begin{array}{c} \pm \\
(\mathrm{mm})\end{array}$ & $\begin{array}{c}\text { Min } \\
(\mathrm{mm})\end{array}$ & $\begin{array}{c}\text { Max } \\
(\mathrm{mm})\end{array}$ \\
\hline Hydra CX & 25 & 30 & 5 & 20 & 46 \\
Unamended & 100 & 32 & 8 & 15 & 50 \\
Biochar & 100 & 35 & 5 & 20 & 50 \\
Basalt & 100 & 37 & 6 & 29 & 60 \\
Biochar and basalt & 100 & 42 & 7 & 24 & 60 \\
\hline
\end{tabular}

By the end of the trial, the biochar:basalt group had produced significantly taller shoots than that of the Hydra CX treatment ( $\leq \leq 0.001)$, the unamended group $(p \leq 0.001)$, the biochar group $(\mathrm{p} \leq 0.001)$ and the basalt group ( $\leq 0.002)$ (ANOVA: $\mathrm{F}[4,420]$ = 28.34) (Table 6.18 and Figure 6.40). 


\subsubsection{Above-ground biomass}

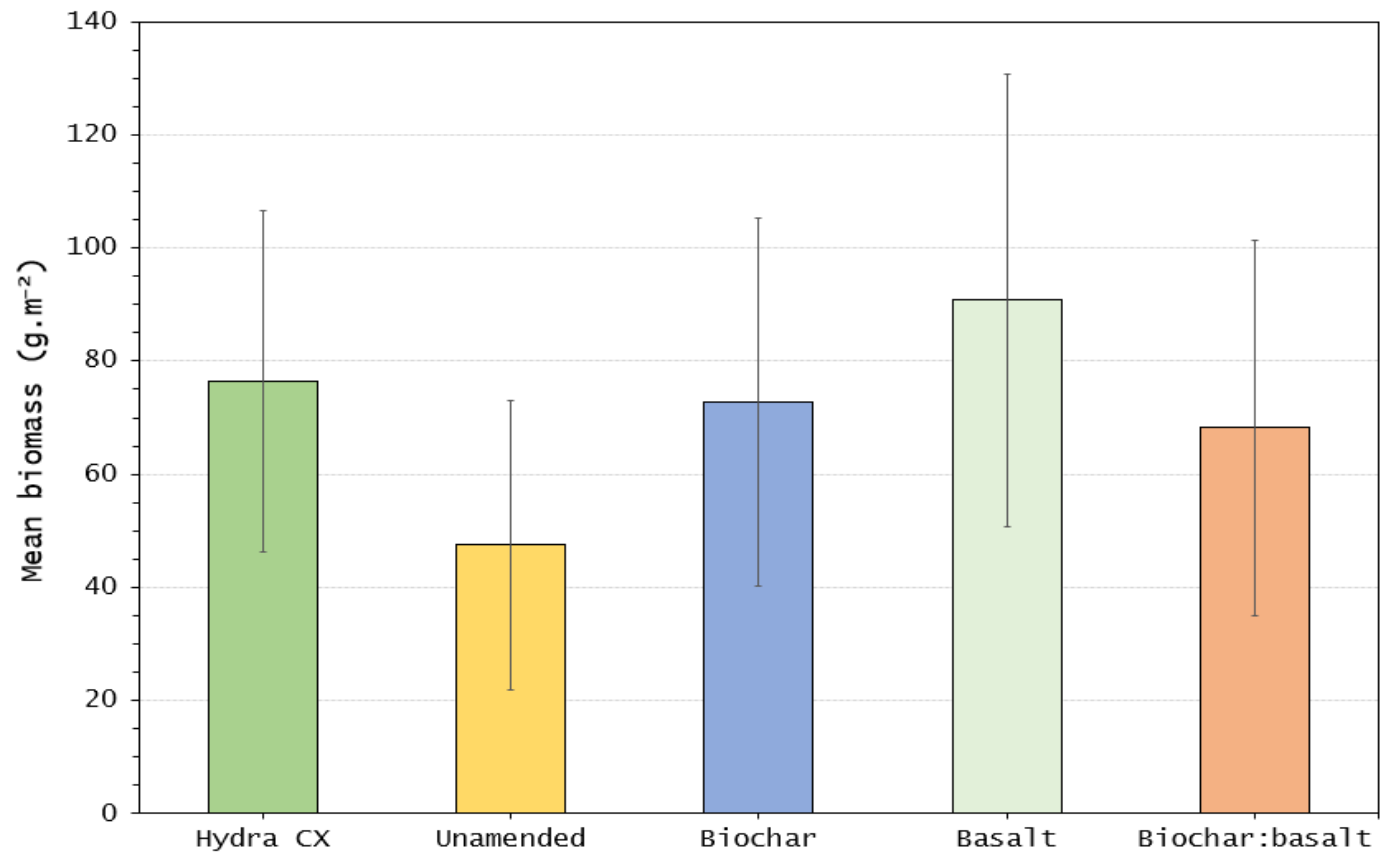

Figure 6.40: Mean above-ground biomass $\left(g . \mathrm{m}^{-2}\right)$ produced by each treatment group, the Hydra CX $(n=8)$, the unamended treatments $(n=32)$, those that contained biochar $(n=32)$, those that contained basalt $(n=32)$ and those that contained biochar and basalt $(n=32)$ at the end of the six-week germination trial. Error bars represent the sample standard deviation

Table 6.19: Mean weight of dried above-ground biomass $\left(\right.$ g. $\left.m^{-2}\right)$ for each of the treatment groups, the Hydra CX, the unamended treatments, those that contained biochar, those that contained basalt, and those that contained both biochar and basalt, at the end of the six-week germination trial (August 2018). \pm indicates the sample standard deviation

\begin{tabular}{cccccc}
\hline Group & $\mathrm{n}$ & $\begin{array}{c}\text { Mean } \\
\left(\mathrm{g} . \mathrm{m}^{-2}\right)\end{array}$ & $\begin{array}{c} \pm \\
\left(\mathrm{g} . \mathrm{m}^{-2}\right)\end{array}$ & $\begin{array}{c}\text { Min } \\
\left(\mathrm{g} \cdot \mathrm{m}^{-2}\right)\end{array}$ & $\begin{array}{c}\text { Max } \\
\left(\mathrm{g} \cdot \mathrm{m}^{-2}\right)\end{array}$ \\
\hline Hydra CX & 25 & 76.4 & 30.1 & 21 & 130 \\
Unamended & 100 & 47.5 & 25.6 & 10 & 131 \\
Biochar & 100 & 72.8 & 32.5 & 10 & 160 \\
Basalt & 100 & 90.7 & 39.9 & 10 & 170 \\
Biochar:basalt & 100 & 68.2 & 33.1 & 10 & 150 \\
\hline
\end{tabular}


The taller grass shoots of the biochar:basalt group did not correspond to an overall increase in above-ground biomass (Table 6.19 and Figure 6.40).

The unamended group produced the least biomass of any treatment group (36\% less than the biochar:basalt group, $\mathrm{p} \leq 0.001)$.

The use of basalt alone corresponded to significantly more biomass $(28 \% \mathrm{p} \leq 0.001)$ than when used in combination with biochar (ANOVA: $F[4,420]=28.34)$ (Table 6.19). In this trial, the biochar:basalt group produced a similar quantity of biomass to that of the biochar group (72.8 and 68.2 g.m $\mathrm{m}^{-2}$, respectively). Overall, the amendments were more successful at producing biomass when used exclusively than when combined.

The biochar:basalt group yielded grass with a greater shoot length than the other treatment groups (Table 6.19), however, this data coupled with the reduced biomass data indicated that the biochar:basalt treatments had produced taller shoots but fewer of them. This culminated in a sparser ground cover which can be confirmed visually (Figures 6.41 and 6.42). 


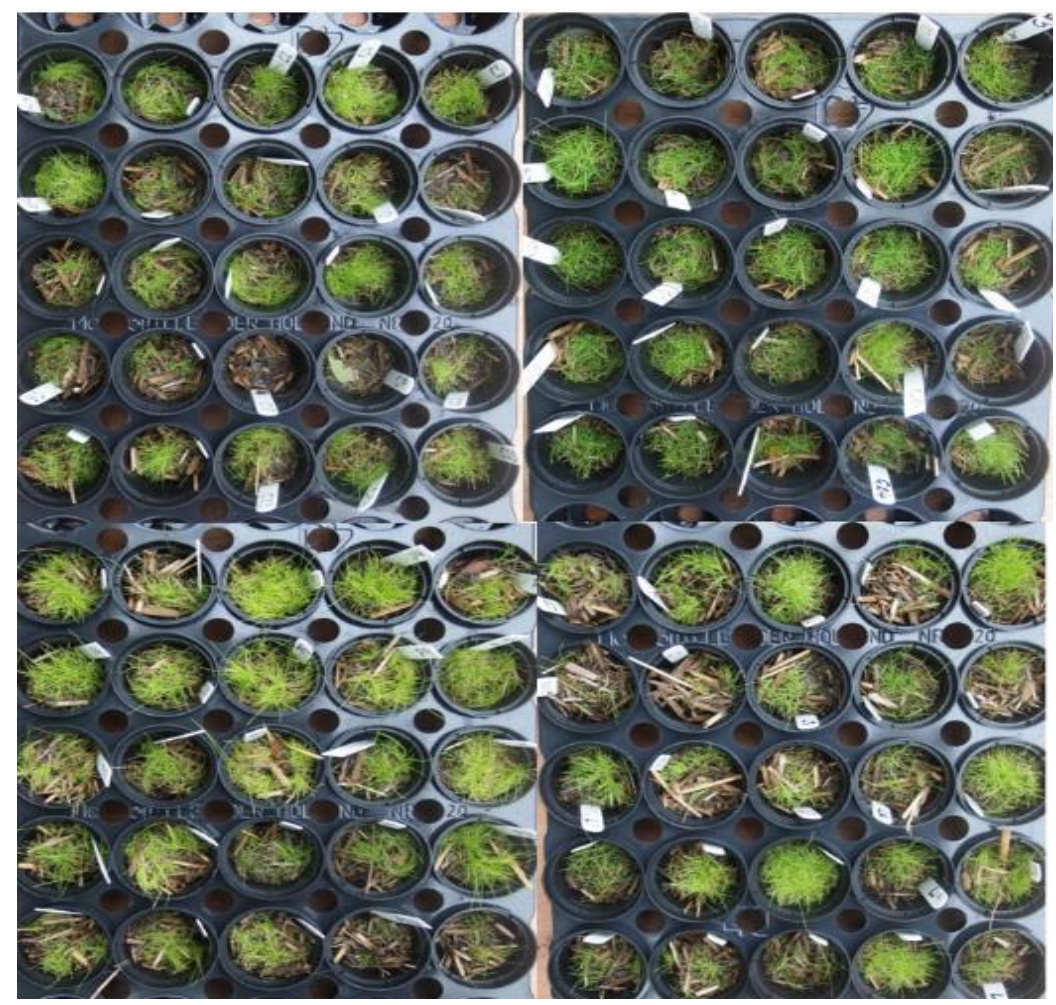

Figure 6.41: The grass produced by the soils which contained basalt, at the end of the six-week germination trial (August 2018)

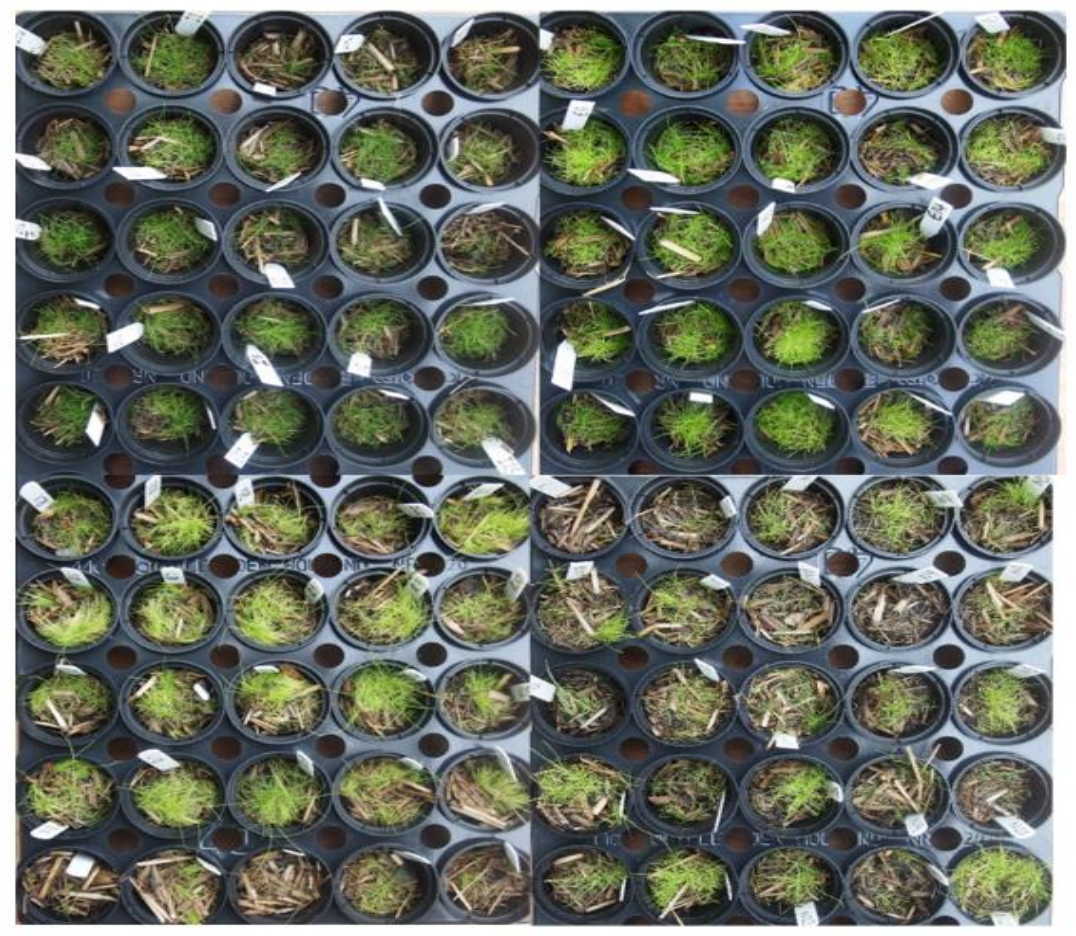

Figure 6.42: The grass produced by the soils which contained biochar and basalt, at the end of the six-week germination trial (August 2018) 


\subsubsection{Root biomass}

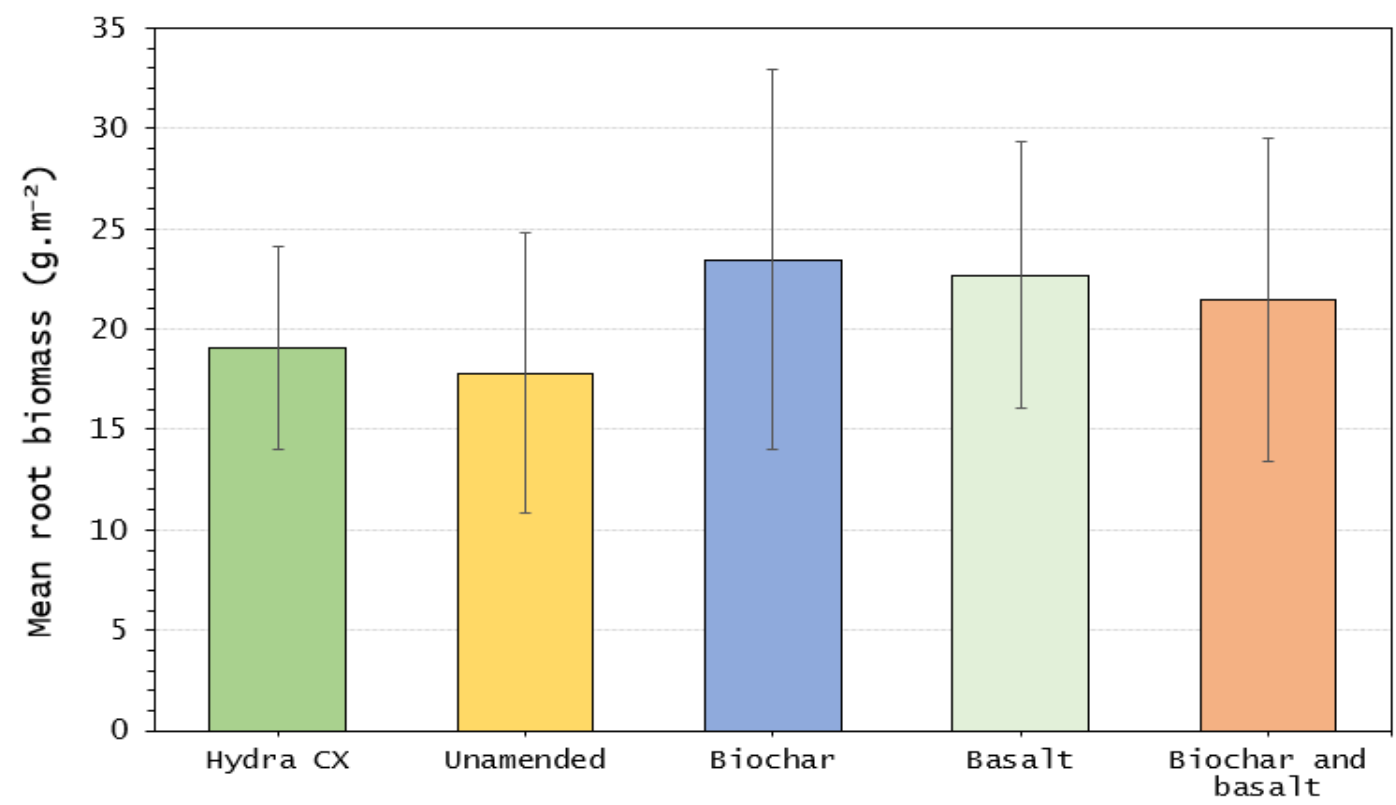

Figure 6.43: Mean root biomass $\left(g . \mathrm{m}^{-2}\right)$ produced by each treatment group, the Hydra CX $(n=8)$, the unamended treatments $(n=32)$, those that contained biochar $(n=32)$, those that contained basalt $(n=32)$ and those that contained biochar and basalt $(n=32)$ at the end of the six-week germination trial. Error bars represent the sample standard deviation

Table 6.20: The mean weight of root biomass $\left(g . \mathrm{m}^{-2}\right)$ for each of the treatment groups, Hydra CX (one treatment of eight replicates), unamended (four treatments of eight replicates), basalt (four treatments of eight replicates) biochar (four treatments of eight replicates) and biochar:basalt (four treatments of eight replicates). \pm indicates the sample standard deviation.

\begin{tabular}{cccccc}
\hline \hline Group & $\mathrm{n}$ & $\begin{array}{c}\text { Mean } \\
\left(\mathrm{g} \cdot \mathrm{m}^{-2}\right)\end{array}$ & $\begin{array}{c} \pm \\
\left(\mathrm{g} \cdot \mathrm{m}^{-2}\right)\end{array}$ & $\begin{array}{c}\text { Min } \\
\left(\mathrm{g} . \mathrm{m}^{-2}\right)\end{array}$ & $\begin{array}{c}\text { Max } \\
\left(\mathrm{g} \cdot \mathrm{m}^{-2}\right)\end{array}$ \\
\hline Hydra CX & 8 & 19.0 & 4.6 & 12.5 & 26.3 \\
Unamended & 32 & 17.8 & 7.1 & 8.7 & 39.9 \\
Biochar & 32 & 23.4 & 9.4 & 1.2 & 46.9 \\
Basalt & 32 & 22.6 & 6.8 & 8.6 & 35.4 \\
Biochar:basalt & 32 & 21.4 & 8.1 & 1.8 & 36.4 \\
\hline
\end{tabular}


No pairwise differences in the quantity of root biomass were found (ANOVA: $\mathrm{p} \leq 0.05$ ) (Figure 6.43 and Table 6.20).

\subsubsection{Summary of the germination trial results}

The treatments were grouped according to variations made to the surrogate soil materials (a single or two-stage application, the proportion of guar gum, and the amendments included). The parameters of shoot length, above-ground biomass and root biomass yield informed on the effects of these variations to the soil.

No differences were observed in the germination rate, and seedling emergence commenced on either day four or five for all treatments (Section 6.2.3.1).

When compared as a collective, the single-stage treatment group and two-stage treatment group produced similar mean quantities of biomass (Table 6.7). Though, by the end of the trial, three of the two-stage treatment pairs produced significantly more biomass than their single-stage counterpart (Figure 6.14).

In almost all treatment comparisons, the unamended treatments were outperformed by the amended treatments. The inclusion of basalt had the greatest impact on aboveground biomass (a 65\% increase, $\mathrm{p} \leq 0.001$ ) (Table 6.19). Root growth was improved equally by the inclusion of biochar or basalt, and both led to a $24 \%$ increase compared to the unamended treatments $(\mathrm{p} \leq 0.014)$ (Table 6.19).

When used exclusively, both biochar and basalt improved grass growth. However, when the amendments were combined, the results were no greater than that of either amendment used individually (Table 6.19). Conversely, basalt was more effective at encouraging biomass production when not combined with biochar $(\mathrm{p} \leq 0.001)$.

While the inclusion of amendments had the greatest impact on above-ground biomass yield, the proportion of guar gum also exerted a strong effect on early grass growth. Collectively, the $10 \%$ group produced a mean of $22 \%$ more biomass than the $8 \%$ group $(\mathrm{p} \leq 0.028)($ Table 6.17).

Many of the amended test soils produced quantities of above-ground biomass that were comparable to the revegetation and erosion control product, Hydra CX $\left(76.4\right.$ g.m ${ }^{-2}$ in the Hydra CX, and $65.5-134.0$ g.m ${ }^{-2}$ in the amended test soils, Table 6.19). Both the 
8 and $10 \%$ groups also produced quantities of biomass equivalent to the Hydra CX $\left(62.1,77.5\right.$, and 76.4 g.m $\mathrm{m}^{-2}$, respectively, Table 6.10). Root biomass was similar for all treatments (Table 6.17). Overall, the test surrogate soils performed comparably to that of the commercial revegetation product. 


\subsection{Germination trial - Discussion}

The germination trial was conducted to assist the development of an adhesive surrogate soil. The soil was ultimately to be applied to mine tailings in order to revegetate and reduce erosion via two mechanisms. Firstly, the resistance to raindrop erosion through the provision of biomass, which slows the velocity of water, and disperses and reduces the impact of raindrops (De Baets et al., 2006). Secondly, the anchoring of the soil and tensile strength that is provided by the roots (Operstein \& Frydman, 2000). Both functions can be fulfilled by rapid vegetation growth, and in this trial the success of the surrogate soils were measured by the quantity of above and below-ground biomass that was produced in a short (six-week) germination trial.

Several adaptions were made to the soil to assess the value of:

i) Including basalt fines and/or biochar.

ii) Adding a base layer of high nutrient and high water-holding capacity materials.

iii) Different proportions of guar gum (8 or $10 \% \mathrm{v} / \mathrm{v})$.

Seedling emergence occurred on the same day in all treatments. Yet, the rate of growth throughout the six weeks, the final biomass yield and ground cover varied.

The widely used revegetation medium, Hydra CX, is an erosion control surrogate soil product and has been demonstrated to assist rapid grass growth (Section 4.2.1). In the germination trial, the surrogate soils were required to produce at least as much biomass as the Hydra CX soil (76.4 g.m ${ }^{-2}$, Table 6.19) in a six-week period to be of acceptable standards. The unamended treatments consistently fell below this standard and yielded less biomass than all other treatments (47.5 g.m ${ }^{-2}$, Table 6.19) and a sparser ground cover. By comparison, the biochar amended soils produced a similar quantity of biomass to the Hydra CX $\left(72.8\right.$ g.m $\left.\mathrm{m}^{-2}\right)$, whereas the basalt amended soils yielded $17 \%$ more (90.7 g.m ${ }^{-2}$,Table 6.19). 


\subsubsection{Basalt}

In this trial, basalt had the greatest impact on above-ground biomass yield (Table 6.19), which can largely be attributed to the high $\mathrm{P}$ content of basalt $\left(\sim 3000 \mathrm{mg} \cdot \mathrm{kg}^{-1}\right.$, Table 4.8). It is widely agreed that $\mathrm{P}$ is central to soil processes that regulate water relations, nutrient cycling, $\mathrm{C}$ storage, biodiversity, and OM content and quality (Porder \& Ramachandran, 2012; Anda et al., 2013; Abreuq et al., 2015; Macdonald et al., 2016). The ground basalt used in this study contained a substantially higher $P$ content (2094 \pm 953 mg. $\mathrm{kg}^{-1}$, Table 4.8), than that of all other soil materials used (12 - 1000 mg.kg-1 ${ }^{-1}$ Table 4.6 and 4.7).

Compared to the other soil amendments, basalt is also high in $\mathrm{Si}, \sim 160,000 \mathrm{mg} \cdot \mathrm{kg}^{-1}$ (Table 4.8), which is a key component of cell walls and is essential for the production of strong shoots (Gillman et al., 2002). The additional Si provided by the basalt amended soils would have assisted seedling emergence, which is when the $\mathrm{Si}$ requirements of the grasses are the greatest (Marschner, 1995).

While $\mathrm{Si}$ is not generally considered to be an essential element, $\mathrm{Si}$ has been found to increase the uptake of $\mathrm{K}, \mathrm{Ca}$ and $\mathrm{Mg}$, particularly in stressed plants (Akter \& Akagi, 2010; Greger et al., 2018). Basalt is also high in $\mathrm{K}, \mathrm{Ca}$ and $\mathrm{Mg}$.

The addition of Si through a basalt soil amendment was hypothesised to be of most benefit in the field trial when the surrogate soils were applied to the mine tailings, rather than the germination trial. Basalt is commonly included in artificial, surrogate, and constructed soils for reclamation purposes (Adam, 1995; Pogue, 2010; Manning et al., 2013). In these surrogate soils, basalt has been included at a range of application rates, from $30-60 \%$ of the total soil volume, and the main limitation to its usage is the high $\mathrm{pH}$ which is unfavourable for some plants. As with many previous studies (Abreu et al., 2015; Macdonald et al., 2016; Greger et al., 2018) this trial confirmed basalt as a valuable addition to a surrogate soil.

\subsubsection{Biochar}

When applied to uncontaminated soils, in studies of $<1$ year the inclusion of biochar has led to variable results, and has been occasionally reported to impede plant germination and growth rates (Wisnubroto et al., 2010; Jay et al., 2015; Jeffery et al., 
2017). The initially detrimental impact of biochar addition has been attributed to its capacity to adsorb nutrient cations on the biochar's surface, which renders the nutrients less plant available (Agegnehu et al., 2016). The soils used in the germination trials were uncontaminated, and based on other short-term studies, any positive effects that biochar may exert on plant growth were unlikely to be seen in a six-week trial (Deenik et al., 2010; Free et al., 2010; Agegnehu et al., 2017).

While short-term germination trials with biochar soils have produced variable results, long-term studies almost universally report that biochar has a positive effect on plant growth, particularly when applied to contaminated soils (Jeffery et al., 2011; Verheijen et al., 2009; Chen et al., 2018). In a longer trial, such as the field trial in this research, the advantages of biochar such as an improved soil aeration, temperature, and water regulation (Prasad et al., 2017; Aller et al., 2017) were hypothesised to outweigh the initial slower plant growth.

For the benefit of the short germination trial, the biochar amended soils were not necessarily required to produce more growth than the unamended soils, only to not be detrimental to growth. Contrary to expectations, in this trial, the inclusion of biochar significantly increased grass growth, with more consistent ground cover (Figures 6.28) than the unamended soils $(42 \%, \mathrm{p} \leq 0.001$, Section 6.2.5.2).

The increased plant biomass cannot necessarily be attributed to the addition of biochar, as the Hydra CX and the biochar soils produced very similar results overall. Hydra CX does not state that it contains biochar, thus it cannot be assumed that it does. Consequently, it is not possible to confirm a correlation between the addition of biochar and the increased biomass. Instead, the unamended treatments lacked an advantage that was provided to the Hydra CX and the biochar soils.

\subsubsection{Water-holding capacity}

The germination trial was conducted over six weeks of unusually hot and dry weather, with $123 \mathrm{~mm}$ of rainfall over 42 days (Section 6.2.1). The mean daytime temperature was $2.2^{\circ} \mathrm{C}$ higher than the long-term average (Met Office, $2018^{1},{ }^{3}$ ), and sunshine was $138 \%$ of the long-term average (Met Office, $2018^{1}{ }^{3}$ ), both conditions which cause 
high evapotranspiration rates (Nguyen et al., 2012). Due to the anomalous weather, soil water retention was crucial in this period of the study.

The biochar amended soils had a higher WHC $(70-85 \%)$ than the surrogate soils without biochar (66-71\%, Tables 6.1 and 6.3). The Hydra CX had a WHC of $75 \%$ (Table 4.1). The higher WHC during the dry weather will have proved advantageous and coincided with the greater quantity of biomass in the biochar and Hydra CX soils compared to the unamended soils $\left(72.8,76.4\right.$, and 47.5 g.m ${ }^{-2}$, respectively, Table 6.17).

The basalt amended soils produced the most biomass, and these soils did not contain biochar. Therefore, the WHC of the soil was not the most influential factor for early plant growth. In this trial, the additional $\mathrm{P}$ and Si provided by the basalt was more valuable for seedling emergence and early growth than the moisture content.

Multiple mine reclamation trials have failed due to drought (Hester \& Harrison, 1997; Leavitt et al., 2000; Yao et al., 2012; Davies et al., 2016; Courtney, 2018). In all cases, the authors have suggested an increase in OM to mitigate this, however, the rainsplash pilot trials demonstrated that the OM cannot be increased as a deeper soil led to deformation. In this trial, the WHC of the soil had to be balanced with the drainage. The main components of the surrogate soils had a high WHC. The anaerobic digestate WHC was 914\% (Table 4.4), and the coir's was 440\% (Table 4.5). The miscanthus straw also had a high WHC (307\%, Table 4.3). Overall, however, the WHC of the surrogate soil was not as high as any other the component parts (66-85\%, Table 6.2 and 6.4) as the large straw particles provided structure and aeration to the soil and allowed the soil to drain freely. In the rainsplash trial, the free drainage eliminated any soil deformation, yet in the germination trial the free drainage became a hindrance. While the WHC of the soil is an important factor, it has to be balanced with the drainage. In this case, the drainage is sufficient, therefore the surrogate soils with the highest WHC should be selected for use in the field trial. These were the soils with $10 \%$ guar gum, and with two layers of soil. 


\subsubsection{Biochar and basalt}

It was hypothesised that the grass grown in the biochar:basalt treatment would benefit from both amendments; however, this was not the case. The treatments which contained both biochar and basalt produced above and below ground biomass comparable to that of the biochar treatments (Table 6.19 and 6.20). When combined with biochar, basalt exerted no significant effects on the measured parameters.

It is not anomalous that basalt would be less effective when combined with biochar. Numerous studies have reported that when biochar and $\mathrm{P}$ fertiliser are applied together in soil, the $\mathrm{P}$ can precipitate onto the biochar which leads to a short-term reduced availability (Xu et al., 2012; Mukherjee \& Zimmerman, 2013; Kim et al., 2015). In these circumstances, biochar acted as a competitor for nutrients and was counterproductive to growth. It is possible that this effect took place in this trial, although, without further investigation this cannot be confirmed.

\subsubsection{Root growth}

Few significant differences in root biomass yield were found (Table 6.20). The addition of biochar and basalt individually significantly improved root biomass yield compared to the unamended treatments (a mean 27\% increase, $\mathrm{p} \leq 0.018$, and $24 \%$ increase, $\mathrm{p} \leq 0.014$, respectively) (Tables 6.14 and 6.17). However, no pairwise differences existed in the amended treatments (biochar, basalt, biochar:basalt, Section 6.2.7.3).

The biochar treatments produced the greatest quantity of root biomass $(22.6 \pm$ $9.4 \mathrm{~g} . \mathrm{m}^{-2}$ ), yet the root production was highly variable and ranged from $1.2 \mathrm{~g} . \mathrm{m}^{-2}$ to 46.9 g.m $\mathrm{m}^{-2}$. By comparison, the basalt treatments produced a mean $22.6 \pm 6.8$ g.m $\mathrm{m}^{-2}$, and while still highly variable, the range was considerably smaller $\left(8.6-35.4\right.$ g.m $\left.\mathrm{m}^{-2}\right)$ and therefore produced a more consistent root growth.

The method of separating the roots from the soil was particularly time-consuming and more destructive than anticipated. Despite heavy rainfall in the final week of the trial, the guar gum remained very evident in the soils. The strong adhesive bond made the roots challenging to separate, and a large proportion of the fine roots were lost during the washing and separation process. The roots in the Hydra CX treatments were easier 
to separate which may have been due to the different colloids used (Section 4.2.1). It is undetermined how the imperfect separation method affected the root biomass analyses, and so it is difficult to draw conclusions from the results.

Studies which have examined root biomass have typically expressed results as grams per pot, as root analysis is far more common in pot trials than in field trials (Craine et al., 2001; Lyons et al., 2007). Another common reporting style is to compare the results within the study to one another, but without mention of the specific values which are being compared (Sweeney et al., 2001; Schlossberg \& Karnock, 2002; Craine et al., 2003). This style of reporting makes the comparison of results difficult, as the dimensions of the pots are rarely provided and values are often omitted.

One field trial which has reported detailed values of root biomass is that of Jordan et al. (2003), which also evaluated the root biomass production of Agrostis grasses, albeit grown on a golf course. Samples were analysed using the same soil washing method to that of this trial. Root biomass values ranged between 19 and $39 \mathrm{~g} . \mathrm{m}^{-2}$. Also from a golf course, Sweeney et al., (2001) conducted a field trial where Agrostis roots were harvested and analysed in the same manner as Jordan et al. (2003) and that of the sixweek germination trial. Sweeney et al. (2003) reported a root biomass of $10-60$ g.m $\mathrm{m}^{-2}$, and a strong correlation was found between root growth and $\mathrm{NH}_{4}+$ fertiliser application. In both studies the grasses were well-established and were years rather than weeks old.

The mean root biomass of the four soil treatment groups (Hydra CX, unamended, biochar, basalt, biochar:basalt) ranged from $19-23$ g.m $\mathrm{m}^{-2}$, which can be considered as satisfactory when compared to the results reported by Jordan et al. (2003) and Sweeney et al. (2001). As all of the surrogate soils produced root growth comparable to that of samples taken from established golf courses, all of the soils can be evaluated as having supported sufficient root growth during the six-week time period. 


\subsubsection{Guar gum}

The type and proportion of binding agents for soil has important implications for water relations and soil stability (Wang et al., 2000; Dou et al., 2012). If too little is applied, soil adhesion is low and the material is eroded. If too much is applied, the soil retains too much water, and the increased self-mass can compromise the stability of the material on the slope, as seen in the rainsplash pilot trials (Appendix 2). In the worst cases, excessive use of binding agents can cause the soil surface to become impenetrable, water does not infiltrate and overland flow is increased (Dou et al., 2012). This leads to low germination rates and poor plant establishment.

The rainfall trial demonstrated that 8 or $10 \%(\mathrm{v} / \mathrm{v})$ guar gum was required to resist prolonged rainsplash erosion (Section 5.2). Both percentages of guar gum were tested to observe any effects the guar gum would exert on germination.

Again, the water-holding capacity (WHC) of the soils had a strong effect on plant growth. The soils with the lowest WHC (8\% guar gum, a WHC of $66-72 \%$, Tables 6.1 and 6.5) produced the least biomass and thinnest ground cover. The Hydra CX (a WHC of $75 \%)$ produced $21 \%$ more biomass than the $8 \%$ treatments $(\mathrm{p} \leq 0.029)$. The $10 \%$ treatments contained the highest WHC of all treatments $(69-65 \%)$ and yielded an average of $33 \%$ more biomass than the $8 \%$ guar soils $(\mathrm{p} \leq 0.029$, Section 6.2.4.2). The difference between the 8 and $10 \%$ treatments is unlikely to be attributed to any additional nutrients provided by the guar gum, as the guar contained negligible quantities of $\mathrm{N}$ (400 mg. $\mathrm{kg}^{-1}$ ) and P (483 mg. $\mathrm{kg}^{-1}$, Table 4.2).

The pairwise differences in above-ground biomass did not translate to variations in root biomass production (Table 6.20). Again, it is unclear if no genuine differences existed, or the sub-optimal soil washing method and loss of root mass.

\subsubsection{Single-stage and two-stage treatments}

It is well-understood that $\mathrm{N}$ is the key arbiter of plant health (Oldfield et al., 2018). Adding N-rich materials to the soil increases productivity and reduces the reliance on mineral fertilisers and irrigation (Robertson et al., 2014). Half of the treatments benefit from a base layer of $\mathrm{N}$-rich anaerobic digestate $\left(18,600 \mathrm{mg} \cdot \mathrm{kg}^{-1} \mathrm{~N}\right)$ and coir $\left(30,000 \mathrm{mg} \cdot \mathrm{kg}^{-1} \mathrm{~N}\right)$ and was capped with miscanthus straw and digestate. The other 
half of the treatments contained one homogenised layer of straw $\left(7340 \mathrm{mg} \cdot \mathrm{kg}^{-1} \mathrm{~N}\right)$ and digestate (18600 mg. $\left.\mathrm{kg}^{-1} \mathrm{~N}\right)$.

It was hypothesised that the addition of an N-rich base layer to the soil would improve germination, and the two-stage treatments would out-perform the single-stage. However, in order to maintain the same $2 \mathrm{~cm}$ depth for all treatments, the two-stage treatments were constructed with a shallower depth of the erosion-resistant top layer $(1 \mathrm{~cm}$, Section 6.1.3). If erosion occurred faster in the two-stage treatments, seed and material losses would affect seedling germination and root development, which would further increase erosivity.

When grouped as the SS (single-stage) and TS (two-stage) groups, no significant differences were found (Section 6.2.3.). This was as when the individual treatments were grouped and a mean taken, the mean of the group obscured the individual differences between the treatment pairs. These differences were revealed when the treatments were examined as pairs in a T-test (for example, SS 8\% guar gum with biochar, and TS $8 \%$ guar gum with biochar).

Three of eight pairs benefitted more so from the two-stage approach than the singlestage (Section 6.2.3). Although when differences were found the effect was strong (a $49-68 \%$ increase, $\mathrm{p} \leq 0.001$, Section 6.2.3.2), the effect was not found universally. As the two-stage treatments contained a higher WHC than the single-stage $(69-85 \%$, and $66-82 \%$, respectively, Tables 6.1 and 6.3) it is possible that WHC had an influence on grass yield as well as $\mathrm{N}$ provision.

The additional base layer had the least effect on biomass production of any variable. Root biomass production was largely the same for all treatments, regardless of the inclusion of additional OM (Table 6.6).

\subsubsection{Recommendations for future trials}

The results of the germination trial highlighted several important points which directed the field study.

It was hypothesised that the greatest changes to the soil (by volume) would exert the largest effect on growth. Conversely, the smallest changes produced the strongest effect. These were the addition of different amendments, principally, the basalt. Due 
to the high $\mathrm{pH}$ of the basalt and the inclusion of acid grass species, basalt was added to the soil at the very low rate of $0.5 \%(\mathrm{v} / \mathrm{v})$, which was $\sim 260 \mathrm{~g} \cdot \mathrm{m}^{-2}$, less than the 500 g. $\mathrm{m}^{-2}$ recommended by the supplier (Remin Scotland, 2018). Still, the basalt treatments produced the greatest quantity of biomass, the longest shoots and the densest ground cover (Section 6.2.6). Basalt does not provide any $\mathrm{N}$ (Table 4.8), however, and the $\mathrm{N}$ content of the soil should be increased through the application of fertiliser to improve the soil nutrient content.

Water availability was a crucial factor within this study. Consistently, the most successful treatments were those characterised by a high WHC, whether it be through the addition of biochar or guar gum. The treatments which contained $10 \%(\mathrm{v} / \mathrm{v})$ guar gum almost universally produced more biomass than those that contained 8\% (Table 6.8). The positive plant response to the guar gum was not only a product of WHC, but as the rainsplash trials demonstrated, the soil retention of the $10 \%$ treatments was more favourable than the $8 \%$ (Section 5.2). In the field trials, it would be expedient for all soils to contain $10 \%(\mathrm{v} / \mathrm{v})$ guar gum.

The impact of the coir and digestate base layer was slight and inconsistent (Section 6.2.3.2). However, as WHC has proven to be an important consideration, and the twostage treatments had a higher WHC (Tables 6.1 and 6.3) a two-stage approach was recommended for the field trial. 


\section{Field trial introduction}

A field trial was conducted to test the ability of the experimental surrogate soil at producing grass growth and controlling erosion when applied to $\mathrm{Pb} / \mathrm{Zn}$ metal-mine tailings. The field trial is divided into two main time periods, September to December 2018 (Chapter 7) and January to June 2019 (Chapter 8).

Chapter 7 is further subdivided into Section 7.1 (the methods used to conduct the field trial, the data collection and the analyses), Section 7.2 (the results of this stage of the trial), and Section 7.3 (the discussion of the results). The following chapter will only discuss the results found during the September to December stage of the field trial. Chapter 8 will discuss the later stage of the field trial. 


\subsection{Field trial - Method}

\subsubsection{Location}

The field trial was conducted at the Deep Boat Level of the abandoned Nantymwyn $\mathrm{Pb}$ mine, Wales, coordinates 5204’31.74 N, 346’48.28 W (detailed in Figure 3.2). The field trial commenced on the $10^{\text {th }}$ September 2018 and was concluded on the $21^{\text {st }}$ June 2019.
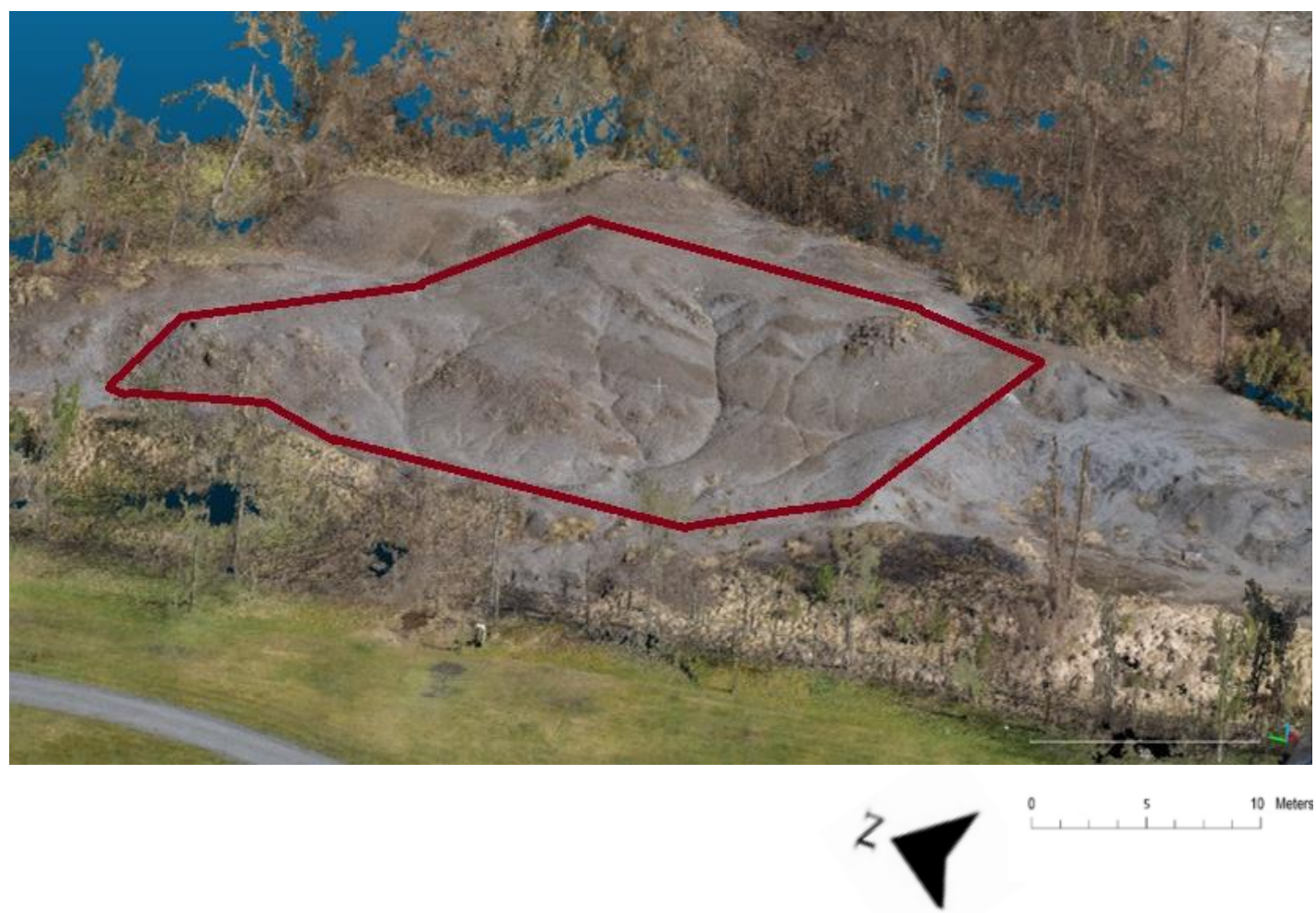

Figure 7.1: The field site. The red line indicates the placement of the fencing

A rabbit-proof fence was erected around the perimeter of the site to deter animals (Figure 7.1). On the tailings, 154 plots $\left(30 \times 30 \mathrm{~cm}^{2}\right)$ were marked using a wooden 30 x $30 \mathrm{~cm}^{2}$ board for accuracy, with tent pegs at the corners (Figure 7.2). 


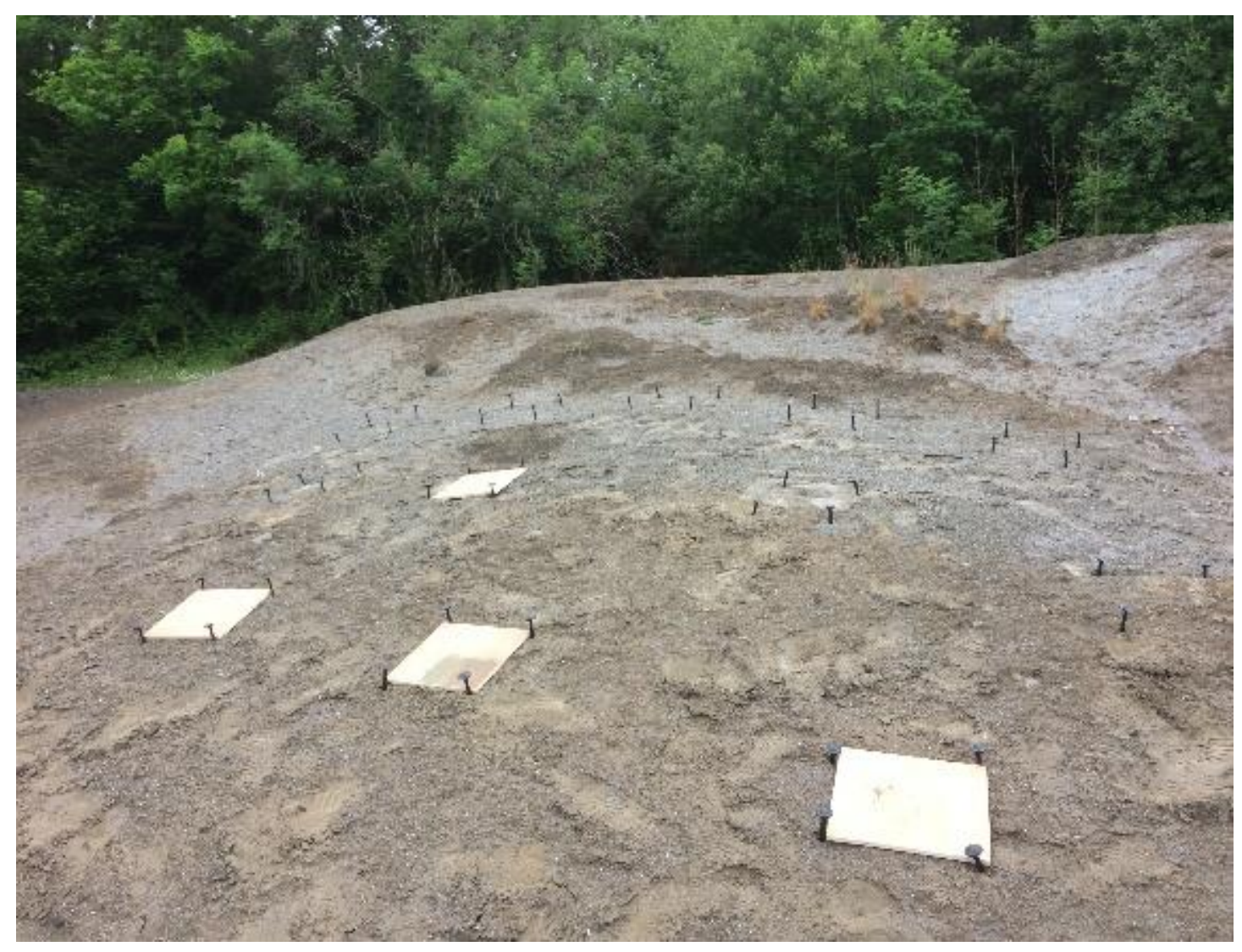

Figure 7.2: Wooden boards were used to create consistent $30 \mathrm{~cm}^{2}$ plot sizes

\subsubsection{Experimental design}

A randomised experimental design was composed of 11 treatments with 14 repetitions $(\mathrm{N}=154$, Table 7.1).

All of the surrogate soils were based on the two-stage treatments from the germination trial (Chapter 6). The treatments consisted of a $1 \mathrm{~cm}$ bottom layer of growing medium capped with a $1 \mathrm{~cm}$ top layer of erosion control material.

No surrogate soil was applied in two control conditions; one unseeded control provided baseline data for existing vegetation on site, while the second control treatment was seeded to determine the efficacy of direct seeding without the addition of a surrogate soil. 
Eight variations of the surrogate soil were tested (Table 7.1).

i) The unamended surrogate soil (only straw, coir, and anaerobic digestate).

The amended surrogate soils contained straw, coir and digestate with:
ii) $\quad \operatorname{Biochar}(5 \% \mathrm{v} / \mathrm{v})$.
iii) Basalt $(0.5 \% \mathrm{v} / \mathrm{v})$.
iv) Fertiliser $(10 \% \mathrm{v} / \mathrm{v})$.
v) Biochar (5\% v/v) and basalt $(0.5 \% \mathrm{v} / \mathrm{v})$.
vi) $\quad \operatorname{Biochar}(5 \% \mathrm{v} / \mathrm{v})$ and fertiliser $(10 \% \mathrm{v} / \mathrm{v})$.
vii) $\quad$ Basalt $(0.5 \% \mathrm{v} / \mathrm{v})$ and fertiliser $(10 \% \mathrm{v} / \mathrm{v})$.
viii) Biochar $(5 \% \mathrm{v} / \mathrm{v})$, basalt $(0.5 \% \mathrm{v} / \mathrm{v})$, and fertiliser $(10 \% \mathrm{v} / \mathrm{v})$.

One soil treatment of Hydra CX was also applied to the tailings ( $700 \mathrm{ml}$ per plot) to compare the erosion resistance of the test treatments with an already available erosion control product.

For all soil treatments, the total volume of the base layer materials was $\sim 350 \mathrm{ml}$ per plot. Where the amendments of biochar, basalt and $\mathrm{NH}_{4}+$ fertiliser were added the relevant proportions of coir and digestate were reduced in order to maintain similar total quantities for each soil plot.

All of the test treatments received the same top layer of erosion control material which was composed of straw, digestate and guar gum (350 ml per plot). 
Table 7.1: The experimental design of the 11 surrogate soil treatments which were applied to the bare Nantymwyn tailings. $S$ indicates a seeded treatment; $U$ indicates an unseeded treatment.

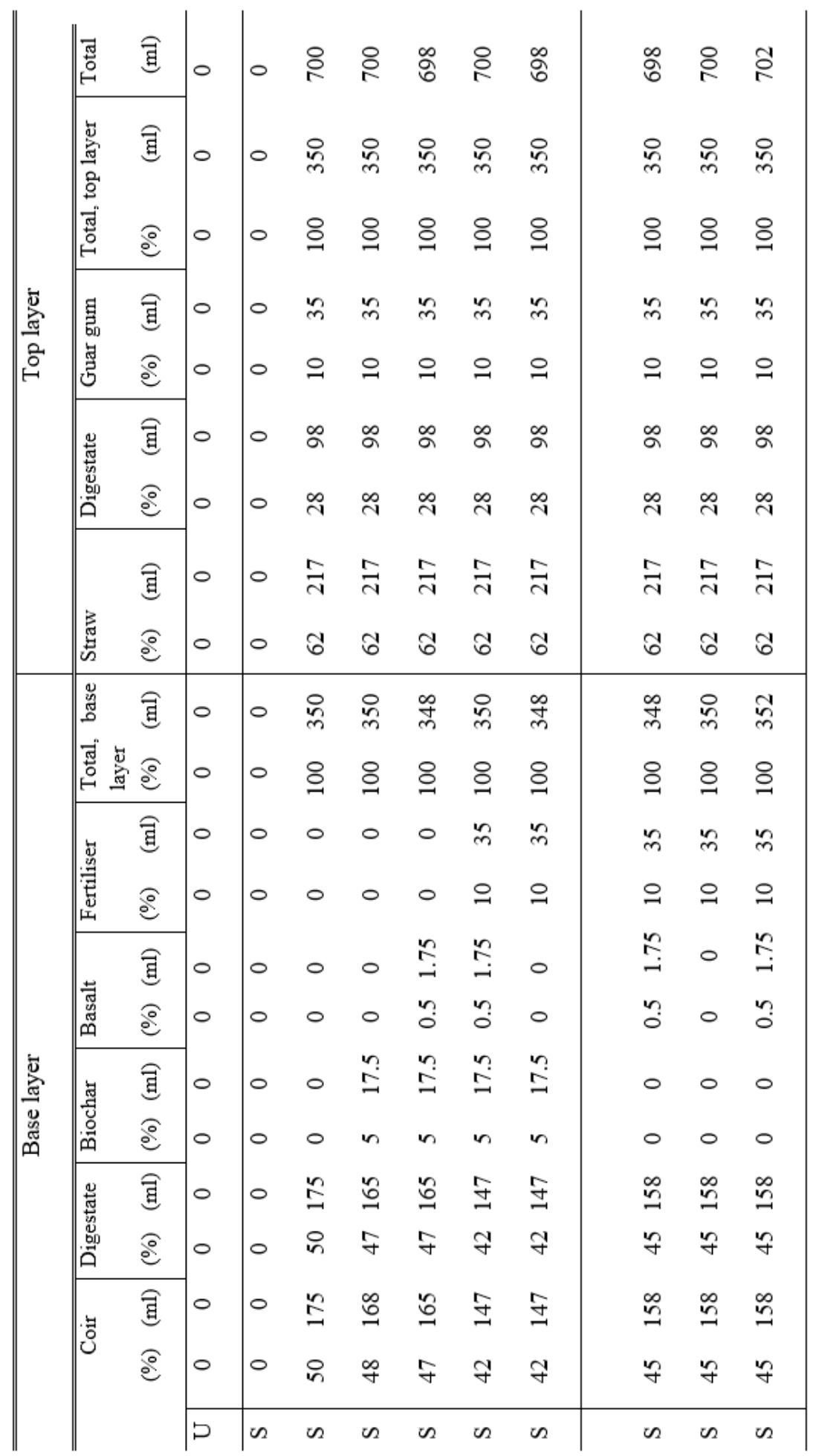




\subsubsection{Preparing the surrogate soil materials}

The dry soil materials were prepared in the laboratory prior to the field trial. For each treatment, the relevant proportions of materials for the base layer were measured using a glass beaker and combined in a plastic bag and labelled with the treatment and replicate number (Figure 7.3). The process was repeated for the top layer of materials, and the two bags were stapled together. The materials were prepared seven days before the field trial began.
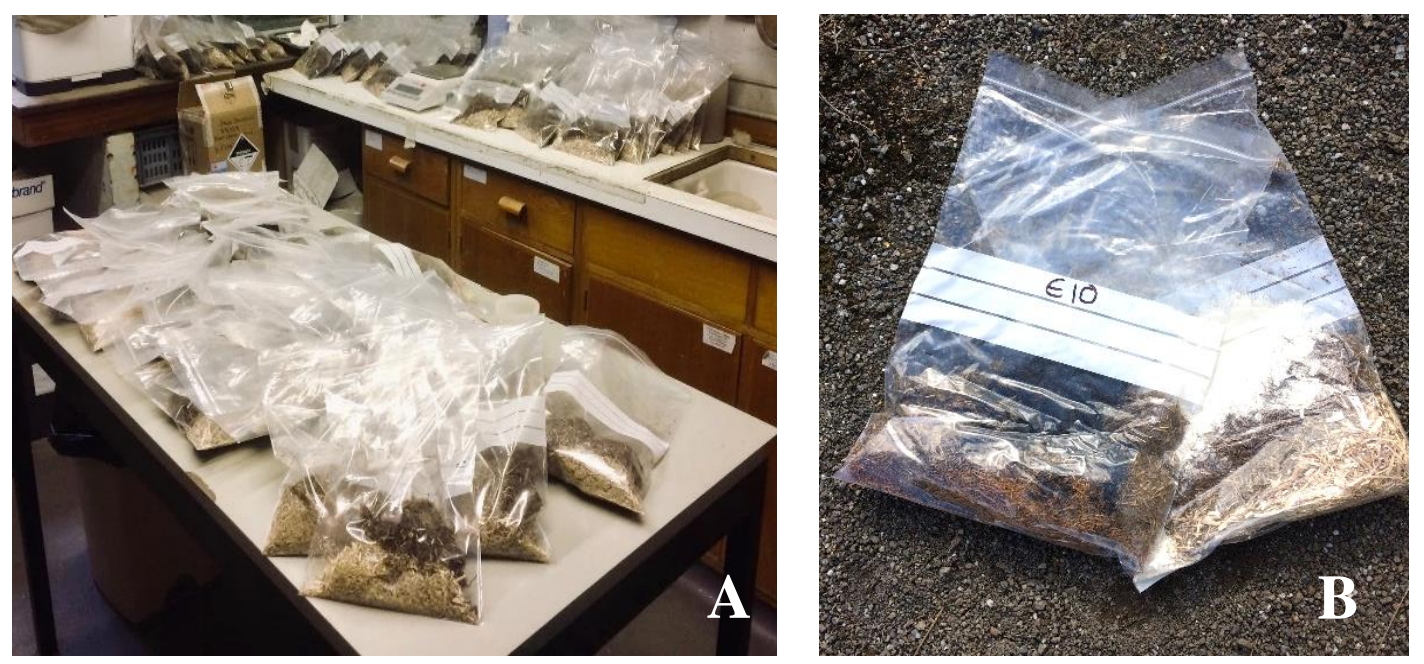

Figure 7.3: A) The sample bags containing the dry materials required for the base layer and top layer, and B) two bags per plot, the base layer and top layer

\subsubsection{Construction of the field trial}

The bagged materials for the plots were transported to Nantymwyn. On site, two retort stands were used to support two electric hand blenders, one for the base layer and one for the top layer. The hand blenders were used to produce consistent mixing conditions for the samples.

One sample was prepared at a time. The two bags of material were emptied into the two separate plastic jugs, and the metals beaters of the blender were placed inside. 
Two separate volumes of $1500 \mathrm{ml}$ municipal water (1:2 dry materials:water) were measured, and the water was slowly poured into the plastic jugs whilst the hand blender operated at a low speed ( $~ 60$ revolutions per minute). A timer was used to allow for 15 minutes of homogenisation.

After 15 minutes, the homogenised base layer material was transferred from the container to a plot using a trowel, as hydroseeding equipment can only be used to apply soil to large areas and was unsuitable for this use. The plots were randomly assigned using R (R Core Team, 2018). The soil material was spread onto the plot to an even 1 $\mathrm{cm}$ depth. A small gap was left around the perimeter for settling and spread of the soil materials (Figure 7.4).

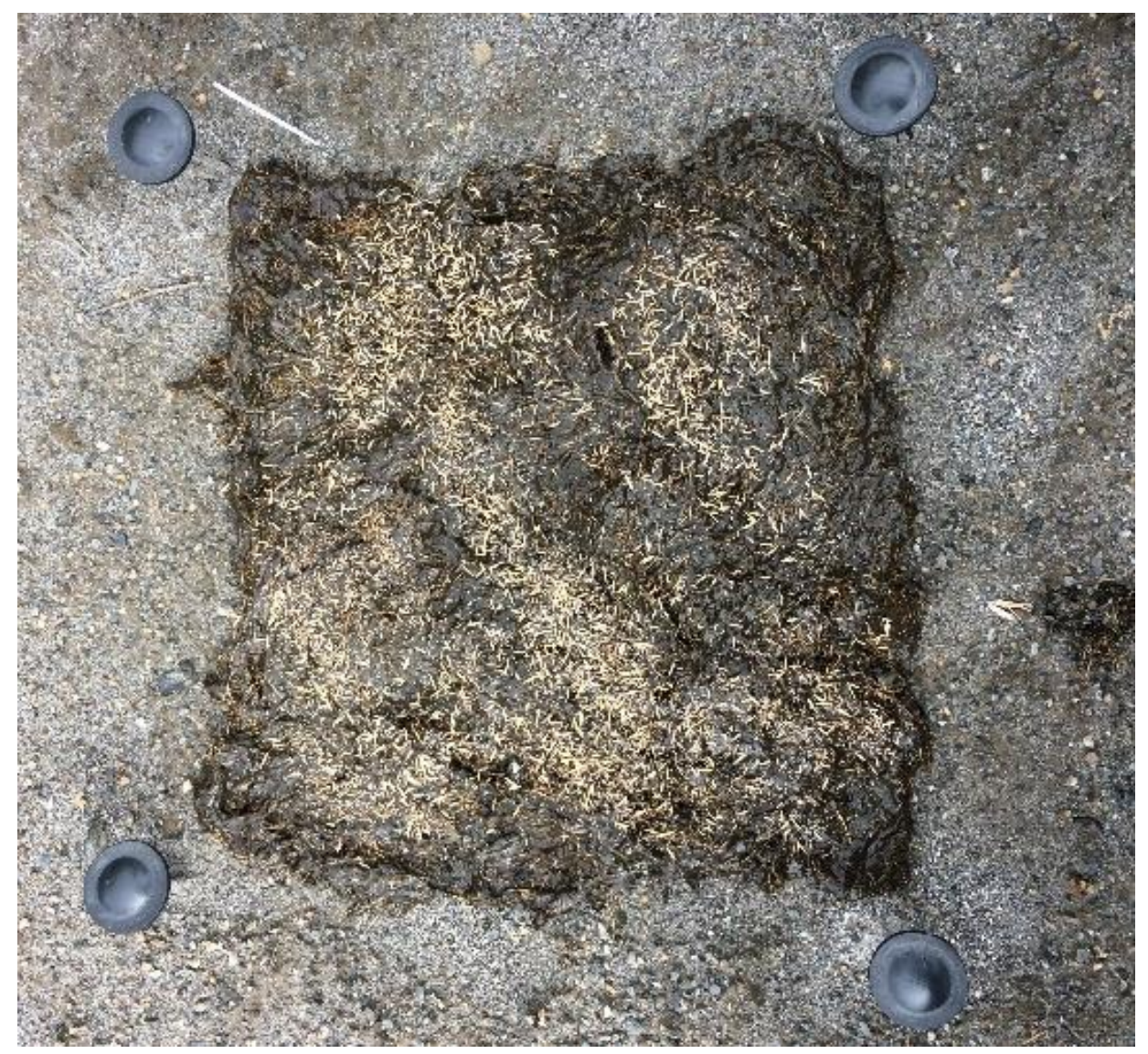

Figure 7.4: The seeded base layer of one plot 
The treatment without amendments was constructed first to reduce the risk of contamination. Following the unamended soils, the soils that did not contain biochar were constructed, and those that contained biochar were last. All instruments and containers were thoroughly cleaned between treatments.

A seeding rate equivalent to $250 \mathrm{~kg} \cdot \mathrm{ha}^{-1}$ was adopted $\left(25 \mathrm{~g} \cdot \mathrm{m}^{-2}\right)$, which was the seeding rate of other cap and cover studies (Gil-Loaiza et al., 2016; Touceda-González et al., 2017). Each $30 \times 30 \mathrm{~cm}^{2}$ plot received $12.5 \mathrm{~g}$ of seed mix (Agrostis capillaris, Agrostis stolonifera, Festuca ovina, Festuca rubra, Anthoxanthum odoratum in equal proportions). After the base layer was applied to the mine tailings, $6.25 \mathrm{~g}$ of seed mix was hand-distributed across the layer.

Next, the top layer of soil material was applied onto the base layer to a depth of $1 \mathrm{~cm}$. The remaining volume of seeds, $6.25 \mathrm{~g}$, were hand distributed onto the plot (Figure 7.5). Each sample was labelled with the corresponding treatment and replicate number and marked on a map.

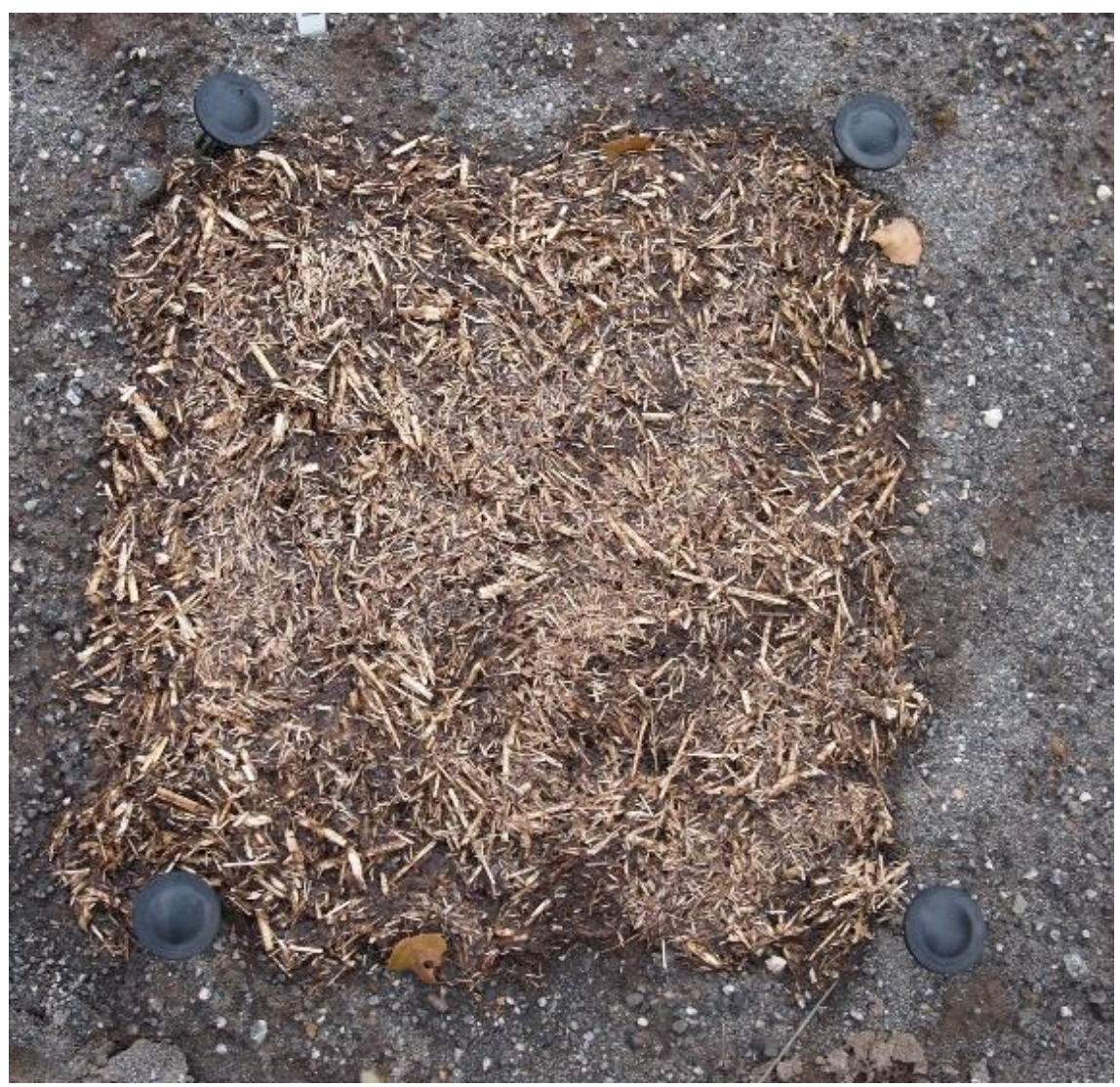

Figure 7.5: The seeded top layer, applied on top of the base layer 
Hydra CX was applied as a single layer. For each plot, $700 \mathrm{ml}$ of material was placed in a plastic container with $1500 \mathrm{ml}$ of water. The electric hand blender homogenised the sample for 15 minutes. After 15 minutes the Hydra CX was transferred to the assigned plot and spread to a $2 \mathrm{~cm}$ depth using a trowel, with a small gap around the perimeter left for spread and settling (Figure 7.6). 12.5 $\mathrm{g}$ of seed mix was hand distributed across the top of the plot.

For the seeded control plots, $12.5 \mathrm{~g}$ of seed mix was hand distributed directly on top of the tailings (Figure 7.7). As it rained every day during the construction of the trial it was not necessary to water the plots.

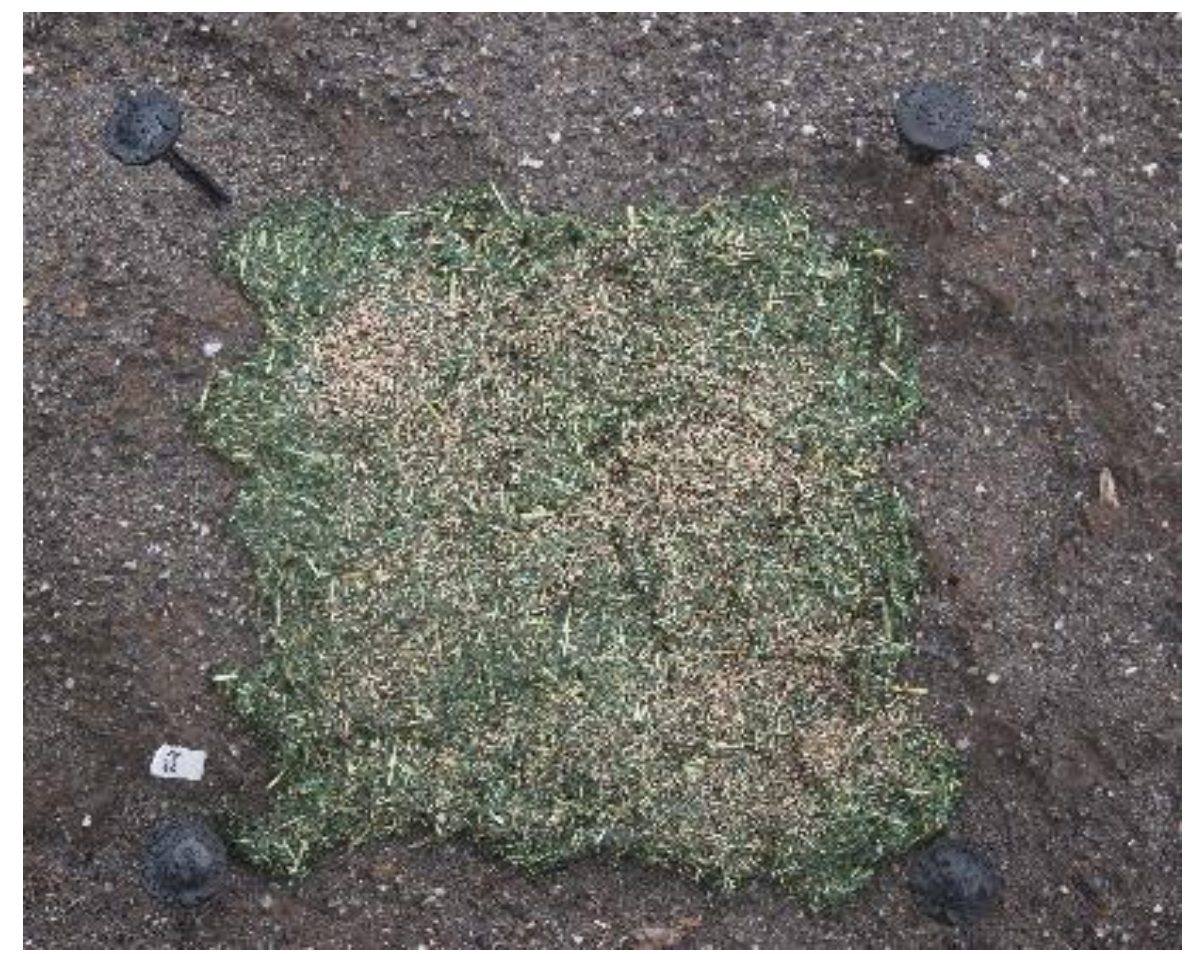

Figure 7.6: One seeded Hydra CX plot 


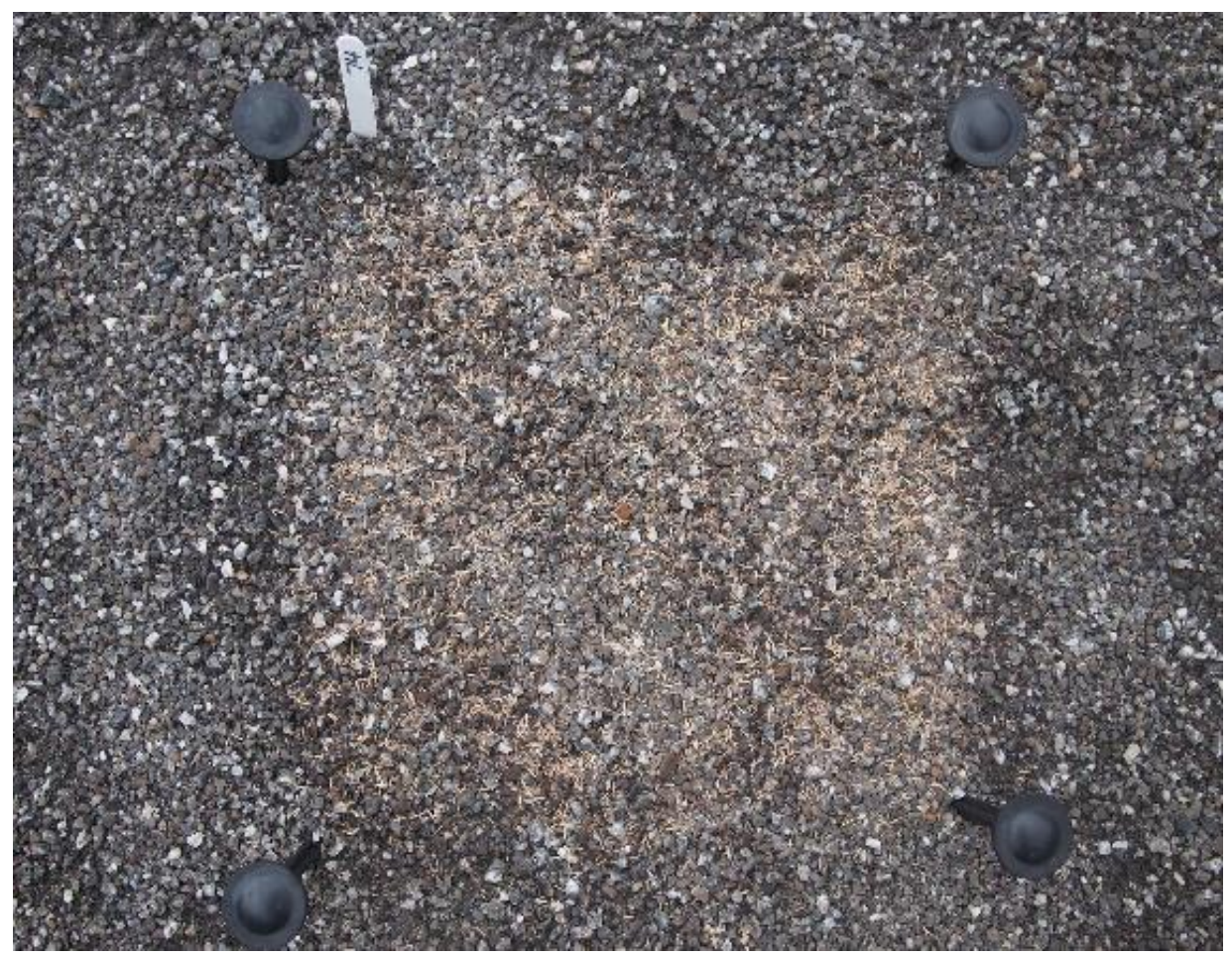

Figure 7.7: One seeded tailings plot

\subsubsection{Data collection}

Temperature data was provided by an in-situ Maxim iButton ${ }^{\circledR}$ (DS1920) temperature logger. The temperature was recorded every hour and provided 12 day and 12 nighttime temperature readings. A mean of the daytime and night-time readings provided the mean daytime high and night-time low temperatures. Precipitation at the trial site was monitored using the Met Office data collected from the weather station at Rhandirmwyn, the location of which is shown in Figure 3.5, and reported in the monthly NRW Water Situation Reports (NRW, 2018 $1,3,6$; NRW, 2019 $9^{1,2,3,7}$ ) and www.Metoffice.gov.uk ${ }^{1}$.

Average sunlight hours per day and snowfall data was retrieved from World Weather Online (www.worldweatheronline.com, 20182; www.worldweatheronline.com, 2019, which provided hourly updates from the local village, Rhandirmwyn. Historic monthly averages were also retrieved (www.worldweatheronline.com, 20181).

The soil moisture deficit for the Nantymwyn area was calculated using data produced by the Met Office Water Situation reports MORECS [Meteorological Office rainfall 
and evaporation calculation system] square 133, which was reported by NRW (NRW, $\left.2018^{3,6,7,8} ; \mathrm{NRW}, 2019^{1,2,3,4}\right)$.

\subsubsection{Seedling emergence and shoot length}

For all treatments, the day on which seedling emergence began was noted. Once seedlings had emerged, weekly measurements were taken of the tallest stem in each plot. Using a ruler, shoot length was measured from the base to the tip of the stem, as suggested in ISO 18763:2016. The measurements were averaged (mean) to provide the mean tallest shoot length of the whole treatment $(n=14)$. Any volunteer species were noted as well as any visual changes to the sample. Large pieces of debris, such as wind-blown branches, were removed from the plot, however, smaller debris such as leaves and small sticks were left.

At the end of each week each plot was photographed. The photos were consolidated by treatment to provide a visual representation of each treatments progress. The first stage of the field trial lasted 14 weeks.

\subsubsection{Data collection after 14 weeks}

The random number generator in $\mathrm{R}$ version 3.4.3 ( $\mathrm{R}$ Core Team, 2018) was used to generate seven replicate numbers from each treatment (77 in total) for sampling at the end of week 14 (14 ${ }^{\text {th }}$ December).

At the end of the 14 weeks, after the shoot length was measured and photographs taken, the shoots in each randomly chosen plot were cut at the base using small metal scissors and were collected in individual plastic sample bags. Both the dead and living biomass were collected.

As an example of the potential biomass production in comparatively uncontaminated soil, at the same time as the samples were collected from the field trial site, biomass samples were also taken from a field adjacent to the mine $(n=7)$. The field predominantly contained Agrostis and Festuca grasses.

The samples were stored in a cool box packed with ice packs until the end of the day (> 7 hours). The temperature of the cool box was monitored every hour during the 
daytime using an Edu Logger Temperature Logger (mean temperature of $0.2 \pm 1.6^{\circ} \mathrm{C}$ ). The daytime air temperatures were between 1 and $3{ }^{\circ} \mathrm{C}$.

As the samples were to undergo freeze drying (for preservation), the samples were required to be frozen as soon as possible after being harvested to limit decay. At the end of each day the grass samples were frozen in a domestic freezer $\left(-19{ }^{\circ} \mathrm{C}\right)$ for $\geq 5$ days until the data collection was complete. The grass samples were then transferred to a laboratory freezer $\left(-18^{\circ} \mathrm{C}\right)$. Transit time was $\sim 90$ minutes.

\subsubsection{Living and dead biomass}

The frozen grass samples were partially defrosted during transfer from the domestic freezer to a laboratory freezer. When the samples were defrosted sufficiently to allow for the separation of the individual grass blades, for each grass sample, the grass blades were divided into living and dead blades. Dead grass blades were those which were visually estimated as $\geq 70 \%$ brown. The dead and living grass blades were bagged separately and marked with the treatment name and replicate number.

The biomass samples remained frozen at $-5{ }^{\circ} \mathrm{C}$ for up to 20 days before being freeze dried in a Thermo Savant MODULYOD-230 vacuum freeze dryer. The living and dead biomass was weighed separately using a Mettler Toledo A3204-S weighing scale. The weights were recorded and calculated as a percentage of the total living and total dead biomass in each replicate.

\subsubsection{Statistical analyses methods}

The randomised experimental design was composed of nine treatments (after omissions) each with 14 repetitions.

The ground cover was qualitatively assessed using a combination of the shoot length measurements, the quantity of biomass produced and the photographs. This allowed for differentiation between grass swards that were tall but with a thin ground cover, and those that were short but densely matted.

A Shapiro-Wilks test confirmed that the the shoot length measurement data were normally distributed $(\mathrm{p} \leq 2.24, \mathrm{~N}=126)$, therefore the mean of all 14 treatments was 
accepted and parametric statistical tests were selected. For shoot length analyses, a T-Test was used to compare the means of two groups $(\mathrm{p} \leq 0.05)$. A one-way ANOVA compared the means of three or more groups $(\mathrm{p} \leq 0.05)$, and a Tukey's post-hoc test informed of any pairwise differences indicated by the ANOVA. A Bonferroni correction was used to control for experiment-wise error. All analyses were completed using the statistical software R, version 5.3.2 (R Core Team, 2018).

The above-ground biomass could only be measured after it was cut. As only half of the samples were collected fewer values were available $(n=7)$. The data were not normally distributed, as determined by a Shapiro-Wilks test $(\mathrm{p} \leq 0.011, \mathrm{~N}=63)$, therefore non-parametric testing was selected for the analysis of biomass production. A Mann-Whitney U-test assessed for differences between two medians $(\mathrm{p} \leq 0.05)$. For comparisons of three or more groups a Kruskal-Wallis with Dunn's post-hoc test was performed with a Bonferroni correction to control for the experiment-wise error rate. The statistical software R (version 5.3.2, R Core Team, 2018) was used for all analyses.

Throughout the text, the sample standard deviation is presented as \pm . 


\subsection{Field Trial - Results, September to December 2018}

At the end of week 14 (late December 2018) the biomass was collected in half of the plots (seven replicates of 11 treatments, $\mathrm{N}=77$ ).

At the same time as biomass samples were collected from the field site, seven biomass samples were also taken from a field adjacent to the mine (Section 7.1.7). The field predominantly contained Agrostis and Festuca grasses (a median of $139.8 \pm$ 20.0 g. $\left.\mathrm{m}^{-2}\right)$.

No biomass grew in the unseeded, untreated plots (Figure 7.8). As these plots could not provide a useful statistical comparison they were omitted from analyses.

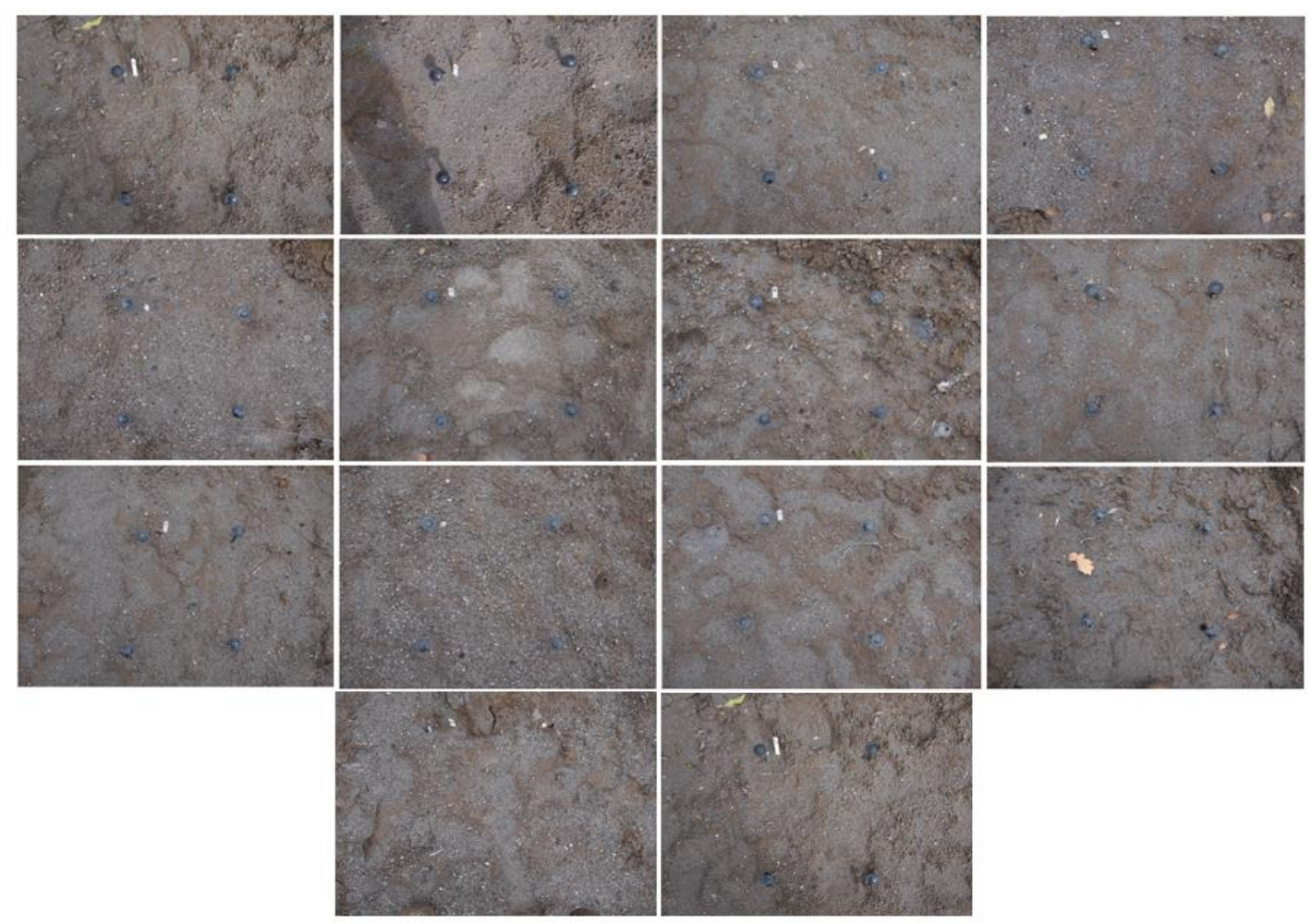

Figure 7.8: The 14 replicates of the $30 \mathrm{~cm}^{2}$ unseeded tailings plots of the field trial (Nantymwyn, December 2018) 
In the seeded tailings plots, where no surrogate soil was applied, the amount of biomass produced was very low (shoot length, mean $0.46 \mathrm{~mm} \pm 0.02, \mathrm{n}=14$. Above-ground biomass, median 0.71 g.m $\mathrm{m}^{-2} \pm 0.61, \mathrm{n}=7$ ) (Figure 7.9). As these values were almost 0 , the data from this treatment did not provide a meaningful statistical comparison with the other treatments, and the seeded tailings treatment was omitted from analysis.

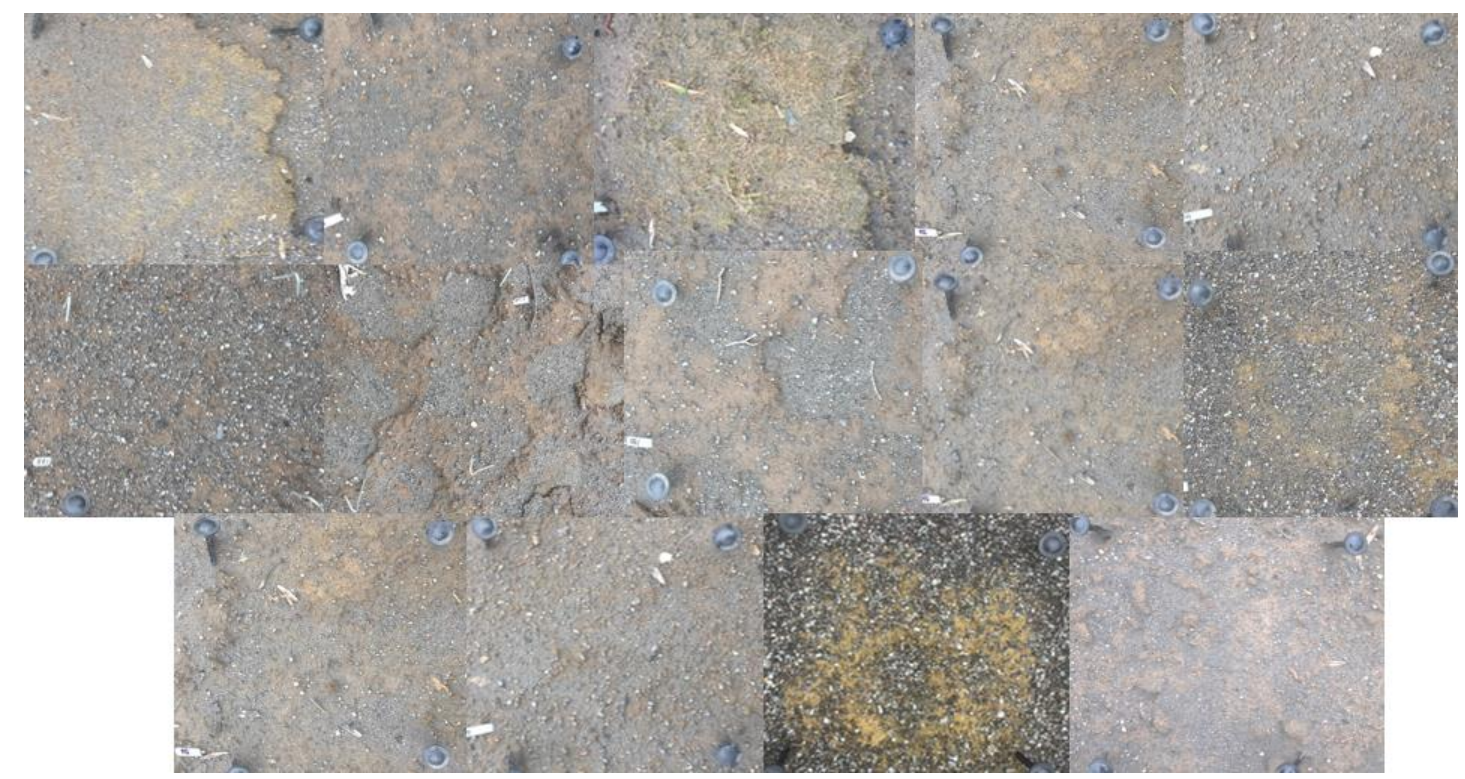

Figure 7.9 The $30 \mathrm{~cm}^{2}$ plots of the seeded tailings treatment at week 14 (Nantymwyn, December 2018)

\subsubsection{Weather conditions}

Weather data provided by the National Climate Information Centre (NCIC), the Met Office (Met Office, 2018 ${ }^{2}$; Met Office, 20197,8), and the Water Situation Reports (NRW, $2018^{3,6,7,8}$ ) were used to compare the weather throughout the field trial with that of the long-term average $(1961-1990)$. 


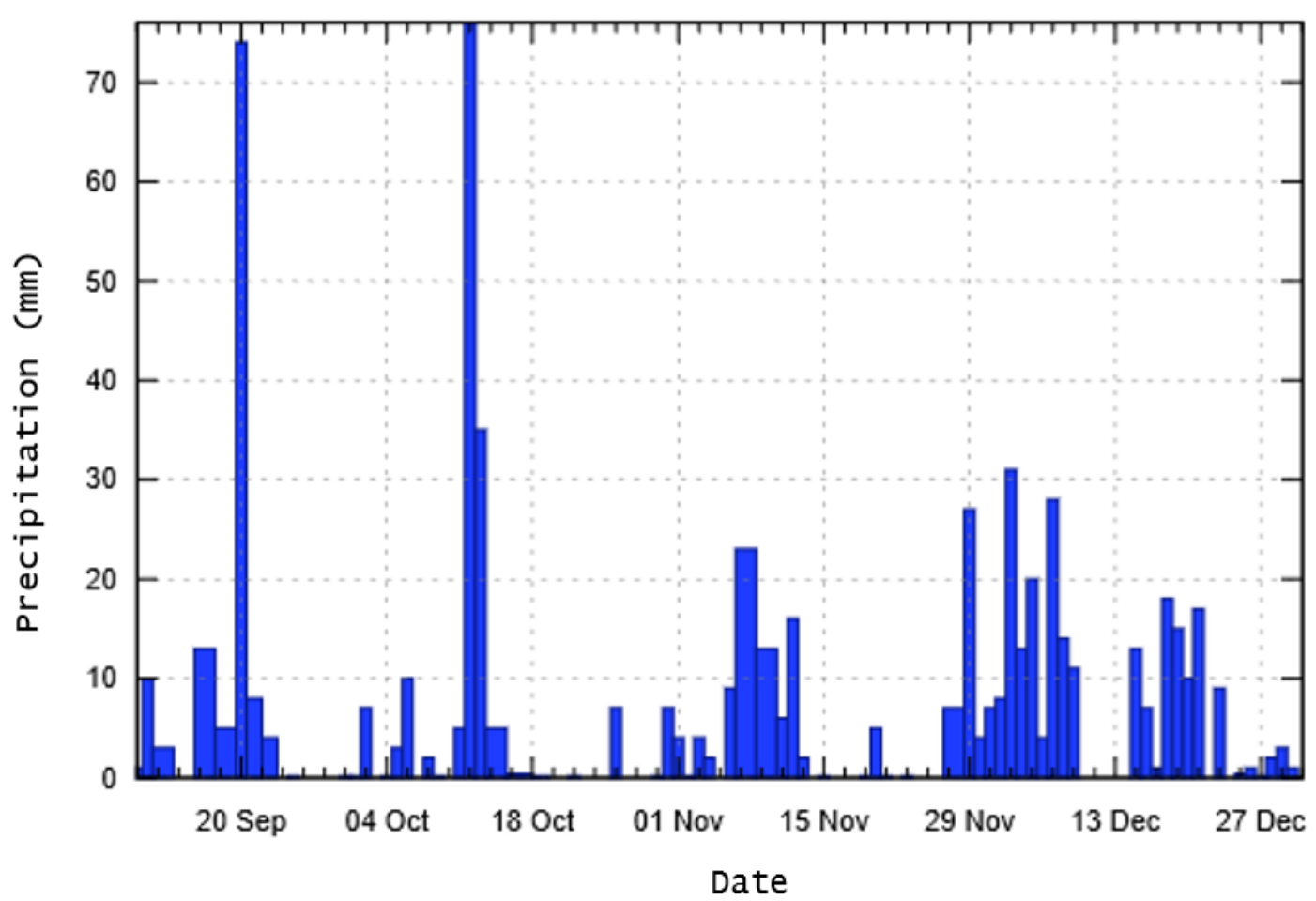

Figure 7.10: Precipitation (mm) at Rhandirmwyn from September to December 2018. Source - www.worldweatheronline.com ${ }^{l}$

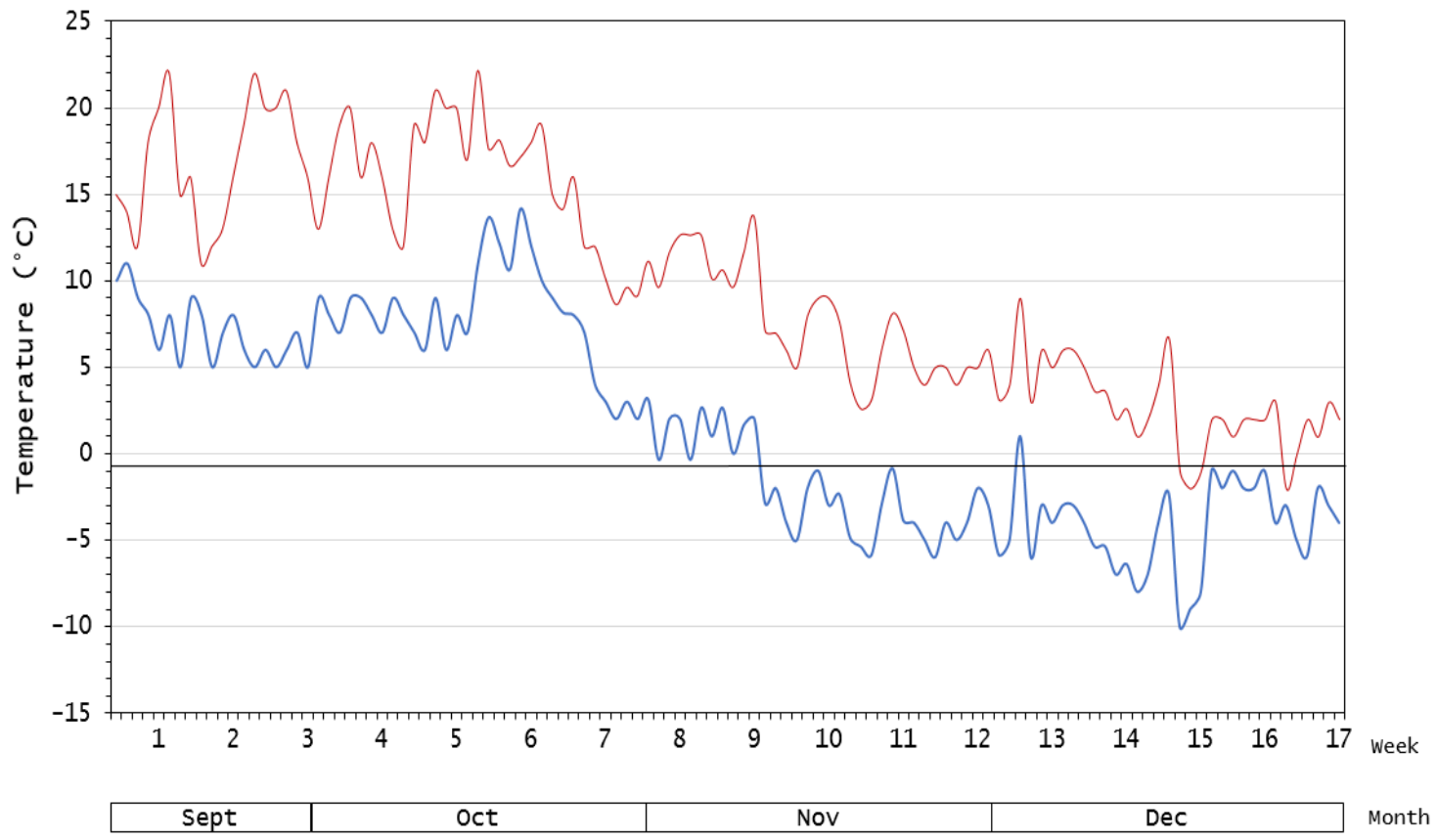

Figure 7.11: Daytime (red) and evening (blue) temperatures $\left({ }^{\circ}\right.$ C) from September to December 2018, as recorded by an in-situ data logger at Nantymwyn. The values have been calculated as a mean of 12 daytime temperatures and 12 evening temperatures 


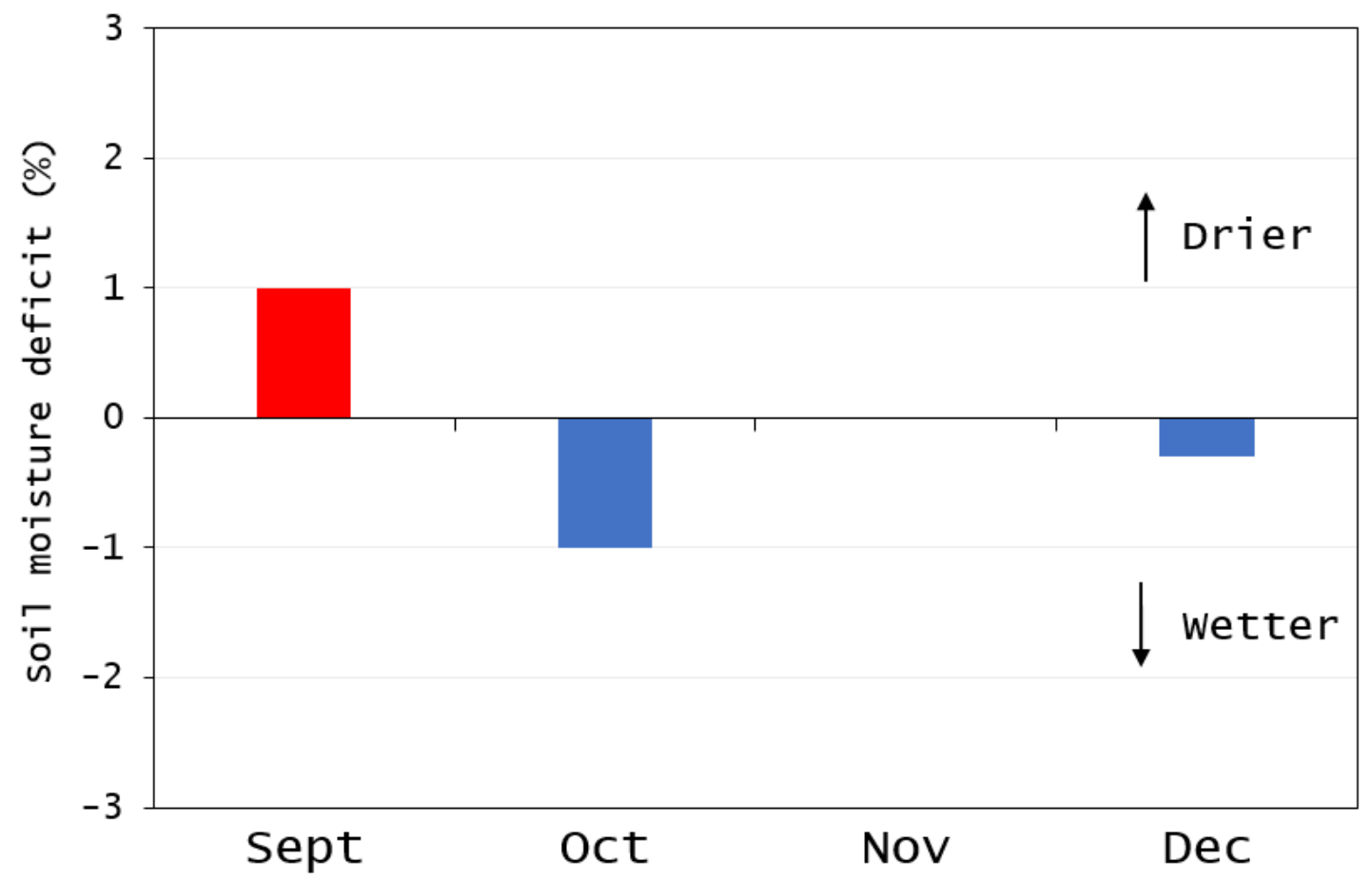

Figure 7.12: Soil-moisture deficit at Nantymwyn, September 2018 to December 2018. Anomalies ( $\mathrm{mm}$ ) from the long-term average (1961 - 1990, as determined from the September to December Water Situation Reports produced by Natural Resources Wales)

In November, the soil-moisture deficit was $0 \%$.

In August, rainfall (Figure 7.10) was $94 \%$ of the long-term average (NRW, 2018 ${ }^{1}$ ) and the mean monthly temperature (Figure 7.11 ) was $0.2^{\circ} \mathrm{C}$ higher than usual (Met Office, $2018^{1}$ ). This created a soil moisture deficit of $1 \%$ in September prior to the start of the field trial (Figure 7.12) (NRW, 2018 ${ }^{1}$ ). After the surrogate soil was applied in September, storms bought heavy rainfall for several weeks immediately after application. Rainfall was $18 \%$ higher than was typical in the month for that region (NCIC, 2019).

Temperatures throughout September and October were close to the seasonal average in the daytime, but lower than usual in the evenings (NCIC, 2019). Storm Callum led to 15 days of rainfall on site throughout October, and the 24-hour rainfall exceeded $77 \mathrm{~mm}$ (NRW, 2018 ${ }^{7}$ ). Despite heavy rains, the temperature remained close to the seasonal average for the first half of October (NCIC, 2019). In the final days of October, temperatures dropped rapidly and caused frosts (Met Office, 201977). In November and December, the valley bottom where Nantymwyn is situated received 
only three or four hours of direct sunlight a day. Sunlight was often obscured by storms and fog, and sunshine hours for the area were less than half the usual amount for the area (Met Office, $2018^{3},{ }^{6}$ ).

From October to December, the soil moisture was higher than the long-term average (1961-1990), which corresponded with the precipitation data for the same period (Figure 7.10). Storm Deirdre caused sleet and heavy snow throughout December, and daytime temperatures, as recorded by the in-situ i-Button data logger, were a mean of $4{ }^{\circ} \mathrm{C}$. Evening temperatures were a mean of $-4{ }^{\circ} \mathrm{C}$ (Figure 7.10).

\subsubsection{Adhesion and germination}

Weekly photographs allowed for the visual assessment of changes to the soil. Notes were made regarding any eroded material which may have been surrounding, and often downhill of, the treatment plots.

Adhesion was immediate with very little settling and spreading of the material. Minimal soil displacement or deformation were observed, and erosion of the plots was visually evaluated as very low during the initial months.

Seedling emergence occurred within the first week in all seeded treatments (Figure 7:13).

Although the grass showed signs on browning in all plots, the biomass and ground cover sustained until the time of sampling in December (Figures $7.14-716$ ). 

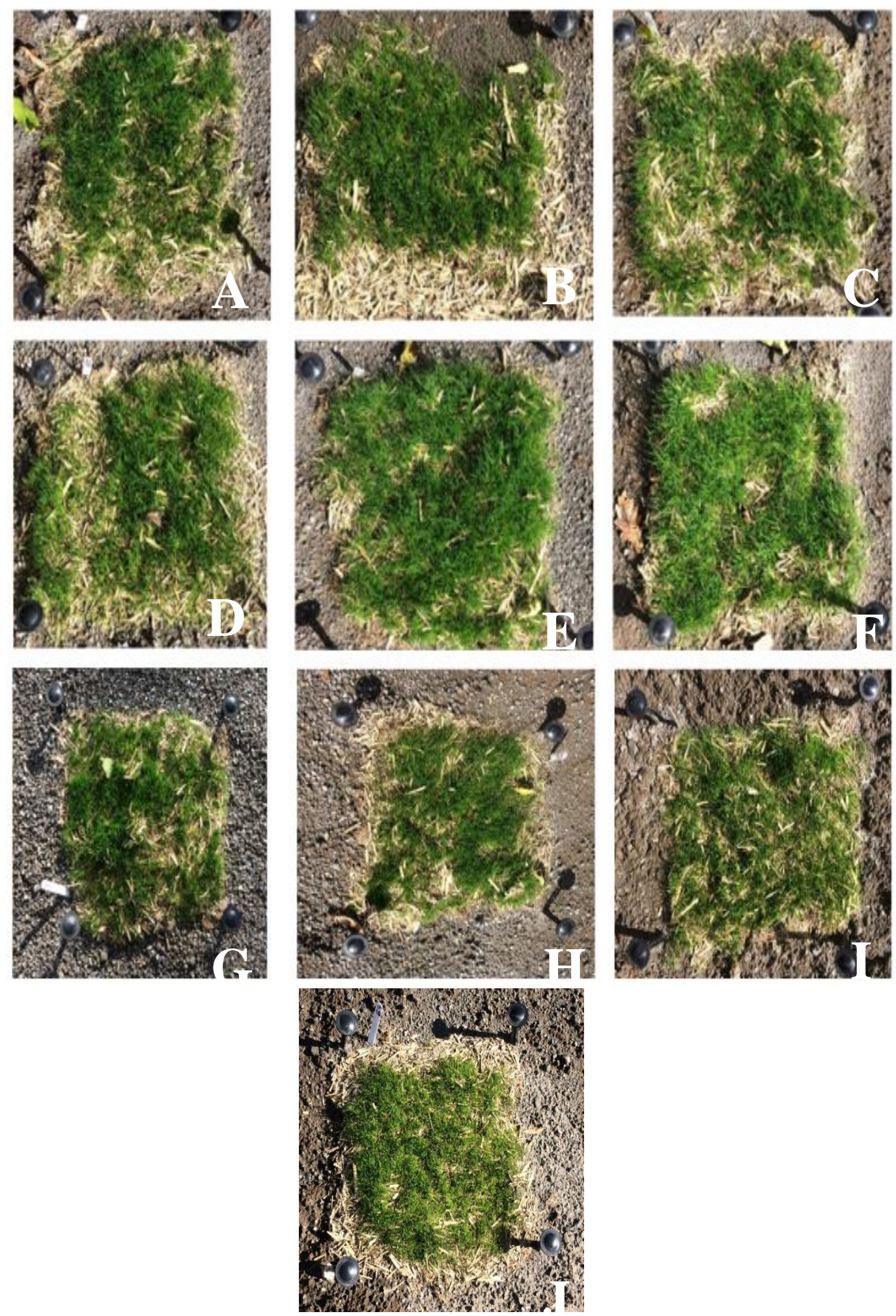

Figure 7.13: One $30 \mathrm{~cm}^{2}$ plot from each of the 10 seeded treatments, one week after application at Nantymwyn. The photos were taken in September 2018. The photos are labelled:

A) Hydra CX B) Unamended C) Biochar D) Basalt E) Fertiliser F) Basalt:fertiliser G)Biochar:fertiliser H) Biochar:basalt I)Biochar:fertsilier J) Biochar:basalt:fertiliser 

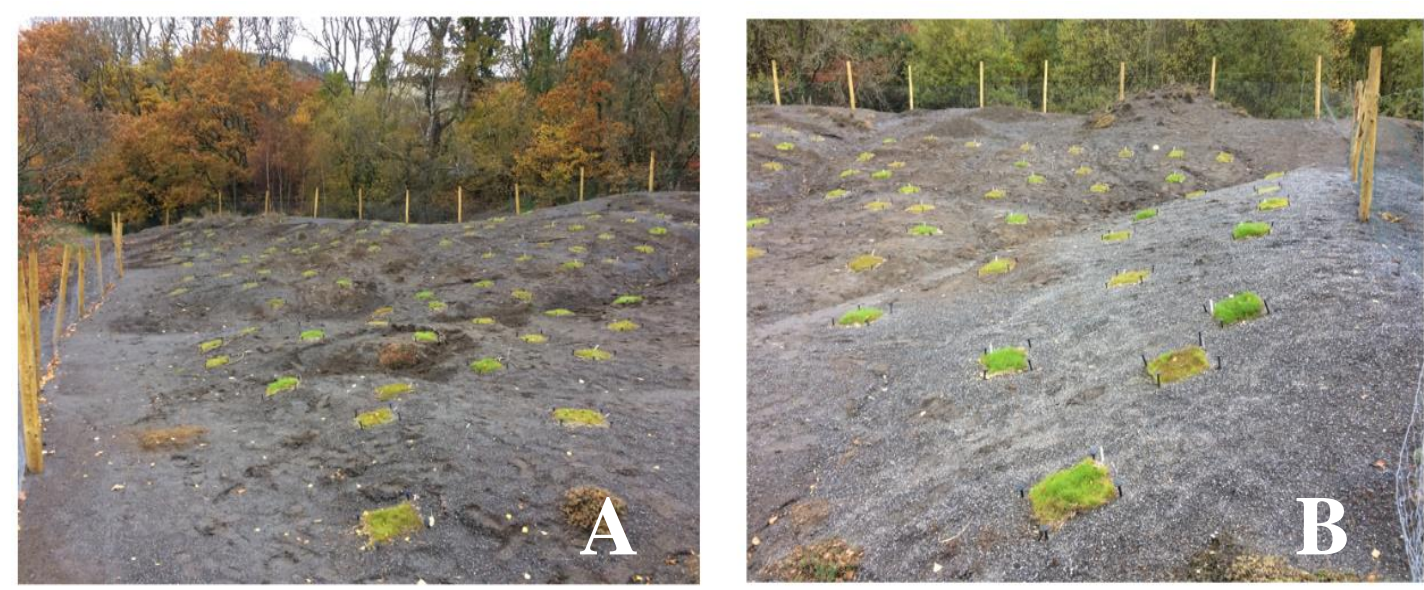

Figures 7.14a and b: Nantymwyn, week 2 (September 2018) of the field trial
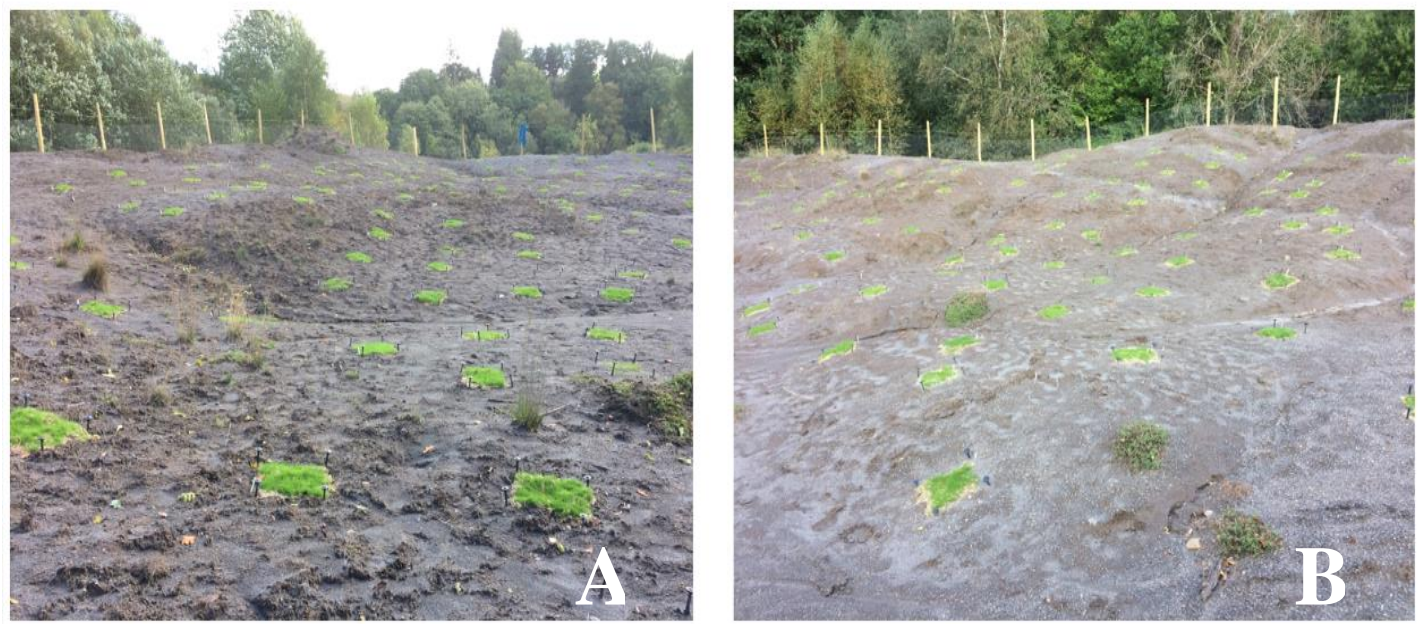

Figures 7.15a and b: Nantymwyn, week 8 (November 2018) of the field trial
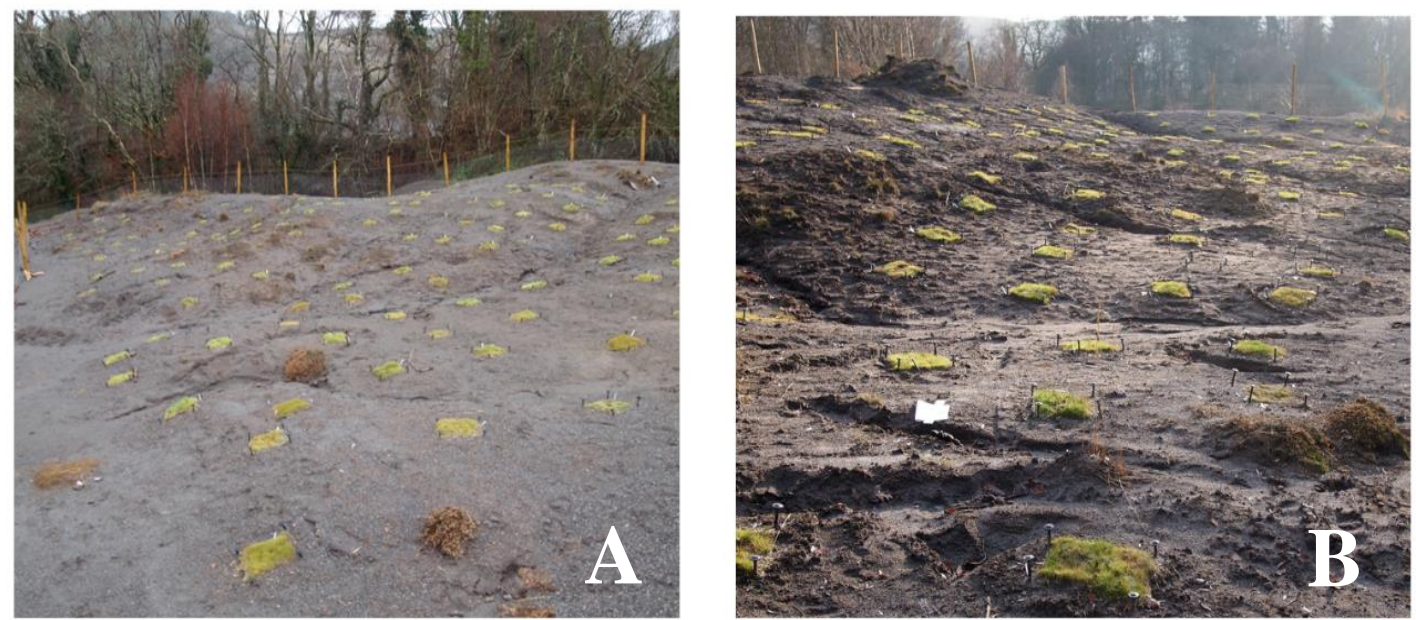

Figures $7.16 a$ and b: Nantymwyn, week 13 (December 2018) of the field trial 
In all treatments, the shoot growth increased steadily until early to mid-November (Figure 7.17). In late November, the temperature fell rapidly and the shoots began to wilt. Heavy rainfall throughout November also flattened the shoots (Figure 7.18), which resulted in a decreased recorded shoot length in some plots and confounded the shoot length data slightly. This presented as a decrease in shoot length from late November onwards.

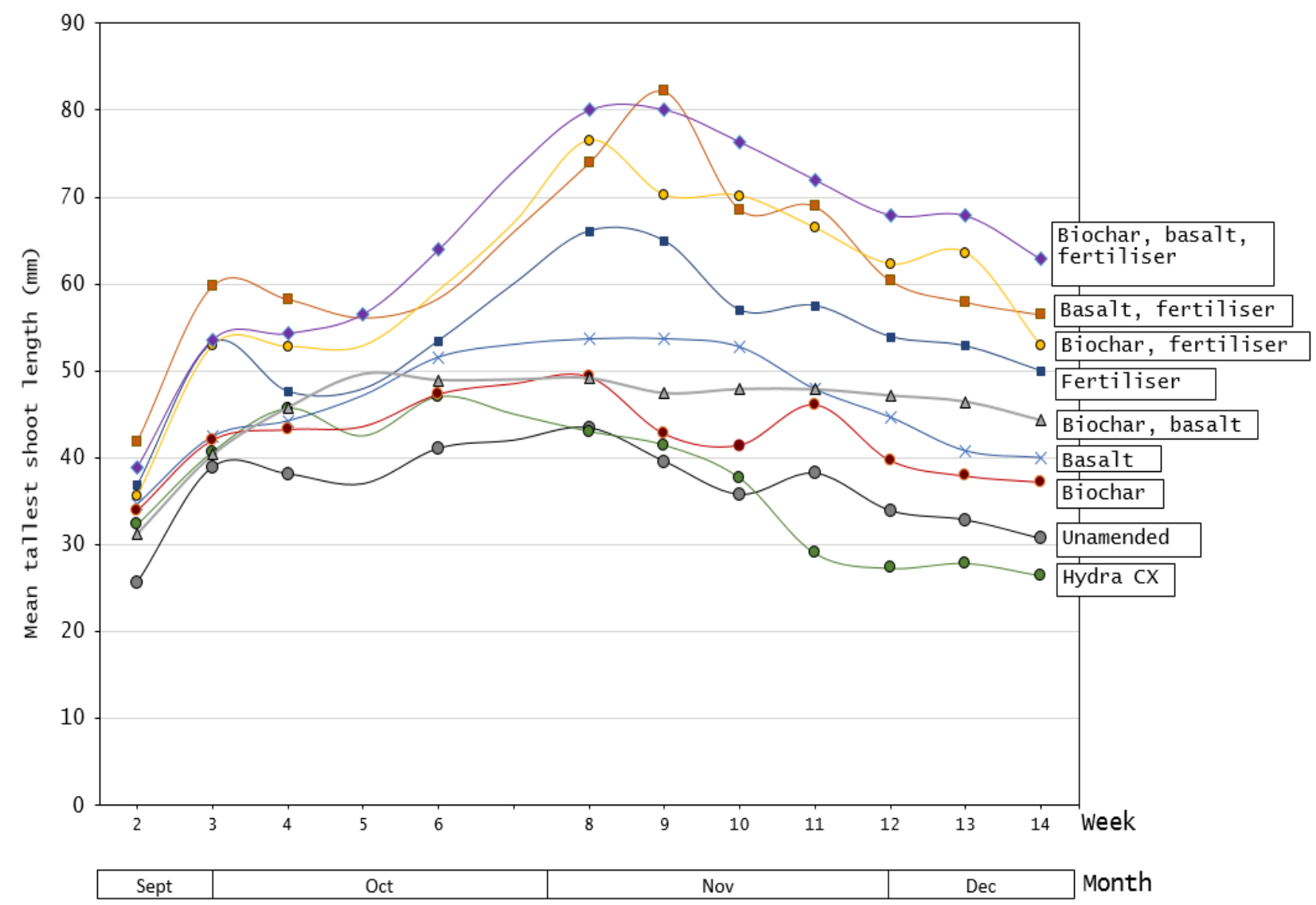

Figure 7.17: The mean tallest shoot length $(\mathrm{mm})$ for each of the nine surrogate soil treatments applied during the field trial at Nantymwyn. Omitting week 7, the measurements were taken weekly from September to December 2018. $N=126$ 

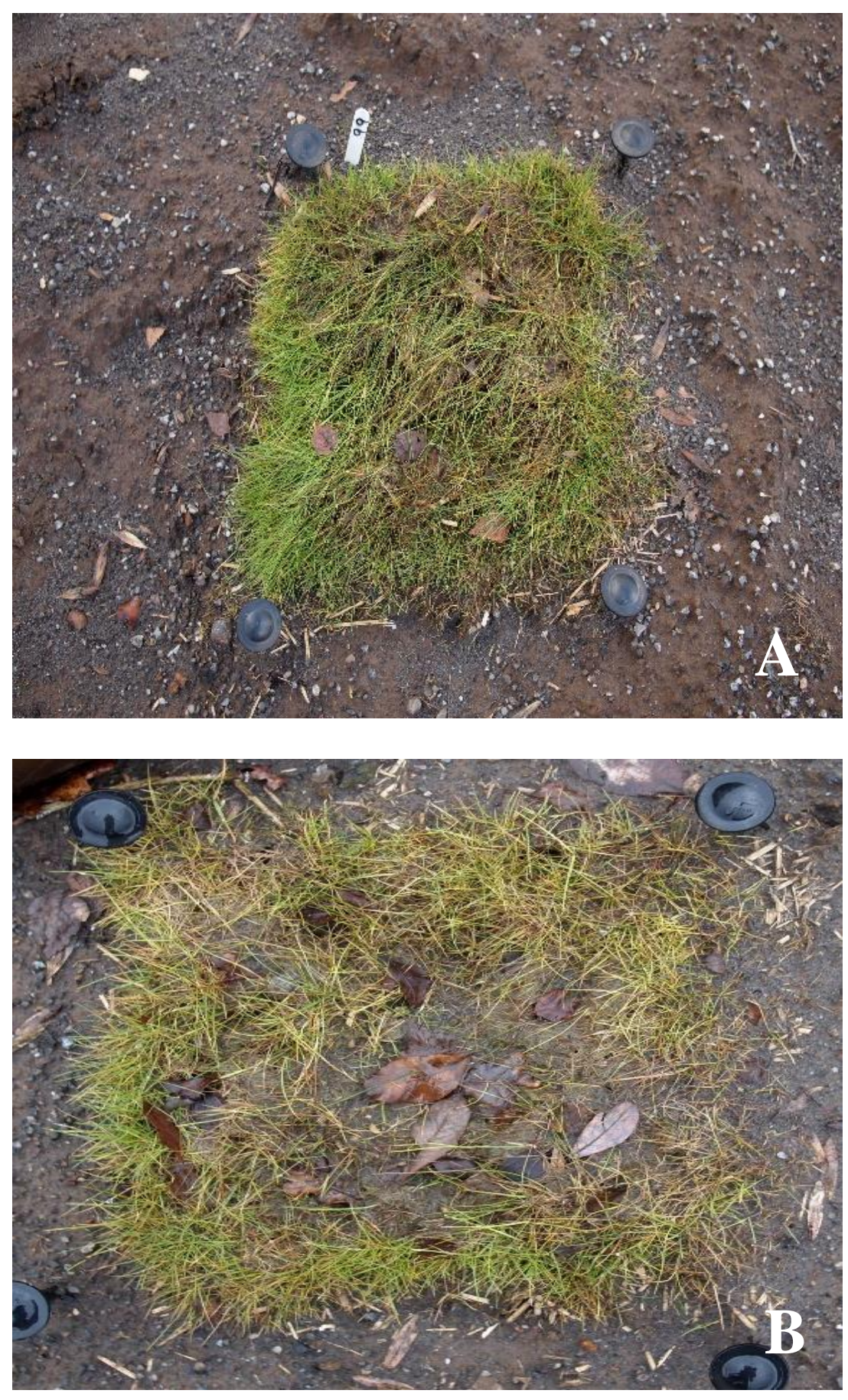

Figure 7.18 a and b: Two $30 \mathrm{~cm}^{2}$ grass plots at the field trial, Nantymwyn. The grass was flattened by heavy rain (November 2018) 


\subsubsection{Hydra CX}

The grass in the Hydra CX treatment grew steadily until week nine, after which the grasses were flattened by the heavy rainfall, as was seen in all treatments. Visually, the grass production, the ground cover and soil adhesion were satisfactory (Figure 7.19). At the time of sampling the Hydra CX plots had produced a median of $10.0 \pm$ 0.3 g.m $\mathrm{m}^{-2}$ biomass $(\mathrm{n}=7)$.

Whilst the Hydra CX did support grass production it was the least successful treatment in terms of biomass yield $\left(10.0 \pm 0.3 \mathrm{~g} \cdot \mathrm{m}^{-2}, \mathrm{n}=7\right)$. At the point of harvest, $30 \%$ of the biomass grown in this treatment had died (Figure 7.20).

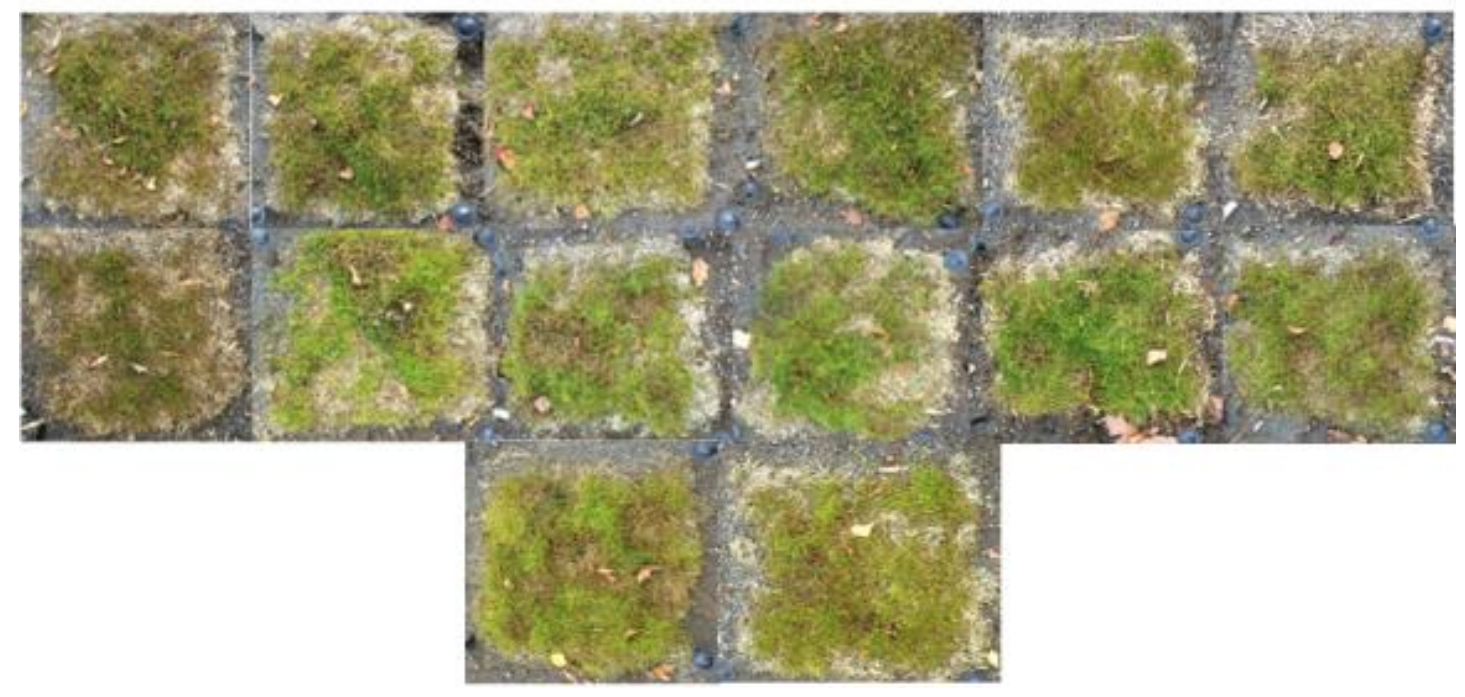

Figure 7.19: $30 \mathrm{~cm}^{2}$ Hydra CX plots at the field trial, Nantymwyn. The photos were taken in week 8 (November 2018)

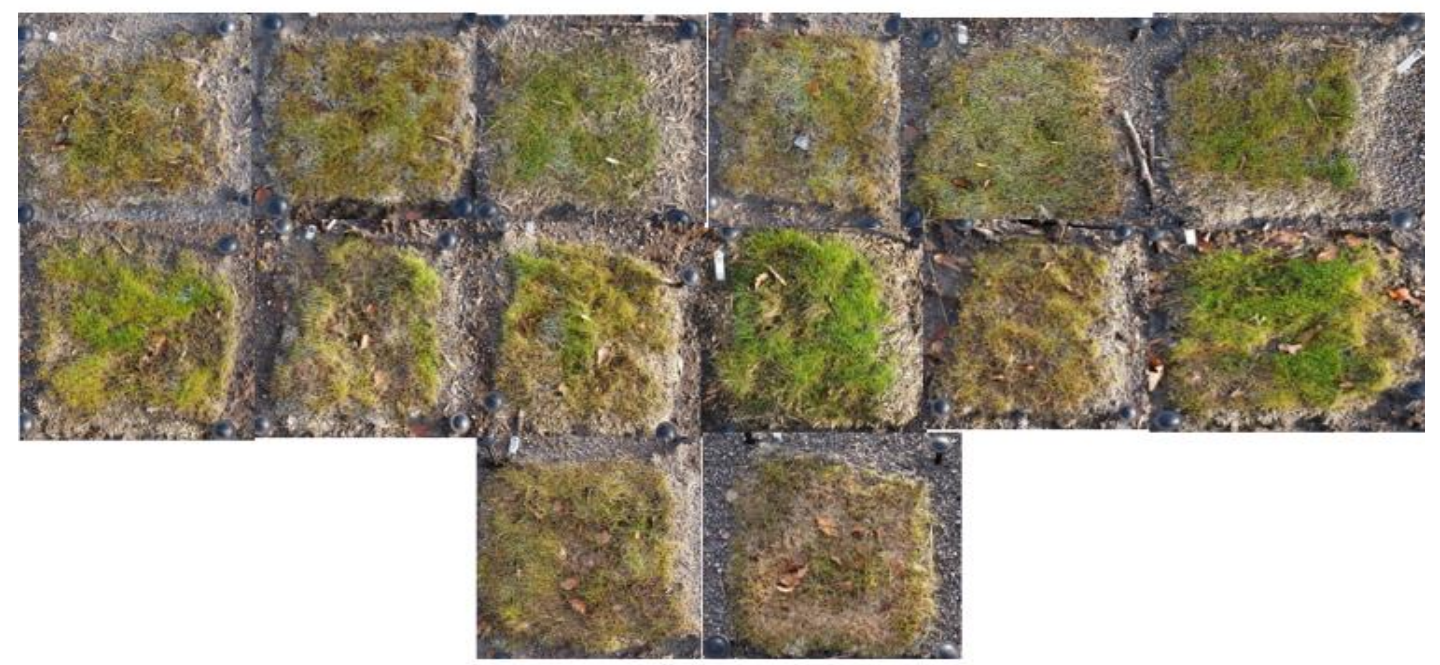

Figure 7.20: $30 \mathrm{~cm}^{2}$ Hydra CX plots at the field trial, Nantymwyn. The photos were taken in week 14 (December 2018) 


\subsubsection{The unamended soil}

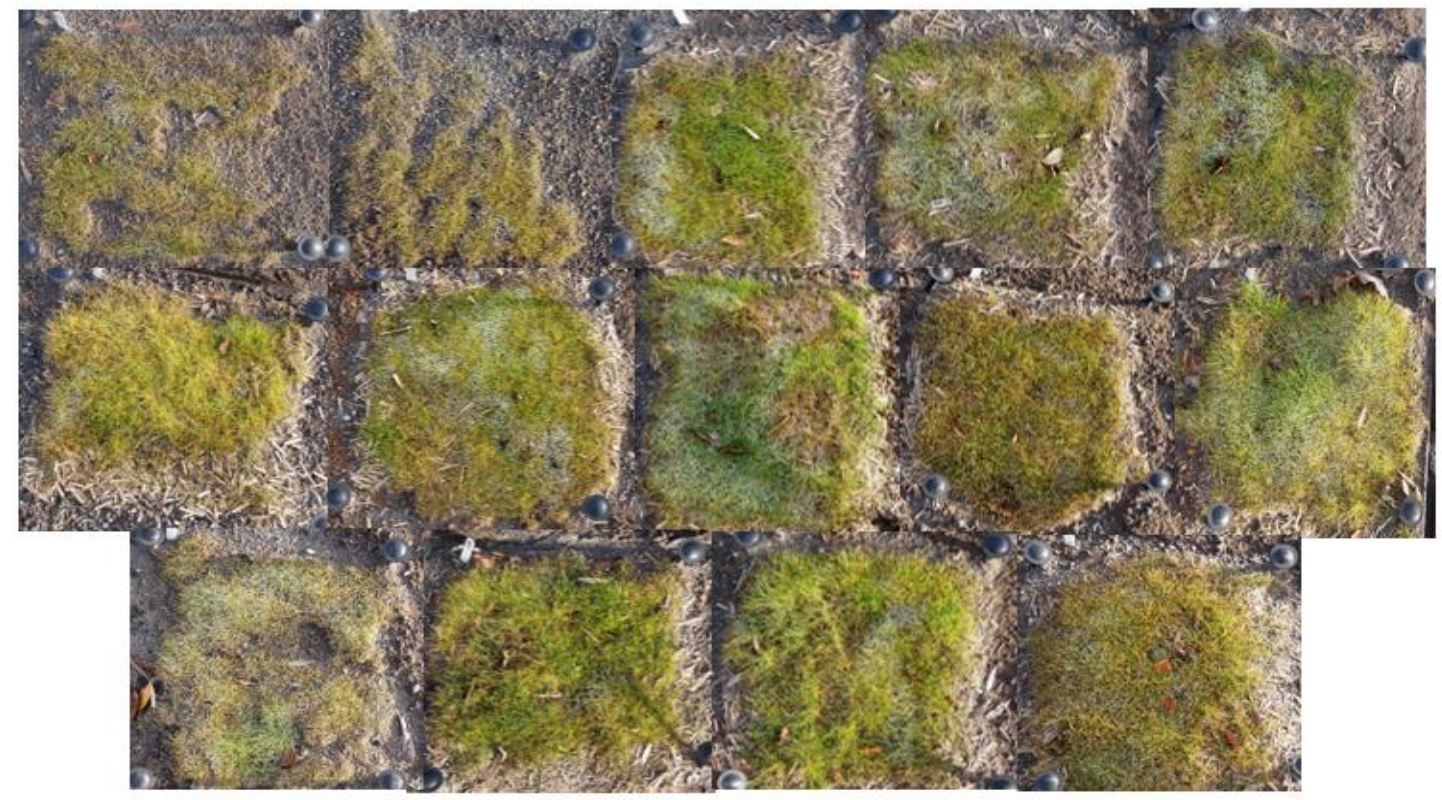

Figure 7.21: The $30 \mathrm{~cm}^{2}$ plots of the unamended treatment of the field trial, Nantymwyn. The photos were taken at week 14 (December 2018) before sample collection

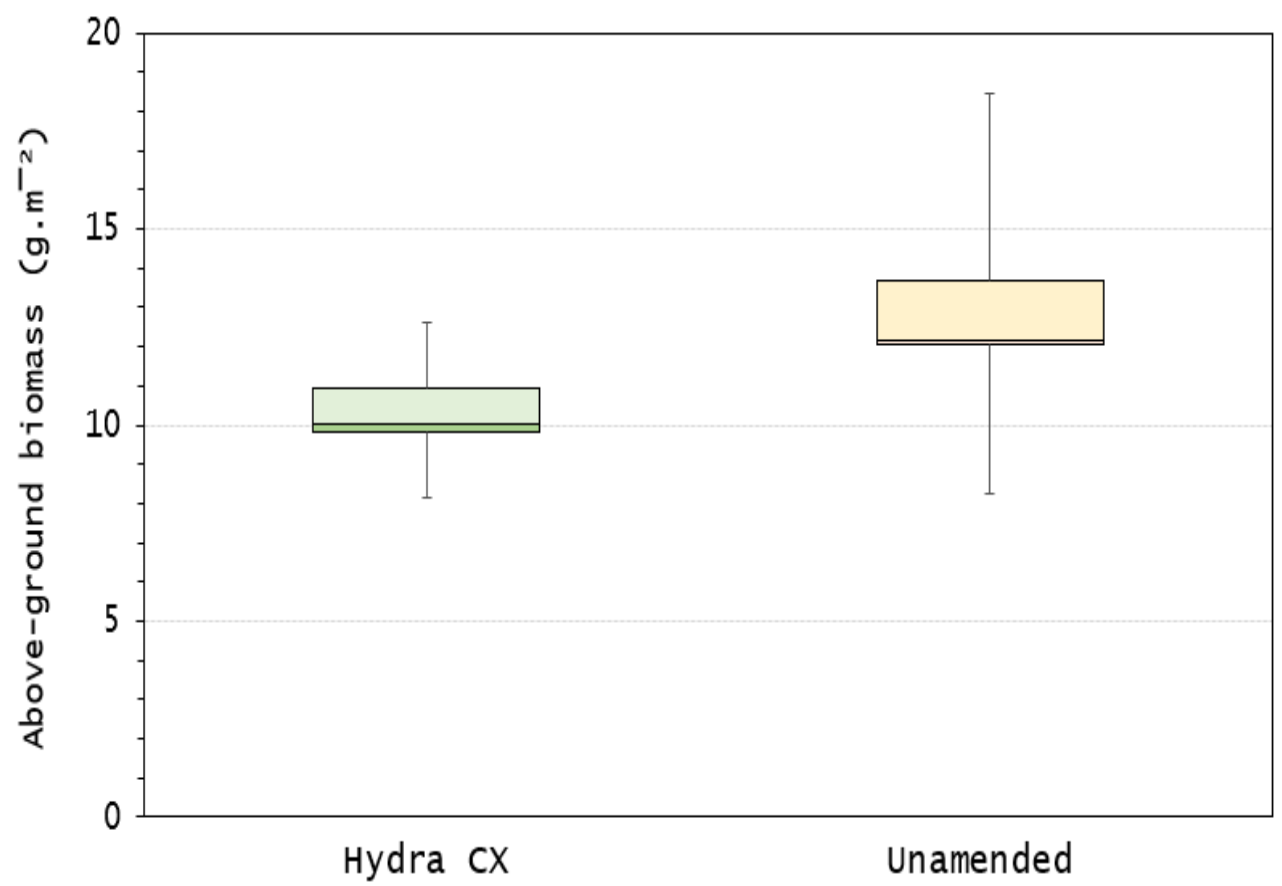

Figure 7.22: Biomass yield $\left(\mathrm{g} . \mathrm{m}^{-2}\right)$ for the Hydra CX and the unamended treatment plots at the time of sampling the Nantymwyn field trial, December $2018(n=7)$ 


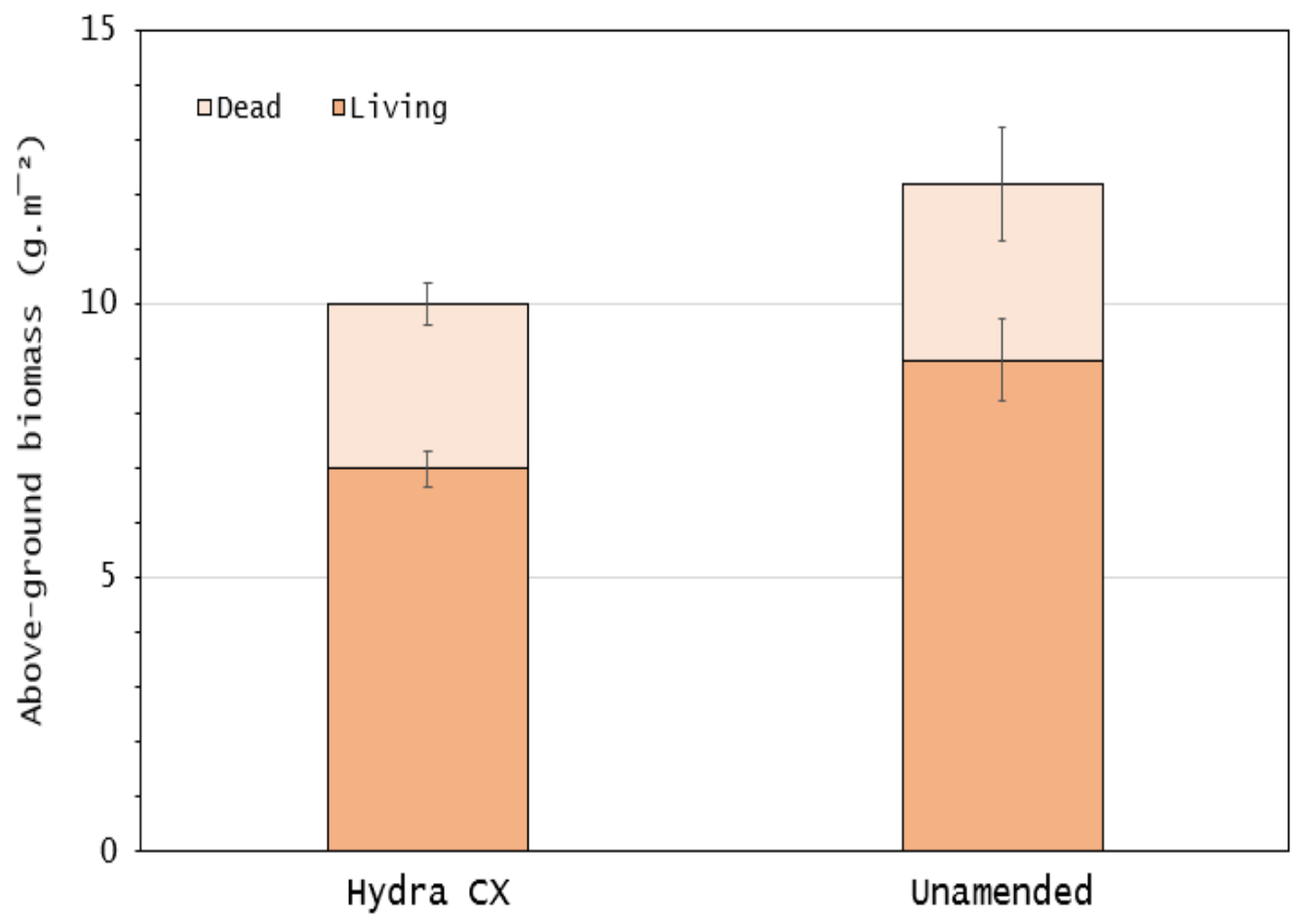

Figure 7.23: The median proportions of dead and living grass in the Hydra CX and the unamended treatments plots after 14 weeks of the Nantymwyn field trial (n=7). Error bars represent the sample standard deviation.

A Mann-Whitney $U$ test determined that the unamended treatment (no biochar, basalt or fertiliser) yielded significantly more biomass than that of the Hydra $\mathrm{CX}$ ( $\mathrm{p} \leq 0.032$, $\mathrm{r}=0.495,12.1$ g. $\mathrm{m}^{-2} \pm 0.7, \mathrm{n}=7$, Figure 7.22). As biomass was greater in the unamended treatment (Figure 7.22) and shoot length was comparable for both the unamended and Hydra CX treatments (Figure 7.17), the unamended soil treatment produced a denser ground cover.

At week 14, 74\% of the biomass in the unamended treatment was still alive, $4 \%$ more than the Hydra CX (Figure 7.23). 


\subsubsection{Single-amendment soils}

The single-amendment surrogate soils were those which contained:

- Only biochar,

- Only basalt, or

- Only fertiliser

\subsubsection{Shoot length}

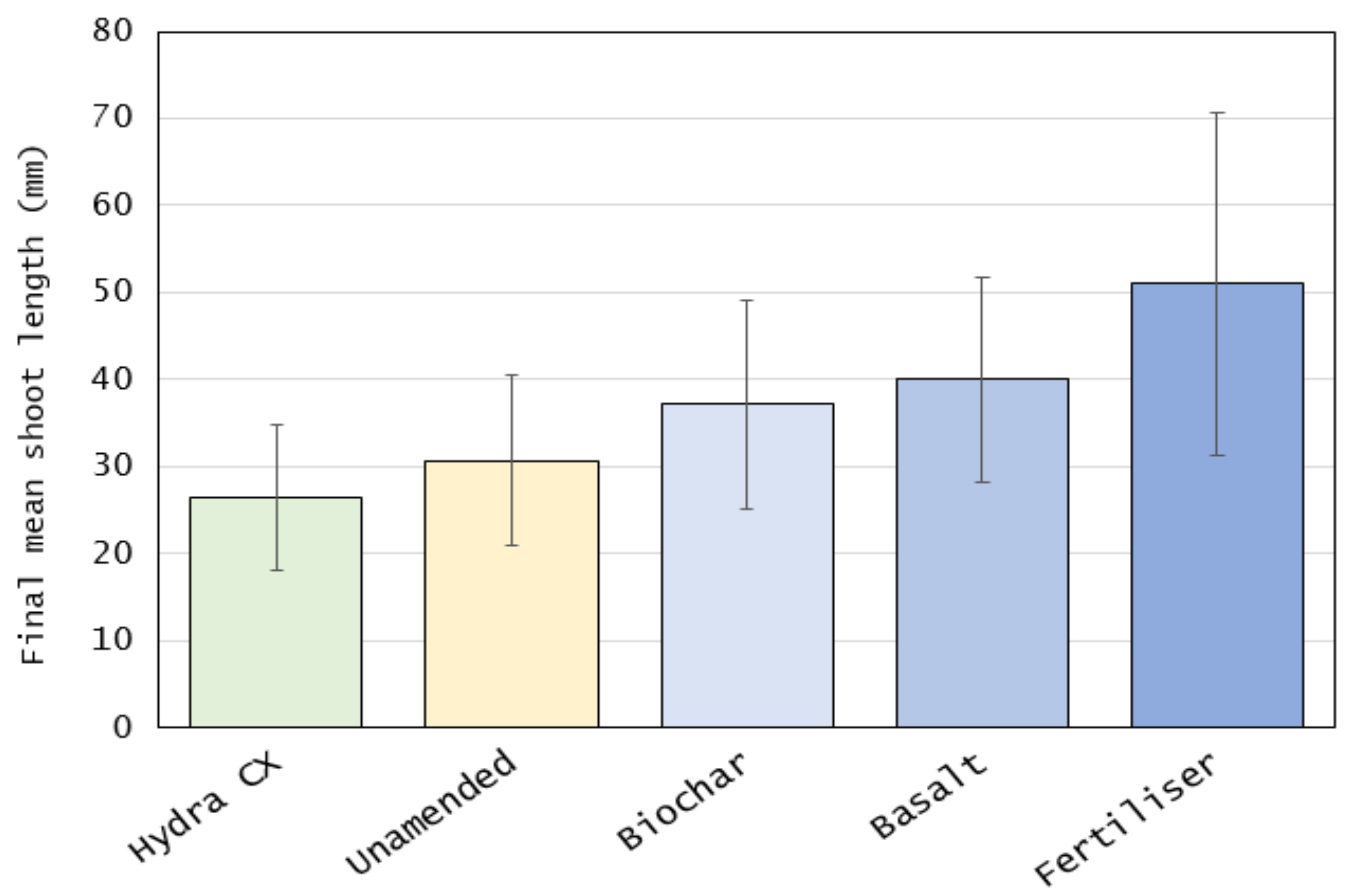

Figure 7.24: The mean final tallest shoot ( $\mathrm{mm}$ ) of the grass produced by the Hydra CX, the unamended treatment, and the single-amendment treatments after 14 weeks of the field trial at Nantymwyn. The samples were collected in December 2018.

For all treatments, $n=14$. Error bars represent the sample standard deviation. 
Table 7.2: The mean tallest shoot length $(\mathrm{mm})$ of the grass in each of the three singleamendment treatments and the Hydra CX plots at the Nantymwyn field trial. The data was collected after 14 weeks, in December 2018. \pm refers to the sample standard deviation.

\begin{tabular}{cccccc}
\hline \hline Treatment & $\mathrm{n}$ & $\begin{array}{c}\text { Mean } \\
(\mathrm{mm})\end{array}$ & $\begin{array}{c} \pm \\
(\mathrm{mm})\end{array}$ & $\begin{array}{c}\text { Min } \\
(\mathrm{mm})\end{array}$ & $\begin{array}{c}\text { Max } \\
(\mathrm{mm})\end{array}$ \\
\hline Hydra CX & 14 & 26 & 8 & 10 & 41 \\
Unamended & 14 & 30 & 9 & 15 & 50 \\
Biochar & 14 & 37 & 12 & 10 & 60 \\
Basalt & 14 & 40 & 12 & 10 & 50 \\
Fertiliser & 14 & 51 & 20 & 11 & 79 \\
\hline
\end{tabular}

The mean final shoot length of the grass grown in the fertiliser treatment was significantly greater than that of the Hydra $\mathrm{CX}(\mathrm{p} \leq 0.001)$ and the unamended soil treatment $(\mathrm{p} \leq 0.001)($ ANOVA: F:[4, 64] = 6.76) (Table 7.2 and Figure 7.24). 


\subsubsection{Biomass}

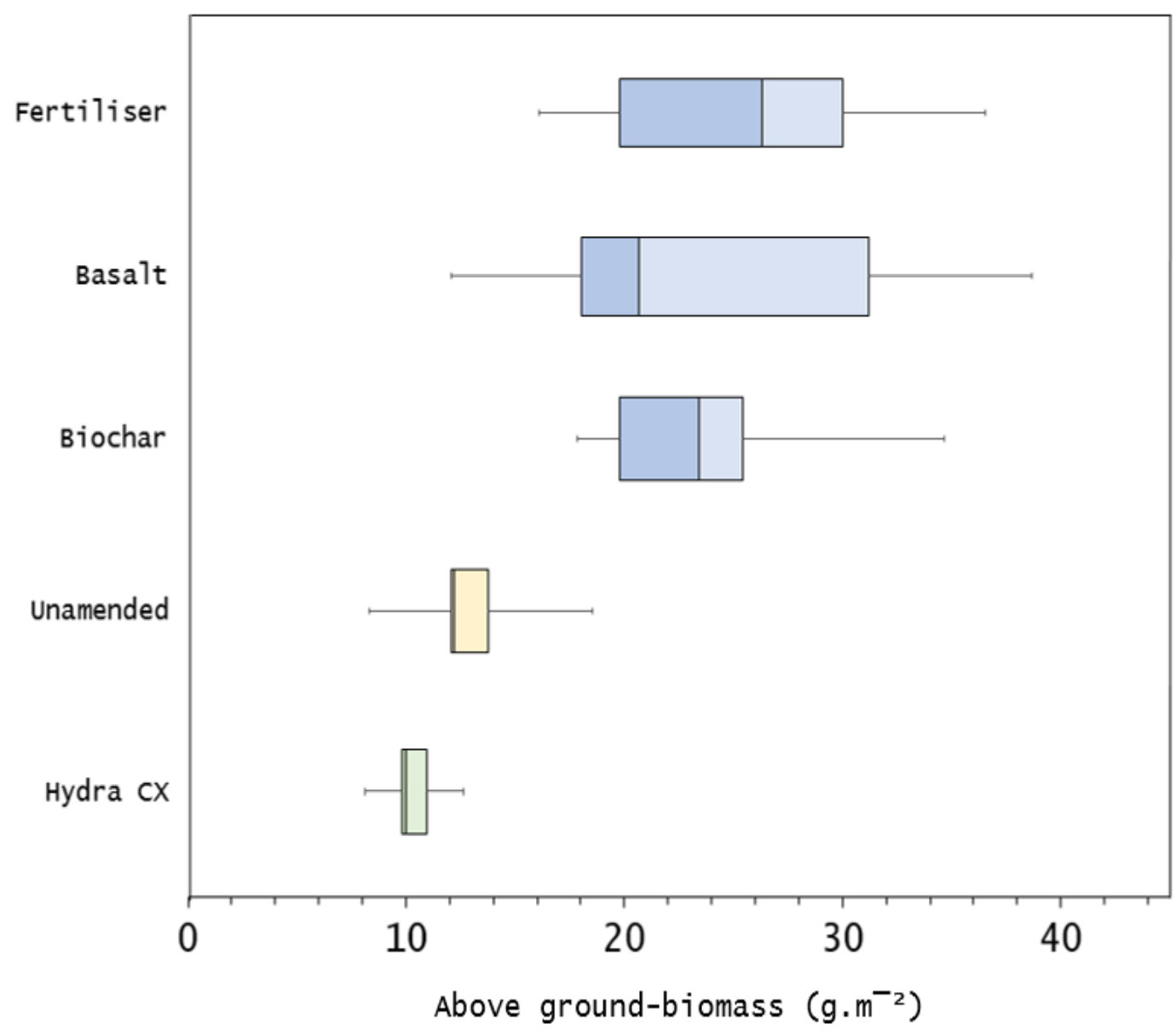

Figure 7.25: Above-ground biomass $\left(g . \mathrm{m}^{-2}\right)$ which was produced by the Hydra CX, the unamended treatment, and the single-amendment treatments trialled at the Nantymwyn field trial, September to December 2018. The samples were collected at week 14, December 2018. For each treatment, $n=7$ 
Table 7.3: The median weight $\left(g . \mathrm{m}^{-2}\right)$ of dried above-ground biomass that was produced by the Hydra CX, the unamended treatment, and the single-amendment treatments of the Nantymwyn field trial after 14 weeks. The samples were collected in December 2018. \pm indicates the sample standard deviation.

\begin{tabular}{cccccc}
\hline Treatment & $\mathrm{n}$ & $\begin{array}{c}\text { Median } \\
\left(\mathrm{g} . \mathrm{m}^{-2}\right)\end{array}$ & $\begin{array}{c} \pm \\
\left(\mathrm{g} . \mathrm{m}^{-2}\right)\end{array}$ & $\begin{array}{c}\text { Min } \\
\left(\mathrm{g} . \mathrm{m}^{-2}\right)\end{array}$ & $\begin{array}{c}\text { Max } \\
\left(\mathrm{g} . \mathrm{m}^{-2}\right)\end{array}$ \\
\hline Hydra CX & 7 & 10.0 & 0.3 & 8.1 & 12.6 \\
Unamended & 7 & 12.1 & 0.7 & 8.2 & 18.4 \\
Biochar & 7 & 23.3 & 1.3 & 17.8 & 34.5 \\
Basalt & 7 & 20.6 & 2.2 & 12.0 & 38.6 \\
Fertiliser & 7 & 26.2 & 1.8 & 16.0 & 36.4 \\
\hline
\end{tabular}

A Kruskal-Wallis test determined that all amendments had a significant impact on biomass yield when compared to the unamended treatment $(H[3]=11.93, p \leq 0.008$, $\mathrm{N}=28$ ). A Dunn's post-hoc test indicated that the biochar treatment produced significantly more biomass than the unamended treatment $(63 \%, \mathrm{p} \leq 0.006)$, as did the basalt treatment $(69 \%, \mathrm{p} \leq 0.009)$. However, as a single amendment, fertiliser had the greatest impact on grass growth (a 73\% increase in biomass compared to the unamended treatment, $\mathrm{p} \leq 0.002$ ) (Table 7.3 and Figure 7.25).

No significant differences existed between the biochar, basalt, or fertiliser treatments. 


\subsubsection{Living and dead biomass}

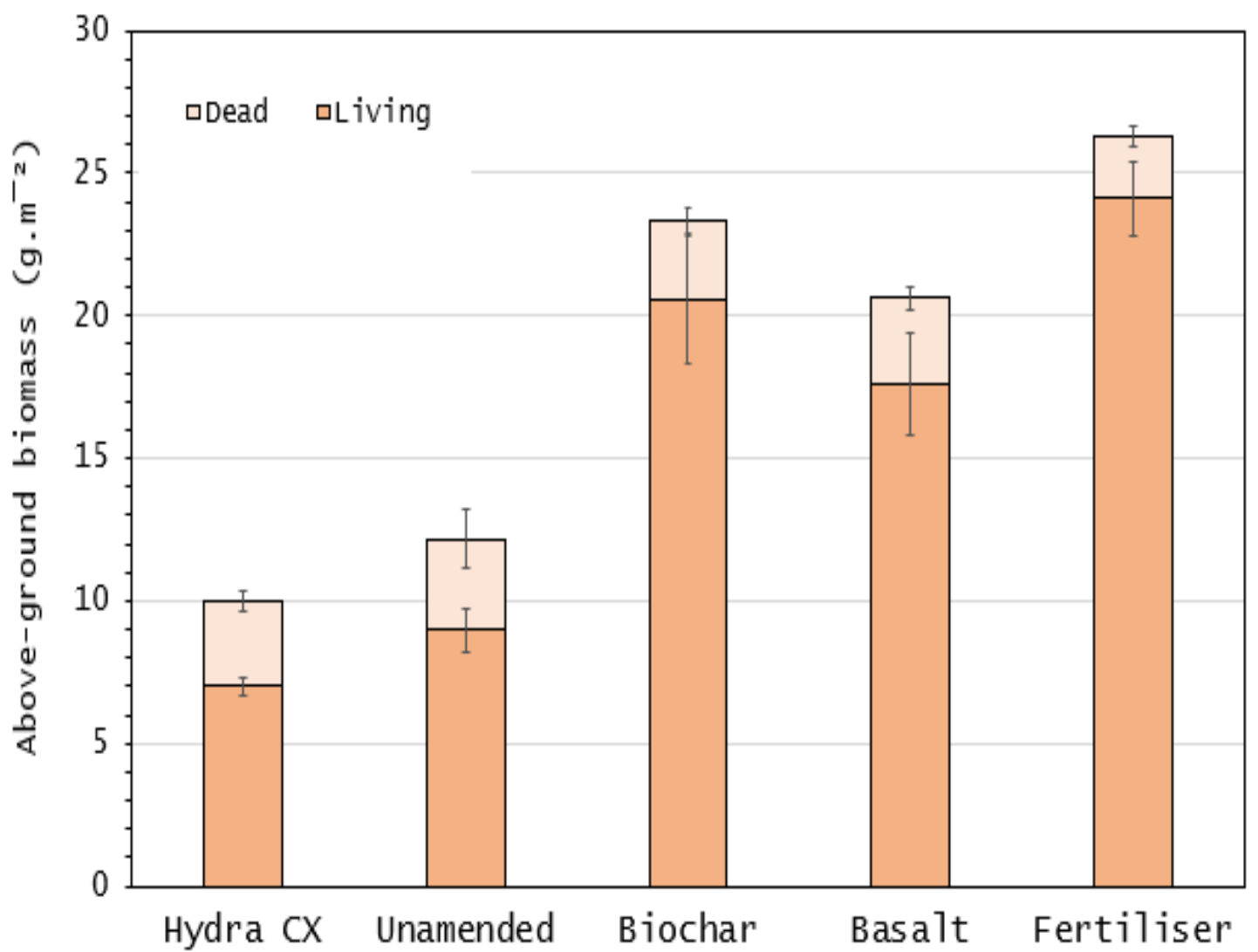

Figure 7.26: The median proportions of dead and living grass in the Hydra CX, the unamended treatment and the single-amendment treatment plots after 14 weeks of the Nantymwyn field trial (n=7). Samples were collected in December 2018. Error bars represent the sample standard deviation

Table 7.4: Median weight $\left(g^{-2} \mathrm{~m}^{-2}\right)$ of living and dead biomass in each singleamendment treatment of the Nantymwyn field trial (September to December 2018). The samples were collected in December 2018.

\begin{tabular}{cccc}
\hline \hline Treatment & $\mathrm{n}$ & \% living & \% dead \\
\hline Hydra CX & 7 & 70.0 & 30.0 \\
Unamended & 7 & 73.7 & 26.3 \\
Biochar & 7 & 88.0 & 12.0 \\
Basalt & 7 & 85.2 & 14.8 \\
Fertiliser & 7 & 91.8 & 8.2 \\
\hline
\end{tabular}


By week 14, all three single-amendment soils (biochar, basalt, or fertiliser) had produced comparable median quantities of biomass $\left(23.3,20.6\right.$, and 26.2 g.m , $^{-2}$ respectively, Figure 7.26). The proportions of living:dead biomass for the biochar, basalt, and fertiliser treatments were also similar $(88,85$, and $92 \%$, respectively, Table 7.4 and Figure 7.26). The treatments were visually indistinguishable (Figures 7.27, $7.28,7.29)$. 


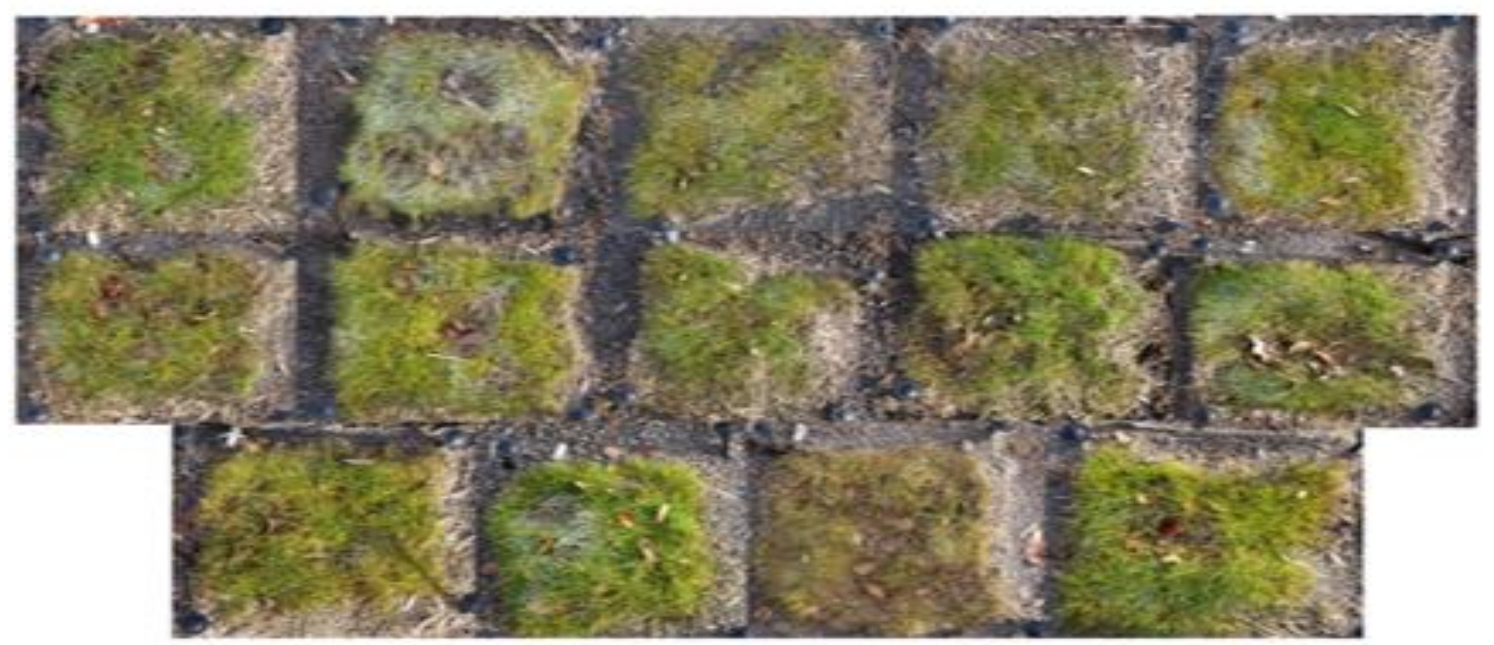

Figure 7.27: The $30 \mathrm{~cm}^{2}$ plots of the biochar treatment at the Nantymwyn field trial, week 14 (December 2018)

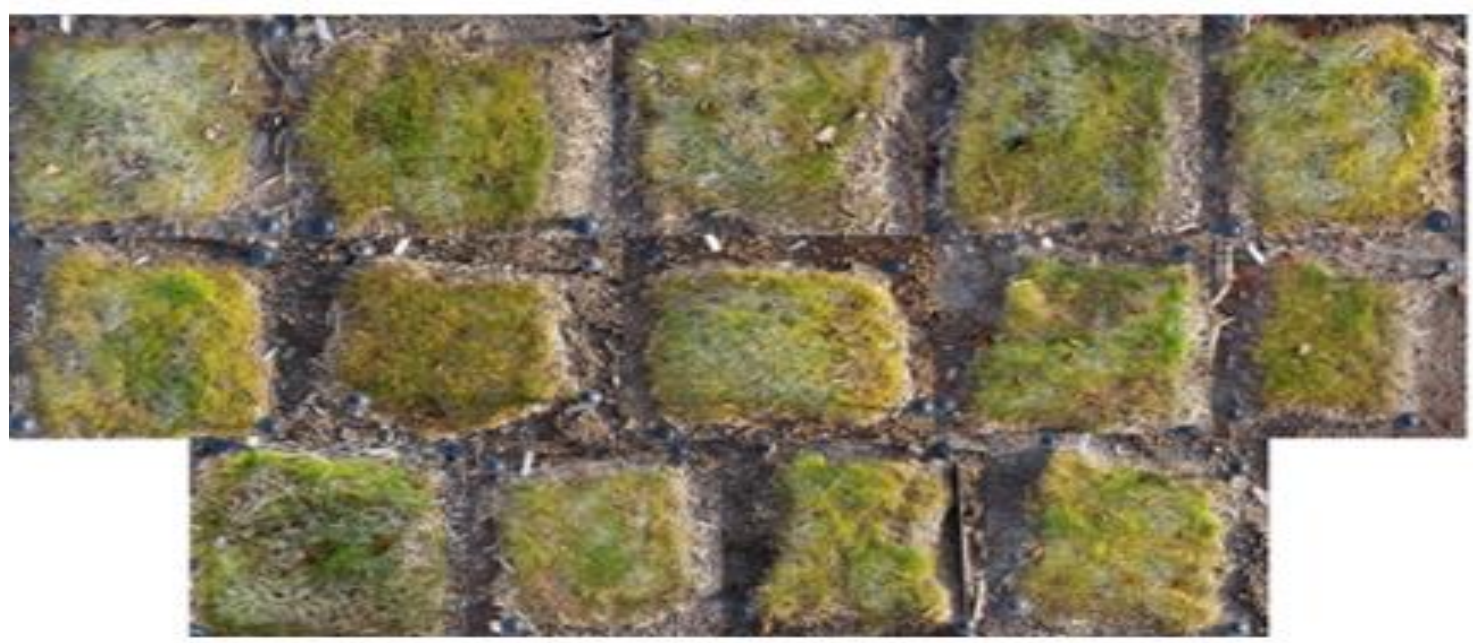

Figure 7.28: The $30 \mathrm{~cm}^{2}$ plots of the basalt treatment at the Nantymwyn field trial, week 14 (December 2018)

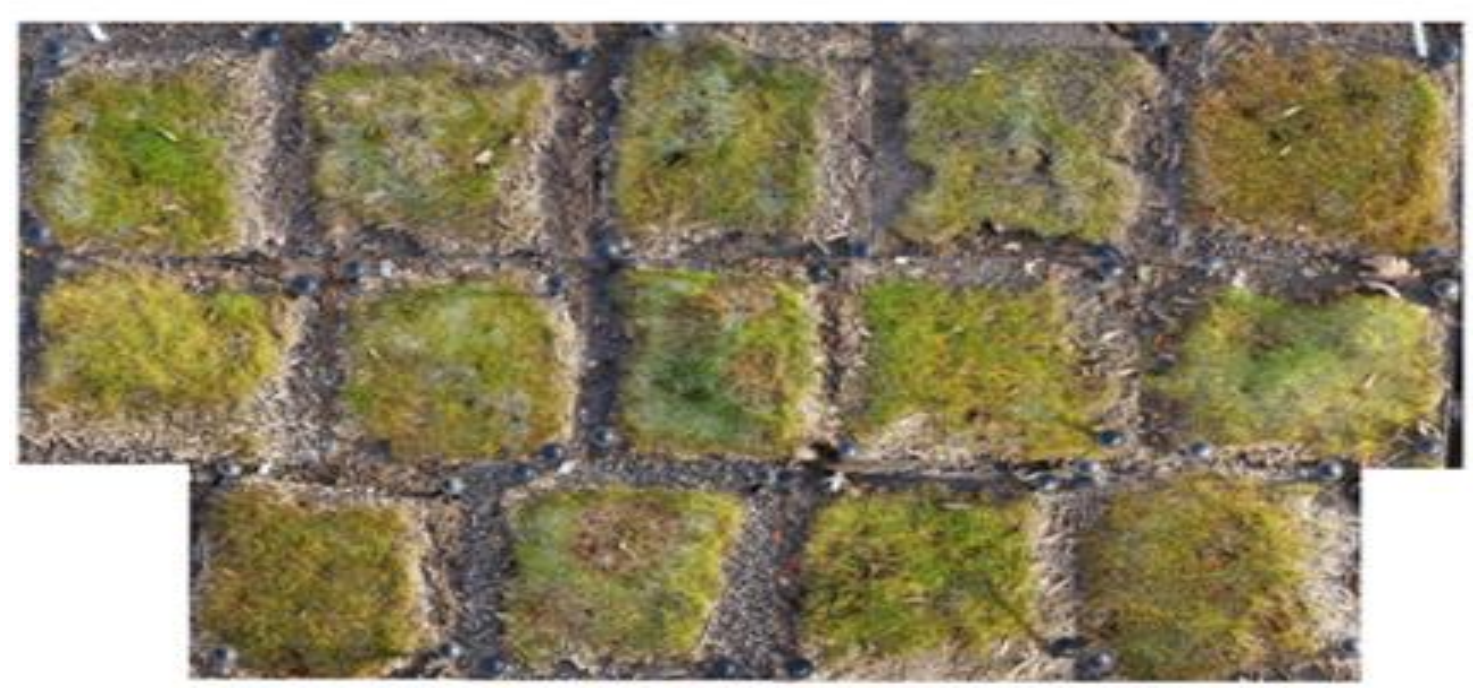

Figure 7.29: The $30 \mathrm{~cm}^{2}$ plots of the fertiliser treatment at the Nantymwyn field trial, week 14 (December 2018) 


\subsubsection{Two-amendment soils}

The two-amendment surrogate soils were those which contained:

- Basalt and fertiliser (basalt:fertiliser),

- Biochar and basalt (biochar:basalt),

- Biochar and fertiliser (biochar:fertiliser)

\subsubsection{Shoot length}

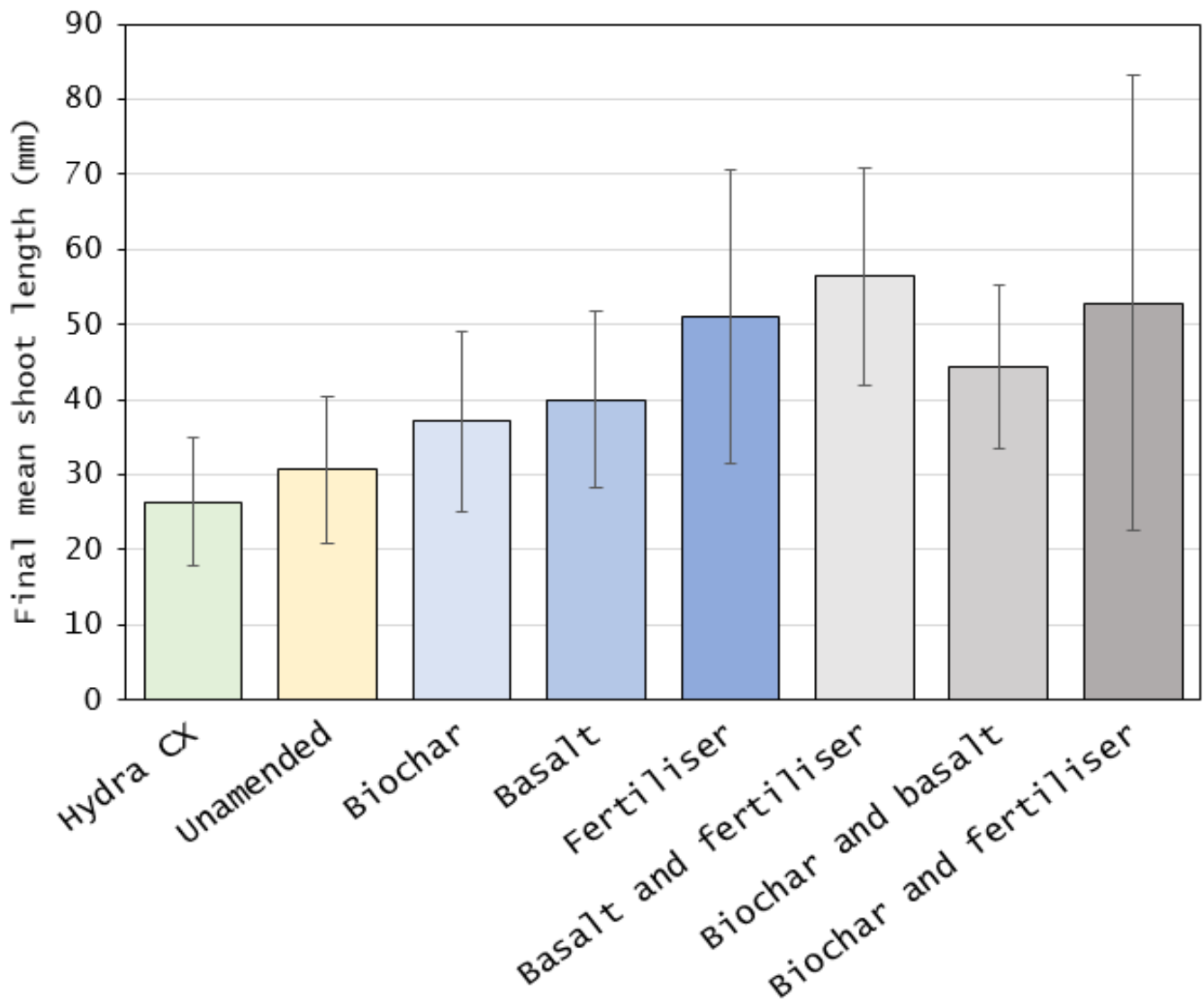

Figure 7.30: The mean final tallest shoot ( $\mathrm{mm}$ ) of the grass produced by the Hydra CX, the unamended treatment, the single-amendment, and two-amendment treatments in the Nantymwyn field trial after 14 weeks. The samples were collected in December 2018. For all treatments, $n=14$. Error bars represent the sample standard deviation 
Table 7.5: The mean tallest shoot length $(\mathrm{mm})$ of the grass in each of the singleamendment, two-amendment, and the Hydra CX plots at the Nantymwyn field trial. The data was collected after 14 weeks, in December 2018. \pm refers to the sample standard deviation.

\begin{tabular}{cccccc}
\hline Treatment & $\mathrm{n}$ & $\begin{array}{c}\text { Mean } \\
(\mathrm{mm})\end{array}$ & $\begin{array}{c} \pm \\
(\mathrm{mm})\end{array}$ & $\begin{array}{c}\text { Min } \\
(\mathrm{mm})\end{array}$ & $\begin{array}{c}\text { Max } \\
(\mathrm{mm})\end{array}$ \\
\hline Hydra CX & 14 & 26 & 8 & 10 & 41 \\
Unamended & 14 & 30 & 9 & 15 & 50 \\
Biochar & 14 & 37 & 12 & 10 & 60 \\
Basalt & 14 & 40 & 12 & 10 & 50 \\
Fertiliser & 14 & 51 & 20 & 11 & 79 \\
Basalt and fertiliser & 14 & 56 & 14 & 29 & 81 \\
Biochar and basalt & 14 & 44 & 11 & 21 & 59 \\
Biochar and fertiliser & 14 & 53 & 30 & 11 & 119 \\
\hline
\end{tabular}

An ANOVA with Tukey's post-hoc test $(\mathrm{p} \leq 0.05)$ was used to compare the mean shoot lengths of the grass grown in each treatment.

In the two-amendment treatments, fertiliser again had the greatest impact on shoot growth (Table 7.5). The basalt:fertiliser and the biochar:fertiliser treatments produced taller shoots than the Hydra CX (both $\mathrm{p} \leq 0.001$ ) and the unamended treatment (the basalt:fertiliser soil, $\mathrm{p} \leq 0.001$, and the biochar:fertiliser soil, $\mathrm{p} \leq 0.01)(\mathrm{F}:[7,103]=$ 5.97) (Figure 7.30).

Regarding the two-amendment treatments, no significant pairwise differences in shoot length were found. 


\subsubsection{Biomass}

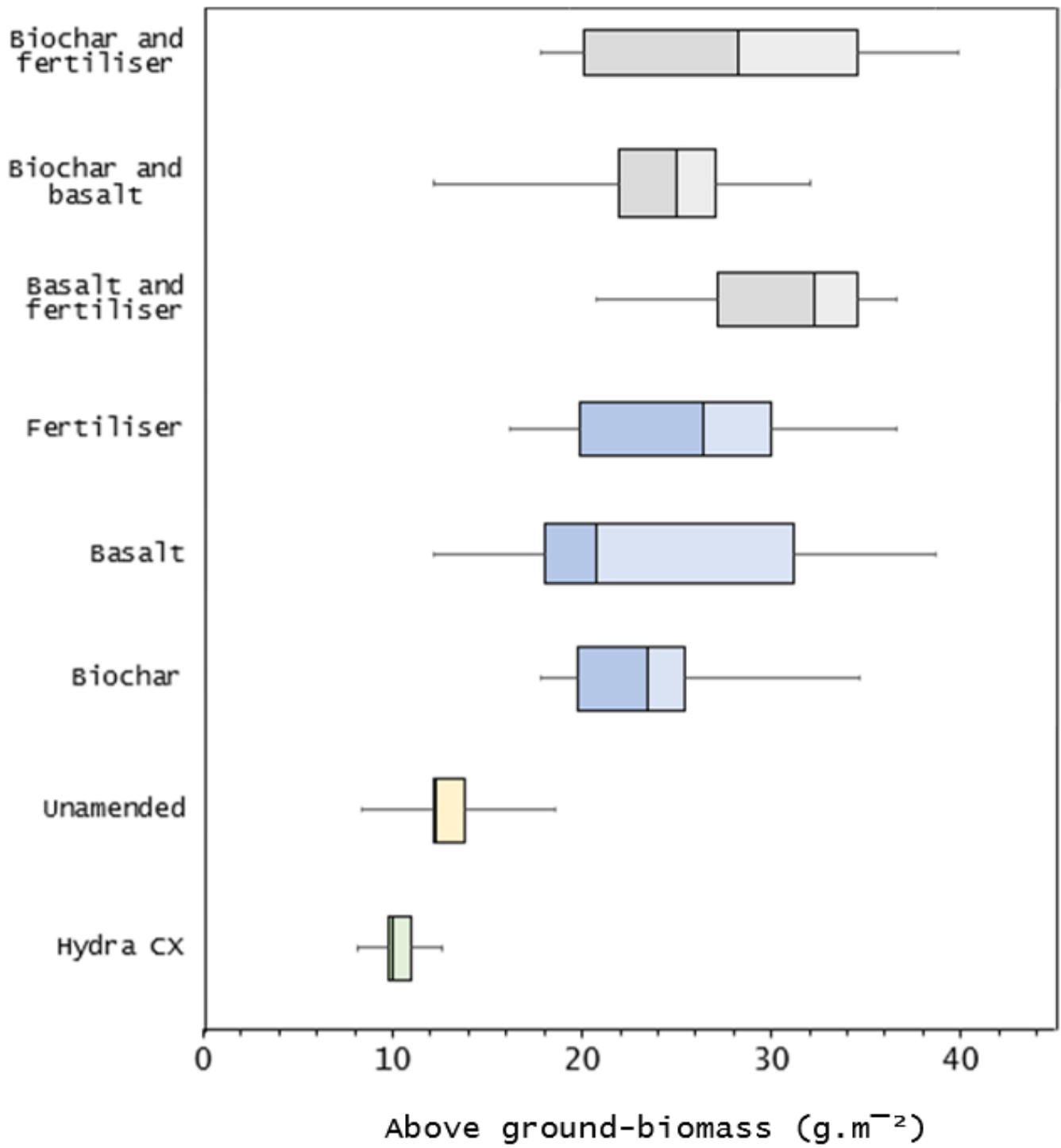

Figure 7.31: Above-ground biomass $\left(g . m^{-2}\right)$ which was produced by the Hydra CX, the unamended treatment, and the single-amendment and two-amendment treatments trialled at the Nantymwyn field trial, September to December 2018. The samples were collected at week 14, December 2018. For each treatment, $n=7$ 
Table 7.6: The median weight $\left(g . \mathrm{m}^{-2}\right)$ of dried above-ground biomass that was produced by the Hydra CX, the unamended treatment, the single-amendment and twoamendment treatments of the Nantymwyn field trial after 14 weeks. The samples were collected in December 2018. \pm indicates the sample standard deviation.

\begin{tabular}{cccccc}
\hline \hline Treatment & $\mathrm{n}$ & $\begin{array}{c}\text { Median } \\
\left(\mathrm{g} \cdot \mathrm{m}^{-2}\right)\end{array}$ & $\begin{array}{c} \pm \\
\left(\mathrm{g} . \mathrm{m}^{-2}\right)\end{array}$ & $\begin{array}{c}\text { Min } \\
\left(\mathrm{g} . \mathrm{m}^{-2}\right)\end{array}$ & $\begin{array}{c}\text { Max } \\
\left(\mathrm{g} . \mathrm{m}^{-2}\right)\end{array}$ \\
\hline Hydra CX & 7 & 10.0 & 0.3 & 8.1 & 12.6 \\
Unamended & 7 & 12.1 & 0.7 & 8.2 & 18.4 \\
Biochar & 7 & 23.3 & 1.3 & 17.8 & 34.5 \\
Basalt & 7 & 20.6 & 2.2 & 12.0 & 38.6 \\
Fertiliser & 7 & 26.2 & 1.8 & 16.0 & 36.4 \\
Basalt and fertiliser & 7 & 32.2 & 1.4 & 20.6 & 36.4 \\
Biochar and basalt & 7 & 25.0 & 1.5 & 12.2 & 32.0 \\
Biochar and fertiliser & 7 & 28.2 & 1.9 & 17.8 & 39.8 \\
\hline
\end{tabular}

A Kruskal-Wallis test revealed significant yield differences between the unamended soil and two-amendments soil treatments $(\mathrm{H}[3]=15.84, \mathrm{p} \leq 0.001, \mathrm{~N}=28)$.

The combination of basalt and fertiliser was of notable success, and generated the greatest quantity of biomass, a median of $32.2 \pm 1.4$ g.m ${ }^{-2}$, almost twice that of the unamended treatment (Dunn's: $p \leq 0.001$ ) (Figure 7.31 and Table 7.6). The basalt:fertiliser treatment also produced the tallest grass. The basalt:fertiliser treatment also yielded $44 \%$ more plant growth than basalt alone $(\mathrm{p} \leq 0.002)$ and $20 \%$ more than fertiliser alone $(\mathrm{p} \leq 0.042)(\mathrm{H}[6]=18.81, \mathrm{p} \leq 0.004, \mathrm{~N}=42)$.

No significant pairwise differences in biomass yield (or shoot length) existed between any of the two-amendment treatments. Therefore, overall, each two-amendment treatment produced a similar ground cover. This was confirmed visually (Figures $7.32-7.34)$. 


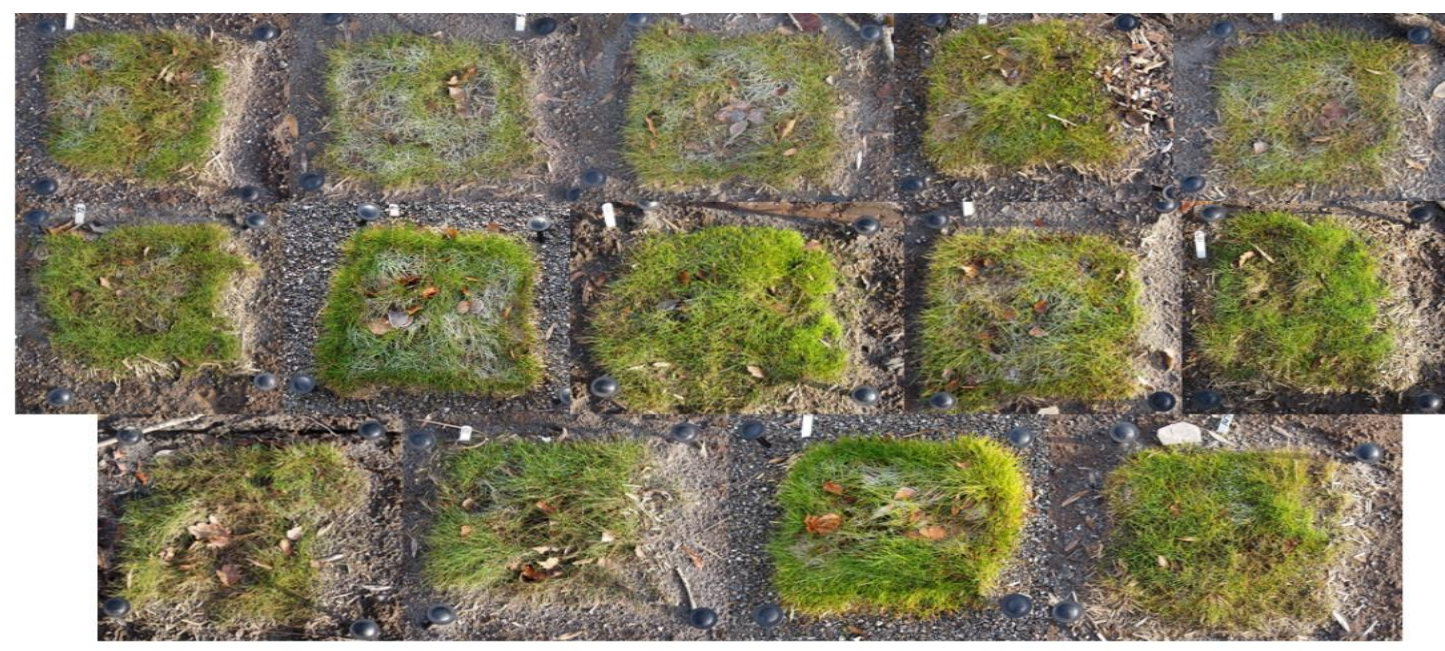

Figure 7.32: The 14 replicates of the $30 \mathrm{~cm}^{2}$ plots of the basalt:fertiliser treatment at the Nantymwyn field trial. The photos were taken in week 14, December 2018

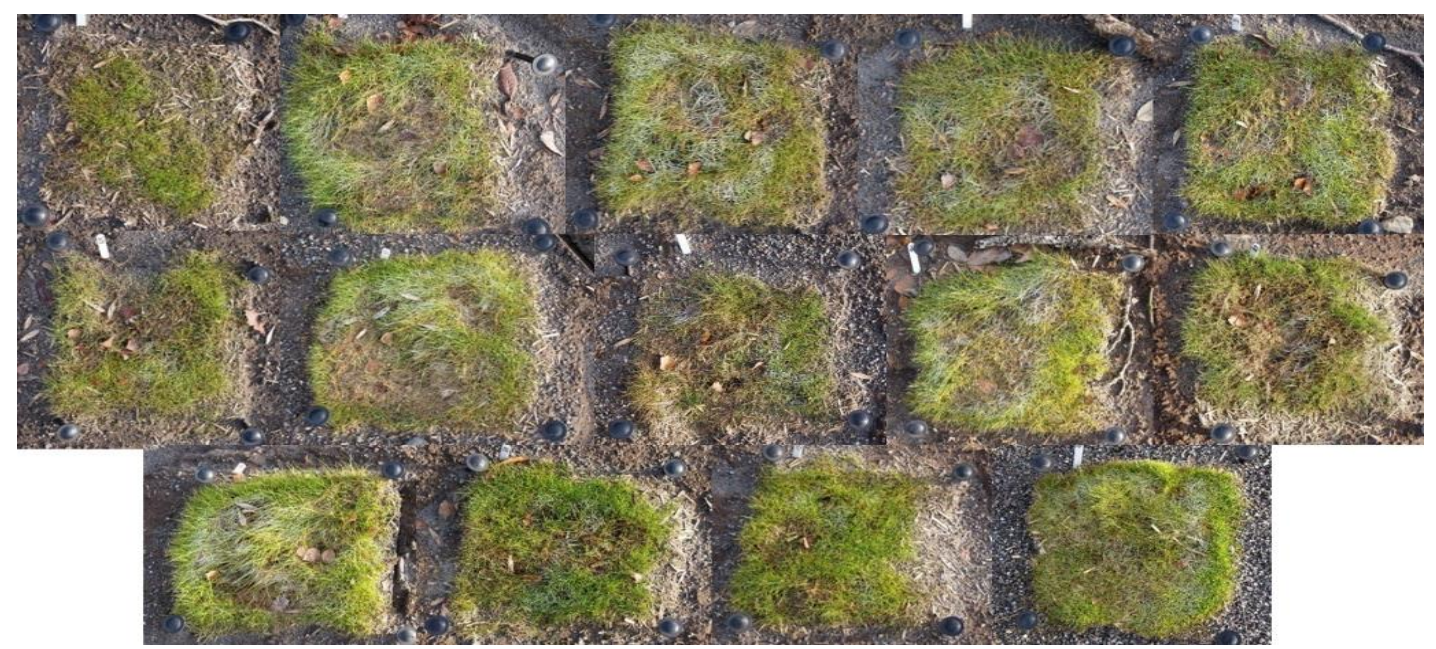

Figure 7.33: The 14 replicates of the $30 \mathrm{~cm}^{2}$ plots of the biochar:basalt treatment at the Nantymwyn field trial. The photos were taken in week 14, December 2018

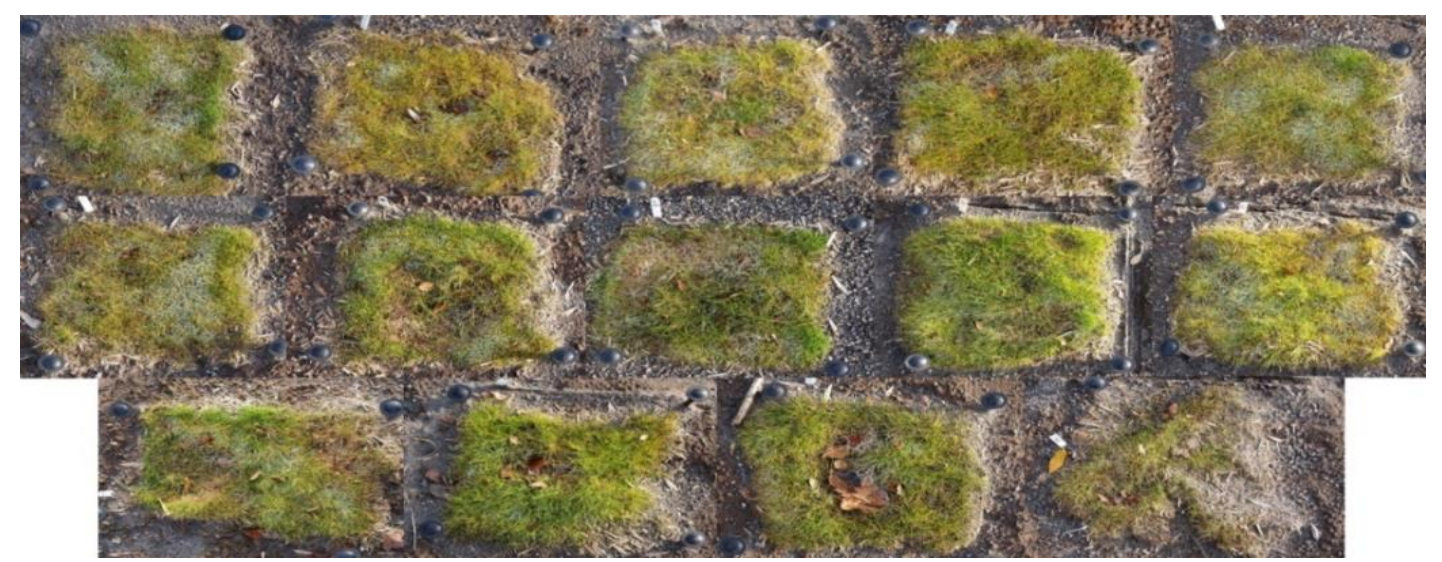

Figure 7.34: The 14 replicates of the $30 \mathrm{~cm}^{2}$ plots of the biochar:fertiliser treatment at the Nantymwyn field trial. The photos were taken in week 14, December 2018 


\subsubsection{Living and dead biomass}

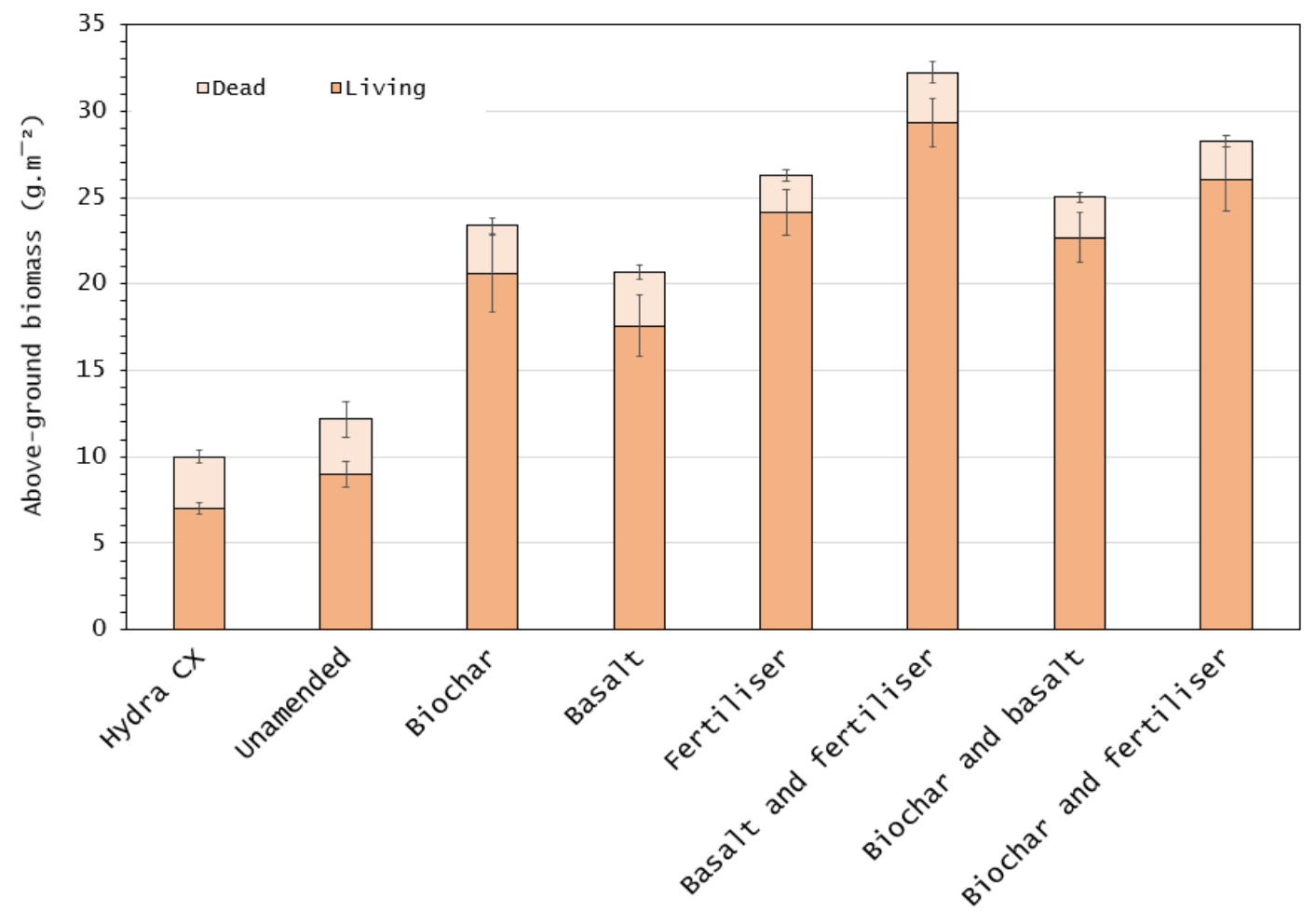

Figure 7.35: The median proportions of dead and living grass in the Hydra CX, the unamended treatment, the single-amendment and two-amendment treatment plots after 14 weeks of the Nantymwyn field trial $(n=7)$. Error bars represent the sample standard

Table 7.7: Median weight $\left(\mathrm{g} \cdot \mathrm{m}^{-2}\right)$ of living and dead biomass in each singleamendment and two-amendment treatment of the Nantymwyn field trial (September to December 2018). The samples were collected in December 2018.

\begin{tabular}{cccc}
\hline \hline Treatment & $\mathrm{n}$ & \% living & \% dead \\
\hline Hydra CX & 7 & 70.0 & 30.0 \\
Unamended & 7 & 73.7 & 26.3 \\
Biochar & 7 & 88.0 & 12.0 \\
Basalt & 7 & 85.2 & 14.8 \\
Fertiliser & 7 & 91.8 & 8.3 \\
Basalt and fertiliser & 7 & 90.3 & 9.8 \\
Biochar and basalt & 7 & 90.7 & 9.3 \\
Biochar and fertiliser & 7 & 92.1 & 7.9 \\
\hline
\end{tabular}


Similar proportions of living and dead grass were recorded in all two-amendment surrogate soils, $90.3 \%$ (basalt:fertiliser), $90.7 \%$ (biochar:basalt), and $92.1 \%$ (biochar:fertiliser) (Figure 7.35 and Table 7.7).

\subsubsection{Three-amendment treatment}

A single three amendment treatment was created: biochar, basalt and fertiliser.

\subsubsection{Shoot length}

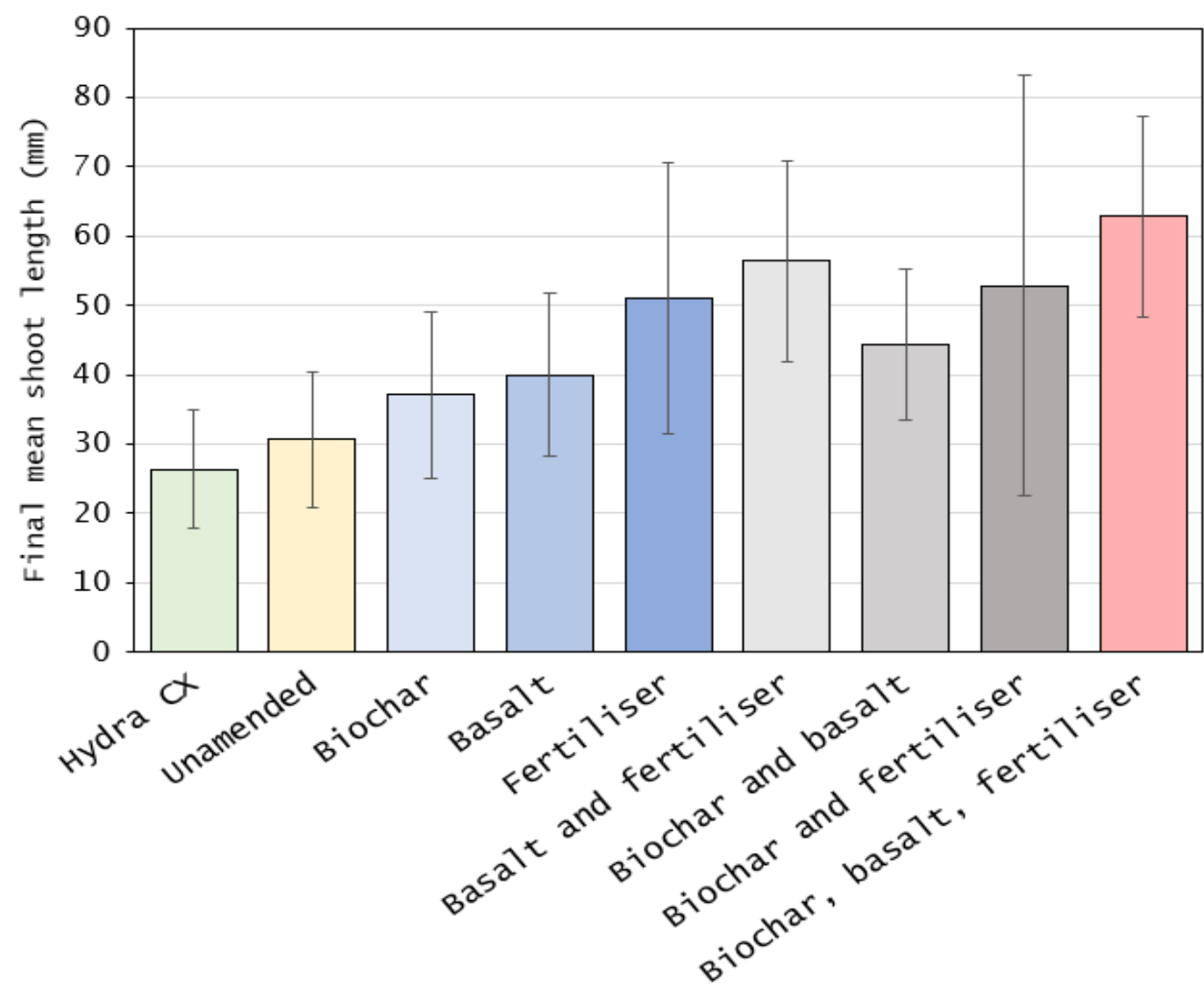

Figure 7.36: The final mean tallest shoot length $(\mathrm{mm})$ of the grass produced by each of the treatments in the Nantymwyn field trial. The data was collected in December 2018. For every treatment, $n=14$. Errors bars represent the sample standard deviation 
Table 7.8: The mean tallest shoot length $(\mathrm{mm})$ of the grass in each of the treatment plots at the Nantymwyn field trial. The data was collected after 14 weeks, in December 2018. \pm refers to the sample standard deviation.

\begin{tabular}{cccccc}
\hline Treatment & $\mathrm{n}$ & $\begin{array}{c}\text { Mean } \\
(\mathrm{mm})\end{array}$ & $\begin{array}{c} \pm \\
(\mathrm{mm})\end{array}$ & $\begin{array}{c}\text { Min } \\
(\mathrm{mm})\end{array}$ & $\begin{array}{c}\text { Max } \\
(\mathrm{mm})\end{array}$ \\
\hline Hydra CX & 14 & 26 & 8 & 10 & 41 \\
Unamended & 14 & 30 & 9 & 15 & 50 \\
Biochar & 14 & 37 & 12 & 10 & 60 \\
Basalt & 14 & 40 & 12 & 10 & 50 \\
Fertiliser & 14 & 51 & 20 & 11 & 79 \\
Basalt and fertiliser & 14 & 56 & 14 & 29 & 81 \\
Biochar and basalt & 14 & 44 & 11 & 21 & 59 \\
Biochar and fertiliser & 14 & 53 & 30 & 11 & 119 \\
Biochar, basalt, fertiliser & 14 & 63 & 30 & 10 & 111 \\
\hline
\end{tabular}

A one-way ANOVA and Tukey's post-hoc test indicated that the three-amendment treatment produced significantly taller shoots than that of the Hydra $\mathrm{CX}(\mathrm{p} \leq 0.01)$, the unamended $(\mathrm{p} \leq 0.01)$ and the biochar treatments $(\mathrm{p} \leq 0.047)(\mathrm{F}:[8,48.2]=10.27$, $\mathrm{p} \leq 0.001)$ (Figure 7.36 and Table 7.8). 


\subsubsection{Biomass}

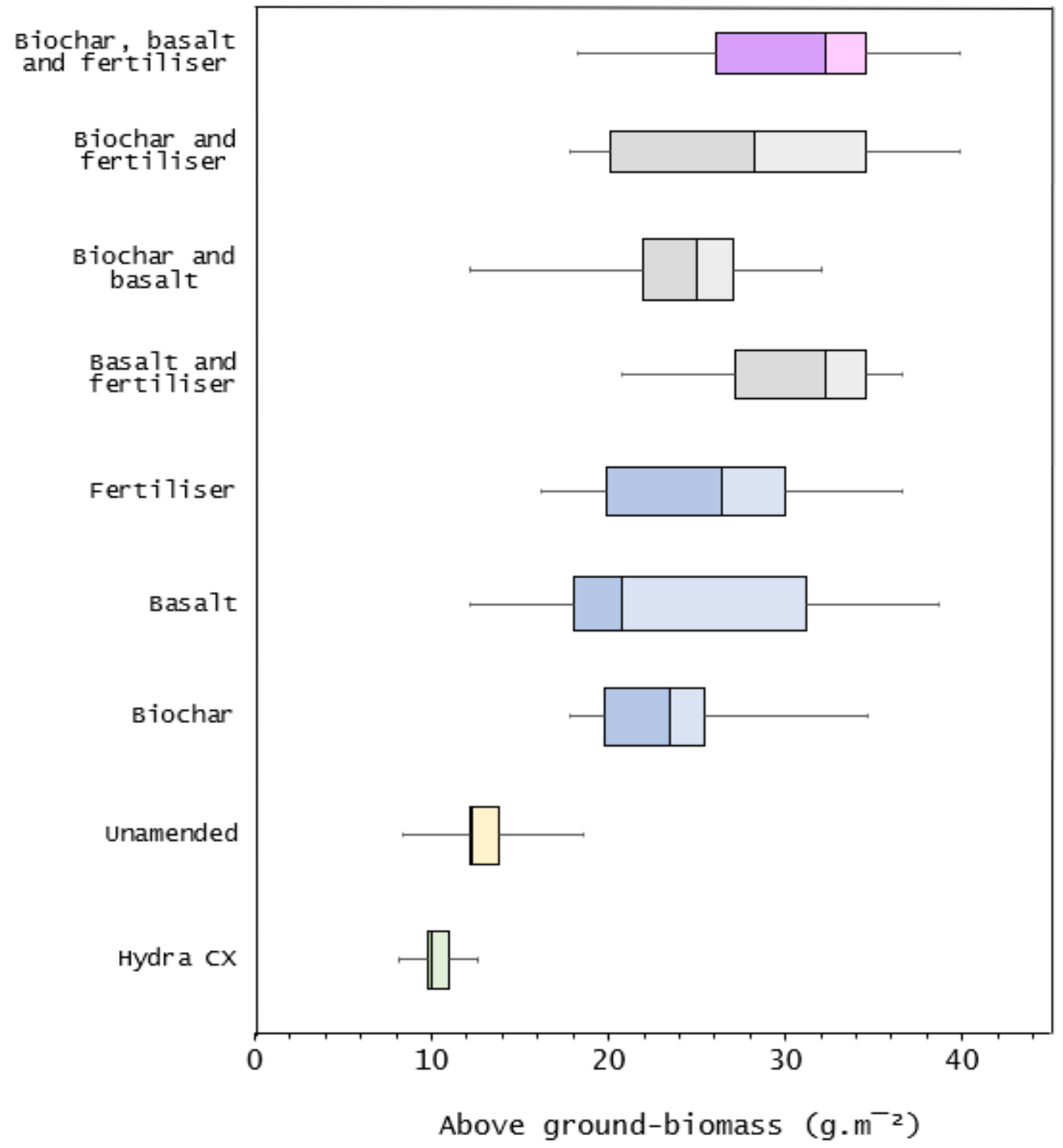

Figure 7.37: Above-ground biomass $\left(g . \mathrm{m}^{-2}\right)$ which was produced by the treatments at the Nantymwyn field trial, September to December 2018. The samples were collected at week 14, December 2018. For each treatment, $n=7$ 
Table 7.9: The median weight $\left(g . \mathrm{m}^{-2}\right)$ of dried above-ground biomass that was produced by the treatments after 14 weeks of the Nantymwyn field trial. The samples were collected in December 2018. \pm indicates the sample standard deviation.

\begin{tabular}{cccccc}
\hline Treatment & $\mathrm{n}$ & $\begin{array}{c}\text { Median } \\
\left(\mathrm{g} . \mathrm{m}^{-2}\right)\end{array}$ & $\begin{array}{c} \pm \\
\left(\mathrm{g} . \mathrm{m}^{-2}\right)\end{array}$ & $\begin{array}{c}\text { Min } \\
\left(\mathrm{g} . \mathrm{m}^{-2}\right)\end{array}$ & $\begin{array}{c}\text { Max } \\
\left(\mathrm{g} . \mathrm{m}^{-2}\right)\end{array}$ \\
\hline Hydra CX & 7 & 10.0 & 0.3 & 8.1 & 12.6 \\
Unamended & 7 & 12.1 & 0.7 & 8.2 & 18.4 \\
Biochar & 7 & 23.3 & 1.3 & 17.8 & 34.5 \\
Basalt & 7 & 20.6 & 2.2 & 12.0 & 38.6 \\
Fertiliser & 7 & 26.2 & 1.8 & 16.0 & 36.4 \\
Basalt and fertiliser & 7 & 32.2 & 1.4 & 20.6 & 36.4 \\
Biochar and basalt & 7 & 25.0 & 1.5 & 12.2 & 32.0 \\
Biochar and fertiliser & 7 & 28.2 & 1.9 & 17.8 & 39.8 \\
Biochar, basalt, fertiliser & 7 & 32.2 & 1.8 & 18.2 & 39.8 \\
\hline
\end{tabular}

The biomass yield in the biochar:basalt:fertiliser soil was the same as that of the basalt:fertiliser treatment (both 32.2 g.m ${ }^{-2}$, Figure 7.37 and Table 7.9). Biochar had no effect on biomass yield when basalt and fertiliser were combined.

Significantly more biomass was produced in the three-amendment treatment (Figure 7.38) than in the Hydra CX (Dunn's, $\mathrm{p} \leq 0.001)$ the unamended soil $(\mathrm{p} \leq 0.001)$, the biochar amended soil $(\mathrm{p} \leq 0.043)$ and the basalt amended soil $(\mathrm{p} \leq 0.042)$ (KruskalWallis: $\mathrm{H}[8]=34.47, \mathrm{p} \leq 0.001, \mathrm{~N}=63$ ).

No pairwise differences were found between the three-amendment soil and the soils which contained fertiliser. 


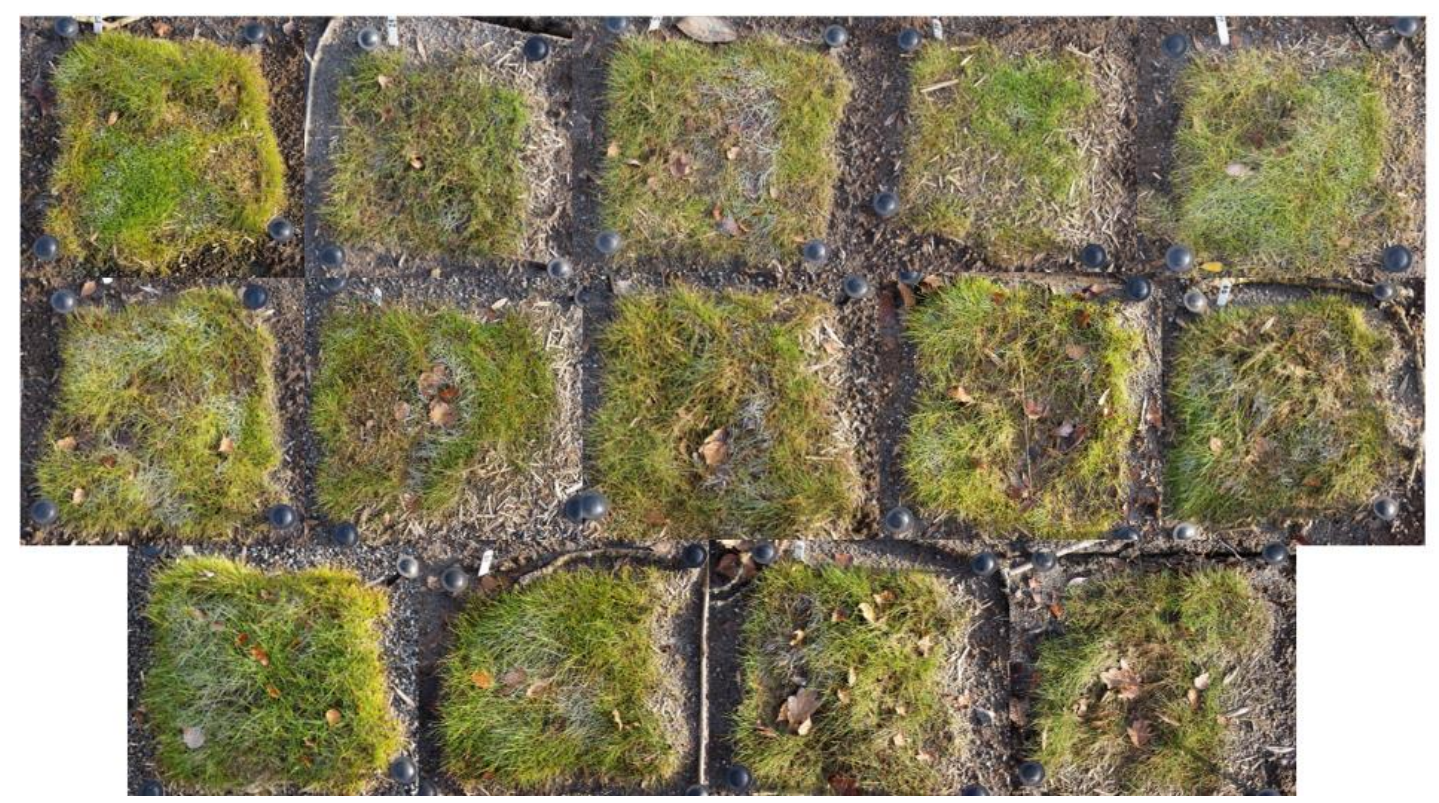

Figure 7.38: The 14 replicates of the biochar:basalt:fertiliser treatment at the Nantymwyn field trial (December 2018)

\subsubsection{Living and dead biomass}

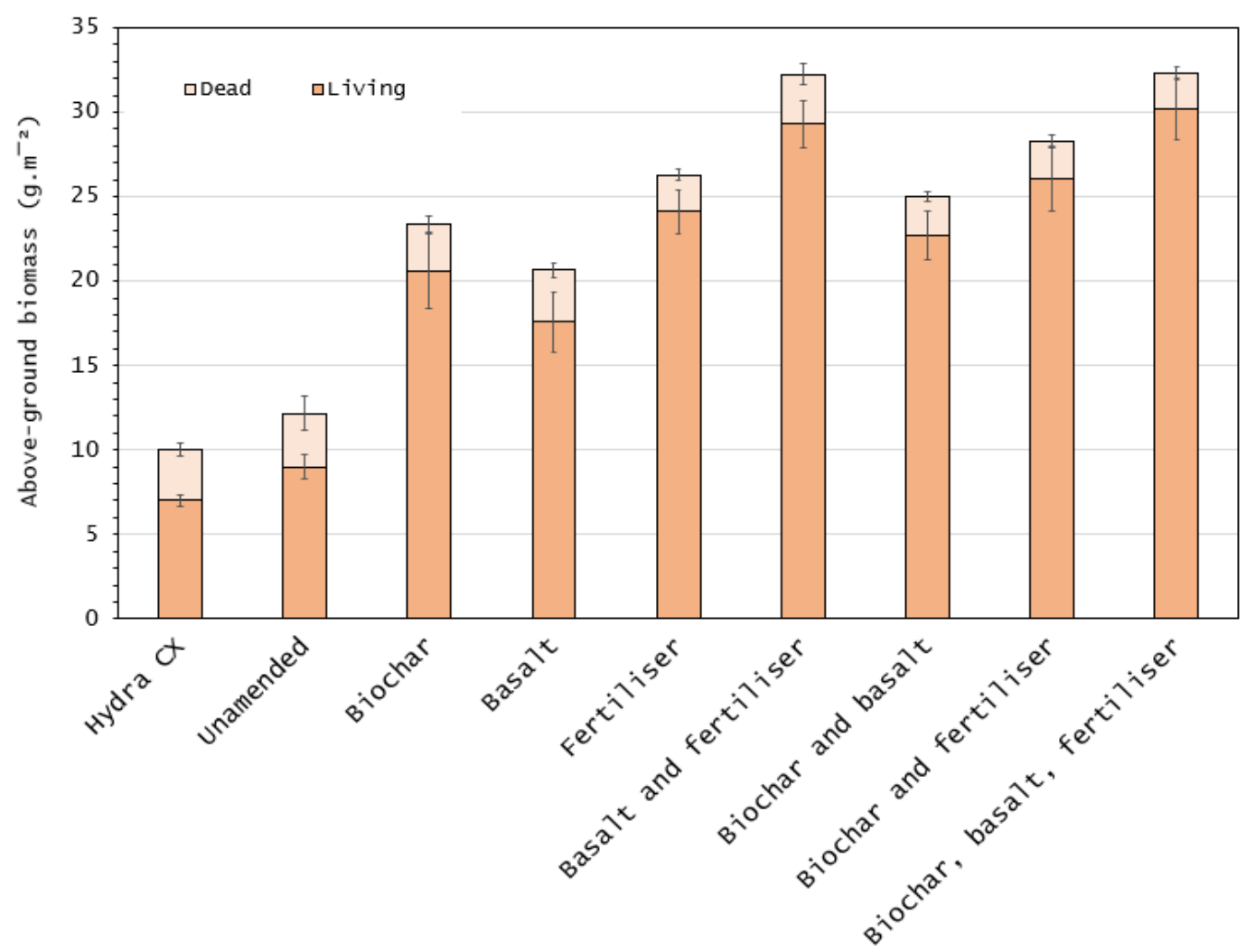

Figure 7.39: The median proportions of dead and living grass in treatment plots after 14 weeks of the Nantymwyn field trial $(n=7)$. Error bars represent the sample standard deviation. 
Table 7.10: Median weight $\left(\mathrm{g} \cdot \mathrm{m}^{-2}\right)$ of living and dead biomass in each treatment of the Nantymwyn field trial (September to December 2018). The samples were collected in December 2018.

\begin{tabular}{cccc}
\hline \hline Treatment & $\mathrm{n}$ & \% living & \% dead \\
\hline Hydra CX & 7 & 70.0 & 30.0 \\
Unamended & 7 & 73.7 & 26.3 \\
Biochar & 7 & 88.0 & 12.0 \\
Basalt & 7 & 85.2 & 14.8 \\
Fertiliser & 7 & 91.8 & 8.3 \\
Basalt and fertiliser & 7 & 90.3 & 9.8 \\
Biochar and basalt & 7 & 90.7 & 9.3 \\
Biochar and fertiliser & 7 & 92.1 & 7.9 \\
Biochar, basalt, fertiliser & 7 & 93.4 & 6.7 \\
\hline
\end{tabular}

By week 14, the biochar:basalt:fertiliser soil had the highest proportion of living grass remaining (93\%, Figure 7.39 and Table 7.10). A Kruskal-Wallis and Dunn's post-hoc test determined this as significantly more than the Hydra CX $(\mathrm{p} \leq 0.042)$ and the unamended soil $(\mathrm{p} \leq 0.042)(\mathrm{H}[3]=21.33, \mathrm{p} \leq 0.043, \mathrm{~N}=21)$. No pairwise differences among the amended treatments were found, however.

\subsubsection{Summary of results}

The key results to be discussed in Section 7.3 are as follows:

- No biomass grew on the unseeded, untreated bare mine tailings plots. The seeded tailings plots supported negligible quantities of biomass (a median of $\left.0.71 \mathrm{~g} \cdot \mathrm{m}^{-2}\right)$.

- Soil adhesion was satisfactory in all plots that were treated with the surrogate soils.

- Seedling emergence began within the first week for all seeded plots. 
- Hydra CX, an erosion control and revegetation product, yielded the least biomass $\left(10.0 \pm 0.3\right.$ g.m $\left.\mathrm{m}^{-2}\right)$. Comparatively, significantly more biomass was recorded in the unamended soil treatment $\left(12.1 \pm 0.7\right.$ g.m $\left.\mathrm{m}^{-2}, \mathrm{p} \leq 0.032\right)$. By December, $26 \%$ of the grass in the unamended treatment had died, compared to $30 \%$ in the Hydra CX plots.

- Compared to the unamended soil, all soil amendments improved grass growth throughout this stage of the trial. As a single amendment, fertiliser had the greatest effect on biomass yield $\left(26.2 \pm 1.8\right.$ g.m $\left.\mathrm{m}^{-2}\right), 73 \%$ more than the unamended soil $(\mathrm{p} \leq 0.001)$. No pairwise differences existed between the singleamendment treatments.

- The most productive two-amendment treatment was the basalt:fertiliser soil, which yielded almost twice the biomass of the unamended treatment $(32.2 \pm$ 1.4 g. $\left.\mathrm{m}^{-2}, \mathrm{p} \leq 0.002, \mathrm{r}=0.768\right)$. The basalt:fertiliser treatment was also the only two-stage treatment to produce more biomass than when either amendment was used exclusively.

- No pairwise differences existed between the two-amendment treatments, and by December all had similar proportions of dead plant matter (basalt:fertiliser, 10\%; biochar:basalt, 9\%; and biochar:fertiliser, $8 \%$ ).

- The three-amendment treatment (biochar:basalt:fertiliser) yielded the same median quantity of biomass as the basalt:fertiliser treatment $\left(32.2 \pm 1.8 \mathrm{~g} . \mathrm{m}^{-2}\right.$ and $32.2 \pm 1.4$ g.m $\mathrm{m}^{-2}$, respectively).

- The three-amendment treatment produced significantly more biomass than when biochar or basalt were used exclusively, but not when fertiliser was used exclusively.

- The highest proportion of living grass was recorded in the three-amendment treatment $(93 \%), \sim 28 \%$ more than in the unamended soil. 
- Biomass was sampled from a field adjacent to the mine (a median of $139.8 \pm$ 20.0 g. $\left.\mathrm{m}^{-2}, \mathrm{n}=7\right)$. Whilst all experimental soils adhered to the tailings and produced vegetative cover, even the most successful treatment produced only one quarter the biomass of that in a neighboring field. 


\subsection{Field trial - Discussion, September to December 2018}

Data were collected to evaluate the grass production three months into a 12-month field trial at the abandoned $\mathrm{Pb}$ mine, Nantymwyn. Biomass yield data, coupled with the shoot length measurements and the photographic documentation, allowed for an assessment of the ground cover. The erosion of the surrogate soil was assessed visually.

When combined with a binding agent (guar gum), the soils were found to be highly resistant to rainsplash erosion in a laboratory setting $(200 \mathrm{~mm} / \mathrm{h}$ for 60 minutes, $97 \%$ adhesion, Section 5.2.5.2). During the first three months of the field trial precipitation was higher than the long-term average, (1961 - 1990, NRW, 20187; NCIC, 2019). When applied to the field site, the surrogate soils experienced prolonged, heavy rainfall beyond the conditions in which they were tested, yet the surrogate soil remained insitu for several months. The high retention of the soil throughout the trial provided a positive indication for the long-term stability of the soil on the slope.

In the field trial, the Hydra CX and the unamended surrogate soil performed similarly (10.0 and 12.1 g.m ${ }^{-2}$ of biomass, respectively, Figure 7.22). Hydra CX was not intended for application to mine waste, therefore served only as a demonstration of what a revegetation product could already achieve without adaptation for mine waste. Still, the similarity in the biomass production of the Hydra CX and unamended treatment was unexpected. It may be that the $\mathrm{N}$ from the Hydra $\mathrm{CX}$ was quickly leached, or that the material rapidly degraded, but as no leachate was collected from the soils this is unknown. The $\mathrm{N}$ content stated in the Hydra CX product was reported as $15900 \mathrm{mg} \cdot \mathrm{k}^{-1}$, however, when tested, the $\mathrm{N}$ content was substantially less (8700 mg.k ${ }^{-1}$, Table 4.1), which was less than the anaerobic digestate (18600 mg.k ${ }^{-1}$, Table 4.4) and the coir (30,000 mg.k ${ }^{-1}$, Table 4.5).

As all of surrogate soils (even the unamended soil) produced more above-ground biomass than the Hydra CX (Table 7.9), it was concluded that all surrogate soils were more suitable for application to metal-mine tailings than another, widely-used revegetation product (Kamala et al., 2014; Middleton \& King, 2019). 
As single amendments, the biochar, basalt, and fertiliser produced comparable median quantities of biomass, and were visually indistinguishable from one another (Table 7.3, Figures 7.27 - 7.29). The amendments were more effective when used in tandem, in particular the basalt:fertiliser combination, which yielded $44 \%$ more biomass than the basalt alone and $20 \%$ more than the $\mathrm{NH}_{4}{ }^{+}$fertiliser alone.

\subsubsection{Fertiliser}

The addition of $\mathrm{NH}_{4}{ }^{+}$fertiliser had the greatest impact on plant growth. In the single, two, or three-amendment surrogate soils, those which contained fertiliser produced more biomass than those without (Table 7.9). Of the materials used, the $\mathrm{NH}_{4}{ }^{+}$fertiliser contained the most $\mathrm{N}, 7.5 \%$, compared to $<1 \%$ in basalt and biochar (Chapter 4.2). Similar cap and cover reclamation studies have determined fertiliser to be essential in the construction of surrogate soils (Smith \& Bradshaw 2006; Wijesekara et al., 2016), so much so that when $\mathrm{N}$ fertilisers were not applied annually grass growth declined to an unrecoverable state (Johnson et al., 1977). It has been recommended that fertiliser be applied annually for > 5 years (Harley, 1976; Simcock \& Ross, 2014).

Fertilisers have been applied to soil covers at a range of application rates, from 11 g.m ${ }^{-2}$ (Malloch et al., 2015) to 30 g.m ${ }^{-2}$ (Martínez-Ruiz et al., 2007), although it was not clear in these studies what percentage of the fertiliser was N. In this trial $\mathrm{NH}_{4}{ }^{+}$ fertiliser was applied at 50 g.m $\mathrm{m}^{-2}$, which was higher than other studies but lower than the product recommended application rate of $100-250 \mathrm{~g} \cdot \mathrm{m}^{-2}$ (Internationale Geotextil $\mathrm{GmbH}, 2019)$. The high recommended application rate may be due to the relatively low $\mathrm{N}$ content compared to other fertilisers $(7.5 \%$, compared to an average of $33.5-34.5 \%$ N, British Grassland Society, 2002) therefore a higher fertiliser application rate was recommended by the manufacturer. A lower application rate was chosen for the field trial as the grass species favoured nutrient-deficient soils (Thompson \& Proctor, 1983; Dunifon et al., 2011) and the cow manure anaerobic digestate applied contained a high proportion of $\mathrm{N}\left(18,600 \mathrm{mg} \cdot \mathrm{kg}^{-1}\right.$, Table 4.4). As the soils which contained $\mathrm{NH}_{4}{ }^{+}$fertiliser produced more biomass than those that did not, and repeat applications were required in other trials (Tordoff et al., 2000; Simcock \& Ross, 2014; Malloch et al., 2015), a higher application rate may have been of benefit at Nantymwyn. 


\subsubsection{Basalt}

As a single amendment, basalt produced the least biomass and the highest variability of all treatments $\left(20.6 \pm 2.2 \mathrm{~g} . \mathrm{m}^{-2}\right.$, Table 7.9). Basalt was included in the surrogate soil as a source of $\mathrm{P}$, which is often the limiting nutrient in soils due to its low mobility (Linkohr et al., 2002), and to mitigate the low $\mathrm{pH}$ of the tailings (pH 3.5, Section 3.2.9).

Phosphate has a profound effect on root production (Anda et al., 2009; Williamson et al., 2001; Akter \& Akagi, 2010). Root and shoot growth usually correlate (Linkohr et $a l ., 2002)$, and it was hypothesised that in this study an increase in P would stimulate root growth which would translate to an increase in biomass. However, the addition of basalt produced the least biomass of any amendment (Table 7.9).

The treatment that contained basalt but not $\mathrm{NH}_{4}{ }^{+}$fertiliser may have contained adequate $\mathrm{P}$ but not $\mathrm{N}$, which resulted in rapid root growth and an initial flourish of shoot growth, which stagnated once the $\mathrm{N}$ diminished, an effect observed in wheat grass grown in Cd contaminated soil (Zhang et al., 2004). In the six-week germination trial the basalt soils generated 62\% more biomass than the unamended soil (Table 6.16). However, in the field trial, the growth in the basalt amended soils plateaued in week eight and was overtaken by the grass in the other soils (Section 7.9). As previous attempts to quantify the root biomass were uninstructive this data was not measured in the field trial, and firm conclusions regarding the $\mathrm{P}$ supply, root growth and shoot growth are difficult to draw.

The soil $\mathrm{pH}$ both directly and indirectly influences the solubility of elements, which determines the plant availability (Penn \& Camberato, 2019). For an element to be plant-available it must dissolve into solution. When the element is in solution it is at its most mobile and has the potential to be lost in runoff.

Phosphorus solubility (and therefore, plant availability) most greatly occurs at $\sim \mathrm{pH} 4.5$ and 6.5, which coincides with the least $\mathrm{P}$ fixation by $\mathrm{Ca}, \mathrm{Al}$, and $\mathrm{Fe}$ minerals. The exact $\mathrm{pH}$ value for the maximum $\mathrm{P}$ solubility will vary between soils, however, a $\mathrm{pH}$ of $6-7$ is generally agreed upon as the most suitable for plant $\mathrm{P}$ uptake (Haynes $\&$ Swift, 1986). The $\mathrm{pH}$ of the basalt surrogate soil was $6.51( \pm 0.3$, Table 6.4$)$, and so the $\mathrm{P}$ would have been very mobile within the soil. This would usually be beneficial for plant uptake, however, in the first month of the trial rainfall was $18 \%$ higher than average for the month, with $74 \mathrm{~mm}$ rainfall within a 24 hour period (NCIC, 2019). The 
high solubility of the $\mathrm{P}$ combined with the heavy rainfall most likely resulted with the $\mathrm{P}$ lost in runoff.

\subsubsection{Biochar}

The effects of biochar on the measured parameters were variable. The inclusion of biochar (alone) corresponded to a 93\% increase in biomass compared to the unamended soil (Table 7.3). However, when combined with other amendments the biochar had little additional effect on growth, and instead the results closely mirrored that of the other amendment. For example, the $\mathrm{NH}_{4}{ }^{+}$fertiliser amended soil generated 26.2 g.m $\mathrm{m}^{-2}$ biomass, and the biochar:fertiliser soil yielded 28.2 g.m ${ }^{-2}$ (Table 7.9). Biochar clearly improved plant growth when compared to not using it at all, but the positive effects of the basalt and fertiliser overshadowed that of the biochar.

The most successful surrogate soils were the basalt:fertiliser soil and the biochar:basalt:fertiliser soil, which produced an almost identical quantity of biomass $\left(32.2 \pm 1.4\right.$ g.m $\mathrm{m}^{-2}$ and $32.2 \pm 1.8 \mathrm{~g} . \mathrm{m}^{-2}$, respectively, Table 7.9$)$ and similar shoot survival rate (92 and 93\%, respectively. Table 7.10). Again, the biochar exerted very little additional impact when combined with other amendments. The basalt:fertiliser soil was the most consistently productive and supported a shorter but denser sward than the other soils (Tables 7.5 and 7.6).

A potential conflict of characteristics existed between the biochar amendment and the basalt. The near-neutral $\mathrm{pH}$ of the biochar:basalt soil $(\mathrm{pH} 7.03 \pm 0.01$, Table 6.4) contained P from the basalt in the most soluble form. The high solubility, combined with the high CEC of the biochar ( $48.5 \mathrm{cmol} . \mathrm{kg}^{-1}$, Section 4.2.6), had the potential for the biochar to rapidly immobilise the $\mathrm{P}$. This could lead to a decreased source of $\mathrm{P}$ in the short-term, but a slow release in the long-term as the P is released as the soil and biochar chemistry changed over time, as has been seen in other studies (Dari et al., 2016).

As there were no significant differences in the biomass yield of the basalt-amended soil, the biochar-amended soil, and the biochar:basalt soil (Table 7.9), the biochar and basalt did not appear to directly interact. Instead, it is accepted that the highly soluble 
basalt combined with the heavy rainfall caused the $\mathrm{P}$ to leach from the soil early in the trial (as discussed in Section 7.3.2).

\subsection{Conclusions}

Although in the surrogate soils the grass was typically quite short $(37-50 \mathrm{~mm}$, Table 7.8) the biomass yield and survival rates were sufficiently high $\left(>32\right.$ g.m $\mathrm{m}^{-2}$ biomass and $85-93 \%$ survival, Tables 7.9 and 7.10 ).

To date, no directly comparable study exists. The current most successful analogous reclamation study occurred in Spain (Touceda-González et al., 2017). Cu-rich mine tailings were graded and compost was integrated to a depth of $30 \mathrm{~cm}$ and transplanted with Agrostis seedlings. After two years the study reported 220 g.m ${ }^{-2}$ of biomass, which was almost twice the biomass produced by the field adjacent to the Nantymwyn field site $\left(139.8 \pm 20.0\right.$ g. $\left.\mathrm{m}^{-2}\right)$. As this volume of biomass cannot be produced in the Nantymwyn area in December, the results found by Touceda-González et al. (2017) are not a realistic comparison to those of this study. However, both this study and that of Touceda-González et al. (2017) planted with Agrostis, and it is interesting to note the full potential of this species. Here, the difference in biomass represents the limitations of a shallow cap, and shallow rooting depth, as opposed to a deep cap, and the difference in climate. The method used by Touceda-González et al. (2017) was also considerably more expensive, as discussed in Section 2.3 (£25 - $45 . \mathrm{m}^{-2}$, Kingsbury, 2008), whereas the method used in this study cost $£ 5-6 \mathrm{~m}^{-2}$, depending on whether the amendments were added or not.

The most relevant study to date is that of two field trials conducted at Minera and $\mathrm{Y}$ Fan metal-mines in mid-Wales (Hester \& Harrison, 1997). The two field trials capped mine spoil (not tailings) heaps with $2 \mathrm{~m}$ of imported topsoil. The studies recorded a grass yield of $35-40$ g.m ${ }^{-2}$ (unspecified species) after six months. As the Nantymwyn field trial yielded equivalent quantities of biomass to those at Minera and Y Fan in three months (32.2 ${\mathrm{g} . \mathrm{m}^{-2}}$ in the two most productive treatments, Table 7.9), on a surrogate soil cap $2 \mathrm{~cm}$ deep rather than $2 \mathrm{~m}$, the early results of the Nantymwyn field trial were promising. However, the likelihood existed that the $\mathrm{P}$ in the soil would leach during the heavy rainfall and no longer be of any influence plant growth. It was also possible that the $\mathrm{N}$ reserves in the soil would rapidly leach, due to the combined effects 
of $\mathrm{pH}$, a freely-draining soil, and the heavy rainfall. Therefore, the results in the coming months of the field trial (January to June) had the potential to be not as positive as the early months of the trial. 


\section{Field trial introduction, January to June 2019}

The following stage presents the second time period of the field trial, from January to June 2019. Additional data were collected during this period, the methods of which are given in Section 8.1. The results related to this stage of the trial are presented in Section 8.2, and the discussion of these results is Section 8.3. The final conclusions of the research, which includes the rainfall trials, the germination trial, and both stages of the field trial are given in the final chapter, Chapter 9. 


\subsection{Field trial - Methods of data collection, January to June 2019}

Weather data and shoot length data continued to be collected from mid-January to late June (week 40), in the manner described in Sections 7.1

The following sections detail the additional data also collected during this period.

\subsubsection{Soil moisture and temperature}

In mid-January, a random number generator (version 5.3.2, R Core Team, 2018) was used to randomly select one plot from each treatment $(n=11)$ to be fitted with a Decagon ECH20 5TM volumetric water content and temperature sensor (Decagon Devices Incorporated, 2012). The sensors measured the dielectric permittivity of the soils using an electromagnetic wave, which was supplied to sensor prongs and charged according to the dielectric of the soil. This provided a permittivity value from which a water content value was produced. A surface mounted thermistor within the prongs provided soil temperature data.

The sensors were calibrated and installed according to the manufacturer's recommendations (Decagon Devices Incorporated, 2012). For each plot to be fitted with a sensor, a small shallow hole was dug to the side of the plot (Figure 8.1a). This allowed the pointed tips of the sensor to be pushed into the surrogate soil plots from underneath and positioned to ensure the sensor prongs sat within the soil rather than the tailings. The shallow insertion holes in the tailings were backfilled to the approximate natural bulk density of the material. The sensor cables were positioned to ensure that none interfered with the soil plots. The cables connected to a handheld reader, which was sealed inside a plastic box to reduce the possibility of water damage (Figure 8.1b). 

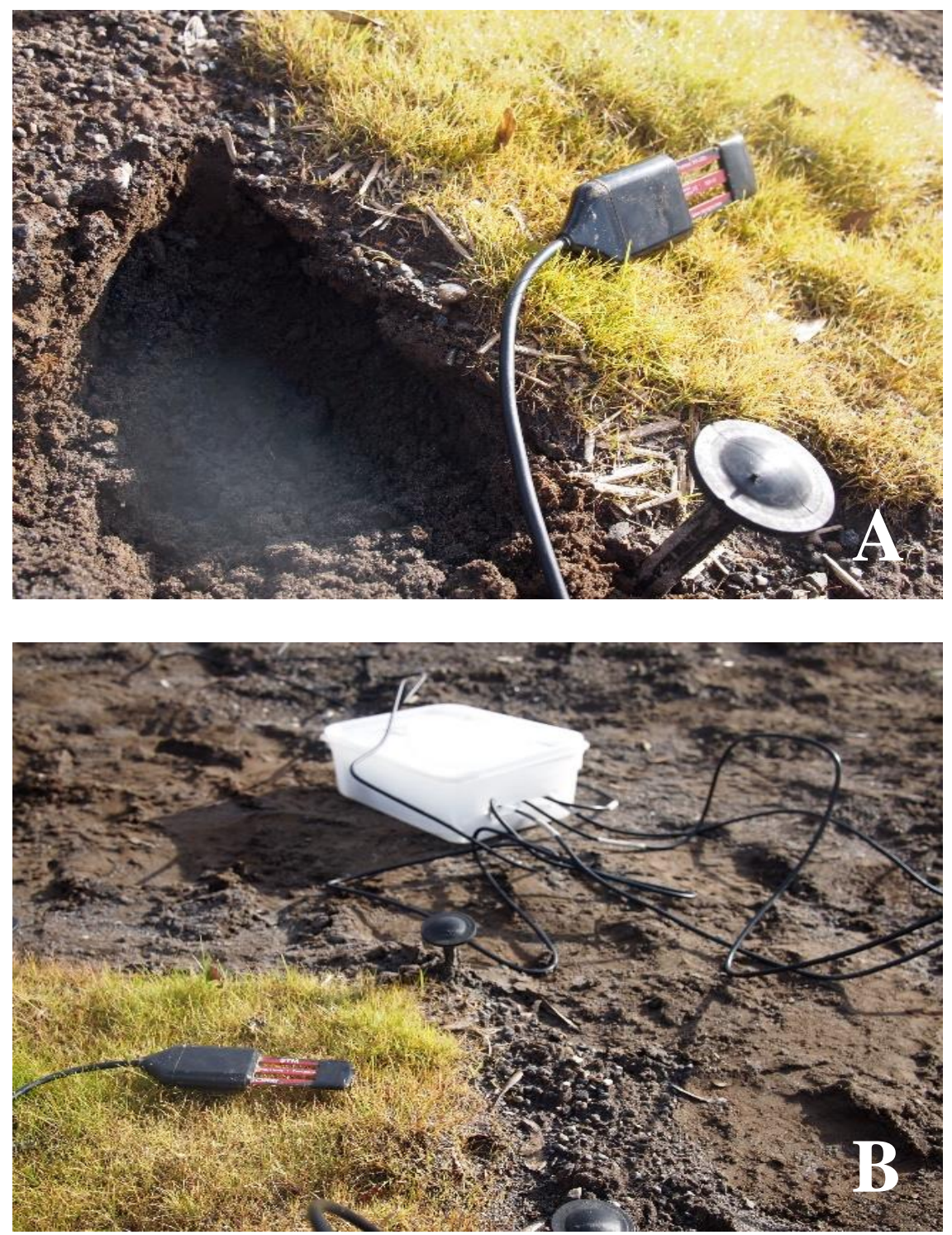

Figure 8.1: A) A soil plot prepared for the insertion of the sensor prongs. $A$ hole was dug underneath the plot to allow the whole sensor to be inserted into the soil from underneath, and $B$ ) the cables leading to a waterproof housing box which contained the data logger. Nantymwyn, January 2019

\subsubsection{Erosion pins}

In February, five rudimentary erosion pins were placed around the field site to provide an estimate of the tailing's erosion throughout the remainder of the trial. Two were placed at the top of the south-west facing slope and one on the north-east slope. Two pins were situated at the bottom of the slope to measure deposition (Figure 8.2).

The steel erosion pins (100 cm length) were hammered $40 \mathrm{~cm}$ into the tailings, perpendicular to the slope, as recommended by Kearney (2018) (Figure 8.3). 
Holes at $1 \mathrm{~cm}$ intervals allowed a metal ring to be threaded through and mark the ground level in January. A second ring was used to mark the height of ground advancement or retreat, often following periods of heavy rainfall. The erosion or deposition rate was calculated at the difference between the two rings.

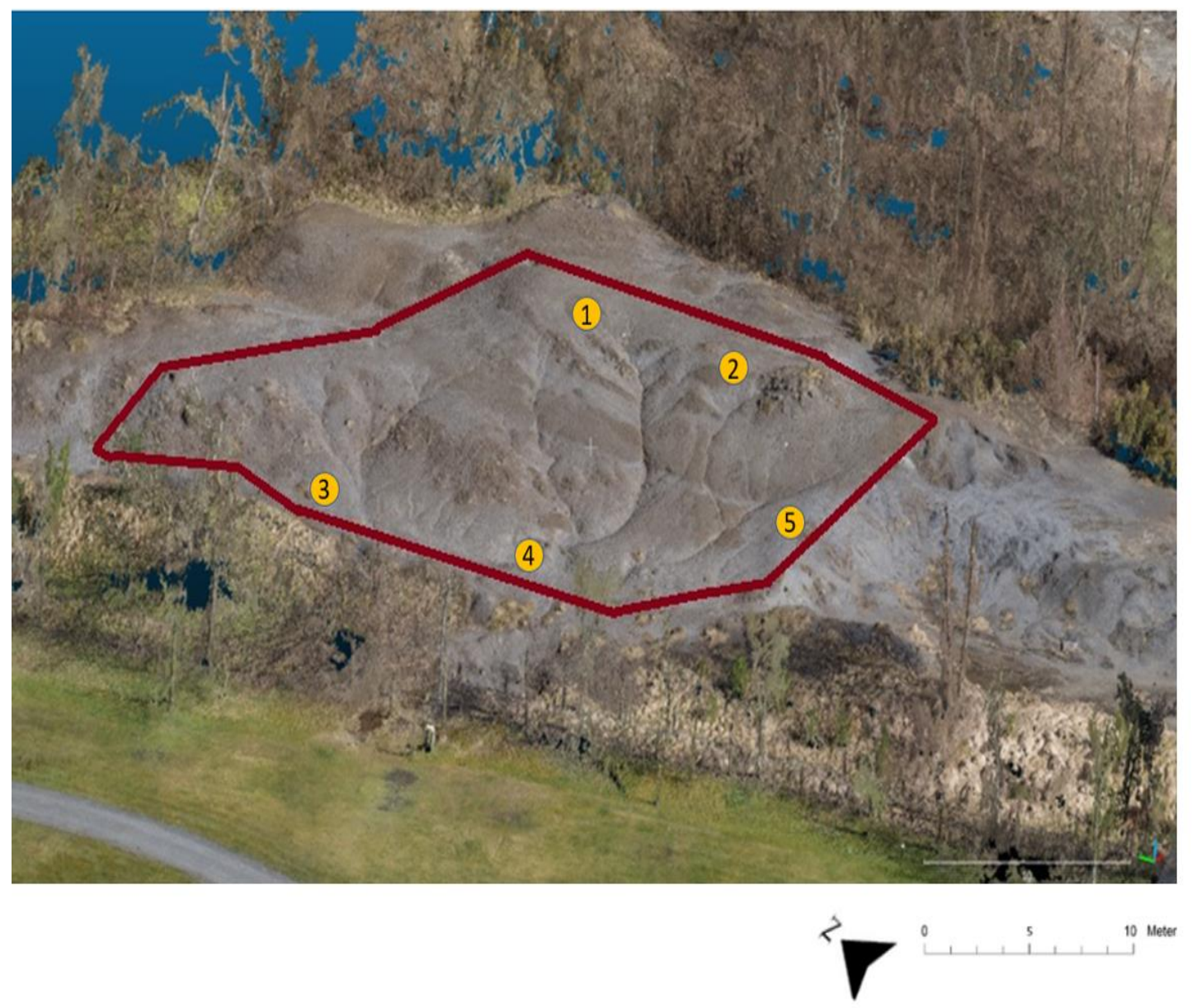

Figure 8.2: Erosion pin placement, indicated by yellow circles. The red line marks the fence. Nantymwyn, January 2019. 


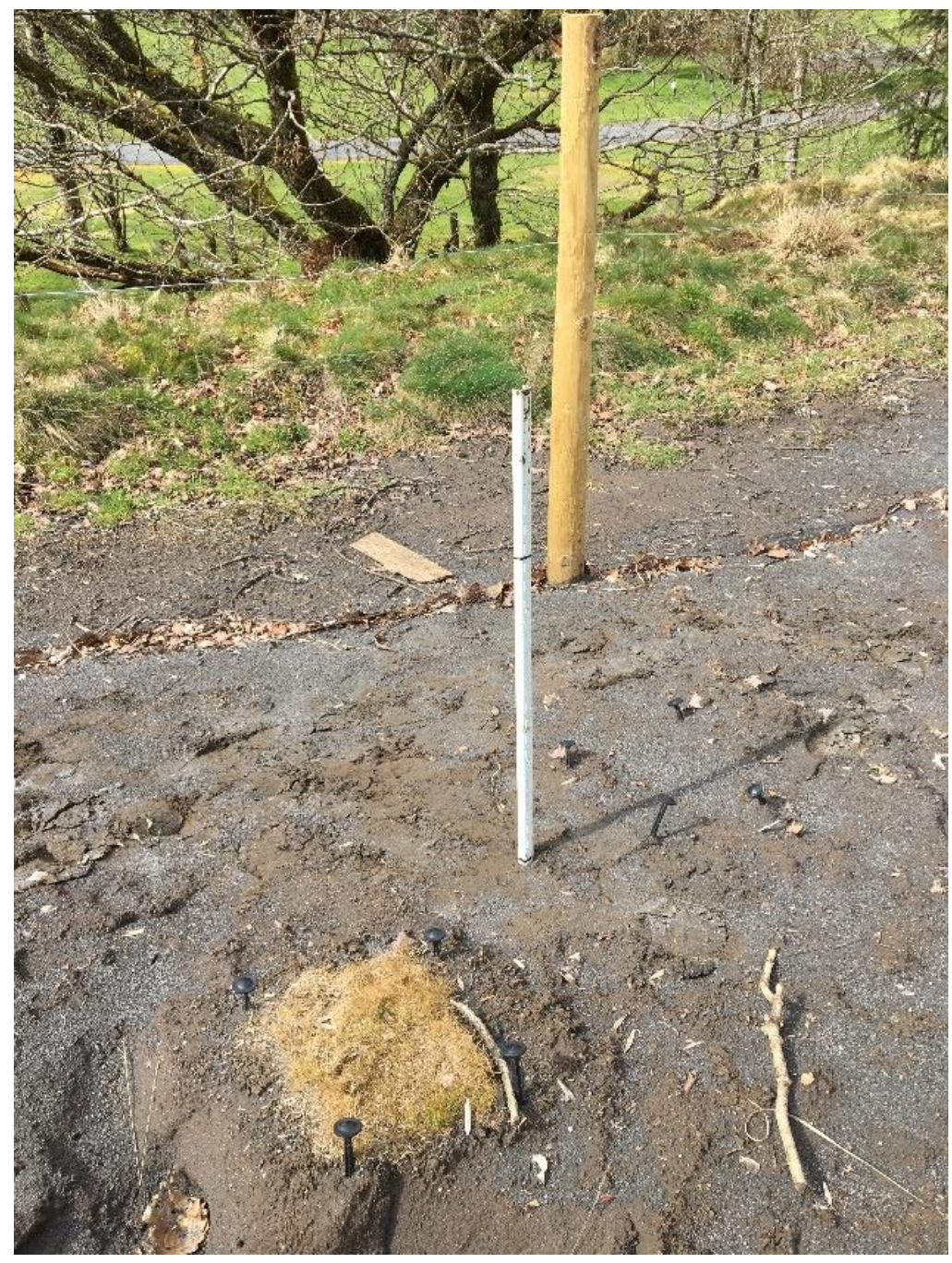

Figure 8.3: Erosion pin number 4, which measured deposition. Nantymwyn, January 2019.

\subsubsection{Final data collection}

At the end of week 40 (late June) the biomass was collected from the remaining seven replicates of the 11 treatments $(\mathrm{N}=77)$ in the manner described in Section 7.1.7. Biomass samples from a nearby pasture were also harvested at this time $(\mathrm{N}=7)$.

The grass blades were separated into living and dead blades, weighed, and freeze dried, as per the method outlined in Section 7.1.7 and 7.1.8.

The freeze-dried living and dead portions of the grasses were combined back into the original sample $(\mathrm{N}=77)$. A random number generator in $\mathrm{R}$ ( $\mathrm{R}$ Core Team, 2018) was used to randomly select five replicates from each treatment. The biomass from each selected replicate was ground to < $1 \mathrm{~mm}$ using a Wahl ZX595 steel blade grinder. The grinder was cleaned between each use to prevent cross-contamination. 
The biomass from the pasture adjacent to the field trial was prepared in the same manner.

\subsubsection{Acid digestion}

Acid digestion is a method of dissolving materials into a solution by adding acid(s) and heating, either on a hot plate or, more commonly, in a microwave. The process completely decomposes the organic fraction and releases the analyte, which produces a solution suitable for the detection and quantification of elements within the material (Agilent, 2018 ${ }^{1}$ ).

As microwave digestion was not available, a method of hot plate digestion was determined by ISO 16729:2013 and the Standing Committe of Analysist (2011).

Prior to digestion, all glassware, instruments, and preparation areas were thoroughly washed in municipal water and rinsed with deionised water. Glassware was submerged in a 10\% HCL (hydrochloric acid) bath for 24 hours, rinsed again in deionised water, and air dried.

For each biomass sample, a $1 \mathrm{~g}$ sub-sample was transferred to an individual borosilicate digestion vessel. The digestion vessel was seated inside a digestion block and placed centrally on a hot plate inside a fume cupboard. Each digestion block held six vessels.

In each vessel, $20 \mathrm{ml}$ of reagent grade $\mathrm{HNO}_{3}$ (nitric acid) was pipetted and allowed to stand until any visible reaction had stopped. The temperature of the digestion mixtures were raised with a heating rate of $10-15^{\circ} \mathrm{C} / \mathrm{min}$ to $120 \pm 5^{\circ} \mathrm{C}$ and held at $120 \pm 5^{\circ} \mathrm{C}$ for 10 minutes. The solutions were then removed from the hot plate and allowed to cool to room temperature. Two thermometers were used to determine the temperature of the solutions.

Whatman 41 ashless filter paper was used to filter the cooled sample into a glass volumetric container. Using a glass pipette, $1 \mathrm{ml}$ of the filtered solution was transferred to a stoppered container and diluted to $10 \%$ concentration using deionised water, as per the requirements of a microwave plasma atomic emission spectroscopy (MP-AES) instrument (Agilent, 2018²). 


\subsubsection{Microwave plasma atomic emission spectroscopy}

MP-AES is an atomic emission technique for the analysis of elements in solution. The element in solution is nebulised, and the aerosol is introduced into nitrogen fuelled microwave plasma at $\sim 5000{ }^{\circ} \mathrm{C}$. At this temperature, excitation of the atoms occurs, and light is emitted at wavelengths characteristic of certain elements. The elements can then be quantified by comparing the colour of the emission to that of known concentrations of the element (Agilent, 2018 ${ }^{1}$ ).

An Agilent 4200 MP-AES instrument was used for analysis. Multi-elemental standards of 2, 4, 6, 8 and 10 mg.L $\mathrm{L}^{-1}$ were used for calibration before analysis began, again half-way through the samples, and at the end of the run. Each sample was analysed three times and a mean was produced for each sample.

The detection limits for each element are tabulated in Table 8.1.

Table 8.1: The Agilent 4200 MP-AES detection limits for heavy metals

\begin{tabular}{c|c}
\hline \hline Element & Detection limit $\left(\mu \mathrm{g} . \mathrm{L}^{-1}\right)$ \\
\hline $\mathrm{Pb}^{1}$ & 2500 \\
$\mathrm{Zn}^{2}$ & 3200 \\
$\mathrm{Cd}^{2}$ & 30 \\
$\mathrm{Cu}^{1}$ & 0.05
\end{tabular}

${ }^{1}$ Agilent $\left(2018^{2}\right)^{2}$ Smirnova et al., (2018)

\subsubsection{Concentration and uptake}

The total metal uptake in above-ground biomass can be calculated with respect to the total weight of biomass produced and the concentration of the metal in question. The following calculation, provided by Ashjaei et al., (2011) was used to produce the uptake for each replicate: 


\section{Element concentration (mg. $\left.\mathrm{kg}^{1}\right) \times$ Weight of grass (mg)}

$1,000,000$

\subsubsection{Statistical analyses methods}

The randomised experimental design was composed of nine treatments (after omissions) with seven remaining repetitions $(\mathrm{N}=63)$.

The median final shoot length and the biomass yield allowed for an assessment of the ground cover which was confirmed visually using fortnightly photographs.

A Shapiro-Wilks test for normality was used to assess the distribution of each of the data sets. The shoot length data ( $\mathrm{p} \leq 0.001, \mathrm{~N}=63)$, biomass yield data $(\mathrm{p} \leq 0.011, \mathrm{~N}$ $=63), \mathrm{Zn}$ concentration $(\mathrm{p} \leq 0.001, \mathrm{~N}=50), \mathrm{Zn}$ uptake $(\mathrm{p} \leq 0.045, \mathrm{~N}=50), \mathrm{Pb}$ concentration $(\mathrm{p} \leq 0.045, \mathrm{~N}=50)$ and $\mathrm{Pb}$ uptake data $(\mathrm{p} \leq 0.043, \mathrm{~N}=50)$ were not normally distributed.

A Mann-Whitney U-test assessed for differences between two medians $(\mathrm{p} \leq 0.05)$. For comparisons of three or more groups, a Kruskal-Wallis with Dunn's post-hoc test was performed with a Bonferroni correction to control for the experiment-wise error rate. The statistical software R (version 5.3.2) was used for all analyses (R Core Team, 2018).

Throughout the text, the sample standard deviation is presented as \pm . 


\subsection{Field trial - Results, January to June 2019}

Data collection ceased for four weeks from mid-December 2018 to mid-January 2019 as the area was inaccessible due to snow or flooding.

At the end of week 40 (late June) the biomass was collected from the remaining seven replicates of the 11 surrogate soil treatments $(\mathrm{N}=77)$. Biomass samples from a nearby pasture were also harvested at this time $\left(160.8 \pm 9.9\right.$ g. $\left.\mathrm{m}^{-2}, \mathrm{~N}=7\right)$.

The unseeded, untreated control plots remained bare throughout the trial. In one treatment, no surrogate soil was applied and instead the bare tailings were directly seeded (Figure 8.4). A small amount of biomass initially grew in several of these plots, however, by February 100\% mortality had occurred. The data from these treatments did not provide a meaningful statistical comparison with the other treatments and so were omitted from analysis.

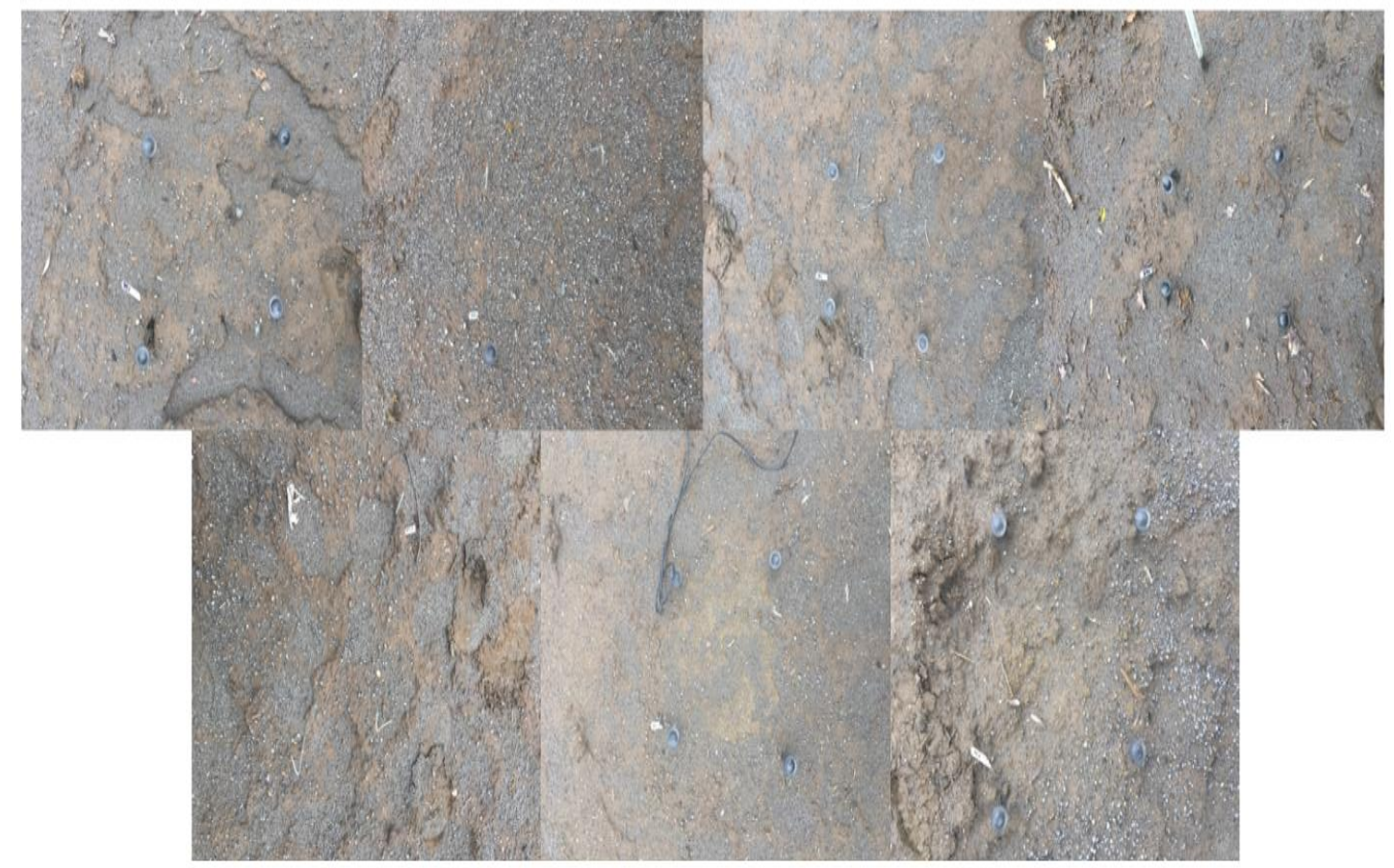

Figure 8.4: The seven replicates of the $30 \mathrm{~cm}^{2}$ seeded mine tailings plots at the Nantymwyn field trial, June 2019. The plots remained bare throughout the trial. 


\subsubsection{Weather conditions}

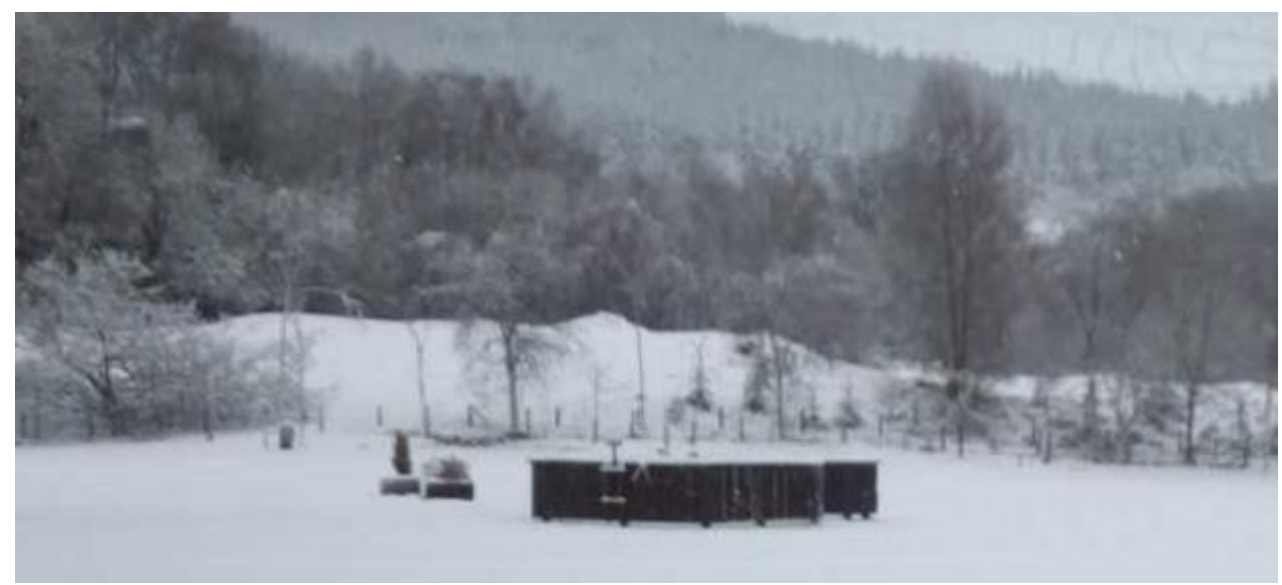

Figure 8.5: Heavy snow in early January 2019, at the Nantymwyn field site

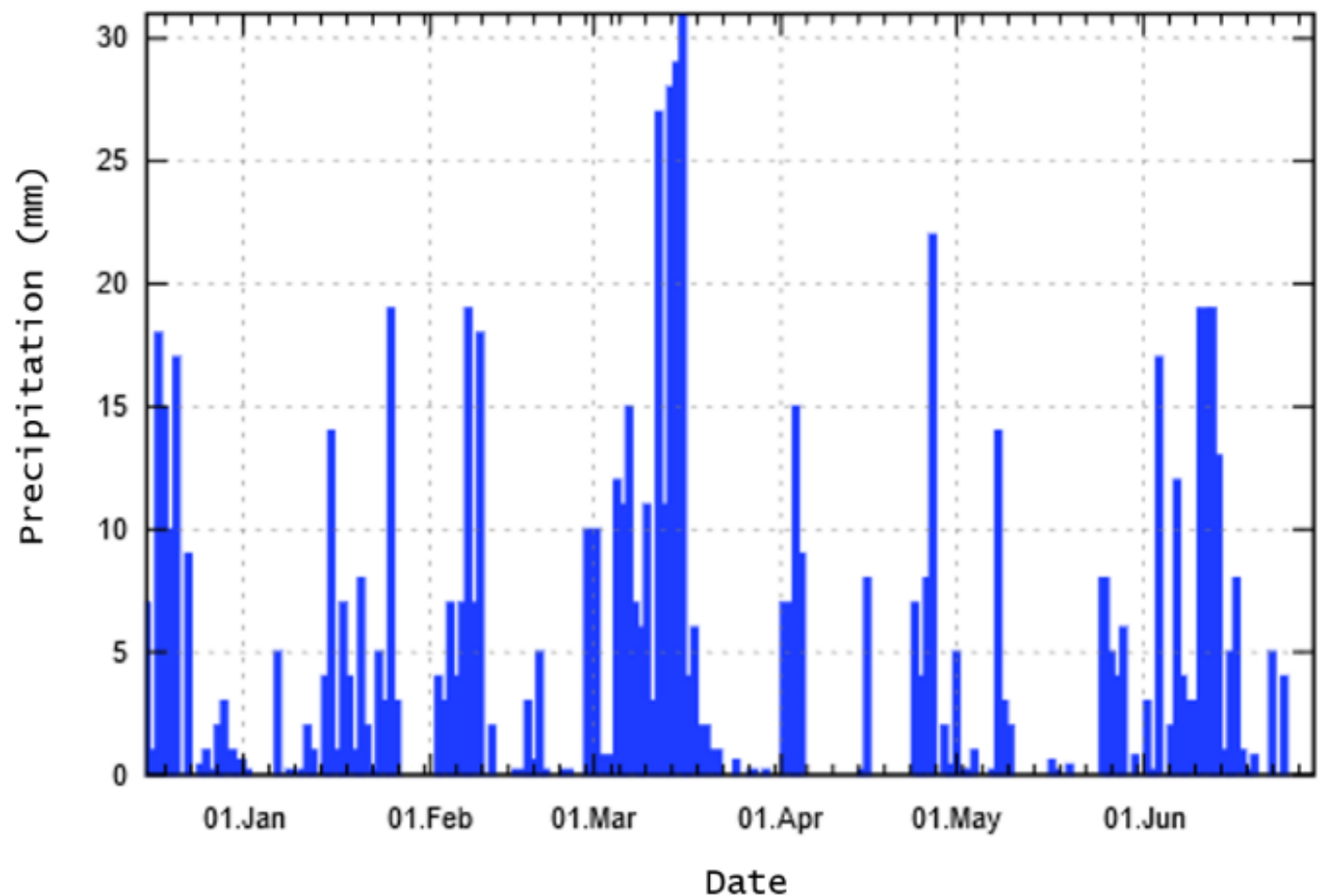

Figure 8.6: Precipitation (mm) at Rhandirmwyn from December to June 2019. Source www.worldweatheronline.com (2019) 


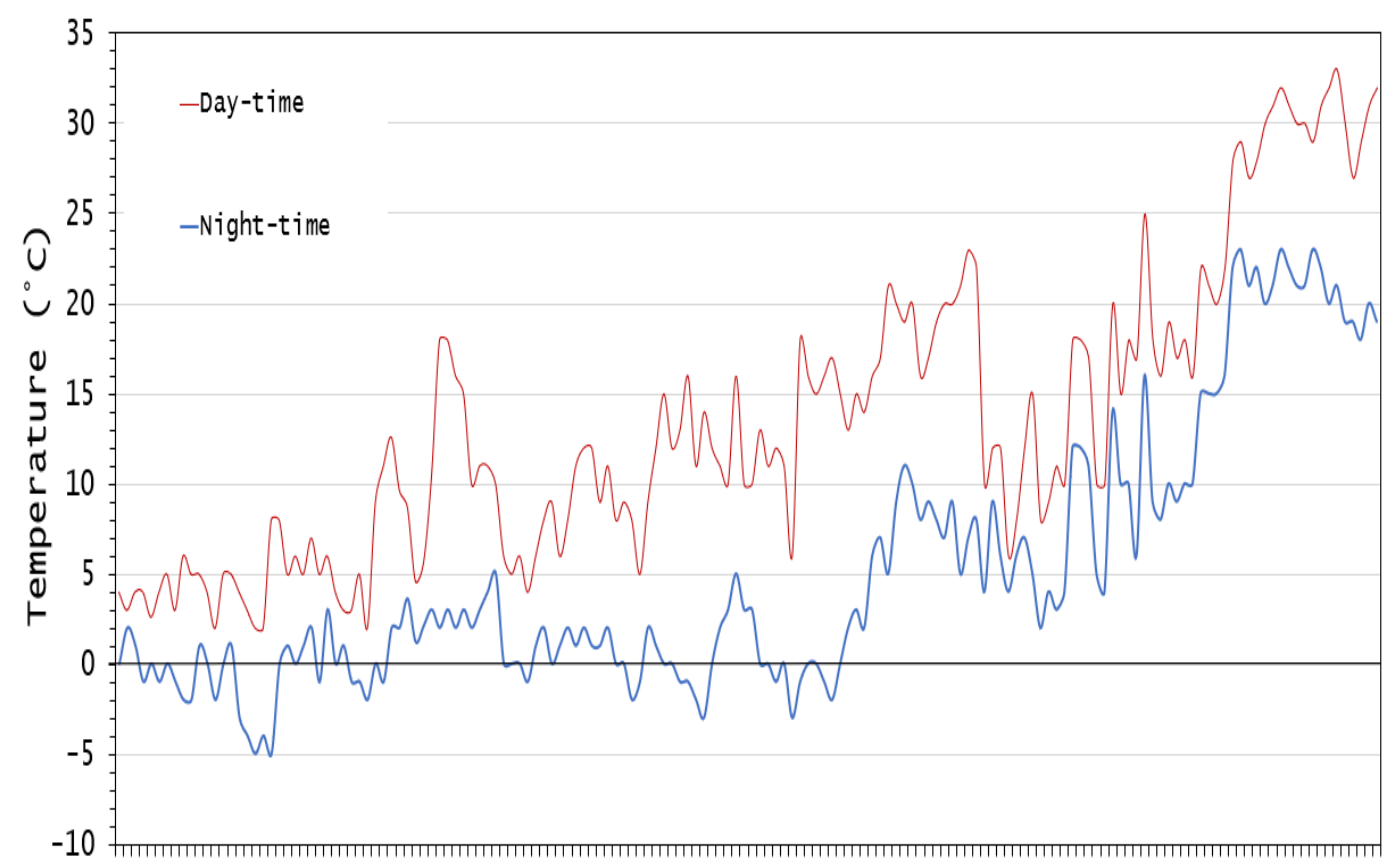

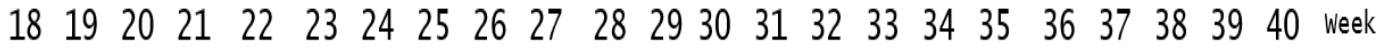
Week

Figure 8.7: Day-time (red) and night-time (blue) air temperatures $\left({ }^{\circ} \mathrm{C}\right)$ from December 2018 to June 2019, as recorded hourly by an in-situ i-Button data logger at Nantymwyn. The values have been calculated as a mean of 12 daytime temperatures ( 7 am to $7 \mathrm{pm}$ ) and 12 night-time temperatures ( $7 \mathrm{pm}$ to $7 \mathrm{am}$ )

January 2019 was dull and cloudy, with several days of heavy snow and frequent evening frosts (Met Office, 2019 ${ }^{3}$ ) (Figure 8.5). Sunshine duration was $80 \%$ of the long-term average (LTA, 1961 - 1990, (Met Office, 2020). Snow fell for three days during February, and this was followed by Storm Erik which deposited $32 \mathrm{~mm}$ of rainfall in two days (Figure 8.6) (NRW, 2019²). February began colder than the LTA, yet concluded with a record-breaking high temperature for the month $\left(18{ }^{\circ} \mathrm{C}\right.$, Met Office, $2019^{2}$, Figure 8.7).

Two named storms occurred in March, and rainfall was 164\% of the LTA (Met Office, $\left.2019^{5}\right)$. However, the soil in the regions MORECS square was drier than the long-term average, the cause of which was cited as the warm and dry end of February (NRW, $2019^{3}$ ). The temperature at Nantymwyn averaged several degrees lower than the surrounding area due to the valley bottom location. Cloud cover persisted for 17 of 31 days, and the site experienced night-time frosts until the end of March (Met Office, $\left.2019^{5}\right)$. 
April began with sleet and heavy rainfall but ended with record-breaking high temperatures (22 ${ }^{\circ} \mathrm{C}$, Met Office, $2019^{1}$ ) (Figures 8.6 and 8.7). Temperatures on site in April were $2.5{ }^{\circ} \mathrm{C}$ higher than the LTA (Met Office, 2020).

May was also hot and dry. On site, the mean temperature throughout May was $0.4{ }^{\circ} \mathrm{C}$ above the LTA, with only $55 \%$ of average rainfall and $107 \%$ of the average sunshine duration (NRW, 20194). The soil moisture deficit in the regions MORECS square was -4.81 to $-38.1 \mathrm{~mm}$ compared to the long-term average (NRW, 20194). Night-time temperatures were higher that previous years, often between 10 and $15{ }^{\circ} \mathrm{C}$ (Met Office, $\left.2019^{6}\right)$.

The mean temperature in June was $2.5^{\circ} \mathrm{C}$ higher than the LTA and sunshine duration was $120 \%$ of the LTA (Met Office, 2020). The days were hot and dry, but sudden and intense rainfall events often occurred overnight. 
8.2.2 Soil temperature

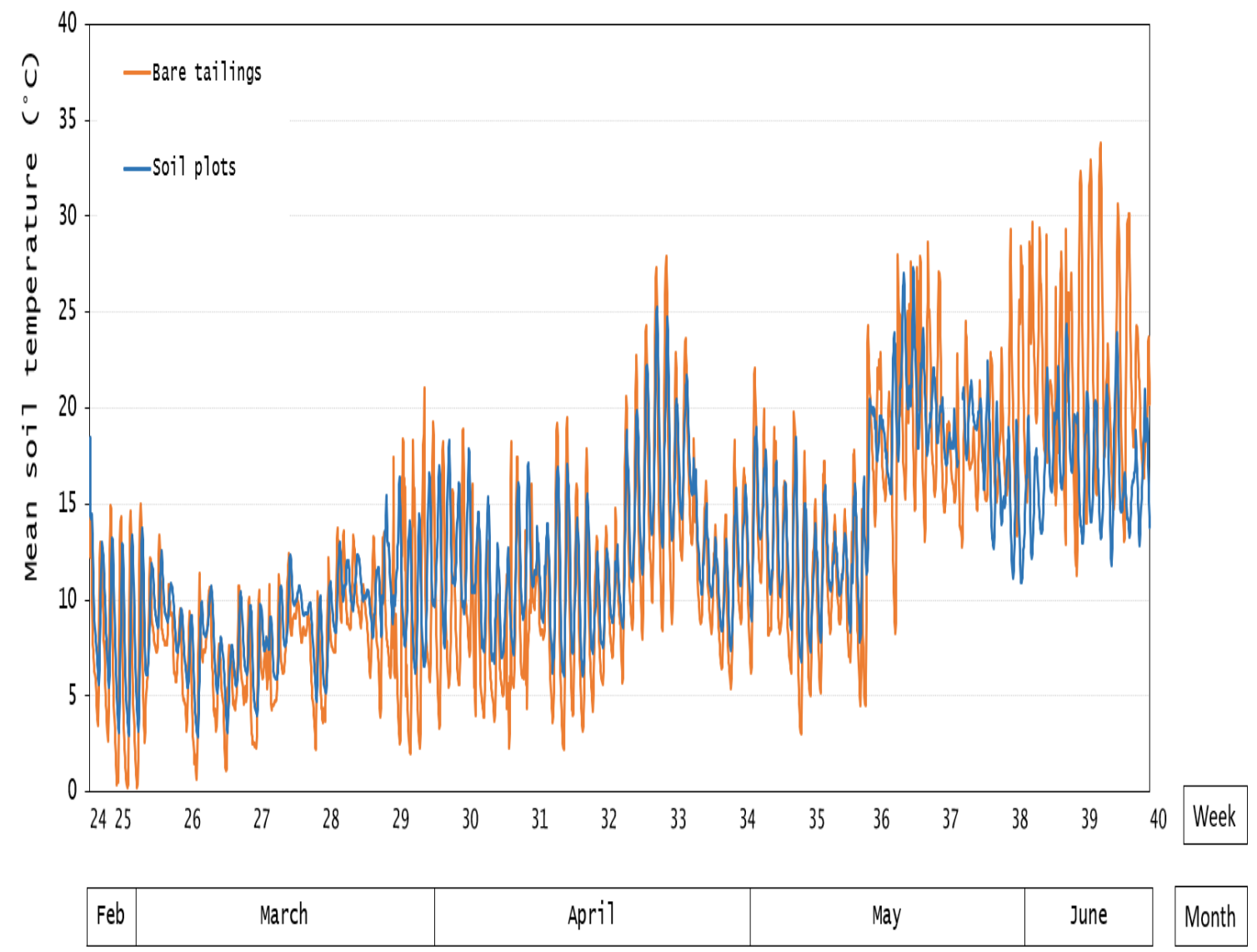

Figure 8.8: The mean hourly temperatures $\left({ }^{\circ} \mathrm{C}\right)$ of the bare tailings plot (orange), and the pooled mean of the nine surrogate soil treatments (blue) from February to June 2019 (Nantymwyn). 
Table 8.2: The monthly mean temperatures $\left({ }^{\circ} \mathrm{C}\right)$ of the one bare tailings plot (with sample standard deviation, \pm ) and the monthly mean of the nine surrogate soils plots (with standard error, S.E) at the Nantymwyn field trial, 2019. The temperature readings from the nine surrogate soil plots ( 6500 readings per month) were pooled to create one monthly mean for the surrogate soils group.

The minimum and maximum hourly reading of any of the nine surrogate soils is tabulated, alongside the minimum and maximum temperature of the one bare tailings plot.

\begin{tabular}{ccccccc}
\hline \hline Treatment & $\left({ }^{\circ} \mathrm{C}\right)$ & February & March & April & May & June \\
\hline Bare & Min & 0.2 & 0.7 & 2.2 & 3.0 & 12.5 \\
tailings & Max & 15.0 & 17.2 & 27.9 & 28.4 & 33.8 \\
& Mean & 7.0 & 7.9 & 12.2 & 18.3 & 19.6 \\
& \pm & 4.4 & 3.4 & 5.0 & 5.0 & 5.0 \\
Surrogate & & & & & \\
soil plots & Min & 2.2 & 4.1 & 3.0 & 7.2 & 6.1 \\
& Max & 17.4 & 24.9 & 25.1 & 26.0 & 29.2 \\
& Pooled mean & 9.4 & 9.3 & 12.5 & 16.4 & 17.6 \\
& S.E & 0.6 & 0.1 & 0.2 & 0.3 & 0.3 \\
\hline
\end{tabular}

One Decagon soil temperature and moisture meter was situated $\sim 3 \mathrm{~cm}$ beneath one replicate from each seeded surrogate soil treatment $(n=9)$. One sensor was also situated beneath a bare tailings plot $(n=1)$. Hourly readings were recorded from late February to June.

There was an approximately two-week delay before changes to the air temperature were expressed in the soil temperature (Figures 8.7 and 8.8).

Table 8.2 and Figure 8.8 show that whilst the mean temperature of the surrogate soil plots fluctuated between daytime highs and night-time lows, the changes were not as great as those observed in the bare tailings plot. This effect was more pronounced in the extremes of temperature, such as February when the site was snow covered, and June when the air temperature was often $>30{ }^{\circ} \mathrm{C}$ (Met Office, 2019²; Met Office, $2019^{4}$ ). The highest temperature recorded in the surrogate soil plots was $29.2{ }^{\circ} \mathrm{C}$, compared to $33.8^{\circ} \mathrm{C}$ in the bare tailings (Table 8.2). The lowest temperature recorded was $2.2{ }^{\circ} \mathrm{C}$ in the surrogate soil plots, and $0.2{ }^{\circ} \mathrm{C}$ in the tailings (Table 8.2). 
Despite the smaller temperature fluctuations, from May onwards the mean surrogate soil temperature remained high and often spiked $>20^{\circ} \mathrm{C}$ (Figure 8.8).

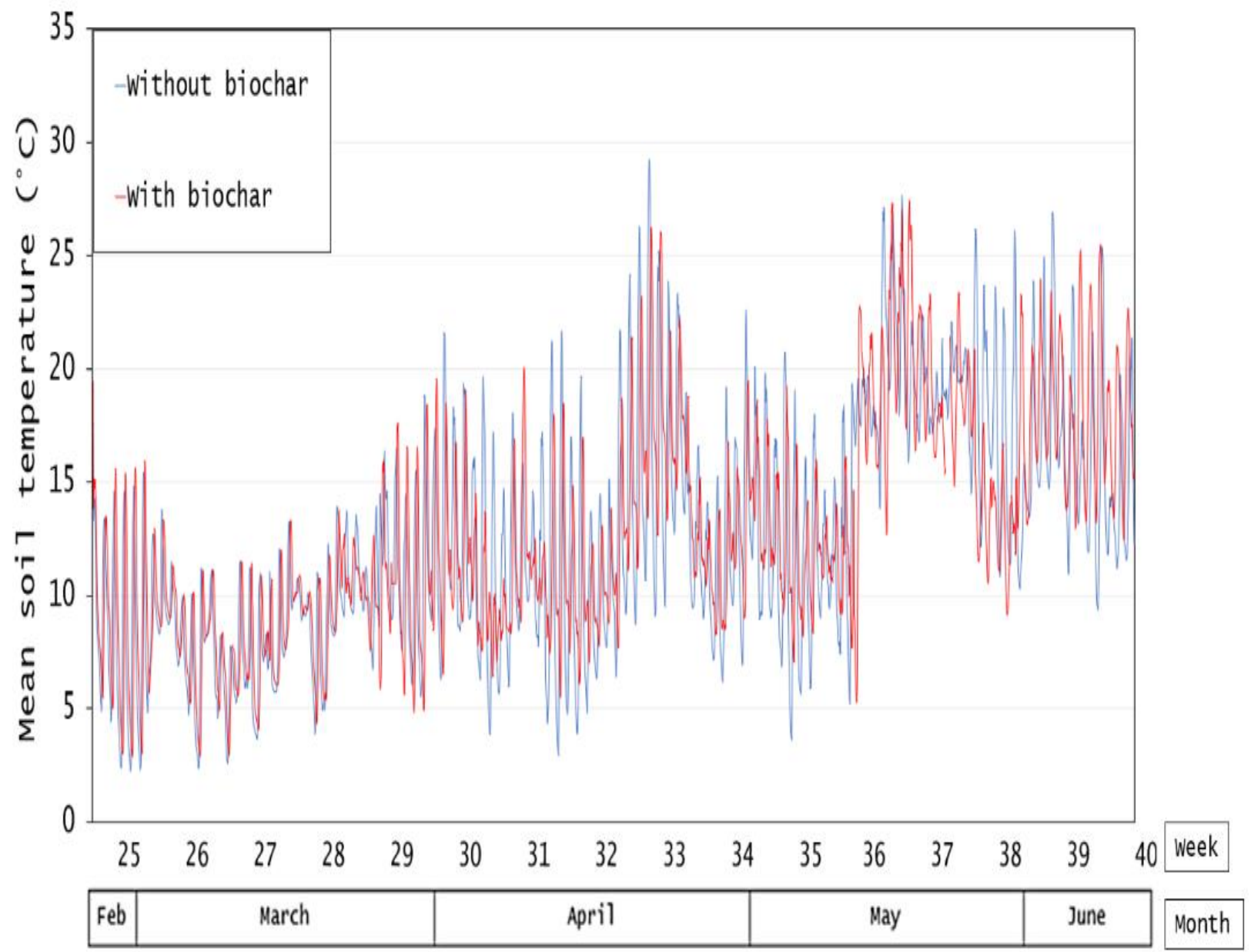

Figure 8.9: The mean hourly soil temperature $\left({ }^{\circ} \mathrm{C}\right)$ of the biochar soil plots $(\mathrm{red}, n=4)$ and the without biochar soils (blue, $n=4$ ), from February to June 2019 (Nantymwyn). 
Table 8.3: The mean monthly temperatures $\left({ }^{\circ} \mathrm{C}\right)$ of the four surrogate soil plots that contained biochar and the mean temperature of the four surrogate soils plots that did not contain biochar (with standard errors, S.E) at the Nantymwyn field trial, 2019. The temperature readings from each group, with biochar or without biochar ( 6500 readings per month) were pooled to create one monthly mean for the group.

The minimum and maximum hourly reading of any of the soil treatments within the treatment groups (with or without biochar) are also tabulated.

\begin{tabular}{ccccccc}
\hline \hline Treatment & $\left({ }^{\circ} \mathrm{C}\right)$ & February & March & April & May & June \\
\hline Without & Min & 2.2 & 4.1 & 3.0 & 7.4 & 7.5 \\
biochar & Max & 17.3 & 24.0 & 25.1 & 26.0 & 29.2 \\
& Pooled mean & 8.2 & 9.3 & 12.4 & 16.3 & 17.6 \\
& S.E & 1.0 & 0.2 & 0.4 & 0.3 & 0.5 \\
& & & & & & \\
With & & & & & & \\
biochar & Min & 3.9 & 4.4 & 3.9 & 7.2 & 6.1 \\
& Max & 17.4 & 24.9 & 22.0 & 22.1 & 26.8 \\
& Pooled mean & 10.3 & 10.4 & 12.5 & 15.5 & 15.7 \\
& S.E & 0.6 & 0.1 & 0.2 & 0.5 & 0.3 \\
\hline
\end{tabular}

Figure 8.9 and Table 8.3 illustrate the pooled mean temperature in the biochar amended soils (all treatments with biochar, regardless of any other amendment, $n=4$ ) and those without biochar (all treatments without biochar, regardless of any other amendment, $n=4)$. The bare tailings and the Hydra $C X$ are not included in the table or the figure.

When divided into surrogate soils with and without biochar, the temperature of the soils with biochar typically fluctuated less than those without biochar, as presented by the minimum and maximum temperatures (Table 8.3).

From February until late March, the temperature of both soil types remained similar. However, as the air temperature began to increase from March onwards, the pooled mean temperature of the soils with biochar remained more consistent than those without-biochar (Figure 8.9). From late March onwards the highest and lowest temperatures of the without-biochar soils were $29.2{ }^{\circ} \mathrm{C}$ and $2.2{ }^{\circ} \mathrm{C}$, respectively. The 
highest and lowest mean temperature of the with-biochar soils were $26.8{ }^{\circ} \mathrm{C}$ and $3.9^{\circ} \mathrm{C}$, respectively.

The basalt and $\mathrm{NH}_{4}+$ fertiliser amendments had no notable impact on the soil temperature.

\subsubsection{Soil volumetric water content}

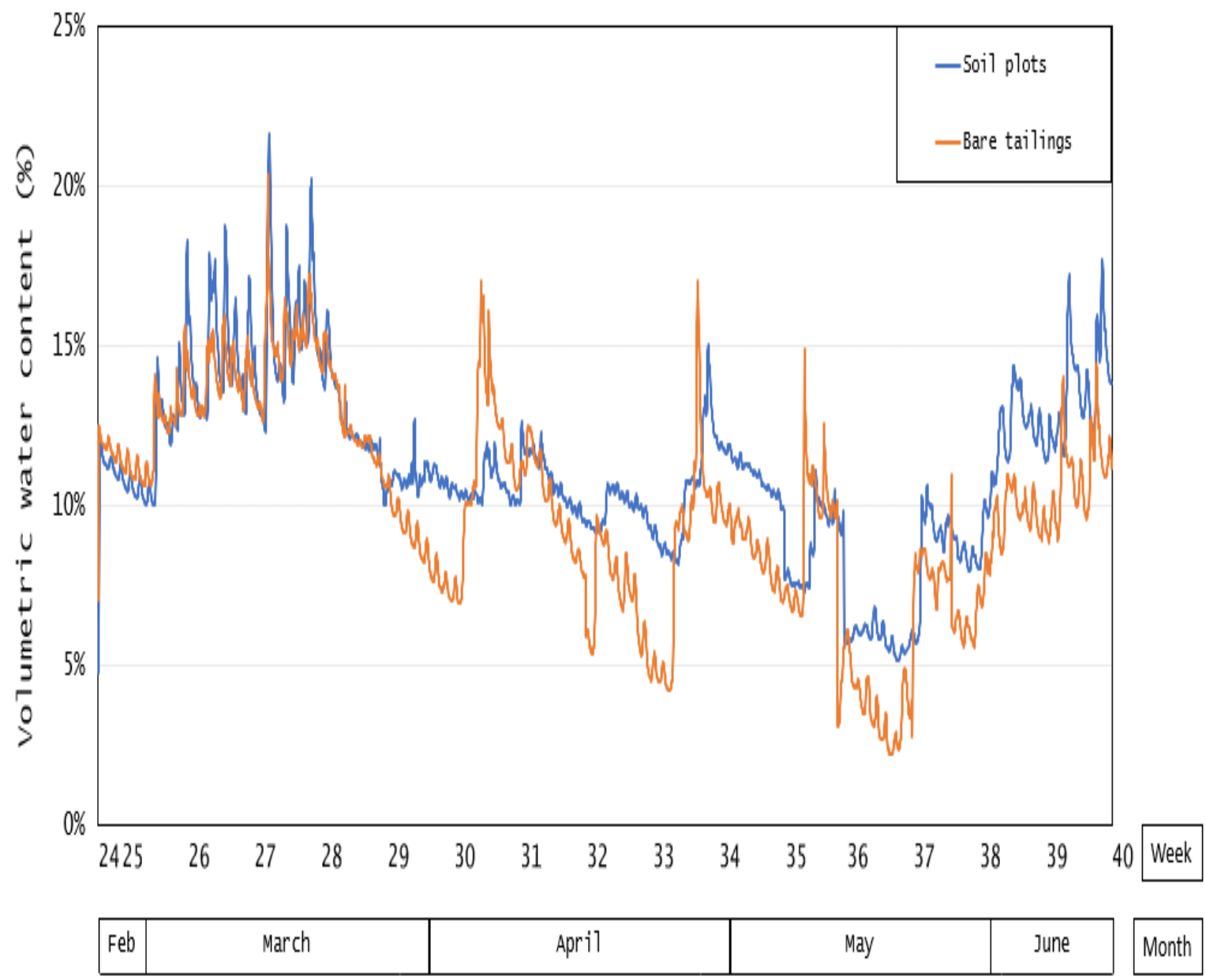

Figure 8.10: The mean volumetric water content (\%) of the surrogate soil plots (blue, $n=7$ ) and the bare tailings (orange, $n=1$ ), from February to June at Nantymwyn, 2019. 
Table 8.4: The monthly mean volumetric water content (\%) of the bare tailings plot ( $n=1$, with sample standard deviation, \pm ) and the nine surrogate soils plots (with standard error, S.E) at Nantymwyn, 2019. The water content readings from the nine surrogate soil plots ( 6500 readings per month) were pooled to create one monthly mean for the surrogate soils group.

The minimum and maximum hourly reading of any of the nine surrogate soils is tabulated, alongside the minimum and maximum reading of the bare tailings temperature.

\begin{tabular}{ccccccc}
\hline \hline Treatment & $(\%)$ & February & March & April & May & June \\
\hline Bare & Min & 0.2 & 0.7 & 2.2 & 3.0 & 12.5 \\
tailings & Max & 15.0 & 17.2 & 27.9 & 28.4 & 33.8 \\
& Mean & 12.0 & 12.6 & 10.4 & 10.0 & 11.4 \\
& \pm & 0.8 & 2.6 & 2.3 & 2.9 & 3.8 \\
Surrogate & & & & & \\
soil plots & Min & 2.2 & 4.1 & 3.0 & 7.2 & 6.1 \\
& Max & 17.4 & 24.9 & 25.1 & 26.0 & 29.2 \\
& Pooled mean & 9.4 & 9.3 & 12.5 & 11.1 & 17.6 \\
& S.E & 0.6 & 0.1 & 0.2 & 0.3 & 0.3 \\
\hline
\end{tabular}

The values from nine soil plots (one replicate of each treatment, 216 readings per day) were pooled to provide a mean hourly volumetric water content (\% VWC) from January to June. Data from one sensor beneath the bare tailings (24 readings per day) were plotted alongside the soil treatments (Figure 8.10).

A two-week delay between heavy precipitation and an increased VWC was observed (Figures 8.6 and 8.10).

The fluctuations in the moisture content of the bare tailings was greater than that of the surrogate soil plots (Figure 8.10). This was particularly prominent throughout April and May. In the warmer months of the trial, May and June, the surrogate soil plots typically contained a higher moisture content than that of the bare tailings (Table 8.4). From week 32 onwards, in the soil plots, $~ 26$ days passed when the mean VWC of the soil plots was $<10 \%$, and seven days passed at $<6 \%$ VWC. By comparison, in the same period 33 days passed when the VWC of the tailings was $<10 \%$, and 12 days at $<6 \%$ (Figure 8.10). 


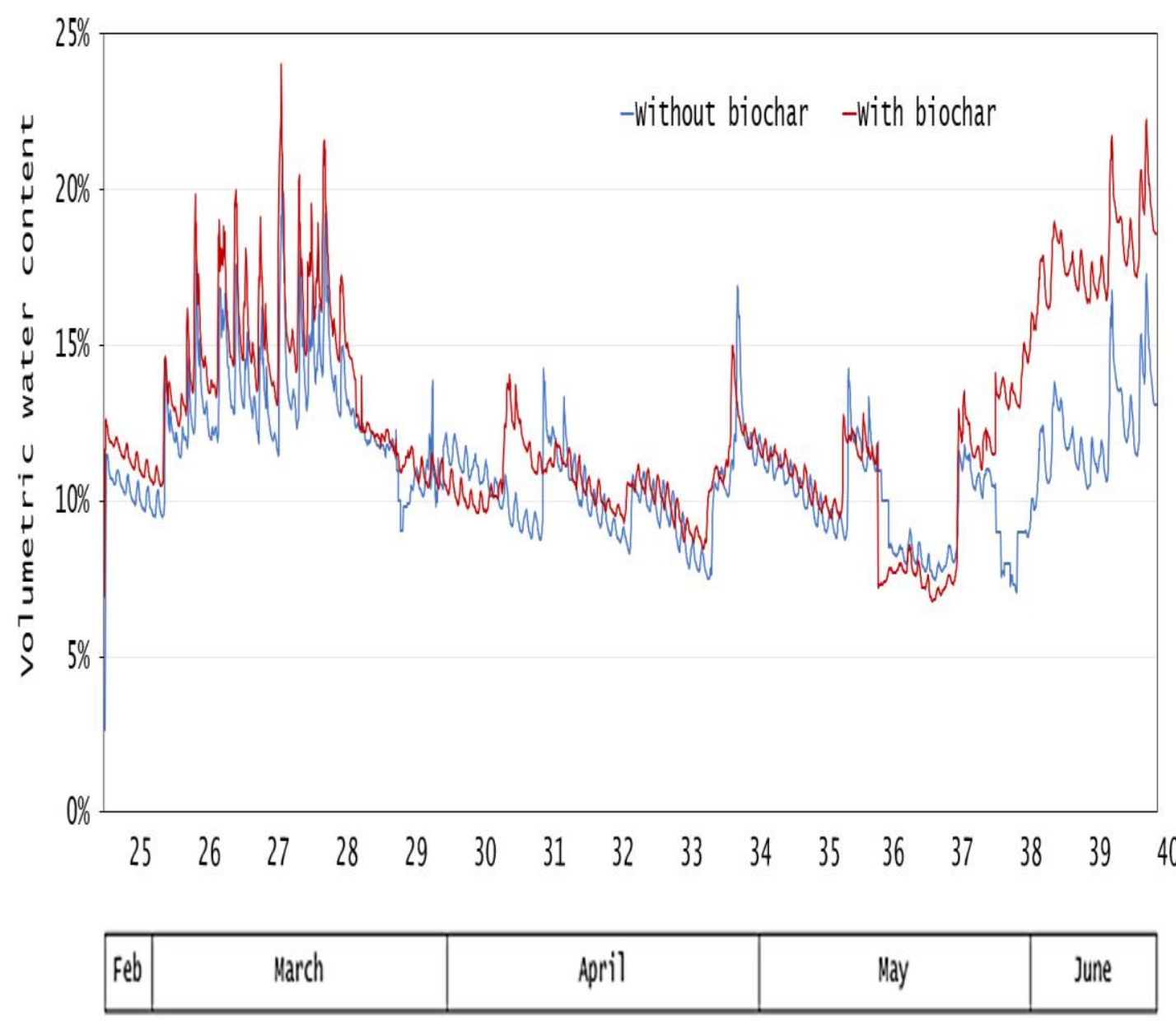

Figure 8.11: The mean volumetric water content of the biochar soils (red, $n=4)$ and the without biochar soils (blue, $n=4$ ), at Nantymwyn, February to June 2019. 
Table 8.5: The monthly mean volumetric water content (\%) of the four surrogate soil plots that contained biochar and the mean of the four surrogate soils plots that did not contain biochar (with standard errors, S.E), at the Nantymwyn field trial, 2019. The soil water content readings from each group, with biochar or without biochar ( 6500 readings per month), were pooled to create one monthly mean for the group.

The minimum and maximum hourly reading of any of the soil treatments within the treatment groups (with or without biochar) are tabulated.

\begin{tabular}{ccccccc}
\hline \hline Treatment & $(\%)$ & February & March & April & May & June \\
\hline Without & Min & 1.8 & 3.9 & 3.9 & 3.1 & 5.4 \\
biochar & Max & 21.6 & 31.3 & 24.4 & 20.0 & 24.4 \\
& Pooled mean & 11.0 & 14.0 & 11.4 & 10.7 & 13.9 \\
& S.E & 0.9 & 2.9 & 2.3 & 1.9 & 1.5 \\
With & & & & & \\
biochar & Min & 2.0 & 7.4 & 6.3 & 5.0 & 5.3 \\
& Max & 18.6 & 30.0 & 19.5 & 23.0 & 27.4 \\
& Pooled mean & 11.5 & 14.9 & 10.8 & 11.4 & 16.4 \\
& S.E & 1.3 & 1.0 & 0.8 & 0.8 & 0.6 \\
\hline
\end{tabular}

When grouped, the VWC of the two soil types, those with and without biochar, were very similar until late May (Figure 8.11). After May, the VWC of the with-biochar soils increased at a faster rate than the soils without biochar.

The VWC of the without-biochar soils first fell below $10 \%$ in late March, however for the biochar soils this did not occur until several weeks later. Between March and June, the VWC of the biochar soils was $<10 \%$ for $\sim 31$ days, whereas in the without-biochar soils the VWC was $<10 \%$ for $\sim 48$ days.

The basalt and $\mathrm{NH}_{4}+$ fertiliser amendments had no discernible impact on the soil VWC. 


\subsubsection{Soil adhesion}

The erosion of the surrogate soil was assessed using fortnightly photographs. Notes were made regarding any soil materials that had eroded from the plots. Where erosion occurred, the soil material was often found slightly downhill and close to the plot of origin (Figure 8.12).

Soil displacement throughout the field trial was visually estimated to be $5-10 \%$ of the overall material. One plot is documented throughout the 40 -week trial as an example of this (Figure 8.13). Several other plots are photographically documented in Appendix $5.3-5.5$. 

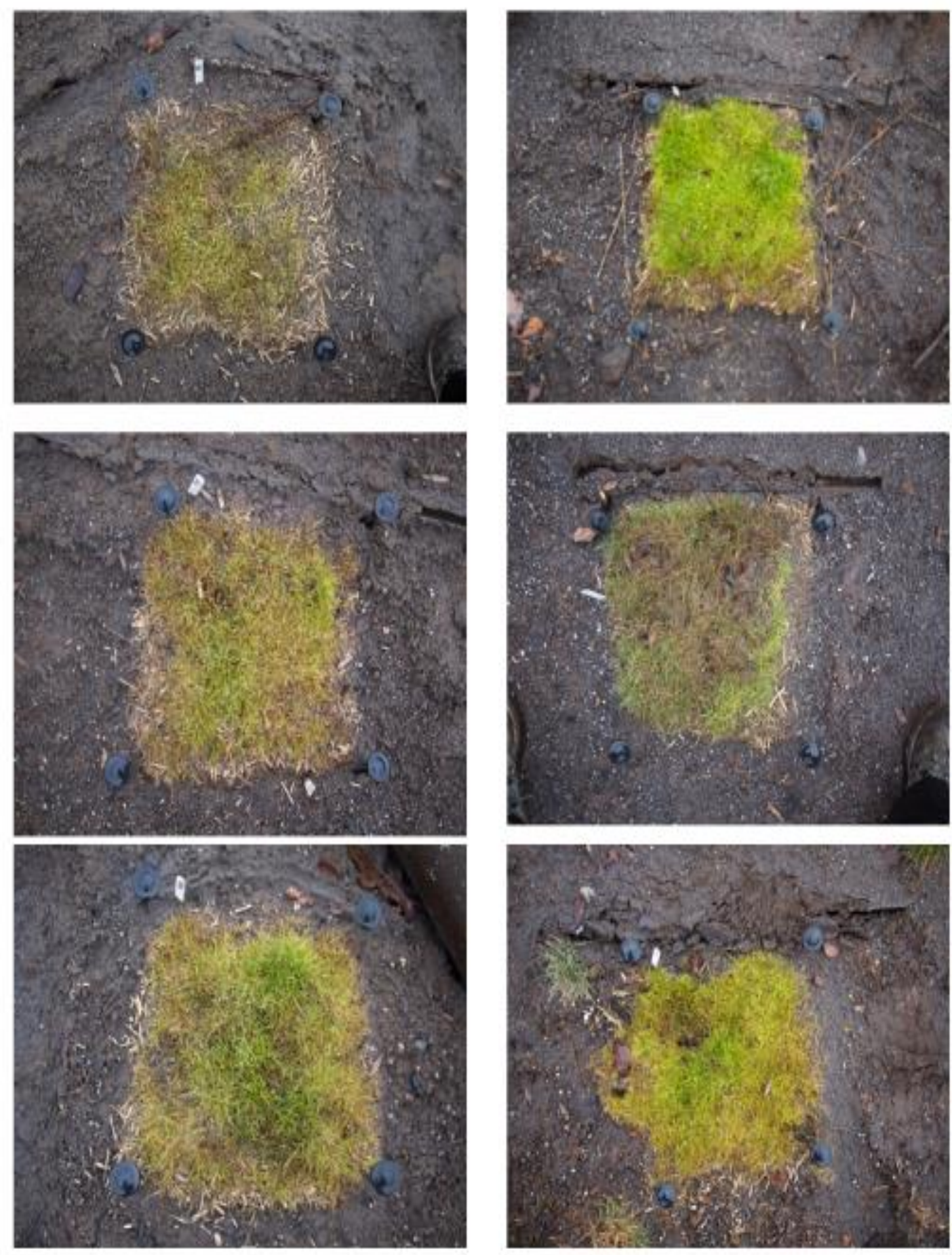

Figure 8.12: Several of the $30 \mathrm{~cm}^{2}$ surrogate soil plots with a small amount of eroded material (straw) surrounding the area (March 2019). 

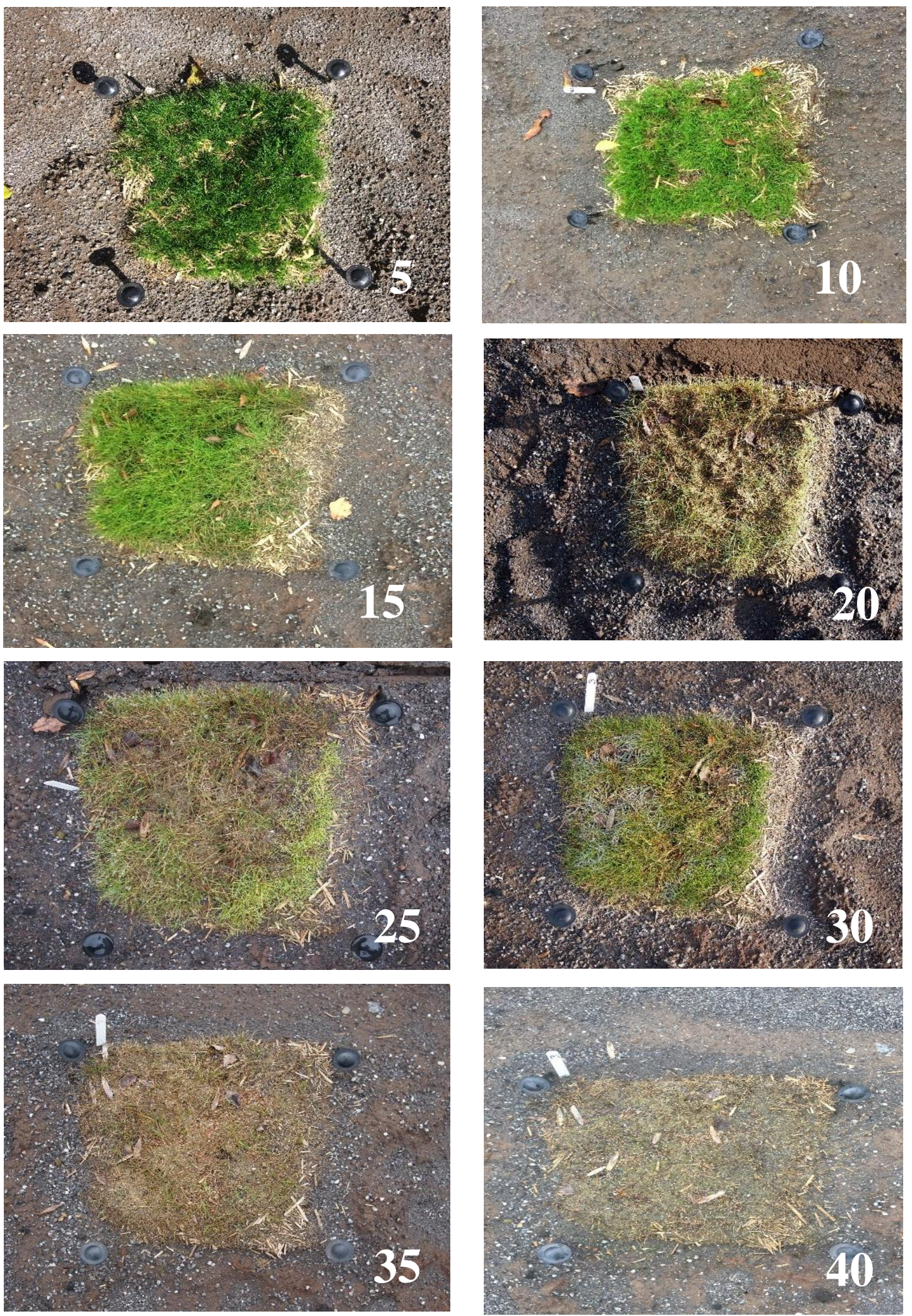

Figure 8.13: Photos of one $30 \mathrm{~cm}^{2}$ plot (biochar:basalt) taken every five weeks throughout the 40 weeks of the Nantymwyn field trial (2018 - 2019) 


\subsubsection{Tailings erosion}

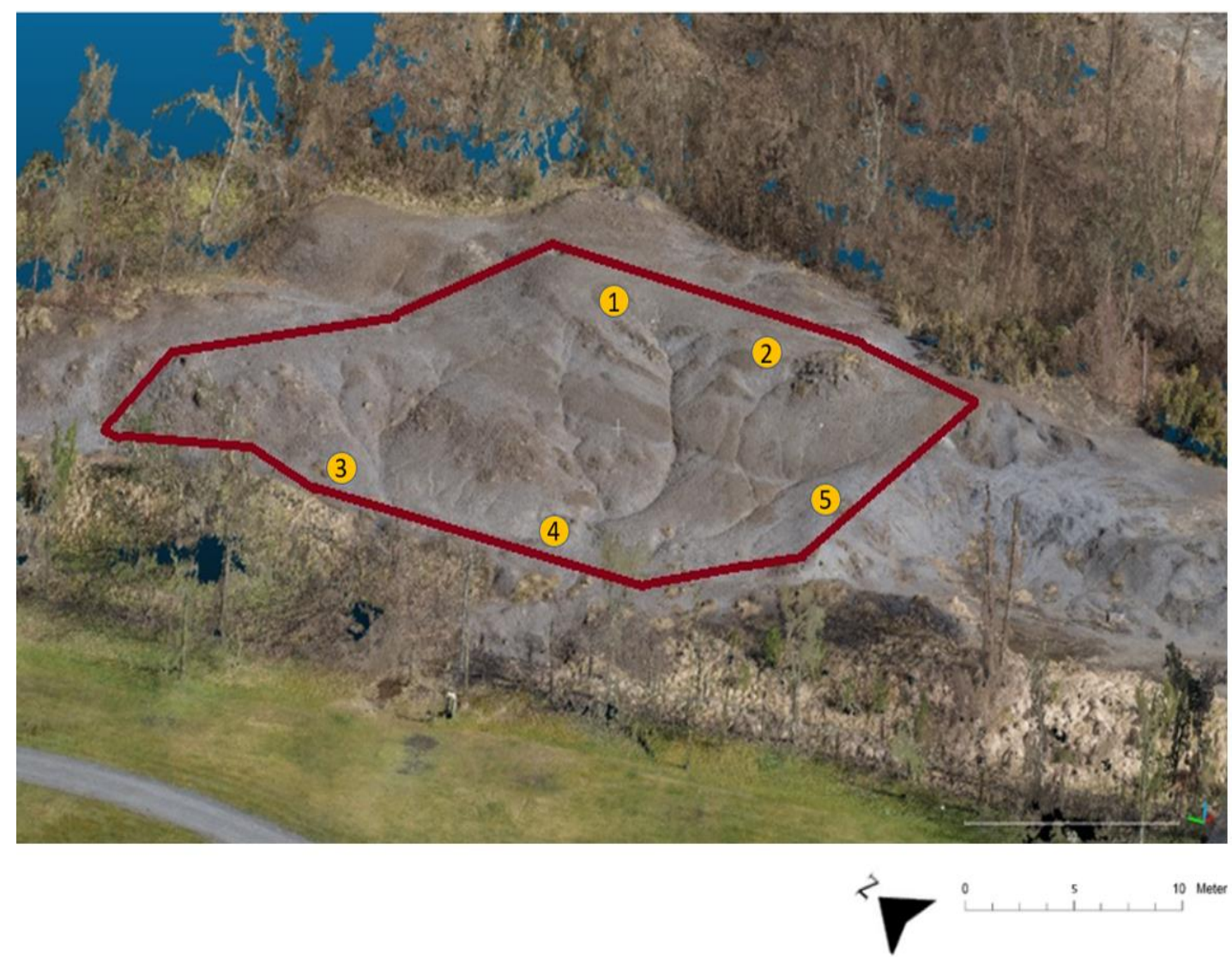

Figure 8.14: A map, produced in Cloud Compare, of the erosion pin placement (yellow circles) at the Nantymwyn field trial, 2019. The red line indicates the line of the fence.

In early February, five rudimentary erosion pins were positioned around the field site (Figure 8.14). The erosion or deposition rate was calculated as per the method detailed in Section 8.1.2. The measurements from erosion pins 1 and 2 were averaged (mean), as the results were very similar throughout the trial, as were pins 3 and 4 .

Much of the erosion on site occurred in short, dramatic events. Erosion pins 1 and 2 indicated that the storm from the $2^{\text {nd }}-5^{\text {th }}$ of February 2019 displaced a mean of $3.5 \pm 0.2 \mathrm{~cm}$ of tailings from the top of the slope, and a storm in March caused a further loss of $4.4 \pm 0.3 \mathrm{~cm}$. Short but heavy rainfall in May and June displaced $2.0 \pm 0.1 \mathrm{~cm}$ and $3.0 \pm 0.1 \mathrm{~cm}$, respectively. An additional $4.0 \mathrm{~cm}$ was lost incrementally throughout the trial. A total loss of $16.9 \mathrm{~cm}$ from the summit of the west-facing slope was measured in five months (pins 1 and 2). 
In the same time period, pin 5 recorded $1.2 \mathrm{~cm}$ of erosion from the summit of the north facing slope.

Pins 3 and 4 were situated at the toe of the west-facing slope and measured soil deposition. The values recorded by pins 3 and 4 were averaged (mean) as the measurements were very similar during the field trial. As it was not possible to read these pins without disturbing them, only one measurement was recorded for each pin at the end of the trial (mean $12.0 \pm 0.7 \mathrm{~cm}$ ).

Throughout the trial, particularly during the wetter months, debris and tailings built up along the fence at the toe of the slope (Figures 8.15a and b). The fence was not erected for the purpose of measuring erosion, and the data from this was not used to numerically assess soil displacement. However, the height of the debris provided a visual indication of the rate of erosion without the need to disturb the pins.

During February $9 \mathrm{~cm}$ of debris was deposited against the fence. In March, a further $2 \mathrm{~cm}$ of debris was deposit (Figure 8.15). This increased by $1 \mathrm{~cm}$ between March and June (Figures 8.16a and b). Large changes in deposition corresponded to the heavy rainfall events throughout these months.

Whilst the erosion of the surrogate soil was low (an estimated $5-10 \%$ ), the erosion of the tailings which surrounded the soil plots remained very high $(16.9 \mathrm{~cm}$ over five months). 


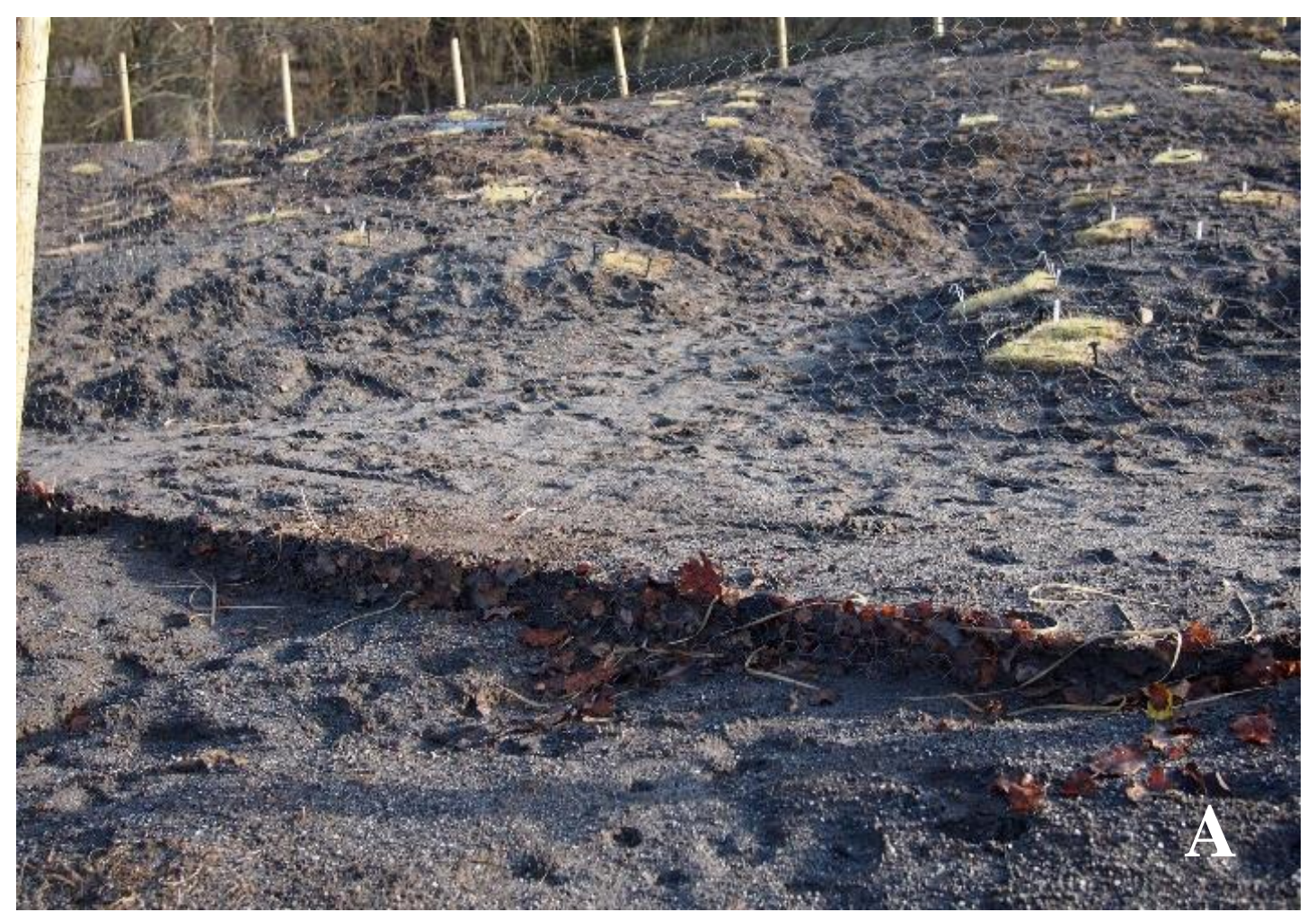

Figures 8.15A and B: Debris build-up along the fence at the bottom of the westfacing tailings slope at Nantymwyn, February 2019

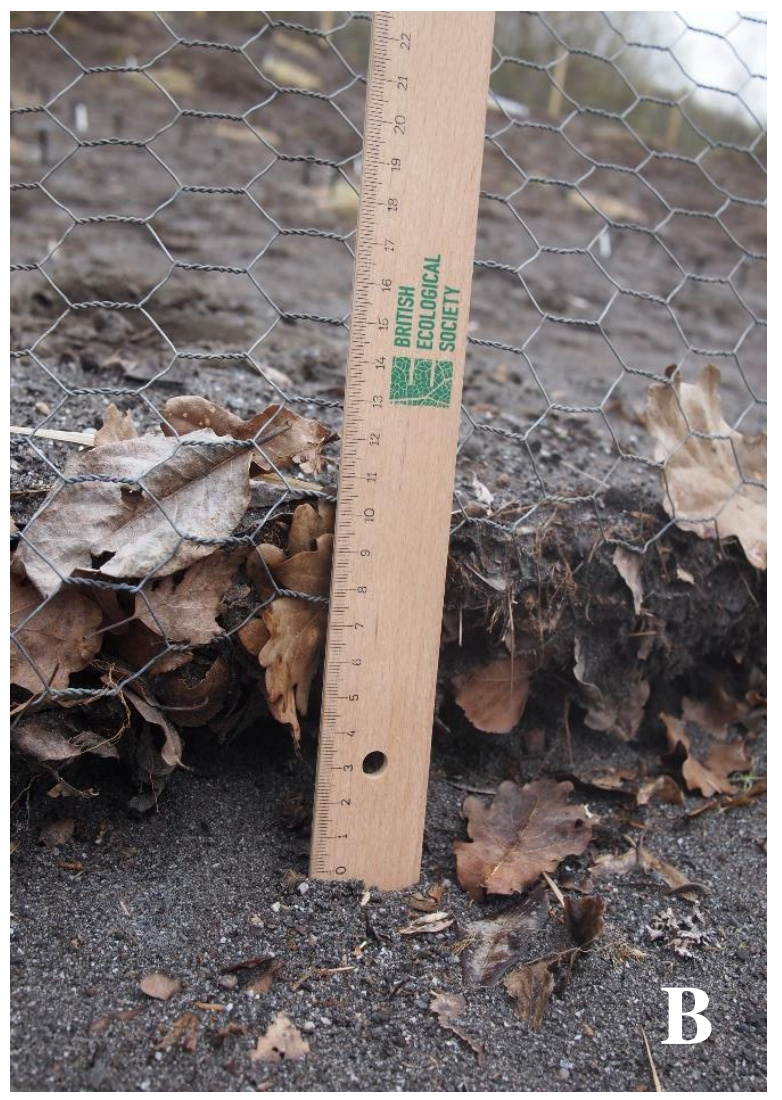




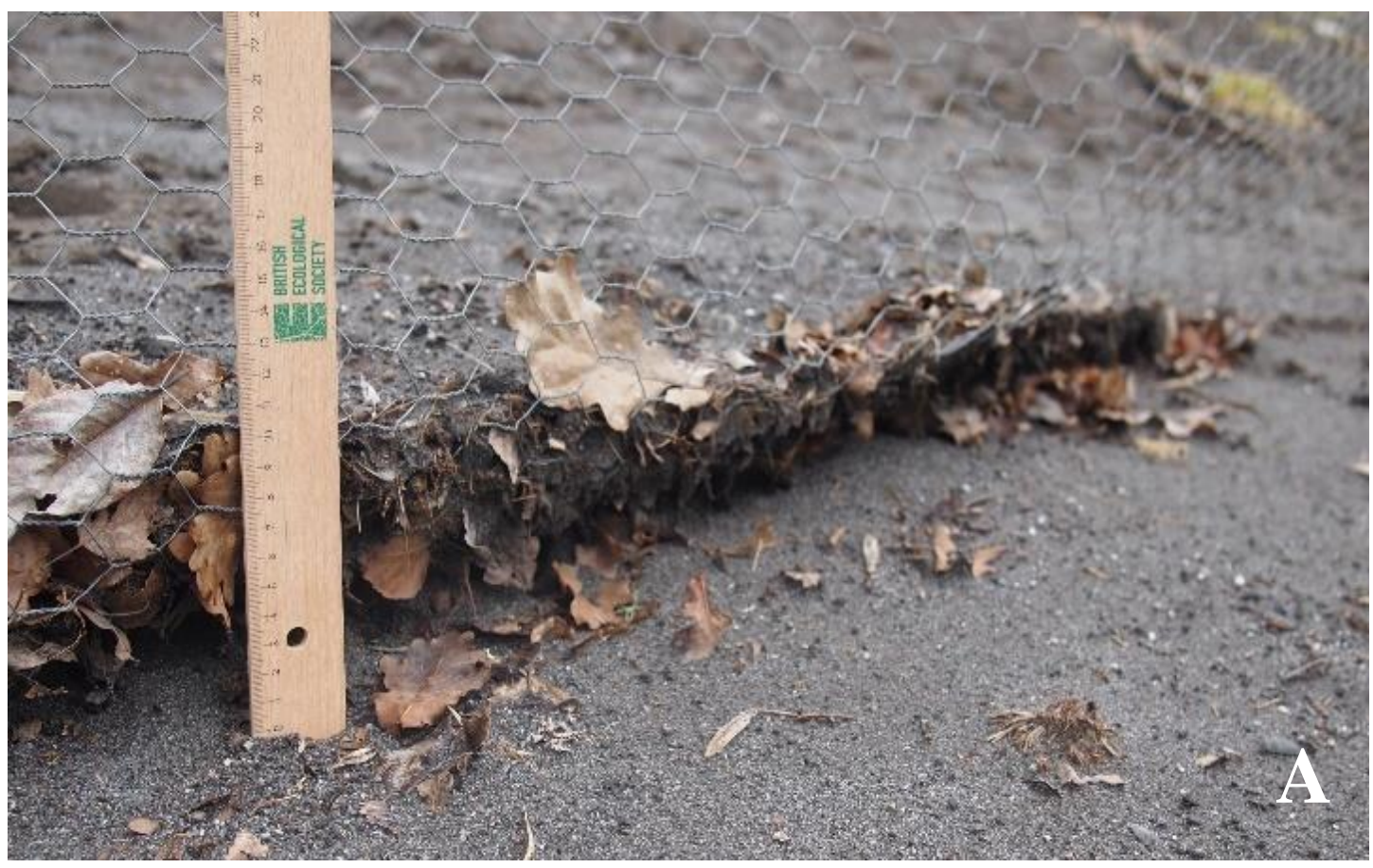

Figures 8.16A and B: Debris build-up along the fence at the bottom of the west-facing tailings slope at Nantymwyn, March 2019

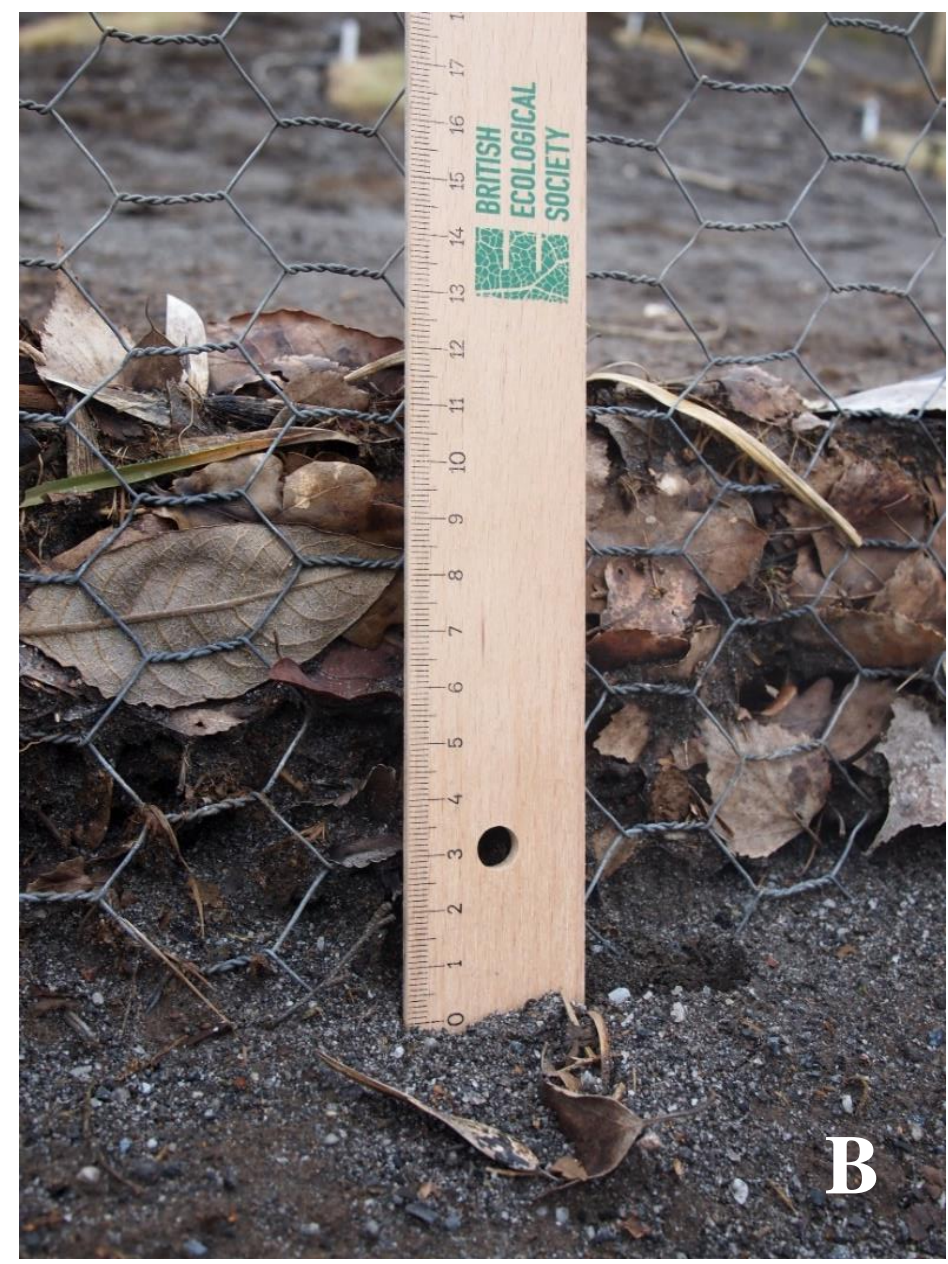




\subsubsection{Grass mortality}

The photographs showed the slow increase in plant growth from February to early April, and the rapid decline from late April onwards (Figure 8.17). The grass in almost all plots exhibited signs of deterioration at approximately the same time (April 2019, weeks 30 -32), and by week 36 (May 2019) almost 100\% above-ground mortality was seen in every plot. The trial was concluded at week 40 when all the grass had died.

Figures 8.17a-d illustrate one plot's stages of decline. The photograph in Figure 8.17a was taken in week 22 (early February), and Figure 8.17b in week 23 after a storm. The shoots were compacted by heavy rainfall, which allowed tailings to accumulate more easily following a second storm in week 30 (Figure 8.17c). By week 39 (Figure 8.17d) the plot was completely buried, and while the soil existed under the tailings the grass had completely perished. The same pattern can be seen in the Figures 8.18a-d also. Several plots are documented from the beginning to the end of the trial in the Appendix $5.3-5.5$.
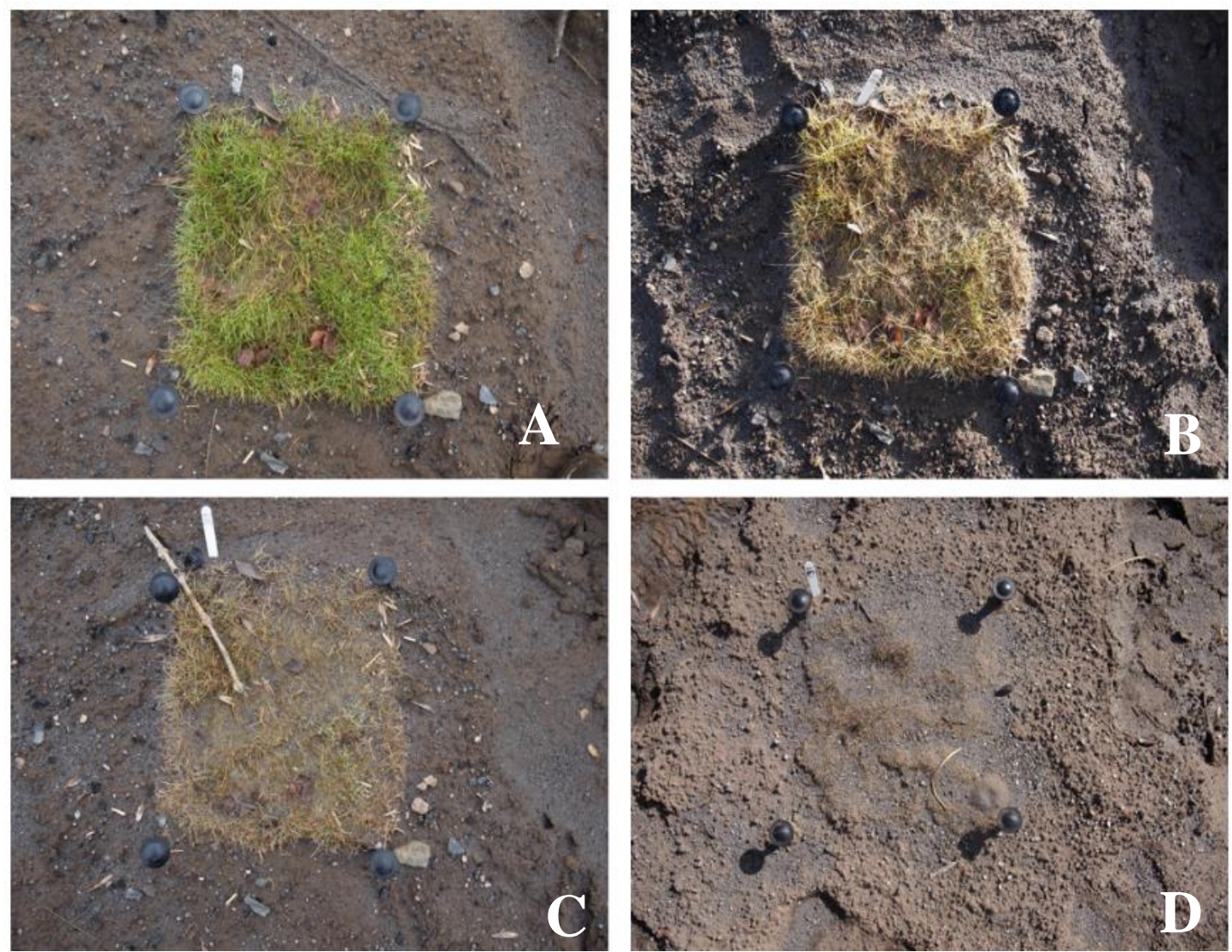

Figures 8.17A - D: One $30 \mathrm{~cm}^{2}$ plot, documented at: (a) week 22, (b) week 23, (c) week 30 and (d) week 39 at Nantymwyn (2019) 

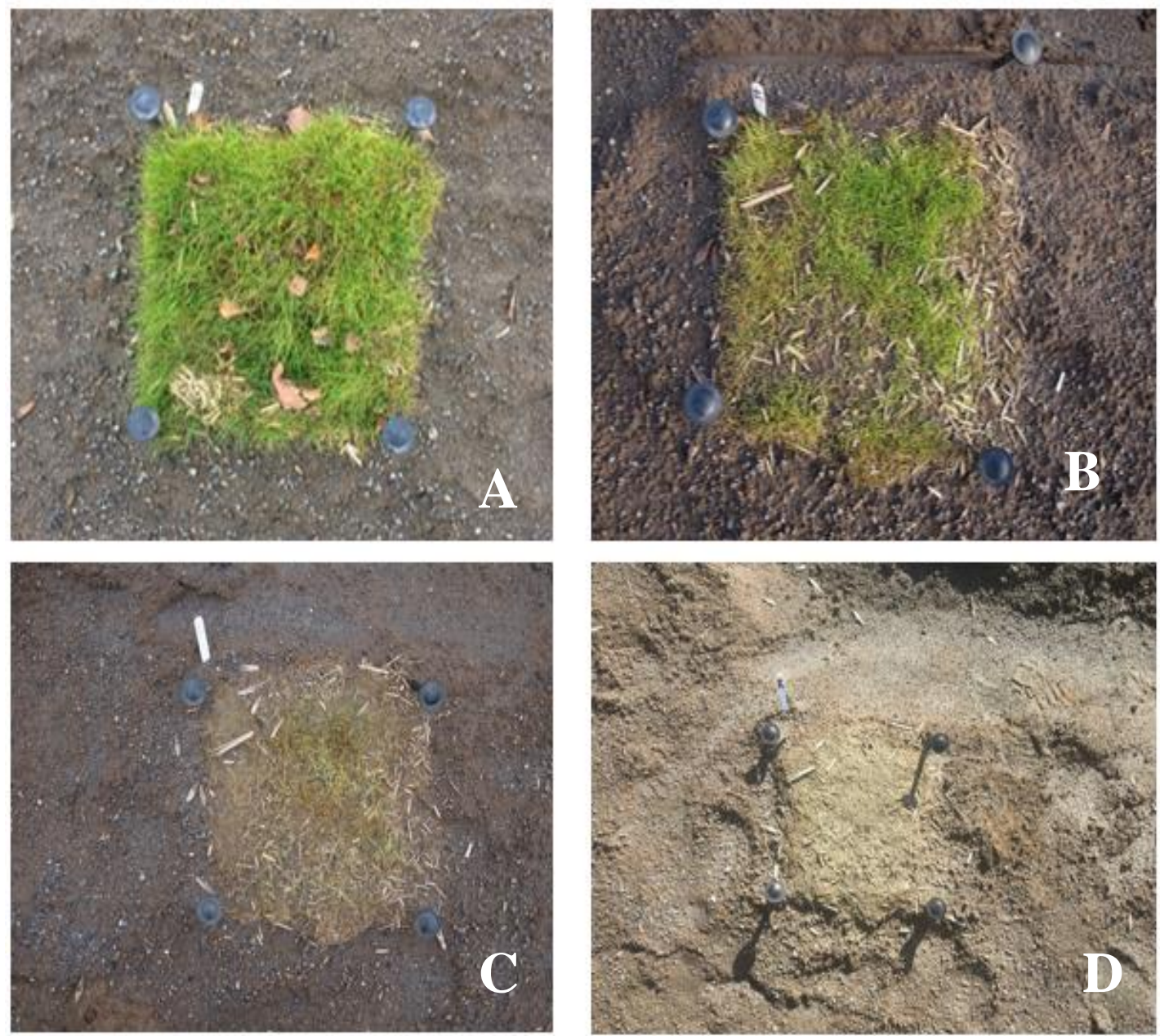

Figures 8.18A - D: One $30 \mathrm{~cm}^{2}$ plot documented at: (a) week 22, (b) week 23, (c) week 30 and (d) week 39 at Nantymwyn (2019) 
Some plots did not experience wash-over of tailings and yet the grass still died. These were predominantly the plots on the north facing slope where erosion was recorded as $1.2 \mathrm{~cm}$ (February - June) rather than the $16.9 \mathrm{~cm}$ on the south west slope. Here, the grasses survived for several weeks longer, and began to show significant signs of stress (browning, wilting) later than other plots. The grass in these plots died predominantly in weeks $39-40$ (Figure 8.19).
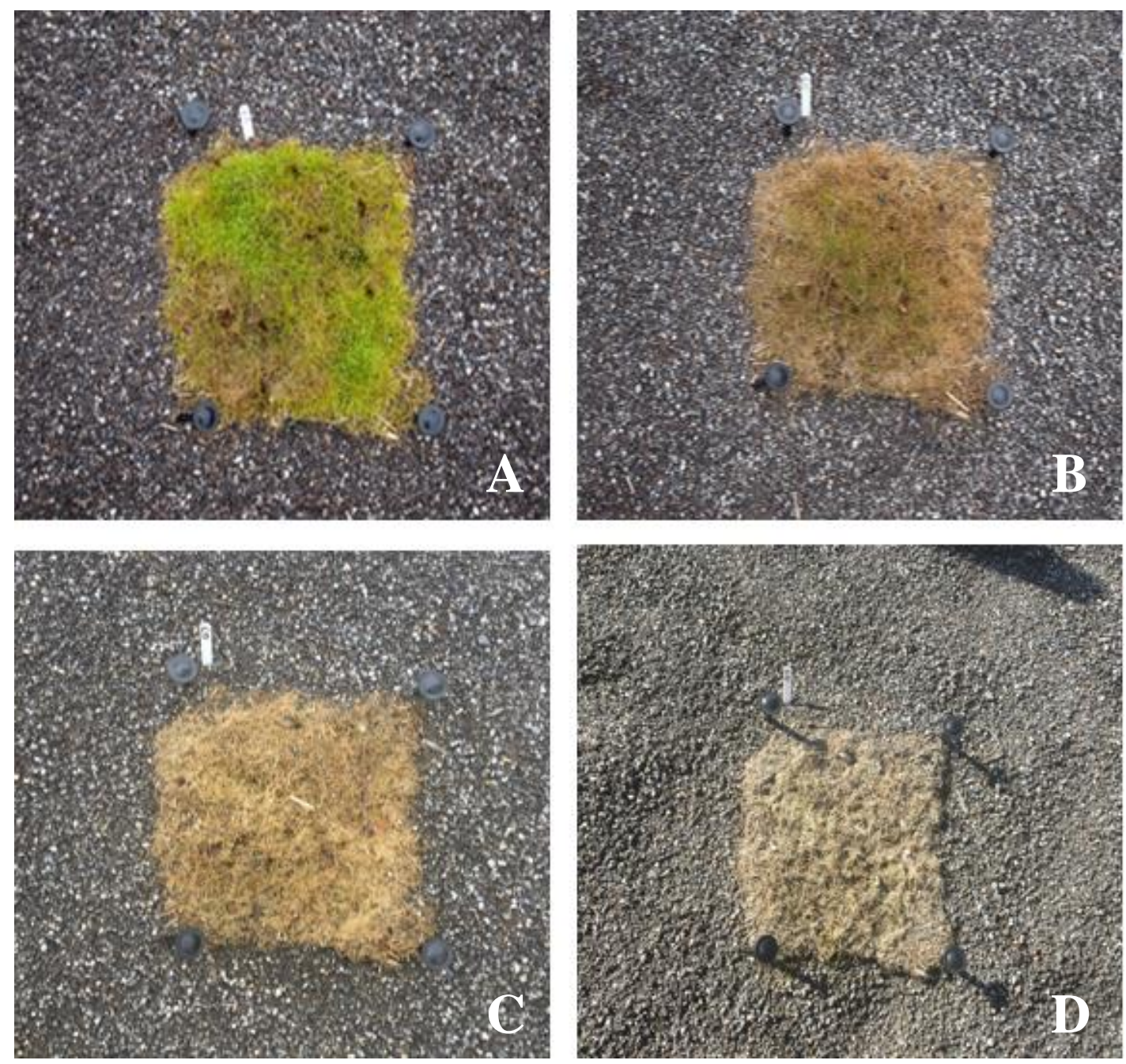

Figures 8.19A - D: One $30 \mathrm{~cm}^{2}$ plot from the north-facing slope, documented at: (a) week 28, (b) week 31, (c) week 34 and (d) week 39 at Nantymwyn (2019) 
8.2.7 Shoot length

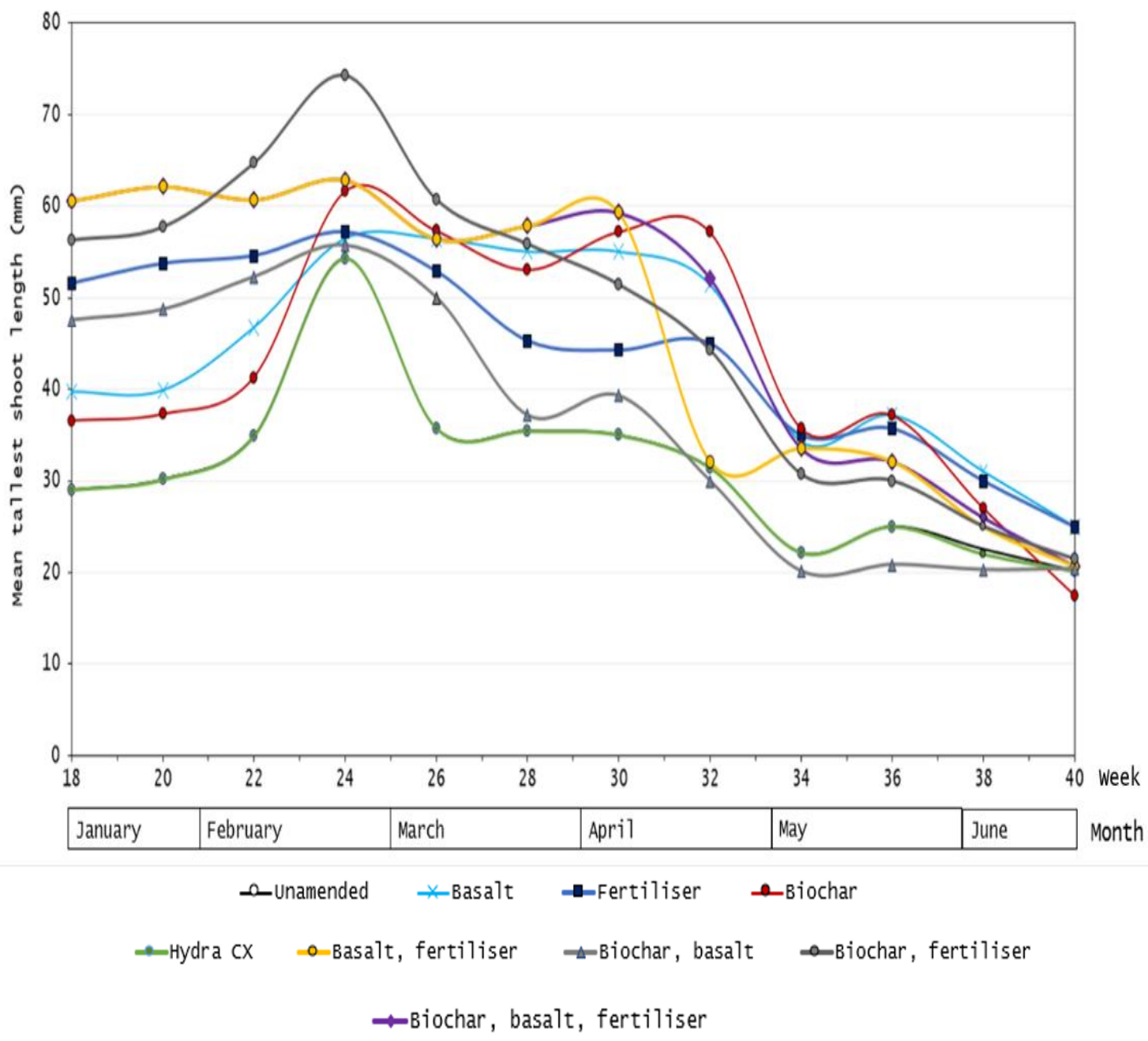

Figure 8.20: The median tallest shoot length $(\mathrm{mm})$ for each of the nine treatments from January to June 2019, at Nantymwyn. $N=63$ 
Table 8.6: The mean tallest shoot length $(\mathrm{mm})$ in each of the treatment groups, recorded at week 40, Nantymwyn, June 2019. \pm refers to the sample standard deviation.

\begin{tabular}{cccccc}
\hline \hline Treatment & $\mathrm{n}$ & $\begin{array}{c}\text { Median } \\
(\mathrm{mm})\end{array}$ & $\begin{array}{c} \pm \\
(\mathrm{mm})\end{array}$ & $\begin{array}{c}\text { Min } \\
(\mathrm{mm})\end{array}$ & $\begin{array}{c}\text { Max } \\
(\mathrm{mm})\end{array}$ \\
\hline Hydra CX & 7 & 20 & 8 & 9 & 35 \\
Unamended & 7 & 18 & 13 & 5 & 40 \\
Biochar & 7 & 25 & 7 & 19 & 35 \\
Basalt & 7 & 27 & 20 & 11 & 70 \\
Fertiliser & 7 & 25 & 11 & 13 & 45 \\
Basalt and fertiliser & 7 & 21 & 18 & 10 & 50 \\
Biochar and basalt & 7 & 20 & 9 & 5 & 35 \\
Biochar and fertiliser & 7 & 21 & 11 & 11 & 43 \\
Biochar, basalt, fertiliser & 7 & 32 & 23 & 16 & 85 \\
\hline
\end{tabular}

Fortnightly measurements of the tallest shoot length in each plot were taken (Figure 8.20). The grass height remained stable throughout January and the beginning of February. As the temperature increased in February the median grass shoot length increased in all treatments. Heavy rainfall in March confounded the results somewhat, as the grass was still present but in some plots had been flattened by the rainfall. This produced a dense mat of grass, which in some cases skewed the median value (Figure $8.21)$. 

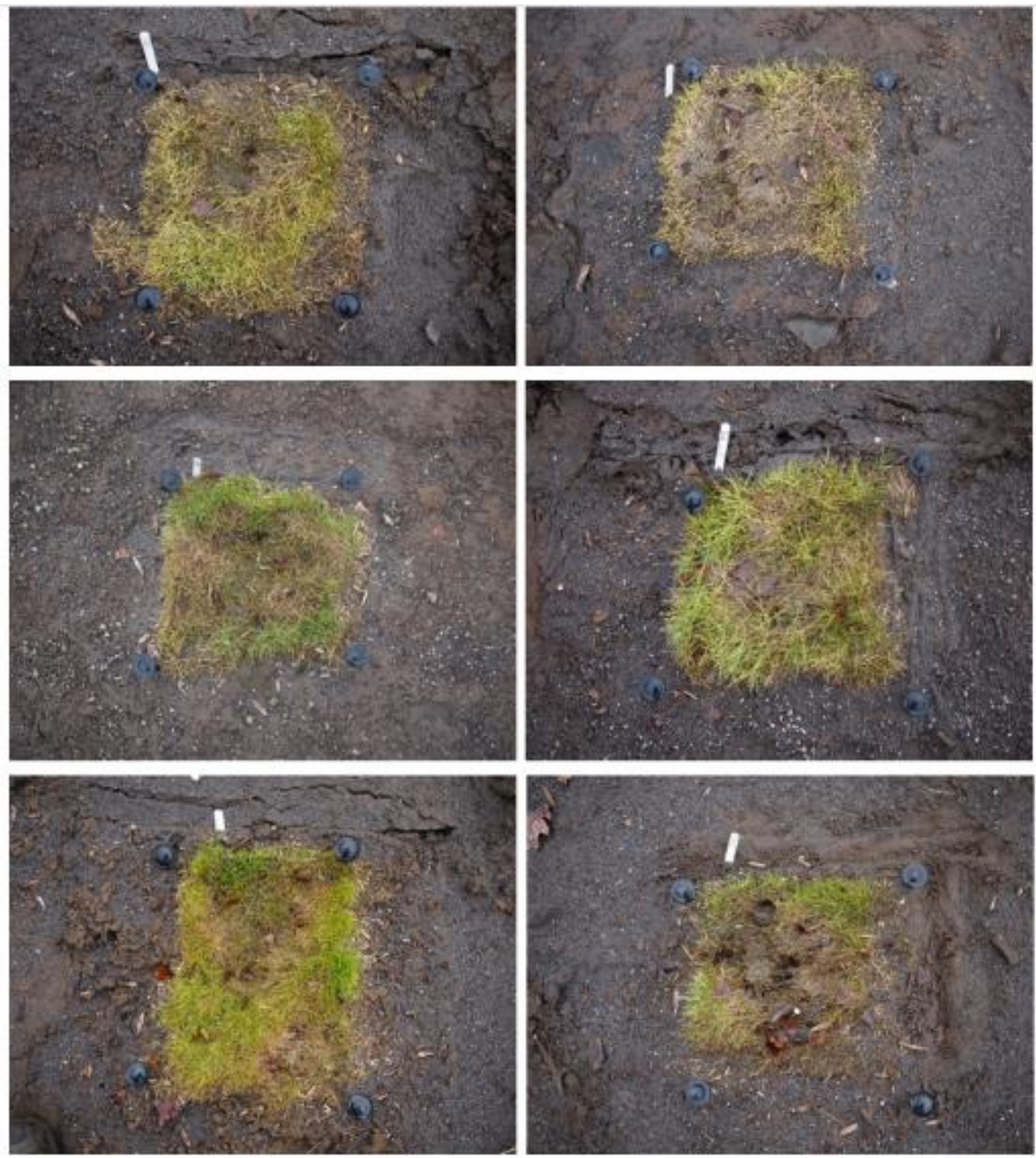

Figure 8.21: Several $30 \mathrm{~cm}^{2}$ surrogate soil plots at Nantymwyn with rain-flattened grass. March 2019.

As discussed in Section 8.2.5, the tailings from the summit were washed downhill throughout the trial. The displacement of the tailings led to many of the soil plots becoming buried. The rainfall flattened grass exasperated the plot submersion, and the shoot length measurements became challenging to read beyond April. Overall, the grass in all plots showed a similar pattern of decline, which led to similar median final shoot lengths (Table 8.6).

A Kruskal-Wallis test determined that there were no significant pairwise differences in the median final shoot lengths $(\mathrm{p} \leq 0.428, \mathrm{df}=7, \mathrm{~N}=63)$. 


\subsubsection{Biomass}

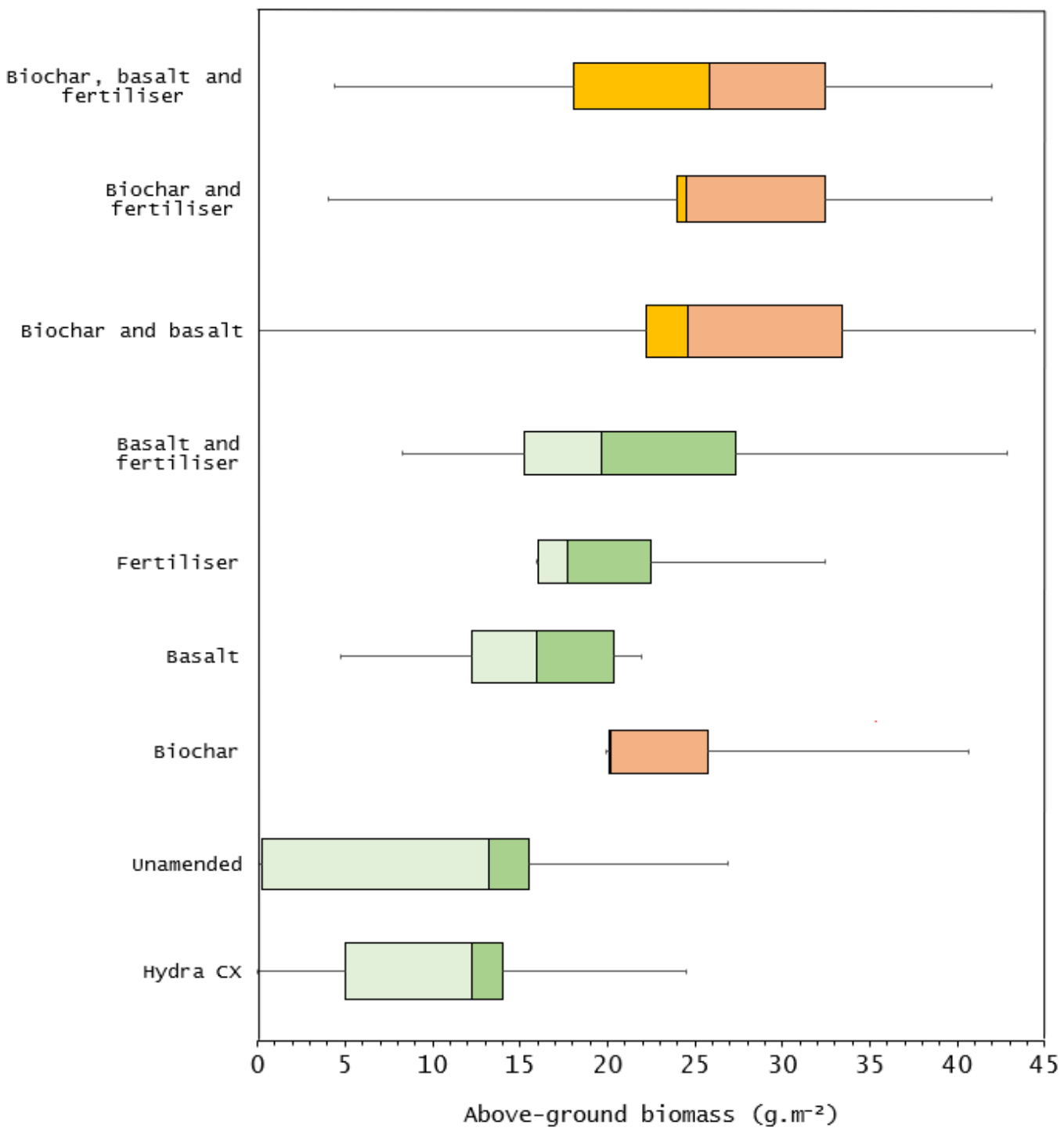

Figure 8.22: The above-ground biomass yield $\left(\mathrm{g} . \mathrm{m}^{-2}\right)$ produced each surrogate soil treatment at Nantymwyn by week 40 (June 2019). The treatments coloured orange indicates a significantly greater biomass yield than the unamended soil treatment 
Table 8.7: The median weight $\left(g . \mathrm{m}^{-2}\right)$ of dried above-ground biomass that was produced by each surrogate soil treatment at Nantymwyn by June 2019. \pm indicates the sample standard deviation.

\begin{tabular}{cccccc}
\hline \hline Treatment & $\mathrm{n}$ & $\begin{array}{c}\text { Median } \\
\left(\mathrm{g} . \mathrm{m}^{-2}\right)\end{array}$ & $\begin{array}{c} \pm \\
\left(\mathrm{g} . \mathrm{m}^{-2}\right)\end{array}$ & $\begin{array}{c}\text { Min } \\
\left(\mathrm{g} \cdot \mathrm{m}^{-2}\right)\end{array}$ & $\begin{array}{c}\text { Max } \\
\left(\mathrm{g} . \mathrm{m}^{-2}\right)\end{array}$ \\
\hline Hydra CX & 7 & 12.2 & 8.0 & 0 & 24.4 \\
Unamended & 7 & 13.2 & 9.7 & 0 & 26.8 \\
Biochar & 7 & 20.2 & 1.7 & 19.9 & 40.6 \\
Basalt & 7 & 16.0 & 5.7 & 4.8 & 22.0 \\
Fertiliser & 7 & 17.8 & 5.7 & 16.0 & 32.4 \\
Basalt and fertiliser & 7 & 19.6 & 7.8 & 8.3 & 42.8 \\
Biochar and basalt & 7 & 24.5 & 3.4 & 0 & 44.9 \\
Biochar and fertiliser & 7 & 24.6 & 11.6 & 4.0 & 42.0 \\
Biochar, basalt, fertiliser & 7 & 25.9 & 13.5 & 4.4 & 42.0 \\
\hline
\end{tabular}

Several significant pairwise different existed in the final biomass yield (KruskalWallis: $\mathrm{H}[8]=18.64, \mathrm{p} \leq 0.01, \mathrm{~N}=63$ ).

A Dunn's post-hoc test revealed that by the conclusion of the trial only the soils which contained biochar had produced significantly more biomass than the unamended soil (Figure 8.22, Table 8.7). These were the biochar surrogate soil $(+42 \%, \mathrm{p} \leq 0.02)$, the biochar:basalt soil $(+60 \%, \mathrm{p} \leq 0.018)$, the biochar:fertiliser soil $(+39 \%, \mathrm{p} \leq 0.014)$ and the biochar:basalt:fertiliser soil $(+65 \%, \mathrm{p} \leq 0.02)$.

No pairwise differences between the biochar soils were found.

\subsubsection{Metal concentration and uptake in biomass}

For each surrogate soil treatment, biomass from five replicates were selected using the random number generator in $\mathrm{R}$ ( $\mathrm{R}$ Core Team, 2018) and analysed for concentrations of $\mathrm{Zn}, \mathrm{Pb}, \mathrm{Cd}$ and $\mathrm{Cu}(\mathrm{N}=45)$ using the acid digestion method outlined in Section 8.1.4, and analysed using MP-AES, as detailed in Section 8.1.5. The plots without the surrogate soil (the seeded tailings treatment) yielded an insufficient quantity of biomass for analysis (Figure 8.4).

The metal concentration in the pasture biomass was also quantified using the same methods $(\mathrm{N}=5)$. 


\subsubsection{Zinc concentration}

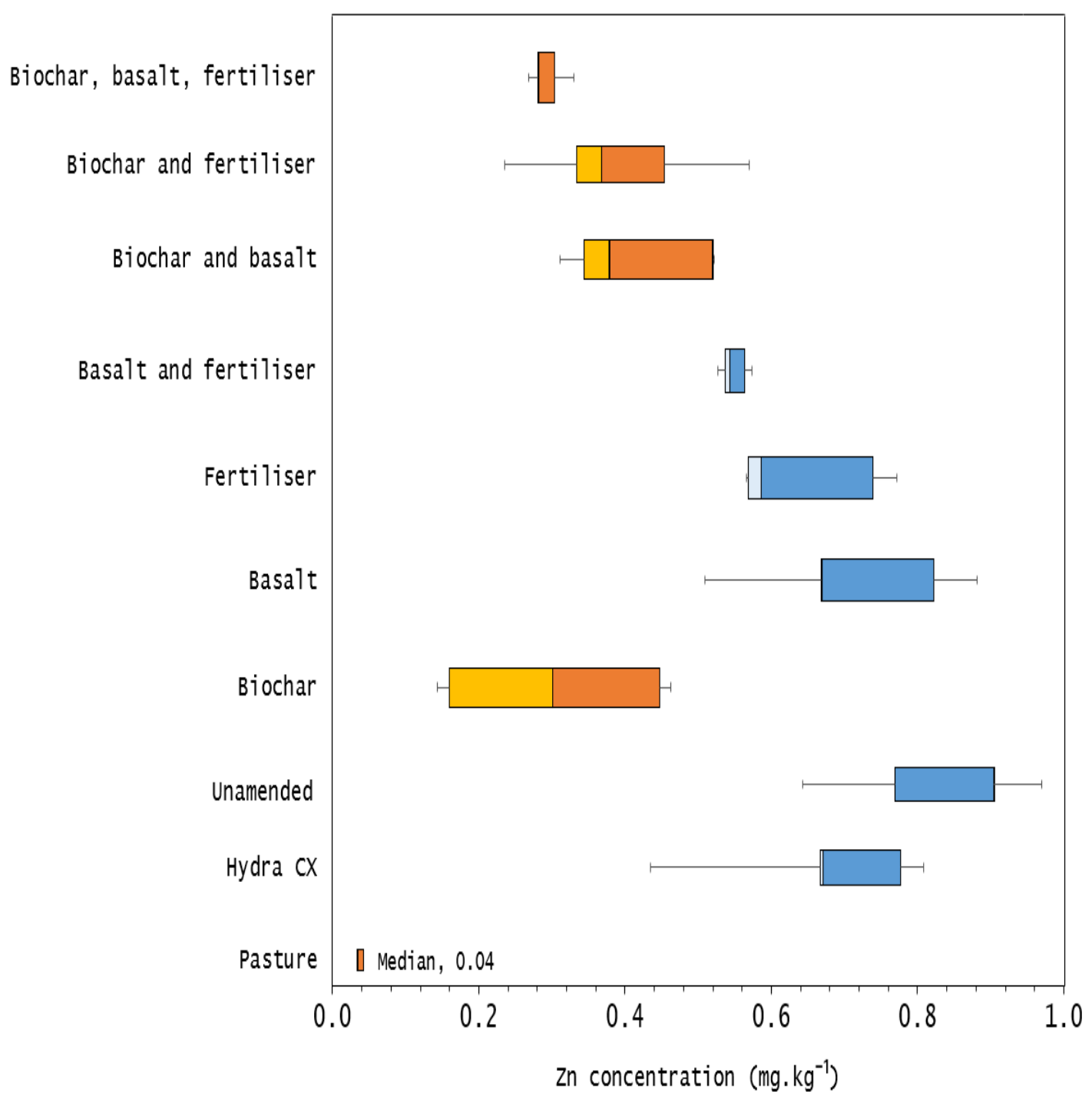

Figure 8.23: The median Zn concentration recorded in biomass produced by each surrogate soil $(n=5)$, in the Nantymwyn field trial by the end of week 40 (June 2019). The treatments coloured orange indicates a significantly lower Zn concentration in biomass than that of the unamended soil treatment 
Table 8.8: Median Zn concentration $\left(\mathrm{mg}^{\mathrm{kg}} \mathrm{kg}^{-1}\right)$ in the dried above-ground biomass that was produced by each surrogate soil treatment at Nantymwyn, and from the local pasture (both in June 2019). \pm indicates the sample standard deviation.

\begin{tabular}{|c|c|c|c|c|c|}
\hline Treatment & $\mathrm{n}$ & $\begin{array}{c}\text { Median } \\
\left(\mathrm{mg} \cdot \mathrm{kg}^{-1}\right)\end{array}$ & $\begin{array}{c} \pm \\
\left(\mathrm{mg} \cdot \mathrm{kg}^{-1}\right)\end{array}$ & $\begin{array}{c}\text { Min } \\
\left(\mathrm{mg} \cdot \mathrm{kg}^{-1}\right)\end{array}$ & $\begin{array}{c}\mathrm{Max} \\
\left(\mathrm{mg}^{\prime} \mathrm{kg}^{-1}\right)\end{array}$ \\
\hline Pasture & 5 & 0.04 & 0.01 & 0 & 0.04 \\
\hline Hydra CX & 5 & 0.67 & 0.10 & 0.44 & 0.81 \\
\hline Unamended & 5 & 0.90 & 0.10 & 0.64 & 0.97 \\
\hline Biochar & 5 & 0.30 & 0.20 & 0.14 & 0.46 \\
\hline Basalt & 5 & 0.67 & 0.10 & 0.51 & 0.88 \\
\hline Fertiliser & 5 & 0.59 & 0.10 & 0.57 & 0.77 \\
\hline Basalt and fertiliser & 5 & 0.54 & 0.01 & 0.53 & 0.57 \\
\hline Biochar and basalt & 5 & 0.38 & 0.10 & 0.31 & 0.52 \\
\hline Biochar and fertiliser & 5 & 0.37 & 0.10 & 0.24 & 0.57 \\
\hline Biochar, basalt, fertiliser & 5 & 0.28 & 0.02 & 0.27 & 0.33 \\
\hline
\end{tabular}

A Kruskal-Wallis with Dunn's post-hoc test indicated that multiple pairwise differences existed $(\mathrm{H}[8]=40.74, \mathrm{p} \leq 0.001, \mathrm{~N}=50)$.

All of the biochar amended soils produced biomass with significantly lower $\mathrm{Zn}$ concentrations than the soils without biochar (Figure 8.23 and Table 8.8).

Of the single amendment soils, the biochar treatment yielded grass with $67 \%$ lower $\mathrm{Zn}$ concentrations compared to the grass in the unamended soil plots, $(\mathrm{p} \leq 0.001)$, and $55 \%$ lower concentrations than the grass in the basalt amended soil plots $(\mathrm{p} \leq 0.003)$.

Of the two amendment treatments, both the biochar:basalt $(\mathrm{p} \leq 0.003)$ and biochar:fertiliser soils $(\mathrm{p} \leq 0.002)$ also produced grass with significantly lower $\mathrm{Zn}$ concentrations than the unamended soil.

The soil which contained the three amendments (biochar:basalt:fertiliser) produced grasses with the lowest $\mathrm{Zn}$ concentrations, less than half that of the unamended soil grasses $(\mathrm{p} \leq 0.001)$, the basalt soil grasses $(\mathrm{p} \leq 0.001)$, the fertiliser soil grasses $(\mathrm{p} \leq 0.002)$ and the basalt:fertiliser grasses $(\mathrm{p} \leq 0.03)$ (Table 8.8). 
No significant differences were found between the treatments which contained biochar.

All of the surrogate soils produced grass with significantly higher Zn concentrations than that of the local pasture (all $p \leq 0.001$ ). The greatest difference was that of the unamended treatment, which contained a $200 \mathrm{x}$ greater concentration of $\mathrm{Zn}$ than was recorded in the pasture grasses.

\subsubsection{Zinc uptake}

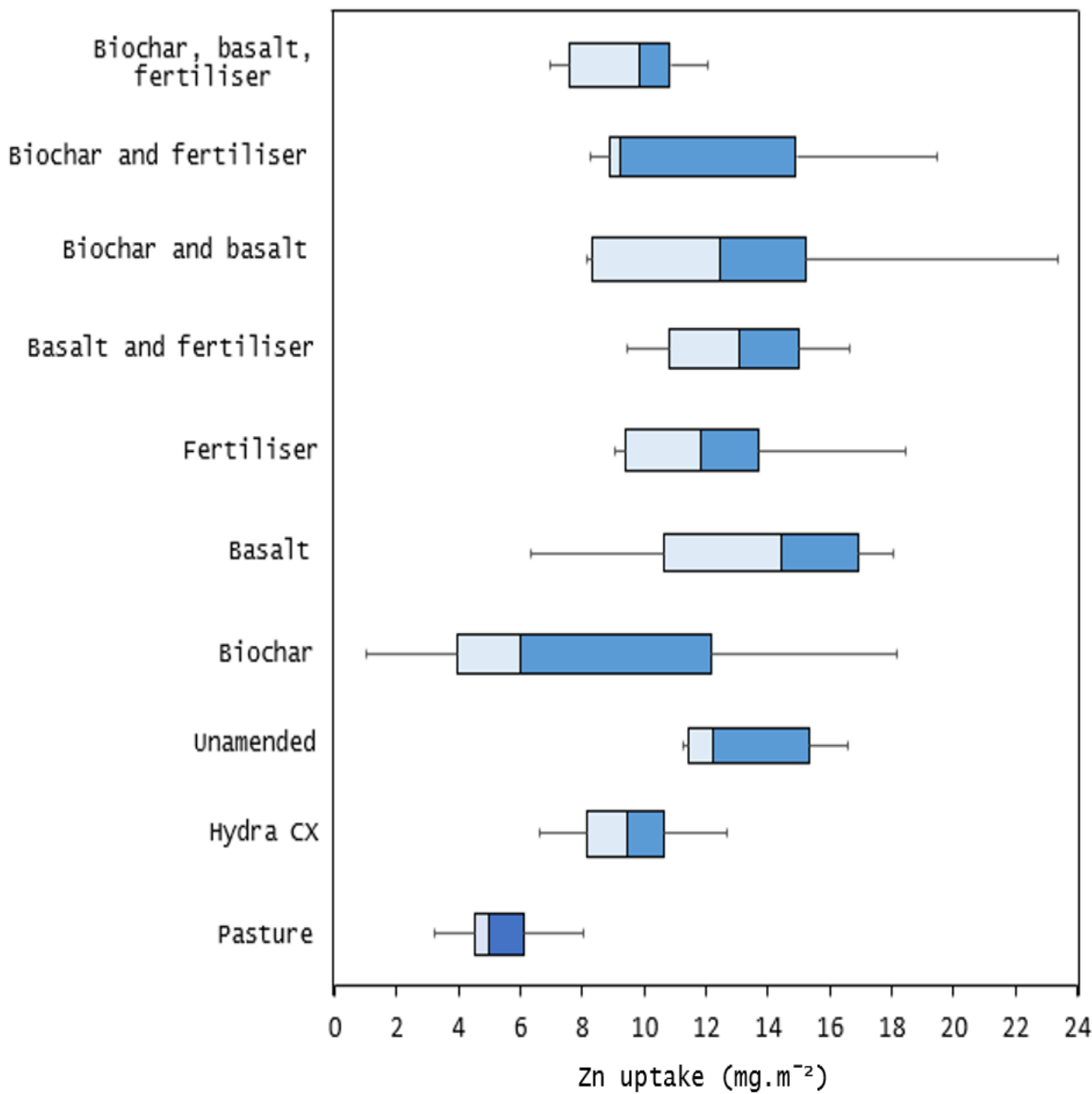

Figure 8.24: The median $\mathrm{Zn}$ uptake $\left(m g . \mathrm{m}^{-2}\right)$ recorded in biomass produced by each surrogate soil treatment $(n=5$ ) in the Nantymwyn field trial by the end of week 40 (June 2019) 
Table 8.9: Median zinc uptake $\left(\mathrm{mg}^{-\mathrm{m}^{-2}}\right)$ in the dried above-ground biomass that was produced by each surrogate soil treatment at Nantymwyn, and from the local pasture (both in June 2019). \pm indicates the sample standard deviation.

\begin{tabular}{cccccc}
\hline \hline Treatment & $\mathrm{n}$ & $\begin{array}{c}\text { Median } \\
\left(\mathrm{mg} \cdot \mathrm{m}^{-2}\right)\end{array}$ & $\begin{array}{c} \pm \\
\left(\mathrm{mg} \cdot \mathrm{m}^{-2}\right)\end{array}$ & $\begin{array}{c}\text { Min } \\
\left(\mathrm{mg} \cdot \mathrm{m}^{-2}\right)\end{array}$ & $\begin{array}{c}\text { Max } \\
\left(\mathrm{mg} \cdot \mathrm{m}^{-2}\right)\end{array}$ \\
\hline Pasture & 5 & 4.96 & 1.8 & 3.22 & 8.03 \\
Hydra CX & 5 & 9.50 & 2.3 & 6.67 & 12.70 \\
Unamended & 5 & 12.79 & 6.8 & 0.15 & 17.28 \\
Biochar & 5 & 6.08 & 6.4 & 2.91 & 18.17 \\
Basalt & 5 & 14.45 & 4.8 & 6.37 & 18.06 \\
Fertiliser & 5 & 11.82 & 3.8 & 9.06 & 18.45 \\
Basalt and fertiliser & 5 & 13.66 & 3.1 & 9.88 & 17.37 \\
Biochar and basalt & 5 & 12.50 & 6.2 & 8.24 & 23.38 \\
Biochar and fertiliser & 5 & 9.21 & 4.9 & 8.24 & 19.47 \\
Biochar, basalt, fertiliser & 5 & 10.32 & 2.2 & 7.34 & 12.64 \\
\hline
\end{tabular}

No significant pairwise differences existed regarding the uptake of $\mathrm{Zn}$ in biomass that was produced by the surrogate soils. Additionally, no significant differences were found between the Zn uptake in the surrogate soil's biomass and that off the pasture grasses (Kruskal-Wallis: $(\mathrm{H}[9]=14.67, \mathrm{p} \leq 0.09, \mathrm{~N}=50)$ (Figure 8.24 and Table 8.9). 


\subsubsection{Lead concentration}

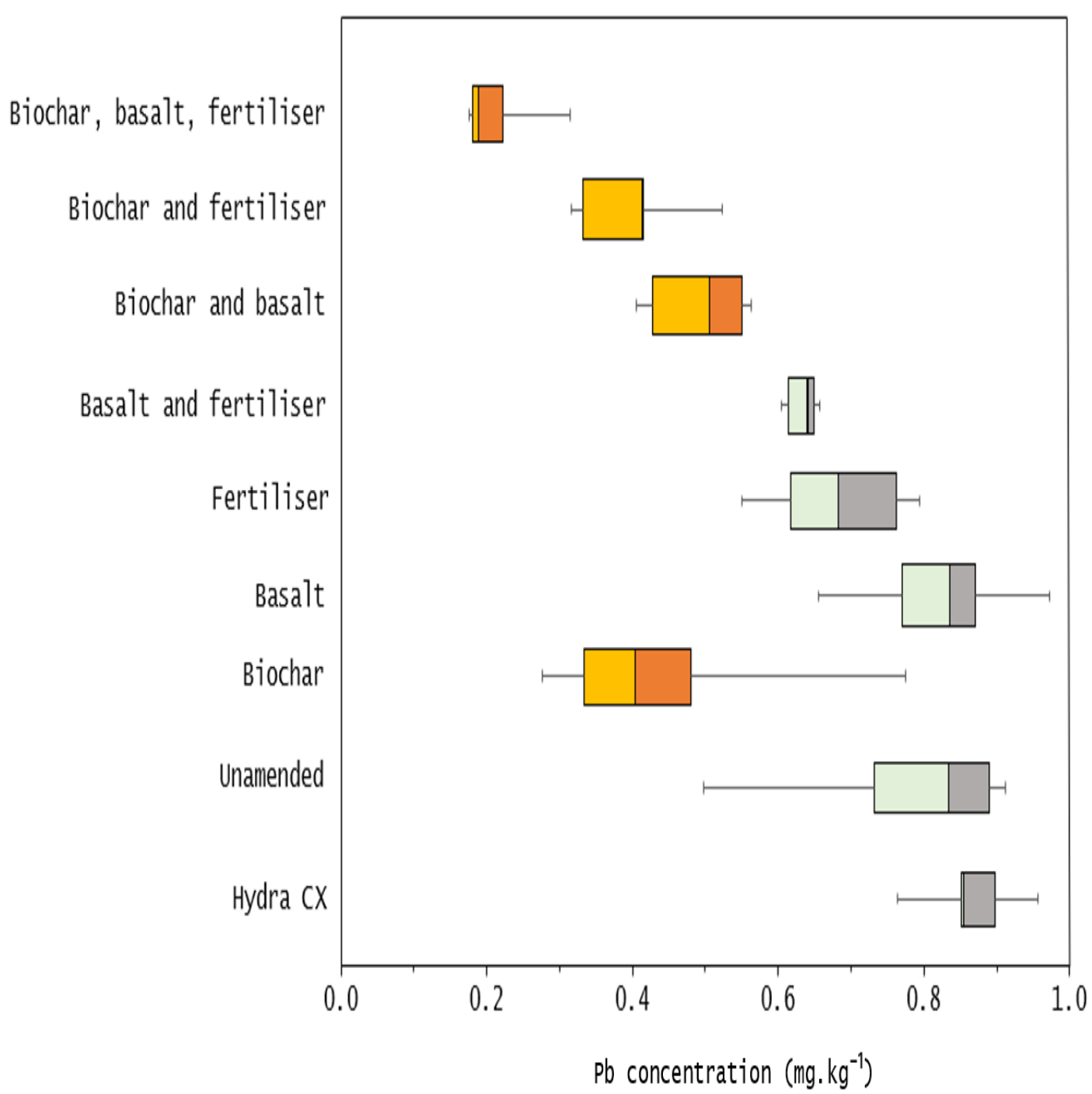

Figure 8.25: The median Pb concentration recorded in biomass for each treatment $(n=5)$, in the Nantymwyn field trial by the end of week 40 (June 2019). The treatments coloured orange indicate a significantly lower $\mathrm{Pb}$ concentration in biomass than that of the unamended soil treatment 
Table 8.10: Median lead concentration $\left(\mathrm{mg}^{\mathrm{kg}} \mathrm{kg}^{-1}\right)$ in the dried above-ground biomass that was produced by each treatment at the Nantymwyn field trial by week 40 (June 2019). \pm indicates the sample standard deviation.

\begin{tabular}{cccccc}
\hline \hline Treatment & $\mathrm{n}$ & $\begin{array}{c}\text { Median } \\
\left(\mathrm{mg} \cdot \mathrm{kg}^{-1}\right)\end{array}$ & $\begin{array}{c} \pm \\
\left(\mathrm{mg}_{\mathrm{kg}} \mathrm{kg}^{-1}\right)\end{array}$ & $\begin{array}{c}\text { Min } \\
\left(\mathrm{mg}_{\mathrm{kg}}^{-1}\right)\end{array}$ & $\begin{array}{c}\text { Max } \\
\left(\mathrm{mg}^{\mathrm{kg}} \mathrm{kg}^{-1}\right)\end{array}$ \\
\hline Hydra CX & 5 & 0.85 & 0.07 & 0.76 & 0.96 \\
Unamended & 5 & 0.85 & 0.2 & 0.51 & 0.93 \\
Biochar & 5 & 0.41 & 0.3 & 0.28 & 0.78 \\
Basalt & 5 & 0.85 & 0.1 & 0.67 & 0.99 \\
Fertiliser & 5 & 0.71 & 0.1 & 0.57 & 0.82 \\
Basalt and fertiliser & 5 & 0.64 & 0.02 & 0.62 & 0.66 \\
Biochar and basalt & 5 & 0.51 & 0.07 & 0.41 & 0.57 \\
Biochar and fertiliser & 5 & 0.41 & 0.08 & 0.32 & 0.52 \\
Biochar, basalt, fertiliser & 5 & 0.19 & 0.58 & 0.18 & 0.32 \\
\hline
\end{tabular}

The concentration of $\mathrm{Pb}$ was below the MP-AES detectable limits of $2.5 \mu . \mathrm{L}^{-1}(2.5$ $\left.\mathrm{mg} \cdot \mathrm{kg}^{-1}\right)$ in the pasture samples.

Multiple pairwise significant differences in $\mathrm{Pb}$ concentration were indicated by a Kruskal-Wallis and Dunn's post-hoc test $(\mathrm{H}[8]=35.07, \mathrm{p} \leq 0.001, \mathrm{~N}=45)$.

Every biochar amended soil produced grass with a lower $\mathrm{Pb}$ concentration than that of the unamended-soil grasses (Figure 8.25 and Table 8.10). The biochar:basalt:fertiliser soil showed the greatest difference (a 78\% reduction in concentration, $\mathrm{p} \leq 0.005$ ).

The concentration of $\mathrm{Pb}$ in the biochar amended soil grasses was less than half the concentration of that of the unamended soil grasses $(p \leq 0.014)$. The biochar:basalt grasses ( $\mathrm{p} \leq 0.024)$, and the biochar:fertiliser grasses also contained significantly lower $\mathrm{Pb}$ concentrations than the unamended soil grasses (both $\mathrm{p} \leq 0.042$ ). 


\subsubsection{Lead uptake}

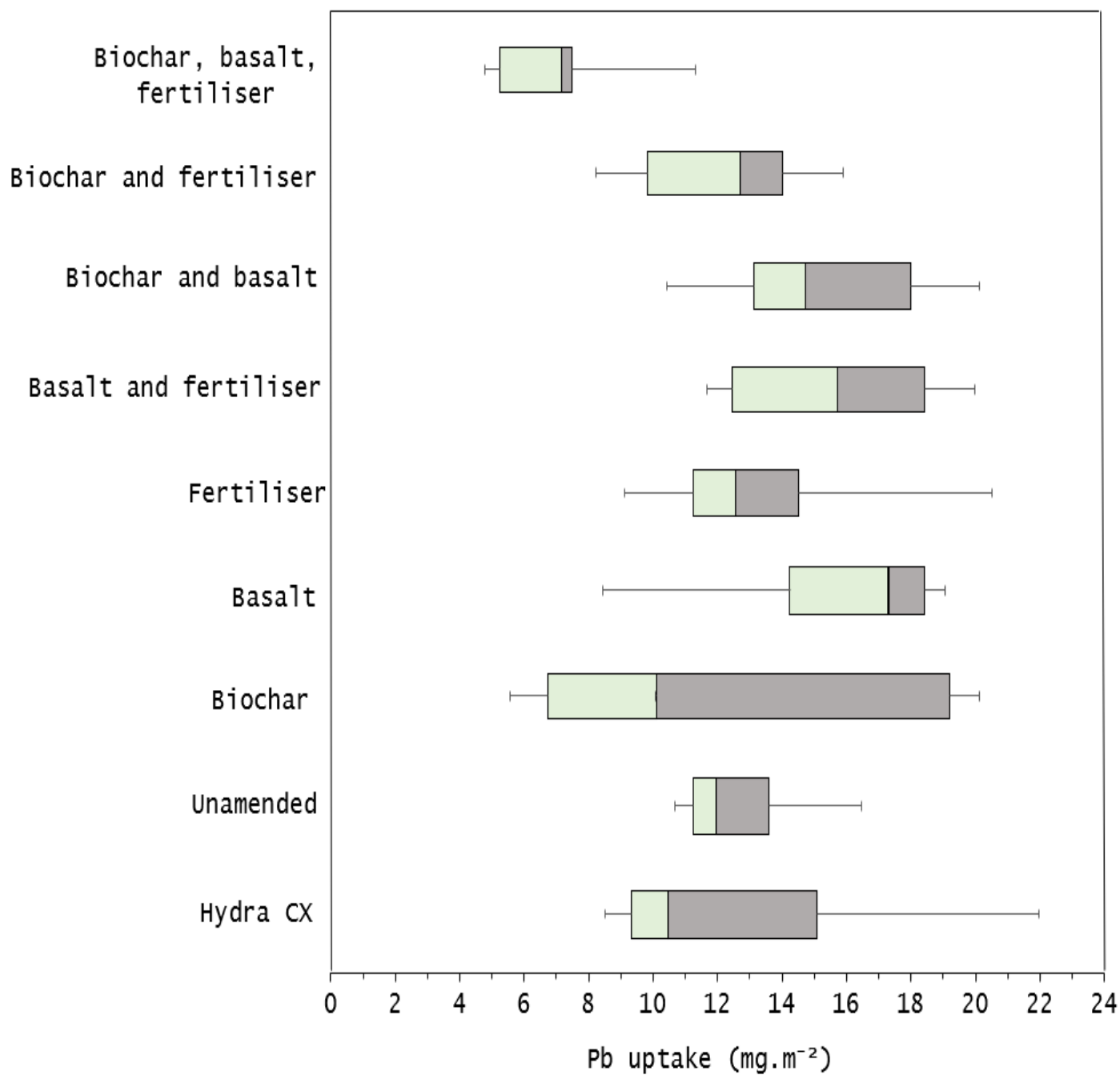

Figure 8.26: The median $\mathrm{Pb}$ uptake (mg. $\left.\mathrm{m}^{-2}\right)$ recorded in biomass for each treatment $(n=5)$, at the Nantymwyn field trial by the end of week 40 (June 2019) 
Table 8.11: Median Pb uptake $\left(\mathrm{mg}^{-\mathrm{m}^{-2}}\right)$ in the dried above-ground biomass that was produced by each treatment in the Nantymwyn field trial by week 40 (June 2019). \pm indicates the sample standard deviation.

\begin{tabular}{cccccc}
\hline \hline Treatment & $\mathrm{n}$ & $\begin{array}{c}\text { Median } \\
\left(\mathrm{mg} \cdot \mathrm{m}^{-2}\right)\end{array}$ & $\begin{array}{c} \pm \\
\left(\mathrm{mg}^{\mathrm{m}} \mathrm{m}^{-2}\right)\end{array}$ & $\begin{array}{c}\text { Min } \\
\left(\mathrm{mg} \cdot \mathrm{m}^{-2}\right)\end{array}$ & $\begin{array}{c}\text { Max } \\
\left(\mathrm{mg} \cdot \mathrm{m}^{-2}\right)\end{array}$ \\
\hline Hydra CX & 5 & 10.45 & 5.6 & 8.5 & 21.98 \\
Unamended & 5 & 11.97 & 6.2 & 0.15 & 16.52 \\
Biochar & 5 & 10.33 & 7.1 & 5.66 & 20.70 \\
Basalt & 5 & 17.27 & 4.4 & 8.38 & 19.03 \\
Fertiliser & 5 & 12.61 & 4.4 & 9.13 & 20.69 \\
Basalt and fertiliser & 5 & 16.02 & 3.7 & 11.85 & 20.36 \\
Biochar and basalt & 5 & 14.96 & 3.9 & 10.54 & 20.48 \\
Biochar and fertiliser & 5 & 12.89 & 3.2 & 8.27 & 16.17 \\
Biochar, basalt, fertiliser & 5 & 7.38 & 2.6 & 4.95 & 11.64 \\
\hline
\end{tabular}

No pairwise differences in $\mathrm{Pb}$ uptake were found (Figure 8.26, Table 8.11).

\subsubsection{Copper and cadmium concentration}

The MP-AES instrument (Agilent 4200) can detect Cd concentrations of $>30 \mu \mathrm{g} . \mathrm{L}^{-1}$ and $\mathrm{Cu}$ concentrations of $>500 \mu \mathrm{g} . \mathrm{L}^{-1}$ (Agilent, 2018 ${ }^{2}$ ). The median concentrations of both $\mathrm{Cd}\left(2-17 \mu \mathrm{g} . \mathrm{L}^{-1}\right)$ and $\mathrm{Cu}\left(1-26 \mu \mathrm{g} . \mathrm{L}^{-1}\right)$ were below the MP-AES detectable limits for all surrogate soils (see Appendix 5.10 and 5.11).

\subsubsection{Summary of results}

The key results to be discussed in Section 8.3 are as follows:

- The soil temperature fluctuations were greater in the bare tailings than in the soil plots (Figure 8.8). Of the soil plots, those which contained biochar typically maintained a more stable temperature than those without. This effect was pronounced in the warmer months of April to June (Figure 8.9). 
- The bare tailings responded to heavy rainfall with dramatic spikes in volumetric water content (VWC) (Figure 8.10). In the soil plots, rainfall did not influence the VWC until approximately two weeks later.

- The biochar amended soils typically contained a higher VWC than those that did not. Still, the VWC of all the test soils fell below 10\% in March or April, and again in May (Figure 8.11).

- The adhesion of the surrogate soil on the tailings was visually assessed as being $90-95 \%$ of the overall material (Section 8.2.4). This was slightly lower than that recorded in the rainfall erosion trials (97\%, Section 5.2.5.2).

- The erosion pins on site measured substantial erosion of the west-facing bank (16.9 $\mathrm{cm}$ from February to March), but minimal displacement from the northfacing bank $(1.2 \mathrm{~cm})$. Deposition at the bottom of the bank was measured as $12.0 \mathrm{~cm}$ (Section 8.2.5).

- In the final stage of the trial, the tailings that had been eroded from the top of the west-facing bank slowly buried the soil plots below. This event did not occur on the north-facing bank (Section 8.2.5).

- The grass in the plots on the west-facing bank had wilted and died by approximately week 36 (Figures 8.17 and 8.18). The grass on the north-facing bank died slightly later, at weeks 39 - 40 (Figure 8.19).

- By the conclusion of the trial, only the soils which contained biochar had produced significantly more biomass than the unamended soil (Figure 8.22). The most successful of these was the three-amendment soil (biochar:basalt:fertiliser), which produced a $65 \%$ increase in biomass yield. No significant differences between the biochar treatments were found.

- All of the biochar amended soils produced grass with significantly lower $\mathrm{Zn}$ and $\mathrm{Pb}$ concentrations than that of the unamended treatment (Figures 8.23 and 
8.25). The three-amendment soil had the greatest impact on decreased metal concentrations. These grasses contained only $1 / 3$ of the $\mathrm{Zn}$ and $1 / 4$ of the $\mathrm{Pb}$ concentrations of the unamended soil grasses. No significant impact on $\mathrm{Zn}$ or $\mathrm{Pb}$ uptake in biomass was observed (Figures 8.24 and 8.26).

- $\mathrm{Cd}$ and $\mathrm{Cu}$ concentration were below the detectable limits in all biomass samples (Section 8.2.9.5). 


\subsection{Field trial - Discussion, January to June 2019}

The field trial was concluded after 40 weeks due to widespread grass mortality. During the January to June stage of the trial, additional data were collected which provided an insight into the causes of this. The biomass metal concentrations, the grass species assemblage, the erosion on site, and the volumetric water content of the soil are discussed in terms of their impact on grass production throughout the trial. The storage of $\mathrm{N}$ and $\mathrm{P}$ in the soil are also speculated upon.

\subsubsection{Concentration of metals in biomass}

$\mathrm{Zn}$ and $\mathrm{Pb}$ were abundant within the tailings $\left(11,666 \pm 106\right.$ and $8980 \pm 94 \mathrm{mg} \cdot \mathrm{kg}^{-1}$, respectively), and $\mathrm{Cd}$ and $\mathrm{Cu}$ to a lesser extent $\left(31 \pm 4\right.$ and $177 \pm 15 \mathrm{mg} \cdot \mathrm{kg}^{-1}$, respectively, Table 3.2). A logical assumption could be made that the grasses died due to the presence of the toxic elements. However, in all treatments, the concentration of $\mathrm{Zn}, \mathrm{Pb}, \mathrm{Cd}$ and $\mathrm{Cu}$ in biomass were $<1$ mg. $\mathrm{kg}^{-1}$ (Section 8.2.9), which was considerably lower than that of similar studies where the same grass species did not die (50 - 70 mg.kg-1 Pb, Varun et al., 2011; and 167 mg.kg-1 Zn, Gil-Loaiza et al., 2016).

The uptake of the metals was calculated relative to the concentration of the element and the biomass yield, i.e., $100 \mathrm{mg} \cdot \mathrm{kg}^{-1}$ of $\mathrm{Pb}$ in $2 \mathrm{~g}$ of biomass would produce a higher $\mathrm{Pb}$ concentration than the same quantity of $\mathrm{Pb}$ dispersed among $20 \mathrm{~g}$ of biomass (Section 8.1.6). Hence, the three parameters (the quantity of biomass, the concentration of each element, and the uptake of the element) were inter-related.

In the field trial, the uptake of $\mathrm{Zn}$ and $\mathrm{Pb}$ was between 6.08 and $17.27 \mathrm{mg} . \mathrm{m}^{-2}$ for all soil treatments (Tables 8.9 and 8.11), and no pairwise differences in metal uptake were found (Sections 8.2.11 and 8.2.13). The biochar amended soils produced grass with lower $\mathrm{Zn}$ and $\mathrm{Pb}$ concentrations than the unamended soils (Tables 8.8 and 8.10), and the biochar amended soils also produced significantly more biomass than the unamended soil (Table 8.7). Therefore, while the uptake of the metals were similar in each treatment, the greater biomass produced by the biochar amended soils diluted the 
concentration of the metals within the biomass. This dilution resulted in lower $\mathrm{Zn}$ and $\mathrm{Pb}$ concentrations in the biochar amended soil grasses (Sections 8.2.10 and 8.2.13).

It was hypothesised that the biochar's CEC would enable the precipitation of heavy metals onto the biochar's surface, thereby minimising the plants metal uptake. However, as no pairwise differences existed in the uptake of $\mathrm{Zn}$ and $\mathrm{Pb}$ (Sections 8.2.11 and 8.2.13), the biochar did not exert any measurable immobilising effect on the metals.

The CEC of the biochar was presumed to be $\sim 48.5 \mathrm{cmol}^{\mathrm{kg}} \mathrm{kg}^{-1}$ (Harries, 2017), as this was the CEC of biochar produced from the same feedstock (larch wood) and by the same pyrolysis unit. A CEC of $48.5 \mathrm{cmol} . \mathrm{kg}^{-1}$ is typical of other woody feedstocks (Jien \& Wang, 2013; Suliman et al., 2016; Zhao et al., 2017), and was higher than the CEC of many alternative feedstocks (Sarfaraz et al., 2020). However, due to time restraints the CEC of the biochar used in this trial was not examined. It was possible that, as biochars are highly heterogenous, the CEC of the biochar used was considerably lower than presumed, and the CEC had no significant effect on metal mobility.

It is also possible that the presumed CEC of the biochar was accurate. However, the necessary CEC to effect metal uptake in plant matter in these grasses within 40 weeks is still to be determined. Few studies which examine the interactions between the biochar, the heavy metals, and plant uptake also report the CEC of the biochar used (Section 4.2.6.1). It is common to examine the physical properties of the biochar, or the metal uptake in plant matter, but it is not common to examine both. Consequently, the CEC required to exert an impact on metal mobility and significantly affect metal uptake in plants is undetermined.

As well as the chemical mechanisms of immobilisation, the lack of physical contact between the biochar and the tailings would have been of influence. Two potential methods of contact existed.

One method of tailing-biochar contact was via the root to shoot translocation of the metals, and the transfer of the metals to the soil surface as the shoots died. However, the grasses used in this research exhibit a strategy of avoidance/exclusion, and if possible, the roots will navigate the metals within the substrate. As an uncontaminated growing medium was provided, it was highly probable that the grasses simply chose 
to not root in the tailings, and instead grew exclusively within the surrogate soil. If the grass roots cannot avoid the toxic elements, the species will isolate the metals within the cell walls of the roots which prevents the movement of tailings upwards into the soil (Dahmani-Muller et al., 2000; Palazzo et al., 2003; Simon, 2005). Therefore, it is doubtful that the tailings were integrated into the soil in this manner, making this an unlikely path of tailings-biochar contact.

The second potential method of tailings-biochar contact was the downward migration of tailings through the soil as the plots were buried. Although this form of contact was highly feasible, the biochar was encapsulated within the adhesive soil and, potentially, physical contact between the tailings and biochar did not widely occur, although this is speculative.

In this trial, the biochar did not appear to affect the metal mobility per se. Nonetheless, the beneficial effects to the soil, such as an increased water-holding capacity and temperature regulation, improved the soil conditions and assisted in the production of biomass, which in turn reduced the biomass metal concentrations.

\subsubsection{Species assemblage}

When compared to the results of similar studies (Varun et al., 2011; Gil-Loaiza et al., 2016), all of the soil treatments produced grass with very low metal concentrations. Whilst the low concentrations were, in part, related to the dilution of the metals throughout the biomass, the low uptake would be partly attributed to the grass species assemblage. As previously discussed, the species chosen are metal excluders, or will isolate the metals within the root cell walls (Dahmani-Muller et al., 2000; Palazzo et al., 2003; Simon, 2005), and the root to shoot transfer remains low in these species, even when the grass roots do penetrate the contaminated substrates.

While the grass species are excluders or isolators, they are also highly metal-tolerant; $>100-150$ mg. $\mathrm{kg}^{-1} \mathrm{~Pb}$ concentration and $500-750 \mathrm{mg} \cdot \mathrm{kg}^{-1} \mathrm{Zn}$ concentration (Wong, 1982; Qureshi et al., 1985; Dahmani-Muller et al., 2000). In all samples analysed, the median concentrations of $\mathrm{Zn}$ and $\mathrm{Pb}$ in biomass were $<1 \mathrm{mg} \cdot \mathrm{kg}^{-1}$, which was $<0.2 \%$ of the tolerable $\mathrm{Zn}$ concentrations and $<0.6 \%$ of the tolerable $\mathrm{Pb}$ concentrations 
(Tables 8.8 and 8.10). Consequently, whilst the grasses did die, they did not do so as a result of metal toxicity.

As metal toxicity was not the cause of the early senescence, the data collected on-site was used to investigate two other factors. The first was the slow but considerable erosion on-site (Section 8.2.5), and the second was the soil's volumetric water content (VWC, Section 8.2.3).

\subsubsection{Erosion and deposition}

The grasses used were metal tolerant and metal excluders, therefore it was very probably that the grasses did not root in the tailings, which was, in part, responsible for the low metal uptake into the biomass. The lack of rooting in the tailings had the potential to cause the surrogate soil to be less stable on the steep-sided tailings. Nonetheless, the adhesion of the surrogate soil throughout the trial was satisfactory $(\sim 90-95 \%$, Section 8.2.4). However, the areas of tailings where the surrogate soil was not applied continued to erode under heavy rainfall. In five months, $16.9 \mathrm{~cm}$ of tailings were eroded from the top of the north-facing bank. Only $12 \mathrm{~cm}$ of this was measured at the toe of the slope, which generally indicated that $\sim 5 \mathrm{~cm}$ of the material was deposit on the slope face. This was monitored using the fortnightly photographs, and many of the soil plots were visibly submerged beneath the tailings (Figure 8.12).

At the time of the previous data collection (December), the tailings deposition was only a minor concern as the grass grew rapidly and was, overall, very dense before any considerable rainfall events (for example, Figures 7.32 - 7.34). However, several inches of snow throughout January flattened the grasses (Figure 8.5). The compressed sward was easily buried by the displaced tailings, a process which began during significant storm events in February (32 $\mathrm{mm}$ in two days, Met Office, 2019²), and March (60 mm in two days, Met Office, $\left.2019^{5}\right)$. As the grass was compressed under the tailings the deposition of tailings increased, which further increased the grass compression.

Although the tailings erosion impacted the grasses survival, this was not the only influencing factor. The grasses that were not buried under the tailings died also. The 
plots that were not buried under the tailings were predominantly on the north-facing bank (Figure 8.19).

The north-facing slope was composed of tailings of a fine gravel texture (Table 3.1), whereas the west-facing slope was of a fine-medium sandy texture, as can be seen in Figures 8.18 and 8.19. Consequently, the finer-grained west-facing slope experienced more erosion than that of the north-facing slope (16.9 and $1.2 \mathrm{~cm}$, respectively, Section 8.2.5). Still, the grass plots on the north bank which were not buried under the tailings also wilted and died, indicating that it was not only the submersion of the grass under tailings that had led to the grasses early senescence.

\subsubsection{Soil volumetric water content and temperature}

An appropriate soil temperature and moisture content are important parameters for the survival of plants, especially in high stress conditions (Lyons et al., 2007; Maiti \& Maiti, 2015). Throughout the final three months of the trial, the soil temperature was higher and the VWC lower than optimal (Sections 8.2.2 and 8.2.3). These combined effects negatively impacted the grass.

From April onwards the mean temperature of the soil plots was often between 15 and $20{ }^{\circ} \mathrm{C}$, and regularly reached $>25{ }^{\circ} \mathrm{C}$ (Figure 8.8). The temperature in the biochar amended soils was more consistent than in the soils without biochar, notably in April, May, and June (Figure 8.9). Still, in the biochar soils the mean temperature reached $25^{\circ} \mathrm{C}$ on multiple occasions. A high soil temperature is a key factor that diminishes both the above and below-ground growth of cool-season grasses (Liu \& Huang, 2005). While soil temperature is not commonly monitored, high air temperatures have been responsible for the failure of several mine reclamation studies (Mendez \& Maier, 2008; Maiti \& Maiti, 2015; Touceda-González et al., 2017). In one metal-mine reclamation trial, high air temperatures for eight weeks $\left(32{ }^{\circ} \mathrm{C}\right)$ led to a $65 \%$ mortality of Agrostis (Touceda-González et al., 2017). Throughout June, the air temperature at Nantymwyn was regularly $>30^{\circ} \mathrm{C}$ (Figure 8.7), and soil temperatures exceeded $20^{\circ} \mathrm{C}$ (Figure 8.8). Periods of high soil temperature often coincide with a low VWC (Nguyen et al., 2012). In this stage of the field trial, the VWC of the surrogate soils rarely exceeded $20 \%$, and $10-15 \%$ was more typical (Figure 8.10). The soils which contained biochar often 
exhibited a higher VWC than those without, particularly in the summer months (Figure 8.11). Despite the more favourable conditions (lower temperature and higher VWC) in the biochar amended soils, the grass in the plots died at the same time regardless of biochar addition. Whilst biochar exerted a slight regulatory effect on the temperature and moisture content this effect was not strong enough to affect the grasses survival.

The VWC necessary to prevent unrecoverable and permanent wilting (the permanent wilting point, PWP) for composts ranges between 20 and 30\% (Aşkıı \& Aygün, 2018). Two of the grasses used in the field trial were Agrostis species, and a loss of $30 \%$ of Agrostis grasses was reported in a mine reclamation project (UK) when the spoil VWC fell to $12 \%$. Losses increased to $90 \%$ when the spoil VWC fell to 5\% (Richardson, 1976).

If the lowest PWP for Agrostis grown in compost is to be assumed (12\%, Richardson, 1976), then from April to June the VWC of all the soils regularly fell below the PWP (Table 8.4). In the soils without biochar, the mean VWC was $<12 \%$ for 68 of the 112 recorded days. By comparison, the VWC was more favourable in the biochar amended soils and was $<12 \%$ for 45 days (Table 8.5 ). Nonetheless, the grass in all the treatments died at approximately the same time.

The weather conditions during late March were influential to the grasses survival. Although rainfall throughout March was unusually high (164\% of the long-term average, Met Office, $2019^{5}$, Section 8.2.1), this did not translate to an increase in soil moisture content. Conversely, late March was when the mean VWC of the soils first fell below 10\% (Figure 8.10), and water loss exceeded supply for the following three weeks, which led to a negative water balance.

The occurrence of a negative water balance is not always due to the lack of precipitation, but more often due to the absence of rapidly available water. Reduced available water can be caused by evapotranspiration (due to the drying effects of wind or direct sunlight) or the draining of highly permeable soil which is not rapidly replenished with water (Nguyen et al., 2012). The large particle size of the soil components was intended to eliminate slumping deformation when water retention was high. However, the large particle and pore soil led to a highly permeable soil. During the January to June stage of the field trial several weeks passed with no precipitation which were broken by day-long deluges (Figure 8.6). The air temperature 
was also often higher than the long-term average, and sunshine hours were $>120 \%$ of the long-term average (Section 8.2.1, Met Office, 2019'1 Met Office, 2019 ${ }^{4}$; Met Office, 2020). The low VWC of the soil signalled that the wind and direct sunlight dried the soil long before the next rainfall, which was compounded by the large pore spaces and freely draining soil structure.

Two events occurred concurrently: the first signs of the grasses browning and wilting, and the beginning of the substantial erosion and deposition of the tailings (Sections 8.2.5 and 8.2.6). As these events occurred simultaneously, it could be unclear if the low VWC or the tailings deposition was of the most influence. However, as the grass plots on the north-facing slope were not buried by the tailings, yet the grass also died (Figure 8.18), it can be proposed that the primary cause of the grasses failure was the heat and drought stress.

Heat stress is a common ailment of mine reclamation projects, as dark tailings have a low albedo and the slopes are often at right angles to the sun (Jutsz \& Gnida, 2015, Martín-Moreno et al., 2016). Heat and drought-related mortality also occurred in studies conducted by Liu \& Huang (2005) and Xu \& Zhou (2006), who reported that the cool-season Festuca ovina and Agrostis capillaris grasses (both used in this research) suffered irrecoverably in soil temperatures $>20^{\circ} \mathrm{C}$, which ultimately led to a complete die-off. Even in a soil temperature of $16{ }^{\circ} \mathrm{C}$, the roots of Festuca and Agrostis have been found to deteriorate by $>35 \%$ (Fitter et al., 1999). Had a more diverse, drought-tolerance species assemblage been used, the grasses might have been more enduring.

\subsection{Comparisons with an analogous trial}

In the week that the Nantymwyn field trial commenced (September 2018), a trial site was also established at Frongoch $\mathrm{Pb} / \mathrm{Zn}$ mine (Wales, UK) by TerrAffix ${ }^{\circledR}$ Soil Solutions Ltd. A $\sim 140 \mathrm{~m}^{2}$ low gradient slope of bare tailings was hydroseeded with a surrogate soil material similar to that of the Nantymwyn trial. A 1.5 cm base layer of compost, digestate, biochar (5\% v/v) and guar gum (10\% v/v) was applied. Hydra CX was used to cap the soil layer to a depth of $\sim 1.5 \mathrm{~cm}$ (S. Brackenbury, 2018, pers. comm.). 
Frongoch is $\sim 18$ miles from Nantymwyn and both mines are within the same $40 \mathrm{~km}^{2}$ MORECS square (Section 7.1.5). Data retrieved from the Water Situation Reports and Met Office Climate Summaries demonstrated that both mines experienced similar weather conditions throughout the trials (NRW, 2019 $9^{1,2,3,4}$, Met Office, 2019 $1,2,3,4,5,6$ ). The seasonal effects on plant production were also alike.

From November 2018 to March 2019, the rainfall in both areas was higher than the long-term average (an increase of +1 to $+17 \mathrm{~mm}$ per month, NRW, 2018 ${ }^{3,6}$; NRW, 2019 1,2,3). However, from April 2019 onwards, both mines experienced several months with a lower than average rainfall (Met Office, 20194). The surrogate soils at Nantymwyn experienced a decline in the VWC, and a corresponding decline in plant health was observed (Figures 8.10 and 8.20). While VWC was not monitored at Frongoch, it is reasonable to assume that the surrogate soil applied to the site also experienced a reduction in VWC.

Similar to the plant deterioration at Nantymwyn, the high air temperatures, erratic precipitation and the long sunshine duration coincided with the die-off of the grasses at Frongoch. At Frongoch, the percentage ground cover was recorded rather than the biomass yield, and the total ground cover fell from $72 \%$ in October 2018 to $23 \%$ in April 2019 (R. Law-Cooper, 2019, pers. comm.) Unlike the biomass at Nantymwyn, however, the biomass at Frongoch partially recovered in August when the rainfall returned to the long-term average (Met Office, 2020), and by October, ground cover at Frongoch had increased to 39\% (R. Law-Cooper, 2019, pers. comm.). More details of the ground cover at Frongoch are provided in Appendix 6.

At Nantymwyn, the deposition of the tailings buried the plots. Conversely, at Frongoch the entire $140 \mathrm{~m}^{2}$ bank was hydroseeded which left no bare tailings to be displaced on to the plots. Consequently, the grass at Frongoch was unaffected by deposition. The thorough hydroseeding of the bank may have been the critical difference in the recovery reported at Frongoch but not at Nantymwyn. Should the entire bank at Nantymwyn have been hydroseeded, the recovery of the grasses at Frongoch indicated that the grass at Nantymwyn will have also suffered above-ground die-off but the roots will have survived. When precipitation returned to that of the long-term average, the grass at Nantymwyn may have recovered at the same time as the grasses at Frongoch. 
The wider area covered with surrogate soil at Frongoch would have also regulated soil VWC and temperature better than the smaller $30 \mathrm{~cm}^{2}$ plots at Nantymwyn. At the Nantymwyn field trial, while the grass plots themselves were cooler than the surrounding tailings (a mean of $3{ }^{\circ} \mathrm{C}$ lower in June 2019, Table 8.2, Figure 8.8), the plots were surrounded by high-temperature tailings. This also applies to the VWC, as the grass plots were surrounded by highly permeable tailings with a lower VWC (a mean of $6.2 \%$ lower in June 2019, Table 8.4, Figure 8.10). A simple method of improving the VWC and regulating the temperature of the surrogate soils is, potentially, to hydroseed larger areas.

\subsection{Soil composition}

The chemical, physical and biological characteristics of soils determine their ability to support plant growth. These characteristics have been extensively studied in trials of > 6 months (Wong, 1995; Pronk et al., 2017; Belyaeva \& Haynes, 2009), however, there is limited information on the soil requirements needed to support long-term plant growth in artificial soils (Schofield et al., 2017).

As $\mathrm{N}$ and $\mathrm{P}$ are essential nutrients, a key long-term requirement for an effective surrogate soil is its ability to retain, store and release $\mathrm{N}$ and $\mathrm{P}$ at the appropriate rate to support plant growth cycles. In this research, the surrogate soil was, among other things, required to provide nutrients for plant growth while also maintaining the CEC necessary to limit nutrient leaching.

The CEC of the biochar was presumed to be comparable to other woody feedstocks (48.5 cmol. $\mathrm{kg}^{-1}$, compared to $10.8-70.2 \mathrm{cmol} . \mathrm{kg}^{-1}$ in similar feedstocks, Section 4.2.6). If the CEC was correct, although biochar accounted for only $5 \%$ of the soil the CEC should have been sufficient for nutrient retention, as lower CEC's have been found to produce a strong effect on metal mobilisation (Fellet et al., 2011; Kim et al., 2014). However, $\mathrm{N}$ and $\mathrm{P}$ are most soluble at $\sim \mathrm{pH} 6.5-7.5$, and the surrogate soil was $\mathrm{pH} 6.51$ (Table 6.5) therefore the nutrients were in their most mobile form within the soil. During the first month of the trial rainfall was $18 \%$ higher than average for the month, with $74 \mathrm{~mm}$ rainfall within a 24-hour period (NCIC, 2019). In March, rainfall was $164 \%$ of the long-term average (Met Office, $2019^{5}$ ). The high solubility of the $\mathrm{N}$ and $\mathrm{P}$ combined with the heavy rainfall is likely to have resulted in the 
nutrients leaching from the soil. The lack of effect that basalt had on grass growth in the first stage of the field trial suggested that the leaching of P began in the early months (Section 7.2.7.2).

The majority of the surrogate soil components had a high $\mathrm{C}: \mathrm{N}$ ratio. In particular, the miscanthus straw (54:1, Table 4.3), the coir (136:1, Table 4.5), and the biochar (289:1, Table 4.6). Combined, these materials accounted for $65 \%$ of the final soil composition (Table 7.1). Only the anaerobic digestate (18600 mg. $\mathrm{kg}^{-1} \mathrm{~N}$, Table 4.4) and the fertiliser (74000 mg.kg-1, Table 4.7) were high in N. Combined, these materials accounted for $\sim 35 \%$ of the surrogate soil. The grasses selected had very low $\mathrm{N}$ requirements (3-7 g.m $\mathrm{m}^{-2}$, Bradshaw et al., 2009), and fertiliser was applied to provide $\mathrm{N}$ in excess of these requirements $\left(20.7 \mathrm{~g} \cdot \mathrm{m}^{-2}\right.$, Section 4.4). Nonetheless, the surrogate soil was low in $\mathrm{N}$ at the start of the trial, and the soil $\mathrm{pH}$, the high solubility of the nutrients, and the heavy rainfall produced a highly leachable soil which lost the nutrients rapidly.

A similar study examined $\mathrm{N}$ leaching in an artificial soil constructed from sand, clay, composted bark and green waste (Schofield et al., 2017). The authors reported that within the first two weeks of the leaching column study, $\mathrm{NO}_{3}{ }^{-}$and $\mathrm{DON}$ in leachate rapidly reduced in concentration by $95 \%$ within approximately two weeks. The concentrations of $\mathrm{NO}_{3}{ }^{-}$and DON continued at $5 \%$ of the original concentrations until week 26, which indicated that the soil contained almost no soluble N. At week 26 an NPK fertiliser (composed of shell, fish meal and poultry litter) was applied to the soil. At the point of application, $\mathrm{NO}_{3}{ }^{-}$and $\mathrm{DON}$ concentrations in leachate increased and remained high throughout the remained of the trial. In week 48, the NPK fertiliser was applied again, which corresponded to further increases in $\mathrm{NO}_{3}{ }^{-}$and $\mathrm{DON}$ concentrations in leachate. The elevated levels remained high until the end of the study in week 52. The authors concluded that almost all of the NPK fertiliser added to the soil from week 26 onwards leached from the soil (hypothesised to be due to the soil microbes in a C-limited soil excreting the excess $\mathrm{N}$ as $\mathrm{NH}_{4}{ }^{+}$, which was rapidly converted to $\mathrm{NO}_{3}{ }^{-}$and leached). Schofield et al. (2017) concluded that the artificial soil's high $\mathrm{C}$ content limited the $\mathrm{N}$ storage and led to the majority of the supplementary $\mathrm{N}$ being leached from the soil. 
In the Nantymwyn field trials the leachate was not collected, and direct comparisons cannot be drawn between the results of Schofield et al. (2017) and this research. However, as the $\mathrm{C}: \mathrm{N}$ ratio of the surrogate soil was high, it is probable that, as seen in the leaching column experiment of Schofield et al. (2017), the N storage of the soil was not sufficient for sustained plant growth.

The particle size and pore size of the soil was of influence to the WHC capacity of the soil, and the soil was designed early on to drain relatively quickly as to avoid the slumping which occurs with a high self-mass. However, the large particle size of the soil also allowed soluble nutrients to drain feely from the soil, which also contributed to the soil's low $\mathrm{N}$ storage. These factors combined ( $\mathrm{N}$ in the most soluble form, large pore size of the soil, low initial $\mathrm{N}$ content) was almost certainly of influence to the plants short lifespan.

The results of Schofield et al. (2017) indicate that N storage contributed to the results seen. However, the deterioration of the grass coincided with the compaction of the grasses under extremely heavy rainfall, and the rainfall-related erosion of the surrounding tailings, therefore it is difficult to determine with certainty what the main driver of the deterioration was. At the Frongoch mine trial, a similar surrogate soil composition to that of the Nantymwyn trial was applied. The grass at Frongoch also began to brown at $\sim$ week 30 , but recovered when the rainfall returned to that of the long-term average (Met Office, 2020). No additional $\mathrm{N}$ was provided to the soil at Frongoch (although the results of Schofield et al., 2017 suggest that the N would leach rapidly if it was). Still, the grasses recovered when the air temperature reduced, and precipitation became more frequent. The comparison of the Nantymwyn trial with that of the Frongoch trial indicated that the WHC and soil temperature were quite probably the main contributing factors to the grasses death, with the low $\mathrm{N}$ content of the soil and the highly leachable soil structure a close second factor. 


\section{Conclusions}

Metal-mine tailings are among the most ecologically hostile environments for plant growth (Tordoff et al., 2000). A poor physical structure, a lack of organic matter and nutrients, poor water relations, extremes of $\mathrm{pH}$, and high concentrations of toxic elements are only some of the issues which must be fully resolved for revegetation to be successful (Mendez et al., 2007; Gutierrez et al., 2016; Venkateswarlu et al., 2016). Natural pedogenic processes take decades or longer, and on mine sites create only a sparse ground cover (Cross et al., 2017). Thus, the most effective, economical, and timely method to establish a soil is to introduce one. The provision of a surrogate soil is a proven technique but, due to the large volumes of compost materials required, can be financially unattainable to the publicly funded bodies responsible for the reclamation of abandoned mines (USDA, 2019). In this research, a relatively inexpensive surrogate soil cover was developed for the hydraulic application to steepsided metal-mine tailings, which at time of writing cost $\sim £ . \mathrm{m}^{-2}$.

Cap and cover techniques typically require the regrading of the tailings for a deep soil cap to be applied (Section 2.3.4). The re-shaping of the material incurs the majority of the cost (Arnold et al., 2015; USDA, 2019), and in order to reduce costs several studies have attempted to apply soil covers to tailings which have not been graded. The field trial at Hope Silver Mine (Anawar et al., 2015; ACES, 2017) demonstrated successful revegetation of metal-mine tailings in one year when the tailings were capped with a coir blanket and $5 \mathrm{~cm}$ of compost with $5 \%$ (v/v) biochar (Section 2.5). A pot trial (DeQuincey, 2017) also demonstrated that metal-tolerant grasses could survive for three months in tailings (not on a slope) covered with $5 \mathrm{~cm}$ of compost and 5\% (v/v) biochar without the use of a geotextile barrier (De-Quincey, 2017) (Section 2.4). The current thesis sought to expand upon the existing research and develop a shallow surrogate soil cover for field application to steep metal-mine tailings dumps, without the use of a geotextile barrier.

Several materials were examined for their suitability as surrogate soil materials, and a final composition was chosen to provide the physical properties and nutrients required 
for plant establishment (Chapter 4.2). As discussed in Section 2.5, for the surrogate soil to produce successful grass growth several challenges needed to be overcome. The soil was required to:

i) Adhere to both coarse and fine-grained surfaces, and once adhered, be resistant to prolonged rainfall,

ii) Be recalcitrant, to ensure a sustained cover of the tailings and provide a lasting growth medium for the grasses,

iii) Provide the nutrients necessary for a rapid and sustained plant growth,

iv) Have an appropriate water-holding capacity, which can retain an available water supply for plant hydration, yet was free draining as not to cause soil deformation through an increased self-mass, and;

v) The resulting soil was required to be highly viscous, with materials of $<2 \mathrm{~mm}$ in size to enable application with the hydroseeder.

The plant species used were required to be fast-growing and metal-tolerant in order to rapidly control erosion and survive in the tailings. The results of this research indicated which of these challenges were overcome and which remained.

\subsection{Adhesion and resistance to erosion}

The rainfall trials (Chapter 5) demonstrated the high performance of the soil and guar gum in resisting intense rainfall erosion, with only $3 \%$ loss of material in a laboratory setting (Section 5.2.5.2). In the field trial, after ten months, material loss was estimated to be $5-10 \%$ (Section 8.2.4). As, in the field trial, the surrogate soil remained adhered to the tailings throughout intense rainfall and reduced the tailing's erosion, the surrogate soil was concluded to have met the first requirement. This key result translated effectively from the laboratory to the field and highlighted rainfall simulations to be a valuable preliminary step in the development of the surrogate soil. However, a compromise was made between creating a soil which drained freely and was not as risk of soil deformation when applied to a slope, and the highly permeable soil structure which did not retain enough soluble nutrients or water. 


\subsection{Recalcitrance of the surrogate soil materials}

As the surrogate soil remained in-situ throughout the trial, observations were made regarding the recalcitrance of the materials. Each soil plot was clearly visible on the tailings heap throughout the trial (Figures 8.17 - 8.19), and the surrogate soil materials (with some grass regrowing) were observed during a site visit 17 months after application (February 2020, Appendix 5.11). As all biomass was harvested in June 2019, the soil material seen on the tailings was not newly decomposed plant matter and was instead entirely composed of the initial material applied at the start of the trial (September 2018), enough to support some new small shoots. The surrogate soil provided a long-lasting physical structure which remained resistant to erosion despite the lack of roots to provide tensile strength. This was quite probably due to the high $\mathrm{C}$ content of that majority of the materials, and a high lignin content in the miscanthus. The recalcitrance of the materials, the continued adhesion, and the provision of a physical soil structure was an essential requirement for the early establishment of vegetation.

\subsection{Provision of nutrients}

In the Research Aims (Section 1.1), it was acknowledged that several restrictions were placed upon the development of the soil-like media. Ultimately, the goal of the research was to produce a soil that not only supported the grasses, but was suitable for deployment via a hydroseeder, cost $<£ 12 . \mathrm{m}^{2}$ (at the time of writing), and a reliable supply of the materials had to exist. If a soil was ideal for plant growth in terms of its nutrient content and physical characteristics but did not meet all three other criteria regarding its real-world application, the constructed soil was not suitable for the intended outcome. These limitations became extremely restrictive during the selection process, and several materials which had more suitable characteristics, such as compost and clay, were omitted, and the resulting composition was not one which would have been chosen should the limitations not have existed.

In the field trial, the early germination, biomass production and consistent ground cover in all plots from September 2018 to April 2019 indicated that the surrogate soil materials met the grasses initial nutrient requirements, even without the addition of amendments. 
The selected grass species have very low $\mathrm{N}$ requirements, $\sim 7 \mathrm{~g} \cdot \mathrm{m}^{-2}$ is sufficient (Bradshaw et al., 2009), and Agrostis and Festuca have been found to colonise substrates with almost no available N (Tallec et al., 2008). The selected grasses also have low but constant $\mathrm{P}$ requirements $\left(\sim 0.04 \mathrm{~g} \cdot \mathrm{m}^{-2}\right)$, although this can be greater in leachable soils (Syers et al., 2008), as was demonstrated in the field trial.

The $\mathrm{NH}_{4}{ }^{+}$fertiliser provided 42.5 g.m ${ }^{-2} \mathrm{~N}$, and the anaerobic digestate provided another 2.9 g.m $\mathrm{m}^{-2}$ (Section 4.4), which was more than adequate for these grasses. The basalt provided $0.03 \mathrm{~g} . \mathrm{m}^{-2} \mathrm{P}$, and the $\mathrm{NH}_{4}{ }^{+}$fertiliser a further $1.1 \mathrm{~g} . \mathrm{m}^{-2} \mathrm{P}$, which also fulfilled the $\mathrm{P}$ requirements. In the first three months of the field trial, basalt and fertiliser positively affected biomass yield (a 69\% and a 63\% increase, respectively, compared to the unamended soil, Table 8.9). However, by the tenth month the amendments ceased to affect plant growth.

The greatest $\mathrm{N}$ and $\mathrm{P}$ losses from the soil occur when dry soils are rapidly wetted, such as through sudden and intense rainfall (Djodjic et al., 2004). Nutrient losses are increased further when the soil is of a low water-holding capacity (Stenberg et al., 1999; Sogbedji et al., 2000). The unusually heavy rainfall from October to April, (Sections 7.2.1 and 8.2.1), the high solubility of the $\mathrm{N}$ and $\mathrm{P}$ in the soil $\mathrm{pH}$, and the large particle size of the soil components contributed to the comparatively low biomass yield recorded in the basalt or fertiliser amended soils in the June sampling (Table 8.7).

The biochar used in this research did not exert any measurable immobilising effect on heavy metal uptake in the grasses, which, combined with the nutrient leaching, indicated that the CEC of the biochar was lower than anticipated, or at least not high enough to counter the solubility of the nutrients, and the large particle size of the soil structure.

Leaching of $\mathrm{N}$ and $\mathrm{P}$ will have contributed to the grasses early senescence; however, without further investigation of the surrogate soil before and after the field trial, and without leachate collected throughout the trial, it cannot be fully confirmed. As other mine reclamation studies have reported that fertiliser should be applied annually to be effective, the tapering impact of $\mathrm{NH}_{4}{ }^{+}$fertiliser and basalt are consistent with previous research (Harley, 1976; Simcock \& Ross, 2014; Malloch et al., 2015; Courtney, 2018). 


\subsection{Water-holding capacity}

While studies have emphasised the importance of $\mathrm{N}$ and $\mathrm{P}$ supply in reclamation soils (Simcock \& Ross, 2014; Courtney, 2018), overall, it was most likely to not have been the soil's nutrient content which was of most influence to plant growth. The germination and field trials found that the soil temperature and volumetric water content (VWC) exerted the most influence on the grasses survival. Soil temperature is directly related to solar radiation, and the most effective way to reduce soil temperature is through the provision of biomass which provides cover (Maiti \& Maiti, 2015). In the absence of biomass, the methods of reducing soil temperature are mostly limited to altering the soils albedo. The integration of the black biochar into the surrogate soil produced a slight regulatory effect on temperature (Figure 8.9), although the soil temperature still reached $20^{\circ} \mathrm{C}$ between May and June, and peaked at $>26.5^{\circ} \mathrm{C}$ (Table 8.2). Similar temperatures were the cause of wide-spread Agrostis die-off reported in other studies (Fitter et al., 1999; Liu \& Huang, 2005; Touceda-González et al., 2017), which indicated that a wider assemblage of heat-tolerant grasses may be required for future trials.

In the field trial, the browning and wilting of the grass coincided with a higher number of sunshine hours and lower precipitation than usual (Section 8.2.1). High transpiration rates and a negative water balance can impact plant success more so than metal toxicity (Richardson, 1976; Tordoff et al., 2000; Mendez \& Maier, 2008). In the field trial, the volumetric water content (VWC) fell below the permanent wilting point for $>68$ days (Figure 8.10). As in other studies where the VWC was reported to surpass the permanent wilting point (Richardson, 1976; Nguyen et al., 2012), the grasses did not survive. The results of this research determine the water-holding capacity of the soil as the main limiting factor in this method and the area that requires the most future development.

\subsection{Metal tolerance of grass species}

The analyses of the metal concentrations within the biomass proved particularly informative. The grasses contained $<0.2 \%$ of the tolerable $\mathrm{Zn}$ concentrations and $<0.6 \%$ of the tolerable $\mathrm{Pb}$ concentrations. The $\mathrm{Cd}$ and $\mathrm{Cu}$ concentrations were below the detectable limits (Section 8.2.9). While the grasses did ultimately perish, the 
analysis determined the metal contamination not to be a factor in the grasses death and supported the conclusion that the VWC was of greatest effect for these grass species. Although $\mathrm{N}$ depletion was not monitored in this study, the low $\mathrm{N}$ content of the soil materials was hypothesised to have been of great influence to the grass's short lifespan. The metal concentration data were an important indicator of the suitability of the species assemblage for metal-mine revegetation. As the concentration of metals was considerably below the grasses tolerance, the species assemblage was regarded as appropriate for the revegetation of metal-mine tailings, albeit in a cooler climate, or with the inclusion of drought and heat tolerant species

\subsection{The suitability of the soil components}

The development of an artificial soil media to revegetate highly contaminated land, which has been barren for $>100$ years, is a slow one. The research was the first step of many on the temporal pathway to restoration. An attempt to accelerate pedogenic processes, which can take decade or longer, to within nine months is ambitious to say the least. It is clear from the results of this study that some of the surrogate soil components that were trialled have potential for mine reclamation, whereas others require more consideration.

A compromise had to be made between creating a deep soil which retained water and soluble nutrients (but became heavy and slipped off a slope, as seen in the rainfall pilot trials), with the need to create a soil which remains on the slope but is too free draining (as was seen in the field trial). The former might be suitable for flatter ground, however the aim of the surrogate soil was to be suitable for application to steep slopes, therefore, a water-retentive soil was not the aim of this study. Other considerations, such as the nutrient content (short and long-term), particle and pore size, cost, supply chain, acceptability of materials, and suitability for the deployment method, had to be considered. Clearly, a balance is to be sought between these characteristics, and the final solution to this was not within the scope of this study. 


\subsection{Conclusions and suggestions for future research}

Metal-mine tailings present a range of issues for plant growth. The effective, economical, and rapid establishment of vegetation on metal-mine tailings characterises one of the most significant challenges facing the mining industry today (Hutchison \& Ellison, 1992; Maco et al., 2018; ICMM, 2019). Developing an effective method to introduce a surrogate soil is, potentially, the only cost-effective method of revegetating tailings in a timely manner (ICMM, 2019).

To date, there is a limited body of research which examines shallow soil covers for metal-mine reclamation. Furthermore, there is a particular lack of field trials in this area. The thesis has contributed to this relatively unexplored field of research by beginning the development of a surrogate soil product for application to mine tailings, in order to provide a habitable environment for pioneer plant species.

The results of the trials have provided valuable information regarding the establishment of soil and vegetation on polluting landforms, and has also highlighted where these challenges still exist. The consistent ground cover and plant survival at Frongoch $\mathrm{Pb} / \mathrm{Zn}$ mine, which applied a similar surrogate soil to that of this trial, is a positive indicator for the development of this method. The results at Frongoch presented that, with adjustments, a fully functioning and self-sustaining soil and plant environment could be established on metal-mine tailings.

The cost of reclamation projects can vary, and is dependent on soil materials, excavation and regrading costs, the seed mix, irrigation, and the maintenance of the site. In the present reclamation trial, the surrogate soil which was developed was relatively inexpensive ( $£ 6 \mathrm{p} \cdot \mathrm{m}^{-2}$ at the time of writing), as costs were intended to be accessible to the publicly funded environmental agencies responsible for abandoned mines. The reduced cost of this method may also be more accessible to developing countries than the traditional chemical methods (Baethke, 2015), which typically range from $£ 200$ - 900 per tonne (Surriya, 2015; FRTR, 2018).

It is clear that the surrogate soil and method of application require development (such as changes to the seed mix, increasing the WHC of the soil, improvements to the $\mathrm{N}$ content, and a more thorough analysis of the biochar), yet the cost of the method is still far below that of similar cap and cover methods ( $£ 12-45$ p.m² , Kingsbury, 2008; P. Edwards, 2019, pers.comm.). The surrogate soil developed in this research was 
therefore an important step in creating a cost-effective method for controlling erosion and revegetating hostile and polluting landforms. 


\section{References}

Abreuq, C., Korchagin, J., Bergmann, M. \& Bortoluzzi, E. (2015). 'Nutrient desorption from basaltic rock', in Precedings of The 16th World Ferilizer Congress, $20^{\text {th }}-24^{\text {th }}$ October, Rio de Janero.

Accumen Waste (2017). A soil washing facility, photograph. Available at: https://acumenwaste.co.uk/services/waste-management/total-waste-management/ (Accessed 22 December 2017).

Adam, P.T. (1995). Artificial soil from recycled materials. U.S. Patent 5,472,475.

Aspen Center for Environmental Studies (2017). Hope Mine Biochar. Available at: https://www.aspennature.org/forest-health-projects/ (Accessed: 22 September 2017).

Agegnehu, G., Bass, A. M., Nelson, P. N. \& Bird, M. I. (2016). 'Benefits of biochar, compost and biochar-compost for soil quality, maize yield and greenhouse gas emissions in a tropical agricultural soil', Science of The Total Environment, 543, pp. $295-306$.

Agegnehy, G. \& Amede, T. (2017). 'Integrated soil fertility and plant nutrient management in tropical agro-ecosystems: A review', Pedosphere, 27(4), pp. 662 680.

Agegnehu, G., Srivastava, A. K. \& Bird, M. I. (2017). 'The role of biochar and biocharcompost in improving soil quality and crop performance: A review', Applied Soil Ecology, 119, pp. $156-170$.

Agilent (2018a). MP-AES systems. 4200 MP-AES. Available at: https://www.agilent.com/en/products/mp-aes/mp-aes-systems/4200-mpaes\#literature (Accessed: 24 September 2019).

Agilent (2018b). Microwave plasma stomic emission spectroscopy (MP-AES). Application ehandbook. Cheadle. Available at: https://www.agilent.com/cs/library/applications/5991-7282EN_MP-AES-eBook.pdf (Accessed: 24 September 2019).

Ahmed, M. B., Zhou, J. L., Ngo, H. H., Guo, W., Chen, W. (2016). 'Progress in the preparation and application of modified biochar for improved contaminant removal from water and wastewater', Bioresource Technology, 214, pp. 836 - 851.

Akter, M. \& Akagi, T. (2010). 'Effect of fine root contact on plant-induced weathering of basalt', Soil Science \& Plant Nutrition, 51(6), pp. $861-871$.

Akhter, J., Mahmood, K., Malik, K., Mardan, A., Ahmad, M. \& Iqbal, M. (2001). 'Effects of hydrogel amendment on water storage of sandy loam and loam soils and seedling growth of barley, wheat and chickpea', Plant, Soil and Environment, 50(10), pp. $463-469$.

Alaniz, L. (2019). Successfully vegetating a jobsite. Available at: https://csengineermag.com/article/successfully-vegetating-a-jobsite/ (Accessed: 12 June 2019). 
Alaska Department of Transport (2018). Qualified products list, Department of Transport, Anchorage. Available at:

http://www.dot.state.ak.us/qploracle/\#stage/advancedsearch (Accessed: 28 March 2020).

Alburquerque, J. A., de la Fuente, C., Ferre-Costa, A., Carrasco, L., Cegarra, J., Abad, M \& Bernel, M. (2012). 'Assessment of the fertiliser potential of digestates from farm and agroindustrial residues', Biomass and Bioenergy, 40, pp. $181-189$.

Alghamdi, A., Kirkham, M., Presley, D., Hettiarachchi, G. \& Murray, L. (2018). 'Rehabilitation of an abandoned mine site with biosolids', in Bolan, N., Kirkham, M. $\&$ Ok, Y. (eds.) Spoil to Soil: Mine site rehabilitation and revegetation. CRC Press, Boca Raton, pp. $241-259$.

Aller, D., Rathke, S., Laird, D., Cruse, R. \& Hatfield, J. (2017). 'Impacts of fresh and aged biochars on plant available water and water use efficiency', Geoderma, 307, pp. $114-121$.

Alvarenga, P., de Varennes, A. \& Cunha-Queda, A. C. (2014). 'The effect of compost treatments and a plant cover with Agrostis tenuis on the immobilization/mobilization of trace elements in a mine-contaminated soil', International Journal of Phytoremediation, 16(2), pp. 138 - 154.

Amougou, N., Bertrand, I., Cadoux, S. \& Recous, S. (2012). 'Miscanthus $\times$ giganteus leaf senescence, decomposition and $\mathrm{C}$ and $\mathrm{N}$ inputs to soil', Global Change Biology Bioenergy, 4(6), pp. $698-707$.

Anawar, H. M, Akter, F., Solaiman, Z., \& Strezov, V. (2015). 'Biochar: An emerging panacea for remediation of soil contaminants from mining, industry and sewage wastes', Pedosphere, 25(5), pp. $654-665$.

Anda, M., Shamshuddin, J., Ishak, C. F., \& Omar, S. (2009). 'Dissolution of ground basalt and its effect on oxisol chemical properties and cocoa growth', Soil Science, $174(5)$, pp. $264-271$.

Anda, M., Shamshuddin, J. \& Fauziah, C. I. (2013). 'Increasing negative charge and nutrient contents of a highly weathered soil using basalt and rice husk to promote cocoa growth under field conditions', Soil and Tillage Research, 132, pp. $1-11$.

Angel, P. N., Barton, C. D., Warner, R. C., Agouridis, C., Taylor, T. \& Hall, S. (2008). 'Forest establishment and water quality characteristics as influenced by spoil type on a loose-graded surface mine in eastern Kentucky', Precedings of The 25th Annual Meetings of the American Society of Mining and Reclamation, $1^{\text {st }}$ June, Wyoming, pp. $28-65$.

Antonovics, J. (2006). 'Evolution in closely adjacent plant populations X: Long-term persistence of prereproductive isolation at a mine boundary', Heredity, 97(1), pp. 33 37.

Archer, M. \& Caldwell, R. (2004). 'Response of six Australian plant species to heavy metal contamination at an abandoned mine site', Water, Air \& Soil Pollution, 157(1), pp. $257-267$.

Arnold, S., Shneider, A., Doley, D. \& Baumgartl, T. (2015). 'The limited impact of vegetation on the water balance of mine waste cover systems in semi-arid Australia', 
Ecohydrology, 8(3), pp. 355 - 367.

Asensio, V., Vega, F. A. \& Covelo, E. F. (2014). 'Effect of soil reclamation process on soil C fractions', Chemosphere, 95 , pp. $511-518$.

Ashjaei, S., Miller, W. P, Cabrera, M.L. \& Hassan, S.M. (2011). 'Arsenic in soils and forages from poultry litter-amended pastures', International Journal of Environmental Research and Public Health, 8(5), pp. 1534 - 1546.

Aşkın, T. \& Aygün, S. (2018). 'Does hazelnut husk compost (HHC) effect on soil water holding capacity (WHC)? An environmental approach', Eurasian Journal of Soil Science, 7(1), pp. $87-92$.

Atkins (2011). 'Nant y Mwyn Metal Mine Scoping Report'. Cardiff.

Atkins (2015). Frongoch Remediation - Phase 2, Validation Report. Cardiff.

Babcock, D. L. \& McLaughlin, R. A. (2013). 'Erosion control effectiveness of straw, hydromulch, and polyacrylamide in a rainfall simulator', Journal of Soil and Water Conservation, 68(3), pp. $221-227$.

Baethke, K. A. (2015). Mine restoration of a native grassland plant community in the British Columbian interior: The use of biochar, hydroseeding and raking. $\mathrm{PhD}$ Thesis, Thompson Rivers University, Kamloops, Canada.

De Baets, S., Poesen, J., Gyssels, G. \& Knapen, A. (2006). 'Effects of grass roots on the erodibility of topsoils during concentrated flow', Geomorphology. 76(1-2), pp. 54 -67 .

Belyaeva, O. N. \& Haynes, R. J. (2009). 'Chemical, microbial and physical properties of manufactured soils produced by co-composting municipal green waste with coal fly ash'. Bioresource Technologies, 100, pp. $5203-5209$.

Banik, C., Lawrinenko, M. \& Bakshi, S. (2018). 'Impact of pyrolysis temperature and feedstock on surface charge and functional group chemistry of biochars', Journal of Environmental Quality, 47(3), pp. 452 - 461.

Bardos, R. P., Thomas, H. F., Smith, J. W. N., Harries, N. D., Evans, F., Boyle, R., Howard, T., Lewis, R., Thomas, O. A. \& Haslam, A. (2018). 'The development and use of sustainability criteria in SuRF-UK's sustainable remediation framework', Sustainability, 10(6), p. 1781.

Beaulieu, M. (2001). 'The evolution of the polluter pays/owner pays principle in relation with the rehabilitation of contaminated sites in Canada and the United States', Fifth Conference of the Ad Hoc International Working Group on Contaminated Land. Swiss Agency for the Environment, Forests and Landscape, Geneva, $17^{\text {th }}$ September, pp. 11.

Bendfeldt, E. S., Burger, J. A. \& Daniels, W. L. (2001). 'Quality of amended mine soils after sixteen years', Soil Science Society of America Journal, 65(6), p. 1736.

Bian, R., Joseph, S., Cui, L., Pan, G., Li, L., Liu, X., Zhang, A., Rutlidge, H., Wong, S., Chia, C., Marjo, C., Gong, B., Munroe, P \& Donne, S. (2014). 'A three-year experiment confirms continuous immobilization of cadmium and lead in contaminated paddy field with biochar amendment', Journal of Hazardous Materials, 272, pp. 121 -128 . 
Blair, T. (1998). 'Lead oxide technology - Past, present, and future', Journal of Power Sources, 73(1), pp. $47-55$.

de Blasio, F. V. (2011). Introduction to the physics of landslides. Springer, Heidelberg.

Block, J. (2020). 'Why copper? The Antakori copper gold project'. Spotlight Mining Conference, $30^{\text {th }}$ April, online. Available at:

https://www.youtube.com/watch?v=nK1en8_GP9k\&list=PL1D7vbPwUu0WqSmTc6 Lb1htAhutAhD-JM\&index=2

Bolan, N., Kunhikrishnan, A., Thangarajan, R., Kumpiene, J., Park, J., Makino, J., Kirkham, M. \& Scheckel, K. (2014). Remediation of heavy metal(loid)s contaminated soils - To mobilize or to immobilize? Journal of Hazardous Materials, 266, pp. 141 166.

Bopp, C., Christl, I., Schulin, R. \& Evangelou, M.W.H. (2016). 'Biochar as possible long-term soil amendment for phytostabilisation of TE-contaminated soils', Environmental Science and Pollution Research, 23(17), pp. 17449 - 17458.

Borchard, N., Prost, K., Kautz, T., Moeller, A. \& Siemens, J. (2012). 'Sorption of copper (II) and sulphate to different biochars before and after composting with farmyard manure', European Journal of Soil Science, 63(3), pp. 399 - 409.

Bowker, L. N. \& Chambers, D. M. (2015). 'The risk, public liability \& economics of tailings storage facility failures', Bowker Associates Science \& Research In The Public Interest, pp. $1-56$.

Brackenbury, S. (2018). Email with Sion Brackenbury, 30th July.

Bradshaw, A. (1997). 'Restoration of mined lands - using natural processes', Ecological Engineering, 8(4), pp. 255 - 269.

Bradshaw, A., Chadwick, M. T., Jowett, D. \& Snaydon, R. W. (2009). 'Experimental investigations into the mineral nutrition of several grass species : IV. Nitrogen level', Journal of Ecology, 52(3), pp. 665 - 676.

British Geological Survey (2014). User guide for the BGS soil chemistry data for environmental assessments, Nottingham.

British Grassland Society (2002). 'Silage decisions factsheet. Better returns program', pp. 1 - 2. Available at: https://www.britishgrassland.com/silage-additivesfactsheet. (Accessed: 22 October 2017).

British Mining (1992). Memoirs, 1992. Northern Mine Research Society, Sheffield.

Brofas, G., Mantakas, G., Tsagari, K., Stefanakis, M. \& Varelides, C. (2007). 'Effectiveness of cellulose, straw and binding materials for mining spoils revegetation by hydro-seeding, in Central Greece', Ecological Engineering, 31(3), pp. 193 - 199.

Brofas, G., Michopoluos, P. \& Alifragis, D. (2000). 'Sewage sludge as an amendment for calcareous bauxite mine spoils reclamation', Journal of Environmental Quality, 29(3), pp. $811-816$.

Brown, A. (2018). Email with Aaron Brown. A geotextile liner being applied to the reprofiled tailings at Frongoch Pb/Zn mine, Wales, 29 ${ }^{\text {th }}$ September 2018.

Brown, G. \& Brinkmann, K. (1992). 'Heavy metal tolerance in Festuca ovina L. from 
contaminated sites in the Eifel Mountains, Germany', Plant and Soil, 143(2), pp. 239 $-247$.

Brown, R. A., Kercher, A., Nguyen, T., Nagle, D. \& Ball, W. (2006). 'Production and characterization of synthetic wood chars for use as surrogates for natural sorbents', Organic Geochemistry, 37(3), pp. 321 - 333.

Bulatovic, S. M. (2007). Handbook of flotation reagents : chemistry, theory and practice : flotation of sulphides ores, Elsevier, Amsterdam.

Burges, A., Epelde, L., Benito, G., Artetxe, U., Becerril, J. \& Garbisu, C. (2016). 'Enhancement of ecosystem services during endophyte-assisted aided phytostabilization of metal contaminated mine soil', Science of the Total Environment, 562 , pp. $480-492$.

Burylo, M., Hudek, C. \& Rey, F. (2011). 'Soil reinforcement by the roots of six dominant species on eroded mountainous marly slopes (Southern Alps, France)', 84(1-2), pp. $70-78$.

Cahn, M. (2018). A guide to using polyacrylamide (PAM) polymers for control of irrigation runoff on the central coast, Irrigation and Water Resources Advisor,

Monterey County. Monterey. Available at:

http://cemonterey.ucanr.edu/files/280667.pdf (Accessed: 9 April 2019).

Cairns, S., Robertson, I., Sigmund, G. \& Street-Perrott, A. (2020). 'The removal of lead, copper, zinc and cadmium from aqueous solution by biochar and amended biochars', Environmental Science and Pollution Research, 27(17), pp. 21702 - 21715.

California Stormwater Handbook (2003). Polyacrylamide (PAM) companion and alternative BMPs advantages and disadvantages, State of Michigan, Lansing. Available at: https://www.michigan.gov/documents/deq/nps-

polyacrylamide_332130_7.pdf (Accessed: 4 January 2018).

Carter, R. A. (2000). 'Contemplating closure.', Engineering and Mining Journal, 96(103), pp. $97-103$.

Chai, C. H., Munroe, P., Joseph, S.D., Lin, Y., Lehamnn, J., Muller, D. A., Xin, H. L., \& Neves, E. (2012). 'Analytical electron microscopy of black carbon and microaggregated mineral matter in Amazonian Dak Earth', Journal of Microscopy, 245 , pp. $129-139$.

Chalker-Scott, L. (2019). Polyacrylamide hydrogels. Available at: http://www.theinformedgardener.com. (Accessed: 18 June 2019).

Chan, K. Y., van Zweiten, L., Maszaros, I., Downie, A. \& Joseph, S. (2007). 'Agronomic values of greenwaste biochar as a soil amendment', Australian Journal of Soil Research, 45(8), pp. $629-634$.

Chen, D., Liu, X., Bian, R., Cheng, K., Zhan, X., Zheng, J., Joseph, S., Crowley, D., Pan, G \& Li, L. (2018). 'Effects of biochar on availability and plant uptake of heavy metals - A meta-analysis', Journal of Environmental Management, 222, pp. 76 - 85.

Chen, X., Chen, G., Chen, Y., Lehmann, J., McBride, M. \& Hay, A. (2011). 'Adsorption of copper and zinc by biochars produced from pyrolysis of hardwood and corn straw in aqueous solution', Bioresource Technology, 102(19), pp. 8877 - 8884. 
Cheng, C. H., Lehmann, J. \& Engelhard, M. H. (2008). 'Natural oxidation of black carbon in soils: Changes in molecular form and surface charge along a climosequence', Geochimica et Cosmochimica Acta, 72(6), pp. 1598 - 1610.

Churr, A. (2020). Responsible raw materials, sharing the benefits - Reducing operating risks and closure liabilities. Available at:

https://www.responsiblerawmaterials.com/post/sharing-the-benefits-reducingclosure-liabilities-and-operating-risk (Accessed: 3 March 2018).

Ciria (2017). Ciria C758 Abandoned mine workings \& SP32 construction over abandoned mine workings. London.

Claoston, N. \& Samsuri, A.W. (2014). 'Effects of pyrolysis temperature on the physicochemical properties of empty fruit bunch and rice husk biochars', Waste Management and Research, 32(4), pp. 331 - 339.

Clarke, M., \& Walsh, R. (2007). 'A portable rainfall simulator for field assessment of splash and slopewash in remote locations', Earth Surface Processes and Landforms, 32, pp. $2052-2093$.

Clemente, A. S., Moedas, A., Oliveira, G., Martins-Loucao, M. \& Correia, O. (2016). 'Effect of hydroseeding components on the germination of Mediterranean native plant species', Journal of Arid Environments, 125, pp. 68 - 72.

Clough, T. J., Condon, L., Kammann, C. \& Muller, C. (2013). 'A review of biochar and soil nitrogen dynamics', Agronomy, 3(2), pp. 275 - 293.

Colonial (2018). Hydroseeding new development, Virginia Beach. Available at: https://colonial-materials.com/portfolio/\#! (Accessed on $17^{\text {th }}$ July 2018).

Concas, S., Ardeu, C., Di Bonito, M., Lattanzi, P. \& Vacca, A. (2011). 'Field sampling of soil pore water to evaluate the mobile fraction of trace elements in the Iglesiente area (SW Sardinia, Italy)', Environmental Pollution, 159, pp. 3078 - 3085.

Coppin, N. J. (2013). 'A framework for success criteria for mine closure, reclamation and post-mining regeneration', in Tibbett, M., Fourie, A. and Dogby, C. (eds.), Proceedings of the Eighth International Seminar on Mine Closure, Australian Centre for Geomechanics, Cornwall, pp. $485-493$

Courtney, R. (2018). Irish mine sites rehabilitation - A case study, bio-geotechnologies for mine site rehabilitation. In Prasad, M., de Campo Favas, P. \& Mati, S. (eds.) Biogeotechnologies for mine site rehabilitation, Elsevier, London.

Craine, J. M., Froehle, J., Tilman, D., Wedin, D. \& Chapin, F. (2001). 'The relationships among root and leaf traits of 76 grassland species and relative abundance along fertility and disturbance gradients', Oikos, 93(2), pp. $274-285$.

Crombie, K., Maske, O., Sohi, S., Brownsort, P. \& Cross, A. (2013). 'The effect of pyrolysis conditions on biochar stability as determined by three methods', $G C B$ Bioenergy, 5(2), pp. 122 - 131.

Cross, A. T., Stevens, J. C. \& Dixon, K. W. (2017). 'One giant leap for mankind: can ecopoiesis avert mine tailings disasters?', Plant and Soil, 421(1-2), pp. $1-5$.

Dafner, E. V. (2015). 'Segmented continuous-flow analyses of nutrient in seawater: intralaboratory comparison of Technicon AutoAnalyzer II and Bran Luebbe 
Continuous Flow AutoAnalyzer III', Limnology and Oceanography: Methods, 13(10), pp. 511-520.

Dahmani-Muller, H., van Oort, F., Geliem B. \& Balabane, M. (2000). 'Strategies of heavy metal uptake by three plant species growing near a metal smelter', Environmental Pollution, 109(2), pp. 231-238.

Dari, B., Nair, V. D., Harris, W. G., Nair, P. K. R., Sollenberger, L. \& Mylavarapu, R. (2016). 'Relative influence of soil-vs. biochar properties on soil phosphorus retention', Geoderma, 280, pp. 82 - 87.

Davies, A. A., Perkins, W. F. \& Bowell, R. J. (2016). 'Geochemical assessment of mine waste cover performance post reclamation at Parc mine, North Wales', Geochemistry: Exploration, Environment, Analysis, 16(2), pp. 127 - 136.

Davin, M. (2019). Email with Moira Davin. The integration of lime and cement into gold mine tailings at the McLaren Gold Mine site, Montana, photograph, $19^{\text {th }}$ September 2019.

De-Quincey, H. (2017). The use of a sustainable biochar compost for the revegetation and stabilisation of metal-mine tailings. MSc Thesis, Swansea University, Wales.

Deenik, J. L., McClellan, T., Uehara, G., Antal, M. \& Campbell, S. (2010). 'Charcoal volatile matter content influences plant growth and soil nitrogen transformations', Soil Science Society of America Journal, 74(4), pp. 1259-1270.

Ding, X. B, Ramey, D., Lee, I. \& Zhang, L. Y. (2016). 'Geoengineering; Study results from University of Arizona update understanding of geoengineering (experimental and numerical investigation into surface strength of mine tailings after biopolymer stabilization)', Journal of Engineering, 17, p. 1997.

Djodjic, F., Börling, K. \& Bergström, L. (2004). 'Phosphorus leaching in relation to soil type and soil phosphorus content', Journal of Environmental Quality, 33(2), pp. $678-684$.

Donze, J. \& Lanze, J. (2015). Hydroseeding substrate and methods of use. Apalachin. Patent number US9193634B2. Available at:

https://patentimages.storage.googleapis.com/c9/b5/c7/1dd6372cfaaed1/US9193634.p df (Accessed: 6 November 2018).

Dou, C.Y., Li, F.H. \& Wu, L. S. (2012). 'Soil erosion as affected by polyacrylamide application under simulated furrow irrigation with saline water', Pedosphere. 22(5), pp. 681-688.

Downie, D., Crosky, A., \& Munroe, P. (2009) 'Physical properties of biochar', in Lehmann, J. \& Joseph, S. (ed.) Biochar for Environmental Management: Science and Technology. London, Earthscan, pp. 13 - 32.

Dunifon, S. N., Evanylo, G., Maguire, R. \& Goately, J. (2011). 'Soil nutrient and Fescue (Festuca spp.) responses to compost and hydroseed on a disturbed roadside', Compost Science \& Utilization, 19(3), pp. 147 - 151.

ECB Verdyol (2019). Case Study: United Kingdom, South Wales. Winnipeg. Available at: https://www.citypopulation.de/en/uk/southeastengland/admin/.

Edraki, M., Baumgartl, T., Manlapig, E., Bradshaw, D., Franks, D. \& Moran, C. 
(2014). 'Designing mine tailings for better environmental, social and economic outcomes: A review of alternative approaches', Journal of Cleaner Production, 84(1), pp. $411-420$.

Edwards, P. (2019) Email from Paul Edwards, 6th November.

Edwards, P., Williams, T. \& Stanley, P. (2016). Surface water management and encapsulation of mine waste to reduce water pollution from Frongoch Mine, Mid Wales, Natural Resources Wales, Cardiff.

Eiland, F., Leth, M., Klamer, M., Lind, A., Jensen, H \& Iversen, J. (2001). 'C and N turnover and lignocellulose degradation during composting of Miscanthus straw and liquid pig manure', Compost Science \& Utilization. 9(3), pp. 186 - 196.

El-Naggar, A., Lee, S. S., Rinklbe J., Farooq, M., Song, H., Sarmah, A., Zimmerman, A., Ahmad, M., Shaheen, S. \& Ok, Y. (2019). 'Biochar application to low fertility soils: A review of current status, and future prospects', Geoderma, 337, pp. 536 - 554.

El-Naggar, A., El-Naggar, A. H., Shaheen, S. Sarkar, B., Chang, S., Tsang, D., Rinklebe, J. \& Ok, Y. (2019). 'Biochar composition-dependent impacts on soil nutrient release, carbon mineralization, and potential environmental risk: A review', Journal of Environmental Management, 241, pp. 458 - 467.

Elad, Y., David, D., Harel, Y., Borenshtein, M., Kalifa, H., Silber, A. \& Graber, E. (2010). 'Induction of systemic resistance in plants by biochar, a soil-applied carbon sequestering sgent', Phytopathology, 100(9), pp. 913 - 921.

Environment Agency (2006). The determination of metals in solid environmental samples. Newbury.

Environment Agency (2019). Soil guideline values for inorganic arsenic in soil, Environment Agency, Bristol.

Falagán, C., Grail, B. M. \& Johnson, D. B. (2017). 'New approaches for extracting and recovering metals from mine tailings', Minerals Engineering, 106, pp. $71-78$.

Farrell, M. \& Jones, D. L. (2009). 'Critical evaluation of municipal solid waste composting and potential compost markets', Bioresource Technology, 100(19), pp. $4301-4310$.

Fashola, M. O., Ngole-Jeme, V. M. \& Babalola, O. O. (2016). 'Heavy metal pollution from gold mines: Environmental effects and bacterial strategies for resistance', International Journal of Environmental Research and Public Health, 13(11), pp 1 20 .

Fazekaš, J., Fazekasova, D., Hronec, O., Benkova, E. \& Boltiziar, M. (2018). 'Contamination of soil and vegetation at a magnesite mining area in Jelšava-Lubeník (Slovakia)', Ekologia Bratislava, 37(2), pp. 101 - 111.

Federal Remediation Technologies (2018). Costs and performance case studies, Federal Remediation Technologies Roundtable. Available at: https://frtr.gov/costperformance/searchresult.cfm (Accessed: 1 December 2018).

Fellet, G., Marchiol, L., Vedove, G. \& Peressotti, A. (2011). 'Application of biochar on mine tailings: Effects and perspectives for land reclamation', Chemosphere, 83(9), pp. $1262-1267$. 
Fields-Johnson, C., Zipper C. \& Evans, D. (2009) 'First year response of mixed hardwoods and improved Amercian chestnuts to compaction and hydroseed treatments on reclaimed mine land', Journal American Society of Mining and Reclamation, 2009(1), pp. $413-432$.

Fitter, A. H., Self, G. K., Brown, T. K., Bogie, D. S., Graves, J. D., Benham, D. \& Ineson, P. (1999). 'Root production and turnover in an upland grassland subjected to artificial soil warming respond to radiation flux and nutrients, not temperature'. Oecologia, 120(4), pp. 575 - 581.

Frantz, J. M., Locke, J., Pitchay, D. \& Krause, C. (1993). 'Actual performance versus theoretical advantages of polyacrylamide hydrogel throughout bedding plant production', American Society for Horticultural Science, 40(7), pp 2040 - 2046.

Free, H. F., McGill, C. R. \& Hedley, M. J. (2010). 'The effect of biochars on maize (Zea mays) germination', New Zealand Journal of Agricultural Research, 53(1), pp. 1 -4 .

Fullen, M. A. (1998). 'Effects of grass ley set-aside on runoff, erosion and organic matter levels in sandy soils in east Shropshire, UK', Soil \& Tillage Research, 46(1), pp. 41- 49 .

Gang, X., Wei, L., Junna, S., Shao, H. \& Chang, S. (2012). 'What is more important for enhancing nutrient bioavailability with biochar application into a sandy soil: Direct or indirect mechanism?', Ecological Engineering, 52, pp. 119 - 124.

Gadgil, R. L. (1969). 'Tolerance of heavy metals and the reclamation of industrial waste', The Journal of Applied Ecology, 6(2), p. 247.

Gai, X., Wang, H., Liu, J., Zhai, L., Lui, S., Ren, T \& Liu, H. (2014). 'Effects of feedstock and pyrolysis temperature on biochar adsorption of ammonium and nitrate', Public Library of Science, 9(12) pp. 1 - 20.

Garcia, D. H. (2008). 'Overview of international mine closure guidelines', 2008 Meeting of the American Institute of Professional Geologists, p. 9.

Gavili, E., Moosavi, A. A. \& Haghighi, A. A. (2019). 'Does biochar mitigate the adverse effects of drought on the agronomic traits and yield components of soybean?', Industrial Crops and Products, 128, pp. 445 - 454.

Georgia Department of Transport (2016) Qualified Products List, Department of Transport, Atlanta. Available at: www.carolinaprecisionfibers.com (Accessed: 19 June 2019).

Gil-Loaiza, J., White, S., Root, R., Solis-Dominguez, F., Hammond, C., Chorover, J. \& Maier, R. (2016). 'Phytostabilization of mine tailings using compost-assisted direct planting: Translating greenhouse results to the field', Science of the Total Environment, 565, pp. $451-461$.

Gillman, G., Burkette, D. \& Coventry, R. (2002). 'Amending highly weathered soils with finely ground basalt rock', Applied Geochemistry, 17(8), pp. $987-1001$.

Glaser, B., Lehmann, J. \& Zech, W. (2002). 'Ameliorating physical and chemical properties of highly weathered soils in the tropics with charcoal - a review':, Biology and Fertility of Soils, 35(4), pp. $219-230$. 
González-Alday, J., Marrs, R. H. \& Martínez-Ruiz, C. (2009). 'Soil seed bank formation during early revegetation after hydroseeding in reclaimed coal wastes', Ecological Engineering, 35(7), pp. 1062 - 1069.

Goodman, G. T. \& Gemmell, R. P. (1978). 'The maintenance of grassland on smelter wastes in the Lower Swansea Valley. II. Copper smelter waste', The Journal of Applied Ecology, 15(3), p. 875.

Greger, M., Landberg, T. \& Vaculík, M. (2018). 'Silicon influences soil availability and accumulation of mineral nutrients in various plant species.', Plants, 7(2), pp. 875 -883 .

Gutierrez, M., Mickus, K. \& Camacho, L. (2016). 'Abandoned Pb/Zn mining wastes and their mobility as proxy to toxicity: A review', Science of the Total Environment, 565 , pp. $392-400$.

Hall, G. (1993) Metal Mines of South Wales. Griffin, Castle Gary.

Hamer, U., Marschner, B., Brodowski, S \& Amelung, W. (2004). 'Interactive priming of black carbon and glucose mineralisation', Organic Geochemistry, 35(7), pp. 823 830 .

Hardie, M., Clothier, B., Bound, S., Oliver, G. \& Close, D. (2014). 'Does biochar influence soil physical properties and soil water availability?', Plant and Soil, 376, pp. $1-2)$.

Harley, D. J. (1976). 'Open cast mining and the environment', in Lenihan, J., \& Fletcher, W. (eds.) Reclamation. Blackie \& Son, London, pp. 32 - 59.

Harries, P. J. E. (2017). Evaluation of a Mobile Fast-pyrolysis / Gasification Unit for Biochar Production from Infected and / or Invasive Plants. PhD thesis, Swansea University, Wales.

Hartmann, J., West, J., Renforth, P., Kohler, P., De La Roche, C., Wolf-Gladrow, D., Durr, H. \& Scheffran, J. (2013). 'Enhanced chemical weathering as a geoengineering strategy to reduce atmospheric carbon dioxide, supply nutrients, and mitigate ocean acidification', Reviews of Geophysics, 51(2), pp. 113 - 149.

Haynes, R. J. \& Swift, R. S. (1986). 'Effects of soil acidification and subsequent leaching on levels of extractable nutrients in a soil'. Plant and Soil, 95(3), pp.327 336.

He, L., Zhong, H., Liu, G., Dai, Z., Brookes, P. \& Xu, J. (2019). 'Remediation of heavy metal contaminated soils by biochar: Mechanisms, potential risks and applications in China', Environmental Pollution, 252, pp. 846 - 855.

Hendershot, W. H., Lalande, H., \& Duquette, M. (2006). 'Soil Reaction and Exchangeable Acidity', in Carter, M. R. \& Greogorich, E. G. (eds.) Soil Sampling and Methods of Analysis. CRC Press, Florida.

Hester, R. E. \& Harrison, R. M. (1997). Contaminated land and its reclamation. Royal Society of Chemistry, Cambridge.

Holl, K. D. (2002). 'Long-term vegetation recovery on reclaimed coal surface mines in the eastern USA', Journal of Applied Ecology, 39(6), pp. 960 - 970. 
Hollingsworth, I., Odeh, I., Bui, E. \& MacLeod, P. (2007). 'Rule base land unit mapping', in Lagacherie, A. B., McBratney, A. B. \& Voltz, M. (eds.) Digital Soil Mapping: Developments in soil science. Elsevier, Amsterdam, pp. $404-414$.

Houben, D. \& Sonnet, P. (2015). 'Impact of biochar and root-induced changes on metal dynamics in the rhizosphere of Agrostis capillaris and Lupinus albus', Chemosphere, 139, pp. 644-651.

Humphrey, M. O., \& Nicholls, M. K. (1984). 'Relationships between tolerance to heavy metals in Agrostis Capillaris L. (A. Tenuis Sibth)', New Phytologist, 98(1), pp. $177-190$.

Hutchison, I. P. G. \& Ellison, R. D. (1992). Mine waste management : a resource for mining industry professionals, regulators, and consulting engineers. Lewis Publishers, Boca Raton.

Idaho Department of Transport (2019). Qualified products list, Department of Transport, Boise. Available at: https://apps.itd.idaho.gov/Apps/Materials/QPL.aspx (Accessed 5 ${ }^{\text {th }}$ July, 2019).

Igwe, O. \& Chukwu, C. (2018). 'Slope stability analysis of mine waste dumps at a mine site in Southeastern Nigeria', Bulletin of Engineering Geology and the Environment, 78(1), pp. $1-15$.

International Council on Mining and Metals (2019). 'Integrated mine closure, Good Practice Guide'. London.

Internationale Geotextil GmbH (2019). 'Product Sheet - Soil conditioner'. Roess Nature Group, Twistringen.

International Organization for Standardization (1989). 'BS ISO 1796-1:1989. Test sieving - Part 1: Methods using test sieves of woven wire cloth and perforated metal plate', British Standard Institution, Geneva.

International Organization for Standardization (1994). 'BS ISO 10390:1994. Soil quality - Determination of pH', British Standard Institution, Geneva.

International Organization for Standardization (1999). 'BS ISO 11267:1999. Soil quality - Part 4: Biological methods', British Standard Institution, Geneva.

International Organization for Standardization (2002). 'BS EN ISO 146881:2002:2015. 'Geotechnical investigation and testing - Identification and classification of soil', British Standard Institution, Geneva.

International Organization for Standardization (2005). '17126:2005. Soil quality. Determination of the effects of pollutants on soil flora. Screening test for emergence of lettuce seedlings (Lactuca sativa L.)', Geneva.

International Organization for Standardization (2013). 'BS ISO 16729:2013. Soil quality - Digestion of nitric acid soluble fractions of elements', British Standard Institution, Geneva.

International Organization for Standardization (2015). 'BS ISO 11536:2015. 'Iron ores - Determination of loss on ignition - Non- oxidised ores’, British Standard Institution, Geneva. 
International Organization for Standardization (2016). 'BS ISO Soil quality Determination of the effects of pollutants on soil flora. Part $2:$ Effects of contaminated soil on the emergence and early growth of higher', British Standard Institution, Geneva.

International Organization for Standardization (2017). 'BS ISO 11272:2017. Soil quality - Determination of dry bulk density', British Standard Institution, Geneva.

Inyang, M., Gao, B., Yao, Y., Xue, Y., Zimmerman, A., Pullammanappallil P \& Cao $X$. (2012). 'Removal of heavy metals from aqueous solution by biochars derived from anaerobically digested biomass', Bioresource Technology, 110, pp. $50-56$.

Jay, C. N., Fitgerlad, J., Hipps, N. \& Atkinson, C. (2015). 'Why short-term biochar application has no yield benefits: Evidence from three field-grown crops', Soil Use and Management, 31(2), pp. $241-250$.

Jayawardhana, Y., Kumarathilaka, P., Herath, I. \& Vithanage, M. (2016). 'Municipal Solid Waste Biochar for Prevention of Pollution From Landfill Leachate', Environmental Materials and Waste: Resource Recovery and Pollution Prevention. Academic Press, Cambridge.

Jeffery, S., Verheijen, F. G. A., van der Velde, M. \& Bastos, A. (2011). 'A quantitative review of the effects of biochar application to soils on crop productivity using meta-analysis', Agriculture, Ecosystems and Environment, 144(1), pp. 175 187.

Jeffery, S., Abalos, D., Prodana, M., Bastos, C., van Groenigen, J., Hungate, B. \& Verheijen, F. (2017). 'Biochar boosts tropical but not temperate crop yields', Environmental Research Letters, 12, pp. 2 - 6.

Jeyaseeli, D. M. \& Raj, S. P. (2010). 'Chemical characteristics of coir pith as a function of its particle size to be used as a soilless medium', Journal of Environmental Sciences, 4, pp. 163-169.

Jeżowski, S., Mos, M., Buckby, S., Cerazy-Waliszewska, J., Owczarzak, W., Mocek, A., Kaczmarek, Z. \& McCalmont, J. (2017). 'Establishment, growth, and yield potential of the perennial grass Miscanthus $\times$ Giganteus on degraded coal mine soils', Frontiers in Plant Science, 8, p. 726.

Jien, S. H. \& Wang, C. S. (2013). 'Effects of biochar on soil properties and erosion potential in a highly weathered soil', Catena, 110, pp. $10-17$.

Johnson, M. S., McNeilly, T. \& Putwain, P. D. (1977). 'Revegetation of metalliferous mine spoil contaminated by lead and zinc', Environmental Pollution, 12(4), pp. 261277.

Jones, A. (2018). Email with Alun Jones. The tailings at the Deep Boat Level, Nantymwyn, circa 1970, before a quantity of the tailings were removed for the construction of the Llyn Brianne Dam, photograph. 10 ${ }^{\text {th }}$ June 2018.

Jones, D. L., Rousk, J., Edwards-Jones, G., DeLuca, T.H \& Murphy, D. V. (2012). 'Biochar-mediated changes in soil quality and plant growth in a three year field trial', Soil Biology \& Biochemistry journal, 45, pp. 113 - 124. 
Jones, J. (1999). Soil Analysis Handbook of Reference Methods. CRC Press, Boca Raton.

Jordan, J. E., White, R. H. Vietor, D. M., Hale, T.C., Thomas, J. C. \& Engelke, M. C. (2003). 'Effect of irrigation frequency on turf quality , shoot density , and root length density of fice bentgrass cultivars.', Crop Science, 43(1), p. 282.

Jutsz, A. M. \& Gnida, A. (2015). 'Mechanisms of stress avoidance and tolerance by plants used in phytoremediation of heavy metals', Archives of Environmental Protection, 41(4), pp. $104-114$.

Kaith, B. S., Sharma, R. \& Kalia, S. (2015) 'Guar gum based biodegradable, antibacterial and electrically conductive hydrogels', International Journal of Biological Macromolecules, 75, pp. 266 - 275.

Kamala, C. T., Balaram, V., Dharmendra, V., Satyanarayanan, M., Subramanyam, K. \& Krishnaiah, A. (2014) 'Application of Microwave Plasma Atomic Emission Spectrometry (MP-AES) for environmental monitoring of industrially contaminated sites in Hyderabad City, 186, pp. $7097-7113$.

Kammann, C. I., Schmidt, H., Messerschmidt, N., Linsel, S., Steffens, D., Muller, C., Koyro, H., Conte, P. \& Joseph, S. (2015) 'Plant growth improvement mediated by nitrate capture in co-composted biochar', Scientific Reports, 9(5), p. 11080.

Kaniki, A. T. \& Tumba, K. (2019). 'Management of mineral processing tailings and metallurgical slags of the Congolese copperbelt: Environmental stakes and perspectives', Journal of Cleaner Production, 210, pp. 1406 - 1413.

Karami, N., Clemente, R., Mornez-Jimenez, E., Lepp, N. \& Beesley, L. (2011). 'Efficiency of green waste compost and biochar soil amendments for reducing lead and copper mobility and uptake to ryegrass', Journal of Hazardous Materials, 191(13), pp. $41-48$.

Kay-shoemake, J., Watwood, M., Lentz, R. \& Sojka, R. (1998). 'Polyacrylamide as an organic nitrogen source for soil microorganisms with potential effects on inorganic soil nitrogen in agricultural soil', Soil Biology and Biochemistry, 30(8-9), pp. 1045 1052.

Kearney, S. P. (2018). 'Improving the utility of erosion pins: absolute value of pin height change as an indicator of relative erosion', Catena, 163, pp. $427-432$.

Kibet, L. C., Saporito, L., Allen, A., May, E., Kleinman, P., Hashem, F. \& Bryant, R. (2014). 'A protocol for conducting rainfall simulation to study soil runoff.', Journal of visualized experiment, 86.

Kim, Y., Kim, K.R, Kim, H., Yoon, J., Yang, J., Ok, Y., Owens, G. \& Kim, K. H. (2015). 'Effect of biochar on heavy metal immobilization and uptakeby lettuce (Lactuca sativa L.) in agricultural soil', Environmental Earth Science, 74, pp. 1249 1259.

Kim, K., Cheong, J., Kang, W., Chae, H \& Chang, C., (2012). 'Field study on application of soil washing system to arsenic- contaminated site adjacent to J . refinery in Korea', International Conference on Environmental Science and Technology, 30, pp. $1-5$. 
Kim, M. S., Min, H., Koo, N., Park, J., Lee, S., Bak, G. \& Kim, J. (2014). 'The effectiveness of spent coffee grounds and its biochar on the amelioration of heavy metals-contaminated water and soil using chemical and biological assessments', Journal of Environmental Management, 146, pp. 124 - 130.

King, D. J. \& Noss, R. R. (1989). 'Toxicity of polyacrylamide and acrylamide monomer.', Reviews on environmental health, 8(1-4), pp. $3-16$.

Kingsbury, M. (2007). 'Revegetation of the Stockton Coal Mine, Buller ', Combined Proceedings International Plant Propagators' Society, 57, pp. 114 - 119.

Kinney, T. J., Masiello, C., Dugan, B., Hockaday, W., Zygourakis, K. \& Barnes, R. (2012). 'Hydrologic properties of biochars produced at different temperatures', Biomass and Bioenergy, 41, pp. $34-43$.

Kloss, S., Zehetner, F., Dellantonio, A., Hamid, R., Ottner, R., Liedtke, V., Schwanninger, M., Gerzabek, M. \& Soja, G. (2012). 'Characterization of slow pyrolysis biochars: Effects of feedstocks and pyrolysis temperature on biochar properties', Journal of Environmental Quality, 41(4), p. 990.

Kuppusamy, S., Thavamani, P., Megharaj, M., Venkateswarlu, K. \& Naidu, R. (2016). 'Agronomic and remedial benefits and risks of applying biochar to soil: Current knowledge and future research directions', Environment International, 87(1), pp. 1 12.

Lahori, A. H., Gup, Z., Zhang, Z., Li, R., Mahar, A., Awasti, M., Shen, F., Sial, S, Kumbhar, F., Wang, P. \& Jiang, S. (2017). 'Use of biochar as an amendment for remediation of heavy metal-contaminated soils: Prospects and challenges', Pedosphere, 27(6), pp. 991 - 1014.

Lamb, D., Sanderson, P., Wang, L., Kader, M. \& Naidu, R. (2018). 'Phytocapping of mine waste at a delerict mine site in New South Wales', in Bolan, N., Kirkham, M. \& Ok, Y. (eds.) Spoil to soil: Mine site rehabilitation and revegetation. CRC Press, Boca Raton, pp. $215-241$.

Lamb, D. T., Venkatraman, K., Bolan, N., Ashwath, N., Choppla, G. \& Naidu, R. (2014). 'Phytocapping: An alternative technology for the sustainable management of landfill Sites', Critical Reviews in Environmental Science and Technology, 44(6), pp. $561-637$.

Law-Cooper, R. (2019). Email with Rhyan Law-Cooper, 30th April.

Leavitt, K. J., Fernandez, G. C. J. \& Nowak, R. S. (2000). 'Plant establishment on angle of repose mine waste dumps', Journal of Range Management, 53(4), p. 442.

Lefebvre, D., Roamn-Danobeytia, F., Soete, J., Cabanillas, F., Coreva, R., Acsorra, C., Fernandez, L. \& Silman, M. (2019). 'Biochar effects on two tropical tree species and its potential as a tool for reforestation', Forests, 10(8), p. 678.

Lehmann, J., Rillig, M., Thies, J., Masiello, C., Hockaday, W. \& Crowly, R. (2011). 'Biochar effects on soil biota - A review', Soil Biology and Biochemistry, 43(9), pp. 1812 - 1836.

Lehmann, J. \& Joseph, S. (2015). Biochar for environmental management: Science, technology and implementation. Routledge, London. 
Lemière, B., Cottard, F. \& Piantone, P. (2015). 'Mining waste characterization in the perspective of the European mining waste directive', Bureau de Recherches Géologiques et Minières, Orléans.

Letcher, T. M. \& Vallero, D. A. (2011). 'Waste: A handbook for management'. Elsevier, Cambridge.

Leuchtmann, A. \& Schardl, C. (2010). 'The epichloë endophytes of grasses and the symbiotic continuum', in Leuchtmann, A. \& Schardl, C. (eds.) The Fungal Community, CRC Press, Boca Raton.

Li, Y., Sun, Q., Zhan, J., Ynag, Y \& Wang, D. (2016). 'Vegetation successfully prevents oxidization of sulfide minerals in mine tailings', Journal of Environmental Management, 177, pp. $153-160$.

Liao, J. D., Boutton, T. W. \& Jastrow, J. D. (2006). 'Organic matter turnover in soil physical fractions following woody plant invasion of grassland: Evidence from natural 13C and 15N', Soil Biology and Biochemistry, 38(11), pp. $3197-3210$.

Linkohr, B. I., Williamson, L., Fitter, A. \& Leyser, H. (2002). 'Nitrate and phosphate availability and distribution have different effects on root system architecture of Arabidopsis', The Plant Journal, 29(6), pp. $751-760$.

Liu, X., Zhang, A., Ji, C., Joseph, S., Bian, R., Li, L., Pan, G. \& Paz-Ferreiro, J. (2013). 'Biochar's effect on crop productivity and the dependence on experimental conditions - a meta-analysis of literature data', Plant and Soil, 373(1 - 2).

Liu, X. \& Huang, B. (2005). 'Root physiological factors involved in cool-season grass response to high soil temperature', Environmental and Experimental Botany, 53(3), pp. $233-245$.

Liu, Y. N., Guo, Z., Xiao, X., Wang, S., Jiang, Z. \& Zeng, P. (2017). 'Phytostabilisation potential of giant reed for metals contaminated soil modified with complex organic fertiliser and fly ash: A field experiment', Science of the Total Environment, 576, pp. $292-302$.

Lopareva-Pohu, A., Verdin, A., Garcon, G., Sahraaoui, A., Pourrut, B., Debaine, D., Waterlot, C., Laruelle, F., Bidar, G., Douay, F. \& Shitali, P. (2011). 'Influence of fly ash aided phytostabilisation of $\mathrm{Pb}, \mathrm{Cd}$ and $\mathrm{Zn}$ highly contaminated soils on Lolium perenne and Trifolium repens metal transfer and physiological stress', Environmental Pollution, 159(6), pp. 1721 - 1729.

Loveland, P. \& Webb, J. (2003). 'Is there a critical level of organic matter in the agricultural soils of temperate regions: a review', Soil and Tillage Research, 70(1), pp. $1-18$.

Lucchini, P., Qulliam, R., Deluca, T., Vamerali, T. \& Jones, D. (2014). 'Does biochar application alter heavy metal dynamics in agricultural soil?', Agriculture, Ecosystems \& Environment, 184, pp. $149-157$.

Lyons, E. M., Pote, J., DaCosta, M. \& Huang, B. (2007). 'Whole-plant carbon relations and root respiration associated with root tolerance to high soil temperature for Agrostis grasses', Environmental and Experimental Botany, 59(3), pp. 307 - 313.

Macdonald, G. K., Jarvie, H., Withers, P., Doody, D., Keeler, B., Haygarth, P., Johnson, L., McDowell, R., Mittiya, M., Powers, S., Sharpley, A., Shen, J., Weintraub, 
M. \& Zhang, T. (2016), 'Guiding phosphorus stewardship for multiple ecosystem services', Ecosystem Health and Sustainability, 2(12), pp. 21 - 51.

Machmuller, M. B., Kramer, M., Cyle, T., Hill, N., Hancock, D. \& Thompson, A. (2015). 'Emerging land use practices rapidly increase soil organic matter.', Nature communications, 6, pp. 6995.

Maco, B., Bardos, P., Coulon, F., Erickson-Mulanax, E., Hansen, L., Harclerode, M., Hou, D., Mielbrecht, E., Wainwright, H., Yasutaka, T. \& Wick, W. (2018). 'Resilient remediation: Addressing extreme weather and climate change, creating community value', Remediation Journal, 29(1), pp. 7 - 18.

Maiti, S. K. \& Maiti, D. (2015). 'Ecological restoration of waste dumps by topsoil blanketing, coir-matting and seeding with grass-legume mixture', Ecological Engineering, 77, pp. $74-84$.

Major, J., Lehmann, J., Rondon, M. \& Goodale, C. (2010). 'Fate of soil-applied black carbon: downward migration, leaching and soil respiration', Global Change Biology, 16(4), pp. $1366-1379$.

Malloch, K., Craw, D. \& Trumm, D. (2015). 'Arsenic forms and distribution at the historic Alexander gold processing site, West Coast', in Proceedings of the Australian Institute of Mining and Metallurgy New Zealand Branch 2015 Annual Conference. July, Dunedin, pp. 241-250.

Manning, D.A., Renforth, P., Lopez-Capel, E., Robertson, S. \& Ghazireh, N. (2013). 'Carbonate precipitation in artificial soils produced from basaltic quarry fines and composts: An opportunity for passive carbon sequestration'. International Journal of Greenhouse Gas Control, 17, pp.309-317.

Marschner, H. (1995). Mineral nutrition of higher plants. 2nd edn. Academic Press, London.

Martín-Crespo, T., Gomex-Ortiz, D., Martin-Velanquez, S., Martinez-Pagan, P., De Ignacio, C., Lillio, J. \& Faz, A. (2018). 'Geoenvironmental characterization of unstable abandoned mine tailings combining geophysical and geochemical methods (Cartagena-La Union district, Spain)', Engineering Geology, 232, pp. 135 - 146.

Martín-Moreno, C., Martin Duque, J., Ibarra, J., Hernando-Rodriguez, N., Santos, M. \& Castillo, L. (2016). 'Effects of topography and surface soil cover on erosion for mining reclamation: The experimental spoil heap at El Machorro Mine (Central Spain)', Land Degradation \& Development, 27(2), pp. 145 - 159.

Martín-Moreno, C., Duque, J., Ibarra, J., Munoz-Martin, A. \& Zapico, A. (2018). 'Waste dump erosional landform stability - a critical issue for mountain mining', Earth Surface Processes and Landforms, 43(7), pp. 1431 - 1450.

Martin, B. \& Wolfgang, B. (2002). 'Organic matter accumulation in stony soils from hard coal mining spoil', World Congress of Soil Science Conference, August 2002, Thailand, pp. $1670-1671$.

Martínez-Ruiz, C., Fernandez-Santos, B., Putwain, P. \& Fernandez-Gomez, M. (2007). 'Natural and man-induced revegetation on mining wastes: Changes in the floristic composition during early succession', Ecological Engineering, 30(3), pp. 286 -294 . 
Martins Azevedo, M., Ambiental, E. \& Macedo, G. (2005). 'The use of digital photographs to quantity vegetation ground cover in degraded areas', Society and Nature, 8, pp. 671 - 682.

Mayes, W., Johnston, D., Potter, H., \& Jarvis, A. (2009). 'A national stratergy for identfication, prioritisation and management of pollution from abandoned non-coal mine sites in England and Wales', Science of the Total Environment, 407(21), pp. 5435 $-5447$.

Mchaina, D. M. (2000). 'Environmental planning considerations for the decommissioning, closure, and reclamation of a mine site.', in Mehrotra, A. K. \& Singhal, R. K. (eds.) Environmental issues and management of waste in energy and mineral production. Balkema, Calgary.

McKenna, G. T. (2002). Sustainable mine reclamation and landscape engineering, Department of Civil \& Environmental Engineering. PhD Thesis, University of Alberta, Canada.

Mcleary, M. B. (2009). "Striving for "walk-away" - focusing an expert group on the " holy grail " of mine closure', Precedings of the Seventh Interntational Conference on Mine Closure, June, Perth, pp. 359 - 373.

Mehta, N., Cipullo, S., Cocerva, T., Coulon, F., Dino, G., Ajmone-Marsan, F., Padoan, E., Cox, S., Cave, M. \& De Luca, D. (2020). 'Incorporating oral bioaccessibility into human health risk assessment due to potentially toxic elements in extractive waste and contaminated soils from an abandoned mine site', Chemosphere, 255, pp. $12-22$.

Mendez, M. O., Glenn, E. P. \& Maier, R. M. (2007). 'Phytostabilization potential of quailbush for mine tailings', Journal of Environmental Quality, 36(1), pp. 245 - 253.

Mendez, M. O. \& Maier, R. M. (2008). 'Phytostabilization of mine tailings in arid and semiarid environments - An emerging remediation technology', Environmental Health Perspectives, 116(3), pp. $278-283$.

Merlin, G., Di-Gioia, L.\& Goddon, C. (1999). 'Comparative study of the various hydrocolloids used for revegetalization by hydroseeding', Land Degradation and Development, 10, pp. $21-34$.

Met Office (2010). 'Changes in the frequency of extreme rainfall events for selected towns and cities'. London.

Met Office (2018¹). 'Climate Summary - August 2018'. London.

Met Office (2018²). 'Climate Summary - December 2018'. London.

Met Office $\left(2018^{3}\right)$. 'Climate Summary - July 2018'. London.

Met Office (2019¹). 'Climate Summary - April 2019'. London.

Met Office (2019²). 'Climate Summary - February 2019'. London.

Met Office (2019³). 'Climate Summary - January 2019'. London.

Met Office (20194). 'Climate Summary - June 2019'. London.

Met Office (20195). 'Climate Summary - March 2019'. London.

Met Office $\left(2019^{6}\right)$. 'Climate Summary - May 2019'. London. 
Met Office $\left(2019^{7}\right)$. 'Climate Summary - October 2018'. London.

Met Office $\left(2019^{8}\right)$. 'Climate Summary - November 2018'. London.

Met Office (2020). 'UK actual and anomaly maps'. London.

Middleton, L. \& King, M. (2019) Public roads - a natural choice. Federal Highway Administration Research and Technology. Available at:

https://www.fhwa.dot.gov/publications/publicroads/03mar/01.cfm (Accessed: 19

June 2019).

Minnesota Department of Transportation (2018). Qualified products - Hydraulic erosion control, 2019. Available at:

https://www.dot.state.mn.us/products/erosioncontrolandlandscaping/hydraulicerosion control.html (Accessed: 19 December 2018).

Miranda, M., Burris, P., Bingcang, J., Shearman, P., Briones, J., La Vina, A. \& Menard, S. (2003). Mining and critical ecosystems: Mapping the risks. World Resources Institute, Washington.

Moreno-Barriga, F., Diaz, V., Acosta, J., Munoz, A., Faz, A. \& Zornoza, R. (2017). 'Creation of technosols to decrease metal availability in pyritic tailings with addition of biochar and barble waste', Land Degradation \& Development, 28(7), pp. 1943 1951.

Moukoumi, J., Munier-Lamy, C., Berthelin, J. \& Ranger, J. (2006). 'Effect of tree species substitution on organic matter biodegradability and mineral nutrient availability in a temperate topsoil', Annals of Forest Science, 63, pp. $763-771$.

Mudd, G. M. \& Borger, D. V. (2013). 'The ever growing case for paste and thickened tailings - Towards more sustainable mine waste management', The Australasian Institute of Mining and Metallurgy Bulletin, (56), pp. 59.

Mudgil, D., Barak, S. \& Khatkar, B. S. (2014). 'Guar gum: processing, properties and food applications - A review.', Journal of food science and technology, 51(3), pp. 409 -418 .

Mukherjee, A. \& Zimmerman, A. R. (2013). 'Organic carbon and nutrient release from a range of laboratory-produced biochars and biochar-soil mixtures', Geoderma, 193 194.

Mukherjee, A., Zimmerman, A. R. \& Harris, W. (2011). 'Surface chemistry variations among a series of laboratory-produced biochars', Geoderma, 163(3-4), pp. $247-255$.

Mukhopadhyay, S. (2019). 'Application of soil quality indicators for the phytorestoration of mine spoil dumps', in Padney, V. \& Bauddh, K. (eds.) Phytomanagement of Polluted Sites. Elsevier, Amsterdam, pp. 361 - 388.

Munksguard, N.C. \& Lottermoser, B. (2010). 'Effects of wood bark and fertilizer amendment on trace element mobility in mine soils, Broken Hill, Australia: Implications for mined land reclamation', Journal of Environment Quality, 39(6), pp. $2054-2062$.

National Academy of Engineering (2010). 'Grand challenges and earth resources engineering'. Washington. Available at: https://www.nae.edu/File.aspx?id=106323. 
(Accessed: 23 August 2017).

National Climate Information Centre (2019). 'UK seasonal weather summary Autumn 2018', Weather, 74(1), pp. $21-21$.

Natural Resources Wales (20181). 'Water Situation Report, August 2018'. Cardiff.

Natural Resources Wales (2018²). 'Water Situtation Report, December 2017'. Cardiff.

Natural Resources Wales (2018³). 'Water Situtation Report, December 2018. ' Cardiff.

Natural Resources Wales (20184). 'Water Situtation Report, July 2018'. Cardiff.

Natural Resources Wales (20185). Water Situation Report, November 2017'. Cardiff

Natural Resources Wales $\left(2018^{6}\right)$. 'Water Situation Report, November 2018'. Cardiff

Natural Resources Wales $\left(2018^{7}\right)$. 'Water situation report, October 2018'. Cardiff

Natural Resources Wales $\left(2018^{8}\right)$. 'Water situation report, September 2018'. Cardiff

Natural Resources Wales (201911). 'Water Situtation Report, February 2019'. Cardiff.

Natural Resources Wales (2019²). 'Water Situtation Report, January 2019'. Cardiff.

Natural Resources Wales (2019³). 'Water Situation Report, March 2019'. Cardiff.

Natural Resources Wales (20194). 'Water Situation Report, May 2019'. Cardiff.

Nave, L. E., Vance, E. D. \& Curtos, P. S. (2009). 'Impacts of elevated N inputs on north temperate forest soil $\mathrm{C}$ storage, $\mathrm{C} / \mathrm{N}$, and net N-mineralization', Geoderma, 153(1-2), pp. $231-240$.

New York State Department of Transportation (2019). Materials - Approved list. New York. Available at: https://www.dot.ny.gov/divisions/engineering/technicalservices/technical-services-repository/alme/pages/795-01.html (Accessed: 19 June 2019).

Nguyen, T., Fuentes, S., Marschner, P. (2012). 'Effects of compost on water availability and gas exchange in tomato during drought and recovery', Plant and Soil Environment, 58(11), pp. 495 - 502.

Nguyen, T. T. N, Xu, C., Tahmasbian, I. Che, R., Zhou, X., Wallace, H. \& Bai, S. (2017). 'Effects of biochar on soil available inorganic nitrogen: A review and metaanalysis', Geoderma, 288, pp. $76-79$.

Noble, D. (2012). 'Managing water and its environment'. Water Management, Godmanchester. Available at:

http://www.fadsdirectory.com/media/dContent/uploads/Managing_Water_Mag/Man aging_Water_Nov.pdf (Accessed: 19 December 2018).

North American Green (2008). 'Hydra CX Martix Series'. Available at: http://www.maritimehydroseed.com/images/HydraMatriCx-Brochure.pdf (Accessed: 19 June 2019).

North American Green (2018). 'North American Green introduces Hydra CM Bonded Fiber Matrix'. Evansville, Indiana. Available at:

https://www.wateronline.com/doc/strwcotton-fiber-erosion-control-introduced-0001 
(Accessed: 19 December 2018).

Northern Mine Research Society (1992). British mining. Memoirs, 1992. Northern Mine Research Society, Sheffield.

Novak, J. M., Ippolito, J., Ducey, T., Watts, T., Spokas, K., Trippe, K., Sigua, G. \& Johnson, M. (2018). 'Remediation of an acidic mine spoil: Miscanthus biochar and lime amendment affects metal availability, plant growth, and soil enzyme activity', Chemosphere, 205, pp. $709-718$.

Nsiah, P. K. \& Schaaf, W. (2019). 'The potentials of biological geotextiles in erosion and sediment control during gold mine reclamation in Ghana', Journal of Soils and Sediments, 19(4), pp. 1995 - 2006.

Nur, O., Abduelghany, N. \& Alsaid, Y. (2013). 'The influence of thermal treatment on physical properties of guar gum', International Journal of Innovations in Pharmaceutical Sciences, pp. 26 - 46.

Nyo Mar, N., Huang, L. \& Liu, Z. (2018). 'Reclamation of heavy metal contaminated soil by using biochar as soil conditioner', International Journal of Advanced Research and Publications, 25(14). p. 3167.

O’Connor, D., Peng, T., Zhang, J., Tsang, D., Alessi, D., Shen, Z., Bolan, N. \& Hou, D. (2018). 'Biochar application for the remediation of heavy metal polluted land: A review of in-situ field trials', Science of the Total Environment, 619, pp. $815-826$.

O'Kane, M. \& Ayres, B. (2012). 'Cover systems that utilise the moisture store-andrelease concept - Do they work and how can we improve their design and performance?', in Fourie, A. B. \& Tibbett, M. (eds.) Mine Closure, Australian Centre for Geomechanics, Perth, pp. $1-9$

Oldfield, E. E., Wood, S. A. \& Bradford, M. A. (2018). 'Direct effects of soil organic matter on productivity mirror those observed with organic amendments', Plant and Soil, 423(1-2), pp. $363-373$.

Oldfield, T. L., Sikirica, N., Mondoni, C., Lopez, C., Kuikman, P., Holden, N. (2018). 'Biochar, compost and biochar-compost blend as options to recover nutrients and sequester carbon', Journal of Environmental Management, 218, pp. 465 - 476.

Oliveira, G., Clemente, A., Nunes, A. \& Correia, O. (2013). 'Limitations to recruitment of native species in hydroseeding mixtures', Ecological Engineering, 57, pp. $18-26$.

Olmo, M. \& Villar, R. (2018). 'Changes in root traits explain the variability of biochar effects on fruit production in eight agronomic species', Organic Agriculture, 9(2), pp. $1-15$.

Operstein, V. \& Frydman, S. (2000). 'The influence of vegetation on soil strength', Proceedings of the Institution of Civil Engineers - Ground Improvement, 4(2), pp. 81 $-89$.

Oregon Department of Transportation (2019). 'Qualified Products - Qualified products list', Department of Transport, Salem. Available at: https://www.oregon.gov/odot/Construction/Pages/Qualified-Products.aspx (Accessed: 28 March 2020). 
Owen, D. (1999). 'Rhandirmwyn. A brief history'. David Owen, Rhandirmwyn.

Palazzo, A. J., Cary, T., Hardy, S \& Lee, C. (2003). 'Root growth and metal uptake in four grasses grown on zinc-contaminated soils.', Journal of Environmental Quality, 32(3), pp. $834-40$.

Panagopoulos, T. (2014). 'Integrating aesthetic and sustainable principles in stream reclamation projects', WSEAS Transactions on Environment and Development, 3(11) pp. $189-195$.

Parry, D. N. \& Chiverrell, C. P. (2019). Abandoned mine workings manual. CIRIA London: Available at:

https://www.ciria.org/ItemDetail?iProductCode=C758D\&Category=DOWNLOAD\& WebsiteKey=3f18c87a-d62b-4eca-8ef4-9b09309c1c91 (Accessed: 9 May 2020).

Patra, M., Niladri, B., Bulbil, B. \& Archana, S. (2004). 'Comparison of mercury, lead and arsenic with respect to genotoxic effects on plant systems and the development of genetic tolerance', Environmental and Experimental Botany, 52(3), pp. 199 - 223.

Pauleit S., Zölch T., Hansen R., Randrup T.B. \& Konijnendijk van den Bosch C. (2017). Nature-based solutions and climate change - Four shades of green. In: Kabisch N., Korn H., Stadler J., Bonn A. (eds.) Nature-based solutions to climate change adaptation in urban areas. Theory and practice of urban sustainability transitions. Springer, Cham.

Peltz, C. \& Harley, A. (2016). 'Biochar application for abandoned mine land reclamation', in Guo, M., He, Z. \& Uchimiya, S. (eds.) Agricultural and environmental applications of biochar: Advances and barriers, Volume 63, Wiley, New Jersey.

Penn, C., \& Camerato, J. (2019). 'A critical review on soil chemical process that control how soil pH affects phosphorus availability to plants', Agriculture, 9, pp. $2-18$.

Pidlisnyuk, V., Erickson, L., Stefanovska, T., Popelka, J., Hettiarachchi, G., Davis , L. \& Trögl, L. (2019). 'Potential phytomanagement of military polluted sites and biomass production using biofuel crop miscanthus $x$ giganteus', Environmental Pollution, 249, pp. $330-337$.

Plante, A. F., Fernandez, J., Haddix, M., Steinweg, J. \& Conant, R. (2011). 'Biological, chemical and thermal indices of soil organic matter stability in four grassland soils', Soil Biology and Biochemistry, 43(5), pp. 1051 - 1058.

Pogue, K. R. (2010). 'Influence of basalt on the terroir of the Columbia Valley American Viticultural Area'. In Presentation at the 8th International Terroir Conference, Soave, Italy.

Porder, S. \& Ramachandran, S. (2012). 'The phosphorus concentration of common rocks - a potential driver of ecosystem P status', Plant Soil, 367(1), pp. 44 - 55.

Poulsen, B., Khanal, M., Rao, A., Adhikary, D. \& Rao, B. (2014). 'Mine overburden dump failure: A case study', Geotechnical and Geological Engineering, 32(2), pp. 297 -309 .

Prasad, M., Tzortzakis, N. \& McDanial, N. (2017). 'Biochar, chemical 
characterization, nutrient effects, dynamics and preliminary plant growth tests', Journal of Environmental Management, 6, pp. 46 - 59.

Priscu, C. (2017). Challenges of working in mining, AngloAmerican. Available at: https://www.angloamerican.com/futuresmart/our-industry/technology/challenges-ofworking-in-mining (Accessed: 7 March 2019).

Walker, K., Stevens, P., Stevens, D., Mountford, J., Manchester, S. \& Pywell, R. (2004). 'Th restoration and re-creation of species-rich lowland grassland on land formerly managed for intensive agriculture in the UK', Biological Conservation, 119, pp. 1 - 18.

Waste and Resources Action Programme (2012). Desk top study on digestate enhancement and treatment: Enhancement and treatment of digestates from anaerobic digestion. A review of enhancement techniques, processing options and novel digestate products. Banbury. Available at: http://www.wrap.org.uk/sites/files/wrap/Digestates from Anaerobic Digestion A review of enhancement techniques and novel digestate products_0.pdf (Accessed: 29 March 2018).

Pronk, G. J., Heister, K., Vogel, C., Babin, D., Bachmann, J., Ding, G. C., Ditterich, F., Gerzabek, M. H., Giebler, J., Hemkemeyer, M. \& Kandeler, E. (2017). 'Interaction of minerals, organic matter, and microorganisms during biogeochemical interface formation as shown by a series of artificial soil experiments'. Biology and Fertility of Soils, 53 (1), pp. 9 - 22.

Puga, A. P., Abreu, C. A., Melo, L. C. A. \& Beesley, L. (2015). 'Biochar application to a contaminated soil reduces the availability and plant uptake of zinc, lead and cadmium', Journal of Environmental Management, 159, pp. 86 - 93.

Purakayastha, T. J., Das, K., Gaskin, J., Smith, J. \& Savita, K. (2016). 'Effect of pyrolysis temperatures on stability and priming effects of $\mathrm{C} 3$ and $\mathrm{C} 4$ biochars applied to two different soils', Soil and Tillage Research, 155, pp. $107-115$.

Purakayastha, T. J., Kumari, S. \& Pathak, H. (2015). 'Characterisation, stability, and microbial effects of four biochars produced from crop residues', Geoderma, 239-240, pp. $239-303$.

Qureshi, J. A., Thurman, D. A., Hardwick, K. \& Collin, H. A. (1985). 'Uptake and accumulation of zinc, lead and copper in zinc and lead tolerant Anthoxanthum Odoratum L.', New Phytologist, 100(3), pp. 429 - 434.

$\mathrm{R}$ Core Team (2017). Version 3.4.3. A language and environment for statistical computing. R Foundation for Statistical Computing. Vienna, Austria.

$\mathrm{R}$ Core Team (2018) Version 5.3.2. A language and environment for statistical computing. R Foundation for Statistical Computing. Vienna, Austria.

Rai, A. K., Paul, B. \& Singh, G. (2011). 'A study on physico chemical properties of overburden dump materials from selected coal mining areas of Jharia coalfields, Jharkhand, India', International Journal of Environmental Sciences, 1(6), pp. 1350 1360 .

Rajkovich, S., Enders, A., Hanley, K., Hyland, C., Zimmerman, A. \& Lehmann, J. (2012). 'Corn growth and nitrogen nutrition after additions of biochars with varying properties to a temperate soil', Biology and Fertility of Soils, 48(48), pp. 271 - 284. 
Rantec (2009). 'Super tack ®'. Ranchester. Available at:

http://www.ranteccorp.com/products/erosion-control-3/super-tack/ (Accessed: 12 November 2017).

Rao, G. \& Dutta, R. (2005). 'Strength characteristics of sand reinforced with coir fibers and coir geotextiles', Electronic Journal of Geotechnical Engineering, 10, pp. 1 - 17.

Remin Scotland Ltd (2018). Volcanic rockdust. Available at: https://www.reminscotland.com/ (Accessed: 14 July 2018).

Richardson, J. (1976). 'Pit heap into pasture', in Leniham, J. \& Fletcher, W. (eds.) Reclamation. London: Blackie, pp. 60 - 93.

Rizwan, M., Ali, S., Farooq-Qayyum, M., Ibrahim, M., Zia-ur-Rehman, M. \& Ok, Y. (2016). 'Mechanisms of biochar-mediated alleviation of toxicity of trace elements in plants: A critical review', Environmental Science and Pollution Research, 23(3), pp. $2230-2248$.

Robertson, G. P., Gorss, K., Hamilton, S., Landis, D., Schmidt, T., Snap, S. \& Swinton, S. (2014). 'Farming for ecosystem services: An ecological approach to production agriculture', BioScience, 64(5), pp. $404-415$.

Rodríguez-Vila, A., Covelo, E., Forjan, R. \& Asensio, V. (2014). 'Phytoremediating a copper mine soil with Brassica juncea L., compost and biochar', Environmental Science and Pollution Research, 21(19), pp. 11293 - 11304.

Ross, C., Buxton, R., Stanley, J., Alspach, P. \& Morgan, C. (2003). 'Revegetation of steep batters of mine rock dumps using pioneer plants.', in Currie, J. A. \& Hunter, F. (eds.) Environmental Management using Soil-Plant Systems. Massey University, Palmerston North, pp. $160-167$.

Mostaghimi, S. \& Gidley, T. (2019). 'Effectiveness of different approaches for controlling sediment and nutrient losses from eroded land', Journal of Soil and Water Conservation, 74(4), pp. $615-620$.

Saha, D. \& Bhattacharya, S. (2010). 'Hydrocolloids as thickening and gelling agents in food: A critical review.', Journal of Food Science and Technology, 47(6), pp. 587 -97 .

Salix River and Wetland Ltd (2018). Hydroseeding a $45^{\circ}$ railway embankment slope, photograph. Available at: https://www.salixrw.com/solution/erosion-managementrailway-embankment/ (Accessed 27 December 2017).

Salix River and Wetland Services Ltd. (2019). 'Case study erosion management on railway embankment'. Thetford.

Samson, R. (2018). 'Using switchgrass and miscanthus as a sustainable mulch'. Ontario Biomass Producers Cooperative, Ontatio. Available at:

https://www.researchgate.net/publication/325976355_Using_Switchgrass_and_Misc anthus_as_a_Sustainable_Mulch (Accessed: 6 April 2019).

Sanchez-Monedero, M. A., Cayuela, M., Roig, A., Jindo, K., Mondini, C. \& Bolan, N. (2018). 'Role of biochar as an additive in organic waste composting', Bioresource Technology, 247, pp. 1155 - 1164.

Sarfaraz, Q., Silva, L., Drescher, G., Zafar, M., Severo, F., Kokkonen, A., Molin, G., 
Shafi, M., Shafique, Q. \& Solaiman, Z. (2020). 'Characterization and carbon mineralization of biochars produced from different animal manures and plant residues', Scientific Reports, 10(1), pp. 1 -9.

Schoenholtz, S., Burger, J. \& Kreh, R. (1992). 'Fertilizer and organic amendment effects on mine soil properties and revegetation success'. Soil Science Society of America, 56(4), pp. 1177 - 1184.

Schofield, K. H., Pettitt, T., Tappin, A, D., Rollinson, G. K. \& Fitzsimons, M. (2017). "Does carbon limitation reduce nitrogen retention in soil?', Nature, 16 (2), pp. 623 630.

Setton, Bernier, P. \& Lefrant, S. (2002). 'Structure, texture, and thermal behaviour of polyaromatic solids', in Carbon Molecules and Materials. CRC Press, Boca Raton.

Shaaban, M., Van Zweiten, L., Bashir, S., Younas, A., Nunez-Delgado, A., Chajro, M., Kubar, K., Ali, U., Rana, M., Mehmood, M. \& Hu, R. (2018). 'A concise review of biochar application to agricultural soils to improve soil conditions and fight pollution', Journal of Environmental Management, 228(15), pp. 429 - 440.

Shanmugasundaram, R.m Jeyalaksmi, T., Mohan, S., Saravanan, M., Goparaju, A. \& Murthy, B. (2014). 'Coco peat - An alternative artificial soil ingredient for the earthworm toxicity testing', 6(1), pp. 5-12.

Sharma, S. \& Pathak, H. (2014). 'Basic techniques of phytoremediation', International Journal of Scientific \& Engineering Research, 5(4), pp. $584-605$.

Shen, Z., Som, A., Wang, F., Jin, F., McMillan, O. Al-Tabba, A. (2016). 'Long-term impact of biochar on the immobilisation of nickel (II) and zinc (II) and the revegetation of a contaminated site', Science of the Total Environment., 542, pp. $771-776$.

Shen, Z., Zhang, Y., McMillan, O. \& Al-Tabbaa, A. (2017). 'Qualitative and quantitative characterisation of adsorption mechanisms of lead on four biochars', Science of the Total Environment, 609, pp. 1401 - 1410.

Sheoran, A. \& Poonia, P. (2010). 'Documenting the cutting edge of environmental stewardship.', International Journal of Soil, Sediment and Water, 3(2), pp. 20 - 26.

Sierra, C. A., Del Valle, J. I. \& Orrego, S. A. (2003). 'Accounting for fine root mass sample losses in the washing process: A case study from a tropical montane forest of Colombia', Journal of Tropical Ecology, 19(05), pp. 599 - 601.

Simcock, R. \& Ross, C. (2014). 'Guidelines for mine reclamation in Westland'. Lincoln.

Simcock, R. \& Ross, C. (2018). 'Mine rehabilitation in New Zealand: Overiew and case studies', in Bolan, N., Kirkham, M. \& Ok, Y. (eds.) Spoil to soil: Mine site rehabilitation and revegetation. CRC Press, Boca Raton, pp. 335 - 363.

Simcock, R., Ross, G. (2014). 'Guidelines for mine rehabilitation in Westland Envirolink Advice Grant: 937 - WCRC83', Environlink, Auckland, p. 84.

Simon, L. (2005). 'Stabilization of metals in acidic mine spoil with amendments and red fescue (Festuca rubra L.) growth', Environmental Geochemistry and Health, 27(4), pp. $289-300$. 
Slingerland, N.\& Beier, N. (2018). 'Geomorphic analysis for tailings dam design in consideration of a 1000-year closure design life', Procedings of The $2^{\text {nd }}$ International Congress on Planning for Closure of Mining Operations, November, Alberta, pp. 1 9.

Smetanová, A., Dotterweich, A., Diehl, M., Dorte, D., Uta, U. \& Fohrer, D. (2013). 'Influence of biochar and terra preta substrates on wettability and erodibility of soils', Zeitschrift für Geomorphologie, 57(1), pp. 111 - 134.

Smirnova, S. V., Samarina, T., Ilin, D. \& Pletnev, I. (2018). 'Multielement determination of trace heavy metals in water by microwave-induced plasma atomic emission spectrometry after extraction in unconventional single-salt aqueous biphasic system', Analytical Chemistry, 90(10), pp. 6323 - 6331.

Smith, K., Grylls, J., Metacalf, P., Jeffrey, B. \& Sinclair, A. (2007). 'Nutrient value of digestate from farm-based biogas plants in Scotland. Report for Scottish Executive Environment and Rural Affairs Department-ADA/009/06', p. 44. Available at: http://www.gov.scot/resource/doc/1057/0053041.pdf (Accessed: 16 August 2018).

Smith, R. A. H. \& Bradshaw, A. D. (2006). 'The use of metal tolerant plant populations for the reclamation of metalliferous wastes', The Journal of Applied Ecology, 16(2), p. 595.

British Geological Survey (2012). 'User guide for the BGS soil chemistry data for environmental assessments', British Geological Survey, p. 41.

Sogbedji, J. M., van Es, H., Yang, C., Geohring, L. \& Magdoff, F. (2000). 'Nitrate leaching and nitrogen budget as affected by maize nitrogen rate and soil type', Journal of Environmental Quality, 29(6), pp. 1813 - 1820.

Soupir, M. L., Mostaghimi, S., Masters, A. Flahive, K., Vaughan, D., Mendez, A. \& McClellan, P. (2004). 'Effectiveness of polyacrylamide (PAM) in improving runoff water quality from construction sites', Journal of the American Water Resources Association, 40(1), pp. $53-66$.

Van Staden, J. K. F. (2015). 'Analytical continuous flow systems, where two worlds collide, Revue Roumaine de Chimie, 60(5-6), pp. 403 - 414.

Stahl, J. D., Cameron, M., Haslebach, J. Aust, S. (2000). 'Biodegradation of superabsorbent polymers in soil', Environmental Science and Pollution Research, 7(2), pp. $83-88$.

Standing Committe of Analysist (2011). Book 93, Environmental policy and law. Environment Agency, Newbury.

Steiner, C., Glaser, B., Teixera, W., Lehmann, J., Blum, W. \& Zech, W. (2008). 'Nitrogen retention and plant uptake on a highly weathered central Amazonian ferralsol amended with compost and charcoal', Journal of Plant Nutrition and Soil Science, 171(6), pp. $893-899$.

Stenberg, M., Aronsson, H., Linden, B., Rydberg, T. \& Gustafson, A. (1999). 'Soil mineral nitrogen and nitrate leaching losses in soil tillage systems combined with a catch crop', Soil and Tillage Research, 50(2), pp. 115 - 125.

Suliman, W., Harsh, J., Abu-Lail, N., Fortuna, A., Dallmeyer, I., Garcia-Perez, M. (2016). 'Influence of feedstock source and pyrolysis temperature on biochar bulk and 
surface properties', Biomass and Bioenergy, 84, pp. 37 - 48 .

Sun, Y., Gao, B., Yao, Y., Fang, J., Zhang, M., Zhou, Y., Chen, H. \& Yang, L. (2014). 'Effects of feedstock type, production method, and pyrolysis temperature on biochar and hydrochar properties', Chemical Engineering Journal, 240, pp. 574 - 578.

Surriya, O. (2015). 'Soil flushing', in Hakeem, K, Öztürk, M. Sabir, M. \& Mermut, M. (eds.) Soil Remediation and Plants. Elsevier, Amsterdam, pp. 37 - 61.

Sweeney, P., Danneberger, K., Wang, D. \& McBride, M. (2001). 'Root weight, nonstructural carbohydrate content, and shoot density of high-density creeping bentgrass cultivars', Horticultural Science, 36(2), pp. $368-370$.

Syers, J. K., Johnston, A. E. \& Curtin, D. (2008). Efficiency of soil and fertilizer phosphorus use. Reconciling changing concepts of soil phosphorus behaviour with agronomic information. Fertilizer and Plant Nutrition Bulletin 18. Available at: http://www.fao.org/3/a-a1595e.pdf (Accessed: 13 February 2020).

Tallec, T., Diquelou, C., Fauveau, M., Battailee, P, \& Ourrey, A. (2008.) 'Effects of nitrogen and sulphur gradients on plant competition, $\mathrm{N}$ and $\mathrm{S}$ use efficiencies and species abundance in a grassland plant mixture', Plant and Soil, 313(1), pp. $267-282$.

Tang, J., Zhu, W., Kookana, R. \& Katayama, A. (2013). 'Characteristics of biochar and its application in remediation of contaminated soil.', Journal of bioscience and bioengineering, 116(6), pp. $653-9$.

ten Berge, H. F. M., van der Meer, H.G., Steenhuizen, J.W., Goedhart, P.W., Knops, P. \& Verhagen, J. (2012). 'Olivine weathering in soil, and its effects on growth and nutrient uptake in ryegrass (Lolium perenne L.): A pot experiment', Public Library of Science, $7(8)$, pp. $1-8$.

Wu, C., Tsai, H., Yang, K. \& Wen, J. (2012). 'How reliable is X-ray fluorescence (XRF) measurement for different metals in soil contamination?', Environmental Forensics, 13(2), pp. $37-41$.

Tensar (2012). Hydra CX material and performance specification. Blackburn.

Thombare, N., Jha, U., Mishra, S. \& Siddiqui, M.Z. (2016). 'Guar gum as a promising starting material for diverse applications: A review', International Journal of Biological Macromolecules, 88, pp. 361 - 372.

Thombare, N., Jha, U., Mishra, S. \& Siddiqui, M. Z. (2016). 'Guar gum as a promising starting material for diverse applications: A review', International Journal of Biological Macromolecules, 88, pp. 361 - 372.

Thompson, J.\& Proctor, J. (1983). 'Vegetation and soil factors on a heavy-metal mine spoil heap', New Phytologist, 94(2), pp. 297 - 308.

Toé Casagrande, M. D., Coop, M. R. \& Consoli, N. C. (2006). 'Behavior of a fiberreinforced bentonite at large shear displacements', Journal of Geotechnical and Geoenvironmental Engineering, 132(11), pp. 1505 - 1508.

Tordoff, G., Baker, A. J. \& Willis, A. (2000). 'Current approaches to the revegetation and reclamation of metalliferous mine wastes', Chemosphere, 41(1-2), pp. $219-228$.

Touceda-González, M., Alvarez-Lopez, V., Fernandez, A., Rodriguez-Garriso, P., 
Trasar-Crepeda, C., Mench, M., Puschenreiter, M., Quintela-Sabaris, C., MaciasGarcia, F. \& Kidd, P. (2017). 'Aided phytostabilisation reduces metal toxicity, improves soil fertility and enhances microbial activity in Cu-rich mine tailings', Journal of Environmental Management, 186, pp. 301 - 313.

Tsegaye, T., Johnson, A., Mersie, W. \& Golson, K. (2007). 'Transport of atrazine through soil columns with or without switchgrass roots', Journal of Food, Agriculture and Environment, 5(2), pp. $345-350$.

Turner, R. G. \& Marshall, C. (1972). 'The accumulation of zinc subcellular fractions of roots of Agrostis Tenuis Sibth. in relation to zinc tolerance', New Phytologist, 71(4), pp. $671-676$.

United States Department of Agriculture (2019). 'New World Mining District Response and Restoration Project'. Office of Solid Waste and Emergency Response, Washington.

United States Environmental Protection Agency (1983). 'Reclamation of metal and mining contaminated superfund sites using sewage sludgelfly ash amendment'. Available at:

https://cfpub.epa.gov/ncer_abstracts/index.cfm/fuseaction/display.abstractDetail/abst ract/5246 (Accessed: 12 June 2019).

United States Environmental Protecton Agency (2012). 'A citizen's guide to solidification and stabilisation'. Office of Solid Waste and Emergency Response, Washington.

Vanchipura, R. \& Jiji, K. S. (2018). 'Civil engineering advancements for sustainable infrastructure development and environment', in The International Conference in Emerging Trends in Engineering, Science and Technology, $18^{\text {th }}-20^{\text {th }}$ January, Kerala.

Varun, M., Souza, R., Kumar, D. \& Paul, M. (2011). 'Bioassay as monitoring system for lead phytoremediation through Crinum asiaticum L.', Environmental Monitoring and Assessment, 178(1-4), pp. 373 - 381.

Venkateswarlu, K., Nirola, R., Kuppusamy, S., Thavamani, P., Naidu, R. \& Megharaj, M. (2016). 'Abandoned metalliferous mines: Ecological impacts and potential approaches for reclamation', Reviews in Environmental Science and Biotechnology, 15(2), pp. $327-354$.

de Villiers, O. (1961) 'Soil rejuvenation with crushed basalt in Mauritius', International Sugar Journal, 63, pp. 363 - 364.

Wagner, W., Herbst, D., \& Sohmer, S. (1999). Manual of the flowering plants of Hawaii. Revised edition. Honolulu, Hawaii, USA: University of Hawaii Press/Bishop Museum Press.

Wainwright, S. J. \& Woolhouse, H. W. (1977). 'Some physiological aspects of copper and zinc tolerance in Agrostis tenuis sibth.: Cell elongation and membrane damage', Journal of Experimental Botany, 28(4), pp. 1029 - 1036.

Wang, Q., Ellis, P. \& Ross-Murphy, S. (2000). 'The stability of guar gum in an aqueous system under acidic conditions', Food Hydrocolloids, 14(2), pp. 129 - 134.

Wang, W. \& Wang, A. (2009). 'Synthesis, swelling behaviors, and slow-release characteristics of a guar gum-poly (sodium acrylate)/sodium humate superabsorbent', 
Journal of Applied Polymer Science, 112(4), pp. 2102 - 2111.

Washington State Department of Transport (2019). 'Materials laboratory qualified products list'. Department of Transport, Olympia.

Watson, C., Singh, Y., Iqbal, T., Knoblauch, C., Simon, P. \& Wichern, F. (2016). 'Short-term effects of polyacrylamide and dicyandiamide on $\mathrm{C}$ and $\mathrm{N}$ mineralization in a sandy loam soil', Soil Use and Management, 32(1), pp. 127 - 136.

Wen, Q., Chen, Z., Zhao, Y. \& Feng, Y. (2010). 'Biodegradation of polyacrylamide by bacteria isolated from activated sludge and oil-contaminated soil', Journal of Hazardous Materials, 175(1-3), pp. 955 - 959.

Wieder, W. L. \& Shoop, S. A. (2017). 'Vegetation impact on soil strength a state of the knowledge review cold regions research and engineering laboratory', US Army Corps of Engineers, U.S. Army Engineer Research and Development Centre, Hanover.

Wijesekara, H., Bolan N., Kumarathilaka, P. \& Vinthanage, M. (2016). 'Biosolids enhance mine site rehabilitation and revegetation', Environmental Materials and Waste: Resource Recovery and Pollution Prevention, 138, pp. 45 - 71.

Wisconsin Department of Transport (2014). 'Erosion control and storm water product acceptability lists', Department of Transport, Madison. Available at: https://wisconsindot.gov/Documents/doing-bus/eng-consultants/cnsltrsrces/tools/pal/pal-7-14.pdf (Accessed: 19 December 2018).

Williams, M. (2017). Email from Morgan Williams, 27th July. Hope Silver Mine before (July 2010) and after (August 2011) hydroseeding silver mine tailings with a biochar compost, photograph. $27^{\text {th }}$ July 2017.

Williamson, L. C., Ribrioux, S., Fitter, A. \& Leyser, H. (2001). 'Phosphate availability regulates root system architecture in Arabidopsis 1', Plant physiology, 126, pp. $126-$ 128.

Willscher, S., Hertwig, T., Fernzel, M., Felix, M. \& Starke, S. (2010). 'Results of remediation of hard coal overburden and tailing dumps after a few decades: Insights and conclusions', Hydrometallurgy, 104(3-4), pp. $506-517$.

Wilson, J.B \& Rapson, G. L. (1995). 'The genetics of naturalization: a comparison of morphological variation within and between populations of Agrostis capillaris L. as an exotic in New Zealand and as a native in Britain'. New Zealand Journal of Ecology, 19(2), pp. 195 - 202.

Wisnubroto, E. I., Hedley, M., \& Hina, K. (2010). 'The use of biochar from biosolids on waitarere sandy soils: Effect on the growth of rye grass.', in New Zealand Biochar Research Centre Biochar Workshops, July 2010, Palmerston North.

Wong, J. W. C. (1995). 'The production of artificial soil mix from coal fly ash and sewage sludge'. Environmental Technology, 16(8), pp.741-751.

Wong, M. H. (1982). 'Metal cotolerance to copper, lead, and zinc in Festuca rubra', Environmental Research, 29(1), pp. 42 - 47.

Wu, L. \& Antonovics, J. (1975). 'Zinc and copper uptake by Agrostis stolonifera, tolerant to both zinc and copper', New Phytologist, 75, pp. $231-237$. 
World Wildlife Fund (2015). 'Safeguarding understanding natural value, Aviva Investors and Investec annual review 2015'. Available at https://www.wwf.org.uk/sites/default/files/201501/wwf_nwh_investor_report_a4_we b_v2_1.pdf (Accessed: $7^{\text {th }}$ December 2018).

World Weather Online $\left(2018^{1}\right)$. Rhandirmwyn historical weather. Available at: https://www.worldweatheronline.com/rhandirmwyn-weather-history/carmarthenshire /gb.aspx (Accessed: $3^{\text {rd }}$ January 2018).

World Weather Online $\left(2018^{2}\right)$. Rhandirmwyn weather forecast. Available at: https://www.worldweatheronline.com/rhandirmwyn-weather/carmarthenshire/gb. aspx (Accessed: $3^{\text {rd }}$ January 2018).

World Weather Online (2019). Rhandirmwyn weather forecast. Available at: https://www.worldweatheronline.com/rhandirmwyn-weather/carmarthenshire/gb. aspx (Accessed: $1^{\text {st }}$ January 2019).

Xiang, J., Haden, V. R., Peng, S., Bouman, B., Visperas, R., Nie, L., Hunag, J. \& Cui, K. (2009). ' Improvement in nitrogen availability, nitrogen uptake and growth of aerobic rice following soil acidification', Soil Science and Plant Nutrition, 55(5), 705 $-714$.

Xiong, B., Dettam Loss, R., Sheilds, D., Pawlik, T., Hochreiter, R., Zydney, A. \& Kumar, M. (2018). 'Polyacrylamide degradation and its implications in environmental systems', Clean Water, 1(1), pp. 17.

Xu, Z. Z. \& Zhou, G. S. (2006). 'Combined effects of water stress and high temperature on photosynthesis, nitrogen metabolism and lipid peroxidation of a perennial grass Leymus chinensis', Planta, 224(5), pp. 1080 - 1090.

Yang, X., Liu, J., McGrowther, K., Huang, H., Lu, K., Guo, X., He, L., Lin, X., Che, L., Ye, Z. \& Wang, H. (2016). 'Effect of biochar on the extractability of heavy metals $(\mathrm{Cd}, \mathrm{Cu}, \mathrm{Pb}$, and $\mathrm{Zn})$ and enzyme activity in soil', Environmental Science and Pollution Research, 23(2), pp. 974 - 984.

Yao, Y., Gao, B., Zhang, M., Inyang, M. \& Zimmerman, A. (2012). 'Effect of biochar amendment on sorption and leaching of nitrate, ammonium, and phosphate in a sandy soil', Chemosphere, 89(11), pp. 1467 - 1471.

Yargicoglu, E. N., Sadasivam, B., Reddy, K. \& Spokas, K. (2015). 'Physical and chemical characterization of waste wood derived biochars', Waste Management, 36, pp. $256-268$.

Yong, S. \& Abdul-Talib, S. (2018). 'Case studies of successful mine site rehabilitation: Malaysia', in Bolan, N., Kirkham, M. \& Ok, Y. (eds.) Spoil to soil: Mine site rehabilitation and revegetation. CRC Press, Boca Raton, pp. 309 - 335.

Zanuzzi, A., Arocena, J., van Mourik, J. \& Cano, A. (2009). 'Amendments with organic and industrial wastes stimulate soil formation in mine tailings as revealed by micromorphology', Geoderma, 154(1), pp. 1016 - 1035.

Zhang, F., Kang, S., Zhang, J \& Li, F. (2004). 'Nitrogen fertilization on uptake of soil inorganic phosphorus fractions in the wheat root zone', Soil Science Society of America Journal, 68(6), pp. 1890 - 1895.

Zhang, J., Zhao, W., Zhang, H., Wang, Z., Fan, C. \& Zang, L. (2018). 'Recent 
achievements in enhancing anaerobic digestion with carbon-based functional materials', Bioresource Technology, 266, pp. 555 - 567.

Zhang, X., Shao, L., Sun, H. \& Wang, Y. (2012). 'Incorporation of soil bulk density in simulating root distribution of winter wheat and maize in two contrasting soils', Soil Science Society of America Journal, 76(2), p. 638. 


\section{Appendix 1: CEC}

The cation exchange capacity of the biochar was determined by Dr. Phillip Harries using a method determined by Hendershot et al. (2006).

Using a pestle and mortar, two grams of biochar were ground to $<2 \mathrm{~mm}$ and dried in a Swallow OP Series large capacity oven for 24 hours at $105{ }^{\circ} \mathrm{C}$. The biochar was placed in a glass container, and $40 \mathrm{ml}$ of analytical grade $\mathrm{NH}_{4} \mathrm{Ac}$ (ammonium acetate) was added.

A lid was fitted to the sample container, and the container was placed on a Unitwist orbital shaker and shaken for five minutes at $115 \mathrm{rpm}$ (revolutions per minute). After the container stood for 24 hours, it was shaken again for 15 minutes. The solution was transferred to a glass Büchner funnel lined with a Whatman No. 42 ashless filter paper. The funnel was placed over a $500 \mathrm{ml}$ glass Büchner filter flask.

A partial vacuum was applied and four washes of $30 \mathrm{ml} \mathrm{NH}_{4} \mathrm{Ac}$ were conducted under vacuum. The sample was washed a further three times, each with $40 \mathrm{ml}$ isopropanol under partial vacuum. The Büchner filter flask was washed and rinsed with deionised water. The funnel which contained the sample was placed again on the cleaned filter flask and washed again four times with $\mathrm{KCI}$ (potassium chloride) to enable the $\mathrm{K}^{+}$ions to displace the $\mathrm{NH}_{4}^{+}$ions from the sample receptor sites. The leachate was transferred to a $250 \mathrm{ml}$ glass volumetric flask and made up to the required volume with deionised water.

To quantify the concentration of $\mathrm{NH}_{4}{ }^{+}$in the solution, the leachate was analysed using the Berthelot reaction in a continuous flow analyser. Three replicates of each sample were analysed, and a median was taken. The impurities within the water were assessed by the production of one blank sample per run. The CEC was calculated using the following formula from Hendershot et al. (2006): 


$$
\mathrm{CEC}\left(\mathrm{cmol}(+) \mathrm{kg}^{-1}\right)=(\mathrm{N}-\text { blank }) \times \mathrm{D}_{\mathrm{f}} \times 0.1 \times\left(\frac{0.25}{M S}\right)
$$

Where $\mathrm{N}=$ concentration of $\mathrm{NH}_{4}{ }^{+}$in sample $\left(\mu\right.$ mol.L-1), blank = concentration of $\mathrm{NH}_{4}{ }^{+}$ in the blank sample $(\mu$ mol.L-1), Df $=$ the dilution factor of the analysed sample, and Ms $=$ the mass of the biochar sample. 


\section{Appendix 2: Rainfall pilot trials}

\subsection{Pilot trial}

A pilot trial was conducted to inform the rainsplash trial.

The product specifications recommended the application rate of $0.67-2.47 \%(\mathrm{v} / \mathrm{v})$ guar gum per treatment plot. However, the material with $1 \%$ guar gum did not successfully adhere to the boards throughout the drying period (Figure A1). The volume of guar gum was increased to $4 \%(\mathrm{v} / \mathrm{v})$ before adhesion was observed.

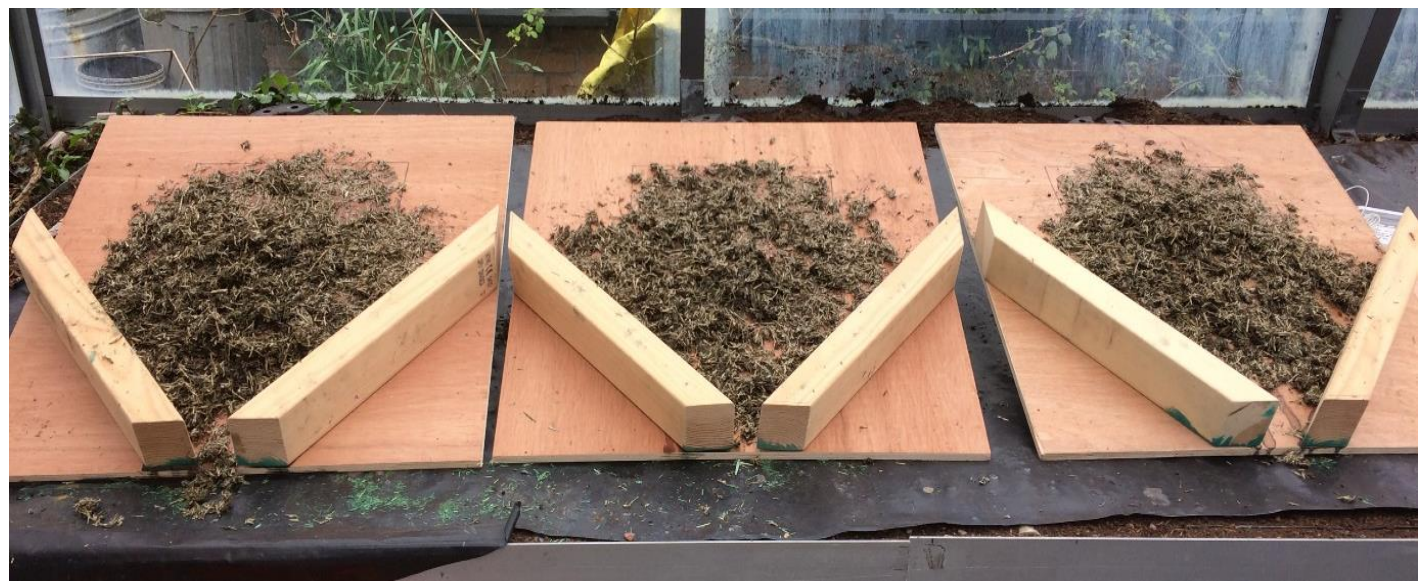

Figure A1: $1 \%(\mathrm{v} / \mathrm{v})$ guar gum in $1000 \mathrm{ml}$ of soil material on a wooden board at $20^{\circ}$

A $3 \mathrm{~cm}$ soil cover with $4 \%$ (v/v) guar gum was applied to the boards. For a $3 \mathrm{~cm}$ depth, $1000 \mathrm{ml}$ of dry soil material was required. A water:dry material ratio of 2:1 was necessary for sufficient homogenisation of the materials.

Throughout the drying period the soil material suffered a translational slump (Figure A2), an erosional process associated with thorough wetting (Shanmugum, 2018). The addition of water increased the self-mass of the material and provided a lubricant for particle displacement. Slumping often occurs when a permeable layer overrides an impermeable planar surface (Shanmugum, 2018). In this treatment, the detached material deformed as it moved down the slope. 


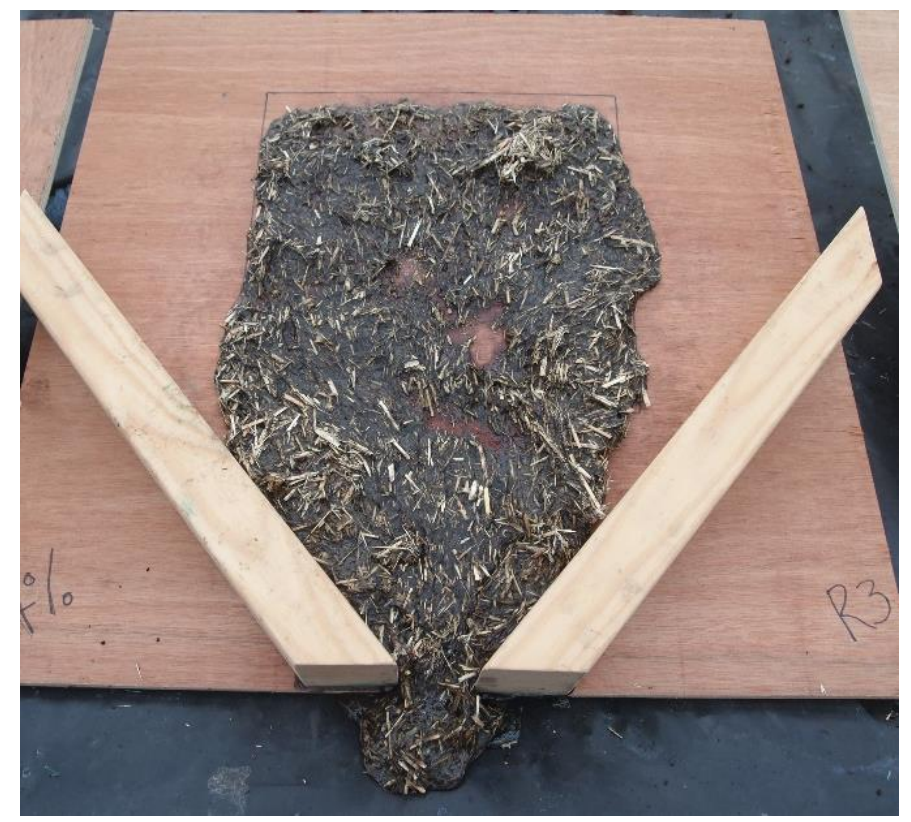

Figure A2: Translational slumping of the surrogate soil material (with $4 \%$ guar gum) on a wooden board at $20^{\circ}$

To ensure that the slump failure was due to an increased self-mass and not due to an insufficient proportion of binding agent, an $8 \%(\mathrm{v} / \mathrm{v})$ guar gum soil was trialled. A similar slump was observed during the drying period. During the rainfall trial, $493.8 \mathrm{~g}$ of soil material was displaced and surface run-off was high.
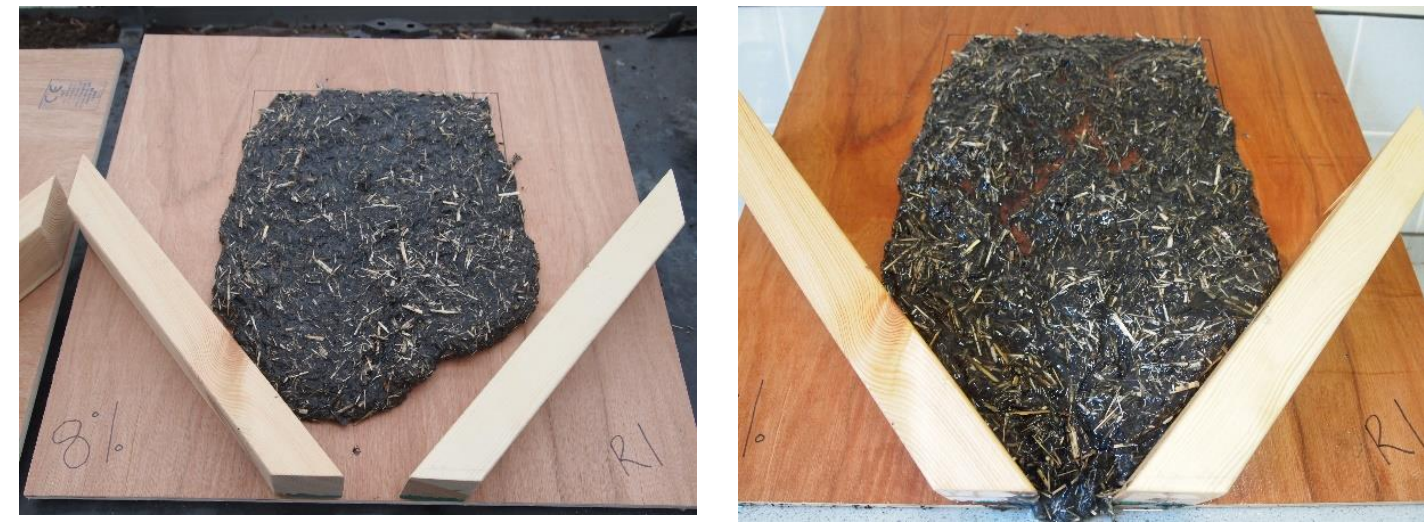

Figures A3 and A4: Slumping of a surrogate soil (1000 ml) with 8\% (v/v) guar gum, on a wooden board at $20^{\circ}$, before (left) and after(right) a one-hour rainfall simulation 
In order to reduce the water required for the homogenisation of the dry materials (and consequently reduce the self-mass of the material), the material was reduced in volume from $\sim 1000 \mathrm{ml}(\sim 3 \mathrm{~cm}$ thickness $)$ to $\sim 700 \mathrm{ml}(\sim 2 \mathrm{~cm}$ thickness $)$. The rainfall trials were conducted from then on using the reduced volume of soil materials.

\subsection{Rainfall simulation results}

Table A1: Data reported in Section 2.1: Aquaculture - The total organic nitrogen (TON), ammonium $\left(\mathrm{NH}_{4}{ }^{+}\right)$and phosphate $\left(\mathrm{PO}_{4}{ }^{3-}\right)(\mu \mathrm{mol} . \mathrm{L})$ in the leachate samples taken from the rainsplash trials. The percentages refer to the proportion of guar gum in the surrogate soil, and the preceding number refers to the replicate number. The sample standard deviation is indicated by "SD".

$$
\text { Guar gum (\%) TON } \quad \mathrm{NH}_{4}{ }^{+} \quad \mathrm{PO}_{4}{ }^{3-}
$$

\begin{tabular}{|c|c|c|c|}
\hline $4 \% 1$ & 76.0 & 42.4 & 41.9 \\
\hline $4 \% 2$ & 82.4 & 84.5 & 60.6 \\
\hline $4 \% 3$ & 79.1 & 34.8 & 34.2 \\
\hline mean & 79.1 & 53.9 & 45.5 \\
\hline SD & 6.0 & 26.8 & 13.6 \\
\hline $6 \% 1$ & 62.1 & 33.2 & 29.4 \\
\hline $6 \% 2$ & 57.0 & 59.0 & 3.5 \\
\hline $6 \% 3$ & 63.0 & 49.1 & 25.6 \\
\hline median & 62.1 & 47.1 & 19.5 \\
\hline SD & 5.0 & 13.0 & 13.9 \\
\hline $8 \% 1$ & 63.6 & 38.3 & 30.8 \\
\hline $8 \% 2$ & 62.0 & 53.5 & 24.4 \\
\hline $8 \% 3$ & 63.5 & 35.6 & 26.6 \\
\hline median & 63.5 & 42.5 & 27.3 \\
\hline SD & 3.0 & 9.6 & 3.3 \\
\hline $10 \% 1$ & 65.4 & 37.9 & 29.6 \\
\hline $10 \% 2$ & 67.3 & 38.2 & 31.2 \\
\hline $10 \% 3$ & 66.1 & 27.7 & 30.7 \\
\hline median & 66.1 & 34.6 & 30.5 \\
\hline SD & 11.0 & 6.0 & 0.8 \\
\hline $8 \% 2$ ST. & 69.6 & 70.7 & 26.7 \\
\hline
\end{tabular}




\begin{tabular}{l|rrr}
\hline 8\% 2S T. & 66.9 & 47.4 & 28.4 \\
\hline 8\% 2 ST. & 70.4 & 43.4 & 27.5 \\
median & 69.6 & 53.8 & 27.6 \\
SD & 8.0 & 14.8 & 0.9 \\
& & & \\
\hline 10\% 2 ST. & 71.7 & 109.2 & 23.0 \\
10\% 2 ST. & 71.3 & 114.7 & 25.3 \\
10\% 2 ST. & 69.8 & 152.1 & 25.9 \\
median & 71.3 & 38.0 & 25.3 \\
SD & 6.0 & 10.0 & 1.5
\end{tabular}

Table A2: Data reported in Section 2.2. The total eroded material $\left(g . m^{-2}\right)$ from each surrogate soil in the rainsplash trials. The percentages refer to the proportion of guar gum in the surrogate soil, and the preceding number refers to the replicate number. The sample standard deviation is indicated by "SD".

Guar gum (\%) Eroded material (g) $\quad$ g.m ${ }^{-2}$

Hydra CX
HCX. 2
HCX.3
Median
SD

$\begin{array}{rr}6.78 & 13.56 \\ 21.63 & 43.26 \\ 9.61 & 19.22 \\ 9.61 & 19.22 \\ 6.44 & 6.44\end{array}$

$4 \% 1$
$4 \% 2$
$4 \% 3$
median
SD

4.40

8.80

7.30

14.60

1.20

2.40

4.40

8.80

2.49

4.98

$6 \% 1$
$6 \% 2$
$6 \% 3$
median
SD

0.92

1.84

0.81

1.62

0.03

0.06

0.81

1.62

0.40

0.79

$8 \% 1$
$8 \% 2$
$8 \% 3$
median
SD

0.17

0.34

0.02

0.04

0.08

0.16

0.08

0.16

0.06

0.12 


\begin{tabular}{l}
$\begin{array}{l}10 \% 1 \\
10 \% 2 \\
10 \% 3 \\
\text { median } \\
\text { SD }\end{array}$ \\
\hline $8 \% 2$ ST. \\
$8 \% 2$ S T. \\
$8 \% 2$ ST. \\
Median \\
SD \\
\hline $10 \% 2$ ST. \\
$10 \% 2$ ST. \\
$10 \% 2$ ST. \\
median \\
SD
\end{tabular}

$\begin{array}{ll}0.05 & 0.10 \\ 0.00 & 0.00 \\ 0.00 & 0.00 \\ 0.02 & 0.04 \\ 0.03 & 0.06\end{array}$

$0.45 \quad 0.90$

$0.13 \quad 0.26$

$0.85 \quad 1.70$

$0.45 \quad 0.90$

$\begin{array}{ll}0.29 & 0.59\end{array}$

$\begin{array}{ll}0.12 & 0.24\end{array}$

$0.23 \quad 0.46$

$1.12 \quad 2.24$

$0.23 \quad 0.46$

$0.45 \quad 0.70$ 


\section{Appendix 3. Germination trial}

\subsection{Pilot germination trial}

A pilot germination trial was conducted from the $1^{\text {st }}-29$ th June 2018 . Both single-and two-stage approaches were tested (Tables A3 and A4).

Table A3: The components of the single-stage surrogate soil treatments (per pot) of the pilot germination trial

\begin{tabular}{lc|cc|cc|cccc|cr}
\hline \hline \multicolumn{2}{c|}{ Straw } & \multicolumn{2}{c|}{ Digestate } & \multicolumn{2}{c|}{ Biochar } & \multicolumn{2}{c|}{ Basalt } & \multicolumn{2}{c|}{ Guar gum } & \multicolumn{2}{c}{ Total } \\
$(\%)$ & $(\mathrm{ml})$ & $(\%)$ & $(\mathrm{ml})$ & $(\%)$ & $(\mathrm{ml})$ & $(\%)$ & $(\mathrm{ml})$ & $(\%)$ & $(\mathrm{ml})$ & $(\%)$ & $(\mathrm{ml})$ \\
\hline 64 & 15 & 28 & 7 & 0 & 0 & 0 & 0 & 8 & 2 & 100 & 25 \\
64 & 15 & 28 & 7 & 0 & 0 & 0 & 0 & 8 & 2 & 100 & 25 \\
64 & 15 & 28 & 7 & 0 & 0 & 0.5 & 0.13 & 8 & 2 & 100 & 25 \\
62 & 15 & 28 & 7 & 5 & 1.25 & 0 & 0 & 8 & 2 & 100 & 25 \\
61 & 15 & 28 & 7 & 5 & 1.25 & 0.5 & 0.13 & 8 & 2 & 100 & 25 \\
\hline & & & & & & & & & & & \\
63 & 15.8 & 27 & 6.8 & 0 & 0 & 0 & 0 & 10 & 2.5 & 100 & 25 \\
63 & 15.8 & 27 & 6.8 & 0 & 0 & 0.5 & 0.13 & 10 & 2.5 & 100 & 25 \\
61 & 15.8 & 24 & 6 & 5 & 1.25 & 0 & 0 & 10 & 2.5 & 100 & 25 \\
59 & 14.8 & 25 & 6.3 & 5 & 1.25 & 0.5 & 0.13 & 10 & 2.5 & 100 & 25 \\
\hline
\end{tabular}


Table A4: The components of the two-stage surrogate soil treatments (per pot) of the pilot germination trial

\begin{tabular}{|c|c|c|c|c|c|c|c|c|c|c|c|c|c|}
\hline \multicolumn{6}{|c|}{ Base layer } & \multicolumn{8}{|c|}{ Top layer } \\
\hline \multicolumn{2}{|c|}{ Coir } & \multicolumn{2}{|c|}{ Biochar } & \multicolumn{2}{|c|}{ Basalt } & \multicolumn{2}{|c|}{$\overline{\text { Straw }}$} & \multicolumn{2}{|c|}{ Digestate } & \multicolumn{2}{|c|}{ Guar gum } & \multicolumn{2}{|c|}{ Total } \\
\hline$(\%)$ & $(\mathrm{ml})$ & $(\%)$ & $(\mathrm{ml})$ & $(\%)$ & $(\mathrm{ml})$ & $(\%)$ & ml) & $(\%)$ & $(\mathrm{ml})$ & $(\%)$ & $(\mathrm{ml})$ & $(\%)$ & $(\mathrm{ml})$ \\
\hline 100 & 12.5 & 0 & 0 & 0 & 0 & 64 & 8 & 28 & 3.5 & 8 & 1 & 100 & 25 \\
\hline 100 & 12.5 & 0 & 0 & 0 & 0 & 64 & 8 & 28 & 3.5 & 8 & 1 & 100 & 25 \\
\hline 100 & 12.5 & 0 & 0 & 0.5 & 0.06 & 64 & 8 & 28 & 3.5 & 8 & 1 & 100 & 25 \\
\hline 100 & 12.5 & 5 & 0.63 & 0 & 0 & 64 & 8 & 28 & 3.5 & 8 & 1 & 100 & 25 \\
\hline 100 & 12.5 & 5 & 0.63 & 0.5 & 0.06 & 64 & 8 & 28 & 3.5 & 8 & 1 & 100 & 25 \\
\hline 100 & 12.5 & 0 & 0 & 0 & 0 & 64 & 8 & 28 & 3.5 & 10 & 1.3 & 100 & 25 \\
\hline 100 & 12.5 & 0 & 0 & 0.5 & 0.06 & 64 & 8 & 28 & 3.5 & 10 & 1.3 & 100 & 25 \\
\hline 100 & 12.5 & 5 & 0.63 & 0 & 0 & 64 & 8 & 28 & 3.5 & 10 & 1.3 & 100 & 25 \\
\hline 100 & 12.5 & 5 & 0.63 & 0.5 & 0.06 & 64 & 8 & 28 & 3.5 & 10 & 1.3 & 100 & 25 \\
\hline
\end{tabular}


Due to unusually hot and dry weather throughout the four-week trial (four days of rain in 42 , mean high temperature of $28^{\circ} \mathrm{C}$, mean low of $23^{\circ} \mathrm{C}$, Figure A5) the cool-season grasses suffered from heat stress. Seedling emergence began during week 2 in all treatments, however, by the third week there was a $100 \%$ loss of seedlings and the trial was ended prematurely (Figures A6 and A7).

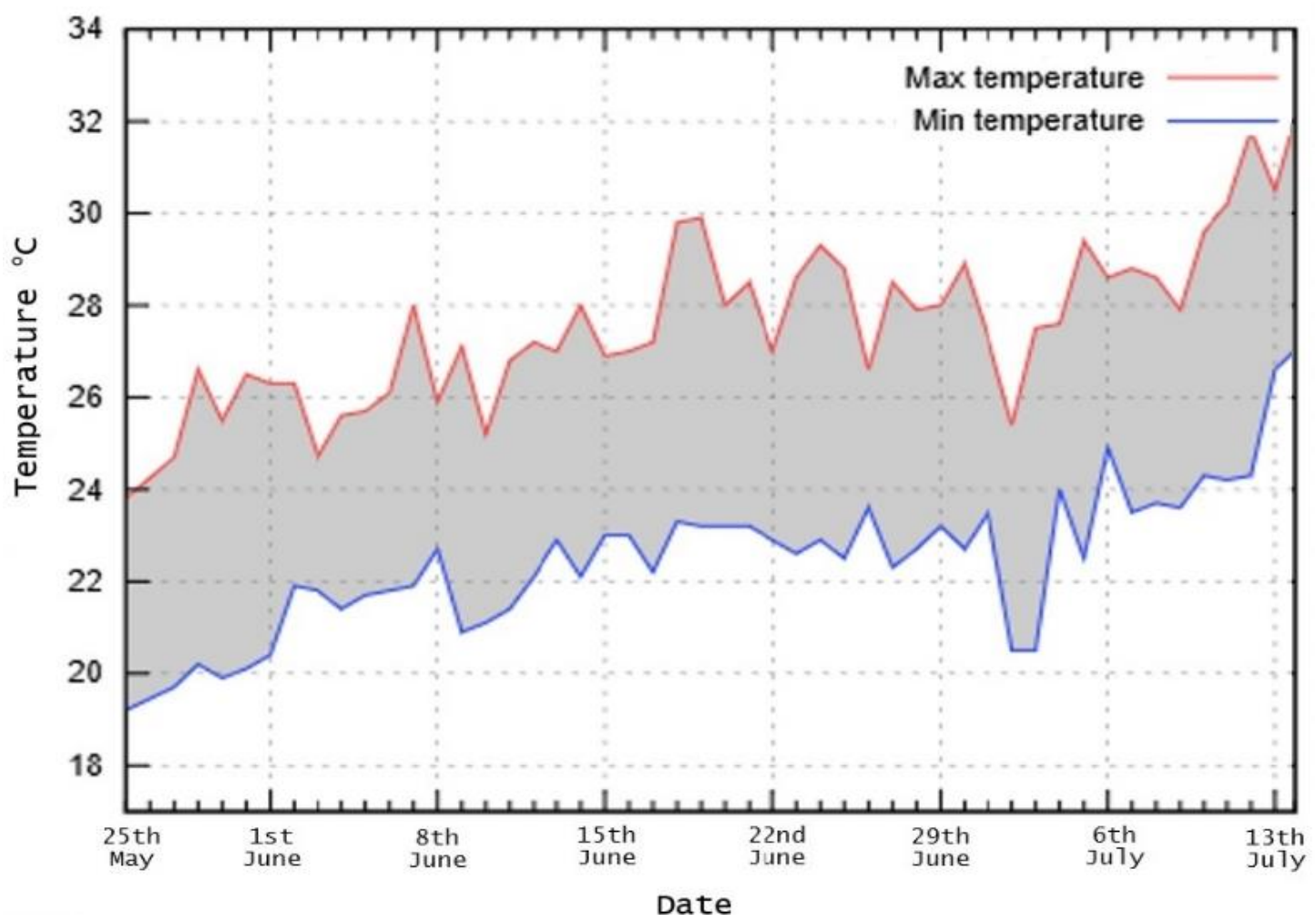

Figure A5: Maximum (red) and minimum (blue) daily temperatures throughout the four-week pilot trial (June to July 2018), as recorded by an in-site temperature logger

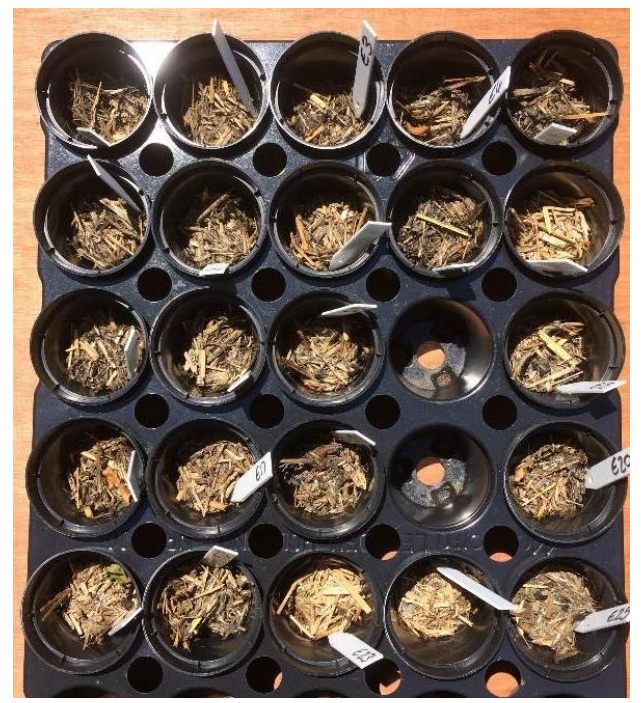

Figure A6: One soil treatment after three weeks of the pilot germination trial (July 2018) 


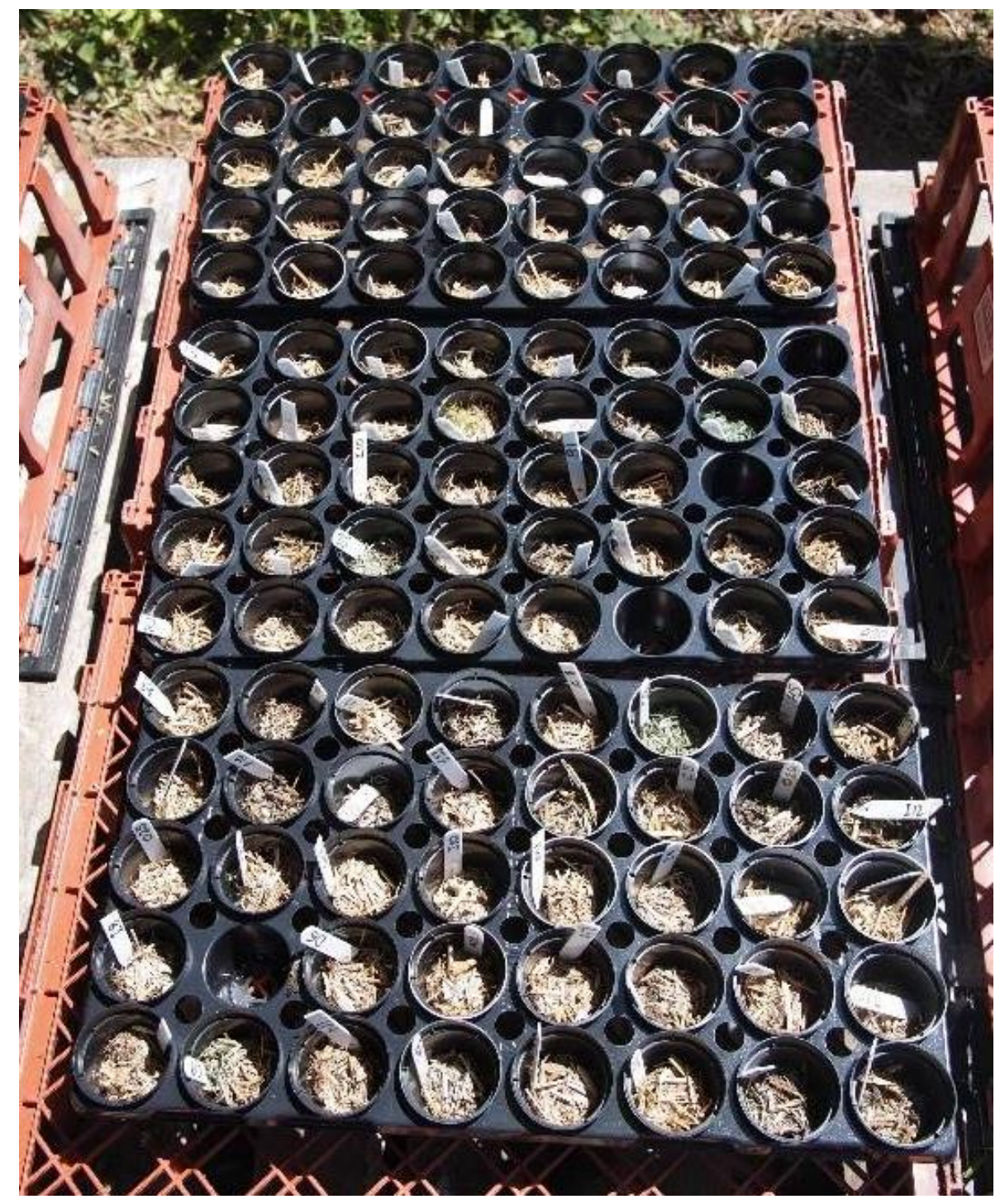

Figure A7: The surrogate soil pots of the germination trial, four weeks after application (July 2018).

As a result of the poor germination and survival rates in the pilot trial, the proportion of digestate was increased in all treatments to improve the water-holding capacity of the material. The watering schedule was also increased from a typical July rainfall event $(6 \mathrm{~mm})$ to a typical September rainfall event $(8 \mathrm{~mm})$ in accordance with the adjusted field-trial start date. Typical rainfall events were calculated from the longterm average $(1981-2010)$.

The second germination trial was conducted using the revised soil material components. 


\subsection{Data reported in Section 6.2}

Table A5: Data reported in Figure 6.13: The mean shoot length ( $\mathrm{mm}$ ) for the grass grown in each surrogate soil treatment in the germination trial (August 2019). For each surrogate soil, $n=25$.

\section{Week number}

\begin{tabular}{|lrrrrrr} 
& $\mathbf{1}$ & $\mathbf{2}$ & $\mathbf{3}$ & $\mathbf{4}$ & $\mathbf{5}$ & $\mathbf{6}$ \\
\hline Single-stage 8\% guar & & & & & & \\
\hline Unamended & 0.0 & 6.8 & 17.3 & 20.4 & 27.6 & 23.5 \\
Basalt & 3.3 & 10.1 & 15.6 & 19.0 & 24.2 & 30.5 \\
\hline Biochar & 4.1 & 12.4 & 20.4 & 24.6 & 30.2 & 32.4 \\
Biochar and basalt & 3.0 & 12.0 & 17.4 & 22.8 & 28.7 & 36.2 \\
\hline Single-stage 10\% guar & & & & & & \\
\hline Unamended & 0.0 & 6.0 & 13.9 & 22.6 & 26.2 & 31.4 \\
Basalt & 0.0 & 0.1 & 12.5 & 26.7 & 30.8 & 34.5 \\
\hline Biochar & 0.0 & 0.0 & 16.1 & 23.9 & 29.3 & 36.1 \\
Biochar and basalt & 0.0 & 0.0 & 19.4 & 25.6 & 35.6 & 43.1 \\
& & & & & & \\
\hline Two-stage 8\% guar & & & & & & \\
\hline Unamended & 3.1 & 11.9 & 20.1 & 25.5 & 32.7 & 40.7 \\
Basalt & 5.9 & 10.4 & 20.2 & 23.4 & 31.0 & 40.6 \\
\hline Biochar & 4.5 & 11.0 & 23.6 & 25.3 & 26.6 & 33.2 \\
\hline Biochar and basalt & 8.6 & 14.2 & 21.6 & 29.8 & 34.8 & 43.2 \\
\hline Two-stage 10\% guar & & & & & & \\
\hline Unamended & 5.2 & 16.8 & 19.7 & 29.4 & 31.1 & 38.9 \\
\hline Basalt & 9.5 & 21.2 & 21.8 & 31.3 & 31.6 & 41.1 \\
\hline Biochar & 7.6 & 13.7 & 22.7 & 27.7 & 31.9 & 36.8 \\
\hline Biochar and basalt & 8.5 & 13.8 & 23.6 & 35.8 & 41.4 & 44.2 \\
\hline Hydra CX & & & & & & \\
\hline & 4.0 & 11.5 & 23.6 & 26.5 & 28.2 & 31.0
\end{tabular}


Table A6: Data reported in Figure 6.14. The mean above-ground biomass $\left(g . \mathrm{m}^{-2}\right)$ for the grass grown in each surrogate soil treatment in the germination trial. For each surrogate soil, $n=25$.

\begin{tabular}{lcc} 
& Mean & $\mathbf{\pm}$ \\
Single-stage 8\% guar & & \\
\hline Unamended & 27.2 & 16.9 \\
Basalt & 83.3 & 40.0 \\
Biochar & 103.2 & 28.4 \\
Biochar and basalt & 65.6 & 25.9
\end{tabular}

Single-stage $10 \%$ guar

$\begin{array}{lll}\text { Unamended } & 45.8 & 29.0 \\ \text { Basalt } & 80.4 & 33.2 \\ \text { Biochar } & 71.2 & 28.2 \\ \text { Biochar and basalt } & 50.4 & 28.4\end{array}$

Two-stage 8\% guar

Unamended

55.2

18.4

Basalt

65.6

19.8

Biochar

$40.8 \quad 14.9$

Biochar and basalt

56.0

27.4

Two-stage $10 \%$ guar

\begin{tabular}{|c|c|}
\hline Unamended & 62.0 \\
\hline Basalt & 134.0 \\
\hline Biochar & 76.0 \\
\hline Biochar and basalt & 100.8 \\
\hline Hydra CX & 77.0 \\
\hline
\end{tabular}


Table A7: Data reported in Figure 6.15. The mean root biomass $\left(g . m^{-2}\right)$ for the grass grown in each surrogate soil treatment in the germination trial. For each surrogate soil, $n=25$.

$\begin{array}{lcc} & \text { Mean } & \mathbf{\pm} \\ \text { Single-stage 8\% guar } & & \\ \text { Unamended } & 15.21 & 4.75 \\ \text { Basalt } & 16.90 & 8.33 \\ \text { Biochar } & 18.95 & 4.78 \\ \text { Biochar and basalt } & 20.18 & 9.63\end{array}$

Single-stage $10 \%$ guar

Unamended

19.58

4.56

Basalt

27.89

3.81

Biochar

19.13

7.40

Biochar and basalt

24.11

7.30

Two-stage 8\% guar

Unamended

19.51

4.36

Basalt

27.55

3.19

Biochar

17.45

13.36

Biochar and basalt

29.34

8.35

Two-stage $10 \%$ guar

Unamended

22.06

4.88

Basalt

27.79

4.58

Biochar

23.55

6.73

Biochar and basalt

12.33

7.11

Hydra CX

19.08

5.08 


\section{Appendix 4: Field trial, Results -}

\section{September to December 2018}

\subsection{Data reported in Section 7.2}

Table A8: Data reported in Figure 7.11: The minimum and maximum daily temperatures $\left({ }^{\circ} \mathrm{C}\right)$ throughout the Nantymwyn field trial, weeks 1-17 (September to December 2018)

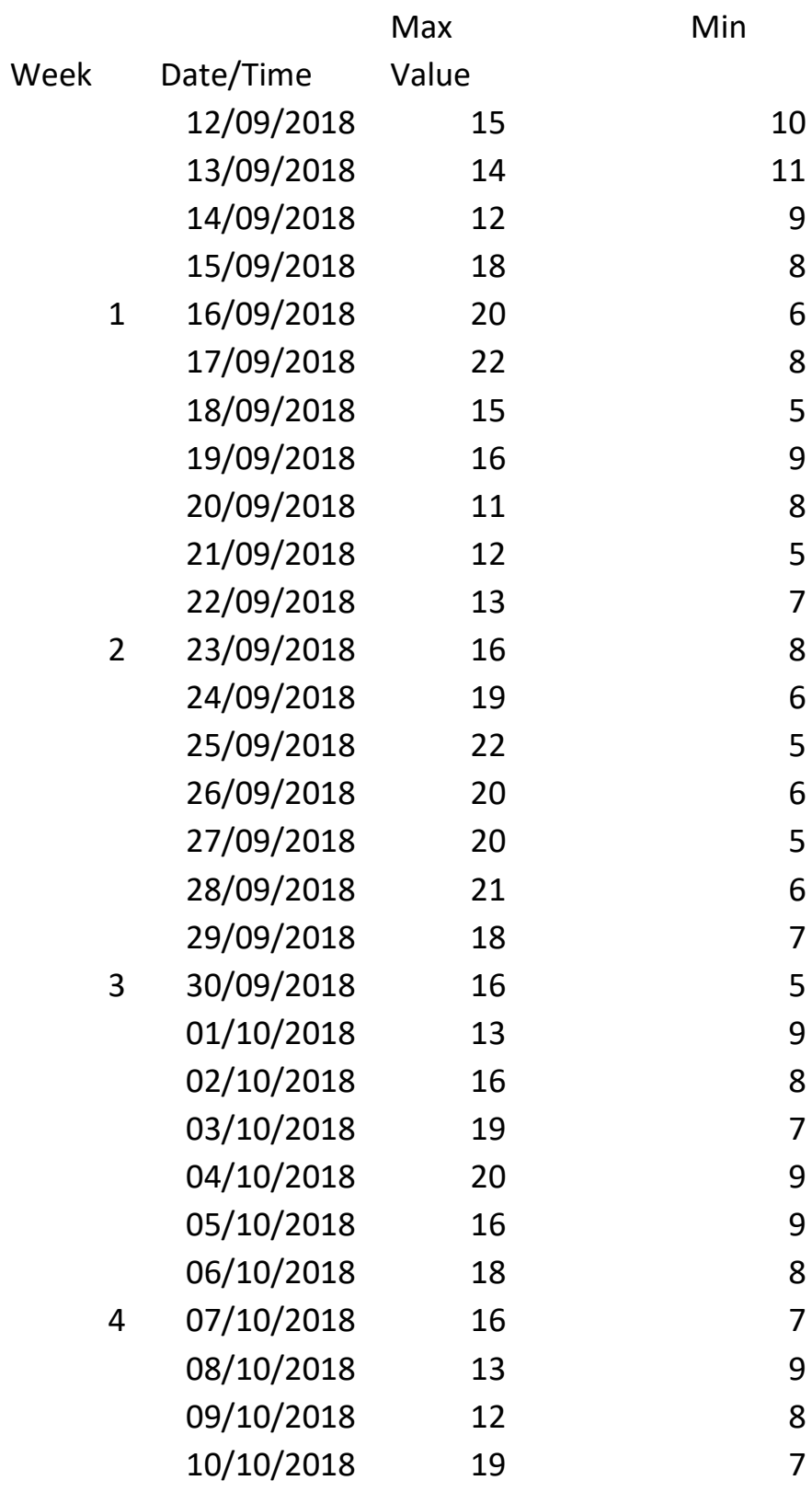




\begin{tabular}{|c|c|c|c|}
\hline & $11 / 10 / 2018$ & 18 & 6 \\
\hline & $12 / 10 / 2018$ & 21 & 9 \\
\hline & $13 / 10 / 2018$ & 20 & 6 \\
\hline \multirow[t]{7}{*}{5} & $14 / 10 / 2018$ & 20 & 8 \\
\hline & $15 / 10 / 2018$ & 17 & 7 \\
\hline & $16 / 10 / 2018$ & 22 & 11 \\
\hline & $17 / 10 / 2018$ & 18 & 14 \\
\hline & $18 / 10 / 2018$ & 18 & 12 \\
\hline & $19 / 10 / 2018$ & 17 & 11 \\
\hline & $20 / 10 / 2018$ & 17 & 14 \\
\hline \multirow[t]{7}{*}{6} & $21 / 10 / 2018$ & 18 & 12 \\
\hline & $22 / 10 / 2018$ & 19 & 10 \\
\hline & $23 / 10 / 2018$ & 15 & 9 \\
\hline & $24 / 10 / 2018$ & 14 & 8 \\
\hline & $25 / 10 / 2018$ & 16 & 8 \\
\hline & $26 / 10 / 2018$ & 12 & 7 \\
\hline & $27 / 10 / 2018$ & 12 & 4 \\
\hline \multirow[t]{7}{*}{7} & $28 / 10 / 2018$ & 10 & 3 \\
\hline & $29 / 10 / 2018$ & 9 & 2 \\
\hline & $30 / 10 / 2018$ & 10 & 3 \\
\hline & $31 / 10 / 2018$ & 9 & 2 \\
\hline & $01 / 11 / 2018$ & 11 & 3 \\
\hline & $02 / 11 / 2018$ & 10 & 0 \\
\hline & $03 / 11 / 2018$ & 12 & 2 \\
\hline \multirow[t]{7}{*}{8} & $04 / 11 / 2018$ & 13 & 2 \\
\hline & $05 / 11 / 2018$ & 13 & 0 \\
\hline & 06/11/2018 & 13 & 3 \\
\hline & $07 / 11 / 2018$ & 10 & 1 \\
\hline & $08 / 11 / 2018$ & 11 & 3 \\
\hline & 09/11/2018 & 10 & 0 \\
\hline & $10 / 11 / 2018$ & 12 & 2 \\
\hline \multirow[t]{7}{*}{9} & $11 / 11 / 2018$ & 14 & 2 \\
\hline & $12 / 11 / 2018$ & 7 & -3 \\
\hline & $13 / 11 / 2018$ & 7 & -2 \\
\hline & $14 / 11 / 2018$ & 6 & -4 \\
\hline & $15 / 11 / 2018$ & 5 & -5 \\
\hline & $16 / 11 / 2018$ & 8 & -2 \\
\hline & $17 / 11 / 2018$ & 9 & -1 \\
\hline \multirow[t]{7}{*}{10} & $18 / 11 / 2018$ & 9 & -3 \\
\hline & $19 / 11 / 2018$ & 8 & -2 \\
\hline & $20 / 11 / 2018$ & 4 & -5 \\
\hline & $21 / 11 / 2018$ & 3 & -5 \\
\hline & $22 / 11 / 2018$ & 3 & -6 \\
\hline & $23 / 11 / 2018$ & 6 & -3 \\
\hline & $24 / 11 / 2018$ & 8 & -1 \\
\hline 11 & $25 / 11 / 2018$ & 7 & -2 \\
\hline
\end{tabular}




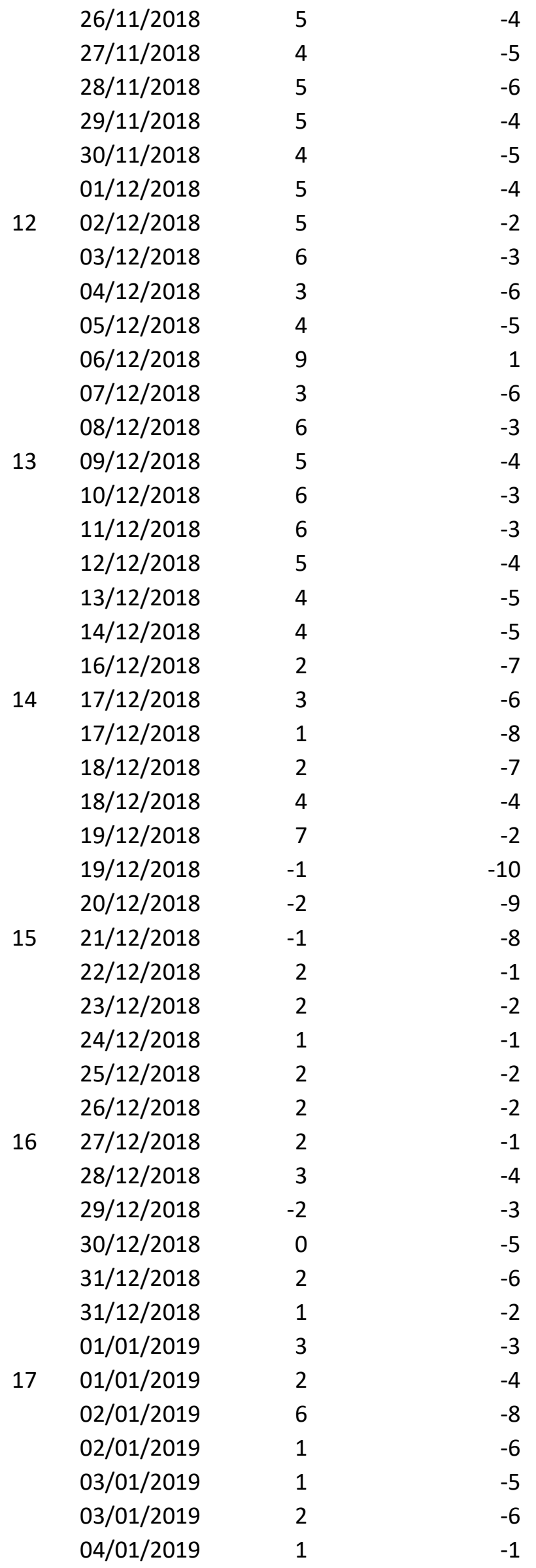


Table A9: Data reported in Section 7.2. The weekly mean shoot length $(\mathrm{mm})$ of each of the surrogate soil treatments at Nantymwyn, from week 2 to 14 , September to December 2018

\begin{tabular}{|c|c|c|c|c|c|c|c|c|c|c|}
\hline$\stackrel{\text { d }}{3}$ & 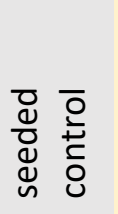 & 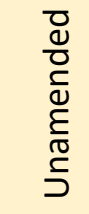 & $\begin{array}{l}\frac{1}{\pi} \\
\frac{5}{U} \\
\frac{0}{0}\end{array}$ & 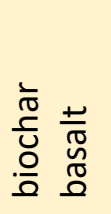 & 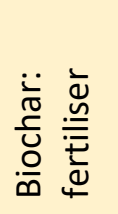 & 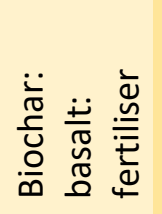 & $\begin{array}{l}\frac{1}{\pi} \\
0 \\
0 \\
0 \\
0\end{array}$ & & 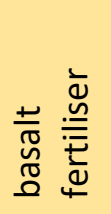 & $\begin{array}{l}x \\
0 \\
\frac{0}{0} \\
0 \\
\text { X }\end{array}$ \\
\hline 2 & 8.0 & 25.6 & 33.9 & 31.3 & 35.6 & 38.9 & 34.6 & 36.9 & 41.8 & 32.3 \\
\hline 3 & 13.3 & 38.9 & 42.0 & 40.4 & 52.9 & 53.6 & 42.4 & 53.2 & 59.7 & 40.6 \\
\hline 4 & 10.5 & 38.1 & 43.2 & 45.8 & 52.8 & 54.3 & 44.2 & 47.6 & 58.2 & 45.6 \\
\hline 5 & 8.4 & 37.0 & 43.6 & 49.6 & 52.9 & 56.5 & 47.1 & 47.9 & 56.1 & 42.5 \\
\hline 6 & 12.0 & 41.1 & 47.3 & 48.9 & 59.2 & 63.9 & 51.5 & 53.5 & 58.3 & 47.0 \\
\hline 7 & 11.0 & 42.0 & 48.5 & 49.0 & 67.0 & 73.0 & 53.0 & 60.0 & 66.0 & 45.0 \\
\hline 8 & 10.4 & 43.4 & 49.3 & 49.1 & 76.5 & 80.0 & 53.6 & 66.1 & 73.9 & 43.0 \\
\hline 9 & 10.1 & 39.6 & 42.7 & 47.4 & 70.2 & 80.1 & 53.6 & 64.9 & 82.2 & 41.4 \\
\hline 10 & 9.1 & 35.8 & 41.4 & 47.9 & 70.1 & 76.4 & 52.7 & 57.0 & 68.6 & 37.6 \\
\hline 11 & 11.1 & 38.2 & 46.1 & 47.9 & 66.4 & 72.0 & 47.9 & 57.5 & 68.9 & 29.0 \\
\hline 12 & 8.4 & 33.9 & 39.6 & 47.1 & 62.3 & 67.9 & 44.6 & 53.9 & 60.4 & 27.3 \\
\hline 13 & 7.4 & 32.9 & 37.9 & 46.4 & 63.6 & 67.9 & 40.8 & 52.9 & 57.9 & 27.9 \\
\hline 14 & 4.6 & 30.7 & 37.1 & 44.3 & 52.9 & 62.9 & 40.0 & 50.0 & 56.4 & 26.4 \\
\hline
\end{tabular}

Table A10: Data reported in Section 7.2. The quantity of biomass (g) produced by each replicate in each surrogate soil treatment at the end of week 14 (December 2018)

\begin{tabular}{|c|c|c|c|c|c|c|c|}
\hline $\begin{array}{l}\text { Seeded } \\
\text { tailings }\end{array}$ & 1.00 & 1.45 & 1.59 & 2.64 & 2.59 & 2.59 & 2.02 \\
\hline Hydra CX & 2.03 & 2.42 & 2.49 & 2.50 & 2.63 & 2.84 & 3.16 \\
\hline Unamended & 2.06 & 3.07 & 3.78 & 3.00 & 3.03 & 3.05 & 4.61 \\
\hline Basalt & 3.01 & 4.00 & 5.00 & 5.16 & 7.70 & 7.87 & 9.66 \\
\hline $\begin{array}{l}\text { Fertiliser } \\
\text { Basalt + } \\
\text { fertiliser }\end{array}$ & 4.02 & 4.03 & 5.86 & 6.98 & 6.57 & 8.00 & 9.12 \\
\hline $\begin{array}{l}\text { Biochar } \\
\text { Biochar + } \\
\text { basalt }\end{array}$ & $\begin{array}{l}4.46 \\
3.06\end{array}$ & $\begin{array}{l}4.90 \\
4.99\end{array}$ & $\begin{array}{l}4.99 \\
5.99\end{array}$ & 6.06 & $\begin{array}{l}5.85 \\
6.54\end{array}$ & 6.62 & $\begin{array}{l}8.65 \\
8.00\end{array}$ \\
\hline $\begin{array}{l}\text { Biochar }+ \\
\text { fertiliser } \\
\text { Biochar:basalt: } \\
\text { fertiliser }\end{array}$ & 4.46 & 5.03 & 5.04 & 7.07 & 8.25 & 9.00 & 9.12 \\
\hline
\end{tabular}




\section{Appendix 5: Field trial - Results, January to June 2019}

\subsection{Temperature data}

Table A11: Data reported in Section 8.2.1. Air temperature $\left({ }^{\circ} C\right)$ at the Nantymwyn field trial, from weeks 18 to 40, January to June 2019, as recorded by an in-situ data logger

\begin{tabular}{|c|c|c|c|}
\hline Week & Date & Minimum & Maximum \\
\hline \multirow[t]{7}{*}{18} & 05/01/2019 & 4 & 0 \\
\hline & 06/01/2019 & 3 & \\
\hline & 07/01/2019 & 4 & \\
\hline & 08/01/2019 & 4 & -1 \\
\hline & 09/01/2019 & 3 & \\
\hline & $10 / 01 / 2019$ & 4 & -1 \\
\hline & $11 / 01 / 2019$ & 5 & 0 \\
\hline \multirow[t]{7}{*}{19} & $12 / 01 / 2019$ & 3 & -1 \\
\hline & $13 / 01 / 2019$ & 6 & -2 \\
\hline & $14 / 01 / 2019$ & 5 & -2 \\
\hline & $15 / 01 / 2019$ & 5 & 1 \\
\hline & $16 / 01 / 2019$ & 4 & 0 \\
\hline & $17 / 01 / 2019$ & 2 & -2 \\
\hline & $18 / 01 / 2019$ & 5 & 0 \\
\hline \multirow[t]{7}{*}{20} & $19 / 01 / 2019$ & 5 & 1 \\
\hline & 20/01/2019 & 4 & -3 \\
\hline & $21 / 01 / 2019$ & 3 & -4 \\
\hline & $22 / 01 / 2019$ & 2 & -5 \\
\hline & 23/01/2019 & 2 & -4 \\
\hline & $24 / 01 / 2019$ & 8 & -5 \\
\hline & $25 / 01 / 2019$ & 8 & 0 \\
\hline \multirow[t]{8}{*}{21} & $26 / 01 / 2019$ & 5 & 1 \\
\hline & $27 / 01 / 2019$ & 6 & 0 \\
\hline & 28/01/2019 & 5 & 1 \\
\hline & 29/01/2019 & 7 & 2 \\
\hline & $30 / 01 / 2019$ & 5 & -1 \\
\hline & $31 / 01 / 2019$ & 6 & 3 \\
\hline & $01 / 02 / 2019$ & 4 & 0 \\
\hline & $02 / 02 / 2019$ & 3 & 1 \\
\hline \multirow[t]{6}{*}{22} & 03/02/2019 & 3 & -1 \\
\hline & $04 / 02 / 2019$ & 5 & -1 \\
\hline & 05/02/2019 & 2 & -2 \\
\hline & 06/02/2019 & 9 & 0 \\
\hline & 07/02/2019 & 11 & -1 \\
\hline & 08/02/2019 & 13 & 2 \\
\hline
\end{tabular}




\begin{tabular}{|c|c|c|c|}
\hline & 09/02/2019 & 10 & 2 \\
\hline & $10 / 02 / 2019$ & 9 & 4 \\
\hline \multirow[t]{7}{*}{23} & $11 / 02 / 2019$ & 5 & 1 \\
\hline & $12 / 02 / 2019$ & 6 & 2 \\
\hline & $13 / 02 / 2019$ & 10 & 3 \\
\hline & $14 / 02 / 2019$ & 18 & 2 \\
\hline & $15 / 02 / 2019$ & 18 & 3 \\
\hline & $16 / 02 / 2019$ & 16 & 2 \\
\hline & $17 / 02 / 2019$ & 15 & 3 \\
\hline \multirow[t]{7}{*}{24} & $18 / 02 / 2019$ & 10 & 2 \\
\hline & 19/02/2019 & 11 & 3 \\
\hline & 20/02/2019 & 11 & 4 \\
\hline & 21/02/2019 & 10 & 5 \\
\hline & $22 / 02 / 2019$ & 6 & 0 \\
\hline & $23 / 02 / 2019$ & 5 & 0 \\
\hline & $24 / 02 / 2019$ & 6 & 0 \\
\hline \multirow[t]{7}{*}{25} & $25 / 02 / 2019$ & 4 & -1 \\
\hline & 26/02/2019 & 6 & 1 \\
\hline & 27/02/2019 & 8 & 2 \\
\hline & 28/02/2019 & 9 & 0 \\
\hline & 01/03/2019 & 6 & 1 \\
\hline & 02/03/2019 & 8 & 2 \\
\hline & 03/03/2019 & 11 & 1 \\
\hline \multirow[t]{7}{*}{26} & 04/03/2019 & 12 & 2 \\
\hline & 05/03/2019 & 12 & 1 \\
\hline & 06/03/2019 & 9 & 1 \\
\hline & 07/03/2019 & 11 & 2 \\
\hline & 08/03/2019 & 8 & 0 \\
\hline & 09/03/2019 & 9 & 0 \\
\hline & $10 / 03 / 2019$ & 8 & -2 \\
\hline \multirow[t]{8}{*}{27} & $11 / 03 / 2019$ & 5 & -1 \\
\hline & $12 / 03 / 2019$ & 9 & 2 \\
\hline & $13 / 03 / 2019$ & 12 & 1 \\
\hline & $14 / 03 / 2019$ & 15 & 0 \\
\hline & $15 / 03 / 2019$ & 12 & 0 \\
\hline & $16 / 03 / 2019$ & 13 & -1 \\
\hline & $17 / 03 / 2019$ & 16 & -1 \\
\hline & $18 / 03 / 2019$ & 11 & -2 \\
\hline \multirow[t]{7}{*}{28} & 19/03/2019 & 14 & -3 \\
\hline & 20/03/2019 & 12 & 0 \\
\hline & 21/03/2019 & 11 & 2 \\
\hline & $22 / 03 / 2019$ & 10 & 3 \\
\hline & 23/03/2019 & 16 & 5 \\
\hline & 24/03/2019 & 10 & 3 \\
\hline & $25 / 03 / 2019$ & 10 & 3 \\
\hline 29 & $26 / 03 / 2019$ & 13 & U \\
\hline
\end{tabular}




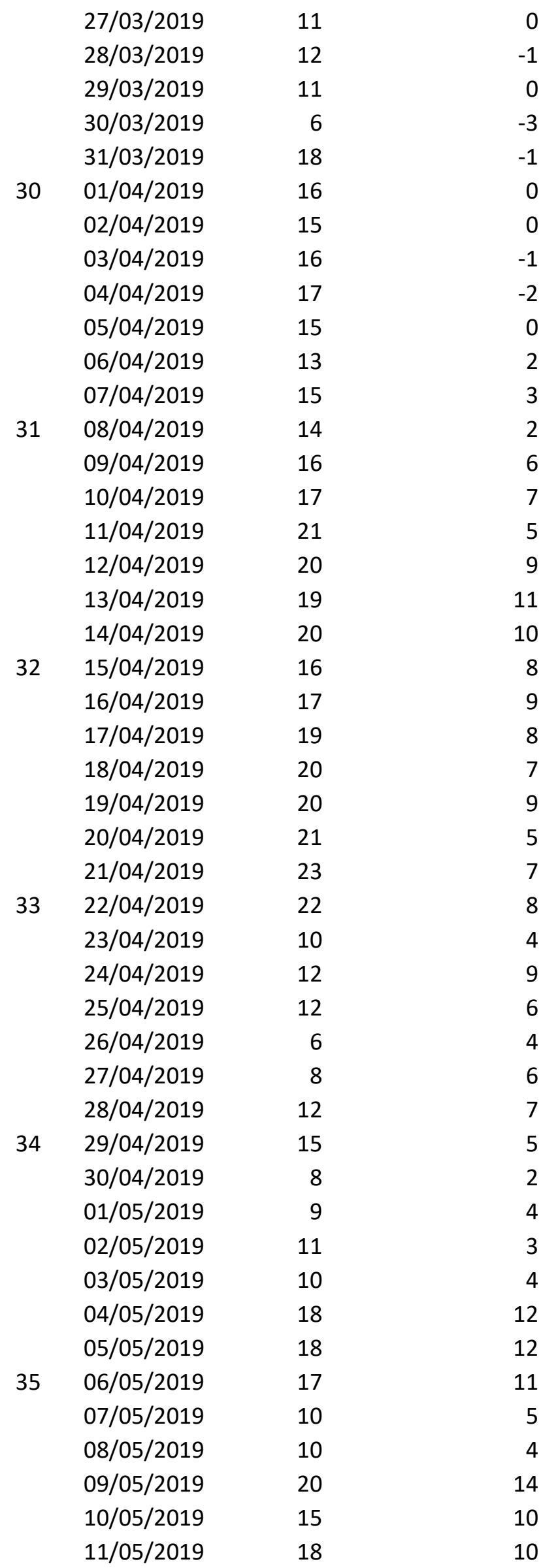




\begin{tabular}{|c|c|c|c|}
\hline & $12 / 05 / 2019$ & 17 & 6 \\
\hline & $13 / 05 / 2019$ & 25 & 16 \\
\hline \multirow[t]{7}{*}{36} & $14 / 05 / 2019$ & 18 & 9 \\
\hline & $15 / 05 / 2019$ & 16 & 8 \\
\hline & $16 / 05 / 2019$ & 19 & 10 \\
\hline & $17 / 05 / 2019$ & 17 & 9 \\
\hline & $18 / 05 / 2019$ & 18 & 10 \\
\hline & 19/05/2019 & 16 & 10 \\
\hline & 20/05/2019 & 22 & 15 \\
\hline \multirow[t]{7}{*}{37} & $21 / 05 / 2019$ & 21 & 15 \\
\hline & $22 / 05 / 2019$ & 20 & 15 \\
\hline & $23 / 05 / 2019$ & 22 & 16 \\
\hline & $24 / 05 / 2019$ & 28 & 22 \\
\hline & $25 / 05 / 2019$ & 29 & 23 \\
\hline & 26/05/2019 & 27 & 21 \\
\hline & $27 / 05 / 2019$ & 28 & 22 \\
\hline \multirow[t]{7}{*}{38} & 28/05/2019 & 30 & 20 \\
\hline & 29/05/2019 & 31 & 21 \\
\hline & 30/05/2019 & 32 & 23 \\
\hline & $31 / 05 / 2019$ & 31 & 22 \\
\hline & 01/06/2019 & 30 & 21 \\
\hline & 02/06/2019 & 30 & 21 \\
\hline & 03/06/2019 & 29 & 23 \\
\hline \multirow[t]{7}{*}{39} & 04/06/2019 & 31 & 22 \\
\hline & $05 / 06 / 2019$ & 32 & 20 \\
\hline & 06/06/2019 & 33 & 21 \\
\hline & 07/06/2019 & 30 & 19 \\
\hline & 08/06/2019 & 27 & 19 \\
\hline & 09/06/2019 & 29 & 18 \\
\hline & $10 / 06 / 2019$ & 31 & 20 \\
\hline 40 & $11 / 06 / 2019$ & 32 & 19 \\
\hline
\end{tabular}




\subsection{Erosion and deposition}

Table A12: Data reported in Section 8.3.3. Erosion rates recorded by the erosion pins, at the Nantymwyn field trial, weeks 19 to 40 (January to June 2019). SD refers to the sample standard deviation.

\begin{tabular}{cllll}
\hline $\begin{array}{c}\text { Erosion pin } \\
\text { number }\end{array}$ & February & March & May & June \\
\hline 1 & 3.45 & 4.3 & 2 & 3.1 \\
2 & 3.48 & 4.7 & 2.1 & 3 \\
Mean & 3.46 & 4.5 & 2.05 & 3.05 \\
S.D & 0.02 & 0.28 & 0.07 & 0.07 \\
\hline
\end{tabular}

\begin{tabular}{clllll}
\hline $\begin{array}{c}\text { Erosion pin } \\
\text { number }\end{array}$ & February & March & May & June & Total \\
\hline 5 & 0.3 & 0.2 & 0.5 & 0.2 & 1.2 \\
\hline
\end{tabular}




\subsection{Progress of surrogate soils pots throughout the field trial (biochar)}

One biochar surrogate soil plot that was situated on the north facing bank at Nantymwyn, throughout the 40 weeks of the field trial, September 2018 to June 2019 (Figure A8).
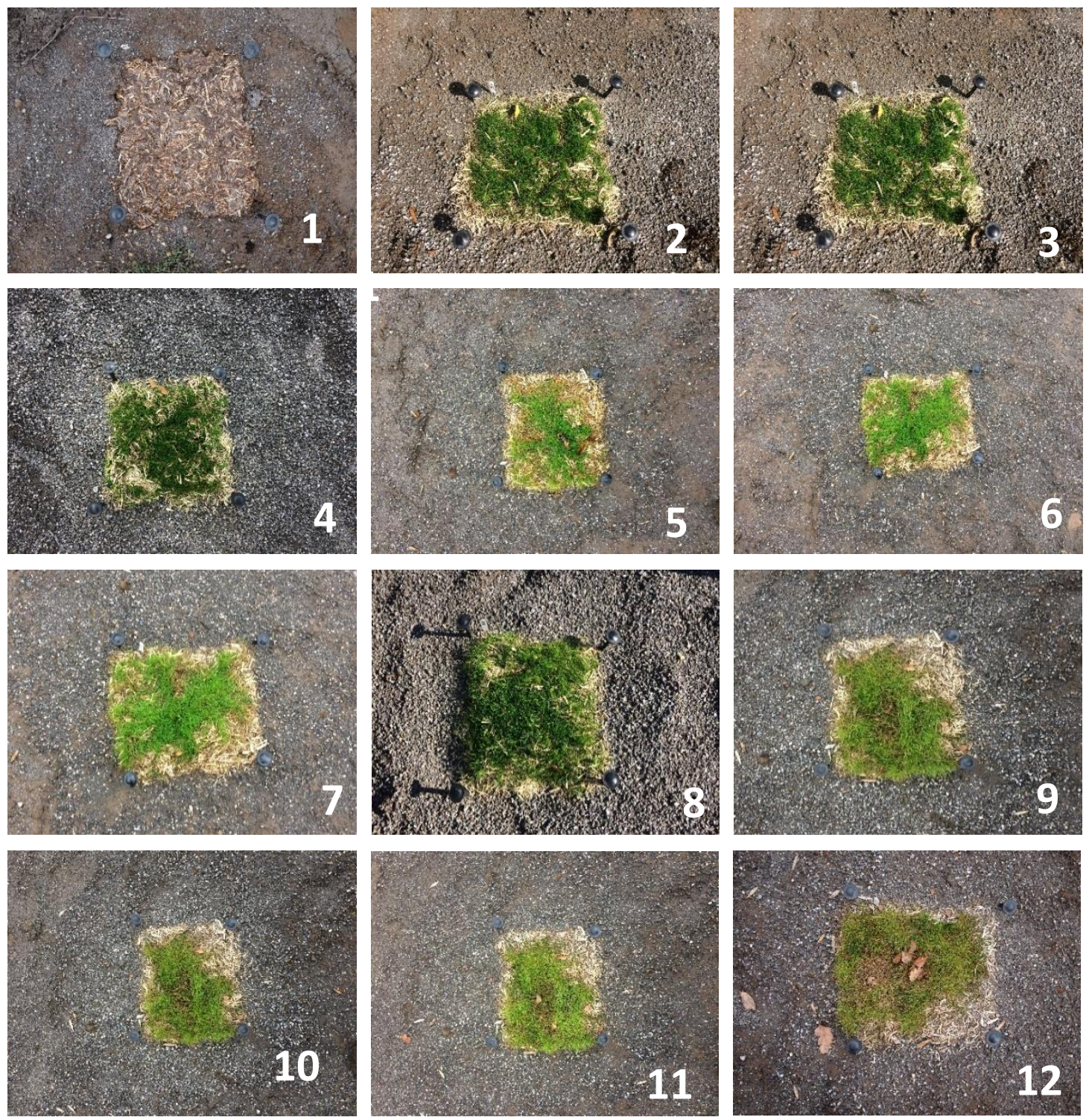

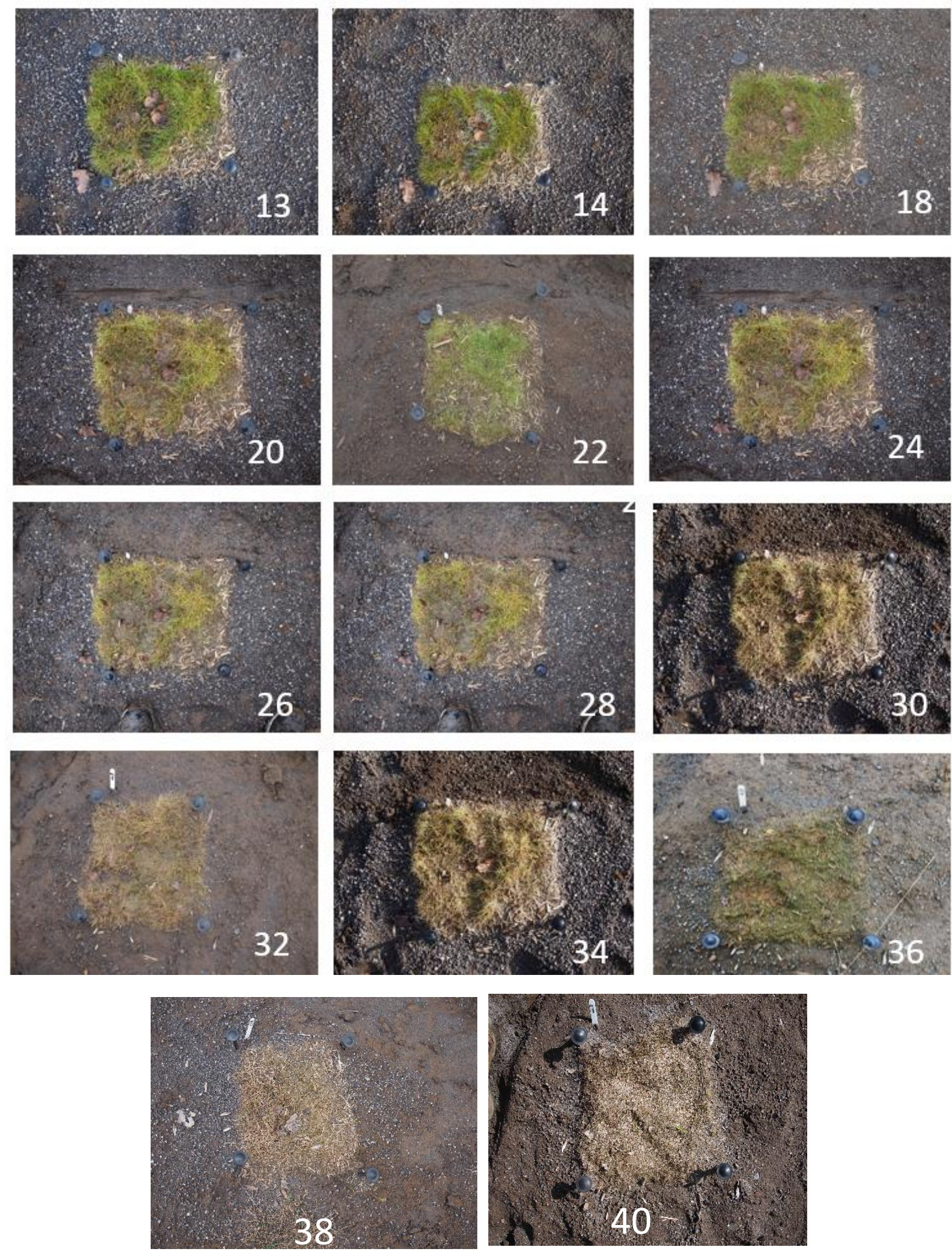

Figure A8: One biochar surrogate soil plot that was situated on the north facing bank al Nantymwyn, throughout the 40 weeks of the field trial, September 2018 to June 2019 


\subsection{Progress of surrogate soils pots throughout the field trial (basalt)}

One basalt surrogate soil plot that was situated on the west facing bank at Nantymwyn, throughout the 40 weeks of the field trial, September 2018 to June 2019 (Figure A9).
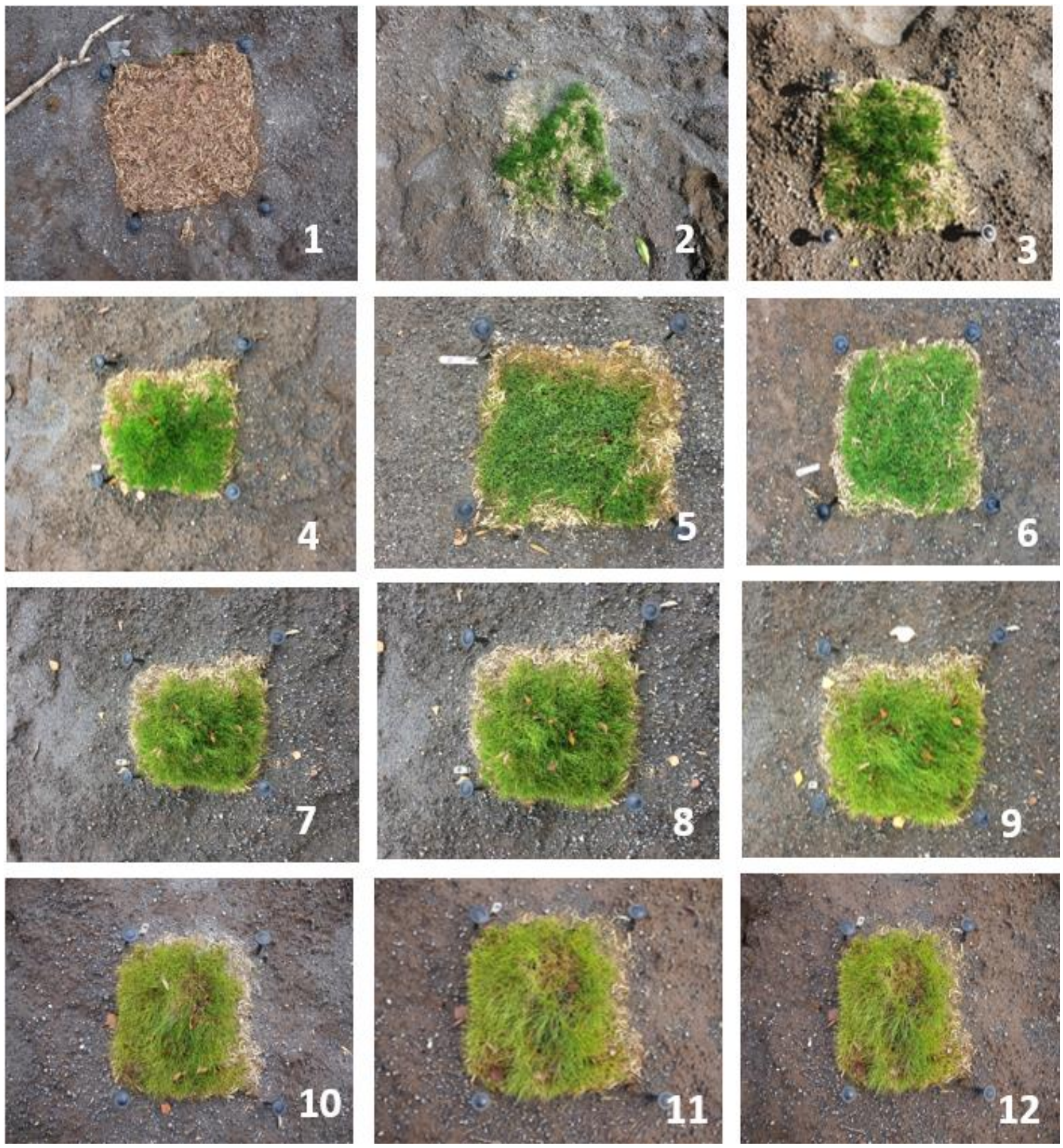

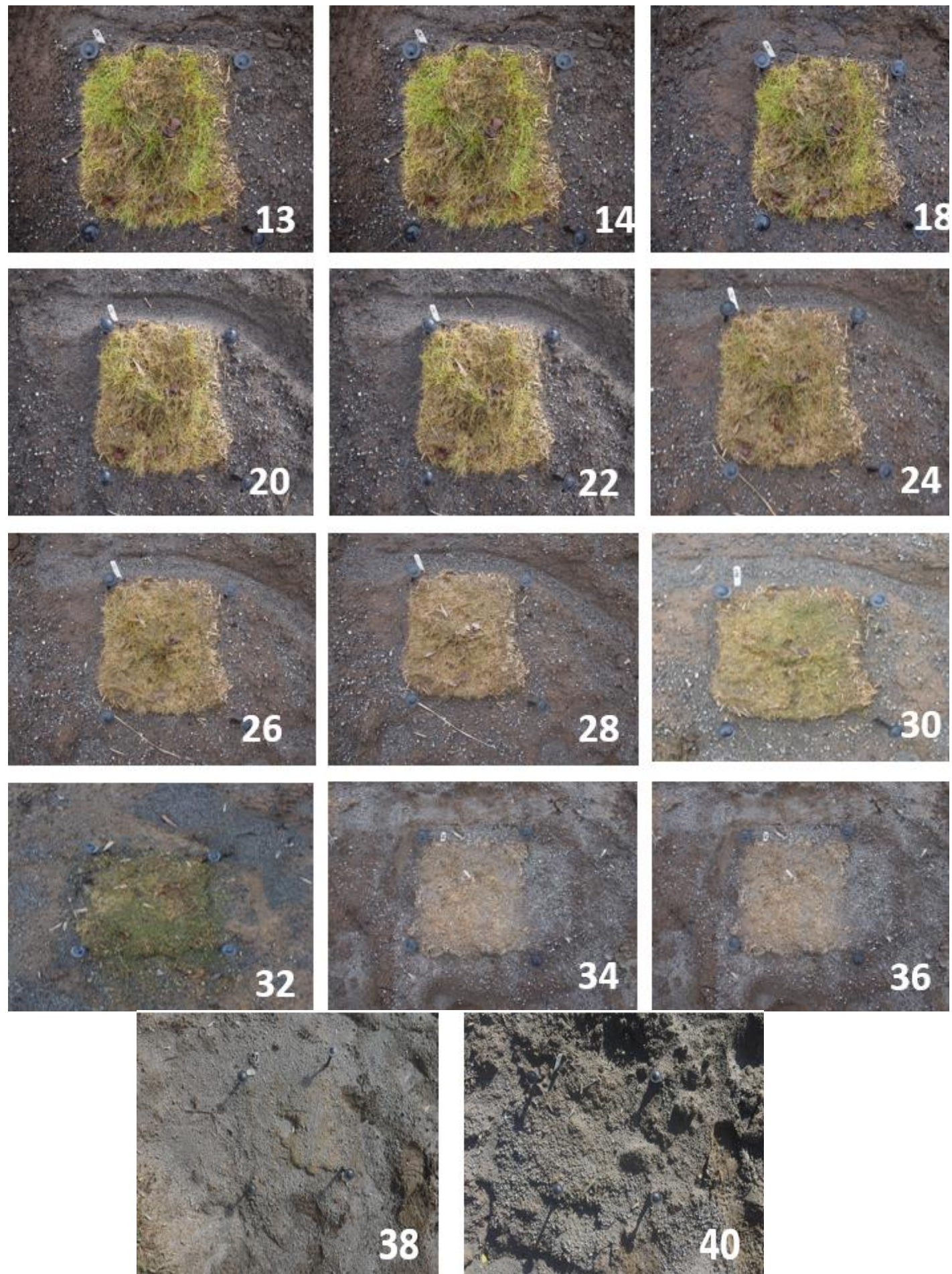

Figure A9: One basalt surrogate soil plot that was situated on the west facing bank at Nantymwyn, throughout the 40 weeks of the field trial, September 2018 to June 2019 


\subsection{Progress of surrogate soils pots throughout the field trial (fertiliser)}

One fertiliser surrogate soil plot that was situated on the west facing bank at Nantymwyn, throughout the 40 weeks of the field trial, September 2018 to June 2019 (Figure A10).
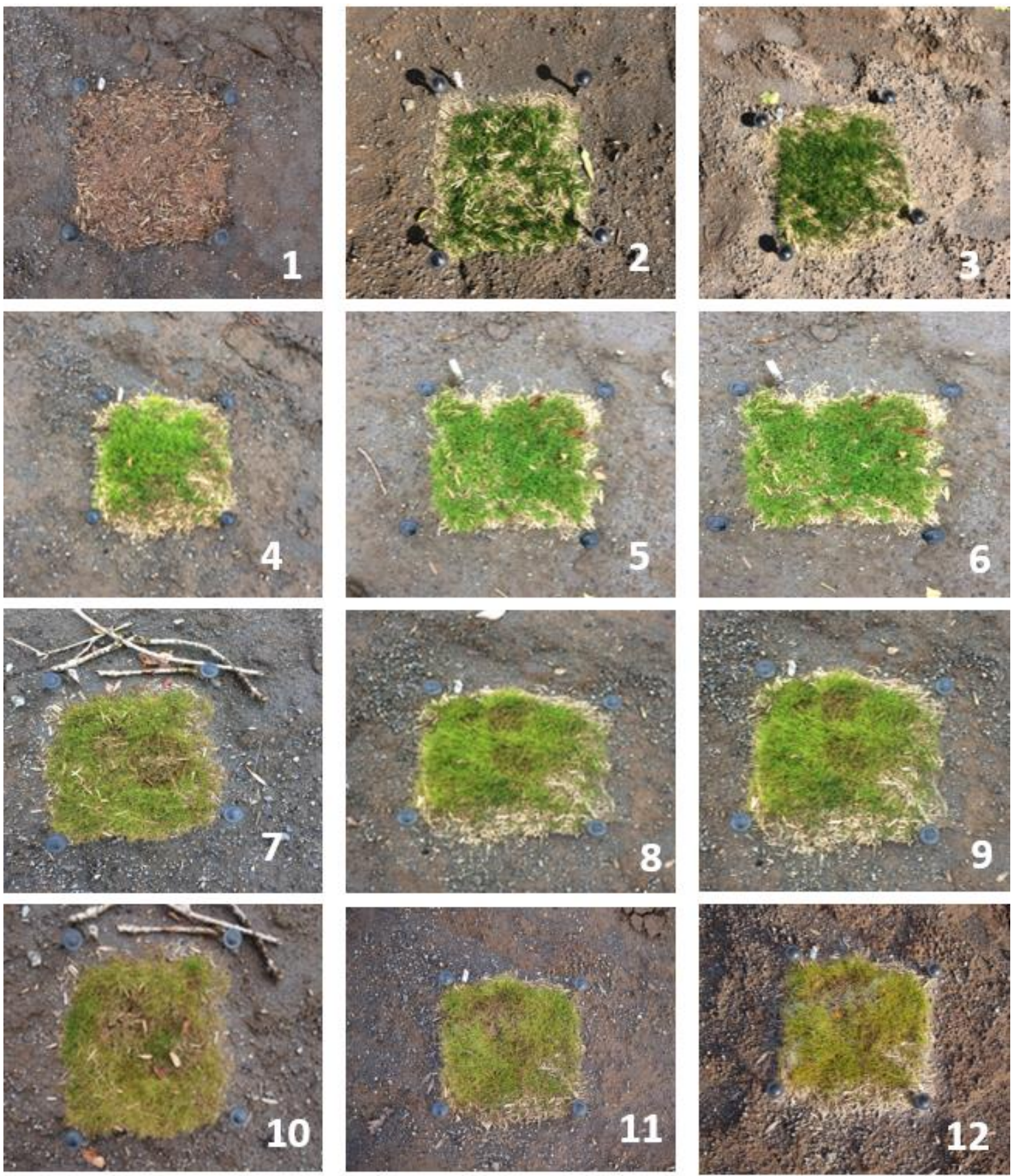

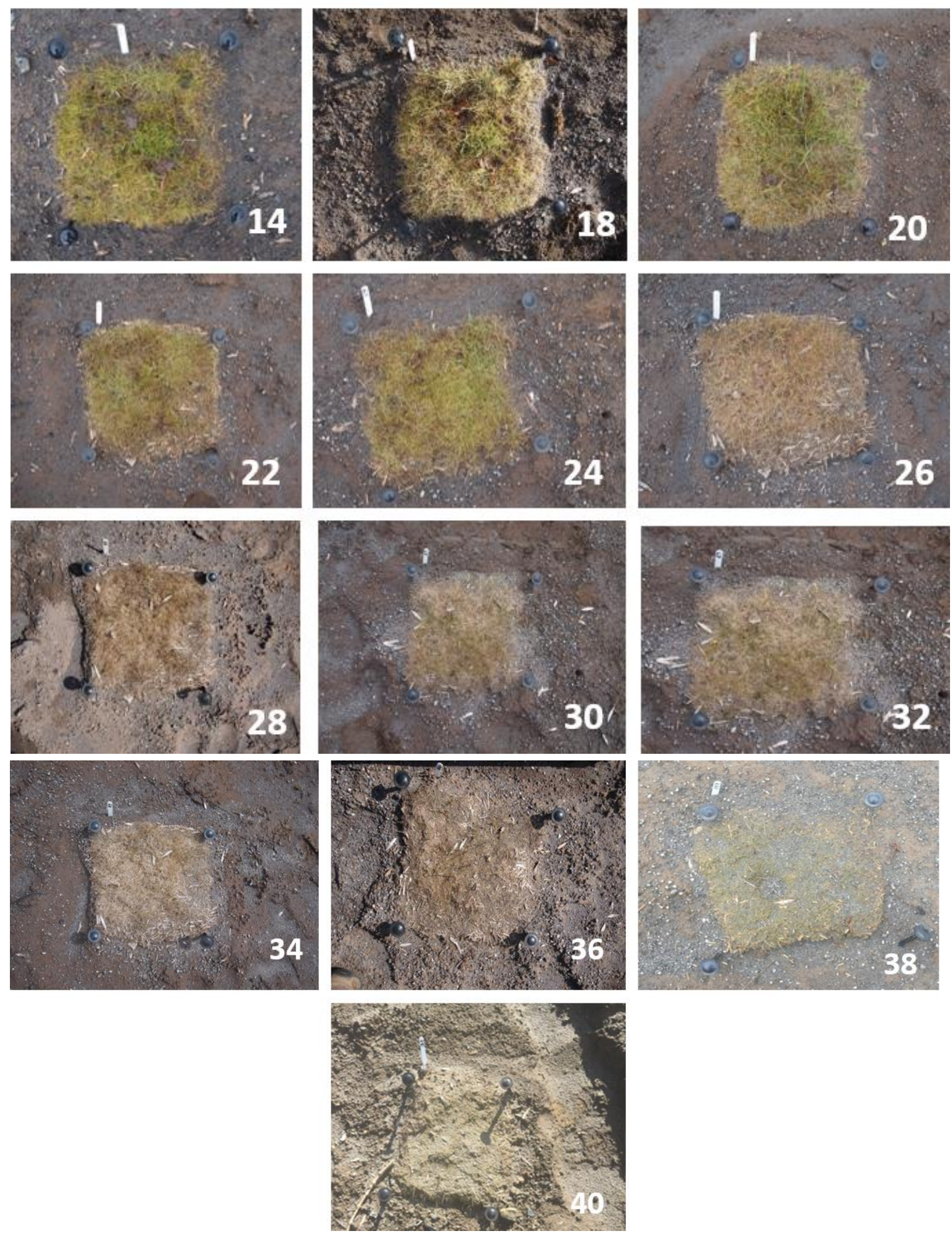

Figure A10: One fertiliser surrogate soil plot that was situated on the west facing bank at Nantymwyn, throughout the 40 weeks of the field trial, September 2018 to June 2019 


\subsection{Data for Section 8.2.7 (shoot length) and 8.3 (above-ground biomass)}

Table A13: The median shoot length ( $\mathrm{mm}$ ) of the grass in the surrogate soil plots throughout the Nantymwyn field trial, January to June 2019

\begin{tabular}{|c|c|c|c|c|c|c|c|c|c|c|}
\hline Week & 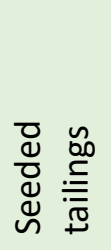 & 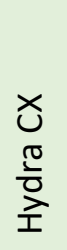 & 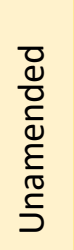 & $\begin{array}{l}\frac{n}{\pi} \\
\widetilde{n} \\
\mathbb{D} \\
\infty\end{array}$ & 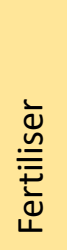 & 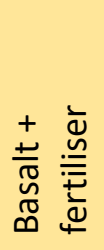 & $\begin{array}{l}\frac{\bar{t}}{\mathrm{c}} \\
\frac{\mathrm{c}}{\mathrm{o}} \\
\frac{0}{0}\end{array}$ & 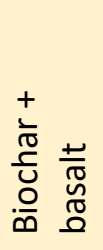 & 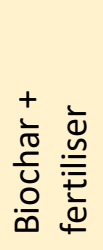 & 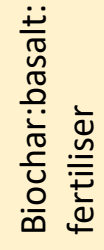 \\
\hline 18 & 4 & 29 & 37 & 42 & 52 & 61 & 40 & 48 & 56 & 41 \\
\hline 20 & 4 & 30 & 37 & 43 & 54 & 62 & 40 & 49 & 58 & 35 \\
\hline 22 & 3 & 35 & 41 & 53 & 55 & 61 & 47 & 52 & 65 & 37 \\
\hline 24 & 3 & 54 & 62 & 61 & 57 & 63 & 56 & 56 & 74 & 47 \\
\hline 26 & 1 & 36 & 57 & 58 & 53 & 56 & 56 & 50 & 61 & 47 \\
\hline 28 & 1 & 35 & 53 & 61 & 45 & 58 & 55 & 37 & 56 & 46 \\
\hline 30 & 0 & 35 & 57 & 54 & 44 & 59 & 55 & 39 & 51 & 48 \\
\hline 32 & 0 & 31 & 57 & 56 & 45 & 32 & 51 & 30 & 44 & 48 \\
\hline 34 & 0 & 22 & 36 & 57 & 35 & 34 & 34 & 20 & 31 & 30 \\
\hline 36 & 0 & 25 & 37 & 60 & 36 & 32 & 37 & 21 & 30 & 33 \\
\hline 38 & 0 & 22 & 20 & 35 & 30 & 25 & 22 & 20 & 25 & 32 \\
\hline 40 & 0 & 20 & 18 & 27 & 25 & 21 & 25 & 20 & 21 & 32 \\
\hline
\end{tabular}

Table A14: The above-ground biomass $(g)$ recorded per plot in the surrogate soil plots at the Nantymwyn field trial, June 2019

\begin{tabular}{lrrrrrrr} 
& $\begin{array}{r}\text { Replicate } \\
1\end{array}$ & 2 & 3 & 4 & 5 & 6 & 7 \\
\hline Seeded tailings & 0.00 & 0.00 & 0.00 & 0.00 & 0.00 & 0.00 & 0.00 \\
Hydra CX & 3.06 & 6.12 & 0.00 & 2.50 & 3.94 & 3.06 & 0.00 \\
Control & 0.00 & 4.44 & 3.30 & 6.72 & 3.30 & 0.05 & 0.02 \\
Basalt & 5.40 & 4.00 & 4.80 & 5.50 & 3.13 & 3.02 & 1.20 \\
Fertiliser & 4.00 & 8.12 & 4.45 & 4.00 & 4.02 & 6.20 & 5.06 \\
Basalt + fertiliser & 7.70 & 6.48 & 4.92 & 4.60 & 7.20 & 2.08 & 3.06 \\
Biochar & 6.60 & 10.16 & 5.05 & 5.06 & 6.30 & 4.99 & 5.02 \\
Biochar + basalt & 6.02 & 11.24 & 6.62 & 10.08 & 6.13 & 5.03 & 0.00 \\
Biochar + fertiliser & 10.72 & 9.72 & 6.54 & 6.01 & 6.15 & 5.99 & 1.01 \\
Biochar, basalt, & 10.36 & 10.52 & 9.15 & 6.04 & 6.48 & 3.03 & 1.10 \\
fertiliser & & & & & &
\end{tabular}


5.7 Data for Section 8.2.9 (metal concentration in biomass)

Table A15: Zinc $(\mathrm{Zn})$, cadmium $(\mathrm{Cd})$, copper $(\mathrm{Cu})$, and lead $(\mathrm{Pb})$ concentrations in biomass for each treatment in the Nantymwyn field trial, June 2019

\begin{tabular}{|c|c|c|c|c|c|c|}
\hline & Unamended & & & & & Median \\
\hline & $\mathrm{C} 2$ & C3 & $\mathrm{C} 4$ & C5 & C6 & \\
\hline $\mathrm{Zn}$ & 9.03 & 9.69 & 6.43 & 9.04 & 7.69 & 9.03 \\
\hline $\mathrm{Cd}$ & 0.024 & 0.16 & 0.13 & 0.15 & 0.13 & 0.13 \\
\hline $\mathrm{Cu}$ & 0.021 & 0.03 & 0.22 & 0.02 & 0.11 & 0.03 \\
\hline $\mathrm{Pb}$ & 9.3 & 8.51 & 5.07 & 9.07 & 7.47 & 8.51 \\
\hline
\end{tabular}

\begin{tabular}{|c|c|c|c|c|c|c|}
\hline & Basalt & & & & & \\
\hline & $\mathrm{H} 1$ & $\mathrm{H} 2$ & $\mathrm{H} 3$ & $\mathrm{H} 4$ & H5 & Median \\
\hline $\mathrm{Zn}$ & 6.69 & 6.68 & 8.81 & 8.21 & 5.09 & 6.69 \\
\hline $\mathrm{Cd}$ & 0.08 & 0.12 & 0.16 & 0.16 & 0.16 & 0.16 \\
\hline $\mathrm{Cu}$ & 0.26 & 0.25 & 0.06 & 0.06 & 0.06 & 0.06 \\
\hline $\mathrm{Pb}$ & 8.51 & 8.88 & 9.91 & 7.85 & 6.69 & 8.51 \\
\hline
\end{tabular}

\begin{tabular}{|c|c|c|c|c|c|}
\hline Fertiliser & & & & & \\
\hline 11 & 12 & 13 & 14 & 15 & Median \\
\hline 5.66 & 5.68 & 7.71 & 7.39 & 5.86 & 5.86 \\
\hline 0.16 & 0.16 & 0.15 & 0.16 & 0.16 & 0.16 \\
\hline 0.06 & 0.06 & 0.07 & 0.07 & 0.06 & 0.06 \\
\hline 7.05 & 6.37 & 8.2 & 7.88 & 5.68 & 7.05 \\
\hline
\end{tabular}

\section{Basalt and fertiliser}

$\begin{array}{lcccccc} & \mathrm{J1} & \mathrm{J} 2 & \mathrm{~J} 3 & \mathrm{J4} & \mathrm{J} 5 & \text { Median } \\ \mathrm{Zn} & 5.64 & 5.27 & 5.74 & 5.37 & 5.43 & 5.43 \\ \mathrm{Cd} & 0.16 & 0.17 & 0.16 & 0.16 & 0.16 & 0.16 \\ \mathrm{Cu} & 0.06 & 0.05 & 0.05 & 0.05 & 0.05 & 0.05 \\ \mathrm{~Pb} & 6.61 & 6.18 & 6.43 & 6.44 & 6.52 & 6.44\end{array}$




\section{Biochar}

$\begin{array}{ccccccc} & \text { D1 } & \text { D2 } & \text { D3 } & \text { D4 } & \text { D5 } & \text { Median } \\ \mathrm{Zn} & 4.62 & 4.47 & 3.01 & 1.44 & 1.6 & 3.01 \\ \mathrm{Cd} & 0.13 & 0.15 & 0.16 & 0.17 & 0.16 & 0.16 \\ \mathrm{Cu} & 0.07 & 0.04 & 0.01 & 0.03 & 0.03 & 0.03 \\ \mathrm{~Pb} & 7.84 & 4.86 & 2.8 & 3.39 & 4.1 & 4.1\end{array}$

\section{Biochar and basalt}

$\mathrm{Zn}$

$\mathrm{Cd}$

$\mathrm{Cu}$

$\mathrm{Pb}$

\section{E2}

5.2

0.16

0.05

4.07
E3

3.11

0.15

0.1

5.65
E4

3.79

0.17

0.08

5.08
E5

3.44

0.16

0.06

4.3
Median

3.79

0.16

0.06

5.08

\section{Biochar and}

\section{fertiliser}

\begin{tabular}{|l|c|c|c|c|c|c|} 
& F1 & F2 & F3 & F4 & F5 & Median \\
\hline $\mathrm{Zn}$ & 4.54 & 2.37 & 5.7 & 3.69 & 3.35 & 3.69 \\
\hline $\mathrm{Cd}$ & 0.13 & 0.13 & 0.14 & 0.14 & 0.14 & 0.14 \\
$\mathrm{Cu}$ & 0.25 & 0.18 & 0.07 & 0.11 & 0.2 & 0.18 \\
$\mathrm{~Pb}$ & 3.32 & 4.16 & 3.16 & 4.13 & 5.24 & 4.13 \\
\hline
\end{tabular}

\section{Biochar, basalt, fertiliser}

$\mathrm{Zn}$

$\mathrm{Cd}$

$\mathrm{Cu}$

$\mathrm{Pb}$
G1

3.05

0.16

0.02

1.78
G2

2.7

0.14

0.02

1.83

\section{G3}

2.82

0.16

0.07

3.18
G4

3.31

0.15

0.02

2.24
G5

2.83

0.16

0.03

1.91
Median

2.83

0.16

0.02

1.91

\section{Hydra CX}

Zn

$\mathrm{Cd}$

$\mathrm{Cu}$

$\mathrm{Pb}$

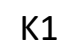

6.7

0.16

0.03

7.63
K2

\subsection{5}

0.15

0.03

8.98
K3

7.76

0.16

0.04

8.54
K4

6.67

0.17

0.04

8.52
K5

8.07

0.16

0.05

9.57
Median

6.7

0.16

0.04

8.54 


\begin{tabular}{|c|c|c|c|c|c|}
\hline Pasture & & & & & \\
\hline P1 & P2 & P3 & P4 & P5 & Median \\
\hline 0.2 & 0.44 & 0.42 & 0.33 & 0.35 & 0.35 \\
\hline 0.16 & 0.17 & 0.17 & 0.17 & 0.15 & 0.17 \\
\hline 0.01 & 0 & 0 & 0.01 & 0.02 & 0.01 \\
\hline 0.024 & 0.18 & 0.16 & 0.23 & 0.25 & 0.18 \\
\hline
\end{tabular}

\subsection{Data for Section 8.2.9 (metal uptake in biomass)}

Table A16: The uptake of zinc in biomass for each treatment in the Nantymwyn field trial, June 2019

\begin{tabular}{|c|c|c|c|c|}
\hline & & & & $\begin{array}{l}* 4 \text { to } \\
\text { convert } \\
\text { to } \mathrm{m} 2\end{array}$ \\
\hline Unamended & $\begin{array}{l}\text { Concentration } \\
\text { (mg.L) }\end{array}$ & $\begin{array}{l}\text { Weight of } \\
\text { biomass } \\
\text { (g) }\end{array}$ & $\begin{array}{c}\text { Total } \\
\text { Uptake } \\
\text { (per plot) }\end{array}$ & Mg.m2 \\
\hline $\mathrm{C} 2$ & 0.90 & 4.44 & 4.01 & 16.04 \\
\hline C3 & 0.97 & 3.30 & 3.20 & 12.79 \\
\hline C4 & 0.64 & 6.72 & 4.32 & 17.28 \\
\hline C5 & 0.90 & 3.30 & 2.98 & 11.93 \\
\hline C6 & 0.77 & 0.05 & 0.04 & 0.15 \\
\hline \multicolumn{5}{|l|}{ Basalt } \\
\hline $\mathrm{H} 1$ & 0.67 & 5.40 & 3.61 & 14.45 \\
\hline $\mathrm{H} 2$ & 0.67 & 4.00 & 2.67 & 10.69 \\
\hline H3 & 0.88 & 4.80 & 4.23 & 16.92 \\
\hline $\mathrm{H} 4$ & 0.82 & 5.50 & 4.52 & 18.06 \\
\hline H5 & 0.51 & 3.13 & 1.59 & 6.37 \\
\hline \multicolumn{5}{|l|}{ Fertiliser } \\
\hline 11 & 0.57 & 4.00 & 2.26 & 9.06 \\
\hline 12 & 0.57 & 8.12 & 4.61 & 18.45 \\
\hline 13 & 0.77 & 4.45 & 3.43 & 13.72 \\
\hline 14 & 0.74 & 4.00 & 2.96 & 11.82 \\
\hline 15 & 0.59 & 4.02 & 2.36 & 9.42 \\
\hline
\end{tabular}




\begin{tabular}{|l|c|c|c|c|}
\hline Basalt and fertiliser & & & \\
J1 & 0.56 & 7.70 & 4.34 & 17.37 \\
J2 & 0.53 & 6.48 & 3.41 & 13.66 \\
J3 & 0.57 & 4.92 & 2.82 & 11.30 \\
J4 & 0.54 & 4.60 & 2.47 & 9.88 \\
J5 & 0.54 & 7.20 & 3.91 & 15.64 \\
\hline
\end{tabular}

\begin{tabular}{|l|r|r|r|r|}
\hline Biochar & & & & \\
\hline D1 & 0.46 & 6.60 & 3.05 & 12.20 \\
\hline D2 & 0.45 & 10.16 & 4.54 & 18.17 \\
\hline D3 & 0.30 & 5.05 & 1.52 & 6.08 \\
\hline D4 & 0.14 & 5.06 & 0.73 & 2.91 \\
\hline D5 & 0.16 & 6.30 & 1.01 & 4.03 \\
\hline
\end{tabular}

Biochar and basalt

\begin{tabular}{|c|c|c|c|c|}
\hline E1 & 0.52 & 6.02 & 3.12 & 12.50 \\
\hline E2 & 0.52 & 11.24 & 5.84 & 23.38 \\
\hline E3 & 0.31 & 6.62 & 2.06 & 8.24 \\
\hline E4 & 0.38 & 10.08 & 3.82 & 15.28 \\
\hline E5 & 0.34 & 6.13 & 2.11 & 8.43 \\
\hline
\end{tabular}

Biochar and fertiliser

\begin{tabular}{l|r|r|c|c|} 
F1 & 0.45 & 10.72 & 4.87 & 19.47 \\
\hline F2 & 0.24 & 9.72 & 2.30 & 9.21 \\
\hline F3 & 0.57 & 6.54 & 3.73 & 14.91 \\
\hline F4 & 0.37 & 6.01 & 2.22 & 8.87 \\
\hline F5 & 0.34 & 6.15 & 2.06 & 8.24 \\
\hline
\end{tabular}

Biochar, basalt, fertiliser

\begin{tabular}{l|r|r|r|r|}
\hline G1 & 0.31 & 10.36 & 3.16 & 12.64 \\
\hline G2 & 0.27 & 10.52 & 2.84 & 11.36 \\
\hline G3 & 0.28 & 9.15 & 2.58 & 10.32 \\
\hline G4 & 0.33 & 6.04 & 2.00 & 8.00 \\
\hline G5 & 0.28 & 6.48 & 1.83 & 7.34 \\
\hline
\end{tabular}

\section{Hydra CX}

K1

K2

K6

K4

K5
0.67

0.44

0.78

0.67

0.81
3.06

6.12

3.06

2.50

3.94
$2.05 \quad 8.20$

$2.66 \quad 10.65$

$2.37 \quad 9.50$

$1.67 \quad 6.67$

$3.18 \quad 12.72$ 


\begin{tabular}{|l|r|l|l|l|}
\hline Pasture & & & \\
\hline P1 & 0.02 & 40.20 & 0.80 & 3.22 \\
\hline P2 & 0.044 & 45.63 & 2.01 & 8.03 \\
P3 & 0.042 & 29.50 & 1.24 & 4.96 \\
\hline P4 & 0.033 & 46.20 & 1.52 & 6.10 \\
\hline P5 & 0.035 & 32.10 & 1.12 & 4.49 \\
\hline
\end{tabular}

Table A17: The uptake of zinc in biomass for each treatment in the Nantymwyn field trial, June 2019

\begin{tabular}{|c|c|c|c|c|}
\hline Unamended & $\begin{array}{c}\text { Concentration } \\
\text { (mg.L) }\end{array}$ & $\begin{array}{l}\text { Weight of } \\
\text { biomass } \\
\text { (g) }\end{array}$ & $\begin{array}{c}\text { Total } \\
\text { Uptake } \\
\text { (per plot) }\end{array}$ & $\mathrm{mg} \cdot \mathrm{m} 2$ \\
\hline $\mathrm{C} 2$ & 0.930 & 4.44 & 4.13 & 16.52 \\
\hline $\mathrm{C} 3$ & 0.851 & 3.30 & 2.81 & 11.23 \\
\hline C4 & 0.507 & 6.72 & 3.41 & 13.63 \\
\hline C5 & 0.907 & 3.30 & 2.99 & 11.97 \\
\hline C6 & 0.747 & 0.05 & 0.04 & 0.15 \\
\hline
\end{tabular}

Basalt

\begin{tabular}{|c|c|c|c|c|}
\hline $\mathrm{H} 1$ & 0.851 & 5.40 & 4.60 & 18.38 \\
\hline $\mathrm{H} 2$ & 0.888 & 4.00 & 3.55 & 14.21 \\
\hline $\mathrm{H} 3$ & 0.991 & 4.80 & 4.76 & 19.03 \\
\hline $\mathrm{H} 4$ & 0.785 & 5.50 & 4.32 & 17.27 \\
\hline H5 & 0.669 & 3.13 & 2.09 & 8.38 \\
\hline
\end{tabular}

Fertiliser

\begin{tabular}{|l|l|l|l|l|}
\hline 11 & 0.705 & 4.00 & 2.82 & 11.28 \\
\hline 12 & 0.637 & 8.12 & 5.17 & 20.69 \\
\hline 13 & 0.820 & 4.45 & 3.65 & 14.60 \\
\hline 14 & 0.788 & 4.00 & 3.15 & 12.61 \\
\hline 15 & 0.568 & 4.02 & 2.28 & 9.13
\end{tabular}

Basalt and fertiliser

$\begin{array}{lllll}\text { J1 } & 0.661 & 7.70 & 5.09 & 20.36 \\ \text { J2 } & 0.618 & 6.48 & 4.00 & 16.02 \\ \text { J3 } & 0.643 & 4.92 & 3.16 & 12.65 \\ \text { J4 } & 0.644 & 4.60 & 2.96 & 11.85 \\ \text { J5 } & 0.652 & 7.20 & 4.69 & 18.78\end{array}$




\begin{tabular}{|c|c|c|c|c|}
\hline \multicolumn{5}{|c|}{ Biochar } \\
\hline D1 & 0.784 & 6.60 & 5.17 & 20.70 \\
\hline D2 & 0.486 & 10.16 & 4.94 & 19.75 \\
\hline D3 & 0.280 & 5.05 & 1.41 & 5.66 \\
\hline D4 & 0.339 & 5.06 & 1.72 & 6.86 \\
\hline D5 & 0.410 & 6.30 & 2.58 & 10.33 \\
\hline
\end{tabular}

Biochar and basalt

\begin{tabular}{|c|c|c|c|}
\hline E1 & 0.553 & 6.02 & 3.33 \\
\hline E2 & 0.407 & 11.24 & 4.57 \\
\hline E3 & 0.565 & 6.62 & 3.74 \\
\hline E4 & 0.508 & 10.08 & 5.12 \\
\hline E5 & 0.430 & 6.13 & 2.64 \\
\hline
\end{tabular}

Biochar and fertiliser

\begin{tabular}{lrrrr|} 
F1 & 0.332 & 10.72 & 3.56 & 14.24 \\
F2 & 0.416 & 9.72 & 4.04 & 16.17 \\
F3 & 0.316 & 6.54 & 2.07 & 8.27 \\
F4 & 0.413 & 6.01 & 2.48 & 9.93 \\
F5 & 0.524 & 6.15 & 3.22 & 12.89
\end{tabular}

Biochar, basalt, fertiliser

\begin{tabular}{l|l|r|c|c|} 
G1 & 0.178 & 10.36 & 1.84 & 7.38 \\
\hline G2 & 0.183 & 10.52 & 1.93 & 7.70 \\
\hline G3 & 0.318 & 9.15 & 2.91 & 11.64 \\
\hline G4 & 0.224 & 6.04 & 1.35 & 5.41 \\
\hline G5 & 0.191 & 6.48 & 1.24 & 4.95
\end{tabular}

Hydra CX

K1

0.763

3.06

$2.33 \quad 9.34$

K2

6.12

$5.50 \quad 21.98$

K6

0.854

3.06

$2.61 \quad 10.45$

K4

0.852

2.50

$2.13 \quad 8.52$

K5

0.957

3.94

$3.77 \quad 15.08$ 


\subsection{Cadmium concentrations in biomass}

The Agilent 4200 MP-AES instrument can detect Cd concentrations of $>30 \mathrm{mg} . \mathrm{L}^{-1}$ (Agilent, $2018^{2}$ ). The instrument provided readings of $2-17 \mu \mathrm{g} . \mathrm{L}^{-1} \mathrm{Cd}$, with the error reading associated with values below the detectable limit.

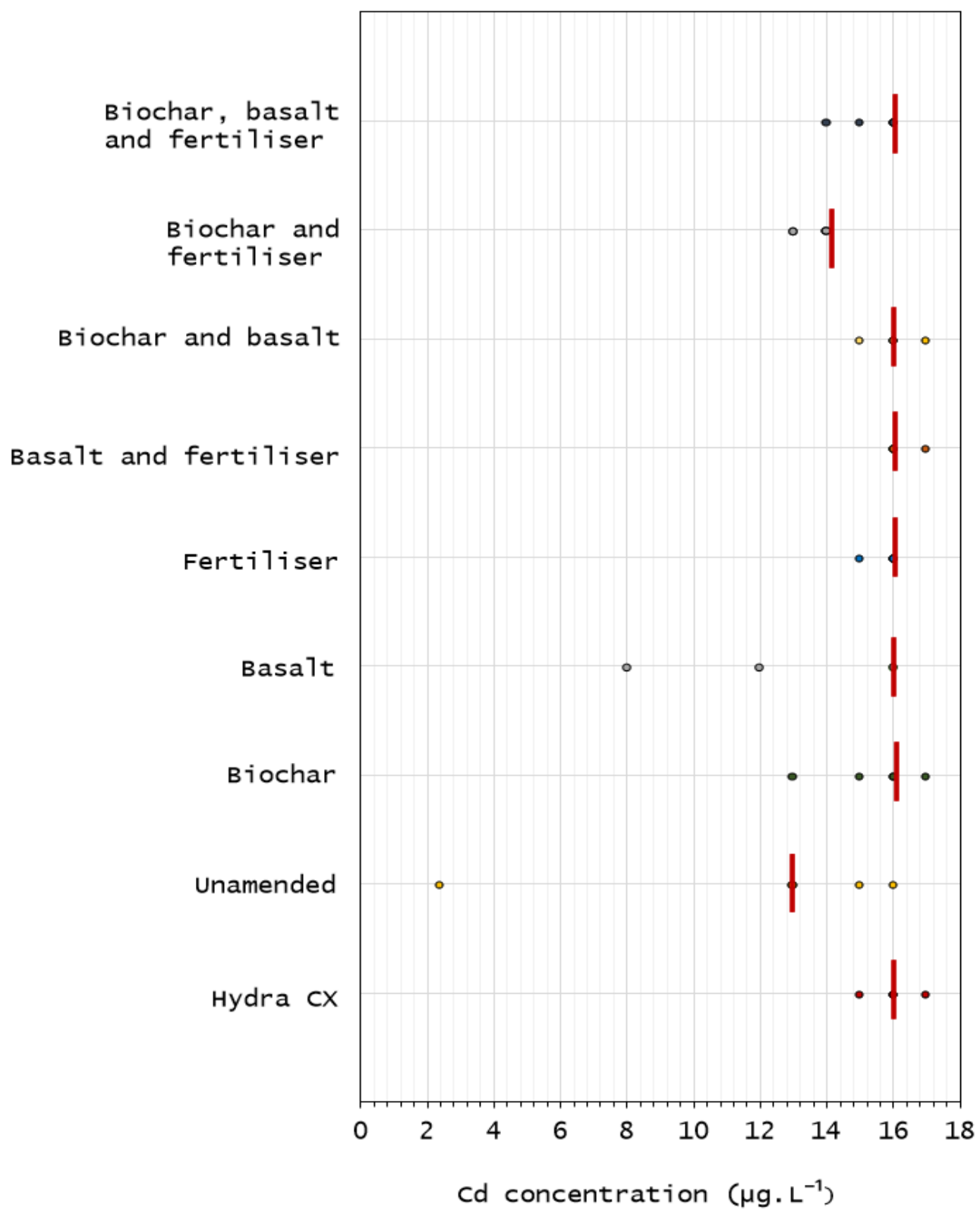

Figure A11: The concentration of cadmium in the biomass produced in the Nantymwyn field trial, 2018 - 2019 


\subsection{Copper concentrations in biomass}

The Agilent 4200 MP-AES instrument can detect $\mathrm{Cu}$ concentrations of $>500 \mathrm{mg} . \mathrm{L}^{-1}$ (Agilent, 2018 ${ }^{2}$ ). The instrument provided readings of $1-26 \mu \mathrm{g} \cdot \mathrm{L}^{-1} \mathrm{Cu}$, with the error reading associated with values below the detectable limit

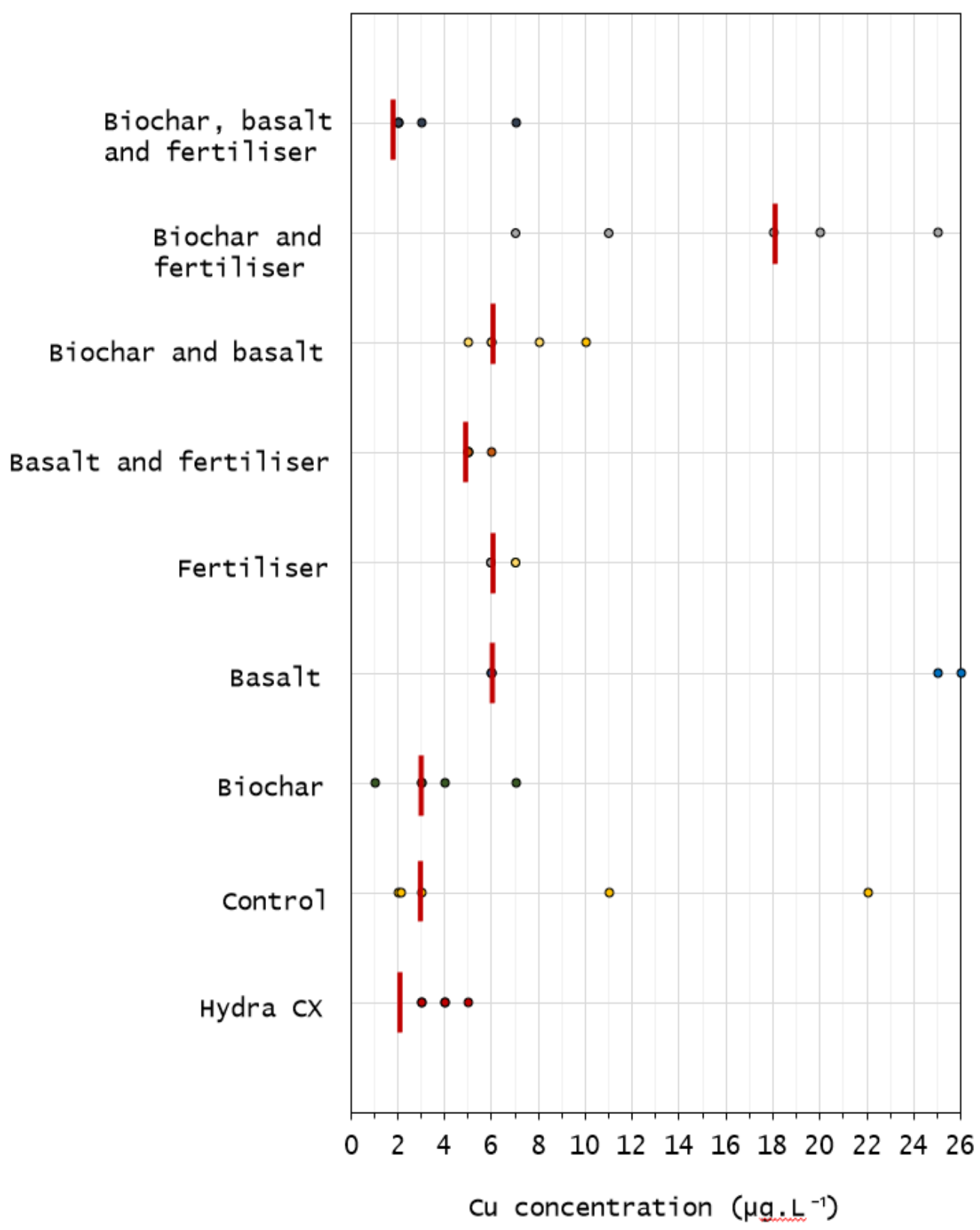

Figure A12: The concentration of cadmium in the biomass produced in the Nantymwyn field trial, 2018 - 2019 
5.11 Photos of the Nantymwyn field trial, February 2020

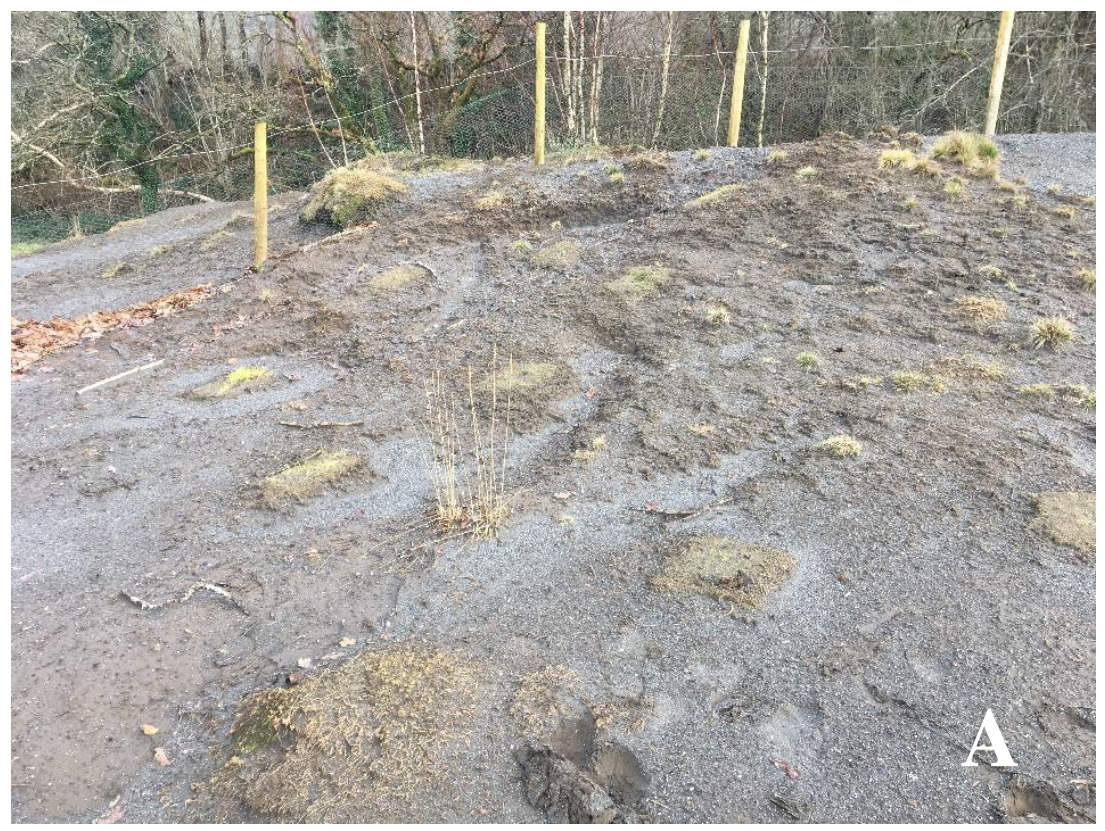

Figures A13 A

and $B:$ Surrogate soils plots at the Nantymwyn field trial, February 2020

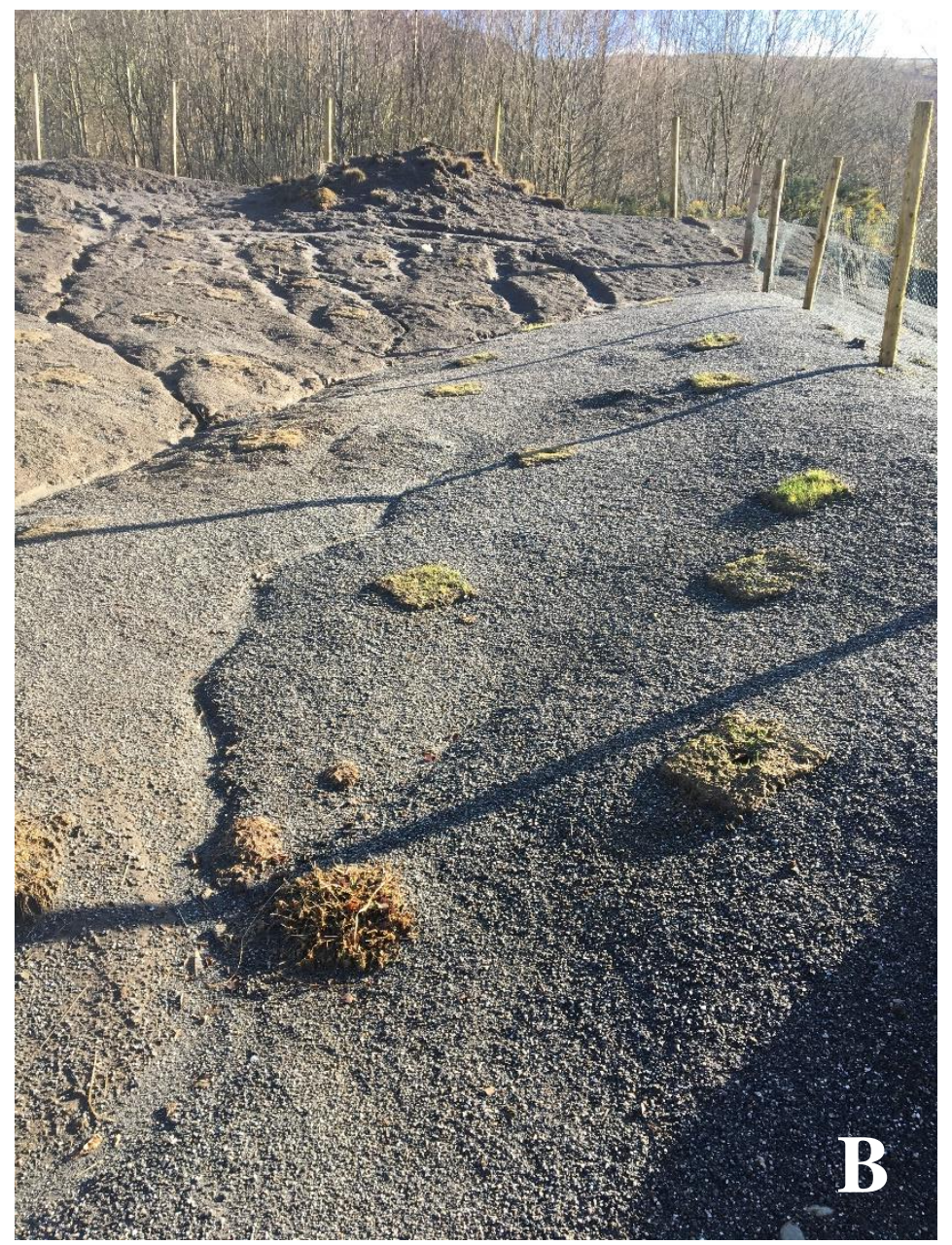



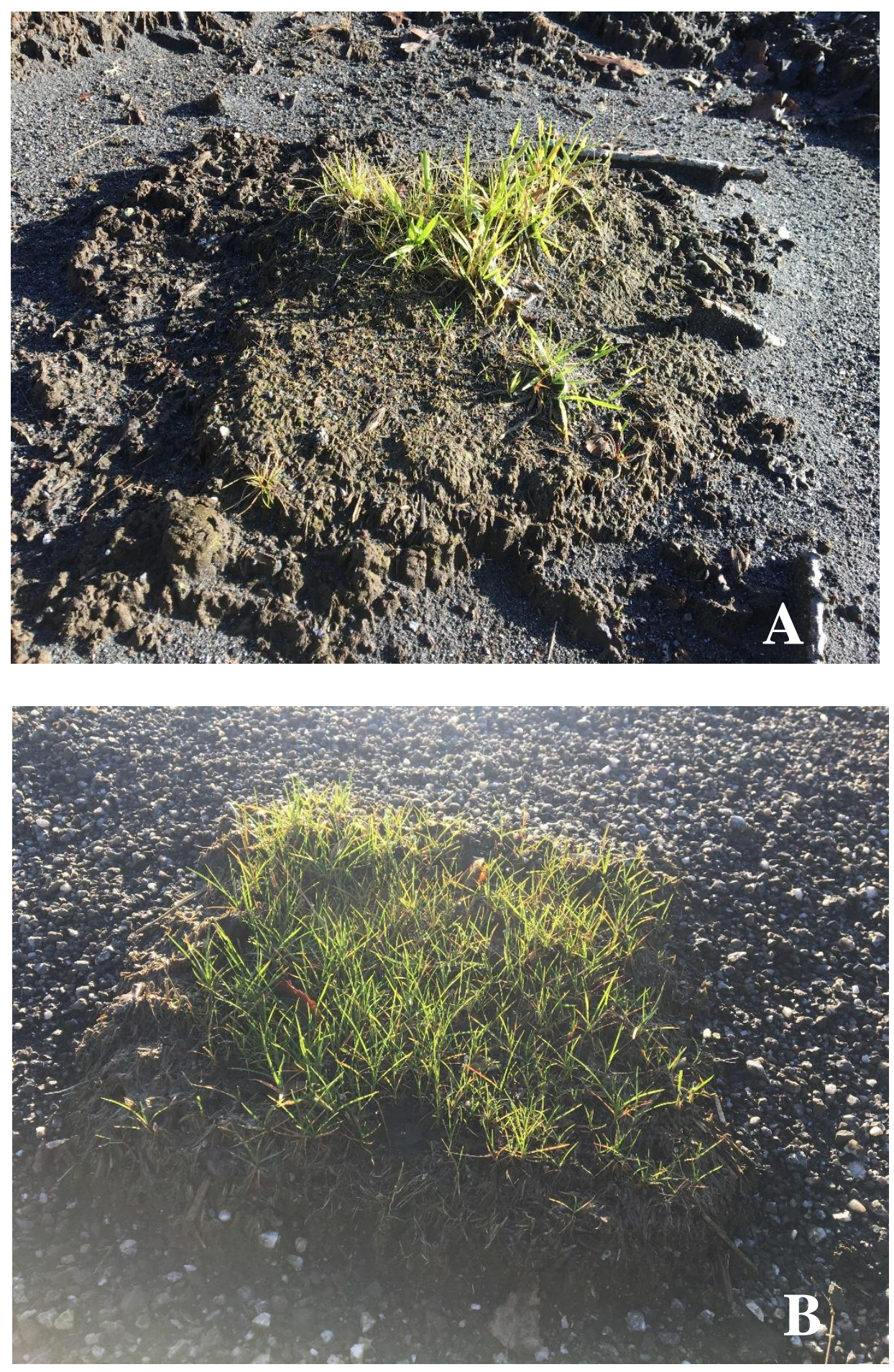

Figure A14 A and B: Grass regrowing in the surrogate soil plots at the Nantymwyn field trial, February 2020 


\section{Appendix 6. Frongoch}

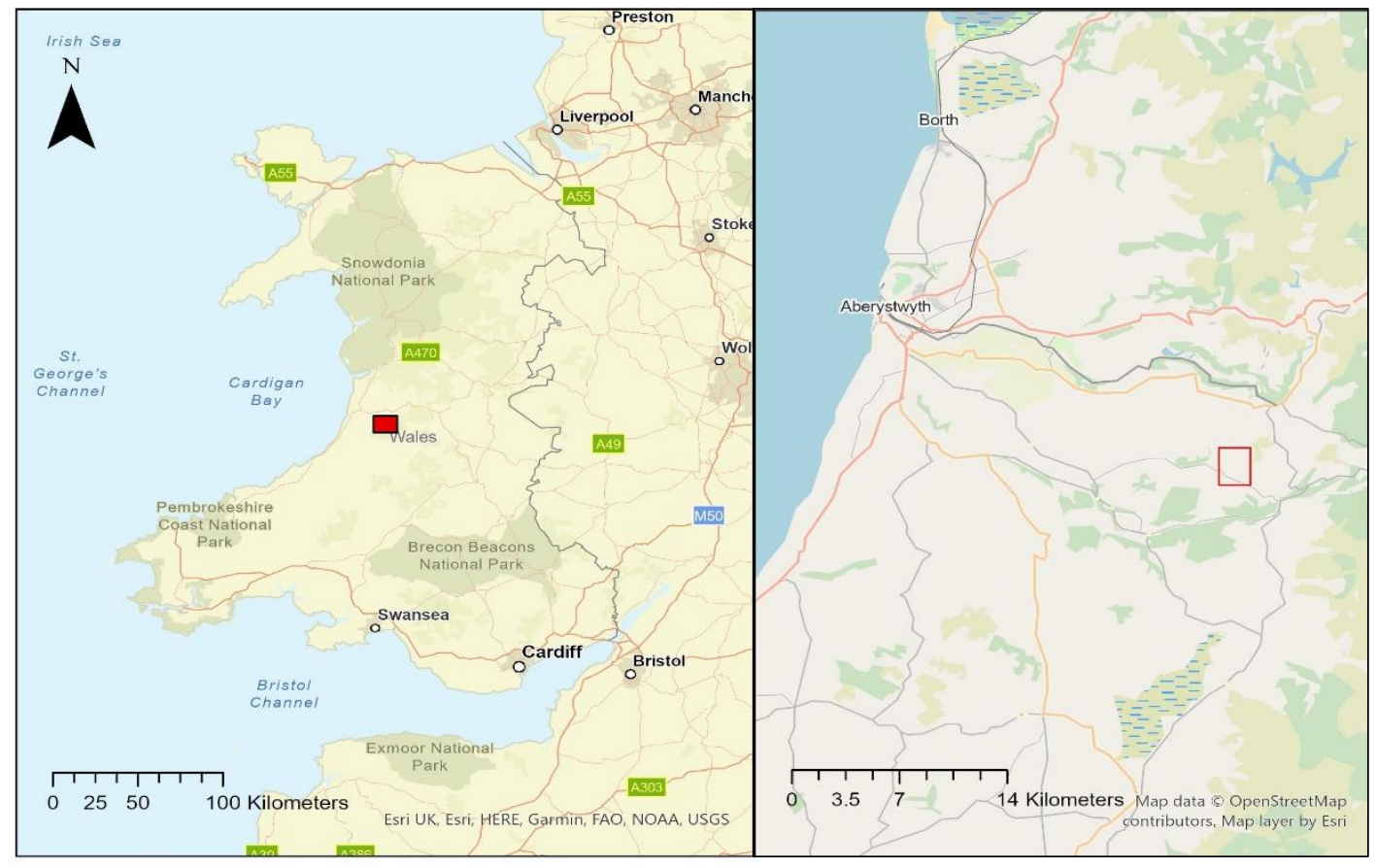

Figure A15: The location of Frongoch lead/zinc mine (in red), situated 14 Km south-east of Aberystwyth (Wales, UK)

Figure A16: An aerial view of Frongoch lead/zinc mine (Wales)
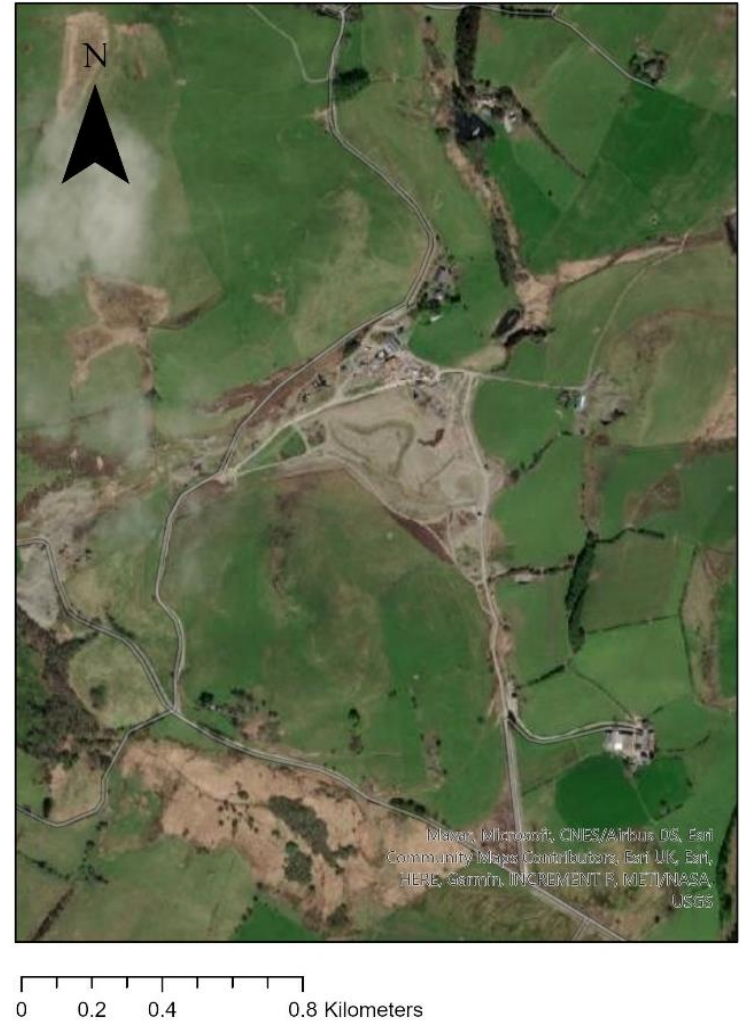


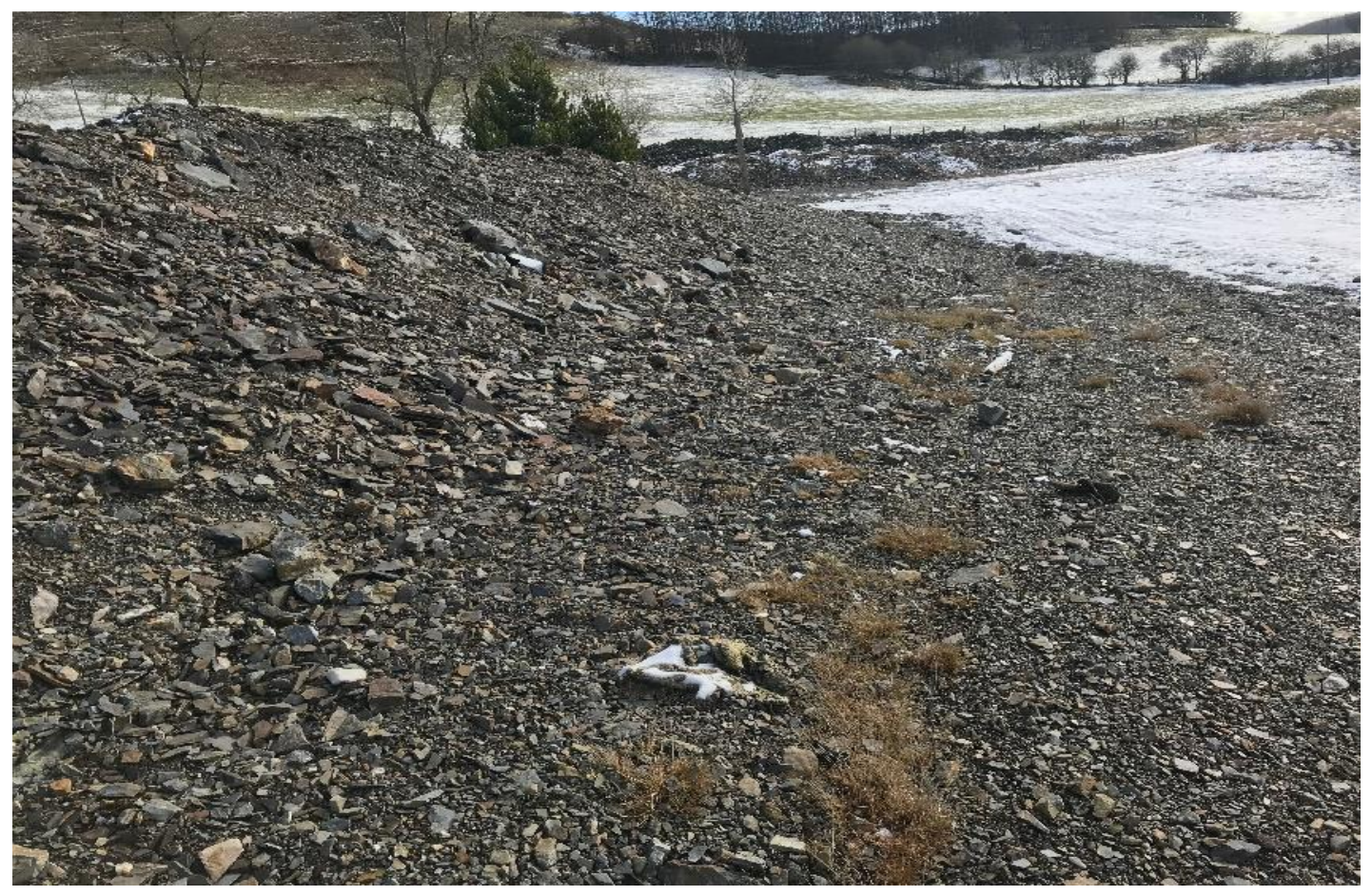

Figure A17: Frongoch lead/zinc mine tailings, before surrogate soil was applied (2017)

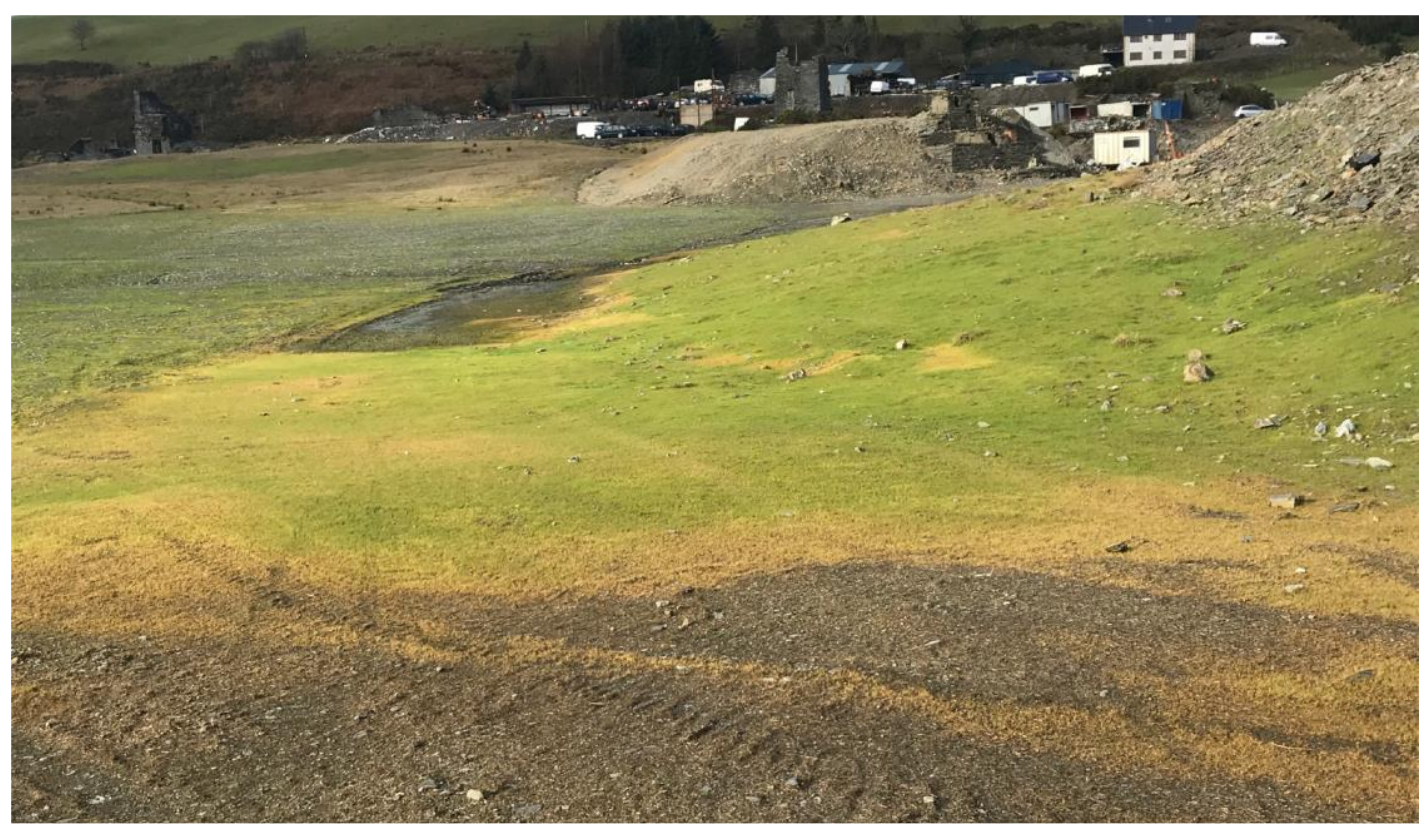

Figure A18: Frongoch lead/zinc mine tailings, three weeks after hydroseeding with biochar $(5 \% \mathrm{v} / \mathrm{v})$, straw, digestate, basalt, fertiliser, and $10 \%(\mathrm{v} / \mathrm{v})$ guar gum. $74 \%$ ground cover was recorded (October 2018) 


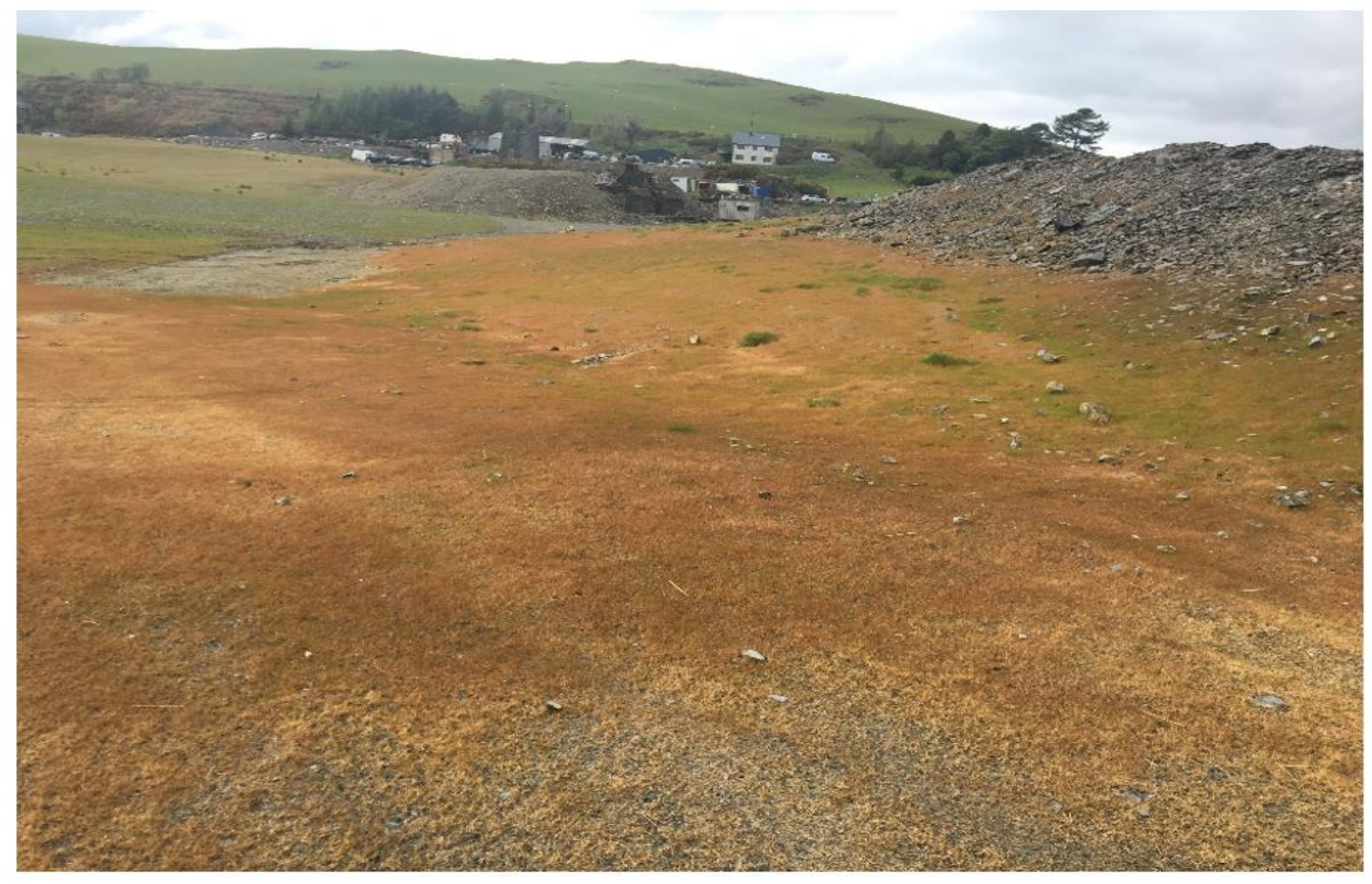

Figure A19: Frongoch lead/zinc mine tailings, seven months after hydroseeding with biochar $(5 \% \mathrm{v} / \mathrm{v})$, straw, digestate, basalt, fertiliser, and $10 \%(\mathrm{v} / \mathrm{v})$ guar gum. $24 \%$ ground cover was recorded (April 2019)

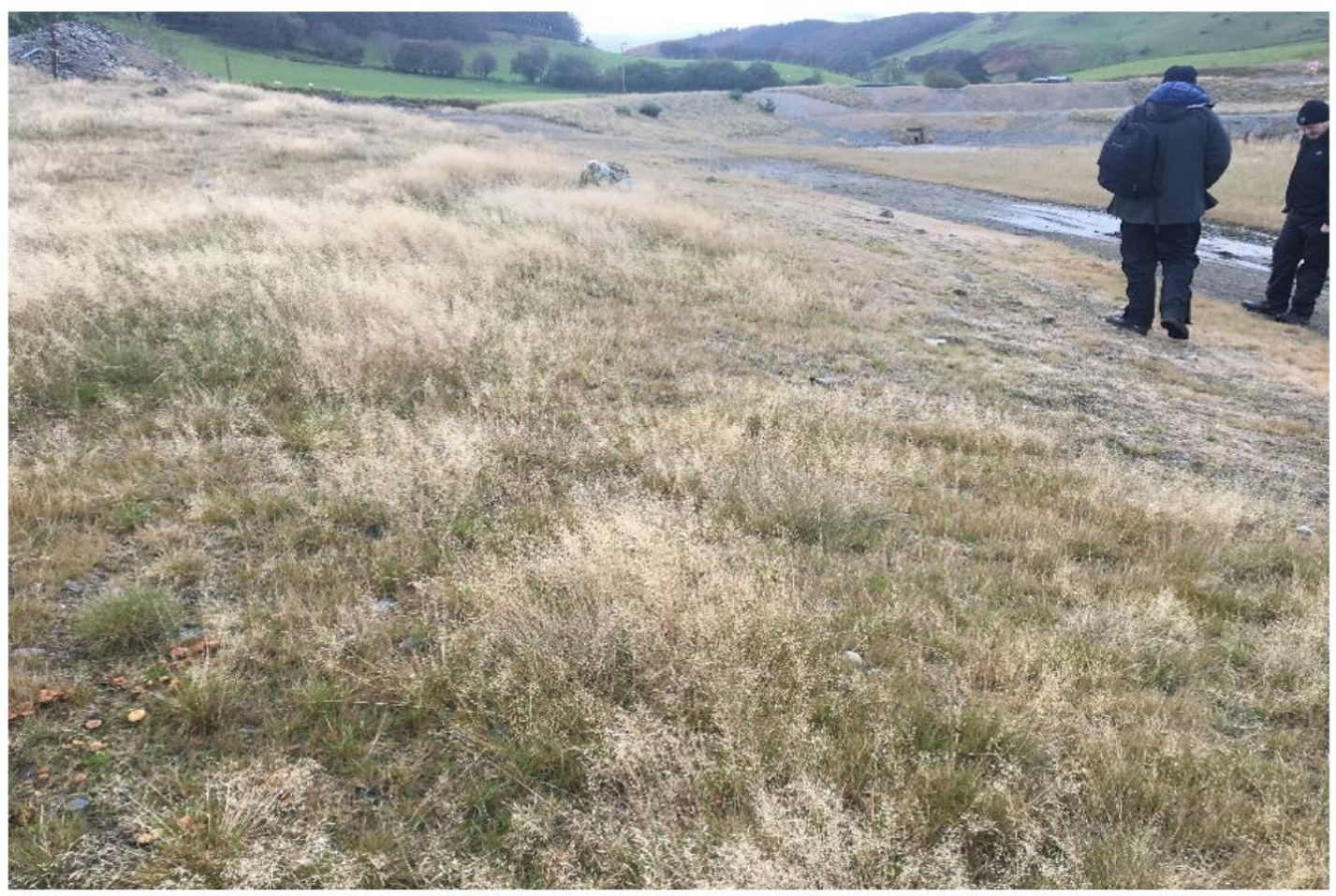

Figure A20: Frongoch lead/zinc mine tailings, 13 months after hydroseeding with biochar $(5 \% \mathrm{v} / \mathrm{v})$, straw, digestate, basalt, fertiliser, and $10 \%(\mathrm{v} / \mathrm{v})$ guar gum. $36 \%$ ground cover was recorded (October 2019) 


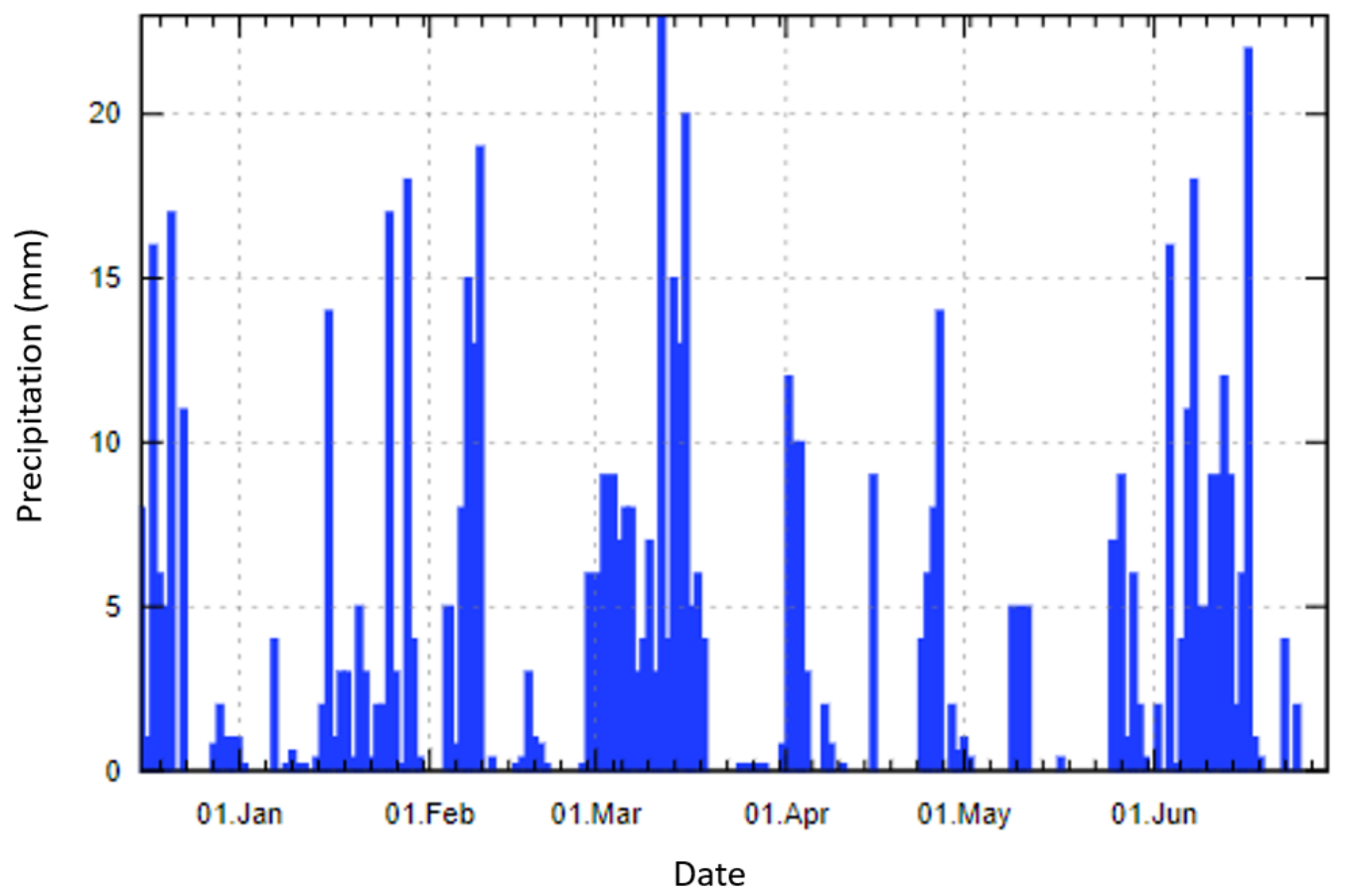

Figure A21: Precipitation $(\mathrm{mm})$ recorded at Trawscoed weather monitoring station, $5 \mathrm{~km}$ south--west of Frongoch lead/zinc mine. Source - www.weatheronline.com

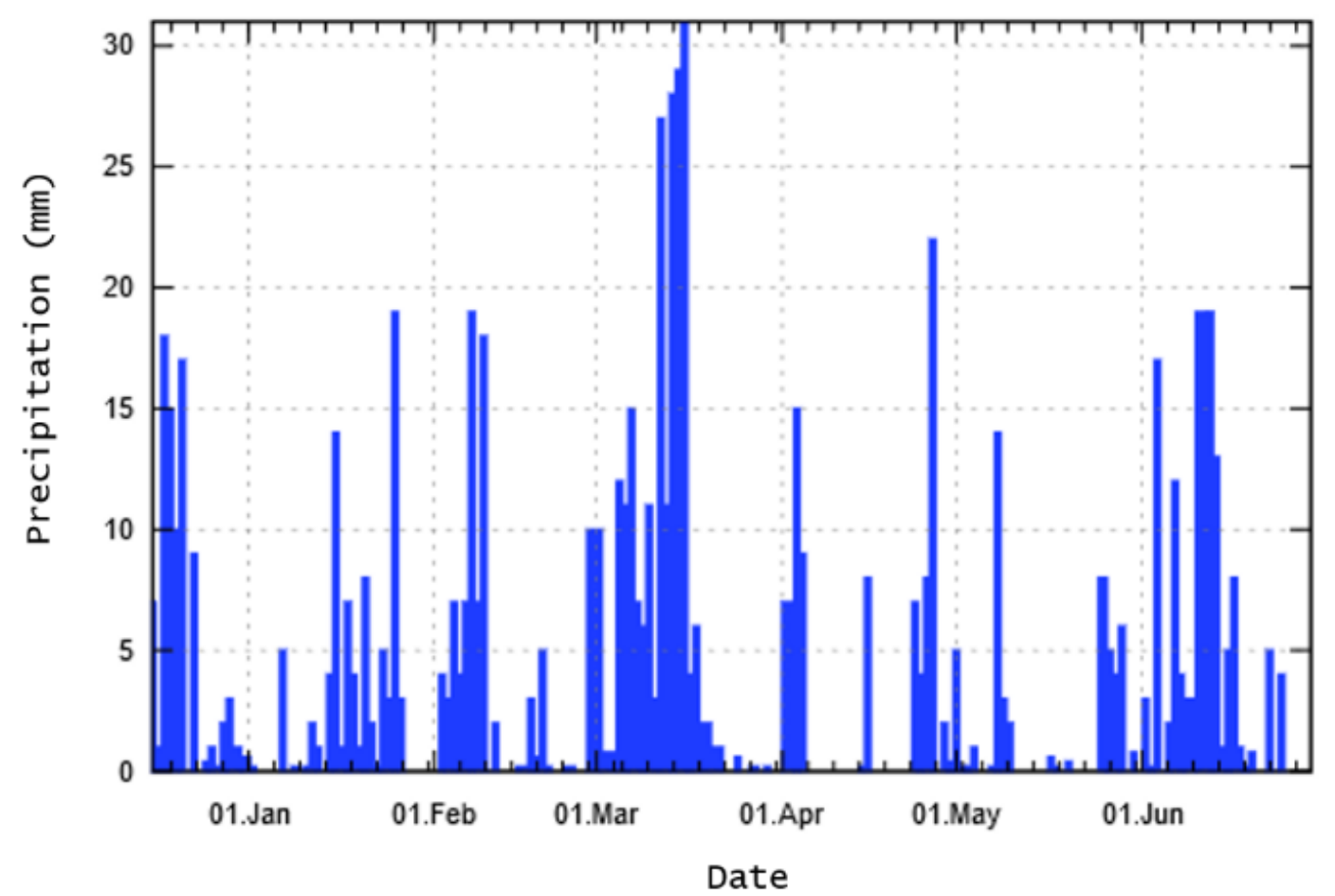

Figure A22: Precipitation ( $\mathrm{mm}$ ) at Rhandirmwyn from January to June 2019. Source www.weatheronline.com 